UNIVERSIDAD NACIONAL DE LA PLATA

FACULTAD DE CIENCAS AGRARIAS Y FORESTALES

MAESTRIA EN MANEJO INTEGRAL DE CUENCAS HIDROGRAFICAS

TITULO

\title{
MODELIZACIÓN HIDROLÓGICA DE UN ÁREA EXPERIMENTAL EN LA CUENCA DEL RÍO GUAYAS EN LA PRODUCCIÓN DE CAUDALES Y SEDIMENTOS
}

TESISTA: Lcdo. Juan Carlos Tapia

Instituto Oceanográfico de la Armada (INOCAR)

Av. De la Marina, vía al Puerto Marítimo. Guayaquil, Ecuador

juancar279@hotmail.com

DIRECTOR: Dra. Fernanda Julia Gaspari

Universidad Nacional de La Plata, Facultad de Ciencias Agrarias y Forestales

CODIRECTOR: Dr. Eduardo Kruse

Universidad Nacional de La Plata, Facultad de Ciencias Naturales y Museo

La Plata, Argentina. Marzo de 2012 


\section{INDICE}

- $\quad$ Titulo, resumen, palabras claves y titulo abreviado $\quad 7$

- $\quad$ Titulo en inglés, abstract y key words 8

\section{CAPÍTULO 1: INTRODUCCION}

1.1. Generalidades 10

1.2. Antecedentes 11

1.3. Fundamentos de elección del tema 14

1.4. Compromiso institucional 15

1.5. Hipótesis de trabajo 15

1.6. Objetivos 15

\section{CAPÍTULO 2: MARCO TEÓRICO}

2.1. Cuenca Hidrográfica 17

2.2. Ciclo Hidrológico 18

2.3. Balance Hídrico 19

2.3.1. Métodos para el cálculo del balance hídrico 21

2.3.2. Cálculo de la evapotranspiración potencial 23

2.4. Estimación de Caudal Liquido $\quad 25$

2.4.1. Generalidades 25

2.4.2. Factores que influyen en el escurrimiento 25

2.4.3. Variables que caracterizan el escurrimiento 26

2.5. Modelos Hidrológicos 26

2.5.1. Modelo hidrológico HEC-HMS $® \quad 28$

2.5.1.1. Generalidades 28

2.5.1.2. Funcionamiento del modelo 30

2.6. Estimación del Caudal Sólido. Erosión Hídrica Superficial 32

2.6.1. Factores físicos determinantes en la erosión hídrica 33

2.6.2. Formas de erosión 34

2.6.3. Métodos de estimación del caudal sólido 36

2.6.3.1. Modelo U.S.L.E 36

2.7. Integración de los Sistemas de Información Geográfica (SIG) en los

2.7.1. Definición, componentes y funciones de los SIG 45 
2.7.2. Modelo de datos en un SIG 45

2.7.3. Fuente de captura de datos y tipos de información espacial 47

2.7.4. Modelación con los SIG 48

2.7.4.1. Modelación en la hidrología 48

2.7.4.2. Modelación en el uso y manejo del suelo agrícola 50

\section{CAPÍTULO 3: CARACTERIZACIÓN DE LA CUENCA DEL RÍO GUAYAS}

3.1. Ubicación geográfica 51

3.2. Hidrografía 52

3.3. Clima 55

3.4. Geología 56

3.5. Relieve 57

3.6. Vegetación y uso del suelo 59

$\begin{array}{lll}\text { 3.7. Suelos } & 61\end{array}$

\section{CAPÍTULO 4: MATERIALES Y MÉTODOS}

4.1. Recopilación de bibliografía y definición del área experimental 64

4.1.1. Definición del área experimental 65

4.2. Morfometría de la cuenca 65

4.2.1. Parámetros de relieve 66

$\begin{array}{ll}\text { 4.2.2. Parámetros de forma } & 68\end{array}$

4.2.3. Parámetros relativos de la red hidrográfica 70

4.2.4. Parámetros automáticos con HEC-GeoHMS® 72

4.3. Análisis y procesamiento de datos meteorológicos 73

$\begin{array}{ll}\text { 4.3.1. Precipitaciones } & 73\end{array}$

$\begin{array}{ll}\text { 4.3.2. Temperaturas } & 75\end{array}$

4.4. Análisis y procesamiento de datos hidrológicos 76

$\begin{array}{ll}\text { 4.4.1. Caudales } & 77\end{array}$

4.5. Análisis del Balance Hídrico 78

4.5.1. Cálculo del balance hídrico 78

4.6. Integración de los Sistemas de Información Geográfica (SIG) 80

4.6.1. Generación del Modelo Cartográfico 80

4.6.1.1. Red de drenaje $\quad 81$

4.6.1.2. Delimitación de cuenca y subcuencas 81

4.6.1.3. Mapa de orientación de laderas 81

4.6.1.4. Mapa de iluminación $\quad 81$ 
4.6.1.5. Mapa de pendientes $\quad 81$

4.6.1.6. Mapa de suelo $\quad 81$

4.6.1.7. Mapa de cobertura vegetal y uso de suelo 82

4.6.1.8. Mapa de isoyetas $\quad 82$

4.6.1.9. Mapa de isotermas $\quad 82$

4.6.1.10. Mapa de zonas climáticas 82

4.7. Cálculo del caudal líquido 83

4.7.1. Método del S.C.S. para las abstracciones 83

4.7.1.1. Obtención del Número de Curva (NC) 83

4.7.2. Modelización matemática con HEC-HMS ${ }^{\circledR}$

4.7.2.1. Selección de los métodos de cálculo en el programa HEC-HMS $® \quad 86$

4.7.2.2. Selección de datos de lluvia $\quad 89$

4.7.2.3. Selección de datos de caudal observado 90

4.8. Pruebas de calibración del modelo HEC-HMS ${ }^{\circledR} \quad 90$

4.9. Sensibilidad de los parámetros del modelo HEC-HMS ${ }^{\circledR}$

4.10. Prueba de validación del modelo HEC-HMS ${ }^{\circledR} \quad 92$

4.11. Determinación de la pérdida de suelo 93

4.11.1. Método de la ecuación universal de pérdida de suelo (U.S.L.E.) 93

4.11.1.1. Factor de erosividad por la lluvia "R" 94

4.11.1.2. Factor de erodabilidad del suelo "K" 98

4.11.1.3. Factor topográfico "LS" 98

4.11.1.4. Factor de cobertura del suelo "C" 99

4.11.1.5. Estimación de la pérdida de suelo "A" 99

\section{CAPÍTULO 5: RESULTADOS}

5.1. Recopilación de bibliografía y definición del área experimental 102

5.1.1. Definición del área experimental 102

5.2. Morfometría de la cuenca 111

$\begin{array}{ll}\text { 5.2.1. Parámetros de relieve } & 111\end{array}$

$\begin{array}{ll}\text { 5.2.2. Parámetros de forma } & 112\end{array}$

5.2.3. Parámetros relativos de la red hidrográfica 113

5.2.4. Parámetros automáticos con HECGeo-HMS ${ }^{\circledR} \quad 114$

5.3. Análisis y procesamiento de datos meteorológicos 124

$\begin{array}{ll}\text { 5.3.1. Precipitaciones } & 124\end{array}$

$\begin{array}{ll}\text { 5.3.2. Temperaturas } & 143\end{array}$ 
5.4. Análisis y procesamiento de datos hidrológicos 147

$\begin{array}{ll}\text { 5.4.1. Caudales } & 147\end{array}$

5.5. Análisis del Balance Hídrico 151

5.5.1. Cálculo del Balance Hídrico 151

5.6. Integración de los Sistemas de Información Geográfica (SIG) 158

5.6.1. Generación del Modelo Cartográfico 158

5.6.1.1. Red de drenaje 160

5.6.1.2. Delimitación de cuenca y subcuencas 161

5.6.1.3. Mapa de orientación de laderas $\quad 161$

5.6.1.4. Mapa de iluminación 163

5.6.1.5. Mapa de pendientes $\quad 164$

5.6.1.6. Mapa de suelo 165

5.6.1.7. Mapa de cobertura vegetal y uso de suelo 167

5.6.1.8. Mapa de isoyetas 170

5.6.1.9. Mapa de isotermas $\quad 170$

5.6.1.10. Mapa de zonas climáticas $\quad 171$

5.7. Cálculo del caudal líquido 173

5.7.1. Método del S.C.S. para las abstracciones 173

5.7.1.1. Obtención del número de curva (NC) 173

5.7.2. Modelización matemática con HEC-HMS ® 175

5.7.2.1. Selección de los métodos de cálculo en el programa HEC-HMS $® \quad 177$

5.7.2.2. Selección de datos de lluvia 180

5.7.2.3. Selección de datos de caudal observado $\quad 180$

5.8. Pruebas de calibración del modelo HEC-HMS $® \quad 181$

$\begin{array}{ll}\text { 5.8.1. Primera prueba } & 181\end{array}$

$\begin{array}{ll}\text { 5.8.2. Segunda prueba } & 184\end{array}$

5.9. Sensibilidad de los parámetros del modelo HEC-HMS ${ }^{\circledR} \quad 186$

5.10. Pruebas de validación del modelo HEC-HMS $® \quad 188$

5.11. Determinación de la pérdida de suelo 190

5.11.1. Método de la ecuación universal de pérdida de suelo (U.S.L.E.) 190

5.11.1.1. Factor de erosividad por la lluvia "R" 191

5.11.1.2. Factor de erodabilidad del suelo "K" 193

5.11.1.3. Factor topográfico "LS" 194

5.11.1.4. Factor de cobertura del suelo "C" 197

5.11.1.5. Estimación de la pérdida de suelo "A" 199 


\section{CAPÍTULO 6: CONCLUSIONES}

Conclusiones

Agradecimientos

208

Bibliografía

210

Anexos

214 


\section{TITULO}

Modelización Hidrológica de un área experimental en la Cuenca del Río Guayas en la producción de caudales y sedimentos.

\section{RESUMEN}

La cuenca del Río Guayas es considerada como la zona de mayor producción agrícolaganadera del Ecuador, por tanto su estudio es importante para tener una producción sustentable y sostenible en el tiempo. Su área abarca una superficie de 3 millones de ha, está conformada por zonas altas ubicadas sobre la Cordillera Occidental, zonas medias situadas en las laderas de la cordillera y zonas bajas que corresponde a las grandes llanuras aluviales de la costa donde se asienta la mayor concentración de población. Debido a la estructura morfológica de la cuenca y a los procesos antropogénicos que se desarrollaron sin tomar en cuenta planes conservacionistas adecuados en manejo de cuencas hidrográficas, las zonas bajas son las que mayormente se han visto afectadas durante años, por eventos de inundación frecuentes y prolongados, que generan grandes pérdidas materiales e incluso vidas humanas, afectando severamente su potencial económico y limitando el transporte fluvial. Siendo por este motivo, de fundamental importancia la determinación de la producción de caudales y sedimentos que se aportan al Río Guayas. El objetivo de esta tesis es la modelación hidrológica de la microcuenca del Río Toachi, tributario del Río Guayas, para cuantificar la producción de caudales líquidos y sólidos que se generan a partir de la caracterización morfológica e hidrometeorológica. Se aplicaron modelos hidrológicos y empíricos integrando los Sistemas de Información Geográfica (SIG) en el tratamiento de información espacial, generando una gran base de datos georreferenciada de la cuenca de estudio. Como resultado, se obtuvieron los parámetros morfológicos del relieve, de la forma y relativos a la red hidrográfica a nivel cuenca de estudio y sus unidades hidrológicas (subcuencas), destacando la forma alargada de la cuenca con pendientes fuertes en la cabecera, accidentadas en la zona media y suave en la desembocadura, con una superficie de 50.371,74 ha. Presenta valores de densidad de drenaje bajos con crecientes de menor magnitud y menor probabilidad de ocurrencia de eventos torrenciales, con un bajo poder erosivo. Se generaron los mapas temáticos como: topográfico, hidrográfico, orientación, iluminación y pendientes de las laderas, suelo, uso del suelo y cobertura vegetal, isotermas, isoyetas, zonas climáticas. Se realizó un estudio de los parámetros hidrometeorológicos y su dinámica en la cuenca de estudio a nivel zonas para cuantificar los caudales líquidos por medio del HECGeo-HMS. Se calibró y validó el modelo hidrológico HEC-HMS ${ }^{\circledR}$ cuantificando el caudal simulado a la salida de la cuenca de estudio para que pueda ser usado en otras cuencas de iguales características morfométricas. Se calcularon los factores de la Ecuación Universal de Pérdida de Suelo (USLE) y la Tasa de Erosión Hídrica Superficial de la cuenca del Río Toachi y de las respectivas unidades hidrológicas. Además se realizó la cartografía particular de los parámetros de la USLE de la cuenca del Río Toachi con SIG para un análisis geoespacial. 


\section{PALABRAS CLAVES}

Modelización hidrológica, integración de los SIG con modelos hidrológicos, determinación de caudales líquidos y sólidos.

\section{TITULO ABREVIADO}

Modelización Hidrológica de un área experimental en la cuenca del Río Guayas

\section{TITULO EN INGLES}

Hydrologic Modelling of an experimental area in the Guayas River basin to quantify liquid and solid flow production.

\section{ABSTRACT}

Guayas River Basin is considered one of the greatest farming land and crop yield production areas of Ecuador. So this study is important to have a sustainable production through the time. It comprises 3 million hectares; which is compound by highlands located on the West mountain range, mountain passes located on the slopes and valleys that correspond to vast alluvial plains where most of the population is concentrated. Because of the basin morphological structure and the anthropogenic processes that have been developed regardless of preservation planning programs appropriate for hydrographic basin management, valleys have been mainly affected by frequent and long floods over years. These latter events have cost both damages and even losses of lives drastically altering the economic potential and limiting fluvial transportation. The fact of determining the water level and sediment production that are provided to Guayas River is, thus, of utmost importance. The aim of this thesis is the hydrologic modeling of Toachi River micro basin located within Guayas River basin to quantify liquid and solid flow production that stems from the morphological and hydrometeorological characterization. To this purpose, hydrological and empirical models were applied integrating the Geographic Information Systems (GIS) in the analysis of spatial data, thus, generating a great georreferencial database of the studied basin. As a result, morphological parameters of the relief, the shape and relating to the hydrographic network at a basin studied level and its hydrological units (sub-basin) were obtained. The elongated shape of the basin with steep slopes at the headwaters source, rugged in the passes and smooth in the mouth of the River with an extension of $50.371,74$ ha. are highlighted. It presents low density drainage values with a growing water level of less scale and less probability of torrential events resulting in a low erosive power of the basin. Topic maps were generated like: topography, hydrography, orientation, illumination and hillside slopes, soil, soil use and vegetation cover, isotherms, isohyets, climate zones. Hydrometeorological parameters study was made and its dynamic in basin studied level to quantify the liquid flows by HECGeo-HMS. The hydrologic model HEC-HMS ${ }^{\circledR}$ was calibrated and validated quantifying the water level simulated at the end of the studied basin 
in order to be used by other basins with similar morphometric characteristics. Universal Soil Loss Equation (USLE) and Superficial erosion rate factors of the Toachi River basin and its hydrologic units were calculated. And the particular cartography of the USLE parameters of the Toachi River basin with GIS for a geospatial analysis was made.

KEY WORDS: hydrologic modeling, GIS integration with hydrologic models, liquid and solid water level determination. 


\section{CAPITULO 1}

\section{INTRODUCCION}

\subsection{Generalidades}

La cuenca hidrográfica es el territorio geográfico delimitado por una divisoria de aguas, que está conformada por un sistema hidrológico cuyos cauces se vierten a un río principal, a un lago o al mar. El principal elemento que forma parte de esta área es sin duda alguna el agua, vital no solo para la vida, sino también básico para el desarrollo de las actividades humanas. Existen además, infraestructuras construidas por el hombre, para producir bienes y servicios generando efectos positivos y negativos para el bienestar humano. Por ello, es necesario conocer el comportamiento de esta área geográfica para poder optimizar sus recursos naturales, minimizar los riesgos y maximizar los efectos positivos.

El desarrollo de teorías sobre las relaciones entre la precipitación y la escorrentía en cuencas hidrográficas están en expansión. Actualmente, no es suficiente la observación y toma de datos de los diferentes parámetros hidrológicos, que muchas veces son mal tomados o se pierden por problemas cotidianos. Pero gracias al avance de la tecnología en el campo de la informática, actualmente se pueden desarrollar modelos matemáticos que simulan procesos hidrológicos con mayor detalle posible a la realidad.

Un modelo es la representación simplificada de un sistema, por lo cual debe necesariamente despreciar variables del sistema real en función del objetivo para el cual fue o será creado. Un modelo está compuesto por variables o elementos interrelacionados en un intervalo de tiempo, que actúan (procesos) sobre una entrada (materia, energía o información) de manera controlada bajo ciertas restricciones para producir una salida (materia, energía o información) (Gaspar et al., 2009).

Un modelo hidrológico es una aproximación al sistema hidrológico real, sus entradas y salidas son variables hidrológicas mensurables y su estructura un conjunto de ecuaciones que conectan las entradas y salidas (Chow et al., 1994). El procedimiento más utilizado con la aplicación de ordenadores en una cuenca hidrológica es la simulación, es decir, la representación en el computador del ciclo hidrológico por un modelo matemático, que pueda reproducir el comportamiento del agua en el suelo permitiendo simular condiciones futuras que afectarían a uno o varios de los procesos que integran dicho ciclo.

En la actualidad, el movimiento y la producción del agua en una cuenca son afectados por la acción antrópica como la deforestación, el manejo inadecuado de las cuencas hidrográficas, la contaminación del recurso agua por mal manejo de desechos sólidos y líquidos, la sobreexplotación de los recursos naturales, la inadecuada construcción de obras de infraestructura sin previos estudios de factibilidad (CISP, 2005). 
En Ecuador, la cuenca del Río Guayas presenta estas características en su parte alta y media, debido a que se ha alterado considerablemente la cobertura vegetal y provocando una alta producción de sedimentos, que está afectando la cuenca baja. Este hecho, se evidencia en la colmatación de los Ríos Babahoyo, Daule y Guayas, limitando la navegación del transporte fluvial por los centros poblados asentados en estos ríos. En la Foto 1, se observa el Nevado Chimborazo (naciente) desde la ciudad de Guayaquil (desembocadura) apreciando las dimensiones de la cuenca del Río Guayas.

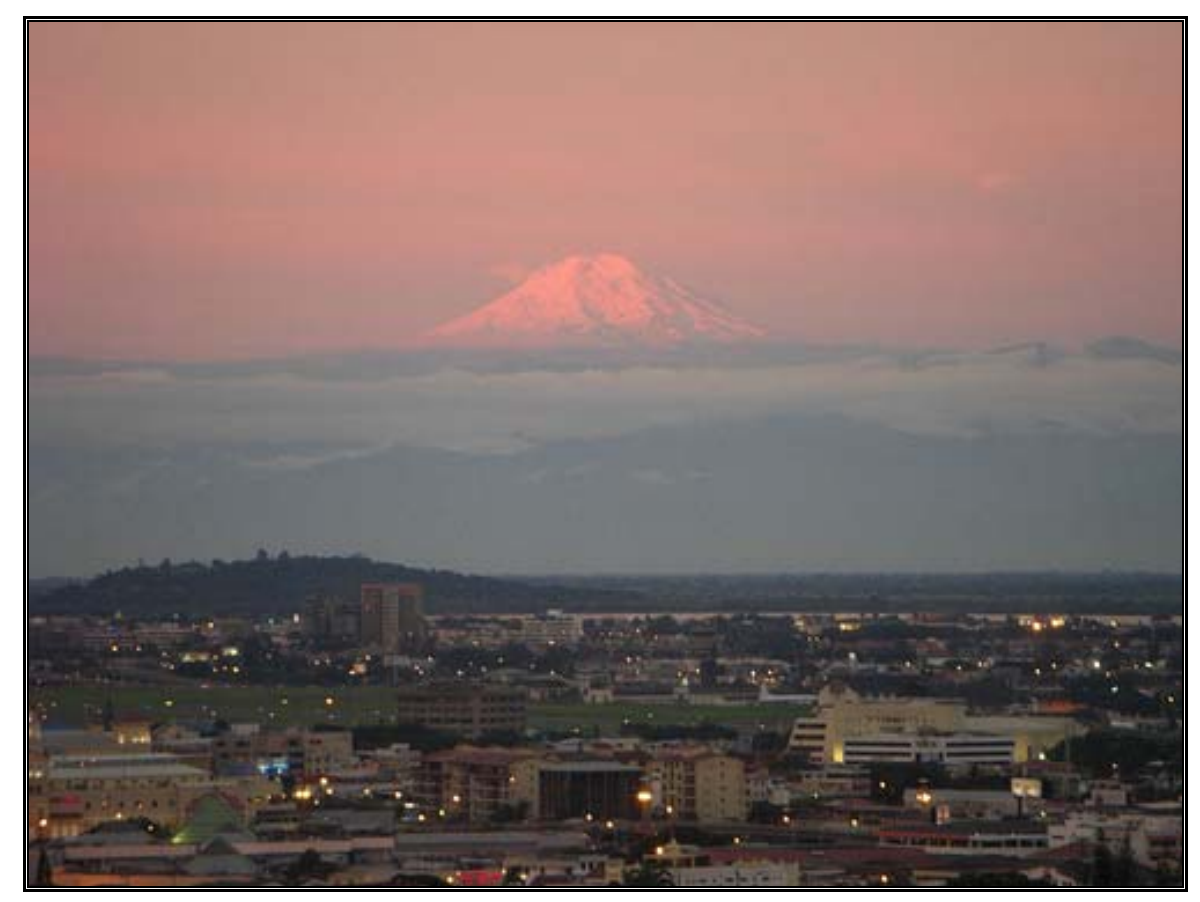

Foto 1. Vista del Nevado Chimborazo desde la ciudad de Guayaquil.

\subsection{Antecedentes.}

La Cuenca del Río Guayas, constituye el sistema fluvial más importante de la costa suroeste de América del Sur. Está ubicada en la principal región agrícola y ganadera del Ecuador que acoge a la mayor concentración de la población nacional. Dependen nueve provincias y sesenta y un cantones. Está constituida por una amplia zona geográfica que capta el sistema fluvial que conforman los Ríos Daule, Babahoyo, Yaguachi y Vinces, su caudal promedio es de $230 \mathrm{~m}^{3} / \mathrm{seg}$, mientras que durante la estación lluviosa sobrepasa los 1500 $\mathrm{m}^{3} / \mathrm{s}$ (ESPOL. 2000). En la Figura 1 se visualiza su ubicación geográfica. 


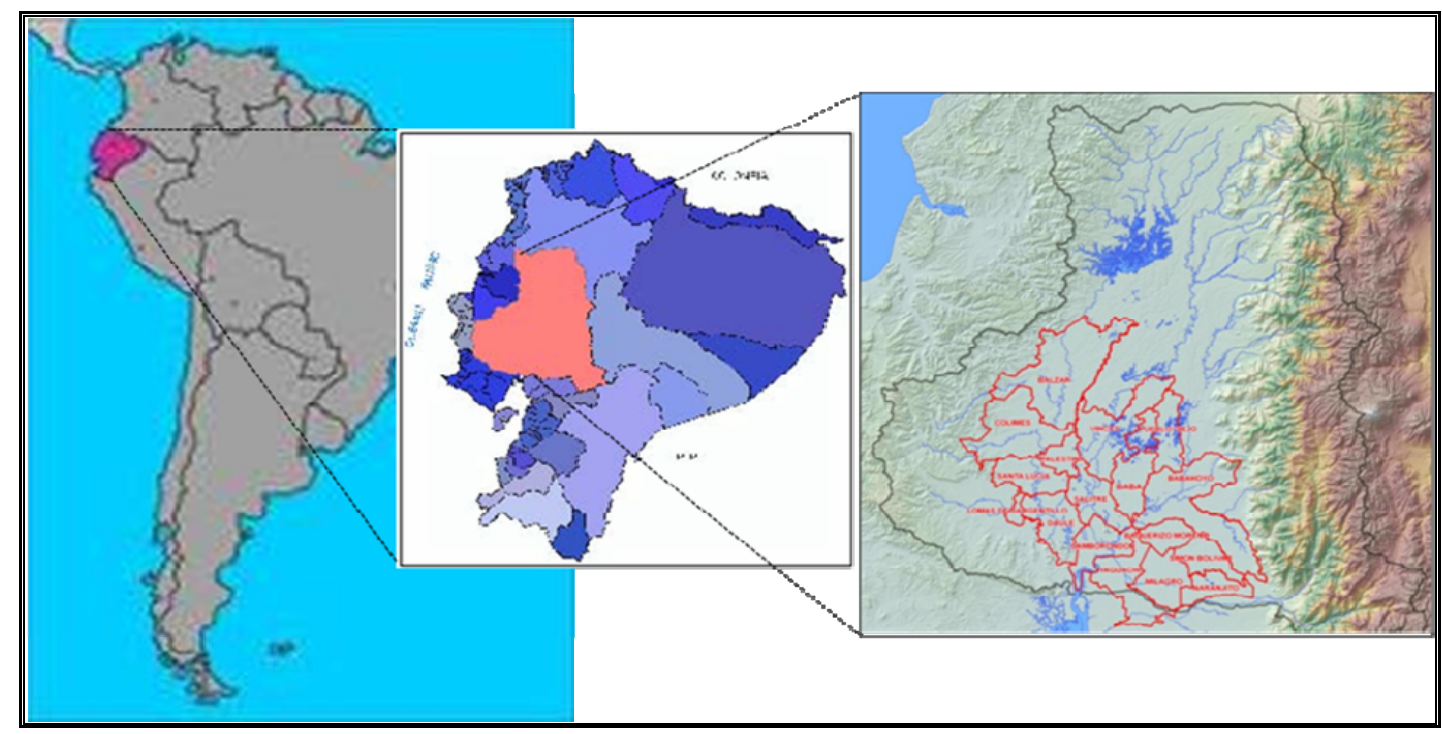

Figura 1. Ubicación de la Cuenca del Guayas. Ecuador.

Esta cuenca constituye el mayor centro de producción de bienes agropecuarios tanto para el consumo interno como para las exportaciones. La misma contribuye a la economía nacional con el $40 \%$ del Producto Interno Bruto y su producción exportable significa el $85 \%$ de las divisas generadas por el cacao, el $80 \%$ por el café, y el $40 \%$ por el banano. Con relación a los productos de consumo interno, aporta el 93\% de la producción de arroz, el 99\% de soya, el $74 \%$ de caña de azúcar, el $35 \%$ de maíz duro y el $15 \%$ de palma africana. (CHL, 2009)

Históricamente la cuenca ha sufrido los embates de la naturaleza, debido predominantemente, a fenómenos físico y antropogénicos que actúan sobre los procesos geomorfológicos que durante todos los años se presenta en forma de inundaciones o sequías. Los inviernos de 1982 y 1997 (Fenómenos del Niño) destruyeron la red vial de la costa, destrozaron miles de hectáreas de tierras cultivables e inundaron cientos de poblaciones rurales y urbanas dejando decenas de víctimas mortales y millones de pérdidas económicas. Esta área se caracteriza por la importancia económica que representa para el erario nacional y por ser un problema frecuente causado por inundaciones periódicas.

Con el fin de solucionar estos problemas, el 2 de diciembre de 1965 se creó la Comisión de Estudios para el Desarrollo de la Cuenca del Río Guayas (CEDEGE) mediante Decreto Supremo No. 2672, cuya finalidad fue ejecutar las investigaciones necesarias para el desarrollo de la cuenca. Desde esa fecha se han realizado varios estudios para mitigar los daños que ocasionan las crecidas de los ríos, así podemos citar los "Estudios de Factibilidad y Diseño del Control de Inundaciones de la Cuenca Baja del Guayas", realizado por HASKONING-CEDEGE (1990); "El Islote El Palmar, Resultado de una Evolución a Largo Plazo de la Distribución del Drenaje entre los Ríos Daule y Babahoyo en la Cuenca del Guayas", realizado por Dumont et al., (2007); "Proyecto de Caracterización HidroOceanográficas y Ambientales del Margen Costero, realizado por INOCAR en convenio con la SENACYT (2010), entre muchos otros. 
Así mismo, se han invertido grandes sumas de dinero para construir obras de ingeniería hidráulica, represas, canales, muros de aluviones, planes de inundación, como la represa "Daule-Peripa", obra del Proyecto Múltiple "Jaime Roldós Aguilera" que permite el control de inundaciones mediante la regulación del caudal del Río Daule, provee de agua para riego a casi toda la cuenca del Guayas y Península de Santa Elena y sirve para generar energía mediante una central hidroeléctrica. Además está la construcción del Proyecto Múltiple "Baba" que complementa al proyecto Daule-Peripa alimentando de agua y sirviendo para el control de las inundaciones en la subcuenca del Río Vinces, a más de la construcción de una central hidroeléctrica y sistemas de riego para la cuenca.

El Consejo Nacional de Recurso Hídricos (CNRH) publicó el mapa de la División Hidrográfica Nacional, mostrando que el Ecuador tiene 31 sistemas hidrográficos que se dividen en 79 cuencas hidrográficas, de las cuales 72 pertenecen a la vertiente del Pacífico y 7 a la vertiente del Amazonas (PNUMA, 2008). La cuenca del Guayas pertenece a la vertiente del Pacífico y está a su vez está dividida en 7 subcuencas: Río Daule, Río Vinces, Río Babahoyo, Río Yaguachi, Río Jujan, Río Macul y Drenajes Menores, como se muestra en la Figura 2.

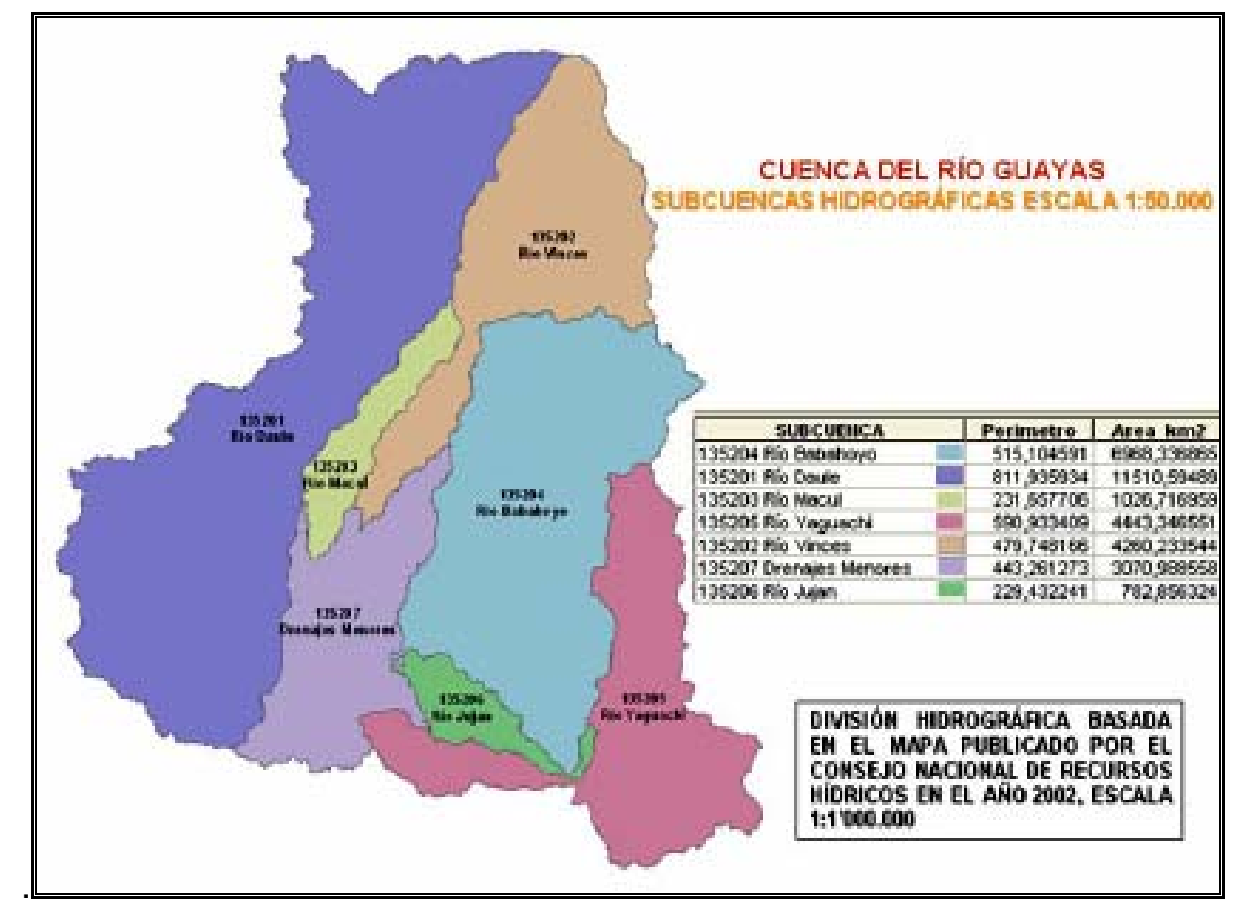

Figura 2. Subcuencas del Guayas. 


\subsection{Fundamentos de elección del tema}

El ecosistema ofrece una gran diversidad de recursos socioambientales: agua, energía, variedad de ecosistemas en ladera, diversidad genética, recursos forestales y minerales, productos agropecuarios, ocio, y turismo, recursos paisajísticos, históricos y culturales, entre otros. De los diferentes flujos de recursos establecidos entre las áreas de montaña y las llanuras adyacentes, el hídrico es posiblemente uno de los que hace más notable la dependencia socioambiental respecto a los ecosistemas montañoso. En efecto, se ha estimado que más de la mitad de la humanidad depende de los recursos hídricos generados en las cuencas de montaña para satisfacer sus necesidades de agua potable, riego, uso industrial y navegación (Gaspari et al., 2009).

La cuenca hidrográfica, es considerada como un sistema donde los procesos hidrológicos, geomorfológicos, edáficos y culturales, se hallan ligados y, además se generan, los peligros hidrometeorológicos, como erosión, remociones en masa, inundaciones y crecidas torrenciales. Por tanto, el mal uso de los recursos naturales en las cuencas altas y medias repercutirá y será una amenaza para la población, sistemas agroproductivos, agua potable, energéticos y de transporte situados aguas abajo (Gonzales et al., 2008). Esta área física sufre el impacto de la contaminación sólida y líquida, la tala irracional de los bosques, la degradación de los suelos producto del uso excesivo de los fertilizantes y agroquímicos, sobreexplotación de los recursos naturales, entre otros problemas producidos por el hombre los cuales deben ser resueltos tomando a la cuenca hidrográfica como una unidad territorial. En ellas funciona la combinación del sistema hídrico que produce agua, simultáneamente con un subsistema económico y social, activado por el hombre, el capital, el trabajo y la tecnología. Sirven como marco práctico y objetivo para la planificación y gestión del desarrollo sostenible funcionando como sistema cuyos elementos se encuentran conectados e interactúa como una unidad.

Existen estudios sobre el manejo de cuencas hidrográficas elaborados siguiendo las formulaciones teóricas de los problemas, sin embargo la aplicación de estos ha tenido variados inconvenientes. Básicamente, los motivos del mal manejo, son la falta de una política definida que se materialice en una institución con planificación estatal, intereses de grandes empresas que tienen su área de producción en las cuencas altas y medias, intereses de poblaciones que solo identifican su fuente de ingreso sin importar el daño que causan a los recursos naturales, falta de apoyo de gobiernos seccionales para exigir al gobierno central ayuda en temas de planificación, entre otros.

A partir de estos antecedentes problemáticos, el objetivo personal e institucional es adquirir conocimientos teóricos y herramientas prácticas necesarias para realizar estudios a nivel de cuencas hidrográficas y emplear modelos matemáticos de simulación hidrológica para cuantificar los caudales líquidos y sólidos en microcuencas de la cuenca del Guayas. 


\subsection{Compromiso Institucional}

El desarrollo de la presente tesis forma parte del pensum académico correspondiente a la Maestría en Manejo Integral de Cuencas Hidrográficas, Carrera de Postgrado propuesta por la Universidad Nacional de La Plata, Argentina, y organizada por la Facultad de Ciencias Agrarias y Forestales.

El trabajo de investigación fue realizado con el auspicio de la Secretaría Nacional de Educación Superior, Ciencia, Tecnología e Investigación (SENESCYT, ex SENACYT) y el Instituto Oceanográfico de la Armada (INOCAR).

EI INOCAR es el organismo oficial del Estado que tiene bajo su responsabilidad el estudio hidrográfico de los ríos y mares territoriales, optimizando los procesos de operación, control y evaluación de las actividades Oceanográficas, Hidrográficas y de Ayudas a la Navegación para garantizar la seguridad de la navegación en el mar, canales y vías navegables del país.

El desarrollo del presente trabajo de investigación se encuadró en las tareas que desarrolla el Instituto Oceanográfico y en su misión de planificar, dirigir, coordinar y controlar las actividades técnicas relacionadas con la Seguridad Marítima. Los resultados obtenidos servirán para coordinar y colaborar con otras instituciones la elaboración, actualización y aplicación de planes de prevención y contingencia frente a emergencias naturales. La metodología desarrollada se aplicará para realizar estudios de navegabilidad del Río Guayas y de los principales ríos navegables del país contribuyendo de esta manera al desarrollo y bienestar de la sociedad.

\subsection{Hipótesis de Trabajo}

La modelización hidrológica en áreas experimentales determina la cuantificación de caudales y sedimentos permitiendo extrapolar su metodología a cuencas homólogas. 


\subsection{Objetivos}

\section{General}

Modelar hidrológicamente una cuenca experimental para cuantificar la producción de caudales y sedimentos.

\section{Objetivos Específicos}

1. Definir un área experimental en la Cuenca del Río Guayas (microcuenca).

2. Calcular los índices morfométricos del relieve y red hidrográfica del área experimental y de las unidades hidrológicas.

3. Caracterizar los parámetros hidrometeorológicos del área experimental.

4. Cuantificar la entrada, salida y almacenamiento de agua en la microcuenca mediante el Balance Hídrico.

5. Crear una base de datos cartográfica georreferenciada utilizando los Sistemas de Información Geográfica (SIG) en el área experimental.

6. Determinar el caudal líquido en la cuenca experimental aplicando la simulación, calibración y validación del modelo HEC-HMS ${ }^{\circledR}$.

7. Determinar la tasa de erosión hídrica en la cuenca experimental utilizando los SIG mediante la implementación del modelo empírico U.S.L.E. 


\section{CAPITULO 2}

\section{MARCO TEÓRICO}

\subsection{Cuenca Hidrográfica}

La cuenca hidrográfica, considerada como el territorio geográfico delimitado por una divisoria de aguas que está conformada por un sistema hídrico, presenta tres secciones bien definidas por las divisorias de aguas donde el nivel de actividad hidrológica es diferente, específicamente el impacto del agua, aunque mantienen una intrínseca interconexión e interacción, así:

- La zona alta o cabecera, donde se produce la mayor cantidad de precipitación, la temperatura es más baja que el resto de la cuenca y las acciones que se realicen aquí influirán en toda la cuenca, por ejemplo el riego. Su estabilización es nula y existe una alta producción de sedimentos líquidos y sólidos.

- La zona media, se comporta como zona de amortiguamiento entre las acciones de la cuenca alta y los efectos de la cuenca baja. En esta área se cumplen la mayor cantidad de actividades productivas ejerciendo presión hacia la parte alta. Su estabilización es baja produciendo más cantidades de sedimentos líquidos y sólidos.

- La zona baja o desembocadura, ubicada en tierras bajas, generalmente cerca de la costa, se caracteriza por presentar fenómenos de estiaje o inundación. En esta zona se expresa los impactos de las acciones que se realizan en la cuenca alta.

Las cuencas hidrográficas en su integridad, deben ser consideradas como unidades de planificación y gestión para el ordenamiento territorial y para el manejo de recursos naturales, ya que la disponibilidad de los recursos hídricos y edáficos no dependen de los límites políticos sino más bien dependen de la influencia de los tratamientos integrados de producción y protección regionales, según elementos sociales, económicos y, del grado de deterioro ambiental (Gaspari et al., 2009).

Las actividades que realizan los habitantes en las diferentes partes de la cuenca, están íntimamente relacionadas debido al funcionamiento como un "sistema indivisible e interdependiente", así por ejemplo cuando en la parte alta se tiene una cobertura forestal adecuada, ayuda a regular y controlar la cantidad de agua y sedimento (líquido y sólido) que escurren hacia las partes media y baja de la cuenca. Esto favorece a las poblaciones de la cuenca baja en calidad y cantidad de agua para consumo, así como también la ocurrencia de inundaciones y sequias (López y Delgado, 2009).

Para la presente tesis, se utilizará la herramienta HEC-GeoHMS, que trabaja bajo plataforma de los Sistemas de Información Geográfica (SIG), para la delimitación de la cuenca y subcuencas, y para generar los valores de los parámetros morfométricos del relieve de la red hidrográfica. 


\subsection{Ciclo Hidrológico}

El análisis hidrológico de una cuenca inicia con el conocimiento particular del movimiento del agua, conocido como "ciclo hidrológico" (Figura 3), de tal manera que permite organizar, ordenar y planificar la misma. Debido a ello, la caracterización del ciclo hidrológico crea un diagnóstico preliminar para todo estudio de esta unidad hidrológica.

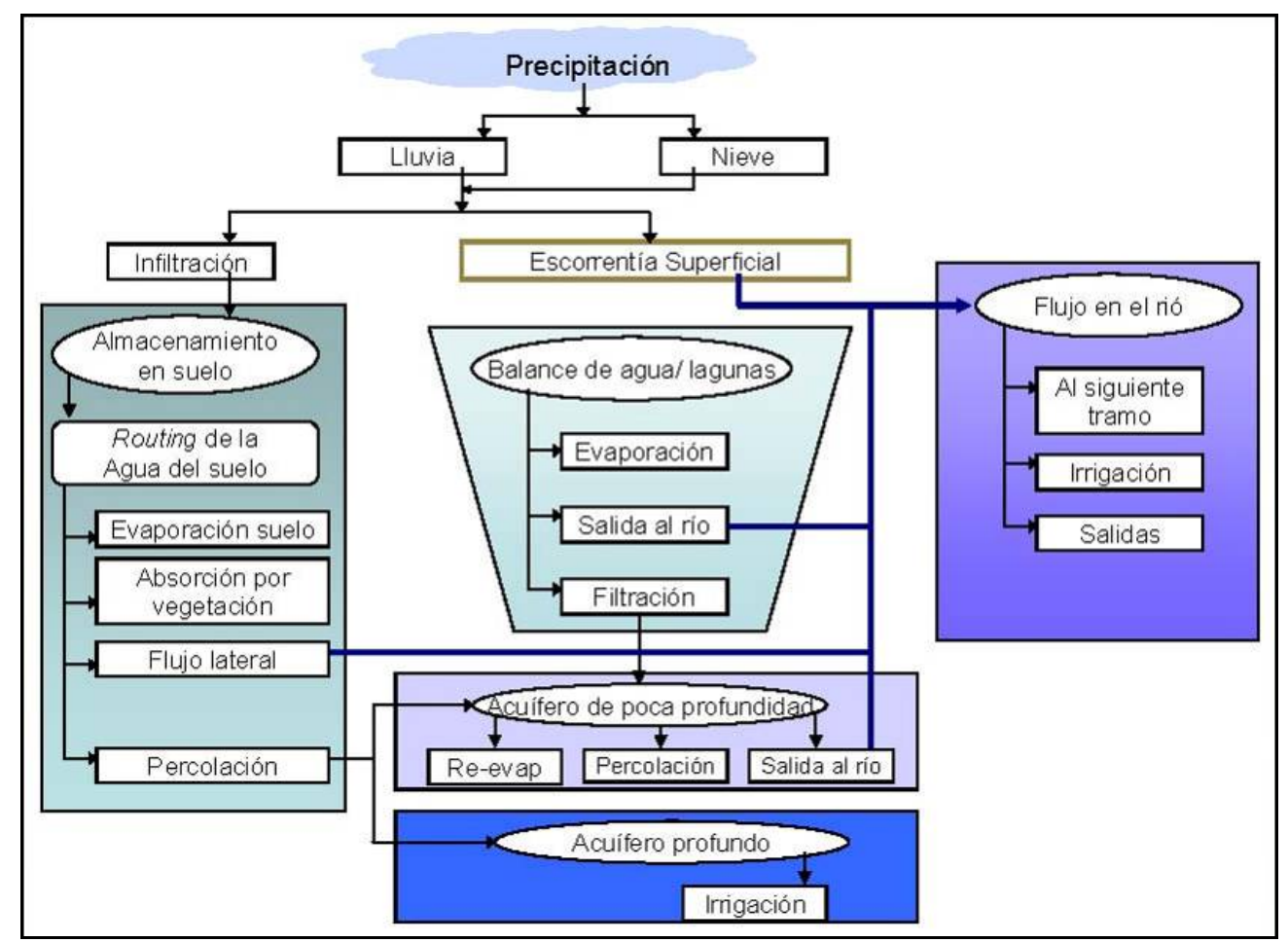

Figura 3. Esquema del ciclo hidrológico. Fuente: Neitsch et al., 2002. Modificado

El ciclo hidrológico es considerado como un ciclo compuesto por procesos continuos e interdependientes de transferencia y movimiento de agua entre la atmósfera, la tierra y los cuerpos de agua. Considerando el inicio del proceso en la precipitación, sea en forma de lluvia o nieve, una parte es interceptada por la vegetación, otra cae en los cuerpos de agua y otra va a la tierra, que dependiendo de las características físicas del suelo se infiltra o escurre superficialmente.

Durante el proceso de infiltración, una parte es retenida por el suelo cuya capacidad de almacenamiento depende de la porosidad del suelo. Una vez saturada la capacidad de almacenamiento, el agua ya no infiltra y se transforma en escorrentía superficial; otra parte se transforma en flujo subsuperficial y el resto percola alimentando los acuíferos profundos. El agua que se infiltra y percola tiene una continuidad horizontal convirtiéndose en escorrentía subsuperficial y subterránea cuyo destino final es un río o el mar. El escurrimiento superficial tiene como destino final un lago, una laguna o el mar. 
La energía solar junto con los factores meteorológicos de temperatura, viento, radiación solar y humedad producen la evaporación en los cuerpos de agua y la evapotranspiración en las plantas y suelo. En ambos procesos se produce la pérdida de agua y la transformación del agua de estado líquido a gaseoso. El vapor de agua mientras sube a la atmósfera, pierde calor y se condensa alrededor de núcleos de condensación transformándose en pequeñas gotas de agua, las cuales se agrupan (nubes) y por su tamaño se precipitan a la tierra en forma de lluvia, granizo o nieve. El ciclo se repite sucesivamente.

\subsection{Balance Hídrico}

El balance hídrico contabiliza las ganancias de agua por lluvia o riego y las pérdidas por evaporación, escorrentía, drenaje profundo y la variación del almacenamiento de aguas en el suelo. El conocimiento del balance hídrico permite determinar la duración y la magnitud a nivel macroclimático de los períodos con exceso o deficiencia de agua, y es de aplicación para definir la hidrología de una zona, realizar la clasificación climática de un área y para la planificación hidráulica.

El balance hídrico o balance de agua, es la cuantificación tanto de los parámetros involucrados en el ciclo hidrológico, como de los consumos de agua de los diferentes sectores de usuarios en un área determinada, o una cuenca, así como la interrelación entre ellos, dando como resultado un diagnóstico de las condiciones reales del recurso hídrico en cuanto a su oferta, disponibilidad y demanda en dicha área, como lo representan López y Delgado (2009) en la Figura 4.

Al calcular el balance hídrico de un área o cuenca, el principal objetivo está en la determinación de las pérdidas totales de agua (o evapotranspiración): la evaporación de superficies de agua, suelo, nieve, hielo, y de cualquier otra superficie, más la transpiración. (Linsey et al., 1993). 


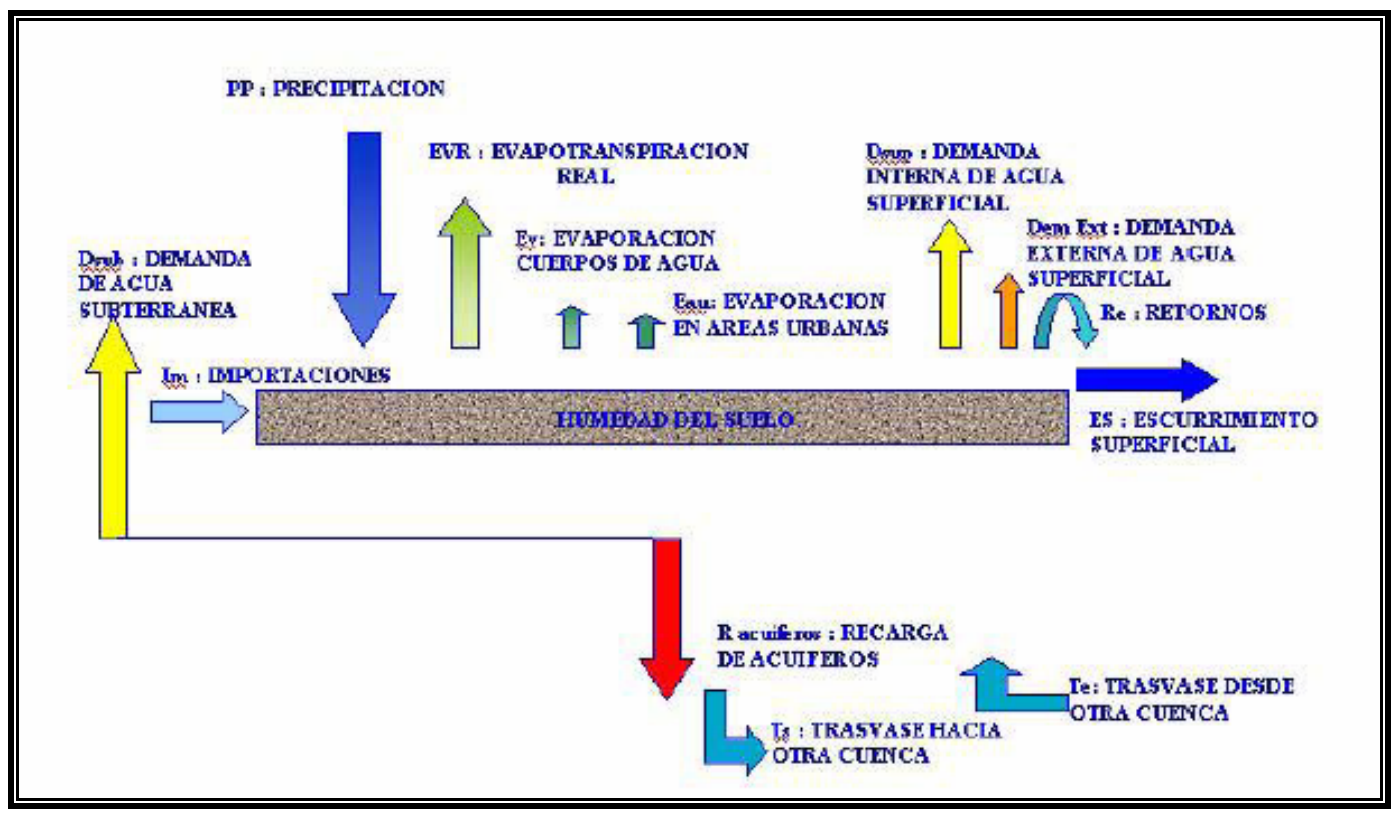

Figura 4. Balance Hídrico. Fuente: López y Delgado (2009)

El modelo de balance hídrico se basa en la ecuación de continuidad la cual se fundamenta en la diferencia que se produce entre las entradas y las salidas de agua (Tabla 1), que se traducen en el agua que queda almacenada (Fórmula 1).

\section{ENTRADAS - SALIDAS = VARIACION DEL ALMACENAMIENTO}

Fórmula 1. Ecuación del Balance Hídrico.

Tabla 1. Factores del Balance Hídrico.

\begin{tabular}{|l|l|}
\hline \multicolumn{1}{|c|}{ Entradas } & \multicolumn{1}{c|}{ Salidas } \\
\hline - Precipitaciones (Iluvia, nieve, granizo) & • Evapotranspiración \\
- Importaciones superficiales de otra cuenca & - Escurrimiento superficial \\
- Retornos de la demanda & $\begin{array}{l}\text { - Evaporación de cuerpos de agua y zonas } \\
\text { urbanas } \\
\end{array}$ \\
& - Demanda interna y externa en la cuenca \\
\hline
\end{tabular}

La precipitación constituye la principal variable del proceso hidrológico para un sistema hídrico, ya que representa la entrada principal de agua al mismo. Resulta importante cuantificar la magnitud y la distribución de las precipitaciones a fin de obtener una respuesta realista del área de estudio. La dificultad e incertidumbre en su evaluación se considera a menudo como la una de las principales fuentes de error en las predicciones de un modelo hidrológico. 
La precipitación incluye la lluvia y otros procesos mediante los cuales el agua cae a la superficie terrestre, tales como granizo, nieve, entre otros. La medición se efectúa por medio de pluviómetros o pluviógrafos; los segundos son utilizados principalmente cuando se trata de determinar precipitaciones intensas de corto período y alta intensidad.

La determinación de los valores precipitados para cada una de las modalidades mencionadas se efectúa con instrumentos especiales estandarizados y registrándose los valores en horarios preestablecidos, con la finalidad de que los valores indicados para localidades diferentes sean científicamente comparables. La altura de precipitación se expresa generalmente en milímetros $(\mathrm{mm})$ e indica la altura del agua de lluvia que cubriría la superficie del suelo en el área de influencia de una estación pluviométrica si pudiese mantenerse sobre la misma sin filtrarse ni evaporarse.

Evapotranspiración se denomina a la evaporación de agua desde el suelo y la transpiración vegetal. La evaporación del agua por las plantas se debe a la necesidad de agua que tienen las plantas para incorporarla a su estructura celular, además de utilizarla como elemento de transporte de alimentos y de eliminación de residuos. La circulación del agua en la planta no es un circuito cerrado, sino que por el contrarío es una circulación abierta. El agua penetra por la raíz, circula por la planta y gran parte de ella se evapora por las hojas.

\subsubsection{Método para el cálculo del Balance Hídrico}

Entre los varios métodos para el cálculo del Balance Hídrico, detallaremos el "método directo", el cual se caracteriza porque el agua del suelo se va perdiendo mes a mes hasta llegar a terminar la reserva para poder cubrir las necesidades de agua (fenómeno de evapotranspiración). El modelo con la información de la temperatura media mensual y precipitación media mensual calcula mes a mes los siguientes parámetros $(\mathrm{mm})$ :

- (ETP) evapotranspiración potencial, que será calculada con el método de Thornthwaite, el cual se describe en la sección 2.3.2.

- $\quad(P-E T P)$ diferencia entre la precipitación y evapotranspiración potencial, es el balance mensual de entradas y salidas potenciales de agua del suelo. La diferencia clasifica los meses en secos si $\mathrm{P}-\mathrm{ETP}<0$ y húmedos si $\mathrm{P}-\mathrm{ETP}>0$, según las entradas superen o no a las salidas potenciales.

- (R) reserva de suelo, cuando en un mes se produzcan más entradas que salidas ( $P>E T P)$ el agua sobrante pasará a ampliar la reserva del suelo, por el contrarío, cuando las salidas sean mayores que las entradas $(E T P>P)$ se reducirá la reserva del suelo. Sin embargo, el suelo tiene una capacidad de retención de humedad en función de sus características físicas y cuando se alcanza la capacidad máxima de retención, el agua añadida en exceso escurrirá superficialmente o percolará en profundidad.

En el balance hídrico, la reserva del mes se calcula agregando los incrementos (P-ETP) cuando estos son positivos. Así la reserva en el mes "i" (función de la del mes anterior "i-1") será según la situación de acuerdo a la Fórmula 2: 


$$
R_{i}=\left\{\begin{array}{lll}
R_{i-1}+\left(P_{i}-E T P_{i}\right) & \text { si } & 0<R_{i-1}+\left(P_{i}-E T P_{i}\right)<R_{\max } \\
R_{\max } & \text { si } & R_{i-1}+\left(P_{i}-E_{T} T P_{i}\right)>R_{\max } \\
0 & \text { si } & 0>R_{i-1}+\left(P_{i}-E T P_{i}\right)
\end{array}\right.
$$

Fórmula 2. Cálculo de la reserva del mes "i”.

Los valores de la reserva se irán acumulando mes a mes en el período húmedo, según los incrementos P-ETP>0, y disminuirán al llegar el período seco, decreciendo mes a mes según los valores mensuales $\mathrm{P}-\mathrm{ETP}<0$. Así la reserva nunca tendrá un valor mayor que la reserva máxima ni será negativo.

Como se muestra en la Fórmula 2, se necesita conocer la reserva del mes anterior para comenzar el cálculo de la reserva actual, por tanto, se asigna un valor hipotético a un mes y se realizan los ciclos anuales de cálculos hasta que la hipótesis se confirme al final del ciclo. A los efectos del cálculo, se suele suponer que después del período seco la reserva del suelo es nula, en consecuencia se empieza el cálculo de "R" con el primer mes húmedo y se asigna al mes anterior una reserva nula. Si después de los cálculos, al final del período seco hubiera agua en el suelo, se deberá recalcular la reserva agregando la existente al final del período seco a las reservas del período húmedo. Si de nuevo se modificase la reserva del último mes seco se volvería a calcular otra vez la reserva.

En el caso de que todos los meses sean húmedos se utilizan los supuestos anteriores, considerando que la reserva es igual a la reserva máxima para todos los meses. Por el contrarío, si todos los meses son secos la reserva será nula en todo los meses.

- (VR) variación de la reserva, es la diferencia entre la reserva del mes en el que se está realizando el cálculo y la reserva del mes anterior (Fórmula 3):

$$
V R_{i}=R_{i}-R_{i-1}
$$

Fórmula 3. Cálculo de la variación de la reserva

- (ETR) evapotranspiración real, es el volumen de agua que realmente se evapotranspira en el mes dependiendo de que haya suficiente agua disponible para evaporar y así llegar a la ETP (por tanto, la ETP es siempre mayor o igual a la ETR). El agua disponible para evaporarse será la que cae como precipitación en el mes considerado y la existente en la reserva del suelo. En el período húmedo, al cubrir la precipitación la demanda potencial la ETR es igual a la ETP (Fórmula 4):

$$
\mathrm{ETR}_{\mathrm{i}}=\mathrm{ETP}_{\mathrm{i}}
$$

Fórmula 4. Cálculo de la evapotranspiración real para el período húmedo

En el período seco, el agua que se evapora será el agua de precipitación más la que extraemos del suelo o variación de la reserva (la reserva menos la del mes anterior, como tendrá signo negativo se toma el valor absoluto) (Fórmula 5): 


$$
\mathrm{ETR}_{\mathrm{i}}=\mathrm{P}_{\mathrm{i}}+\mid \mathrm{VR} \mathrm{R}_{\mathrm{i}}
$$

Fórmula 5. Cálculo de la evapotranspiración real para el período seco

- Déficit o falta de agua, es el volumen de agua que falta para cubrir las necesidades potenciales de agua (para evaporar y transpirar). Por tanto el déficit es (Fórmula 6):

$$
\text { Déficit }=E T P_{i}-E T R_{i}
$$

Fórmula 6. Cálculo del déficit de agua.

- Excedentes o exceso de agua, es el agua que excede a la reserva máxima y que se habrá perdido por escorrentía superficial o percolación profunda. (Fórmula 7):

$$
\begin{aligned}
& \text { Excedentes }_{\mathrm{i}}=\left[\mathrm{P}_{\mathrm{i}}-\mathrm{ETP}_{\mathrm{i}}-\mathrm{VRi}\right] \text { si }\left(\mathrm{P}_{\mathrm{i}}-\mathrm{ETP}_{\mathrm{i}}\right)>0 \\
& \text { Excedentes }_{\mathrm{i}}=\quad 0 \quad \text { si }\left(\mathrm{P}_{\mathrm{i}}-\text { ETP }_{\mathrm{i}}\right) \leq 0
\end{aligned}
$$

Fórmula 7. Cálculo de los excedentes.

Solo puede haber excesos si la precipitación ha compensado previamente la ETP, es decir, en los meses húmedos.

\subsubsection{Cálculo de la Evapotranspiración Potencial}

Con objeto de valorar la capacidad máxima de evaporación y transpiración de un suelo, con determinadas condiciones atmosféricas y de radiación, se define el concepto de Evapotranspiración Potencial como la cantidad de agua transpirada por unidad de tiempo, teniendo el suelo un cultivo herbáceo uniforme de 30-50 cm. de altura y siempre con suficiente agua. En esas condiciones se produce el máximo de transpiración y coincide con las óptimas condiciones de crecimiento de las plantas.

Los cálculos de Thornthwaite (1984) están basados en la determinación de la evapotranspiración en función de la temperatura media mensual, con una corrección en función de la duración astronómica del día y el número de días al mes.

Thornthwaite comprobó que la evapotranspiración es proporcional a la temperatura media afectada por un coeficiente exponencial "a", donde Monsalve (2000) propuso la Fórmula 8:

$$
E_{j}=16 *\left(10^{*} t_{j} / I\right)^{a}
$$

Fórmula 8. Cálculo de la Evapotranspiración Potencial según Thornthwaite sin ajustar Donde:

$E_{j}=$ Evapotranspiración potencial mensual sin ajustar en mm 
$\mathrm{t}_{\mathrm{j}}=$ Temperatura media mensual en ${ }^{\circ} \mathrm{C}$

I = Índice de calor anual

$$
I=\sum i_{j} ; j=1,2, \ldots, 12
$$

Fórmula 9. Cálculo del Índice de calor anual.

Se calcula a partir del índice de calor mensual i, como suma de los doce índices de calor mensuales:

$$
\mathrm{i}_{\mathrm{j}}=\left(\mathrm{t}_{\mathrm{j}} / 5\right)^{1,514}
$$

Fórmula 10. Cálculo del índice de calor mensual.

a = Parámetro que se calcula en función de I, según la expresión:

$$
a=0,\left.000000675^{\star}\right|^{3}-0,\left.0000771^{*}\right|^{2}+0,01792^{*} \mid+0,49239
$$

Fórmula 11. Cálculo del factor "a".

Para el cálculo de la ETP de Thornthwaite de un mes determinado es necesario corregir la ETP sin ajustar "E." mediante coeficiente que tenga en cuenta el número de días del mes y horas de luz de cada día, en función de la latitud. Para lo cual se introduce el índice de iluminación mensual en unidades de 12 horas, que deberá multiplicar a la ETP sin ajustar (Ej) para obtener la ETP según Thornthwaite ( $\mathrm{mm} / \mathrm{mes})$ (Fórmula 12).

$$
E P_{\text {tho }}=E_{j}{ }^{*} L_{i}
$$

Fórmula 12. Evapotranspiración potencial de Thornthwaite ajustada.

Donde:

$\mathrm{ETP}_{\mathrm{th}}$ : Evapotranspiración potencial de Thornthwaite $(\mathrm{mm})$

$E_{j}$ : Evapotranspiración mensual sin ajustar ( $m m$ )

$\mathrm{L}_{\mathrm{i}}$ : Factor de corrección del número de días del mes $\left(\mathrm{Nd}_{\mathrm{i}}\right)$ y la duración astronómica del día $\mathrm{N}_{\mathrm{i}}$ (horas de sol).

$$
\mathrm{L}_{\mathrm{i}}=\mathrm{Nd}_{\mathrm{i}} / 30 * \mathrm{~N}_{\mathrm{i}} / 12
$$

Fórmula 13. Cálculo del factor de corrección solar.

Para obtener la información del número de horas de sol, $\mathrm{N}_{\mathrm{i}}$, existen Tablas diseñadas específicamente para este tema en función de la latitud. En el anexo se presenta la Tabla usada para este análisis. 


\subsection{Estimación del Caudal Líquido}

\subsubsection{Generalidades}

El caudal líquido de una cuenca hidrográfica está constituido por el escurrimiento, al cual se lo puede definir como "el agua procedente de la precipitación que circula sobre o bajo la superficie terrestre y que llega a una corriente para finalmente ser drenada hasta la salida de la cuenca" (Aparicio, 1992)

Las primeras gotas de la precipitación son interceptadas y almacenadas por las plantas, luego de un tiempo estas gotas llegan a la superficie del suelo donde se infiltran a través de las capas de restos vegetales o se almacena en depresiones para continuar el proceso de percolación hacia las capas subterráneas. Durante este proceso el agua va tomando diferentes escurrimientos, así tenemos el escurrimiento superficial, escurrimiento subsuperficial y escurrimiento subterráneo.

Montoya (2010) en sus apuntes de clase de Hidrología, realiza una explicación de los diferentes escurrimientos, estableciendo que el escurrimiento superficial es el producto del agua de la precipitación que no infiltra y que escurre sobre la superficie del suelo y red de drenaje hasta la salida de la cuenca. Considera que su efecto sobre el escurrimiento total es "directo" y solo existirá durante una tormenta o inmediatamente después que esta haya terminado. La parte de la lluvia que contribuye al escurrimiento superficial se llama "precipitación en exceso".

El escurrimiento subsuperficial está constituido por la parte de la precipitación que infiltró en el suelo pero que se mueve horizontalmente sobre el horizonte superior del mismo, debido a un estrato impermeable paralelo a la superficie del suelo, que dependiendo de las características de este, el efecto puede ser rápido considerándolo como escurrimiento superficial, y si es lento se los considera escurrimiento subterráneo.

El escurrimiento subterráneo viene del agua subterránea o zona saturada la cual es recargada por el agua de la precipitación que se infiltra por el suelo una vez que esta se ha saturado. En ocasiones este escurrimiento puede llegar a un río el cual para un análisis de escurrimiento total se denomina escurrimiento "base". Se considera que el escurrimiento total está compuesto por el escurrimiento directo y el escurrimiento base.

\subsubsection{Factores que influyen en el escurrimiento}

Gaspari et al., (2009), indica que el volumen total del escurrimiento y sus valores máximos están influenciados directa o indirectamente por factores de naturaleza climática, de naturaleza fisiográfica y de naturaleza humana. Los mismos se pueden caracterizar de la siguiente manera:

a) Factores climáticos: relacionado con la intensidad y duración de las precipitaciones que determinan el volumen total de agua escurrida en la cuenca, cuanto mayor intensidad más rápido el suelo cumple el proceso de infiltración y el exceso de lluvia producirá escorrentía superficial. Las lluvias de baja intensidad y larga duración 
saturan la capacidad de retención del suelo. También está relacionada con la precipitación antecedente, ya que estando el suelo húmedo debido a una lluvia anterior, es más rápido la generación de escorrentía.

b) Factores fisiográficos: relacionados con las características físicas de la cuenca, que pueden ser, el área, la forma y pendiente media de la cuenca, permeabilidad, geología, tipo de suelo, labores de cultivo, densidad de drenaje, capacidad de evacuación, entre otros.

c) Factores humanos: relacionado con las actividades humanas, por ejemplo obras hidráulicas construidas dentro de la cuenca como represas que al acumular agua reduce los caudales máximo de escorrentía superficial; la rectificación de un río que puede aumentar la velocidad de la escorrentía superficial en el tramo rectificado.

\subsubsection{Variables que caracterizan el escurrimiento}

a) Caudal.- es el volumen de la escorrentía superficial por unidad de tiempo, se lo representa con la letra $Q$. Se expresa en $\mathrm{m}^{3} / \mathrm{seg}$ o l/seg.

Caudal específico (q), se define como el caudal $Q$ dividido por el área $A$ de la cuenca. Se expresa en $\mathrm{m}^{3} / \mathrm{seg} / \mathrm{km}^{2}$ ol $/ \mathrm{seg} / \mathrm{km}^{2}$

Caudales máximos, medios y mínimos, es necesario conocer estos datos para realizar diferentes análisis de manejo, se miden en intervalos de tiempo determinados, como hora, día, mes y año.

b) Coeficiente de escorrentía.- es la relación entre el volumen de agua de escorrentía superficial total y el volumen total de agua precipitada en un período de tiempo especifico. Se lo representa con la letra c.

c) Tiempo de concentración.- es el tiempo que tarda en llegar al punto de aforo la última gota de lluvia que cae en el punto más lejano de la cuenca. Se mide en minutos u horas. Se expresa $t_{c}$

d) Período de retorno.- es el período de tiempo promedio en años en que un determinado evento vuelve a ocurrir. Se expresa con la letra $\mathrm{T}$.

e) Nivel.- es la altura que alcanza el nivel del río en relación a un nivel de referencia. Se mide en metros o centímetros y se representa con la letra $h$.

\subsection{Modelos Hidrológicos}

Con el desarrollo de la tecnología, en la actualidad, el conjunto computadora-programa facilita simular un sin número de fenómenos y acontecimientos físicos o naturales. Para nuestro caso de estudio, permitirá reproducir todos los procesos que conforman el ciclo hidrológico, proporcionando de esta manera al investigador un modelo que permita simular 
diferentes situaciones para determinar el grado de impacto sobre uno o varios de los procesos que conforman este ciclo, además de su bajo costo y la estimación razonable de sus resultados, aún cuando la cantidad de información no sea periódica y directa.

"Un modelo es una representación simplificada de un sistema, por lo cual debe necesariamente despreciar variables del sistema real en función del objetivo para el cual, fue o será creado. Un modelo está compuesto por variables o elementos interrelacionados en un intervalo de tiempo, que actúan (procesos) sobre una entrada (materia, energía o información) de manera controlada bajo ciertas restricciones para producir una salida (materia, energía o información)" (Gaspari et al., 2009).

Los modelos en general se dividen en tres categorías:

1.- Modelos físicos: representan el sistema real en una determinada escala.

2.- Modelos analógicos: analizan un sistema a partir de otro regido por leyes similares.

3.- Modelos matemáticos: el sistema se representa por ecuaciones matemáticas y sentencias lógicas que expresan las relaciones entre variables y parámetros.

La mayoría de los modelos utilizados en hidrología corresponden a los modelos matemáticos para lo cual requieren el uso de computadoras. Se dividen en dos grandes grupos:

1.- Modelos Determinísticos: cuando se tiene conocimiento suficiente sobre el fenómeno para poder describir su comportamiento por medio de una función matemática, se considera exacta y explica toda su variabilidad.

2.- Modelos Estocásticos: las variables son regidas por leyes del azar, por tanto la respuesta se obtiene en términos de probabilidad. Necesita la existencia de datos que permiten caracterizar las variables.

Los modelos de tipo determinísticos serán utilizados en este trabajo debido al alcance temporal y espacial, que respectivamente se clasifican en:

1.- Modelos Continuos: se caracterizan porque están enfocados hacia la estimación a corto y mediano plazo a partir de datos observados que pueden incluirse predicciones meteorológicas como datos de entrada. Un ejemplo de este es el modelo SWAT.

2.- Modelos Agregados: el alcance espacial de este tipo de modelos se limita a un punto, considera a las cuencas y subcuencas como unidades de trabajo, cada unidad es tratada como un promedio ponderado de la superficie real. Un ejemplo es el modelo HEC-HMS ${ }^{\circledR}$.

Los modelos hidrológicos de simulación son un instrumento de predicción basado en procesos de hidrología y erosión. Estos modelos son herramientas valiosas para evaluar el efecto de prácticas de manejo sobre ambiente, escurrimiento, producción de sedimentos, erosión y productividad. La importancia de los modelos radica, entre otros aspectos, en la 
predicción de fenómenos a largo plazo instantáneamente, también permite obtener relaciones de causa-efecto, sin haber realizado cambios en los sistemas reales (TorresBenites et al., 2004).

Debido a que los modelos hidrológicos son una representación simplificada e incompleta de la realidad, es importante a la hora de elegir un modelo considerar el objetivo para el que fue creado, la exactitud de la respuesta, las rutinas y subrutinas que los componen y las variables de entrada que utiliza, estas últimas son las más difíciles debido a la disponibilidad de datos, al costo y tiempo que lleva hacer el levantamiento (Gaspari et al., 2009).

La mayor limitante de los modelos hidrológicos está representada por las técnicas de medición de los fenómenos del mundo real, para lo cual se diseñaron modelos de simulación de diferentes tipos los cuales proveen métodos de extrapolación cuantitativa o de predicción, permitiendo simular situaciones de un sistema hidrológico real cuando los datos son insuficientes.

\subsubsection{Modelo Hidrológico HEC-HMS $®$}

\section{$\underline{\text { 2.5.1.1 Generalidades }}$}

El Centro de Ingeniería Hidrológica del Cuerpo de Ingenieros de los Estados Unidos (U.S. Corps of Engineers) diseñó el modelo computacional HEC-HMS $®$ (Hydrological Engineers Center-Hydrologic Modeling System) para simular procesos de precipitación-escurrimiento en cuencas con drenaje dendrítico, mediante un sistema que integra diferentes métodos hidrológicos ya sean concentrados o distribuidos para tener como respuesta el tránsito de caudales. Esta característica del modelo permite flexibilidad combinando diferentes métodos de cálculo para cada parámetro que se desea obtener, logrando una mejor aproximación al sistema real.

El programa tiene una interfaz gráfica que facilita al usuario la visualización de la aplicación de la cuenca de estudio, introducir datos, añadir componentes y observar los resultados, además la posibilidad de conectarse a un Sistema de Información Geográfica.

El HEC-HMS $®$ es utilizado para obtener, por medio de simulación, el escurrimiento de una cuenca hidrográfica. Para ello, el programa requiere la especificación de los modelos de cuenca, modelos meteorológicos, especificaciones de control y datos de entrada, para crear corridas de precipitación o de la proporción de flujo. Los resultados de la simulación se pueden visualizar en pantalla, generar tablas de toda la información obtenida o por elementos que incluyen datos sobre el flujo máximo y el volumen total e imprimir.

Su aplicación es muy amplia, cuyos hidrogramas generados pueden ser utilizados directamente o con otros programas para el estudio de disponibilidad de agua, problemas relacionados a inundaciones, cálculo de drenaje urbano, pronósticos de flujo, impacto de futuras urbanizaciones, diseño de aliviaderos para represas, predicción de inundaciones, reducción de daños por inundaciones, entre otras. Su obtención es gratuita y se encuentra disponible en Internet en la dirección http://www.hec.usace.army.mil/software/HECHMS/download.html. 
El programa utiliza cuatro procesos de simulación hidrológica (Silva et al., 2005), que se describen a continuación:

- Las pérdidas por infiltración (Loss method). Separación de la lluvia neta, permite calcular que parte de la precipitación caída va a generar escorrentía directa. Pueden ser simuladas mediante diferentes métodos, como se presenta en la Tabla 2.

Tabla 2. Modelos de volumen de escurrimiento.

\begin{tabular}{|l|lll|}
\hline \multicolumn{1}{|c|}{ MODELO } & \multicolumn{3}{|c|}{ CARACTERIZACIÓN } \\
\hline Inicial y de tasa constante & $\begin{array}{l}\text { Evento, concentrado, empírico, ajuste de } \\
\text { parámetros }\end{array}$ & de \\
\hline Número de curva SCS (CN) & $\begin{array}{l}\text { Evento, concentrado, empírico, ajuste de } \\
\text { parámetros }\end{array}$ & $\begin{array}{l}\text { Evento, distribuido, empírico, ajuste de } \\
\text { parámetros }\end{array}$ \\
\hline CN de malla SCS CN & $\begin{array}{l}\text { Evento, distribuido, empírico, ajuste de } \\
\text { parámetros }\end{array}$ \\
\hline Green and Ampt & $\begin{array}{l}\text { Continuo, concentrado, empírico, ajuste de } \\
\text { parámetros }\end{array}$ \\
\hline $\begin{array}{l}\text { Contabilización de humedad } \\
\text { del suelo (SMA) }\end{array}$ & $\begin{array}{l}\text { Continuo, concentrado, empírico, ajuste de } \\
\text { parámetros }\end{array}$ \\
\hline SMA de malla & $\begin{array}{l}\text { Continuo, distribuido, empírico, ajuste de } \\
\text { parámetros }\end{array}$ \\
\hline
\end{tabular}

- Las transformaciones (Transform method). Calcula la escorrentía directa producida por la lluvia neta. Utiliza varios métodos: Hidrogramas Unitario, incluye Clark, Zinder y SCS, así como incluir su propio Hidrograma Unitario, en la Tabla 3, se muestran algunos.

Tabla 3. Modelos de escurrimiento directo

\begin{tabular}{|l|lll|}
\hline \multicolumn{1}{|c|}{ MODELO } & \multicolumn{3}{|c|}{ CARACTERIZACIÓN } \\
\hline $\begin{array}{l}\text { Hidrograma unitario } \\
\text { especificado por el usuario } \\
\text { (HU) }\end{array}$ & $\begin{array}{l}\text { Evento, concentrado, empírico, ajuste de } \\
\text { parámetros }\end{array}$ \\
\hline Hidrograma unitario de Clark & $\begin{array}{l}\text { Evento, concentrado, empírico, ajuste de } \\
\text { parámetros }\end{array}$ \\
\hline $\begin{array}{l}\text { Hidrograma unitario de } \\
\text { Snyder }\end{array}$ & $\begin{array}{l}\text { Evento, concentrado, empírico, ajuste de } \\
\text { parámetros }\end{array}$ \\
\hline Hidrograma unitario SCS & $\begin{array}{l}\text { Evento, concentrado, empírico, ajuste de } \\
\text { parámetros }\end{array}$ \\
\hline ModClark & $\begin{array}{l}\text { Evento, distribuido, empírico, ajuste de } \\
\text { parámetros }\end{array}$ \\
\hline Onda cinemática & $\begin{array}{l}\text { Continuo, concentrado, empírico, ajuste de } \\
\text { parámetros }\end{array}$ \\
\hline
\end{tabular}

- El Caudal Base (Baseflow method). Suma a la escorrentía directa la escorrentía base, en la Tabla 4, se presentan los métodos. 
Tabla 4. Modelos de Flujo Base.

\begin{tabular}{|l|l|}
\hline \multicolumn{1}{|c|}{ MODELO } & \multicolumn{1}{c|}{ CARACTERIZACIÓN } \\
\hline Mensual constante & Evento, concentrado, empírico, ajuste de parámetros \\
\hline Recepción exponencial & Evento, concentrado, empírico, ajuste de parámetros \\
\hline Reservorio lineal & Evento, concentrado, empírico, ajuste de parámetros \\
\hline
\end{tabular}

- El tránsito en canales (Routing). Calcula cómo evoluciona un hidrograma a medida que discurre a lo largo de un cauce o a través de un embalse. Incluye los métodos de Lag, Muskingum, Muskingum-Cunge, Onda Cinemática, entre otros, como se muestra en la Tabla 5.

Tabla 5. Modelos de tránsito de caudales.

\begin{tabular}{|l|l|}
\hline \multicolumn{1}{|c|}{ MODELO } & \multicolumn{1}{|c|}{ CARACTERIZACION } \\
\hline Onda cinemática & $\begin{array}{l}\text { Evento, concentrado, conceptual, parámetro } \\
\text { medido }\end{array}$ \\
\hline Tiempo de retardo & $\begin{array}{l}\text { Evento, concentrado, empírico, ajuste de } \\
\text { parámetros }\end{array}$ \\
\hline Plus modificado & $\begin{array}{l}\text { Evento, concentrado, empírico, ajuste de } \\
\text { parámetros }\end{array}$ \\
\hline Muskingum concentrado, empírico, ajuste de \\
\hline $\begin{array}{l}\text { Muskingum - Cunge. } \\
\text { Sección estándar }\end{array}$ & $\begin{array}{l}\text { Evento, concentrado, cuasi - conceptual, } \\
\text { parámetro medido }\end{array}$ \\
\hline $\begin{array}{l}\text { Muskingum - Cunge. } \\
\text { Sección de 8 puntos }\end{array}$ & $\begin{array}{l}\text { Evento, concentrado, cuasi - conceptual, } \\
\text { parámetro medido }\end{array}$ \\
\hline Confluencia & Continuo, conceptual, parámetro medido \\
\hline bifurcación & Continuo, conceptual, parámetro medido \\
\hline
\end{tabular}

El modelo, de acuerdo a los datos ingresados, identifica las subcuencas en las cuales ejecuta los análisis de las tres primeras fases indicadas. Posteriormente, suma todos los escurrimientos generados y transitados y genera el hidrograma de salida de la cuenca.

\subsubsection{Funcionamiento del Modelo}

El programa tiene una interfaz gráfica que permite introducir la información necesaria para la simulación, manejar los componentes de análisis hidrológico y obtener respuestas en formato de gráfico o tablas.

Para definir la estructura de las subcuencas, el programa dispone de los siguientes elementos hidrológicos:

a) Subcuencas (subbasins)

b) Cauces o tramos de transito (reach)

c) Uniones o confluencias (junctions) 
d) Embalses o almacenamientos (reservoirs)

e) Fuentes (sources)

f) Sumideros o salidas (sinks)

g) Derivaciones o tomas (diversions)

Los cálculos son realizados en una secuencia aguas abajo desde el punto más elevado, desde las subcuencas que conforman las cabeceras aguas arriba hasta el punto de salida de todo el caudal aguas abajo.

El programa funciona con tres modelos básicos que definen en su conjunto el proyecto de simulación hidrológica de la cuenca en estudio:

\section{Modelo de Cuenca}

Representa a la cuenca física, se encuentran los parámetros de los elementos hidrológicos indicados anteriormente, el usuario manipula este modelo añadiendo y conectando elementos para simular el proceso de escorrentía

\section{Modelo Meteorológico}

Consiste en calcular la entrada de precipitación requerida por un elemento, se pueden introducir los datos de precipitación del evento a simular y puede modelar lluvia congelada o liquida junto con evaporación. Dentro de este modelo ingresamos los datos de los pluviógrafos que se van a utilizar y se asigna a cada subcuenca.

\section{Modelo de Control}

Se define el lapso de tiempo de la simulación, es decir, se especifica la fecha y hora de inicio y termino de la precipitación, con un intervalo de tiempo que puede variar según nuestra necesidad.

\section{Datos de Entrada}

Los datos de entrada al modelo está relacionada con los métodos de cálculo que se van a operar. Así tenemos que son cinco grupos básicos de información que debe proveerse al modelo para realizar las simulaciones:

1. Precipitación histórica o de diseño.

2. Características del suelo.

3. Información morfométrica de las subcuencas.

4. Datos hidrológicos del proceso de transformación de lluvia en escorrentía.

5. Características hidráulicas de los tramos de canal y de la capacidad de los embalses (métodos de tránsito).

Para calibrar, validar y realizar el análisis de sensibilidad del modelo, además se necesitan: 
1. Registros concordantes de precipitación y caudales de salida (hietogramas e hidrogramas).

2. Determinación de las condiciones iniciales de humedad en los suelos.

En la Figura 5 se representa la forma como el programa HEC-HMS® genera el escurrimiento.

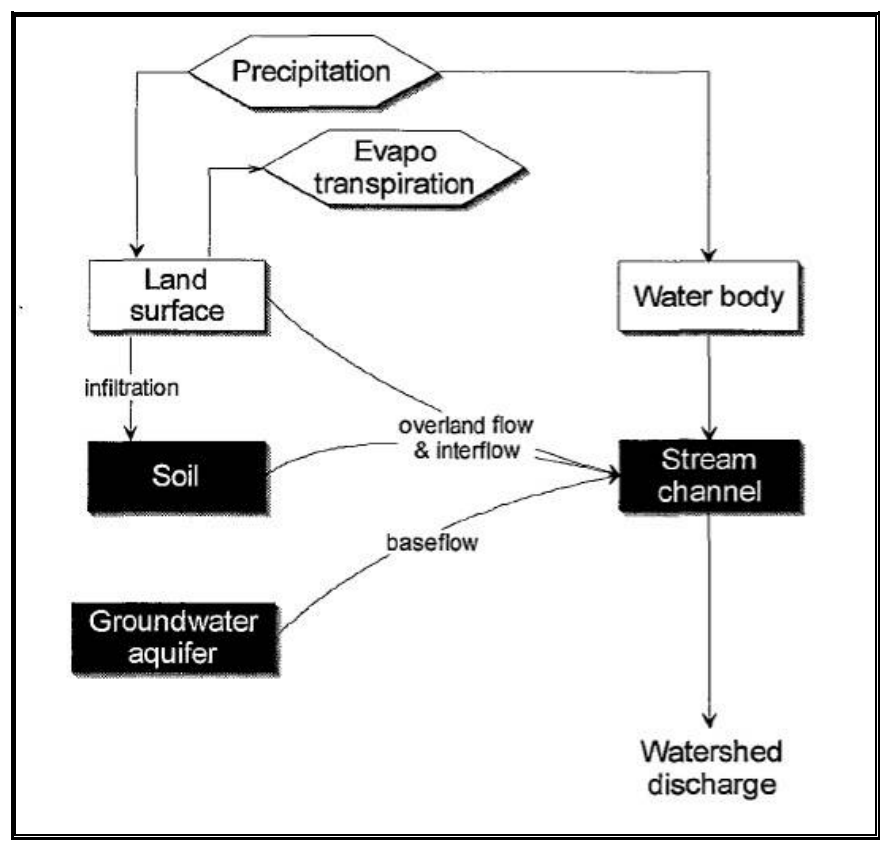

Figura 1. Representación del escurrimiento según HEC-HMS®. Según Feldman (2000)

\subsection{Estimación del caudal sólido. Erosión hídrica superficial}

Se entiende por erosión hídrica al proceso de disgregación y transporte de las partículas de suelo por la acción del agua. El proceso se inicia cuando las gotas de lluvia se precipitan sobre el suelo con suficiente energía para remover sus partículas siendo liberadas y transportadas por la escorrentía superficial hacia los flujos de drenaje. El proceso termina cuando los materiales transportados por las corrientes son acumulados en áreas de sedimentación impidiendo el flujo de las partículas de sedimentos previamente incorporadas al mismo (Mintegui Aguirre y López Unzú, 1990) (Michelena Roberto, 2011)

En la erosión hídrica deben distinguirse dos componentes:

- Acción de las precipitaciones.- cuando la gota de lluvia cae sobre el suelo desnudo golpea la superficie del suelo con tanto poder que produce la disgregación de los agregados del suelo y separación de las partículas individuales, proyectándolas al aire. Este efecto es conocido como "erosión por salpicadura". Mientras mayor intensidad de la lluvia mayor su efecto erosivo. 
- Acción del escurrimiento.- esta acción presenta dos componentes: disgrega los elementos terrosos y al mismo tiempo transporta aquellas partículas que por su tamaño y forma son susceptibles al arrastre. Si a esta acción de disgregación le sumamos la acción de las precipitaciones más los diferentes procesos de meteorización, tendremos como resultado la primera fase de la erosión o formación de elementos susceptibles de ser arrastrados. El grado y longitud de la pendiente son muy importantes en la generación del escurrimiento.

La acción del escurrimiento superficial depende del régimen de las lluvias y de las características hidrológicas del suelo (capacidad de infiltración) ya que la precipitación que llega al suelo puede evaporarse, infiltrarse o quedar en almacenamientos superficiales para posteriormente ponerse en movimiento.

\subsubsection{Factores físicos determinantes en la erosión hídrica}

Gaspari et al., (2009), describen los factores físicos que condicionan el proceso de erosión hídrica, agrupándolos en 4 categorías principales:

\section{1.- $\quad$ Factores climáticos}

Las precipitaciones, que al ser consideradas en el espacio y tiempo, se establecen como unidad natural el aguacero. La intensidad, duración y frecuencia son las características más importantes en la erosión.

La temperatura, influye en forma directa sobre la vida, las temperaturas altas descomponen rápidamente la materia orgánica, haciendo que el suelo pierda la capacidad de absorción de agua, resultando un mayor escurrimiento.

\section{2.- $\quad$ Factores edáficos.-}

El suelo, los factores como la textura, la agregación del suelo, la distribución de las partículas, la permeabilidad del perfil, la humedad inicial del suelo y la pedregosidad superficial son importantes en la erodabilidad del suelo. Los suelos con estructuras bien desarrolladas, estables y son más resistentes a la erosión, absorbiendo las lluvias más rápidamente y reduciendo la magnitud de la acción del escurrimiento.

3.- $\quad$ Factores topográficos.-

El grado de inclinación del suelo, tiene marcada influencia en la magnitud de la erosión debido a que las pérdidas de suelo son mucho mayores en los terrenos de pendientes pronunciadas. La erosión hídrica no se produce en zonas llanas. La longitud de la pendiente, toma importancia, teniendo en cuenta que la velocidad del escurrimiento responde a un movimiento uniformemente acelerado.

La orientación de las laderas, bajo algunas condiciones climáticas, y especialmente cuando las pendientes superan el $3 \%$, existe una relación entre la magnitud de la erosión y la orientación del terreno. Las laderas con orientación al sur están expuestas a menor radiación solar, como consecuencia de ello el suelo posee un 
mayor contenido de humedad provocando más escurrimiento que una ladera con exposición norte.

4.- Cobertura vegetal.-

La parte superior de la cubierta vegetal intercepta la lluvia protegiendo al suelo del impacto directo de las gotas de lluvia, gracias al efecto de amortiguamiento de las gotas disminuyendo su energía cinética inicial. (Michelena Roberto, 2011)

La vegetación contribuye a la disminución de la escorrentía superficial y a decrecer los caudales máximos de avenidas, debido a que aumenta la permeabilidad del suelo incrementando la infiltración, y también disminuye la velocidad de la lámina de escurrido. Este último aspecto considera que la velocidad de agua en una ladera, cubierta de vegetación densa es del orden de la cuarta parte de la velocidad que existiría en esa misma ladera pero con suelo desnudo. (Mintegui Aguirre y López Unzú, 1990).

Las raíces de las plantas protegen el suelo y mejoran su estructura, la infiltración y la capacidad de retención de agua, además de retardar el escurrimiento. La cubierta vegetal también influye en los efectos del sol y el viento sobre la superficie del suelo.

\subsubsection{Formas de erosión}

Existen dos formas generales de erosión causadas por la acción del agua sobre el suelo: erosión superficial y movimientos en masa. En la Figura 6 se presenta un cuadro sinóptico de las formas de erosión según Gaspari et al., (2009). 


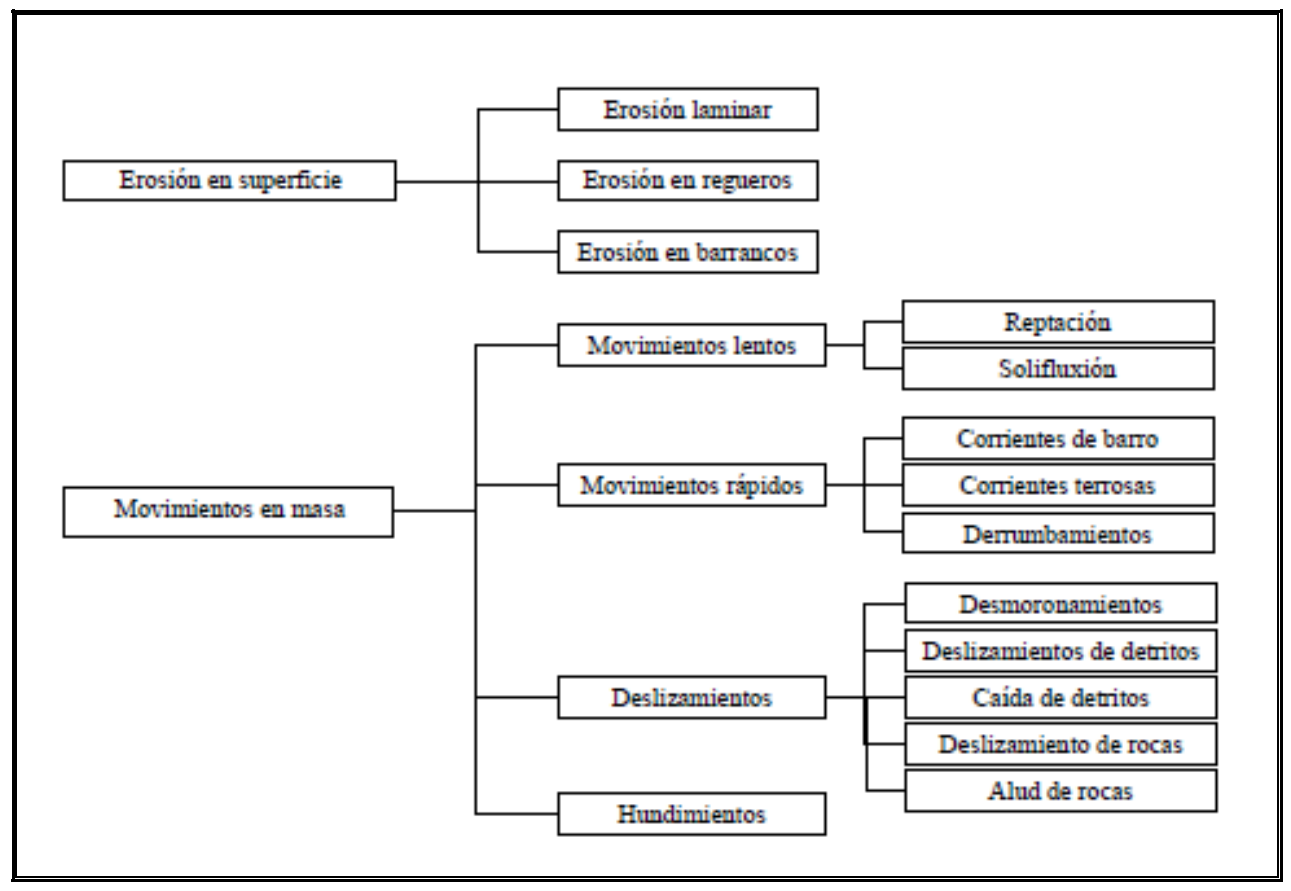

Figura 2. Cuadro sinóptico de los tipos de erosión hídrica.

A continuación se describe las principales formas de erosión en superficie:

\section{Erosión Laminar}

Es aquella en la que se presenta la remoción de delgadas capas de suelo extendidas más o menos uniformemente en toda la superficie. Se la considera como altamente perjudicial debido a las grandes cantidades de sedimentos que aporta a los cursos de agua, además afecta a las partículas más finas del suelo reduciendo la fertilidad de la tierra. Su presencia se manifiesta a través de los siguientes síntomas: plantas con sistema radical al descubierto, presencia de montículos en el suelo, pedregosidad e invasión de especies vegetales especificas de suelos degradados, pérdida total o parcial del horizonte superior y afloramiento del subsuelo.

\section{Erosión digital o pequeños surcos}

Se forman pequeños surcos de menos de $20-30 \mathrm{~cm}$ de profundidad, producidos por el escurrimiento concentrado del agua, en pendientes suaves del terreno.

Su formación se encuentra asociada a las irregularidades y desnivel del terreno siendo favorecida por las lluvias de gran intensidad, lo que facilita identificarlas rápidamente permitiendo la implementación de medidas correctivas oportunamente.

\section{Erosión en cárcavas.}

Son profundas incisiones en el terreno originadas, generalmente, cuando existe una gran concentración de escurrimiento en una zona determinada. Su formación suele 
estar precedida de fuertes erosiones laminares y en regueros que no fueron corregidas a tiempo, sin embargo pueden surgir también como producto de un solo evento pluvial de características torrenciales sobre suelos inestables. Sus perfiles pueden tener formas de $\mathrm{U} \circ \mathrm{V}$, dependiendo de la consistencia que presenta el perfil del suelo y la distribución de sus horizontes. Se originan en pendientes fuertes y largas.

\subsubsection{Método de estimación del caudal sólido}

El fenómeno erosivo, según sea en superficie o por movimientos en masa, tiene diferentes mecanismos que lo originan y que se diferencian básicamente en sus variadas formas de manifestarse en cada caso. Sea la forma en la que se presente la erosión, lo común es que, tanto se produzca en el área de la cuenca vertiente, como se manifieste en los márgenes y lecho de los cauces efluentes, siempre será origen del caudal sólido arrastrado por las avenidas o por las simples corrientes que drenan por la cuenca.

Dentro de los fenómenos de erosión superficial en la cuenca vertiente, se destacan por su importancia y objeto del presente trabajo de investigación, la erosión laminar y digital, para los cuales se han desarrollado diferentes métodos de estimación del caudal sólido basados en la utilización de parámetros factoriales que intervienen en el proceso. Uno de esos métodos y que será aplicado en este trabajo, es el modelo paramétrico U.S.L.E. o Ecuación Universal de Pérdida de Suelo (por sus siglas en ingles).

\subsubsection{Modelo U.S.L.E.}

La Ecuación Universal de Pérdida de Suelo (U.S.L.E.) por erosión laminar, que establecieron W.H. Wischmeier y D.D Smith en 1965, es el resultado de más de cuarenta años de investigaciones y experiencias sobre los parámetros que en ella intervienen, en base a los datos proporcionados por más de 10.000 parcelas año, repartidas por las principales áreas agrícolas de los Estados Unidos, contribuyendo a una mayor precisión su determinación y en consecuencia mejor definición del modelo (Mintegui Aguirre y López Unzú, 1990).

Este modelo matemático de origen empírico, permite estimar la pérdida promedio anual del suelo en tierras agrícolas (tasa de erosión hídrica en Megagramos por hectárea de superficie durante un año) para diferentes sistemas de uso y manejo de unidades de suelos y poder compararla con las tasas de tolerancia aceptables de erosión para ese suelo, si la tasa de erosión es superior a la tasa aceptable, el sistema agropecuario no es sustentable y por lo tanto se debe mejorar algún manejo que permita un control adecuado de la erosión.

La expresión para el cálculo del modelo U.S.L.E. se la representa en la Fórmula 14:

$$
A=R * K * L S * C * P
$$

Fórmula 14. Expresión matemática para determinar la pérdida de suelo según U.S.L.E. 


\section{Modelización Hidrológica de un área experimental en la Cuenca del Rio Guayas}

Donde:

A: Pérdida de suelo promedio anual (Mg.ha/año)

R: Factor de erosión pluvial o de erosionabilidad de la lluvia (MJ.mm/ha.hr.año)

K: Factor de erodabilidad del suelo (Mg.ha.hr/ha.MJ.mm)

LS: Factor topográfico; L: factor longitud de pendiente, S: factor gradiente de pendiente.

C: Factor de ordenación de cultivos

P: Factor de prácticas de conservación de suelos

Nota: los cuatro últimos factores son adimensionales (L, S, C, P)

El producto de estas seis variables estima la erosión hídrica actual para una situación determinada de precipitación, tipo de suelo, topografía del suelo y manejo del suelo.

Mintegui Aguirre y López Unzú (1990), López Cadena De Llano (1998) y Gaspari et al., (2009), describen a cada factor de la siguiente manera:

\section{R: Factor de erosión pluvial o de erosionabilidad de la lluvia.}

Representa la potencia del aguacero para erosionar superficialmente el suelo, se lo considera también un índice de su torrencialidad. Se lo obtiene a partir de tablas de intensidad de lluvia $(\mathrm{mm} / \mathrm{hr})$ y la energía cinética por unidad de lluvia $\left(\mathrm{J} \cdot \mathrm{m}^{2} / \mathrm{cm}\right)$ o puede calcularse a partir de los datos de intensidad del aguacero a intervalos fijos y la intensidad de la lluvia durante el aguacero.

Este factor es el producto de la energía cinética del aguacero por su máxima intensidad en 30 minutos, dividido para 100, siendo su forma de cálculo como se expresa en la Fórmula 15.

$$
\mathrm{R}=\frac{\mathrm{EC} \cdot \mathrm{I}_{30}}{100}
$$

Fórmula 15. Para cálculo del factor pluvial

Donde:

EC: Energía cinética

$\mathrm{I}_{30}$ : Máxima intensidad en 30 minutos

También se puede calcular con la expresión de la Fórmula 16.

$$
\mathrm{R}=\frac{\sum_{j=1}^{n}(210,2+89 \log \mathrm{I}) \cdot(\mathrm{I} \cdot \mathrm{T}) \cdot \mathrm{I}_{30}}{100}
$$

Fórmula 16. Para cálculo del factor pluvial 
Siendo:

T: Período de tiempo, en horas, para intervalos homogéneos de lluvia durante el aguacero.

I: Intensidad del aguacero en los intervalos citados, en cm/hr.

$\mathrm{I}_{30}$ : Intensidad máxima en 30 minutos durante el aguacero, en cm/hr.

\section{K: Factor de erodabilidad del suelo.}

Representa la susceptibilidad de un suelo a ser erosionado y está relacionado con la estabilidad estructural del mismo; se calcula a partir del porcentaje de las distintas fracciones granulométricas, el porcentaje de materia orgánica, la estructura y la permeabilidad del perfil del suelo. La expresión matemática para el cálculo del factor $\mathrm{K}$ se presenta en la Fórmula 17.

$$
100 * K=10^{-4} * 2,71 * M^{1,14 *}(12-a)+4,20(b-2)+3,23(c-3)
$$

Fórmula 17. Para cálculo del factor erodabilidad del suelo

Donde:

M: (\% limo + \% arena muy fina)*(100 - \%arcilla), también se puede expresar como:

(\% partículas entre 0,002 y $0,1 \mathrm{~mm}$ ) * (\%partículas entre $0,002-2,0 \mathrm{~mm}$ )

a: $(\%$ carbono * 1,724$)$ representa el \% de materia orgánica

b: Indica la estructura del suelo:

1. Gránulo muy fino y grumo muy fino $(<1 \mathrm{~mm})$

2. Gránulo fino y grumo medio $(1-2 \mathrm{~mm})$

3. Gránulo medio, grumo medio $(2-5 \mathrm{~mm})$ y gránulo grueso $(5-10 \mathrm{~mm})$

4. Gránulo liso, prismático columnar y muy grueso $(>10 \mathrm{~mm})$

c: Clase de permeabilidad del perfil del suelo según Soil Survey Manual del U.S.D.A.

1. Rápida o muy rápida

2. Moderadamente rápido

3. Moderada

4. Moderadamente lenta

5. Lenta

6. Muy lenta

Nota: Este factor se puede estimar a partir de las curvas de conductividad hidráulica del suelo. 
Con el fin de simplificar la Fórmula 17 se desprecian los factores b y c, obteniendo un $\mathrm{K}$ simplificado que se presenta en la Fórmula 18.

$$
100 * K=10^{-4} * 2,71 * M^{1,14 *}(12-a)
$$

Fórmula 18. Para cálculo del factor erodabilidad del suelo simplificado.

Para el cálculo del factor $\mathrm{K}$, resulta imprescindible determinar en las muestras de suelo, los análisis de granulometría para la estimación del factor $\mathrm{M}$ y el contenido de materia orgánica para definir el valor de a. Con esta información se puede obtener el valor de $\mathrm{K}$ como una primera aproximación aplicando la fórmula simplificada 18.

\section{LS: Factor topográfico.}

Está compuesto por la longitud de la pendiente (L) y el gradiente de la pendiente (S). Son valores adimensionales y teóricamente representan:

L, longitud de la pendiente, es la relación entre el valor medio de las pérdidas de suelo obtenidas en un campo de longitud de pendiente uniforme y dimensión variable, y el valor medio de las pérdidas correspondientes a una parcela de longitud de pendiente uniforme de $22,1 \mathrm{~m}$, para un mismo tipo de aguacero, suelo y pendiente. En la práctica, la longitud de la pendiente $L$, es la distancia entre el punto más alto de caída de la gota de lluvia (origen de la escorrentía superficial) y el punto donde la pendiente disminuye hasta dar comienzo a la deposición de los sedimentos, o hasta el punto donde el escurrimiento entra a formar parte de un canal perfectamente definido.

$S$, gradiente de la pendiente, es la relación entre el valor medio de las pérdidas de suelo en un campo de pendiente cualquiera, con el que se obtendría en una parcela de $9 \%$ de pendiente uniforme, para las mismas condiciones en los restantes factores de lluvia, suelo y longitud de pendiente.

El factor topográfico (LS) como tal solo puede establecerse para laderas y su expresión, después de varias correcciones, quedo establecida en 1982, como se muestra en las Fórmulas 19 y 20 :

$$
\mathrm{LS}=(\lambda / 22,1)^{0,3} *\left(0,43+0,3 \mathrm{~s}+0,043 \mathrm{~s}^{2} / 6,613\right)^{1,3}
$$

Fórmula 19. Para cálculo del factor LS con pendientes menores al $9 \%$.

$$
\mathrm{LS}=(\lambda / 22,1)^{0,3 *}(\mathrm{~s} / 9)^{1,3}
$$

Fórmula 20. Para cálculo del factor LS con pendientes iguales o mayores al $9 \%$. 
Siendo: $\lambda$ : Longitud de ladera $(\mathrm{m})$; y se calcula a partir de la ecuación presentada en la Fórmula 21.

s: Pendiente media de ladera

$$
\lambda=0,5 * D A / L C H
$$

Fórmula 21. Longitud de la ladera

Donde:

$\mathrm{DA}=$ Área de la cuenca $\left(\mathrm{m}^{2}\right)$

$\mathrm{LCH}=$ Longitud total de los cursos que drenan por la cuenca $(\mathrm{m})$.

Estas ecuaciones son estrictamente aplicables en el caso de laderas de pendiente uniforme con un mismo tipo suelo y vegetación en toda su longitud, debiendo utilizarse factores correctores, para el caso en que a lo largo del recorrido de la lámina de escurrimiento se produzcan cambios sensibles de pendiente o de alguno de los otros factores.

Con la ecuación presentada en la Fórmula 22 se obtiene el valor de la pendiente media de una subcuenca $\mathrm{s}_{\mathrm{i}}$.

$$
\mathrm{S}_{\mathrm{i}}=\left[\mathrm{H}^{*}\left(\mathrm{LC}_{\mathrm{j}}+\mathrm{LC}_{\mathrm{i}+\mathrm{j}}\right) /\left(2{ }^{*} \mathrm{DA} \mathrm{A}_{\mathrm{i}}\right)\right]^{* 100}
$$

Fórmula 22. Pendiente media por subcuenca $s_{i}$ en $\%$

Siendo:

$\mathrm{s}_{\mathrm{i}}$ : Porcentaje medio de la pendiente para el área i entre los contornos j y $(\mathrm{j}+1)$

$\mathrm{H}$ : Diferencia de elevación entre contornos

LC : Longitud del contorno j

$\mathrm{DA}_{\mathrm{i}}$ : Área entre los contornos j y $(\mathrm{j}+1)$

Por tanto la pendiente media de la cuenca se determina por la Fórmula 23.

$$
S=\Sigma\left(s_{i}^{*} D_{i j} / D A\right)
$$

Fórmula 23. Pendiente media ponderada para la cuenca.

Donde:

DA: Área Total de la cuenca 


\section{C: Factor de ordenación de cultivos.}

Se puede definir como la relación entre el valor medio de pérdidas de suelo en un campo cultivado o con vegetación y las pérdidas ocurridas en un suelo con barbecho continuo (suelo desnudo, máxima pérdida de suelo) bajo condiciones iguales de lluvia, suelo y topografía. El efecto que la vegetación proporciona al suelo se debe principalmente a:

> La protección aérea que la vegetación proporciona al suelo, creando una especie de pabellón cubierto (Canopy Cover).

> La protección que proporciona la vegetación a ras de suelo, y al efecto beneficioso que se produce en la defensa del suelo contra la erosión, cuando el crecimiento de las plantas es bastante denso (Much and Close Growing Vegatation).

> Los efectos que los residuos de la vegetación tienen en la protección del suelo, tanto porque la cubren, como porque pueden variar algunas de sus propiedades físicas, por ejemplo, produciendo un aumento en la porosidad, siempre que estas no hayan sido consideradas en el factor K (Residual Effects of the Land Use).

El factor C, llamado también de cobertura o de uso de suelo, es un valor adimensional y siempre menor a 1; este factor para el caso de cultivos agrícolas, no es constante a lo largo del año, por lo que se debe considerar cálculos experimentales para cada clase de cubierta. Por ello, su valor estará determinado por las características de la cobertura vegetal: porcentaje de cubrimiento, densidad de población, edad, época del año y estado sanitario.

A continuación se presentan las Tablas 6, 7 y 8 tomadas de Gaspari et al., (2009) con los valores medios anuales del Factor $C$. Para mayor información, se recomienda consultar el Agriculture Handbook Number 537 "Predictic Rainfall Erosion Losses" o publicaciones similares, debido a que la determinación de su valor esta en continua investigación y actualización. 
Tabla 6. Valores de Factor C.

\begin{tabular}{|l|c|}
\hline Cubierta regetal & Valor de Factor C \\
\hline Arbolado forestal denso & 0,01 \\
Arbolado forestal claro & 0,03 \\
Matorral con buena cobertura & 0,08 \\
Matorral ralo y eriales & 0,2 \\
Cultivos arbóreos y viriedos & 0,4 \\
Cultivos anuales y herbáceos & 0,25 \\
Cultivos en regadio & 0,04 \\
\hline
\end{tabular}

Tabla 7. Valores de factor $\mathrm{C}$ para bosques.

\begin{tabular}{|c|c|c|c|}
\hline \multirow{2}{*}{$\begin{array}{c}\text { \% de cabida } \\
\text { cubierta }\end{array}$} & \multirow{2}{*}{$\begin{array}{c}\text { \% de cubierta } \\
\text { en contacto con } \\
\text { el suelo }\end{array}$} & \multicolumn{2}{|c|}{ Tipo de ordenación } \\
\cline { 3 - 4 } & $12)$ & C & NC \\
\hline 11075 & $100-90$ & 0,001 & $0,003-0,011$ \\
$75-40$ & $90-75$ & $0,002-0,004$ & $0,01-0,04$ \\
(3) $40-20$ & $70-40$ & $0,003-0,009$ & $0,02-0,09$ \\
\hline
\end{tabular}

Donde (1): Formada por al menos $5 \mathrm{~cm}$ de restos vegetales o plantas herbáceas.

(2): $\mathrm{C}=$ montes con control estricto del pastoreo; $\mathrm{NC}=$ in control del pastoreo.

(3): Para cubiertas en contacto con el suelo, inferiores al $40 \%$, o cabida cubierta menor del $20 \%$, usar valores de la tabla anterior. 
Tabla 8. Factor $C$ para pastizales, matorrales y arbustos. Valores de $C \times 10-3$.

\begin{tabular}{|c|c|c|c|c|c|c|c|c|}
\hline \multicolumn{2}{|c|}{ Cubierta vegetal } & \multicolumn{7}{|c|}{ Cubierta en contacto con el suelo } \\
\hline \multirow{2}{*}{$\begin{array}{l}\text { Tipo y } \\
\text { altura de } \\
\text { cubierta }\end{array}$} & \multirow{2}{*}{$\begin{array}{c}\% \\
\text { recubrimiento }\end{array}$} & \multirow{2}{*}{ Tipo } & \multicolumn{6}{|c|}{ Porcentaje de cobertura del suelo } \\
\hline & & & 0 & 20 & 40 & 60 & 80 & $95-100$ \\
\hline \multirow{2}{*}{$\begin{array}{c}\text { Cubierta } \\
\text { inapreciable } \\
\text { y matojos } \\
(\leq 0,5 \mathrm{~cm})\end{array}$} & & G & 450 & 200 & 100 & 042 & 013 & 003 \\
\hline & & W & 450 & 240 & 150 & 090 & 043 & 011 \\
\hline \multirow{6}{*}{$\begin{array}{c}\text { Plantas } \\
\text { herbáceas y } \\
\text { matojos } \\
(\leq 0,5 \mathrm{~cm})\end{array}$} & \multirow[t]{2}{*}{25} & G & 360 & 170 & 090 & 038 & 012 & 003 \\
\hline & & $\mathrm{W}$ & 360 & 200 & 130 & 082 & 041 & 011 \\
\hline & \multirow[t]{2}{*}{50} & G & 260 & 130 & 070 & 035 & 012 & 003 \\
\hline & & $\mathrm{W}$ & 260 & 160 & 110 & 075 & 039 & 011 \\
\hline & \multirow[t]{2}{*}{75} & G & 170 & 100 & 060 & 031 & 011 & 003 \\
\hline & & $\mathrm{W}$ & 170 & 120 & 090 & 067 & 038 & 011 \\
\hline \multirow{6}{*}{$\begin{array}{c}\text { Matonal } \\
(\leq 2 \mathrm{~m})\end{array}$} & \multirow[t]{2}{*}{25} & $\mathrm{G}$ & 400 & 130 & 090 & 040 & 013 & 003 \\
\hline & & $\mathrm{W}$ & 400 & 220 & 140 & 085 & 042 & 011 \\
\hline & \multirow[t]{2}{*}{50} & G & 340 & 160 & 085 & 038 & 012 & 003 \\
\hline & & $\mathrm{W}$ & 340 & 190 & 130 & 081 & 041 & 011 \\
\hline & \multirow[t]{2}{*}{75} & G & 280 & 140 & 080 & 036 & 012 & 003 \\
\hline & & $\mathrm{W}$ & 280 & 170 & 120 & 077 & 040 & 011 \\
\hline \multirow{6}{*}{$\begin{array}{c}\text { Arbolado } \\
\text { joven, sin } \\
\text { matorral } \\
\text { apreciable } \\
(\leq 4 \mathrm{~m})\end{array}$} & \multirow[t]{2}{*}{25} & G & 420 & 190 & 100 & 041 & 013 & 003 \\
\hline & & $\mathrm{W}$ & 420 & 230 & 140 & 087 & 042 & 011 \\
\hline & \multirow[t]{2}{*}{50} & G & 390 & 180 & 090 & 040 & 013 & 003 \\
\hline & & $\mathrm{W}$ & 390 & 210 & 140 & 083 & 042 & 011 \\
\hline & \multirow[t]{2}{*}{75} & G & 360 & 170 & 090 & 039 & 012 & 003 \\
\hline & & $\mathrm{W}$ & 360 & 200 & 130 & 083 & 041 & 011 \\
\hline
\end{tabular}

Es conveniente el uso de los mapas en detalle para evitar generalizaciones, teniendo en cuenta siempre la escala de trabajo que se utiliza. Además se recomienda el uso de imágenes satelitales o fotografías aéreas para la interpretación, siendo fundamental el apoyo del trabajo de campo en la verificación. 


\section{P: Factor de prácticas de conservación de suelos.}

Se define como la relación existente entre el valor medio de las pérdidas de suelo producidas en un campo donde se realizan las prácticas de conservación de suelo, y las que se originarían en el mismo suelo si se hicieran labores en la dirección de la máxima pendiente en iguales condiciones de lluvia, suelo, topografía y vegetación.

Estas prácticas al modificar los patrones de flujo y el grado y dirección de la superficie de escurrimiento, influyen directamente en la conservación del suelo. Se incluyen como prácticas el cultivo a nivel, el cultivo en fajas y las terrazas. Otras prácticas como la rotación con especies herbáceas, el empleo de fertilizantes, cubiertas artificiales, entre otras, se consideran dentro de los trabajos de cultivo, y por tanto incluidas en el factor C.

En la Tabla 9, elaborada por el Soil Conservation Service de los Estados Unidos, se presentan los valores de $\mathrm{P}$ obtenidos experimentalmente para cada situación según las medidas de conservación para diferentes gradientes de pendiente. Las parcelas empleadas para los ensayos fueron de $22,1 \mathrm{~m}$ de longitud y $9 \%$ de pendiente.

Tabla 9. Valores del factor $P$.

\begin{tabular}{|c|c|c|c|c|}
\hline \multirow{2}{*}{$\begin{array}{c}\text { Pendiente } \\
(\%)\end{array}$} & \multirow{2}{*}{ Cultivo a nivel } & \multirow{2}{*}{ Cultivo en fajas } & \multicolumn{2}{|c|}{ Cultivo en terrazas } \\
\cline { 3 - 5 } & & & $\begin{array}{c}\text { Terrazas de } \\
\text { desagüe }\end{array}$ & $\begin{array}{c}\text { Terrazas de } \\
\text { infiltración }\end{array}$ \\
\hline $2-7$ & 0,50 & 0,25 & 0,10 & 0,05 \\
$8-12$ & 0,60 & 0,30 & 0,12 & 0,05 \\
$13-18$ & 0,80 & 0,40 & 0,16 & 0,05 \\
$19-24$ & 0,90 & 0,45 & 0,18 & 0,06 \\
\hline
\end{tabular}

En general, los términos $\mathrm{R}, \mathrm{K}$ y LS representan la influencia de los factores físicos del área geográfica, poco modificables por el hombre y constituyen el primer acercamiento para el análisis de erosión del suelo puesto que su producto representa la pérdida de suelo que ocurriría en esa zona si todo el año el suelo estuviera en barbecho continuo, por esta razón a este producto se lo denomina "erosión potencial". En cambio los valores de C y $\mathrm{P}$ dependen del manejo que cada agricultor haga de su campo para disminuir esa erosión potencial.

\section{Tolerancia en las pérdidas de suelo (erosión tolerable)}

La evaluación de tolerancias de pérdidas de suelo en un terreno, depende de diversos factores como profundidad del suelo, propiedades físicas, desarrollo de los sistemas radicales de la vegetación, reducción de la materia orgánica, pérdida de nutrientes y sementeras, etc. Tratándose de suelos fértiles y profundos, las pérdidas de suelo tolerables se estiman en medio $\mathrm{mm}$ del perfil edáfico superior por año. Por tanto, con un peso

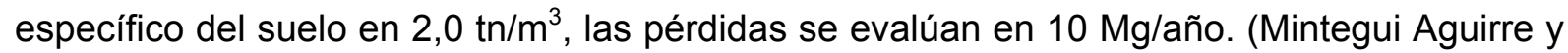
López Unzú, 1990). 
Según Wischmeier, pérdidas de 12,5 Mg.ha/año son admisibles como máximo en un suelo profundo, de textura media, permeabilidad moderada y con un subsuelo favorable a la vida de las plantas. López Cadena de Llano (1998).

En 1981, FAO, PNUMA y UNESCO, presentaron la "Clasificación Provisional para la Evaluación de la Degradación de los Suelos" (ver Tabla 10) con los rangos de valores tolerables según pérdida de suelo por aplicación de la U.S.L.E. (Gaspari, et al., 2009).

Tabla 10. Clasificación en grado de erosión hídrica superficial.

\begin{tabular}{|c|c|}
\hline $\begin{array}{c}\text { Pérdida de suelo } \\
\text { (Mg.ha }^{-1} \cdot \text { año }^{-1} \text { ) }\end{array}$ & $\begin{array}{c}\text { Grado de erosión } \\
\text { hídrica }\end{array}$ \\
\hline$<10$ & Nulo \\
\hline $10-50$ & Moderado \\
\hline $50-200$ & Alto \\
\hline$>200$ & Muy alto \\
\hline
\end{tabular}

\subsection{Integración de los Sistemas de Información Geográfica (SIG) en los Modelos Matemáticos (HEC-HMS ${ }^{\circledR}$ y U.S.L.E.)}

\subsubsection{Definición, componentes y funciones de los SIG}

"Un SIG es un sistema de hardware, software y procedimientos elaborados para facilitar la obtención de información, gestión, manipulación, análisis, modelado, representación y salida espacialmente referenciados, para resolver problemas complejos de planificación y gestión" (Clair, 2011).

Bajo este concepto general, se destaca que los SIG están constituidos por cinco elementos básicos: los componentes físicos, el programa, los datos, los procesos de flujo y los usuarios que juntos interactúan bajo ciertas reglas para desarrollar sus potencialidades operacionales que cada software debe estar en capacidad de cumplir, según su diseño y uso, las cuales son:
a) Entrada de datos y control de calidad
b) Almacenamiento de datos y gestión de bases de datos
c) Modelización y análisis de datos
d) Visualización y salida de datos

\subsubsection{Modelo de datos en un SIG}

Los SIG sirven para representar del mundo real un modelo de la realidad, para analizar propósitos particulares con la finalidad de contribuir con información, para la toma de decisiones y considerarse como una fuente para los sistemas expertos. La materialización 
de los elementos que conforman el mundo real (elementos reales) son representados en forma abstracta y discreta por medio de entidades espaciales (elementos gráficos simples), que básicamente son tres: puntos, líneas y polígonos o áreas. La representación de las entidades espaciales en el modelo de la realidad pueden ser caracterizadas mediante dos modelos de datos: vectorial y raster.

Clair (2011) y Moreno et al., (2008) definen a los modelos de datos vectoriales y raster de la siguiente manera:

\section{Modelo de datos vectorial}

En este modelo la representación del mundo real es discreta, la forma de representar a las entidades espaciales: puntos, líneas y polígonos, se basa en los elementos vectoriales: vértices y segmentos. El punto está representado por un vértice, elemento vectorial más simple, que resulta del cruce de dos coordenadas $\mathrm{X}$ e $\mathrm{Y}$. Es un objeto de cero dimensiones que solo representa la posición en el espacio del elemento real, no representa longitud ni superficie. La línea, es el conjunto de uno o varios segmentos articulados por vértices con sus respectivas coordenadas, a los vértices de los extremos se los denomina nodos y marcan el inicio y el final de la línea, estableciendo el sentido y dirección. Es un objeto de una dimensión, a más de la posición, representa la longitud del elemento real, no la superficie. El polígono, está formado por líneas cerradas donde los nodos de inicio y final coinciden, delimitando un área en su interíor. Objeto de dos dimensiones, representan la longitud y superficie del elemento geográfico. El programa ArcGIS diferencia el desigual comportamiento con mucha claridad, a cada categoría descrita, separándolas siempre en capas (layers) distintas.

Los elementos vectoriales se convierten en objeto cuando su representación (punto, línea, polígono) se asocia a elementos reales (edificio, río, cuenca hidrográfica). Se pueden guardar las propiedades (atributos) de los elementos reales (caudal, temperatura, precipitación, longitud, etc) en bases de datos (Tablas) y asociar, mediante identificadores (ID), cada objeto a sus atributos. Como los objetos son representados bajo un sistema de coordenadas, es posible aplicar relaciones espaciales (topología) explícitas que mantienen entre si, como la proximidad, la conectividad o la inclusión. El programa ArcGIS, utiliza para este modelo, tres formatos diferentes: coberturas (coverages), archivos de formas (shapefiles) y bases de datos geográficas (geodatabase).

\section{Modelo de datos raster}

En estos modelos, la representación de los elementos del mundo real es continua, mediante una superficie dividida en celdas regulares denominada malla o matiz, y donde cada una de las celdas son conocidas como píxel (pix), identificados por un número de fila y columna en la matriz. La posición de los datos se deduce del lugar en la matriz.

Los formatos raster siguen las normas generales de las imágenes digitales, por esto la estructura de una imagen raster es similar a una malla, normalmente regular, a cuyas celdas o pixel se les asigna un número o nivel digital (ND) que representa una cualidad identificable 
de observación, la mínima, representada en cada locación mediante un tono o color, que finalmente conforma la apariencia visual de la imagen. En ocasiones los pixeles no podrán representar características visuales del espacio, sino información como la altura de cada pixel, la pendiente, la orientación o cualquier otra característica continua del terreno. Por ejemplo en un Modelo Digital de Elevaciones (MDE), los pixeles representan el valor de altitud.

Gaspari et al., (2009) estable las diferencias de cada modelo, destacando sus características operacionales, como se presenta en la Tabla 11, donde se muestra un listado de las características de cada tipo de modelo y se indica su beneficio (+) o dificultad para su uso (-).

Tabla 11. Características de los modeles vectorial y raster.

\begin{tabular}{|l|c|c|}
\hline \multicolumn{1}{|c|}{ Características } & $\begin{array}{c}\text { Modelo } \\
\text { Vectorial }\end{array}$ & $\begin{array}{c}\text { Modelo } \\
\text { Raster }\end{array}$ \\
\hline Precisión gráfica (espacial) & + & - \\
\hline Cartografía tradicional & + & - \\
\hline Volumen de datos & + & - \\
\hline Topología & + & - \\
\hline Operaciones de cálculo & - & + \\
\hline Actualización & - & + \\
\hline Variación espacial continua & - & + \\
\hline Integración & - & + \\
\hline Variación espacial discontinua & + & - \\
\hline
\end{tabular}

\subsubsection{Fuente de captura de datos y tipos de información espacial}

Los principales métodos utilizados para introducir datos geográficos en el modelo seleccionado (vectorial o raster) encontramos a los equipos de percepción remota, fotografías aéreas, imágenes satelitales, datos capturados con GPS, digitalización manual escaneado de de mapas, encuestas y censos.

Durante todas las etapas del proceso SIG la calidad de los datos necesita ser revisada, para evitar no solo los errores de los datos originales e introducidos durante los procedimientos de entrada, sino también durante, los procesos de almacenamiento y gestión de datos, análisis y modelización, y presentación de resultados, para lo cual debe ser implementado un sistema de metadatos.

Un sistema de metadatos tiene por objeto posibilitar que los usuarios de información geográfica puedan, de forma distribuida, localizar datos geográficos con sus características y el acceso a los mismos con distinto grados de valor añadido, como un aporte de iniciativa regional para el establecimiento de la Infraestructura de Datos Espaciales (IDE). 
En la Tabla 12, elaborada por el suscrito, se presentan las diversas coberturas o capas de información geoespacial y sus fuentes de datos.

Tabla 12. Información geoespacial y fuente de datos. Fuente: Hammerly et al., 2006.

\begin{tabular}{|l|l|}
\hline \multicolumn{1}{|c|}{ Fuente de Datos } & \multicolumn{1}{|c|}{ Información geoespacial } \\
\hline $\begin{array}{l}\text { Modelos Digitales de Terreno } \\
\text { (MDT) }\end{array}$ & $\begin{array}{l}\text { Información referente a la topografía: posición (X,Y), } \\
\text { altura, curvas de nivel, pendiente, orientación, longitud } \\
\text { de flujo, área de aportes, subcuencas y redes de } \\
\text { drenaje. }\end{array}$ \\
\hline $\begin{array}{l}\text { Digitalización de mapas } \\
\text { analógicos, fotografías aéreas o } \\
\text { relevamiento de campo. MDT. }\end{array}$ & $\begin{array}{l}\text { Cuencas y subcuencas hidrográficas y redes de } \\
\text { drenaje, disponible como información digitalizada } \\
\text { (proporcionada por organismo gubernamentales, } \\
\text { comerciales o usuarios) }\end{array}$ \\
\hline $\begin{array}{l}\text { Digitalización o rasterización de } \\
\text { de relevamientos de suelos } \\
\text { originales o mapas analógicos }\end{array}$ & $\begin{array}{l}\text { Datos de tipo de suelo disponible en formato analógico } \\
\text { ydigital (vectorial) en varias escalas (reconocimiento y } \\
\text { semidetalle) }\end{array}$ \\
\hline $\begin{array}{l}\text { Combinación de imágenes de } \\
\text { vuelos aerofotogramétricos y/o } \\
\text { captura de datos desde satélites } \\
\text { espaciales. }\end{array}$ & $\begin{array}{l}\text { Datos de ortofotocartas digitales y cartas imágenes, } \\
\text { con la calidad geométrica de un mapa. }\end{array}$ \\
\hline Imágenes de sensores remotos & $\begin{array}{l}\text { Precipitación, uso y cobertura del suelo, índices de } \\
\text { vegetación, redes de drenaje y cuencas hidrográficas, } \\
\text { temperatura de superficie, humedad del suelo y } \\
\text { nieve/hielo, entre otros aspectos relevantes de la } \\
\text { cubierta terrestre. }\end{array}$ \\
\hline
\end{tabular}

\subsubsection{Modelación con los SIG}

Durante la última década el desarrollo de los Sistemas de Información Geográfica (SIG) han tenido un verdadero auge, no solo porque facilita la producción cartográfica y la evaluación de áreas de riesgos; permite la generación de bases de datos del medio físico, biológico, socioeconómico, catastro, marketing; sino que también constituye una herramienta muy útil en los procesos de modelación de diversa índole.

\subsubsection{Modelación en la hidrología}

Según Hammerly et al., 2006, los fundamentos de la integración de los SIG y los modelos hidrológicos fueron descriptos por Bulhones Mendes, en 1996, enumerando las siguientes fases de desarrollo: 
1.- obtención de datos de campo y digitales,

2.- operaciones y análisis de los datos de entrada,

3.- operaciones en los SIG,

4.- simulación hidrológica, y

5.- simulación visual de los resultados

El mismo autor manifiesta que en la práctica la integración entre la modelación hidrológica y los SIG puede ser ejecutada de dos maneras:

a) Modelación interna en el SIG, es decir usando lenguaje de programación específico del software SIG a utilizar o diseñando la construcción de funciones internas del software SIG mediante algebra de mapas; esta manera de integración se circunscriben a modelos basados en funciones empíricas y demasiado simplificadas.

b) Formatos idénticos en el modelo y en el SIG, actualmente la mayoría de modelos hidrológicos se desarrollan bajo plataforma SIG. La manipulación de los componentes, el ingreso de datos al modelo, las bases de datos, la visualización de la información en pantalla, la generación de resultados y elaboración de mapas se realiza en ambiente SIG, requiriendo la utilización de programas de conversión de formatos y mayor consumo de tiempo de procesamiento. (ver Figura 7)

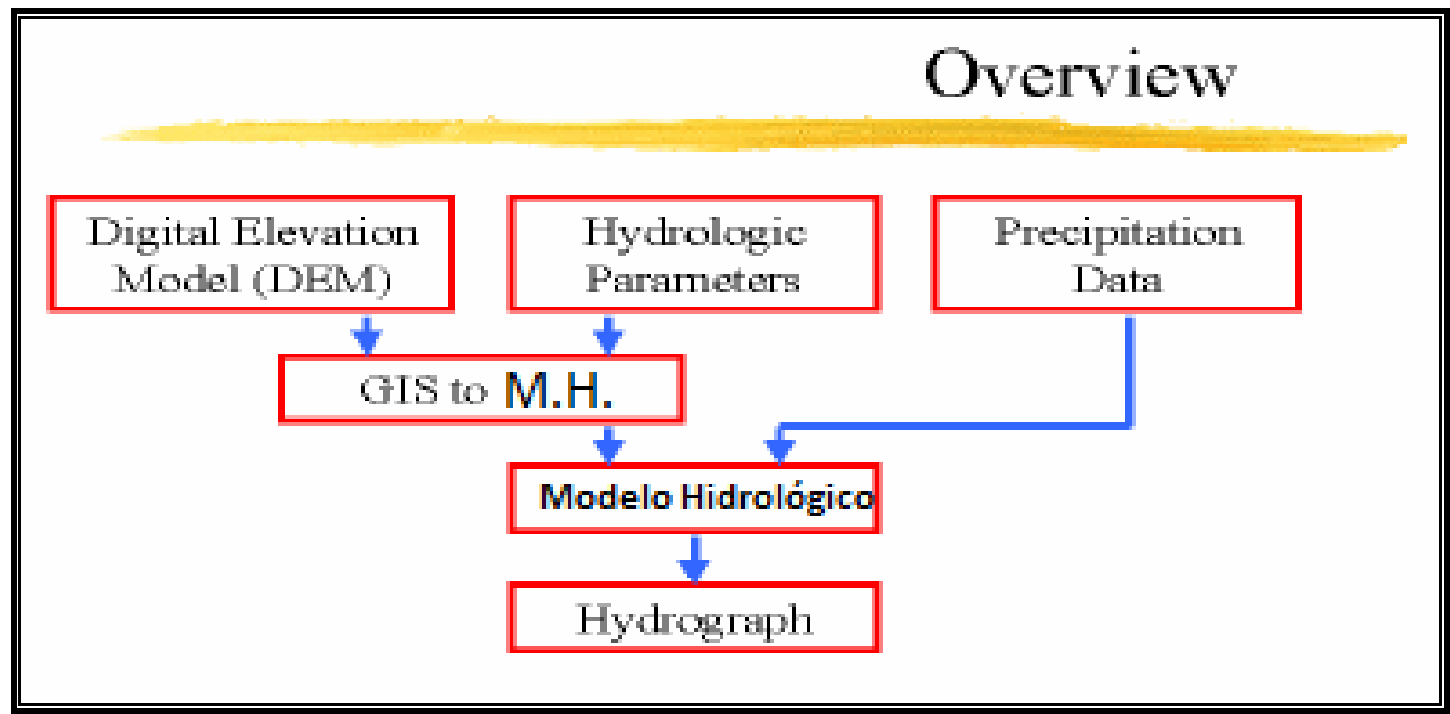

Figura 3. Esquema de integración Modelo Hidrológico y SIG. Modificado.

En cualquier caso, la utilización de un SIG en un proceso de modelación hidrológica tiene como propósito facilitar la adquisición y preparación de los datos espaciales y posteriormente la presentación y despliegue de resultados. 


\subsubsection{Modelación en el uso y manejo del suelo agrícola}

La integración de los SIG en la planificación del manejo y uso de los suelos agrícolas, ha empezado a tomar importancia, pues esta interrelación permite cuantificar la pérdida de suelo de manera rápida a escala de cuenca, con un mínimo de trabajo de campo y con la complejidad de las escalas grandes (Flores et al., 2003), a fin de proporcionar datos para el diseño de planes de conservación y reducir los efectos perjudiciales de la pérdida de suelo. 


\section{CAPITULO 3}

\section{CARACTERIZACIÓN DE LA CUENCA DEL RÍO} GUAYAS

\subsection{Ubicación Geográfica}

La cuenca del Río Guayas se ubica entre las provincias de Los Ríos, Guayas, Cotopaxi, Bolívar, Manabí, Cañar, Chimborazo y Santo Domingo, en el centro occidental del Ecuador. Limita al norte con la cuenca del Río Esmeraldas; al sur con las cuencas de los Ríos Zapotal, Taura, Cañar y Santiago; al este con las cuencas de los Ríos Esmeraldas y Pastaza; y al oeste con las cuencas del Jama, Chone, Portoviejo y Jipijapa. Se extienden entre los paralelos $00^{\circ} 14^{\prime} \mathrm{S}, 02^{\circ} 27^{\prime} \mathrm{S}$ y los meridianos $78^{\circ} 36^{\prime} \mathrm{W}, 80^{\circ} 36^{\prime} \mathrm{W}$ (ver Figura 8).

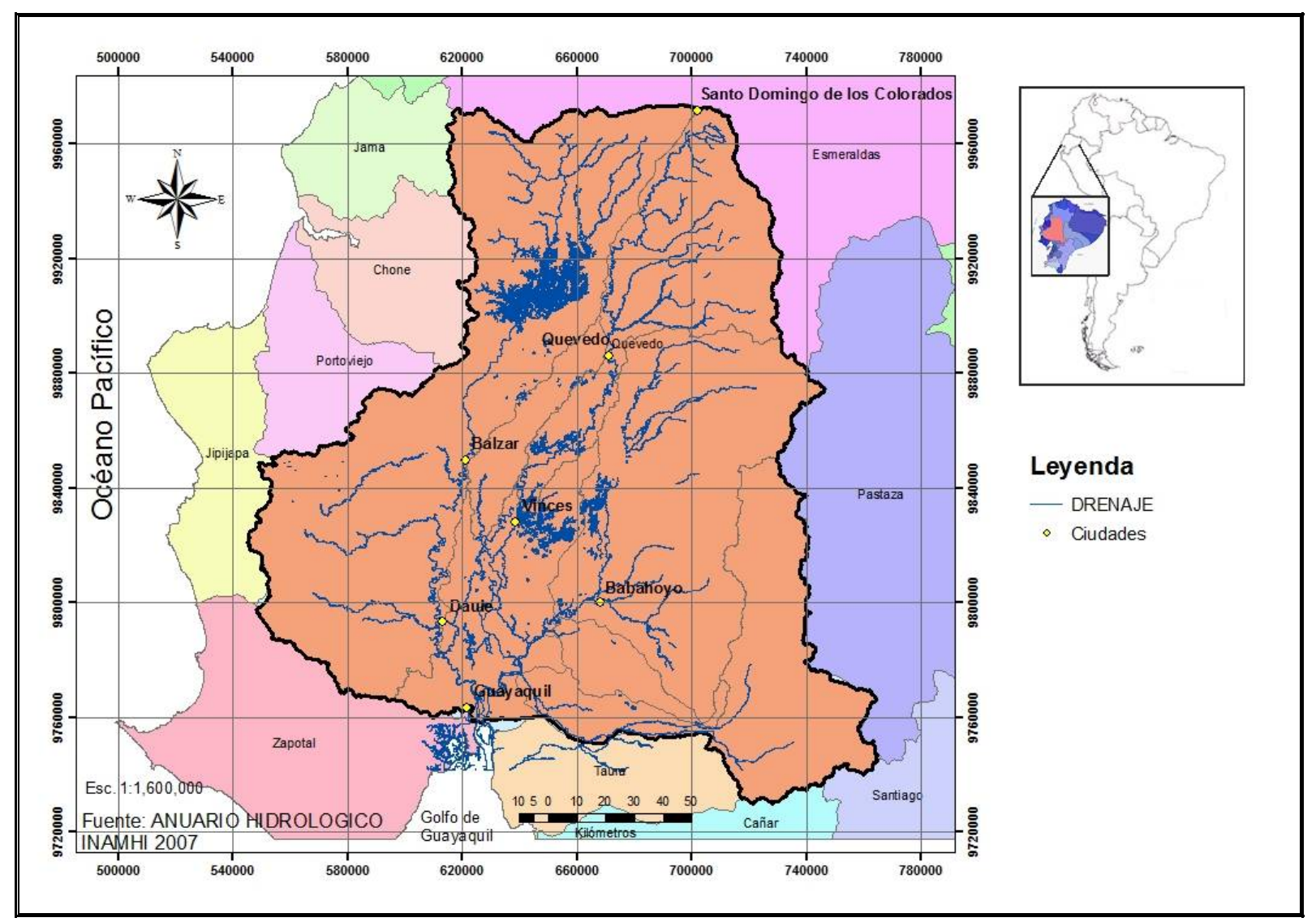

Figura 4. Ubicación de la Cuenca del Guayas. 
Se caracteriza por la gran variedad de actividad agrícola, ganadera, forestal, acuicultura, pesca, entre otros, gracias a la buena calidad de sus suelos y a la interacción de la tierra con el mar en la zona estuarina (cuenca baja), que la ubica como el mayor centro de producción de bienes agropecuarios a nivel nacional, tanto para el mercado interno y como para el externo a través de las exportaciones desde los puertos marítimos del Ecuador.

Pertenece a la vertiente del Pacífico, con un área aproximada de $34.500 \mathrm{~km}^{2}$ contribuye a la generación de energía hidroeléctrica nacional. El área de la cuenca corresponde al 12,57\% del territorio nacional, la población que habita en esta cuenca se estima en 5'592.025 habitantes, representado al $39,37 \%$ del total de la población nacional. (SENAGUA-DED, 2009).

La industria en esta área está representada por numerosas piladoras de arroz, fábricas de alimentos balanceados, haciendas donde se embalan frutas como banano, mango, piña, limón, procesamiento del café y cacao; empacadoras de camarón e industrias donde se elaboran abonos orgánicos y químicos.

Por estar situada en el centro del país y por ser una zona de gran movimiento comercial, cruzan la mayoría de las vías estatales constituyendo el corazón vial nacional para el intercambio de productos entre la costa, la sierra y el oriente tanto para el mercado interno como para las exportaciones.

\subsection{Hidrografía}

La cuenca del Guayas pertenece a la vertiente Occidental, constituye el sistema fluvial más importante de la costa sudoccidental del Pacífico, está conformada por siete subcuencas ${ }^{1}$ cuya red de drenaje nacen en las estribaciones occidentales de la Cordillera de los Andes y en la vertiente oriental de la Cordillera Costanera Chongón-Colonche que conforman los ríos Daule y Babahoyo, los cuales unen sus caudales 5 kilómetros antes de la ciudad de Guayaquil dando origen al Río Guayas el cual tiene una longitud de $93 \mathrm{~km}$ desde La Puntilla en la provincia del Guayas hasta Punta Arenas en la Isla Puná (estuario) para desembocar al Océano Pacífico en el Golfo de Guayaquil (INOCAR, 2010) (ver Figura 9).

\footnotetext{
${ }^{1}$ De acuerdo a sus características hidrográficas. CLIRSEN. 2009
} 


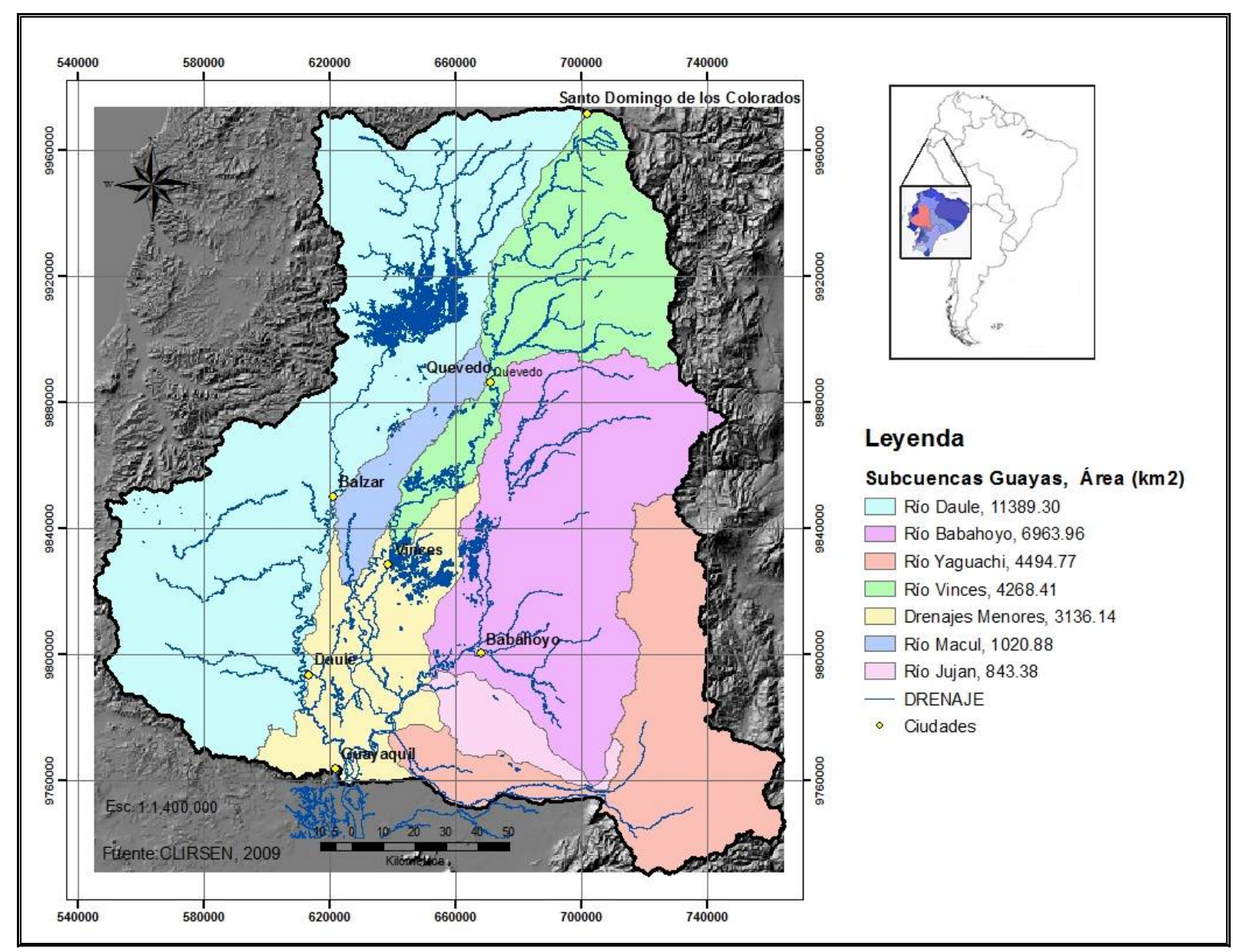

Figura 5. Subcuencas Hidrográficas de la Cuenca del Guayas.

Su ancho fluctúa entre $1,5 \mathrm{~km}$ y $3 \mathrm{~km}$, excepto a la altura de la ciudad de Guayaquil donde se divide en 2 ramales que bordean a la Isla Santay con $5 \mathrm{~km}$ de ancho, su profundidad varía entre $5 \mathrm{~m}$ y $12 \mathrm{~m}$ respecto al MLWS $^{2}$. El Río Guayas descarga anualmente 30 mil millones de $\mathrm{m}^{3}$ de agua, la abundante disponibilidad del recurso agua llega a 8.847 $\mathrm{m}^{3} / \mathrm{hb} / a n ̃ o$, siendo superior a la media mundial de $6.783 \mathrm{~m}^{3} / \mathrm{hb} / a n ̃ o$. (INOCAR, 2010). Su caudal varía según la estación, en la época seca el caudal promedio es de $230 \mathrm{~m}^{3} / \mathrm{seg}$, mientras que en la época húmeda es de más de $1.500 \mathrm{~m}^{3} / \mathrm{seg}$. (ESPOL, 2000) (ver Figura 10).

\footnotetext{
${ }^{2}$ Nivel Medio de Bajamares de Sicigia (Mean Low Water Spring)
} 


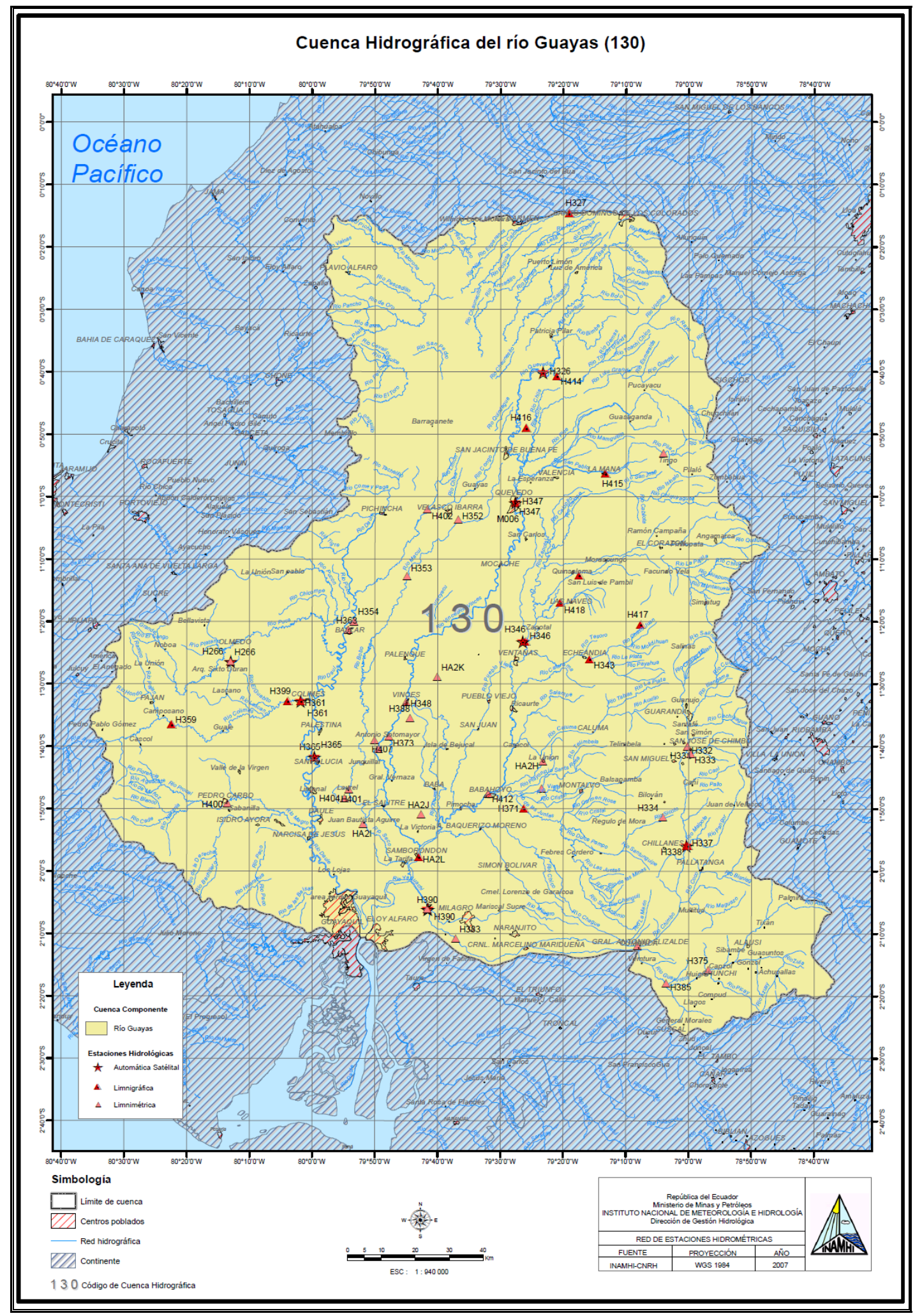

Figura6. Sistema Hídrico de la Cuenca del Guayas. Fuente: Anuario Hidrológico INAMHI. 2006 


\subsection{Clima}

El clima en la región está influenciado por tres factores que modifican el clima de manera estacional durante todo el año:

- La circulación atmosférica continental identificada por los vientos alisios del SE.

- El Océano Pacífico como generador permanente de las masas de aire húmedo que sumado a los efectos de las corrientes marinas (fría de Humboldt y cálida del Niño) son los mayores reguladores de los efectos estacionales del clima.

- Las características propias de las estribaciones andinas que con su altura, relieve y orientación encauzan las masas de humedad.

Debido a estos factores, en la región litoral o costa, se caracteriza por tener una marcada estacionalidad que provoca un desbalance de precipitaciones. De enero a mayo es la estación lluviosa o "invierno", produciéndose inundaciones durante largos períodos; y de junio a diciembre es la estación seca o "verano" caracterizada por la escases de lluvias entre septiembre y octubre (garúas).

En la cuenca del Guayas encontramos 16 zonas climáticas según la clasificación del Dr. Pierre Pourrut, en la cual se considera las precipitaciones totales anuales y sus regímenes, que van desde menos de $500 \mathrm{~mm}$ (seca) a más de $3000 \mathrm{~mm}$ (lluviosa); y las temperaturas medias mensuales que varía de $4^{\circ} \mathrm{C}$ (alta montaña) a mas de $22^{\circ} \mathrm{C}$ (megatérmico). (CLIRSEN, 2009) La combinación de estas dos variables nos dan las diferentes zonas climáticas, que se observa en la Figura 11.

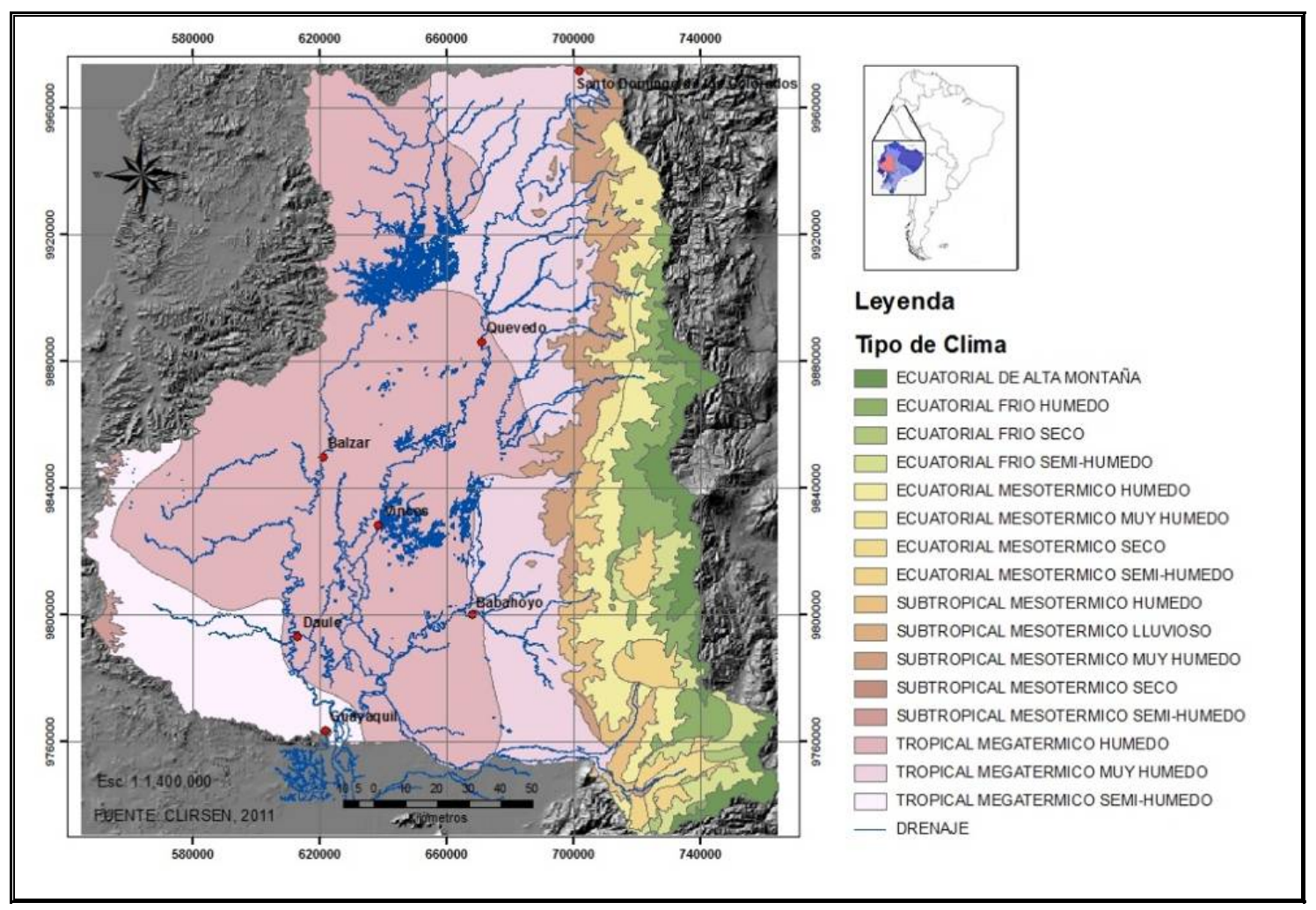

Figura 7. Zonas climáticas en la Cuenca del Guayas. 
En la Tabla 13 se detalla los rangos de temperatura media anual $\left({ }^{\circ} \mathrm{C}\right)$ y los rangos de precipitaciones totales anuales $(\mathrm{mm})$ para la cuenca del Río Guayas de acuerdo a las zonas climáticas.

Tabla 13. Detalle de los tipos de clima en la Cuenca del Guayas (CLIRSEN, 2009).

\begin{tabular}{|l|c|c|c|}
\hline \multicolumn{1}{|c|}{ Tipo de Clima } & Símbolo & $\begin{array}{c}\text { Rango Temp } \\
\left({ }^{\circ} \mathbf{C}\right)\end{array}$ & $\begin{array}{c}\text { Rango Precip } \\
(\mathbf{m m})\end{array}$ \\
\hline ECUATORIAL DE ALTA MONTAÑA & $\mathrm{Pf}$ & $04-08$ & $>500$ \\
\hline ECUATORIAL FRÍO HUMEDO & $\mathrm{Ew}$ & $08-12$ & $>1000$ \\
\hline ECUATORIAL FRÍO SECO & $\mathrm{Eb}$ & $08-12$ & $<500$ \\
\hline ECUATORIAL FRÍO SEMI-HUMEDO & $\mathrm{Eh}$ & $08-12$ & $500-1000$ \\
\hline ECUATORIAL MESOTERMICO HUMEDO & $\mathrm{Cw}$ & $12-18$ & $1000-2000$ \\
\hline ECUATORIAL MESOTERMICO MUY HUMEDO & $\mathrm{Cm}$ & $12-18$ & $>2000$ \\
\hline ECUATORIAL MESOTERMICO SECO & $\mathrm{Cb}$ & $12-18$ & $<500$ \\
\hline ECUATORIAL MESOTERMICO SEMI-HUMEDO & $\mathrm{Ch}$ & $12-18$ & $500-1000$ \\
\hline SUBTROPICAL MESOTERMICO HUMEDO & $\mathrm{Sw}$ & $18-22$ & $1000-2000$ \\
\hline SUBTROPICAL MESOTERMICO LLUVIOSO & $\mathrm{Sf}$ & $18-22$ & $>3000$ \\
\hline SUBTROPICAL MESOTERMICO MUY HUMEDO & $\mathrm{Sm}$ & $18-22$ & $2000-3000$ \\
\hline SUBTROPICAL MESOTERMICO SECO & $\mathrm{Sb}$ & $18-22$ & $<500$ \\
\hline SUBTROPICAL MESOTERMICO SEMI-HUMEDO & $\mathrm{Sh}$ & $18-22$ & $500-1000$ \\
\hline TROPICAL MEGATERMICO SEMI-HUMEDO & $\mathrm{Ah}$ & $>22$ & $500-1000$ \\
\hline TROPICAL MEGATERMICO MUY HUMEDO & $\mathrm{Am}$ & $>22$ & $2000-3000$ \\
\hline TROPICAL MEGATERMICO HUMEDO & $\mathrm{Aw}$ & $>22$ & $1000-2000$ \\
\hline
\end{tabular}

\subsection{Geología}

Geológicamente, la formación de la Cuenca del Guayas se originó durante la época del Plioceno junto con la aparición de la Cordillera de la Costa al final de la misma época, esta nueva formación provocó una concentración del drenaje al pie de los Andes induciendo que los flujos sean evacuadas al sur por el Golfo de Guayaquil y al norte por los corredores de fallas de Esmeraldas y de Bahía Ancón de Sardinas. (Dumont et al., 2007).

Esta formación originó que se forme un basamento de rocas basálticas correspondiente a la formación Piñón (antiguo piso oceánico), sobre cuyo material, desde la edad del cretáceo, se han venido acumulando diferentes tipos de sedimentos hasta formar lo que corresponde a la formación Cayo. Encontrándose afloramientos típicos de esta última unidad litológica en la cordillera de Chongón-Colonche y en el costado de la Cordillera Occidental. Sobre estos materiales, se acumularon grandes cantidades de sedimentos de material detrítico no consolidados que representan a los depósitos cuaternarios que son los actuales suelos.

Los materiales sedimentarios del terciario y cuaternario comprenden los extensos depósitos no consolidados de la gran Llanura Costera entre los que se encuentran gravas y arenas que se observan en los lechos de los valles fluviales, hasta la llanura aluvial al sur de la cuenca drenada por grandes ríos meándricos y parcialmente inundables. En la Figura 12 se muestra la ubicación de la cuenca del Guayas en el mapa de las regiones geológicas del Ecuador. 


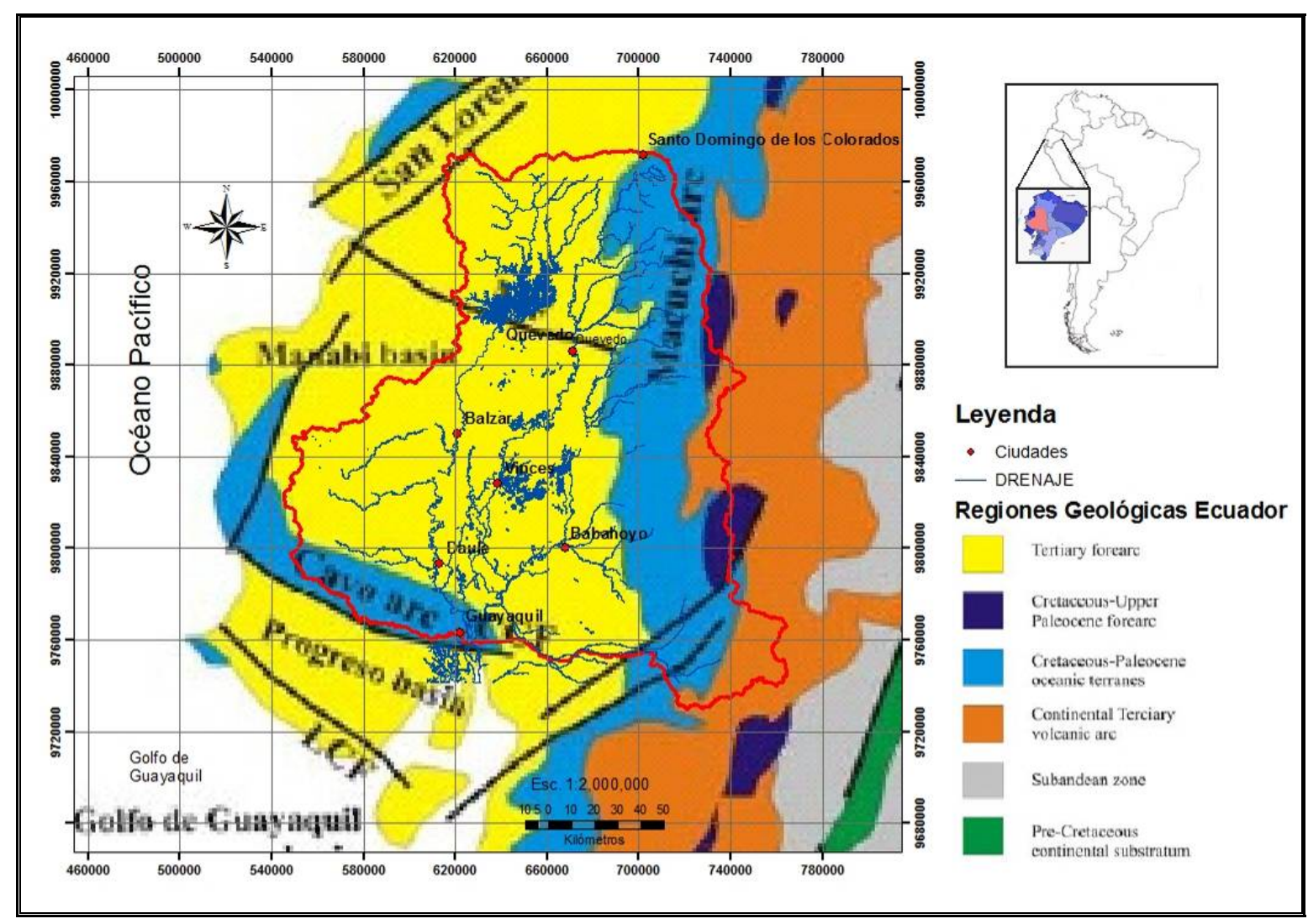

Figura 8. Regiones Geológicas del Ecuador. Fuente: Granja, 2010.

\subsection{Relieve}

Desde el punto de vista geomorfológico la cuenca del Guayas es una fosa de hundimiento con relleno fluvio marino que se extiende de norte a sur, rodeada de conos de deyección al este que se consolidan con la Cordillera de los Andes, y al oeste por la Cordillera de la costa Chongón Colonche y los cerros Balzar y Puca, al norte por los relieves sedimentarios levantados, atravesados por la garganta antecedente del Río Esmeraldas y al sur por la llanura aluvial y el delta del Río Guayas. (Gonzales et al., 2008).

En general la cuenca presenta los siguientes tipos de relieve: $28 \%$ plano entre 0 y 40 m.s.n.m.; $41,2 \%$ ondulado entre 40 y 200 m.s.n.m.; 13,3\% montañoso entre 200 y 800 m.s.n.m.; y 16,7\% andino sobre 800 m.s.n.m. (ESPOL, 2000), de los cuales los relieves más susceptibles a las inundaciones son los valles y terrazas aluviales (cuenca baja) cuya pendiente es plana a ondulada. En la Figura 13 se ilustra las pendientes en la cuenca. 


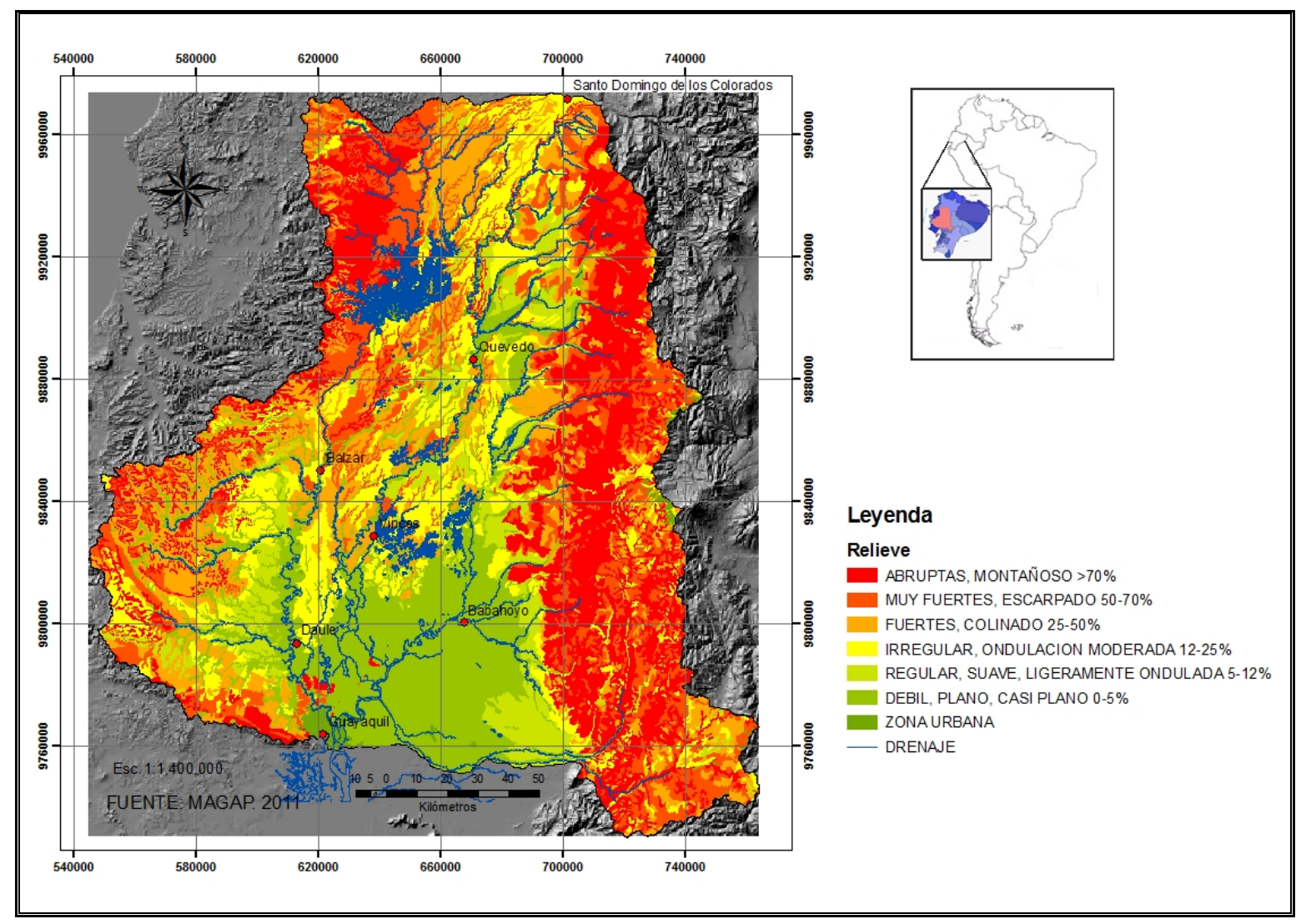

Figura 9. Mapa de relieve en la Cuenca del Guayas.

En el sector de la cuenca media alta los suelos se han desarrollado sobre depósitos antiguos compuestos de pizarras, areniscas, tobas y cantos rodados en su mayoría de origen volcánico caracterizados por ser suelos minerales con un incipiente desarrollo de horizontes pedogenéticos como es el caso de los arcillosos, buena fertilidad y alta retención de humedad. Suelos aptos para cultivos extensivos de banano, cacao, café, palma africana y arboricultura tropical. (Gonzales et al., 2008)

En la cuenca media baja, constituida por valles fluviales y llanuras aluviales costeras con pocas depresiones (sabanas) predominan los suelos aluviales recientes, producto de los aportes permanentes de los ríos que conforman la red de drenaje del Guayas (material aluvial), cuyas características son de texturas finas diversas y estratificadas con sedimentos fluviales y arcillosos de profundidad variable (color pardo), predominan los suelos arcillosos o franco-arcillosos. Unidades ocupadas mayormente por cultivos de arroz.

En la cuenca baja propiamente, el suelo presenta sedimentos cuaternarios (arcillas y marinas estuarinas) con presencia de arenas, areniscas y conglomerados. Además, los suelos son mal drenados, saturados con agua todo el año; con sales, colores obscuros, profundos. Suelos destinados a la acuicultura, pesca artesanal, captura de cangrejo. (MINISTERÍO DEL AMBIENTE, 2000) 
Con el fin de representar la morfología de la cuenca del Guayas se construyó el mapa de iluminación (ver Figura 14) que representa las zonas de luz y sombra derivadas de la posición del Sol con respecto a la Tierra, para este caso se utilizó como acimut o posición relativa $315^{\circ}$ y la altura o ángulo de elevación $45^{\circ}$. El acimut indica la procedencia del la luz solar sobre la Tierra y se expresa en grados $\left({ }^{\circ}\right)$ respecto al norte. La pendiente y la orientación del terreno modifican sensiblemente la incidencia de los rayos solares sobre un punto concreto (Moreno et al., 2008).

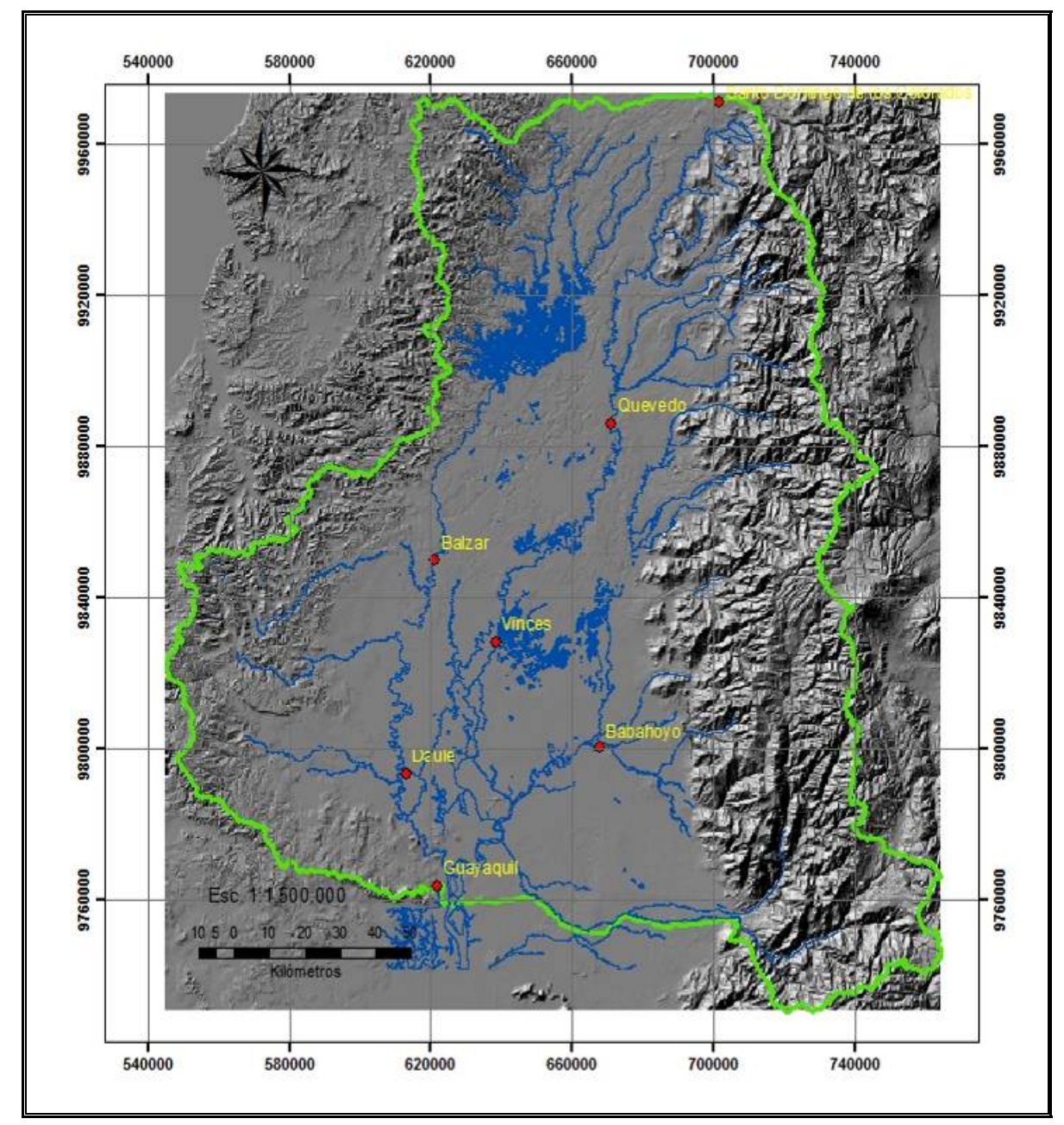

Figura10. Mapa de Iluminación de la Cuenca del Guayas.

\subsection{Vegetación y Uso del Suelo}

El uso del suelo es principalmente agrícola (sistemas agrícolas intensivos altamente tecnificados), las principales actividades, son el banano, el cultivo de arroz, café, cacao, maíz, palma africana, frutas tropicales como, mango, naranjas, melón, caña de azúcar, entre otras. La subcuenca del Daule es una de las zonas de mayor concentración de producción agrícola del país (ver Figura 15). 
El arroz se siembra principalmente en las llanuras inundables de las provincias de Los Ríos y Guayas, es un producto de alto consumo interno y externo. El café y cacao se cultiva especialmente en la subcuenca del Daule, su producción se orienta al mercado nacional e internacional. La Palma Africana, cultivada por medianos y grandes productores. El Banano se cultiva en algunas regiones de la costa, pero en la cuenca media es donde encuentra su mejor sitio de adaptación y desarrollo, es uno de los principales productos de exportación agrícola del país. Los cultivos de cítricos, además del melón, sandia, piña y mango que se está exportando a los mercados internacional. Estos cultivos se producen en todas las provincias de la zona de la cuenca del Río Guayas.

En la cuenca baja luego del banano predominan los pastos, la caña de azúcar y en menor escala el cultivo de camarón, todas estas actividades están definidas como intensivas en el uso del suelo y agroquímicos; disponen de una importante infraestructura vial, de riego, de mantenimiento, cosecha, embalaje e incluso de comercialización de la fruta. Otros cultivos como arroz, maíz y otros semipermanentes como la piña, yuca y variedades de plátano son de menor importancia en cuanto a superficie pero constituyen un rubro importante de ingresos familiares y del producto interno provincial y regional. (Granja, 2010.)

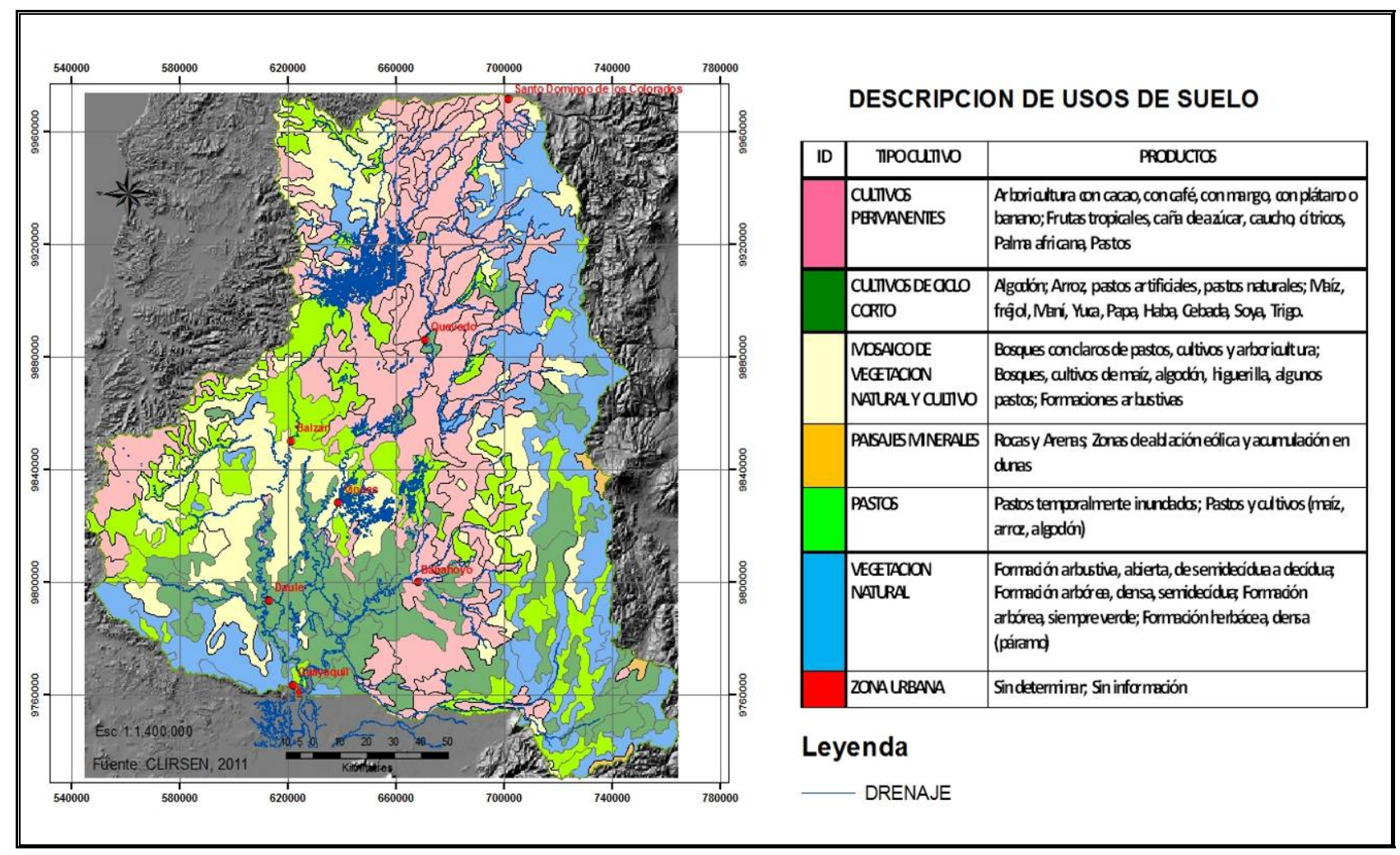

Figura11. Descripción de Usos de Suelo. 


\subsection{Suelos}

En la cuenca del Guayas, de manera general, el suelo se clasificó en seis tipos a nivel Orden, según la Soil Taxonomy, cuyos porcentajes se muestran en la Figura 16, y el mapa general de la cuenca del Guayas se presenta en la Figura 17. Para lo cual CLIRSEN, (2009) (2) los describe de la siguiente manera:

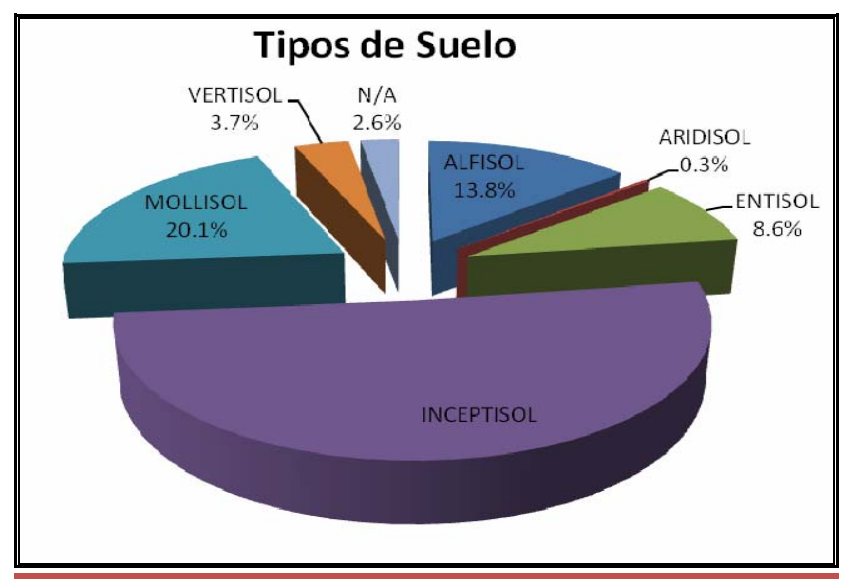

Figura12. Porcentajes de tipos de suelos en la Cuenca del Guayas.

- Alfisoles.- Son suelos que poseen un epipedón ócrico eluvial sobre un horizonte argílico (aluvial) y moderada a alta saturación de bases, en donde el proceso más importante asociado a estos suelos lo constituye la translocación de arcillas y su acumulación para formar los horizontes argílicos; generalmente se desarrollan sobre superficies antiguas o en paisajes jóvenes pero estables, sin embargo son suelos aún suficientemente jóvenes pues retienen cantidades notables de minerales primarios, arcillas, minerales y nutrientes para las plantas.

- Entisoles.- Son suelos que tienen muy poca o ninguna evidencia de formación o desarrollo de horizontes pedogenéticos, debido a que el tiempo de desarrollo ha sido muy corto o porque se encuentran sobre fuertes pendientes sujetas a erosión y otros porque están sobre planicies de inundación, condiciones que no permiten el desarrollo del suelo. Las condiciones de poco espesor o desarrollo del suelo limitan su uso; los principales problemas para su aprovechamiento constituyen la erosión, rocosidad, excesivos materiales gruesos, susceptibilidad a la inundación, saturación permanente de agua.

- Inceptisoles.- Son suelos que evidencian un incipiente desarrollo pedogenético, dando lugar a la formación de algunos horizontes alterados; los procesos de translocación y acumulación pueden presentarse. Constituyen una etapa subsiguiente de evolución, en relación con los Entisoles, sin embargo son considerados inmaduros en su evolución. Estos suelos se han originado a partir de diferentes materiales parentales (materiales resistentes o cenizas volcánicas); en posiciones de relieve extremo, fuertes pendientes o depresiones o superficies geomorfológicas jóvenes. Abarca suelos que son muy pobremente drenados a 
suelos bien drenados y como ya se ha indicado con la presencia de algunos horizontes diagnósticos, sin embargo el perfil ideal de los Inceptisoles incluiría una secuencia de un epipedón ócrico sobre un horizonte cámbico.

- Mollisoles.- Son suelos en su mayoría aquellos de color negro, ricos en bases de cambio, muy comunes de las áreas originalmente de praderas que han dado lugar a la formación de un horizonte superior de gran espesor, oscuro, con abundantes materiales orgánicos y de consistencia y estructura favorables al desarrollo radicular (epipedón móllico), debiendo destacarse para ello la acción de microorganismos y lombrices. En estos suelos pueden presentarse también procesos de translocación de arcillas que permitirán la formación de un horizonte de aluviación o argílico. Estos suelos en las llanuras y valles aluviales presentan texturas franco arenosas, arcillosas o franco arcillosas, $\mathrm{pH}$ ligeramente ácido a neutro y buena fertilidad.

- Vertisoles.- Son suelos arcillosos que presentan como característica principal grietas anchas y profundas en alguna época del año. Por lo general tienen poca materia orgánica, alta saturación en bases y predominio de montmorillonita en su composición mineralógica. Sus características físicas especialmente definen limitaciones para su utilización, muy pesados en húmedo y extremadamente duros en seco y reducido movimiento del agua; son suelos de colores oscuros, negros o grises; de difícil laboreo; profundidad variable. Se ubican en superficies sedimentarias, con relieves planos a ondulados; sobre pequeñas colinas, cuencas o antiguas playas levantadas de la región costera a partir de sedimentos de origen marino o fluvio marino y sobre relieves planos de la llanura costera, a partir de sedimentos aluviales $y$ en donde además se caracterizan por su nivel freático superficial.

- Aridisoles.- Son suelos que no poseen horizonte argílico. Se desarrollan sobre superficies de sedimentos más o menos jóvenes. Presentan colores oscuros, texturas arcillosas limosas y con encostramientos blanquecinos en superficie producto de la acumulación de sales provocada por efecto de la capilaridad y evaporación del agua salina. Se distribuye sobre los relieves planos de zonas litorales y marinas (salitrales) y se hallan cubiertos por una vegetación raquítica (pastos) tolerante a la salinidad. (Granja, 2010). 


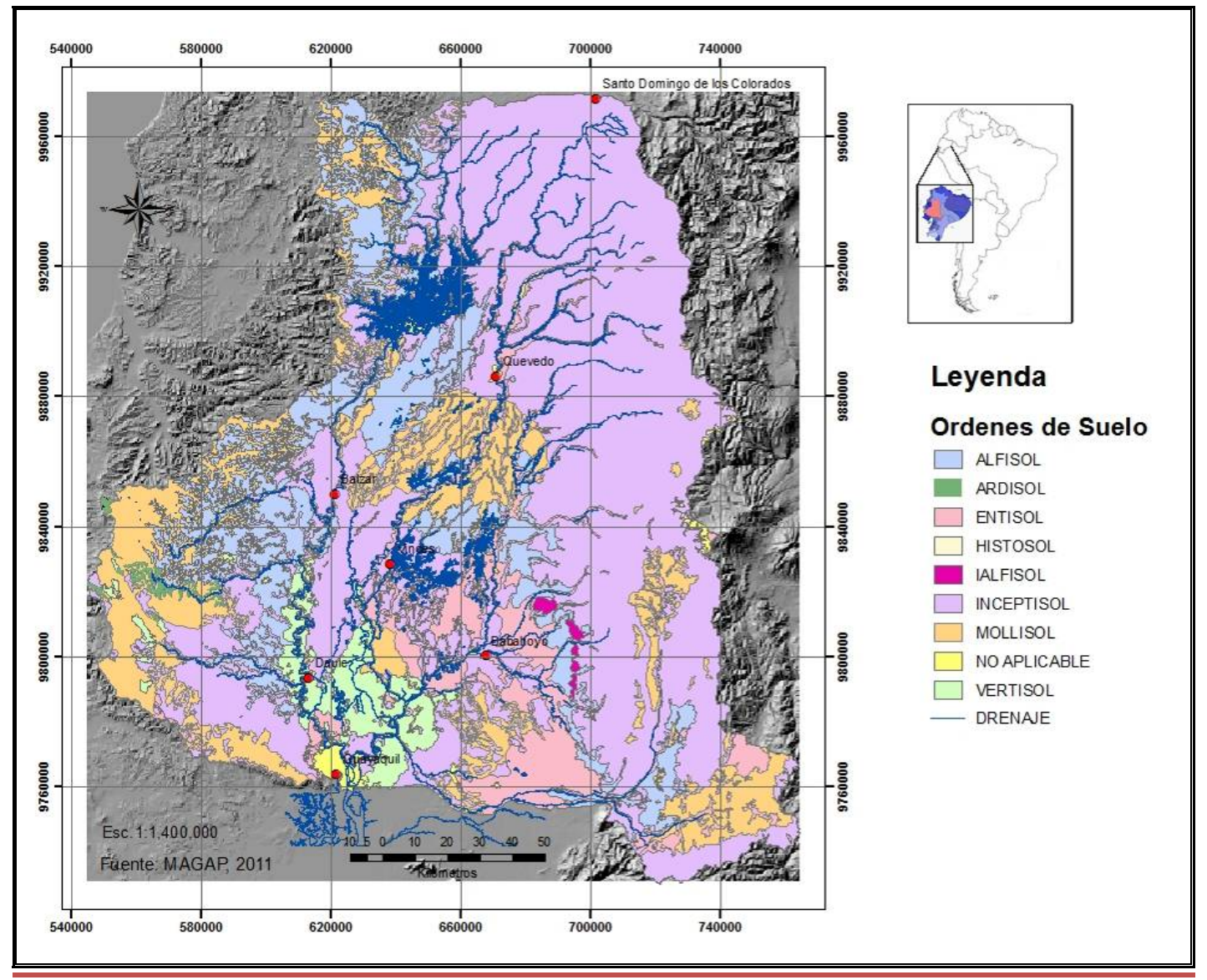

Figura13. Mapa de Suelos de la Cuenca del Guayas. Fuente: MAGAP, 2011. 


\section{CAPITULO 4}

\section{MATERIALES Y MÉTODOS}

Para el cumplimiento de los objetivos planteados en el proyecto de tesis sobre la producción de caudales y sedimentos en un área experimental en la cuenca del Río Guayas utilizando modelos hidrológicos, es fundamental contar con la información básica (mínima) necesaria para, definir el área experimental realizar la calibración y validación del modelo planteado. Una vez definida el área experimental de acuerdo a la información disponible y ayuda del instituto auspiciante de la beca, se procedió a subdividir la cuenca experimental en subcuencas o microcuencas más pequeñas y homogéneas de tal manera de realizar una caracterización de ellas. Cada unidad hidrológica presenta características morfológicas propias que la diferencian de otras, sin embargo las leyes físicas que rigen en la naturaleza son aplicables a todas las cuencas del mundo. La interpretación y medición de estas leyes naturales, el conocimiento morfológico del área de estudio y la relación de estas en el ambiente permitieron, mediante la aplicación de técnicas de simulación (modelos), predecir el comportamiento hidrológico de la cuenca experimental.

Para el desarrollo de la presente tesis, se utilizó una computadora portátil Laptop HP modelo ProBook 4410, procesador Intel Core 2 DUO $2.1 \mathrm{Ghz}, 2,9 \mathrm{~GB}$ de RAM y una impresora Epson TX135. En cuanto a los programas, para el tratamiento y procesamiento de la información geoespacial se trabajó con el programa ArcGIS $9.3 \AA$ de ESRI $®$. Para el cálculo del caudal liquido, se utilizó el modelo hidrológico HEC-HMS $®$ (Hydrologic Enginering Center's - Hydrologic Modeling System,), versión 3.5 de agosto del 2010. Para el análisis, interpretación y desarrollo de resultados se emplearon los utilitarios de Microsoft $₫$ como la hoja de cálculo de Excel $\AA$, Power Point $\AA$, Visio ${ }^{\circledR}$ y Word $2007 \AA$. Además se utilizó la red de internet de la Facultad de Ciencias Agrarias y Forestales de la Universidad Nacional de La Plata (F.C.A.F.) para bajar los programas de modelización y antecedentes disponibles.

\section{1.- Recopilación de bibliografía y definición del área experimental}

Se realizó la búsqueda de recopilación bibliográfica, estudios antecedentes, artículos técnicos-científicos del área de estudio disponibles en internet, así como datos de las instituciones oficiales encargadas de la captura, procesamiento y publicación de información topográfica, tipos de suelo, uso actual del suelo y cobertura vegetal, datos meteorológicos con registros diarios e históricos, datos de caudales y niveles diarios e históricos, imágenes satelitales, entre otros. 


\subsubsection{Definición del Área Experimental}

Para la definición de la cuenca experimental se seleccionó la zona nororiental de la cuenca del Guayas como área representativa de interés debido a que no está afectada por la influencia de la marea, no existen estructuras de ingeniería que influyan en los caudales de los ríos y tiene la naciente de algunos ríos importantes de estudio. Para lo cual se tomaron en consideración aspectos técnicos, morfométricos y operacionales, como:

- Disponibilidad de información meteorológica, hidrológica, suelo y relieve.

- Semejanza u homogeneidad con el resto de la cuenca.

- Consultas con personal técnico experimentado.

- Áreas Protegidas o Proyectos importantes.

\subsection{Morfometría de la Cuenca}

La cuenca funciona como un colector que recibe agua de la precipitación (lluvia o nieve) y la transforma en escurrimiento. Durante esta transformación, se producen pérdidas de agua que están en función de las condiciones físicas de la cuenca y de las características climáticas de la zona. Desde el punto de vista hidrológico, interesa el volumen de escurrimiento (balance hídrico) y también el reparto en el tiempo (hidrograma), que son funciones de esas condiciones y características. (López Cadena de Llano et al., 1998). Desde el punto de vista de su funcionamiento, la cuenca hidrográfica puede caracterizarse por su morfometría, por la naturaleza del suelo y por la cobertura vegetal y uso del suelo.

La influencia de estos factores sobre la transformación de la precipitación en escorrentía es fácilmente intuible cualitativamente, siendo la dificultad en expresar estos factores mediante parámetros sencillos. Sin embargo es posible definir cierto número de índices, susceptibles de servir, por lo menos de referencia, en la clasificación de cuencas y facilitar los estudios de semejanza (Gaspari et al., 2009).

Las características fisiográficas de una cuenca pueden ser expresadas a partir de ciertas medidas o parámetros que se consiguen del procesamiento de la información cartográfica y conocimiento de la topografía del área de estudio. Los parámetros morfométricos son indicadores de la influencia que tiene la forma de la cuenca en el movimiento y captación del agua de lluvia y permiten el análisis de las características morfológicas y funcionales de la cuenca hidrográfica. La forma de la cuenca controla la velocidad con que la gota de lluvia llega al cauce principal desde la divisoria hasta el punto de aforo o desembocadura y por lo general son invariables.

Los parámetros morfométricos se pueden caracterizar según (diferentes autores):

1. De relieve

2. De forma

3. Relativos a la red hidrográfica

4. Parámetros automáticos 
De los cuales los tres primeros ítems corresponden a los análisis realizados a nivel cuenca en forma manual utilizando las fórmulas mediante el programa de análisis de datos numéricos.

Para facilitar la administración y manejo de las cuencas hidrográficas, y dependiendo del tamaño de estas, es recomendable dividir a la cuenca de estudio en subcuencas que determinan áreas homogéneas de paisaje y uso. Siendo subsecuentes con esta técnica, se aplicó la herramienta HEC-GeoHMS bajo plataforma SIG, la cual calcula, entre otros datos, algunos parámetros morfométricos a nivel subcuenca en forma automática que se presenta en la sección 4.2.4. También se presentan los demás índices que no fueron calculados en forma automática por esta herramienta, usando las fórmulas correspondientes a nivel subcuenca.

\subsubsection{Parámetros de Relieve}

La influencia del relieve sobre la cuenca de estudio tiene afectación directa en la duración del tiempo de concentración de las aguas de escorrentía en la red de drenaje y afluentes al curso principal. A mayor pendiente corresponde menor duración de la concentración de la gota de agua. Los parámetros de relieve utilizados en el presente estudio a nivel cuenca, son los siguientes:

\section{a.- Área (A)}

Es la superficie encerrada por la divisoria de aguas. El área de la cuenca se considera como la superficie que contribuye con la escorrentía superficial y está delimitada por la divisoria topográfica. Es considerada como el parámetro físico básico que define a una cuenca, siendo determinante de la escala de varios fenómenos hidrológicos tales como, el volumen de agua que ingresa por precipitación, la magnitud de los caudales, etc.

\section{$\underline{\text { b. - Perímetro }(P)}$}

Es la longitud del límite exterior de la cuenca y depende de la superficie y la forma de la cuenca. Es la medición de la línea envolvente del área de la cuenca.

\section{c.- Longitud Axial (La)}

Es la distancia existente entre la desembocadura y el punto más lejano de la cuenca. Es el mismo eje de la cuenca.

\section{d.- Ancho promedio (Ap)}

Es la relación entre la superficie de la cuenca y su longitud axial. (Fórmula 24)

$$
A P=\frac{A}{L a}
$$

Fórmula 24. Ancho promedio de la cuenca 
Donde:

Ap: Ancho promedio de la cuenca $(\mathrm{km})$
A: Área $\left(\mathrm{km}^{2}\right)$
La: Longitud axial $(\mathrm{km})$

\section{e.- Altura media (h)}

Es la relación entre la diferencia de cotas (máxima y mínima) del área de estudio dividida para 2, se la expresa en metros o kilómetros. (Fórmula 25).

$$
\overline{\mathbf{h}}=\frac{\mathrm{Hmax}-\mathrm{H} \min }{2}
$$

Fórmula 25. Altura media.

Donde:

$\overline{\mathbf{h}}$ : altura media $(\mathrm{m})$

Hmax: cota máxima $(m)$

Hmin: cota mínima $(\mathrm{m})$

\section{$\underline{\text { f.- Pendiente Media de la Cuenca (PM) o Factor Topográfico }}$}

Es indudable el carácter decisivo que afecta el relieve en los fenómenos erosivos. El proceso de degradación a que se ve sometida una cuenca al igual que el caudal máximo, está muy influenciados por la configuración topográfica, ya que el poder erosivo se manifiesta en mayor o menor grado de acuerdo a los distintos rangos de pendiente.

Mintegui Aguirre (1988) propuso una clasificación de la pendiente según seis rangos porcentuales que explican las diferentes clases de pendiente en estudio, las cuales fueron utilizadas para la confección de la cartografía en esta tesis (ver Tabla 14). A esta tabla se le dio una interpretación personal, en base de varios autores, del tipo de relieve según el rango de la pendiente.

Tabla 14. Rangos y tipos de pendiente, modificado.

\begin{tabular}{|c|c|}
\hline Pendientes (\%) & Tipo de relieve \\
\hline $0-3$ & Plano \\
\hline $3-12$ & Suave \\
\hline $12-18$ & Mediano \\
\hline $18-24$ & Levemente Accidentado \\
\hline $24-30$ & Accidentado \\
\hline$>30$ & Fuerte \\
\hline
\end{tabular}


El cálculo de la pendiente media para la cuenca se efectuó tomando como base el desnivel altimétrico de la cuenca de estudio sobre la longitud axial, obtenida a partir del modelo de elevación digital, aplicando la Fórmula 26:

$$
P M(\%)=\frac{D}{\text { La }}
$$

Fórmula 26. Pendiente Media de la Cuenca. (Factor Topográfico)

Donde:

PM (\%): Pendiente media (\%)

$\mathrm{D}$ : Desnivel topográfico $(\mathrm{m})$

La: Longitud axial $(\mathrm{m})$

\subsubsection{Parámetros de Forma}

La forma de la cuenca influye sobre los escurrimientos y sobre el recorrido del hidrograma resultante de una lluvia (ver Figura 18). En una cuenca de forma alargada (cuenca $A$ en la gráfica) con un solo cauce principal recolector con tributarios cortos y poco ramificados, tendrá un hidrograma de crecientes achatado ya que el agua que proviene de los tributarios presenta una larga circulación a través del canal principal. Además el agua de los tributarios cercanos a la cabecera tarda mucho más tiempo en llegar a la desembocadura de la cuenca que el agua de los afluentes más cercanos al punto de salida, que lo hacen más rápido atenuando el caudal de salida.

En cuencas de forma semicircular a circular (cuencas B y C en la gráfica) el tiempo de recorrido del agua dentro del perímetro de la cuenca es aproximadamente igual, se caracterizan por tener tributarios más abundantes y el cauce principal corto, por lo que el hidrograma de crecientes se presenta más elevado que las cuencas alargadas de similares condiciones, siendo la descarga más elevada y demora menos tiempo ante lluvias iguales. El caudal pico es menor en la cuenca alargada, pero se alcanza más rápido que en la cuenca circular, mientras que el retorno al nivel base es más lento en la alargada que en la circular (Busnelli, 2009).

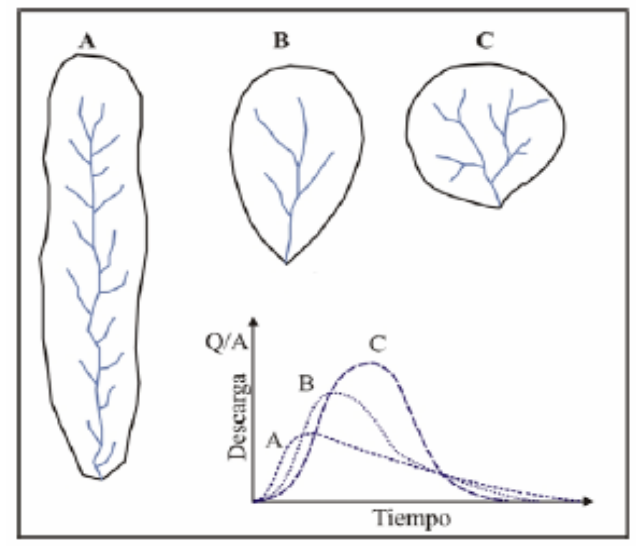

Figura 14. Formas de la cuenca de drenaje. 
A continuación se detallan los principales parámetros que fueron utilizados para este análisis:

\section{a.- Coeficiente de Gravelius ( $\mathrm{Cg}$ ) o Índice de compacidad (Kc)}

Es la relación entre el perímetro de la cuenca con el perímetro de un círculo de área similar al de la cuenca. Este coeficiente es igual a 1 cuando la cuenca es perfectamente circular. Es un índice adimensional y su expresión es la siguiente (Fórmula 27):

$$
C g=\frac{P}{2 \sqrt{\pi \cdot A}}=0,28 \frac{P}{\sqrt{A}}
$$

Fórmula 27. Coeficiente de Gravelius o Índice de compacidad.

Donde:

Cg: Coeficiente de Gravelius

P: Perímetro $(\mathrm{km})$

A: Superficie de la cuenca $\left(\mathrm{km}^{2}\right)$

Gaspari et al., 2009, presenta una clasificación de este coeficiente que crecerá con la irregularidad de la forma de la cuenca, establecida en la Tabla 15:

Tabla 15. Clasificación del coeficiente de Gravelius.

\begin{tabular}{|c|c|}
\hline $\mathbf{C g}$ & Forma de la Cuenca \\
\hline 1,00 & Redonda \\
\hline 1,25 & Oval redonda \\
\hline 1,50 & Oblonga \\
\hline 1,75 & Rectangular oblonga \\
\hline
\end{tabular}

El índice de compacidad está relacionado con el tiempo de concentración, que es el tiempo que tarda una gota de lluvia en trasladarse desde la parte más lejana de la cuenca hasta la salida. Durante este tiempo ocurre la máxima concentración de agua puesto que están llegando las gotas de lluvia de todos los puntos de la cuenca.

Está ligado a la forma de la cuenca. Cuando más irregular es la cuenca, mayor será su Cg. Una cuenca circular tendrá un coeficiente de compacidad mínimo, igual a 1, aumentando la circularidad en el cauce e incrementando una mayor probabilidad de producir avenidas máximas (eventos de torrencialidad), ya que sus tiempos de concentración para diferentes puntos de concentración serán iguales. 


\section{b.- Factor de forma (IF)}

Este factor tiene relación con las crecidas en la cuenca, interpretando la tendencia de la cuenca hacia las crecidas de los ríos. Regula la concentración de la escorrentía superficial, relacionando el movimiento del agua y la respuesta de la cuenca a dicho movimiento, controlando la velocidad con que el agua llega al cauce. (Cellini, 2005)

Es un índice adimensional que formula la relación entre el ancho promedio a la longitud axial de la cuenca. (Fórmula 28)

$$
I F=\frac{A P}{L a}
$$

Fórmula 28. Factor de Forma

Donde:

IF: Factor de forma (adimensional)

Ap: Ancho promedio (Km)

La: Longitud axial $(\mathrm{km})$

Una cuenca alargada, con un colector de mayor longitud que la totalidad de los tributarios, estará sujeta a crecientes de menor magnitud. Una cuenca de forma triangular, con dos vértices en las cabeceras, afluentes de similar longitud y sincronismo en la llegada, provocara crecidas más significativas (Gaspari et al., 2009)

Cuando IF es similar a 1, se tiene una cuenca de forma redondeada, y cuando el IF es menor a 1 se caracteriza por ser una cuenca alargada.

\subsubsection{Parámetros relativos de la red hidrográfica}

Se refiere como red hidrográfica al drenaje natural, permanente o temporal por el que fluyen las aguas de las escorrentías superficiales, su estudio es importante porque permite estudiar los escurrimientos sobre todo cuando no se dispone de información cuantitativa de los factores hidrometeorológicos.

La forma y densidad de la red de drenaje corresponde a la distribución de los afluentes que lo conforman. Esta distribución se ha venido creando a través de muchos años sobre la superficie terrestre y se expresa mediante índices o parámetros que describen de alguna manera la geometría de la red.

\section{a.- Densidad de drenaje (D)}

La densidad de drenaje representa la respuesta de la cuenca frente a una tormenta, evacuando el agua en menos tiempo. Se considera que la densidad de drenaje caracteriza 
cuantitativamente la red hidrográfica de la cuenca, definiendo el grado de relación entre el tipo de red y la clase de material predominante, los cuales permiten el escurrimiento y nos ponen de manifiesto el tipo de manejo que se debe aplicar sobre esa cuenca para evitar el deterioro de los cauces (Henao, 1988).

La densidad de drenaje está definida como la relación entre la suma de las longitudes de todos los cursos de agua que drenan la cuenca con respecto al área de la misma (López Cadenas de Llano, 1998). La ecuación utilizada para este cálculo fue la establecida por Horton y se expresa en $\mathrm{km} / \mathrm{km}^{2} \circ \mathrm{km}^{-1}$, se enuncia en la Fórmula 29.

$$
D=\frac{\sum L_{i}}{A}
$$

Fórmula 29. Densidad de drenaje.

Donde:

D: Densidad de drenaje $\left(\mathrm{km}^{-1}\right)$

$\sum L_{i}$ : Sumatoria de las longitudes de todos los cursos de agua que drenan en la cuenca $(\mathrm{km})$.

A: Superficie de la cuenca $\left(\mathrm{km}^{2}\right)$.

En principio, y sin tener en cuenta otros factores del medio físico de la cuenca, cuanto mayor sea la densidad del drenaje, más rápida será la respuesta de la cuenca frente a una tormenta, evacuando el agua en menos tiempo. En efecto, al ser la densidad de drenaje alta, una gota deberá recorrer una longitud de ladera pequeña, realizando la mayor parte del recorrido a lo largo de los cauces, donde la velocidad de la escorrentía es mayor; por tanto los hidrogramas en principio tendrán un tiempo de concentración corto (López Cadena de Llano, 1998).

\section{$\underline{\text { b.- Pendiente media del cauce (J) }}$}

La pendiente media del cauce resulta del desnivel topográfico sobre el cauce principal y la longitud del mismo (López Cadena de Llano, 1998). Se expresa en porcentaje, según la Fórmula 30.

$$
J=\frac{(H \max -H \min )}{L} \times 100
$$

Fórmula 30. Pendiente media del cauce (\%)

Donde:

$\mathrm{J}$ : Pendiente media del cauce (\%)

$\mathrm{H}$ max: Cota máxima sobre el curso de agua $(\mathrm{m})$

$\mathrm{H}$ min: Cota mínima sobre el curso de agua $(\mathrm{m})$ 


\section{L: Longitud del río más largo $(\mathrm{m})$ \\ c: Tiempo de concentración (Tc)}

Llamado también tiempo de respuesta o de equilibrio, López Cadena de Llano (1998) lo define como el tiempo que tarda en llegar a la sección de salida la gota de lluvia caída en el extremo hidráulicamente más alejado de la cuenca. Para ello se supone que el tiempo de duración de la lluvia es por lo menos igual al tiempo de concentración y que se distribuye uniformemente en toda la cuenca.

Este parámetro tiene relación directa con el gasto pico y con el tiempo de recesión de la cuenca, ya que tiempos de concentración muy cortos tienen gastos picos intensos y recesiones muy rápidas, en cambio, los tiempos de concentración más largos determinan gastos pico más atenuados y recesiones mucho mas sostenidas en el tiempo (Gaspari et al., 2009).

La ecuación usada para calcular el Tc fue la fórmula que propone Gaspari et al., (2009), en función de la pendiente media del cauce (\%) (Fórmula 31):

$$
\mathrm{TC}=0,3^{*}\left(\mathrm{~L} / \mathrm{J}^{1 / 4}\right)^{0,76}
$$

Fórmula 31: Tiempo de Concentración

Donde:

Tc= Tiempo de concentración (horas)

$\mathrm{L}=$ Longitud del cauce $(\mathrm{km})$

$\mathrm{S}=$ Pendiente media del cauce $(\%)$

\subsubsection{Parámetros automáticos con HEC-GeoHMS}

A partir del uso del programa ArcGIS $9.3 \AA$ y la extensión HEC-GeoHMS $®$ se obtuvieron las características morfométricas del relieve de la cuenca experimental a nivel subcuenca.

Para que la herramienta HEC-GeoHMS $®$ pueda procesar los datos de entrada, fue necesario que estos hayan sido anteriormente preparados por el programa ArcGIS 9.3 ®. Los datos de entrada que se usaron para trabajar con esta herramienta fueron el modelo de elevación digital (MED) del área de estudio, la capa georreferenciada de los cauces y la estación de aforo.

Una vez ingresado estos datos, el HEC-GeoHMS ${ }^{\circledR}$ arrojó una serie de información hidrológica que sirvió como datos de entrada para el programa HEC-HMS $®$ y estimar el caudal líquido (sección 4.7.2). Sin embargo para este estudio, se utilizaron los datos correspondientes a los parámetros morfométricos del relieve y de la red hidrográfica que se presentan en la Tabla 16. 
Tabla 16. Parámetros morfométricos generados con HEC-GeoHMS $®$.

\begin{tabular}{|c|c|}
\hline $\begin{array}{c}\text { PARÁMETROS MORFOMÉTRICOS } \\
\text { DEL RELIEVE }\end{array}$ & $\begin{array}{c}\text { PARÁMETROS MORFOMÉTRICOS DE } \\
\text { LA RED HIDROGRÁFICA }\end{array}$ \\
\hline 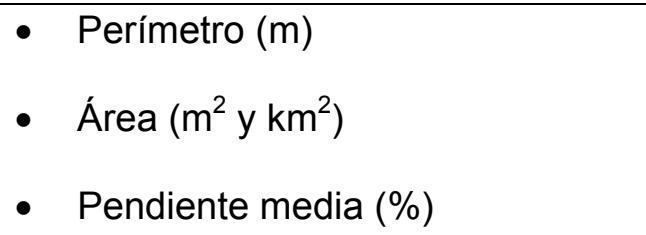 & $\begin{array}{l}\text { - } \quad \text { Longitud de los ríos }(\mathrm{m}) \\
\text { - Pendiente del cauce }(\mathrm{m} / \mathrm{m}) \\
\text { - Cotas de cauce: máxima y mínima }(\mathrm{m})\end{array}$ \\
\hline
\end{tabular}

Se analizaron los parámetros de relieve de las subcuencas, las pendientes media de las subcuencas máximas y mininas, la longitud de la red hidrográfica, la longitud de los ríos principales que atraviesan las subcuencas y la longitud total del río principal, las pendientes de los cauces y las cotas máximas y mininas que presentan en cada caso.

Se generaron análisis gráficos del perfil longitudinal de los ríos, en el cual se representa la relación elevación altimétrica versus la longitud del río.

El resto de parámetros que no fueron calculados automáticamente por la herramienta HECGeoHMS $®$, se realizaron en forma manual utilizando para esto una hoja de cálculo, de acuerdo a las fórmulas de las secciones 4.2.1, 4.2.2 y 4.2.3.

\subsection{Análisis y procesamiento de datos meteorológicos}

La entidad encargada del manejo de la información hidrológica y meteorológica es el Instituto Nacional de Meteorología e Hidrología (INAMHI) ${ }^{3}$, que opera la Red Hidrometeorológica Nacional, de la cual se obtuvo la información necesaria para los análisis que se detallan a continuación.

Para el desarrollo de estos estudios y dada la información hidrometeorológica disponible en el área representativa, se utilizó una metodología muy sintética de tal manera que, mediante la aplicación de cálculos simples poder presentar los parámetros más importantes y sus características hidrometeorológicas con una confiabilidad aceptable de una forma rápida y de buena calidad.

\subsubsection{Precipitaciones}

La precipitación es un fenómeno muy variable en el espacio y el tiempo. Es el resultado del enfriamiento de las masas de aire calientes saturadas de agua, las cuales al perder temperatura por el ascenso a niveles superiores, se condensan formando pequeñas gotas,

\footnotetext{
${ }^{3}$ La instalación de las estaciones, así como la ubicación del instrumental para la toma y/o registro de los datos meteorológicos han sido realizadas de acuerdo a normas internacionales establecidas por la Organización Meteorológica Mundial (OMM).
} 
que se precipitan a la tierra en forma de lluvia. Se mide en altura de precipitación (en $\mathrm{mm}$ ), que equivale a la altura obtenida por la caída de un litro de agua sobre la superficie en un metro cuadrado.

La medición de la precipitación en la cuenca, se efectuó por medio de pluviómetros y pluviógrafos del INAMHI, el cual define a estos como:

\section{a) Pluviómetro}

Instrumento destinado a medir las alturas de agua de las precipitaciones, cuya superficie receptora es un anillo de doscientos centímetros cuadrados de superficie, bajo la suposición que las precipitaciones están uniformemente distribuidas sobre una superficie horizontal impermeable y que no están sujetas a evaporación. Se mide las precipitación a una altura de un metro con veinte centímetros para evitar corrientes turbulentas a baja altura y salpicado en la superficie terrestre.

\section{b) Pluviógrafo}

Instrumento similar al pluviómetro que incluye un dispositivo para registrar gráfica y cronológicamente las alturas de las precipitaciones.

Para el análisis pluviométrico global del área representativa, se realizó el cálculo de la precipitación media por el método de las Isoyetas. Para lo cual se utilizó la información proporcionada por CLIRSEN (2009), en formato shape (.shp) con una red de Isoyetas medias anuales en intervalos de $100 \mathrm{~mm}$ para toda la cuenca del Guayas, en el período 1985-2006, en la cual los autores no consideraron los años 1997 y 1998, por tratarse de años excepcionales. Con la ayuda de la herramienta de los Sistemas de Información Geográfica (SIG) se procedió a recalcular la precipitación media anual para el área representativa.

Luego, para realizar el análisis pluviométrico particular, se usó el programa de cálculo Excel ${ }^{\circledR}$, con el cual se utilizaron tres pluviómetros ubicados en el área representativa de la siguiente manera:

- En el centro del área la estación meteorológica La Libertad-Río Blanco (MB89).

- En la zona alta la estación meteorológica Las Pampas (M362).

- En la zona baja la estación meteorológica Puerto lla (M026).

La estación meteorológica Puerto lla (M026) es una estación climatológica ordinaria permanente (CO) y las estaciones meteorológica Las Pampas (M362) y La Libertad (MB89) son estaciones pluviográficas permanentes (PG) todas pertenecientes al INAMHI.

Se efectuó un estudio de los datos pluviométricos de las tres estaciones en la cual se tuvieron en cuenta los valores medios de las precipitaciones anuales, mensuales y diarias en los períodos que se indican en la Tabla 17, junto con información general de las estaciones mencionadas. Los valores diarios fueron usados para ingresar en el modelo meteorológico del programa HEC-HMS $®$ para la simulación hidrológica. 
Tabla 17. Estaciones Meteorológicas usadas para el análisis pluviográfico.

\begin{tabular}{|c|c|c|c|c|c|}
\hline $\begin{array}{c}\text { Estación } \\
\text { (código) }\end{array}$ & $\begin{array}{c}\text { Posición } \\
\text { (PSAD 56) }\end{array}$ & $\begin{array}{c}\text { Altura } \\
\mathbf{( m )}\end{array}$ & $\begin{array}{c}\text { Fecha de } \\
\text { instalación }\end{array}$ & $\begin{array}{c}\text { Zona } \\
\text { Hidrológica }\end{array}$ & $\begin{array}{c}\text { Período } \\
\text { analizado }\end{array}$ \\
\hline $\begin{array}{c}\text { Puerto lla } \\
\text { (M026) }\end{array}$ & $\begin{array}{c}00^{\circ} 28^{\prime} 34^{\prime \prime} \mathrm{S} \\
79^{\circ} 20^{\prime} 20^{\prime \prime} \mathrm{W}\end{array}$ & 260 & $1-\mathrm{ENE}-1963$ & $\begin{array}{c}130-\text { Cuenca } \\
\text { del Río } \\
\text { Guayas }\end{array}$ & $1990-2010$ \\
\hline $\begin{array}{c}\text { La Libertad } \\
\text { (MB89) }\end{array}$ & $\begin{array}{c}0^{\circ} 31^{\prime} 54^{\prime \prime} \mathrm{S} \\
79^{\circ} 07^{\prime} 20^{\prime \prime} \mathrm{W}\end{array}$ & 689 & $2-\mathrm{MAY}-2005$ & $\begin{array}{c}130-\text { Cuenca } \\
\text { del Río } \\
\text { Guayas }\end{array}$ & $2005-2010$ \\
\hline $\begin{array}{c}\text { Las } \\
\text { Pampas } \\
\text { (M362) }\end{array}$ & $\begin{array}{c}0^{\circ} 26^{\prime} 36^{\prime} \text { ' S } \\
78^{\prime} 00^{\prime \prime} \mathrm{W}\end{array}$ & 1640 & $1-\mathrm{ENE}-1965$ & $\begin{array}{c}80 \text { - Cuenca } \\
\text { del Río } \\
\text { Esmeraldas }\end{array}$ & $1990-2010$ \\
\hline
\end{tabular}

Fuente (INAMHI. 2000-2008).

\subsubsection{Temperatura}

EI INAMHI dispone de instrumental específico para medir la temperatura del aire, los cuales, para evitar la influencia de la radiación directa, reflejada y difusa, se ubican en un abrigo meteorológico (caseta) a dos metros de altura. Se mide en grados centígrados y décimas de grado. La temperatura del aire es importante medir por una serie de precauciones que hay que tomar en cuenta para el análisis hidrometeorológico. El instrumental lo define de la siguiente manera:

a) Termómetro seco. Dispositivo que utiliza la diferencia de dilatación del líquido (mercurio en este caso), y el vidrio que lo contiene para poder medir la temperatura del aire. Junto con el termómetro de bulbo húmedo forma parte del Psicrómetro.

b) Termómetro de mínima. Dispositivo de líquido (alcohol) en vidrio destinado a medir las temperaturas más bajas ocurridas en el día. El menisco de la columna de alcohol (extremo de la columna) arrastra un índice (metálico o de arcilla) conforme va reduciendo el tamaño de la columna al ir disminuyendo la temperatura, hasta llegar al menor valor de ese día, lo que por lo general sucede alrededor del momento anterior a la salida del sol. Al aumentar luego la temperatura el índice deja pasar el alcohol en su marcha ascendente. Pero queda en la posición de la temperatura mínima para su lectura a las 07:00 Hrs.

c) Termómetro de máxima. Dispositivo de líquido (mercurio) en vidrio destinado a medir la mayor temperatura ocurrida durante el día. Tiene una pequeña estrangulación que permite que el mercurio fluya libremente mientras aumenta la temperatura, pero al principiar su disminución impide el regreso de la columna de mercurio, o sea queda marcando la temperatura más alta del día se lee diariamente a las 17:00 Hrs. 
d) Termógrafo. Aparato destinado a registrar de manera gráfica las variaciones cronológicas de la temperatura del aire durante un tiempo determinado, el INAMHI usa registro gráfico en fajas de duración semanal. Se utiliza este aparato ante la incapacidad del ser humano de estar observando de manera continua la variación de la temperatura en el tiempo. La parte sensible está constituida por una placa bimetálica que tiene dos capas metálicas, con metales de diferentes coeficientes de dilatación lo que permite una deformación del bimetálico debido a los cambios de temperatura y diferente grado de dilatación de los metales.

Se utilizará los datos provenientes de la estación meteorológica completa Puerto lla (M026) que dispone de información histórica y de la estación pluviográfica Las Pampas (M362).

El análisis de datos que se presenta en este trabajo incluye valores de temperatura media, máxima y mínima a nivel mensual y anual, en los períodos que se indican en la Tabla 18 junto con información general de las estaciones consideradas para este estudio. De la estación Las Pampas solo se pudo obtener información desde el 2005 al 2010.

Tabla 18. Estaciones Meteorológicas usadas para el análisis de temperatura

\begin{tabular}{|c|c|c|c|c|c|}
\hline $\begin{array}{c}\text { Estación } \\
\text { (código) }\end{array}$ & $\begin{array}{c}\text { Posición } \\
\text { (PSAD 56) }\end{array}$ & $\begin{array}{c}\text { Altura } \\
\mathbf{( m )}\end{array}$ & $\begin{array}{c}\text { Fecha de } \\
\text { instalación }\end{array}$ & $\begin{array}{c}\text { Zona } \\
\text { Hidrológica }\end{array}$ & $\begin{array}{c}\text { Período } \\
\text { analizado }\end{array}$ \\
\hline $\begin{array}{c}\text { Puerto lla } \\
\text { (M026) }\end{array}$ & $\begin{array}{c}0^{\circ} 28^{\prime} 34^{\prime \prime} \mathrm{S} \\
79^{\circ} 20^{\prime} 20^{\prime \prime} \mathrm{W}\end{array}$ & 260 & 1 -ENE-1963 & $\begin{array}{c}130 \text { - Cuenca } \\
\text { del Río } \\
\text { Guayas }\end{array}$ & $1990-2010$ \\
\hline $\begin{array}{c}\text { Las } \\
\text { Pampas } \\
\text { (M362) }\end{array}$ & $\begin{array}{c}0^{\circ} 26^{\prime} 36^{\prime} \text { ' S } \\
78^{\prime} 00^{\prime \prime} \mathrm{W}\end{array}$ & 1640 & $1-\mathrm{ENE}-1965$ & $\begin{array}{c}80 \text { - Cuenca } \\
\text { del Río } \\
\text { Esmeraldas }\end{array}$ & $2005-2010$ \\
\hline
\end{tabular}

Fuente: (INAMHI. 2000-2008).

\section{4.- Análisis y procesamiento de datos hidrológicos}

El Instituto Nacional de Meteorología e Hidrología (INAMHI) es la institución rectora del manejo de la información hidrometeorológica a nivel nacional, para lo cual dispone de redes con estaciones hidrométricas o fluviométricas que sirven para definir el régimen de un río, de una cuenca, de una región o del país ${ }^{4}$.

A continuación se transcriben algunas definiciones que hace el INAMHI relacionadas con los estudios hidrológicos que se aplican en este trabajo:

\footnotetext{
${ }^{4}$ La instalación de las estaciones, así como la ubicación del instrumental para la toma y/o registro de los datos hidrológicos, han sido realizadas de acuerdo a normas internacionales. Anuarios INAMHI.
} 


\section{a) Estación hidrométrica o fluviométrica}

Es el lugar donde se realizan sistemáticamente mediciones de caudal, sedimentos, muestreo hidroquímico y/u observaciones del nivel de agua, lo que permite conocer el régimen en un río, canal o el nivel de un lago o embalse.

Caudal es el volumen de agua que pasa por una sección transversal de una corriente en la unidad de tiempo y se mide en $\mathrm{m}^{3} / \mathrm{s}$ o en $\mathrm{l} / \mathrm{s}$.

Una sección hidrométrica está compuesta por:

- Sección de aforo

- Sección limnigráfica

- Sección limnimétrica

b) Aforo

Es la medición de un caudal o volumen de sedimento en suspensión.

c) Altura Limnimétrica o nivel de agua

Es la cota de la superficie de agua con relación a un punto de referencia que puede tener una cota arbitraria o el nivel del mar.

El instrumento de medida se denomina llimnímetros o piezómetro constituida por una regla con escala métrica de lectura directa. Además la estación hidrométrica puede tener un instrumento de registro continua llamado limnígrafo o piezógrafo que realiza las lecturas de caudales por medio de registro gráfico continúo de los niveles de agua.

\section{d) Obtención de la información}

La toma de la información Limnimétrica se la obtiene mediante mediciones periódicas realizadas por el observador de la estación. Para el caso de la red hidrométrica se registra la lectura en la mañana a las 07:00 horas y otra en la tarde a las 17:00 horas.

Adicionalmente a la toma de datos por el observador y operador de la estación, también se dispone de registros gráficos (limnigramas), los cuales determinan la variación del nivel en el tiempo de una manera continua, pudiendo ser diarios, semanales o mensuales, dependiendo del instrumento registrador y del mantenimiento de la estación.

Las estaciones automáticas están compuestas por un sensor de nivel, sensor medidor de $\mathrm{pH}$, sensor que mide la temperatura del agua y del aire, sensor pluviométrico y un sensor que mide la conductividad.

\section{e) Procesamiento de la información}

Para el cálculo de caudales a partir de las lecturas limnimétricas y/o limnigráficas, es necesario contar con la curva de gasto líquido (ecuación o curva de descarga), la que es obtenida mediante un ajuste de mínimos cuadrados a partir de los caudales obtenidos de los aforos de gasto líquido realizados en una estación. 
Los caudales medios diarios se obtienen como un promedio aritmético ponderado de los valores parciales de caudales generados en base de los niveles observados, a través de su respectiva curva de gasto líquido.

\subsubsection{Caudales}

La estación utilizada para el estudio fue la estación limnigráfica (LG) H414 Toachi AJ Baba ubicada a la salida de la cuenca del Río Toachi, sobre el río del mismo nombre (ver Tabla 19), durante el período 2003-2010 debido a la mayor cantidad de datos disponibles.

La estación limnigráfica Toachi AJ Baba está localizada $4 \mathrm{~km}$ antes de la confluencia del Río Toachi con el Baba. La estación dispone de un limnígrafo y varios llimnímetros instalados sobre la margen izquierda y los aforos se los ejecuta con el sistema cable-carro.

Tabla 19. Estación usada para el análisis hidrológico

\begin{tabular}{|c|c|c|c|c|c|}
\hline $\begin{array}{c}\text { Estación } \\
\text { (código) }\end{array}$ & $\begin{array}{c}\text { Posición } \\
\text { (PSAD 56) }\end{array}$ & $\begin{array}{c}\text { Altura } \\
\text { (msnm) }\end{array}$ & $\begin{array}{c}\text { Fecha de } \\
\text { instalación }\end{array}$ & $\begin{array}{c}\text { Zona } \\
\text { Hidrológica }\end{array}$ & $\begin{array}{c}\text { Período } \\
\text { analizado }\end{array}$ \\
\hline $\begin{array}{c}\text { Toachi AJ } \\
\text { Baba } \\
\text { (H414) }\end{array}$ & $\begin{array}{c}00^{\circ} 40^{\prime} 44^{\prime \prime} \mathrm{S} \\
79^{\circ} 21^{\prime} \text { 09" W }\end{array}$ & 107 & $1-\mathrm{MAY}-84$ & $\begin{array}{c}130- \\
\text { Cuenca del } \\
\text { Río Guayas }\end{array}$ & $2003-2010$ \\
\hline
\end{tabular}

Fuente: (INAMHI. 2000-2008).

La información hidrológica usada en este trabajo corresponde a datos de caudales diarios y caudales mensuales. Los datos a nivel diario fueron usados para la simulación hidrológica, y los datos mensuales para realizar los siguientes análisis: distribución de los caudales medios mensuales, variación mensual del caudal medio mensual y la distribución de los caudales mensuales durante el período 2003-2010.

Se presenta además el análisis de la relación caudal medio mensual (QMM) de la estación Toachi AJ Baba durante el período 2003-2010 versus la precipitación media mensual (PMM) de la estación La Libertad durante el período 2005-2010.

\subsection{Análisis del Balance Hídrico}

Para el presente análisis, partiendo del conocimiento de las lluvias medias mensuales y de la evapotranspiración potencial mensual (calculada con el método de Thornthwaite), se determinó el balance del agua en el suelo aplicando el método directo durante los períodos correspondientes.

\subsubsection{Cálculo del Balance Hídrico}

El método directo, descrito en la sección 2.3.1, se basa en que el agua del suelo va disminuyendo mes a mes hasta agotar la reserva para poder cubrir las necesidades de 
agua. El modelo está dividido en dos partes: primero el cálculo de la evapotranspiración potencial y segundo el cálculo propiamente del balance de agua en el suelo.

- Para el cálculo de la evapotranspiración potencial, se aplicó el método de estimación de Thornthwaite (1944), el cual necesita como datos de entrada la temperatura media mensual, el número de días del mes y el número de horas de sol (de acuerdo a la latitud de las estaciones).

Se utilizó el programa Excel ${ }^{\circledR}$, en el cual se ingresó los datos de la temperatura media mensual de la estación meteorológica correspondiente y el número de horas de luz, de esta manera se obtiene la evapotranspiración potencial corregida (ETP corr).

- Una vez obtenida la ETP corregida y con la información de la precipitación media mensual se procede a ingresar en la hoja de Excel $®$ adecuada, obtenido de esta manera la evapotranspiración real (ETR), el Déficit, la Reserva y los Excedentes de agua para el suelo del área correspondiente a la estación meteorológica en estudio.

Para este trabajo se estableció como capacidad máxima de retención de agua en el suelo el valor de $300 \mathrm{~mm}$ para el cálculo de la estación Puerto lla y de $200 \mathrm{~mm}$ para las estaciones La Libertad y las Pampas, valores sugeridos por CLIRSEN, 2009.

Con la metodología descrita, se calcularon los Balances Hídricos del área representativa de estudio, sin embargo como la estación La Libertad, ubicada en la zona media, no dispone de mediciones de temperatura y solo posee precipitación del período 2005-2010, se realizó un cálculo entre las temperaturas medias de las estaciones Las Pampas y Puerto lla, parte alta y parte baja respectivamente, durante el período 2005-2010, según el siguiente procedimiento:

- Se utilizó la información proporcionada por el CLIRSEN y mediante el uso de los SIG, se verificó la ubicación y características climáticas de la estación la Libertad, como zona climática e intervalo de temperatura, luego se comparó con los rangos de temperatura de las estaciones Puerto lla y Las Pampas para comprobar la variabilidad climática y obtener mediante el promedio aritmético los valores mensuales de la temperatura media para el cálculo del Balance Hídrico del suelo. En la Tabla 20 se presentan los datos de las estaciones utilizadas para el cálculo del Balance Hídrico en el área representativa, según la zona.

Tabla 20. Estaciones usada para el Balance Hídrico

\begin{tabular}{|c|c|c|c|}
\cline { 2 - 3 } \multicolumn{1}{c|}{} & \multicolumn{2}{c|}{ PERÍODOS } & \multicolumn{1}{c}{} \\
\hline ZONA & $\begin{array}{c}\text { PRECIPITACION } \\
\text { MEDIA MENSUAL }\end{array}$ & $\begin{array}{c}\text { TEMPERATURA } \\
\text { MEDIA MENSUAL }\end{array}$ & ESTACIÓN \\
\hline BAJA & $1990-2010$ & $1990-2010$ & Puerto lla (M026) \\
\hline MEDIA & $2005-2010$ & $2005-2010$ & La Libertad (MB89) \\
\hline ALTA & $2005-2010$ & $2005-2010$ & Las Pampas (M362) \\
\hline
\end{tabular}

Fuente: (INAMHI. 2000-2008). 


\section{6.- Integración de los Sistemas de Información Geográfica (SIG)}

Los SIG son una herramienta poderosa para colectar, almacenar, recuperar a voluntad, transformar y desplegar datos espaciales del mundo real para propósitos particulares, con la finalidad de contribuir con información para la toma de decisiones. (Flores et al., 2003). La integración de los SIG en los análisis y presentación de resultados de la presente tesis permitió cumplir los objetivos propuestos inicialmente.

La cartografía digital que se recopiló tanto del Instituto Geográfico Militar (IGM), del Centro de Levantamientos Integrados de Recursos Naturales por Sensores Remotos (CLIRSEN) y del Sistema de Información Geográfica y Agropecuaria del Ministerio de Agricultura (SIGAGRO), corresponden a la proyección WGS_1984_UTM, Zona 17S y los archivos digitales para trabajar con la herramienta SIG, están en formato .shp (shape file). El tamaño de la celda es de $100 \times 100$, de 455 columnas $\times 288$ filas, en formato GRID, de tipo de fuente continuo y pixel de tipo flotante.

\subsubsection{Generación del Modelo Cartográfico}

El área representativa tiene tres zonas fisiográficas bien definidas que demuestran diferencias según el grado de pendiente y capacidad erosiva. Las mismas han sido analizadas y los resultados se presentan tanto a nivel cuenca de estudio como a nivel unidades hidrológicas.

Utilizando las cartas topográficas digitales y el modelo digital de elevación del IGM; información temática de suelo, uso de suelo y cobertura vegetal del Ministerio de Agricultura, Ganadería, Acuacultura y Pesca (MAGAP) y CLIRSEN, imágenes satelitales y material bibliográfico disponible en internet (digital) y recibido por correo (papel, discos compactos) se construyó el "modelo cartográfico", el cual mediante la aplicación del programa ArcGIS $9.3 \circledR$ fue utilizado para la elaboración de los Mapas Temáticos.

\section{Mapa Topográfico y Modelo de Elevación Digital (MED)}

La cartografía base utilizada para realizar la delimitación de la cuenca experimental corresponde a las cartas topográficas digitales del IGM disponibles en la página web a escala 1:50.000, con una equidistancia altitudinal de 20 metros, las cuales se presentan en la Tabla 21.

Tabla 21. Denominación de las cartas topográficas

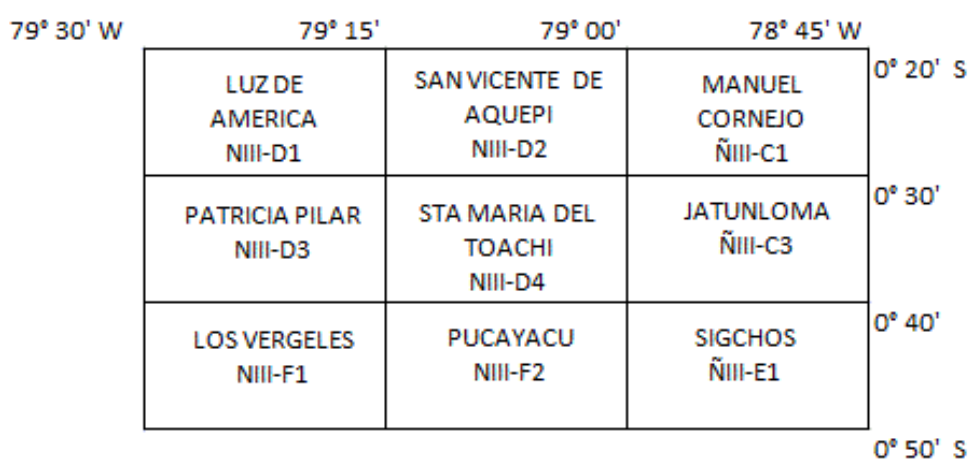


Utilizando las capas de las curvas de nivel correspondientes, con cotas sobre el nivel del mar, y mediante el programa ArcGIS $9.3 \AA$ se elaboró el mapa topográfico manteniendo la equidistancia original de la cartografía base.

El Modelo de Elevación Digital (MED) SRTM de 30 metros x 30 metros fue proporcionado por el CLIRSEN, con el datum WGS_1984_UTM_Zona_17S, al cual, mediante el programa ArcGIS $9.3 \circledR$, se realizó el tratamiento correspondiente para su presentación.

A continuación se detallan los mapas generados bajo el esquema del modelo cartográfico:

\subsubsection{Red de Drenaje}

Para la elaboración del mapa de drenaje se utilizó como base las cartas topográficas digitales, de las cuales se extrajeron las respectivas capas de ríos (shape). Los ríos corresponden a cursos de agua permanentes. Este mapa se superpuso con las imágenes satelitales Landsat 19870326 TM y 19991114 para corroborar la distribución del drenaje en el espacio.

\subsubsection{Delimitación de cuenca y subcuencas}

Se definió el límite de la cuenca y subcuencas a partir de la divisoria de aguas, establecida por medio del modelo digital del terreno y la red de drenaje anteriormente mencionada. Posteriormente se corroboró la delimitación de la cuenca y subcuencas a partir del procesamiento con el programa HEC-GeoHMS ${ }^{\circledR}$.

\subsubsection{Mapa de Orientaciones de ladera}

El mapa de orientaciones o exposición del área de estudio se generó a partir del modelo de elevación digital (MED), con la aplicación del programa ArcGIS 9.3 ®. El cálculo se realizó a partir de la línea de máxima pendiente entre cada celda y las próximas. Los valores resultantes de la operación oscilan entre $0^{\circ}$ y $360^{\circ}$ siguiendo el sentido de las agujas del reloj, y representan la dirección de esta línea con respecto al norte (Moreno et al., 2008). Este mapa representa la orientación del terreno con respecto al norte geográfico.

\subsubsection{Mapa de lluminación}

Mediante el uso del programa ArcGIS 9.3 $®$, se generó la cartografía que describe la iluminación o sombreado de las laderas con respecto a la dirección del flujo solar, considerando un azimut de $315^{\circ}$, que corresponde al Noroeste, y la altura del Sol a $45^{\circ}$ de inclinación.

\subsubsection{Mapa de Pendientes}

A partir del MED se realizó un mapa de pendiente según su gradiente porcentual, mencionado en la sección 4.2.1.f. Se zonificó el área según intervalos de clases de pendientes empleando el programa ArcGIS 9.3 §. Este mapa brinda información para establecer pautas de manejo de los suelos con el fin de minimizar los procesos erosivos. 


\subsubsection{Mapa de Suelos}

Para la elaboración del mapa de suelos, se realizó a partir de la cartografía temática existente disponible en la página web del MAGAP ${ }^{5}$ (El mapa fue realizado por PRONAREGORSTOM en 1980). El MAGAP, para realizar la clasificación de los suelos utilizó el Sistema de Clasificación del Departamento de Agricultura de los Estados Unidos (USDA-2006) "Soil Taxonomy" ${ }^{6}$. Utilizando el programa ArcGIS $9.3{ }^{\circledR}$ se procedió a extraer el área de estudio y con la hoja de cálculos Excel $®$ a realizar los gráficos.

\subsubsection{Mapa de Cobertura Vegetal y Uso de Suelo}

El mapa de la cobertura vegetal y uso del suelo del área de estudio, se realizó a partir de la cartografía temática elaborada del CLIRSEN con la ayuda de la información disponible en la página web del Ministerio de Agricultura, Ganadería, Acuacultura y Pesca (MAGAP), que comprende toda la cuenca del Guayas.

\section{$\underline{\text { 4.6.1.8 Mapa de Isoyetas }}$}

Para realizar el mapa de Isoyetas, se usó el mapa digital proporcionado por CLIRSEN de toda la cuenca del Guayas, el cual utilizó el período de 1985 a 2006, y mediante el programa ArcGIS $9.3{ }^{\circledR}$, se procedió a extraer la cuenca de estudio.

\subsubsection{Mapa de Isotermas}

Se utilizó el mapa digital proporcionado por CLIRSEN de toda la cuenca del Río Guayas, realizando para esto un estudio de correlación lineal temperatura-altura con los valores de las temperaturas medias registrados en las estaciones meteorológicas existentes en la cuenca. Se trazaron las isotermas de cada grado centígrado, con base en la topografía, aplicando para cada zona la correlación lineal más adecuada (CLISEN 2009 (2)). Luego con el programa ArcGIS $9.3 \AA$, se procedió a extraer la cuenca de estudio.

\subsubsection{Mapa de Zonas Climáticas}

Para realizar el mapa de las zonas climáticas de la cuenca de estudio, se usó el mapa climático de la cuenca del Guayas realizado por CLIRSEN. Para realizar esta selección de zonas, CLISEN 2009 (2) utilizó la clasificación climática propuesta por el Dr. Pierre Porrut, que está basada en parámetros simples y divididos en números limitados por categorías. Los parámetros utilizados para la elaboración del mapa climático son las precipitaciones totales anuales y sus regímenes, así como las temperaturas medias mensuales que, combinados dan los diferentes tipos de clima.

\footnotetext{
5

http://www.magap.gob.ec/sinagap/index.php?option=com jdownloads\&ltemid=397\&view=viewcategory\&cati $\underline{d=6}$

6 "Una clasificación de suelos en función de varios parámetros (y propiedades) que se desarrollan en niveles: Orden, Suborden, Gran Grupo, Subgrupo, Familia y Serie. Desarrollada y coordinada internacionalmente por el Ministerio de Agricultura de los Estados Unidos (USDA)". Fuente: Internet.
} 


\subsection{Cálculo del caudal líquido}

El cálculo del caudal líquido, está constituido fundamentalmente por el escurrimiento superficial, que es el agua procedente de las precipitaciones que corre por la superficie terrestre y luego se reúne en los cauces de los ríos.

\subsubsection{Método del S.C.S. para las abstracciones}

Para calcular la lluvia efectiva, se utilizó el método desarrollado, en el año de 1972, por el Servicio de Conservación de Suelos de los Estados Unidos (Soil Conservation ServiceS.C.S.) denominado Número de Curva (NC), como una función de la lluvia acumulada, la cobertura vegetal del suelo, el uso del suelo y las condiciones de humedad antecedente. Este método permite calcular las abstracciones de una tormenta, las cuales incluyen la interceptación, la detención superficial y la infiltración, que por diferencia se establece el escurrimiento (Monsalve, 2000).

Se utilizó dicho método, porque es ideal para situaciones que se dispone de poca información de datos en sitios de aforo, pero se debe conocer el tipo de suelo y la cobertura vegetal, puesto que la asociación, suelo-vegetación, se comporta de una misma manera frente a la infiltración. Sin embargo, es conocido que para una tormenta se generan diferentes caudales de escurrimiento en función del grado de permeabilidad del suelo (Gaspari et al., 2009).

A partir de la combinación suelo-vegetación, se pueden obtener las curvas de escurrimiento superficial ante una tormenta particular, debiendo tener presente que durante la primera parte de la curva caudal-tiempo existe un "umbral" de precipitación denominado abstracción (la), en el cual toda la precipitación es interceptada por la asociación suelo-vegetación, por lo tanto, en esa situación, el escurrimiento superficial es nulo. Una vez que el suelo se satura, se supera el valor de la, y comienza la segunda parte de la curva en la que aumenta el escurrimiento en función que aumenta la precipitación (López Cadena de Llano, 1998).

Este método asigna un valor a la combinación "suelo-vegetación" en función de las características hidrológicas del suelo denominado Número de Curva o Número Hidrológico (NC). Cada valor fue tabulado y difundido en publicaciones a nivel internacional. Para determinar el valor de NC, se utilizaron las herramientas del SIG que tiene como datos de entrada el mapa geológico, el mapa del suelo y el mapa de uso de suelo y cobertura vegetal.

\subsubsection{Obtención del Número de Curva (NC)}

Primeramente, en una planilla de cálculo, se realizó una clasificación de los suelos de acuerdo a la establecida por el Soil Conservation Service (1972), la cual ordena a los suelos en "grupos" según el comportamiento ante un evento de lluvia, es decir, la capacidad infiltración o escurrimiento. De esta forma, se clasificaron los diferentes tipos de suelo según su textura, estructura y permeabilidad, en el grupo que corresponda dependiendo así también su comportamiento hidrológico, denominados "grupos hidrológicos". 
En la Tabla 22 se presentan una clasificación del suelo según los grupos hidrológicos elaborada de varios autores (Mintegui Aguirre y López Unzú, 1990; López Cadena de Llano, 1998, Gaspari et al., 2009).

Tabla. 22. Descripción de los Grupos Hidrológicos.

\begin{tabular}{|c|c|c|c|c|}
\hline & \multicolumn{4}{|c|}{ GRUPO HIDROLÓGICO } \\
\hline & A & B & C & D \\
\hline ESCORRENTIA & Baja & Moderadamente baja & Moderadamente alta & Alta \\
\hline NC & Bajo & Moderadamente bajo & Moderadamente alto & Alto \\
\hline INFILTRACIÓN & Alta & Moderada & Lenta & Muy lenta \\
\hline $\begin{array}{c}\text { CLASE } \\
\text { TEXTURAL }\end{array}$ & $\begin{array}{l}\text { Arenosa } \\
\text { Arenosa- } \\
\text { Franca } \\
\text { Franco- } \\
\text { Arenosa }\end{array}$ & $\begin{array}{l}\text { Franco-Limosa Franca } \\
\text { Limosa }\end{array}$ & $\begin{array}{l}\text { Franco-Arcillo- } \\
\text { Arenosa Franco- } \\
\text { Arcillo-limosa } \\
\text { Franco-Arcillosa }\end{array}$ & $\begin{array}{l}\text { Arcillo-Arenosa } \\
\text { Arcillo-Limosa } \\
\text { Arcillosa }\end{array}$ \\
\hline OBSERVACIÓN & $\begin{array}{l}\text { Suelos } \\
\text { profundos. } \\
\text { Alta tasa de } \\
\text { transmisión } \\
\text { de agua. } \\
\text { De } 0 \text { a } 10 \% \\
\text { de arcilla. } \\
\text { Más arena. }\end{array}$ & $\begin{array}{l}\text { Mediana a buena } \\
\text { profundidad. De } 10 \text { a } \\
30 \% \text { de arcilla. } \\
\text { Granulometría entre } \\
\text { gruesa y fina. Más } \\
\text { arena. }\end{array}$ & $\begin{array}{l}\text { Suelos generalmente } \\
\text { poco profundos }(0,5 \text { a } \\
1 \mathrm{~m}) . \text { Permeabilidad } \\
\text { lenta. De } 30 \\
\begin{array}{l}\text { a } 70 \% \text { de arcilla. } \\
\text { Menos arena. }\end{array}\end{array}$ & $\begin{array}{l}\text { Suelos poco } \\
\text { profundos. Nivel } \\
\text { freático alto } \\
\text { permanentemente } \\
\text { Presencia de sales. } \\
\text { De } 70 \text { a } 100 \% \\
\text { arcilla. Coloración } \\
\text { negra, fumíferos. } \\
\text { Material casi } \\
\text { impermeable }\end{array}$ \\
\hline
\end{tabular}

Elaboración: propia

Para la definición de los grupos hidrológicos $(\mathrm{GH})$ del suelo en la cuenca en estudio, se basó en la información recopilada y proporcionada por las diferentes instituciones gubernamentales como CLIRSEN, SIGAGRO, entre otras. Esta información de base fue para la Cuenca del Guayas, el mapa geológico y el mapa de suelo. La interpretación que para la clasificación de los suelos, fue en función de la escala en la que están elaborados los mapas originales (1:250.000).

Conocido el grupo hidrológico al que pertenecen los tipos de suelo de la cuenca de estudio, y teniendo en cuenta el uso y la cobertura vegetal que tienen, se asignaron los Números de Curva en las diferentes áreas de la cuenca. Para ello se utilizaron las Tablas de NC correspondientes que se encuentran disponibles en la bibliografía consultada (Mintegui Aguirre y López Unzú, 1990; López Cadena de Llano, 1998; Manual en internet ${ }^{7}$ ). Obtenidos los Números de Curva para cada una de las áreas de la cuenca, se utilizó la herramienta de

\footnotetext{
${ }^{7}$ http://onlinemanuals.txdot.gov/txdotmanuals/hyd/nrcs_runoff_curve_number_methods.htm\#i1026928
} 
los SIG para realizar el entrecruzamiento de los mapas de cobertura vegetal y uso del suelo con el mapa de Grupo Hidrológico (GH). De esta manera se obtuvo el mapa del Número de Curva (NC) ponderado para cada subcuenca utilizando el programa ArcGIS $9.3 \AA$ de ESRI.

\subsubsection{Modelización Matemática con HEC-HMS $®$}

Para el cálculo del caudal liquido, se utilizó el modelo hidrológico HEC-HMS $®$, que es un programa de simulación hidrológica de tipo evento, lineal y semidistribuido, desarrollado para estimar los hidrogramas de salida en una o varias cuencas (subcuencas) a partir de diversas condiciones de lluvias. Para la simulación, se aplican diversos métodos de cálculo de hidrogramas de diseño, pérdidas por infiltración, flujo base y conversión en escorrentía directa (Silva, 2005).

Para el desarrollo de la presente tesis, se aplicó la modelación del programa HEC-HMS $®$ a nivel diario, seleccionando métodos de cálculo globales, lo cual implicó que las características fisiográficas y climatológicas se consideraran homogéneas en toda la cuenca.

En base al supuesto de homogeneidad, la cuenca de estudio se dividió en tres zonas que representan similitud fisiográfica y climatológica. Estas zonas se denominan alta, media y baja, permitiendo obtener resultados representativos a nivel regional.

La zona alta desde la divisoria de aguas ubicada a $3640 \mathrm{msnm}$ hasta una altura promedio de $1100 \mathrm{msnm}$, la zona media hasta $450 \mathrm{msnm}$ promedio y la zona baja hasta $160 \mathrm{msnm}$, donde está ubicado el punto de aforo.

El modelo HEC-HMS ${ }^{\circledR}$ tiene la capacidad de abrir automáticamente archivos con información topológica y topográfica obtenida a partir de un SIG, (Modelo Digital de Terreno), que facilita la entrega de los parámetros hidrológicos en forma distribuida para ser usados como inputs del modelo. La filosofía de este modelo con respecto a su integración SIG, es que ambas herramientas pueden utilizar información geoespacial, pero no dependen de ella para su ejecución.

Para este trabajo de tesis, el nexo entre el modelo HEC-HMS ${ }^{\circledR}$ y los SIG, se utilizó la herramienta HECGeo-HMS, cuyos resultados descritos en la sección 4.2.4 fueron utilizados como información de entrada para el modelo hidrológico.

En la Figura 19, se muestra el esquema de integración entre el modelo hidrológico HECHMS $\circledast$ y SIG. 


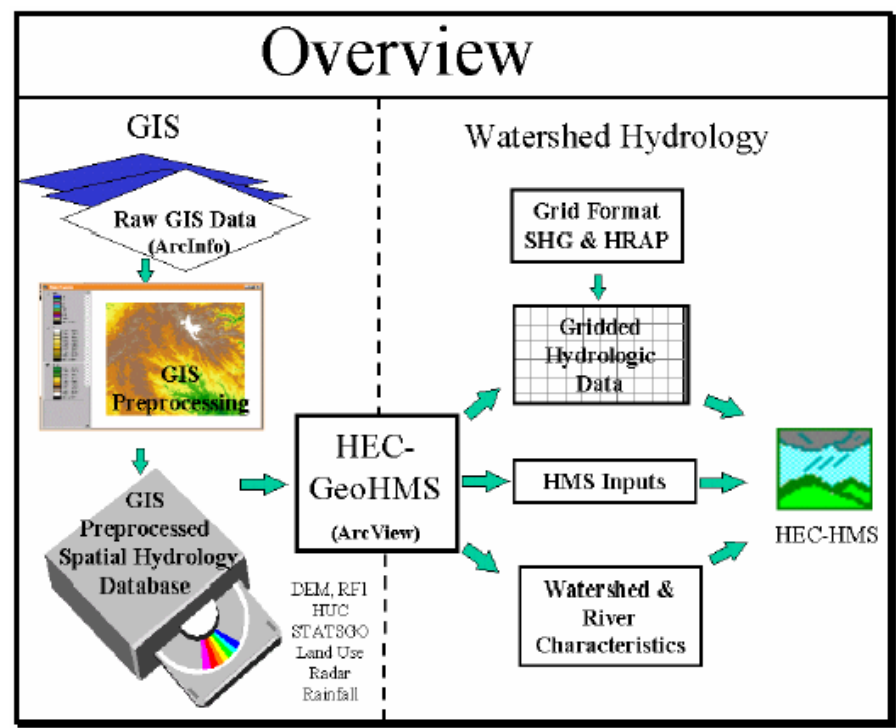

Figura 15. Esquema de integración entre el modelo HEC-HMS y SIG.

Fuente: Hammerly et al., 2006

\subsubsection{Selección de los Métodos de Cálculo en el programa HEC-HMS $®$}

Los métodos elegidos para simular las diferentes pruebas con el programa HEC-HMS $®$ son:

\section{Modelo para Cálculo del Volumen de Escurrimiento (Pérdidas por Infiltración)}

\section{Método Pérdida Inicial y Tasa Constante}

Feldman (2000) indica que este modelo se basa en el concepto de que la tasa potencial máxima de pérdida de precipitación, $f_{c}$ es constante a lo largo de un evento. De esta forma, si $p_{t}$ es la intensidad de lluvia durante un intervalo de tiempo $\mathrm{t}$ a $\mathrm{t}+\Delta \mathrm{t}$, el exceso, $p e_{t}$, durante el intervalo es dado por la Fórmula 32:

$$
p e_{t}=\left\{\begin{array}{cc}
p_{t}-f_{c} & \text { if } p_{t}>f_{c} \\
0 & \text { otra condición }
\end{array}\right\}
$$

Fórmula 32: Determinación del exceso durante el intervalo de tiempo.

Se suma una pérdida inicial (la), en el modelo para representar el almacenamiento por interceptación y depresión. El almacenamiento por interceptación es consecuencia de la absorción de la lluvia por la cobertura del suelo, incluyendo la vegetación de la cuenca. El almacenamiento en las depresiones esta dado por la topografía de la cuenca, el agua se almacena en estos lugares, una parte se infiltra y otra se evapora. Estas pérdidas ocurren previas al inicio del escurrimiento superficial. Es decir, hasta que la precipitación acumulada en el área permeable exceda el volumen de pérdida inicial, no ocurre escurrimiento. Entonces el exceso esta dado por la Fórmula 33: 


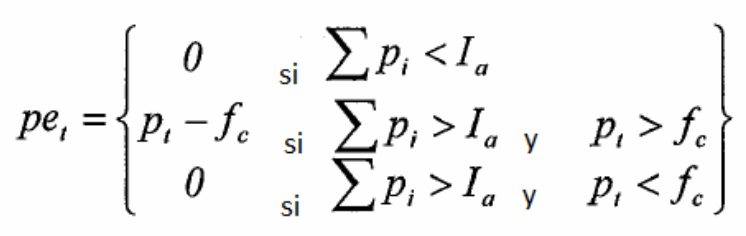

Fórmula 33: Determinación del exceso durante el intervalo de tiempo, según la.

Este método incluye el parámetro "tasa constante" que representa a las propiedades físicas del suelo de la cuenca y una condición inicial o "pérdida inicial" que representa al uso del suelo y condición de humedad antecedente.

La pérdida inicial (la) está determinada por el $20 \%$ a partir de la retención potencial máxima (S). $l a=0,2 * S(\mathrm{~mm})$

Se denomina S a la retención máxima de la lluvia caída absorbida por la cuenca. Para la obtención del valor de $S$ se utiliza el Número de Curva (NC) del suelo para cada subcuenca, la ecuación usada se presenta en la Fórmula 34.

$$
S=\frac{25400}{C N}-254, \text { en } \mathrm{mm}
$$

Fórmula 34: Establecer la retención potencial máxima.

Si la cuenca está en una condición saturada, la pérdida inicial será aproximadamente cero. Si la cuenca está seca, la pérdida inicial se incrementará para representar la intensidad de precipitación máxima que puede caer en la cuenca sin producir escurrimiento; dependiendo del terreno de la cuenca, uso del suelo y tipo del suelo.

Silva et al., 2005, manifiesta que a partir de estos antecedentes, se define tasa constante de pérdida, como la última capacidad de infiltración del suelo. El SCS (1986) clasificó los suelos en las cuencas en base a la capacidad de infiltración. Skagga y Khaleel (1982) publicaron estimaciones de tasa de infiltración para estos suelos, que se presentan en la Tabla 23.

Tabla 23. Grupo de suelos y tasa de pérdidas de infiltración.

\begin{tabular}{|c|c|}
\hline $\begin{array}{c}\text { GRUPO } \\
\text { DEL SUELO }\end{array}$ & $\begin{array}{c}\text { RANGO DE TASA DE } \\
\text { INFILTRACIÓN (mm/h) }\end{array}$ \\
\hline A & $7,62-11,43$ \\
\hline B & $3,81-7,62$ \\
\hline C & $1,27-3,81$ \\
\hline D & $0,00-1,27$ \\
\hline
\end{tabular}

Fuente: Silva et al., 2005. 


\section{Modelo de Transformación en Escurrimiento Directo}

\section{Método del Hidrograma Unitario (HU) del SCS}

En esta tesis, se utilizó el método propuesto por el Servicio de Conservación de Suelos (SCS) de los Estados Unidos que está basado sobre los promedios de los hidrogramas unitarios (HU) derivados de los pluviógrafos y escorrentía para un extenso número de pequeñas cuencas agrícolas. Estos estudios encontraron que en hidrogramas unitarios de diversas cuencas, el tiempo de retraso (Tlag) es aproximadamente igual al $60 \%$ del tiempo de concentración (Tc) de la cuenca (Feldman. 2000).

La ecuación usada para calcular el Tlag fue la fórmula que propone Feldman 2000, en función del tiempo de concentración de la cuenca. Para calcular el tiempo de concentración se usó la Fórmula 31. Una vez obtenido el Tc se calcula el tiempo de retraso Tlag (horas) con la Fórmula 35.

$$
\text { Tlag }=0,6^{*} \mathrm{Tc}
$$

Fórmula 35: Cuantificación del Tlag.

\section{Modelo del Flujo Base}

\section{Método de Valores Mensuales Constantes}

Una parte de la precipitación puede percolarse hasta llegar al nivel freático. Este aumento en el agua subterránea puede descargarse ocasionalmente en los ríos como flujo de agua subterránea (Ilamado también flujo base o descarga de estiaje) si el nivel freático intersecta los cauces de las corrientes de la cuenca. Por conveniencia es costumbre considerar al flujo total compuesto únicamente por dos partes: escorrentía directa y flujo base. La diferencia está realmente en el tiempo de llegada a la corriente y no en el camino seguido. Se considera al flujo base compuesto en su mayoría de agua subterránea (Linsey et al., 1993).

En la tesis, se aplicó el Método de Valores Mensuales Constantes, que es el más sencillo y simple en el programa HEC-HMS ${ }^{\circledR}$. Los valores representan el caudal base mensual para cada mes, el cual es sumado al caudal directo en cada proceso de la simulación. En la Figura 20 se representa la composición del caudal final de salida y cómo influye en el hidrograma.

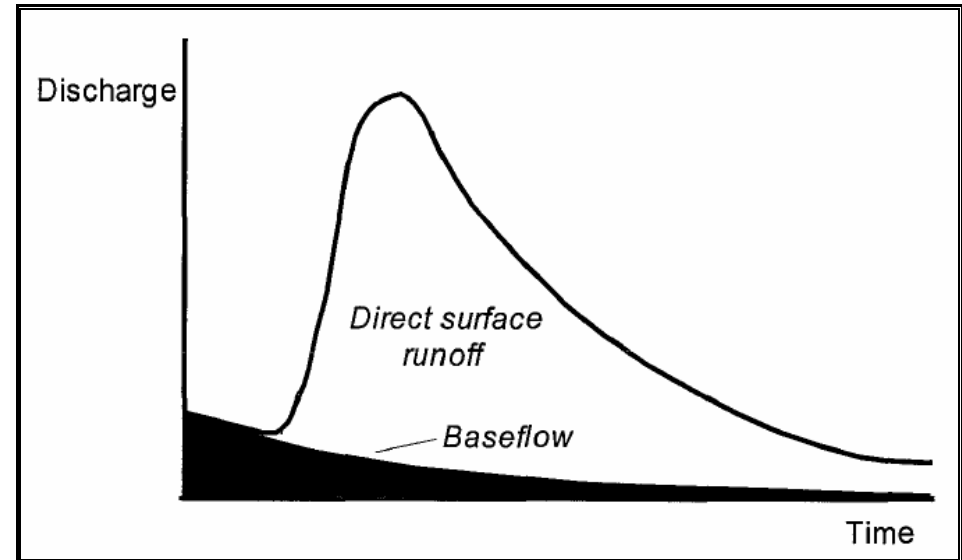

Figura 16. Esquema del caudal base y del caudal directo. Feldman. 2000 
A partir, de una recomendación de Feldman (2000), este método se aplicó únicamente para la subcuenca baja, de acuerdo a un análisis de la variación anual de los caudales observados, según los períodos: lluvioso (entre enero y junio) y seco (de julio a diciembre).

\section{Modelo de Tránsito de Caudales}

\section{Método de Muskingum Cunge}

El modelo de Tránsito de Caudales corresponde al curso por donde circula el hidrograma. Se utilizó el método de Muskingum Cunge, que utiliza como parámetros de entrada, para cada uno de los cauces, el largo total del tramo $(\mathrm{m})$, la pendiente del cauce $(\mathrm{m} / \mathrm{m})$, una sección transversal del río. La sección fue considerada de manera particular según dos diferentes formas de cauces: para los ríos de la parte media-alta la forma de un rectángulo, para lo cual se consideró el ancho del río; y para los ríos de la cuenca baja se eligió la forma de ocho puntos que requiere una sección transversal del cauce construida a partir de ocho puntos (x,y) (Figura 21). Además se definió el valor del número de Manning para cada planicie de inundación (del lado derecho y del izquierdo) y del lecho.

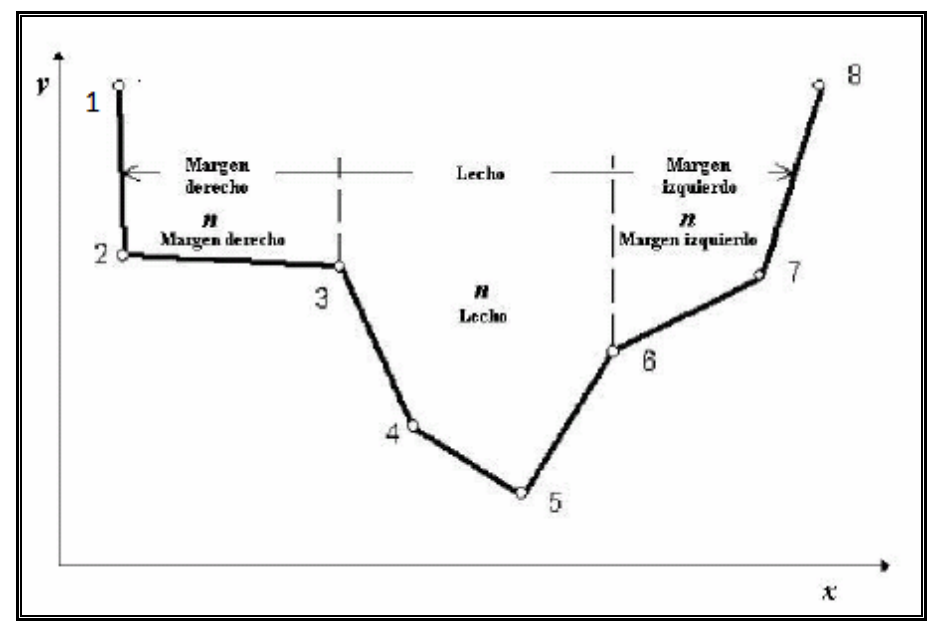

Figura 17. Esquema para describir la geometría de canal de 8 puntos. Adaptado de Feldman.2000

\subsubsection{Selección de datos de lluvia}

De acuerdo a Silva (2005), la respuesta de una cuenca es manejada por la precipitación que cae en la cuenca y la evapotranspiración desde ésta. La precipitación debe ser observada a partir de un evento histórico y los datos de precipitación histórica son útiles para la calibración y verificación de parámetros del modelo, para pronóstico a tiempo real y para evaluar el funcionamiento de diseños propuestos o regulaciones.

Para alimentar el modelo meteorológico para el desarrollo de la base de datos de HEC-HMS ${ }^{\circledR}$, se utilizó la precipitación diaria en milímetros ( 24 horas) de las estaciones que por su ubicación geográfica representan influencia en el área de la cuenca de estudio. La 
información fue proporcionada por el INAMHI, vía correo electrónico, y desde los anuarios en la página $w^{8}{ }^{8}$. Para determinar el área de influencia de los pluviómetros a las subcuencas del área de estudio, se aplicó el método de los Polígonos de Thiessen utilizando el SIG. Las estaciones y los períodos utilizados tanto para la simulación como para las pruebas de calibración y validación, fueron presentadas en la sección 4.3.1

\subsubsection{Selección de datos de caudal observado}

Para ingresar los datos del caudal observado al modelo HEC-HMS $®$ y poder cumplir con las pruebas de calibración y validación, se utilizaron los aforos medidos en la estación H414 Toachi DJ Baba, la cual posee una serie de mediciones a partir de enero 2003 a junio 2010, que corresponde a observaciones diarias, presentadas en la sección 4.4.1. La información fue proporcionada por INAMHI, vía correo electrónico, y a través de la página web.

\subsection{Pruebas de Calibración del Modelo HEC-HMS ${ }^{\circledR}$}

La calibración consistió en la experimentación con varias combinaciones de valores de parámetros, en un esfuerzo por minimizar (o maximizar) alguna función criterio de optimización. Este procedimiento se puede realizar de forma manual o automática y la solución apropiada puede depender mucho del criterio utilizado durante el análisis. Las funciones objetivo son expresiones matemáticas que expresan una medida de la diferencia entre los valores observados y modelados, y por tanto, son usados en la calibración como una medida de rendimiento del modelo (Mena, 2010).

La calibración de un modelo radica en lograr un ajuste satisfactorio entre los escurrimientos observados y los calculados, mediante el cambio en los valores de los parámetros de mayor influencia, aún de aquellos que se consideraban conocidos (IRENAT, 2002).

A partir de estas definiciones, para que los resultados obtenidos en la simulación con el programa HEC-HMS $®$, representen confiabilidad al comportamiento de la misma, es necesario someter a los parámetros involucrados a pruebas de calibración, según los métodos elegidos.

Para cumplir la calibración de esta tesis, se utilizó dos series anuales de lluvia dentro de la serie total que fue presentada en la sección 4.3.1. En ambos casos la identificación de los parámetros, para la calibración, se realizó de forma manual, por el método de prueba y error, y posteriormente, se comprobó de forma automática usando la Función Objetivo que incluye en la herramienta de Optimización del programa HEC-HMS ${ }^{8}$.

Para cuantificar la eficiencia del modelo y verificar la certeza de los datos obtenidos una vez ejecutado el programa, vale decir la relación entre el hidrograma observado y el hidrograma simulado, se utilizaron los conceptos de validación y verificación: coeficiente de determinación $\mathrm{R}^{2}$ y el índice o coeficiente de eficiencia de Nash y Sutcliffe (1970).

\footnotetext{
${ }^{8}$ http://www.inamhi.gov.ec/html/anuarios.htm
} 
El coeficiente de determinación $\mathrm{R}^{2}$, es el cuadrado del coeficiente de correlación, varía entre 0 y 1 y representa el porcentaje de varianza en los datos observados respecto de lo explicado por el modelo, es mejor mientras está más cercano a 1. Se usa como medida de dispersión del modelo y se calcula mediante la Fórmula 36 (Mena, 2010):

$$
R^{2}=\frac{\operatorname{Cov}\left(Q_{0}, Q_{S}\right)}{\operatorname{Sd}\left(Q_{0}\right) \times \operatorname{Sd}\left(Q_{s}\right)}
$$

Fórmula 36. Cuantificación de $\mathrm{R}^{2}$

Donde:

Cov (Qo, Qs) es la covarianza entre los valores observados y los calculados con el modelo;

Sd (Qo), es la desviación típica de los valores observados;

Sd (Qs), es la desviación típica de los valores calculados con el modelo.

El problema de este coeficiente es que es muy sensible a desviaciones constantes o proporcionales, es decir que si cumple que $\mathbf{Q} \mathbf{=} \mathbf{a}+\mathbf{b Q o}$, entonces $R^{2}$ será igual a 1 haciendo creer que el modelo responde perfectamente a la realidad. Otro problema es que es muy sensible a los valores extremos que hacen creer su valor dando nuevamente una falsa apariencia de buen ajuste (Mena. 2010). Por esta situación es recomendable tomar el resultado de $\mathrm{R}^{2}$ como un valor inicial o referencial que debe ser complementado con otros índices que midan el grado de ajuste del modelo, como el coeficiente de Nash Sutcliffe.

El coeficiente de eficiencia de Nash y Sutcliffe (1970), corresponde a una medida del rendimiento o eficiencia de un modelo simulado respecto a un modelo perfecto (real) (Fórmula 37).

$$
N S=1-\frac{\sum_{i=1}^{n}\left(o_{i}-m_{i}\right)^{2}}{\sum_{i=1}^{n}\left(o_{i}-\bar{o}\right)^{2}}
$$

Fórmula 37: Coeficiente de eficiencia de Nash y Sutcliffe

Donde:

$\mathrm{o}_{\mathrm{i}}$, son los valores observados, ${ }^{\bar{o}}$ es la medida de los valores observados; y $\mathrm{m}_{\mathrm{i}}$ son los valores calculados con el modelo.

El coeficiente NS presenta resultados menores o iguales a 1 . Si el resultado es 1 la calibración es perfecta; si es cero significa que el error es del mismo orden de magnitud que la varianza de los datos observados, es decir, la media de los datos observados tendrá una capacidad predictiva igual a la del modelo. Los valores menores a cero implica que la medida tiene una capacidad predictiva más alta que el modelo, lo que implica que le modelo es muy malo. 
Este coeficiente no es sensible al efecto de los valores proporcionales, pero sigue siendo sensible a los valores extremos. (Arias, 2010)

Para realizar esta comprobación se utilizó el programa disponible en Internet, basada en herramientas para análisis hidrográfico, en la web por sus siglas en ingles WHAT, desarrollado por el Departamento de Ingeniería de la Universidad de Purdue ${ }^{9}$ (EUA).

\subsection{Sensibilidad de los parámetros del Modelo HEC-HMS ${ }^{\circledR}$}

El análisis de sensibilidad mide cuanto pueden llegar a afectar a los resultados de un modelo variaciones relativamente pequeñas en los valores de los parámetros (Sarria et al., 2008). Este análisis permite definir la importancia de cada parámetro, comprobar la lógica interna de un modelo (entender cómo funciona el modelo o por qué no funciona correctamente y aprender más acerca de su funcionamiento) y detectar si el modelo está sobreparametrizado, es decir si existen parámetros a los que el modelo resulta insensible (Mena, 2010).

En este trabajo de investigación, el análisis de sensibilidad se efectuó al mismo tiempo que se realizaron las pruebas de calibración manual indicadas anteriormente, puesto que al variar manualmente, mediante el método de prueba y error, los parámetros para encontrar el valor óptimo de calibración se identificaron los de mayor influencia en los resultados finales. Para realizar este análisis se modifica el parámetro a sensibilizar, mientras los otros se mantienen fijos.

\subsection{Prueba de Validación del Modelo HEC-HMS ${ }^{\circledR}$}

La validación del modelo consiste en medir su capacidad predictiva mediante la comparación de los escurrimientos calculados y los observados con los parámetros determinados en la fase de calibración, pero en un período de tiempo diferente del utilizado en la calibración. Generalmente, el ajuste entre escurrimientos observados y calculados obtenido durante la validación es menos satisfactorio que el obtenido en la calibración, pero es más representativo de la exactitud de las predicciones que se hagan con el modelo (IRENAT, 2002).

Para el presente trabajo de investigación, dependiendo de la mejor prueba de calibración que se obtenga para el período de lluvias seleccionado, se utilizaron parámetros que reemplazaron el período de precipitación, y obtener el hidrograma del caudal simulado para la prueba de validación.

\footnotetext{
${ }^{9}$ https://engineering.purdue.edu/ what/compute_r2_nash_sutcliffe.html
} 


\subsection{Determinación de la Pérdida de Suelo}

La erosión es un proceso natural producido por diferentes factores, pudiendo ser de tipo climático como las precipitaciones, o por la susceptibilidad del tipo de suelos, la pendiente e incluso la cobertura vegetal presente. Es normal que una cuenca hidrográfica presente cierta pérdida de suelo como producto de la erosión, que en muchos casos puede ser poco perceptible, para la cuenca de estudio se estimó la tasa de pérdida de suelo por erosión hídrica.

La estimación de la tasa de erosión hídrica refleja si los planes de manejo agrícola en un área determinada son eficaces y para esto se debe comparar con tasas tolerables de erosión para ese suelo adoptadas por las Autoridades competentes del país o publicadas por Organismos Internacionales de manejo de recursos naturales. Por ello, si se logra mantener o disminuir la erosión lo más cerca posible de la que ocurriría en condiciones naturales, se obtienen resultados beneficiosos, en adición al mantenimiento de la productividad del recurso. Menor erosión significa menores externalidades, es decir menor salida de sedimentos del predio con el agua de escurrimiento, lo que reduce la sedimentación en cauces y cuerpos de agua superficiales. La sedimentación colmata cauces y cuerpos de agua, reduciendo su capacidad de regulación hidrológica y resultando en desbordes y crecientes más frecuentes.

\subsubsection{Método de la Ecuación Universal de Pérdida de Suelo (U.S.L.E.)}

A efectos de estimar la cantidad de sedimentos que se produce en la cuenca de estudio, se utilizó la Ecuación Universal de Pérdida de Suelo (U.S.L.E.), por sus siglas en ingles Universal Soil Loss Equation desarrollada por Wischmeier y Smith en 1965 y usada muy ampliamente a nivel mundial.

Este modelo permite evaluar la pérdida de suelo por erosión laminar y en regueros, estimando la tasa de erosión hídrica en toneladas de suelo perdido por hectárea de superficie durante un año (Mg.ha/año) en función de los parámetros de precipitación, suelo, relieve, cobertura del suelo y la aplicación o no de prácticas conservacionistas (Irurtia et al., 2007)

La ecuación general de la U.S.L.E., fue presentada en la Fórmula 14, en la sección 2.6.3.1, donde se establecía la pérdida de suelo promedio anual (Mg.ha/año) a partir del producto de seis factores incidentes, como ser de erosión pluvial o de erosividad, de erodabilidad del suelo, topográfico (longitud y gradiente), ordenación de cultivos y control de erosión mediante prácticas de cultivo.

Para el presente análisis, al no contar con información detallada de las diferentes prácticas conservacionistas que se aplican en el área de estudio, se decidió por no utilizar este factor. Cabe mencionar que se identificaron las zonas en donde el potencial erosivo requiere intervención para su conservación.

Para esquematizar la secuencia en la obtención de cada uno de los parámetros que intervienen en la ecuación general de la U.S.L.E. y para representar la elaboración de los mapas temáticos correspondientes a cada factor, se construyó un Modelo Cartográfico, el 
cual presenta como producto final la distribución espacial de los cambios en las tasas de erosión de la cuenca de estudio. La aplicación y desarrollo del modelo cartográfico se realizó empleando los Sistema de Información Geográfica (SIG) y el tratamiento de la información fue efectuado utilizando el software ArcGIS 9.3 ®.

La integración de los SIG en la U.S.L.E. ha empezado a tomar importancia, pues esta interrelación permite cuantificar la pérdida de suelo de manera rápida a escala de cuenca, con un mínimo de trabajo de campo y con la complejidad de las escalas grandes (Flores et al., 2003).

\section{Estructura del análisis}

Para el desarrollo de este estudio, se realizaron los análisis en dos niveles: a nivel cuenca de estudio y a nivel unidades hidrológicas (subcuencas).

Primero, se realizaron los cálculos de estimación de los factores del modelo U.S.L.E. a nivel cuenca de estudio para observar el comportamiento general de cada uno de ellos. Luego, se realizó un estudio particular a nivel unidades hidrológicas para observar la influencia de los factores de la U.S.L.E. sobre cada una de las subcuencas que fueron creadas en el estudio de los parámetros morfométricos con HEC-Geo.

A continuación se detalla el procedimiento para la estimación de los factores del modelo U.S.L.E. a nivel cuenca de estudio:

\subsubsection{Factor de Erosividad por la Lluvia "R"}

El Factor de Erosividad (R) es la capacidad potencial de la lluvia para provocar erosión en función de las características físicas de la lluvia. A pesar que este factor puede ser calculado para una sola tormenta, se considera representativa la cuantificación de todas las tormentas significativas registradas durante el período.

Para la determinación del Factor "R", se utilizaron los resultados obtenidos por la empresa Efficacitas para el Estudio de Impacto Ambiental dentro del Proyecto Multipropósito Baba (2006), el cual propone el siguiente procedimiento:

\section{1.- Obtención de datos de lluvia (pluviometría):}

Para el cálculo del factor de erodabilidad $(\mathrm{R})$, es necesario tener la distribución temporal de la precipitación en el área de estudio, para eso se requiere la información pluviométrica o pluviográfica de las estaciones meteorológicas del sector, la cual fue proporcionada por el INAMHI y obtenida de los anuarios meteorológicos correspondientes.

Las estaciones meteorológicas utilizadas para caracterizar las condiciones de precipitación del área de estudio, se presentan en la Tabla 24. 
Tabla 24. Estaciones Meteorológicas utilizadas para el análisis de la Erosividad de la lluvia.

\begin{tabular}{|c|c|c|}
\hline ESTACIÓN & COORDENADAS* & INFORMACIÓN \\
\hline Puerto lla & $\begin{array}{l}0^{\circ} 29^{\prime} 26.90678 " \mathrm{~S} \\
79^{\circ} 22 \text { '0.14053" W } \\
\mathrm{H}: 319,00 \mathrm{~m}\end{array}$ & $\begin{array}{l}\text { Lluvias máximas de } 24 \text { horas. } \\
\text { Período 1982-1998. }\end{array}$ \\
\hline La Pitita & $\begin{array}{l}0^{\circ} 42^{\prime} 4.68750 " \mathrm{~S} \\
79^{\circ} 27^{\prime} 10.6797^{\prime \prime} \mathrm{W} \\
\mathrm{H}: 100,00 \mathrm{~m}\end{array}$ & $\begin{array}{l}\text { Lluvias mensuales acumuladas. } \\
\text { Período 1947-1992. }\end{array}$ \\
\hline Salgana & $\begin{array}{l}0^{\circ} 36^{\prime} 30.35957 " \mathrm{~S} \\
79^{\circ} 25^{\prime} 7.0987 " \mathrm{~W} \\
\mathrm{H}: 154,00 \mathrm{~m}\end{array}$ & $\begin{array}{l}\text { Lluvias mensuales acumuladas. } \\
\text { Período 1947-1992. }\end{array}$ \\
\hline Pucayacu & $\begin{array}{l}0^{\circ} 43^{\prime} 1.55754 " \mathrm{~S} \\
79^{\circ} 7,13.6670^{\prime \prime} \mathrm{W} \\
\mathrm{H}: 252,00 \mathrm{~m}\end{array}$ & $\begin{array}{l}\text { Lluvias mensuales acumuladas. } \\
\text { Período 1947-1992. }\end{array}$ \\
\hline Chavica & $\begin{array}{l}0^{\circ} 44^{\prime} 27.33769^{\prime \prime} \mathrm{S} \\
79^{\circ} 24^{\prime} 6.0799 " \mathrm{~W} \\
\mathrm{H}: 140,00 \mathrm{~m}\end{array}$ & $\begin{array}{l}\text { Lluvias mensuales acumuladas. } \\
\text { Período 1947-1992. }\end{array}$ \\
\hline Sto. Domingo & $\begin{array}{l}0^{\circ} 13^{\prime} 58.89158 " \mathrm{~S} \\
79^{\circ} 11^{\prime} 13.5007 " \mathrm{~W} \\
\mathrm{H}: 522.00 \mathrm{~m}\end{array}$ & $\begin{array}{l}\text { Lluvias máximas de } 24 \text { horas. } \\
\text { Período 1959-1987. }\end{array}$ \\
\hline Las Pampas & $\begin{array}{l}0^{\circ} 25^{\prime} 39.60033^{\prime \prime} \mathrm{S} \\
78^{\circ} 58^{\prime} 2.12265^{\prime \prime} \mathrm{W} \\
\mathrm{H}: 1640,00 \mathrm{~m}\end{array}$ & $\begin{array}{l}\text { Lluvias máximas de } 24 \text { horas. } \\
\text { Período 1965-1979. }\end{array}$ \\
\hline Sigchos & $\begin{array}{l}0^{\circ} 41^{\prime} 58.01765^{\prime \prime} \mathrm{S} \\
78^{\circ} 53^{\prime} 24.7023^{\prime \prime} \mathrm{W} \\
\mathrm{H}: 2880,00 \mathrm{~m}\end{array}$ & $\begin{array}{l}\text { Lluvias máximas de } 24 \text { horas. } \\
\text { Período 1964-1979. }\end{array}$ \\
\hline
\end{tabular}

Fuente: Efficacitas, 2006 (modificado). *Datum WGS84

\section{2.- Cálculo de lluvias máximas de 24 horas:}

Con el fin de homogenizar la información pluviométrica (lluvias máximas de 24 horas) disponible, se utilizó como base los datos de lluvia máxima en 24 horas de la estación Puerto lla para calcular las Iluvias máximas de 24 horas en las estaciones de La Pitita, Salgana, Pucayacu y Chavica partiendo de los datos de lluvias mensuales, debido a que estas estaciones no disponen de esta información. El procedimiento seguido es el siguiente:

Utilizando los datos de la estación "Puerto lla", se realizó una relación entre la lluvia máxima de 24 horas para un determinado mes y la lluvia mensual acumulada de dicho mes, obteniendo así el "porcentaje de lluvia máxima de 24 horas en comparación con su correspondiente lluvia mensual" (ver Fórmula 38). Este proceso se realizó con todos los meses para cada año del período de 1982 a 1998.

$$
\frac{\text { Lluvia.máx. }_{24 h_{(i, j)}}}{\text { Lluvia.mensual }_{(i, j)}}=\% \text { Lluvia }_{(i, j)}
$$

Fórmula 38. Relación lluvias máximas 24 horas y lluvias mensuales acumuladas 
Donde:

i: Mes del año (Enero - Diciembre)

j: Año del período (1982 - 1998)

Asumiendo que el comportamiento de la relación "lluvia máxima de 24 horas/lluvia mensual" (Fórmula 38) se mantiene en las estaciones meteorológicas La Pitita, Salgana, Pucayacu y Chavica, se calcularon los valores de lluvia máxima de 24 horas para cada mes durante el período correspondiente (1947-1992), utilizando los datos de lluvia mensual, de acuerdo a la siguiente relación: (ver Fórmula 39):

$$
\text { Lluvia.máx. } 24 h[X]_{(i, j)}=\text { Lluvia.mensual }[X]_{(i, j)} \times \% \text { Lluvia }_{(i, j)}
$$

Fórmula 39. Cálculo de la lluvia máxima 24 horas.

Donde:

X: Valor correspondiente a cada estación meteorológica (mes y año)

De esta manera se obtuvieron los datos de lluvias máximas de 24 horas para las estaciones meteorológicas La Pitita, Salgana, Pucayacu y Chavica.

Con los datos completos de lluvias máximas de 24 horas para cada mes y cada año de todas las estación meteorológica (ver Tabla 25), se procedió a calcular la lluvia máxima de 24 horas para cada mes correspondiente a 2 años como período de retorno ${ }^{10}$.

Este proceso se aplicó a todas las estaciones meteorológicas en estudio y fue realizado mediante el método de Gumbel, obteniendo la Tabla 25 con los valores de las lluvias máximas de 24 horas para todos los meses para 2 años de período de retorno.

\footnotetext{
10 Dentro del análisis de valores extremos, en este caso máximo, es importante considerar el período de retorno, que puede definirse como "el intervalo de tiempo promedio entre las ocurrencias reales de un evento hidrometeorológico de una magnitud dada o mayor". Efficacitas (2006) consideró un período de retorno de 2 años.
} 
Tabla 25. Lluvias Máximas de 24 horas para un período de retorno de 2 años.

\begin{tabular}{|c|c|c|c|c|c|c|c|c|}
\hline & $\begin{array}{c}\text { PUERTO } \\
\text { ILA }\end{array}$ & SALGANA & $\begin{array}{c}\text { LA } \\
\text { PITITA }\end{array}$ & PUCAYACU & CHAVICA & $\begin{array}{c}\text { SANTO } \\
\text { DOMINGO }\end{array}$ & $\begin{array}{c}\text { LAS } \\
\text { PAMPAS }\end{array}$ & SIGCHOS \\
\hline ENE & 86,14 & 72,35 & 53,07 & 131,24 & 46,51 & 77,75 & 43,62 & 17,92 \\
\hline FEB & 77,03 & 70,13 & 40,80 & 122,43 & 45,22 & 76,15 & 43,74 & 18,09 \\
\hline MAR & 85,98 & 76,17 & 42,36 & 149,92 & 48,71 & 89,58 & 42,23 & 25,57 \\
\hline ABR & 83,26 & 78,64 & 42,99 & 119,98 & 48,98 & 88,62 & 51,52 & 22,26 \\
\hline MAY & 57,00 & 55,26 & 28,77 & 89,11 & 35,96 & 62,94 & 29,58 & 18,05 \\
\hline JUN & 27,10 & 27,72 & 28,79 & 42,00 & 33,80 & 37,65 & 23,14 & 9,63 \\
\hline JUL & 19,32 & 20,12 & 14,42 & 23,08 & 14,83 & 18,77 & 11,96 & 7,47 \\
\hline AGO & 14,22 & 11,19 & 5,77 & 10,73 & 9,30 & 13,21 & 8,72 & 8,22 \\
\hline SEP & 21,28 & 14,13 & 11,62 & 15,80 & 10,50 & 22,71 & 20,20 & 16,84 \\
\hline OCT & 18,18 & 18,43 & 14,49 & 29,11 & 14,73 & 22,44 & 21,21 & 16,38 \\
\hline NOV & 20,06 & 19,93 & 21,22 & 38,71 & 20,13 & 32,31 & 15,81 & 11,21 \\
\hline DIC & 56,22 & 42,93 & 54,91 & 72,51 & 32,48 & 53,50 & 32,44 & 14,58 \\
\hline
\end{tabular}

Fuente: Efficacitas, 2006

\section{3.- Cálculo del Factor de Erosividad de la Lluvia (R)}

Efficacitas utilizó el programa de Modelación Hidrológica TR-20 ${ }^{11}$ obteniendo como resultado la Tabla 26 que muestra los datos finales del factor de erosividad $\mathrm{R}$ de las estaciones meteorológicas de estudio, para un período de retorno de 2 años, considerando que para el caso de erosión producida por lluvia, en el período de retorno de 2 años ocurren precipitaciones normales.

Tabla 26. Factores de Erosividad por Lluvia (R).

\begin{tabular}{|c|c|}
\hline ESTACIÓN & $\begin{array}{c}\text { FACTOR R } \\
\text { (Mj.mm/(ha.hr.año) }\end{array}$ \\
\hline Puerto lla & 2838,46 \\
\hline La Pitita & 915,43 \\
\hline Salgana & 2197,93 \\
\hline Pucayacu & 7635,81 \\
\hline Chavica & 882,69 \\
\hline Santo Domingo & 2980,32 \\
\hline Las Pampas & 772,28 \\
\hline Sigchos & 165,95 \\
\hline
\end{tabular}

Fuente: Efficacitas (2006).

\footnotetext{
${ }^{11}$ Es un modelo de eventos simples, desarrollado por el Servicio de Conservación de Suelos de los Estados Unidos para asistir en la evaluación hidrológica de las avenidas para utilizarse en el análisis de proyectos de recursos de agua. El cual calcula la escorrentía directa para un evento de tormenta sintética, pudiendo ser calibrado con datos disponibles de lluvias e hidrogramas. Efficacitas (2006).
} 
Para representar en un mapa la variación espacial de la erosividad de la lluvia en la cuenca de estudio, se diseñó un esquema del proceso de modelo cartográfico el cual inicia con los valores finales del factor $R$ de cada una de las estaciones en estudio (Tabla 26), Para la aplicación de este modelo se empleó la herramienta de los Sistemas de Información Geográfica (SIG) y con el software ArcGIS $9.3 \AA$ se generó el mapa temático respectivo.

\subsubsection{Factor de Erodabilidad del Suelo "K"}

Es una compleja propiedad que se entiende como la facilidad con la cual el suelo es desprendido por el salpicamiento, durante una lluvia o por flujo superficial. Esta propiedad del suelo está relacionada al efecto integrado de la lluvia, escurrimiento e infiltración, es decir, a la erosión hídrica. Su valor está relacionado con las propiedades del suelo, es independiente de la pendiente y depende básicamente de la permeabilidad, porcentaje de materia orgánica, estructura y en el caso de las rocas, de la consolidación.

Para la determinación del Factor "K" en esta tesis, se utilizaron los resultados obtenidos por la empresa Efficacitas para el Estudio de Impacto Ambiental del Proyecto Baba (2006), con los cuales se realizó el siguiente procedimiento utilizando el programa ArcGIS 9.3 ®:

1. Se efectúo una georreferenciación del mapa de erodabilidad de los suelos de Efficacitas (2006) y sobre ésta se cortó el archivo de la cuenca de estudio, identificando de esta manera que valores de $\mathrm{K}$ pertenecientes a la imagen de Efficacitas coincidían en el área de la cuenca de estudio.

2. Con los valores de $\mathrm{K}$ determinados y utilizando la herramienta de interpolación del Análisis Espacial del ArcGis se recalculó el valor de $\mathrm{K}$ para las áreas de la cuenca de estudio.

Con los valores de $\mathrm{K}$ recalculados se procedió a generar el mapa de la distribución espacial de la erodabilidad de los suelos en la cuenca de estudio utilizando el programa ArcGIS 9.3 ß.

\subsubsection{Factor Topográfico "LS"}

El factor topográfico LS considera el efecto de la topografía sobre la erosión, estimando de alguna manera la erosión promedio que tiene lugar sobre toda la pendiente, pero evidentemente, esta erosión no está distribuida uniformemente a lo largo de toda su longitud, por lo tanto las pérdidas de suelo por unidad de superficie aumentan con la longitud y la pendiente del terreno.

Para determinar los valores del factor LS, se construyó un esquema del proceso de modelo cartográfico para ser aplicado utilizando SIG, donde se expresa que partiendo del modelo de elevación digital del área representativa, se obtuvo como resultado final el mapa del factor topográfico del área de la cuenca de estudio. El tratamiento de los datos fue realizado con el software ArcGIS 9.3 ${ }^{\circledR}$. 


\subsubsection{Factor de Cobertura del Suelo "C"}

Este factor considera el efecto de la cobertura vegetal sobre la erosión manifestándose a través de las especies cultivadas, el estado del ecosistema en sincronización con los períodos de lluvias, la forma y número de las labores sobre el suelo (en sentido diferente a las prácticas de conservación), la existencia de mayor o menor erosividad de la lluvia en el período del año en que se realiza el cultivo, las características de la materia orgánica acumulada sobre la superficie del suelo, entre otras (Oñate, 2004)

Para determinar los valores del coeficiente de cobertura del suelo, utilizamos el mapa de uso de suelo y cobertura vegetal del CLIRSEN, identificando los diferentes usos del suelo que existen en la cuenca de estudio, que se presentan en la Tabla 27.

Tabla 27. Clases de Usos del Suelo y Cobertura Vegetal.

\begin{tabular}{|l|}
\hline \multicolumn{1}{|c|}{ Usos del Suelo y Cobertura Vegetal } \\
\hline Café y cacao, pastos \\
\hline Monte y fruticultura \\
\hline Bosque con claros de pastos, cultivos y arboricultura \\
\hline Arboricultura \\
\hline Pastos y cultivos, restos de bosque \\
\hline $\begin{array}{l}\text { Formación arbórea, densa, siempre verde; variante de las } \\
\text { vertientes exteriores de Los Andes }\end{array}$ \\
\hline
\end{tabular}

Una vez obtenidos los valores de C para cada uso de suelo y mediante SIG, se elaboró el mapa representado la distribución espacial del factor de cobertura vegetal en la cuenca de estudio, con la ayuda del programa ArcGIS 9.3 ® para el tratamiento de los datos.

\subsubsection{Estimación de la Pérdida de Suelo "A" (Erosión Actual y Erosión Tolerante del} $\underline{\text { Suelo) }}$

Para la evaluación de las pérdidas de suelo (erosión real o erosión actual) se utilizó el producto final de la ecuación universal de pérdida de suelo (R.K.LS.C), cuyo resultado se compara con los parámetros de tolerancia de las pérdidas de suelo establecidos por la Autoridad Nacional rectora del manejo de suelos u Organismos Internacionales.

Una vez calculados los cuatro factores de la ecuación universal U.S.L.E. con SIG, se convirtieron los factores $\mathrm{K}$ y $\mathrm{C}$ de vectorial a raster para poder realizar la operación aritmética del producto a través de la herramienta "Raster Calculator" del Análisis Espacial del programa ArcGIS 9.3 ${ }^{\circledR}$. Los otros factores R y LS ya son raster. Se multiplicaron las capas de dichos factores obteniendo como resultado una imagen raster stretched (a) (valores extendidos) de toda la cuenca de estudio en la que se representa las áreas con pérdida de suelo promedio por erosión hídrica en Mg.ha/año para cada una de las celdas de una hectárea de superficie en que se dividió el área de estudio. 
La evaluación de tolerancias de pérdida de suelo en un terreno es un aspecto básico para determinar el uso y manejo más adecuado de éste. La erosión tolerable se refiere a la cantidad máxima de pérdida de suelo que pueda ocurrir y aún permita que la productividad del cultivo sea económicamente sostenible (Gaspari et al., 2009) Wischmeier y Smith (1978)

mencionaron que la tolerancia para la pérdida de suelo para los Estados Unidos varía de 2,50 a 12,36 Mg.ha/año, aunque suelos profundos que favorecen el desarrollo radical de los cultivos podrían exceder las 12,36 Mg.ha/año de tolerancia en la pérdida de suelo.

Bajo este criterio, para evaluar el riesgo de pérdida de suelos por erosión hídrica, en la cuenca de estudio, se utilizaron los valores indicados en la Tabla 28, propuestos por FAO, PNUMA y UNESCO (1981), dentro de la "Clasificación Provisional para la Degradación de los Suelos".

Tabla 28. Clasificación en grado de erosión hídrica superficial.

\begin{tabular}{|c|c|}
\hline $\begin{array}{c}\text { Pérdida de suelo } \\
\text { (Mg.ha }^{-1} \cdot \mathbf{a n ̃ o}^{-1} \mathbf{~}\end{array}$ & $\begin{array}{c}\text { Grados de erosión } \\
\text { hídrica }\end{array}$ \\
\hline$<10$ & Nulo \\
\hline $10-50$ & Moderado \\
\hline $50-200$ & Alto \\
\hline$>200$ & Muy alto \\
\hline
\end{tabular}

Con esta información, a la imagen raster obtenida anteriormente (a), se le realizó una clasificación de tres clases, con los tres primeros rangos de pérdida de suelo de la Tabla 28, adaptados a los valores obtenidos en el mapa (a), de esta manera se obtuvo otro mapa raster de toda la cuenca de estudio con los rangos de pérdida de suelo tolerables (b).

Finalmente, se realizó un estudio particular a nivel unidades hidrológicas con el fin de observar la influencia de los factores U.S.L.E. sobre las siete subcuencas. Para este análisis se realizaron dos procedimientos, según el tipo de archivos geoespacial:

1- Para los factores LS, R y A, que son archivos raster:

a.- Para el factor LS:

La capa de la cuenca de estudio, creada con HECGeo, que contiene las siete subcuencas, se convirtió en archivo raster, este archivo se cruzó con la capa raster reclasificada de las pendientes del área de estudio realizando la operación del área tabulada, obteniendo como resultado una Tabla que contiene la información entrecruzada de los dos archivos. A este archivo se exportó como base de datos (.dbf) y se abrió desde el explorador de Windows con el programa Excel ® realizando los análisis pertinentes. 
b.- Para el factor R:

El archivo final raster de las subcuencas del área de estudio se cruzó con la capa raster reclasificada de la interpolación de los valores de $\mathrm{R}$ efectuando el cálculo del área tabulada, generando una Tabla que almacena la información entrecruzada de los dos archivos. Esta Tabla se exportó como base de datos (.dbf) y se abrió desde el explorador de Windows con el programa Excel $®$ realizando los análisis pertinentes.

c.- Para el factor A:

El archivo final raster de las subcuencas del área de estudio se cruzó con la capa raster reclasificada obtenida del producto final de la multiplicación de los factores de la U.S.L.E. (R.K.LS.C) mediante la operación área tabulada, generando una Tabla que almacena la información entrecruzada de los dos archivos. Esta Tabla se exportó como base de datos (.dbf) y se abrió desde el explorador de Windows con el programa Excel $®$ realizando los análisis pertinentes.

2- Para los factores $\mathrm{K}$ y C, que son archivos vectoriales:

Se realizó la intersección de la capa vectorial que contiene las siete subcuencas del área de estudio con los archivos vectoriales creados durante el proceso de generación del factor $\mathrm{K}$ y del factor $\mathrm{C}$, respectivamente. Obteniendo, para cada caso, un archivo que almacena la información entrecruzada de los dos archivos vectoriales. Respectivamente, a este archivo se exportó como base de datos (.dbf) y se abrió desde el explorador de Windows con el programa Excel ${ }^{\circledR}$ realizando los análisis pertinentes para cada factor.

Con el programa Excel $\AA$ se realizaron los análisis correspondientes para calcular los valores ponderados, según la superficie de cada subcuenca, de los factores K, LS y C; y el valor medio para el factor $R$ de la U.S.L.E. que influye en las unidades hidrológicas, así como los gráficos respectivos. 


\section{CAPITULO 5}

\section{RESULTADOS}

\section{1.- Recopilación de bibliografía y definición del Área Experimental}

Durante la fase de recopilación y a medida que se obtenían los datos, bibliografía e información necesaria para el procesamiento de estos, se realizaron conversaciones con personal técnico de las instituciones que mantienen a su cargo la captura, procesamiento y publicación de la información hidrológica, meteorológica, edáfica, suelos, imágenes satelitales, cartas topográficas, quienes orientaron las potenciales áreas para la aplicación de la metodología del tema elegido en función de la información disponible.

\subsubsection{Definición del Área Experimental}

Dentro del área representativa de interés, se seleccionaron las Microcuencas del Río Colimes, del Río Daule, del Río Baba, del Río Toachi, del Rio Lulu y del Río San Pablo. Se descartó la posibilidad de trabajar en la microcuenca del Río Colimes (ver Figura 22) debido a la falta de información hidrometeorológica (necesaria para el análisis hidrológico). También se desechó la cuenca del Río Daule (ver Figura 23) debido a la falta de disponibilidad de información actual e histórica sobre el manejo de caudales de la represa que se ubica en la misma. No se consideraron las zonas de la cuenca baja debido a la influencia de la marea. A partir de estas consideraciones, se delimitó el área superior de la subcuenca del Río Vinces para realizar un estudio más detallado de sus microcuencas (ver Figura 23).

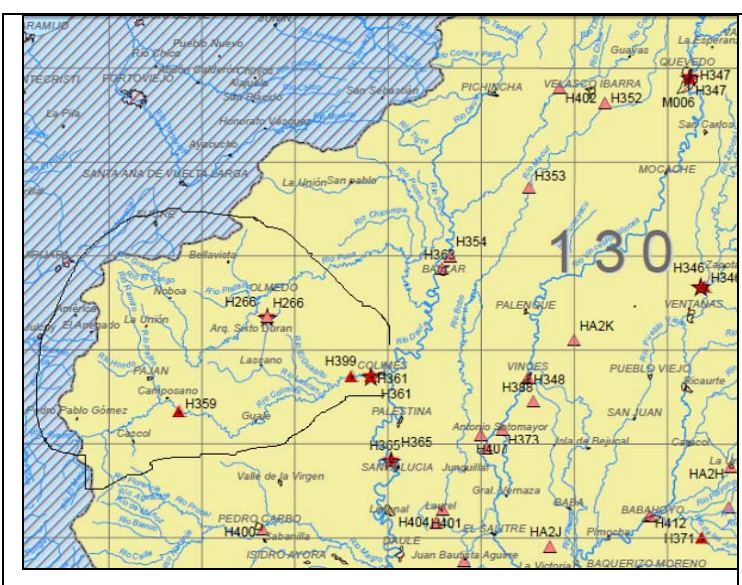

Figura 18. Microcuenca del Río Colimes

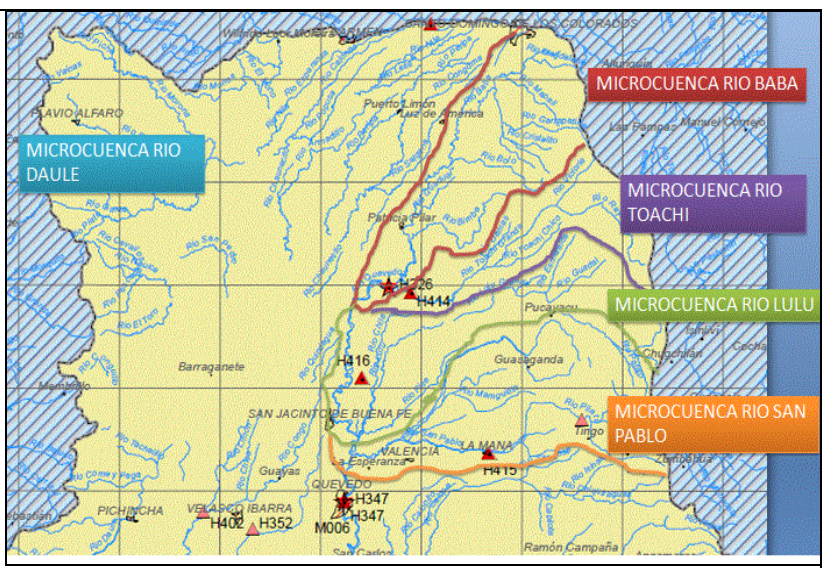

Figura 19. Microcuencas del Río Daule, Río Baba, Río Toachi, Río Lulu y Río San Pablo. 
Para el análisis particular de esta zona se utilizaron 18 cartas topográficas elaboradas por el Instituto Geográfico Militar (IGM) a escala 1:50.000, disponibles en formato digital (shape) en la página web ${ }^{12}$, las cuales se presentan en la Tabla 29.

Tabla 29. Cartas topográficas utilizadas para la definición del Área Experimental.

\begin{tabular}{|c|c|c|c|c|}
\hline $79^{\circ} 30^{\prime} \mathrm{W}$ & & 79 & $78^{\circ} 4$ & \\
\hline & $\begin{array}{l}\text { EL CARMEN } \\
\text { NIII-B3 }\end{array}$ & $\begin{array}{c}\text { SANTO DOMINGO } \\
\text { NIII-B4 }\end{array}$ & $\begin{array}{l}\text { ALLURIQUIN } \\
\text { NIII-S3 }\end{array}$ & $0^{\circ} 10^{\prime} \mathrm{S}$ \\
\hline & $\begin{array}{c}\text { LUZDE AMERICA } \\
\text { NIII-D1 }\end{array}$ & $\begin{array}{l}\text { SAN VICENTE } \\
\text { NIII-D2 }\end{array}$ & $\begin{array}{l}\text { MANUELCORNEJO } \\
\text { NIIII-C1 }\end{array}$ & $0^{\circ} 20^{\prime}$ \\
\hline & $\begin{array}{l}\text { PATRICIA PILAR } \\
\text { NIII-D3 }\end{array}$ & $\begin{array}{c}\text { SANTA MARIA DEL } \\
\text { TOACHI } \\
\text { NIII-D4 }\end{array}$ & $\begin{array}{l}\text { JATUNLOMA } \\
\text { ÑIII-C3 }\end{array}$ & $0^{\circ} 30^{\prime}$ \\
\hline & $\begin{array}{c}\text { LOS VERGELES } \\
\text { NIII-F1 }\end{array}$ & $\begin{array}{l}\text { PUCAYACU } \\
\text { NIII-F2 }\end{array}$ & $\begin{array}{l}\text { SIGCHOS } \\
\text { ÑIII-E1 }\end{array}$ & $0^{\circ} 40^{\prime}$ \\
\hline & $\begin{array}{l}\text { VALENCIA } \\
\text { NIII-F1 }\end{array}$ & $\begin{array}{l}\text { LAMANA } \\
\text { NIII-F4 }\end{array}$ & $\begin{array}{l}\text { PILALO } \\
\tilde{N} I I I-E 3\end{array}$ & $0^{\circ} 50^{\prime}$ \\
\hline & $\begin{array}{l}\text { QUEVEDO } \\
\text { NIV-B1 }\end{array}$ & $\begin{array}{l}\text { EL CORAZON } \\
\text { NIV-B2 }\end{array}$ & $\begin{array}{l}\text { ANGAMARCA } \\
\text { ÑIV-A1 }\end{array}$ & $01^{\circ} 00^{\prime}$ \\
\hline
\end{tabular}

Una vez que se seleccionaron las posibles microcuencas, estas debían cumplir aspectos operacionales como Área Experimental es decir, que cumpla rasgos particulares en función a las características regionales como semejanza u homogeneidad con el resto de la cuenca, existencia de información hidrometeorológica, superficie no muy grande de tal forma de aplicar la metodología planteada y obtener los resultados esperados en el tiempo previsto.

Las microcuencas de los Ríos Baba, Lulu y San Pablo no tienen estaciones de medición de caudales a la salida de la microcuenca para comparar con los datos simulados, sus áreas son extensas, por tal razón se descartaron; la microcuenca del Río Toachi, dispone de una estación limnigráfica a la salida por tal razón se eligió esta microcuenca como el Área Experimental para realizar el análisis particular como un área representativa modal.

Para este trabajo se denominará al área de experimental como Cuenca del Río Toachi y las unidades hidrológicas se llamarán subcuencas.

\section{Ubicación Geográfica del Área Experimental}

La cuenca del área experimental comprende una superficie aproximada de $500 \mathrm{~km}^{2}$, está compuesta principalmente por el Río Toachi y se ubica en la subcuenca del Río Vinces perteneciente a la Cuenca del Guayas (ver Figura 24).

\footnotetext{
${ }^{12}$ http://www.geoportaligm.gob.ec/portal/cartografia-libre
} 


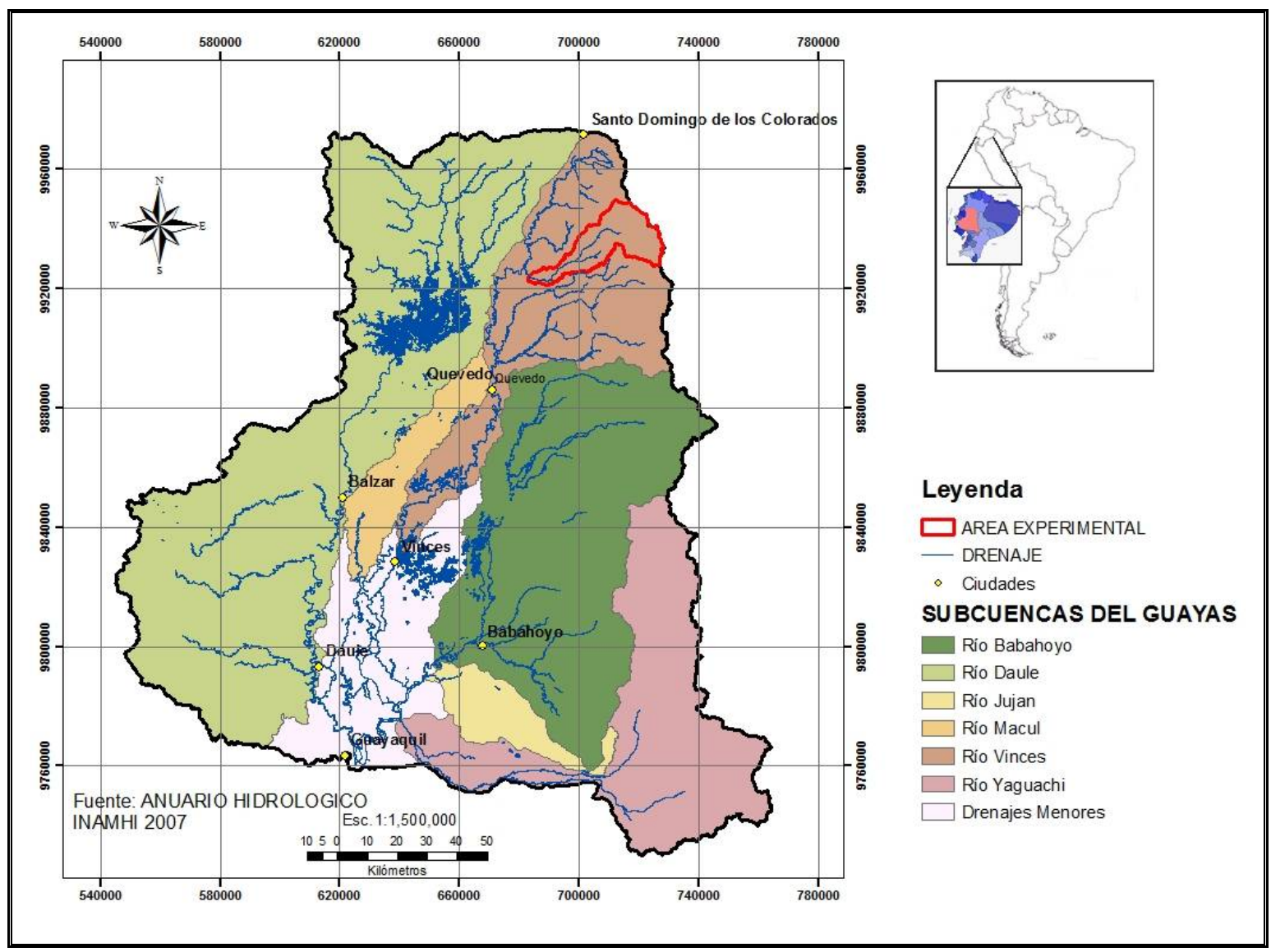

Figura 24. Ubicación geográfica de la microcuenca del Río Toachi

El área se caracteriza por tener suelos de buena calidad por lo cual existen cultivos permanentes como banano, caucho y palma africana, cultivos de ciclo corto como maíz, soya y arroz. Bosques naturales y cultivados y arboricultura tropical. El Río Toachi es el principal río que alimenta a la cuenca contribuyendo con agua todo el año al Río Baba, donde se ubica la estación de aforo H414 Toachi DJ Baba, que luego pasa a llamarse Río Quevedo. Durante los meses de enero a junio se presenta la época "húmeda" y de julio a diciembre la época "seca" o de estiaje. La temperatura varía desde los $8^{\circ} \mathrm{C}$ en la parte alta hasta los $25^{\circ} \mathrm{C}$ en la parte baja.

Administrativamente, el área de estudio, está situada entre las provincias de Los Ríos, Santo Domingo y Cotopaxi. Perteneciente a las cantones Valencia, Santo Domingo, La Mana y Sigchos, como se muestra en la Figura 25. Geográficamente el centroide de la cuenca se ubica en latitud $0^{\circ} 37^{\prime}$ sur y longitud $79^{\circ} 08^{\prime}$ oeste. 


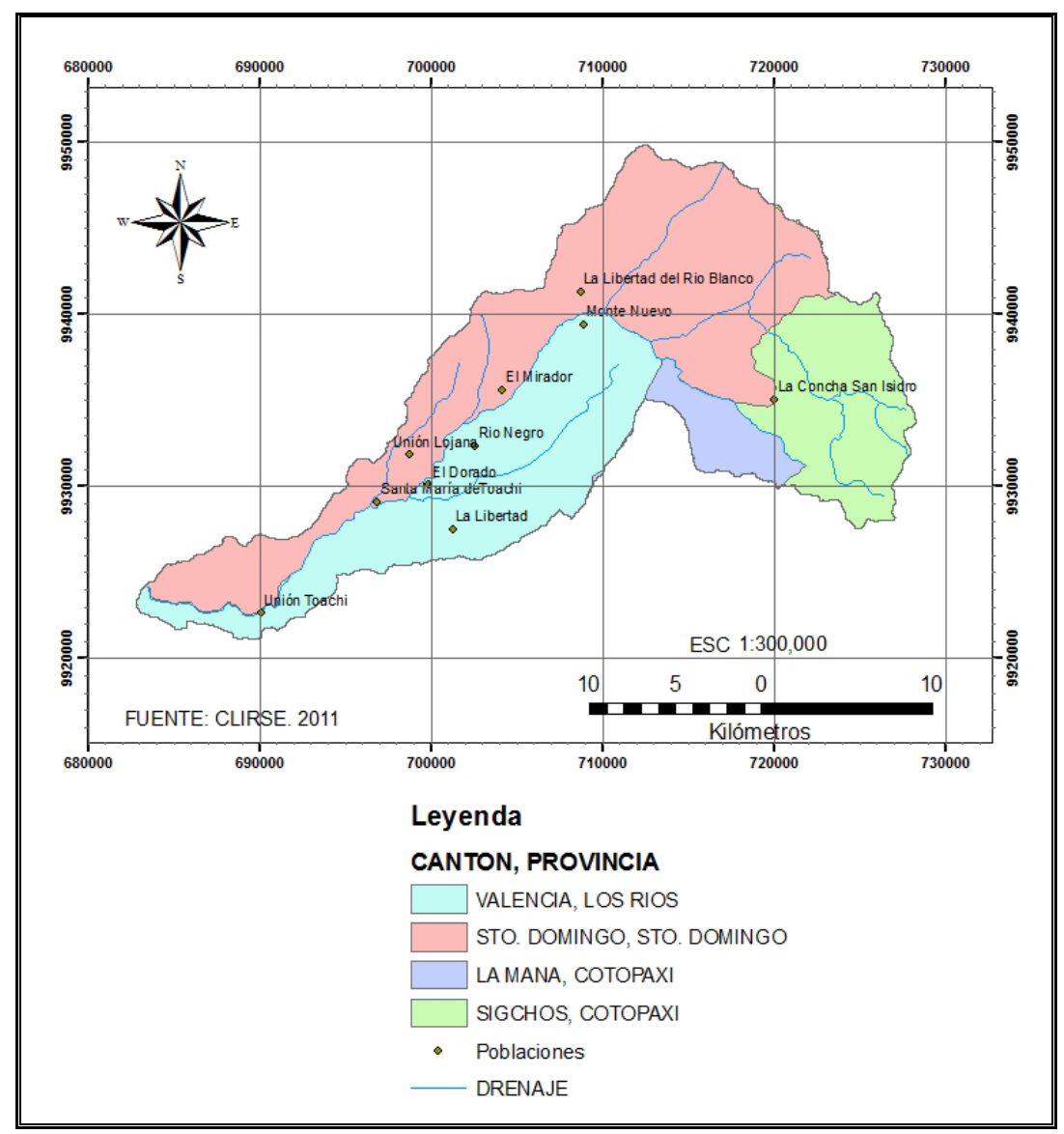

Figura 20. Distribución administrativa-política del área experimental.

\section{Geología}

La ubicación de la Cuenca del Río Toachi se asienta en el área norte de la gran llanura aluvial de la Cuenca del Guayas, en la zona de transición entre la Cordillera Occidental de los Andes, compuesta por depósitos volcano-clásticos y lavas andesíticas del CretácicoPaleogénico (Formación Macuchi), y la Zona Costera, constituida por formaciones de la época Terciaria que ocupan una extensa zona a lo largo de la costa (Formación San Tadeo). (Efficacitas, 2009)

A partir del Mioceno, en el área de estudio, se desarrollo un intenso volcanismo calcoalcalino el cual, prácticamente, continúa hasta los actuales días por cuanto en las cuencas aledañas existen volcanes que son considerados activos como son el Ninahuilca y Quilotoa, responsables de la presencia de enormes depósitos de flujos piroclásticos. La erosión y transporte de estos volcánicos generaron un gigantesco abanico aluvial que forma parte del piedemonte de la Cordillera Occidental de Los Andes y fue generado por la sedimentación de detritos volcánicos acarreados a lo largo de las Cuencas de los Ríos Toachi y Pilatón y Pílalo. Los depósitos de lahar y otros sedimentos volcánicos asociados que se encuentran en este abanico se agrupan bajo la denominación de Formación San Tadeo. (Caminos y Canales, 2007). 


\section{Relieve}

La Cuenca del Río Toachi drena una vasta zona que se extiende desde las cabeceras de la Cordillera Occidental de los Andes, pasando por el pie de las estribaciones hasta la Llanura Costera central, formando parte del drenaje septentrional del sistema fluvial Baba-QuevedoBabahoyo-Guayas que desagua al Océano Pacífico (Caminos y Canales, 2007). Las vertientes más altas se encuentran a $2.800 \mathrm{msnm}$ y el sitio de aforo esta a $162 \mathrm{msnm}$. Esta diferencia de nivel demuestra la variabilidad morfodinámica caracterizada por la geomorfología donde existen pendientes desde muy escarpadas hasta moderadas, según lo demuestra la Figura 26.

En la cuenca experimental se identifican tres unidades geomorfológicas de diferentes características:

- La primera corresponde a la zona alta, pertenecen a esta las mayores elevaciones (msnm) localizadas hacia el este y sureste sobre la cordillera occidental de los Andes y algunos cerros aislados. Corresponde a la zona de recarga y de aporte hídrico, con quebradas de alta pendiente y fuerte erosión. Está constituida por rocas muy duras de origen volcano-clásticas, definidas como turbidíticas, con intercalaciones de basaltos almohadillados (pillow lavas) y brechas volcánicas que conforman un amplio frente montañoso en las primeras elevaciones de la cordillera occidental de la Formación Macuchi. (Efficacitas, 2009)

- La segunda, de mayor extensión territorial, se caracteriza por tener una serie de terrazas subhorizontales de elevaciones bajas con pendientes suaves pero constantes que desciende con dirección sur-oeste, con un drenaje intenso de pequeñas y profundas quebradas. Las terrazas están constituidas por antiguos aluviones, lahares y depósitos tobáceos de la Formación San Tadeo. En esta unidad se encuentra el mayor potencial de desarrollo agrícola el cual es favorecido por los materiales limoarcillosos y espesores de suelo residual del orden de 3 a 5 metros. Además favorecen el clima para la densa cobertura vegetal y ausencia de afloramientos de roca en el área. (Efficacitas, 2009)

- Desde la parte media hacia abajo del área de estudio se observan escarpados en forma de herradura donde se evidencia la existencia de antiguos deslizamientos superficiales que afectaron a la capa de suelo orgánico y vegetal. Los terrenos tienen un relieve ondulado formado por colinas redondeadas y drenajes poco desarrollados. Por el grado de conservación morfológica, se infiere que estos procesos de inestabilidad son antiguos y no experimentaron reacciones posteriores. (Caminos y Canales, 2007). 


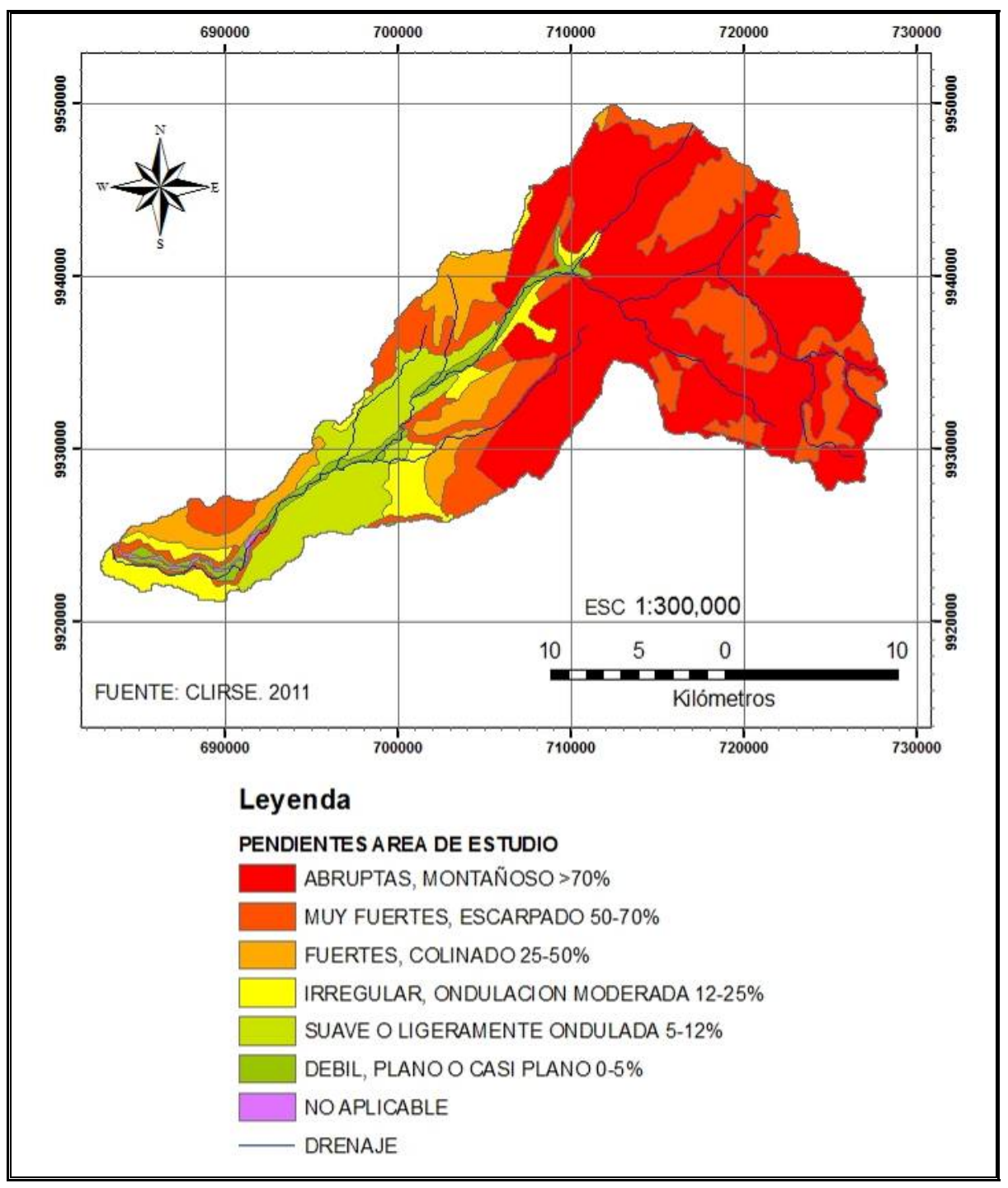

Figura 26. Relieve del área de estudio

Otros autores clasifican la zona de estudio según las unidades morfológicas de la costa, así, la zona al pie de las estribaciones de la Cordillera Occidental de los Andes se denomina "Piedemonte Andino", se extiende desde Santo Domingo al norte hasta Machala al Sur, y está formada por una serie continua de conos de deyección y de esparcimiento. El ancho promedio es de 10 a $20 \mathrm{~km}$ y la altura varía según la posición geográfica desde $1000 \mathrm{~m}$ a $20 \mathrm{~m}$ donde se une con la llanura aluvial. (Granja, 2010)

En la Figura 27 se observa la ubicación del área de estudio con respecto a la formación del Piedemonte Andino, las alturas van desde los 160 metros hasta los $1100 \mathrm{~m}$ en la parte más alta. El modelado es intensamente homogéneo debido a la presencia de una fuerte cobertura de origen piroclástico. 


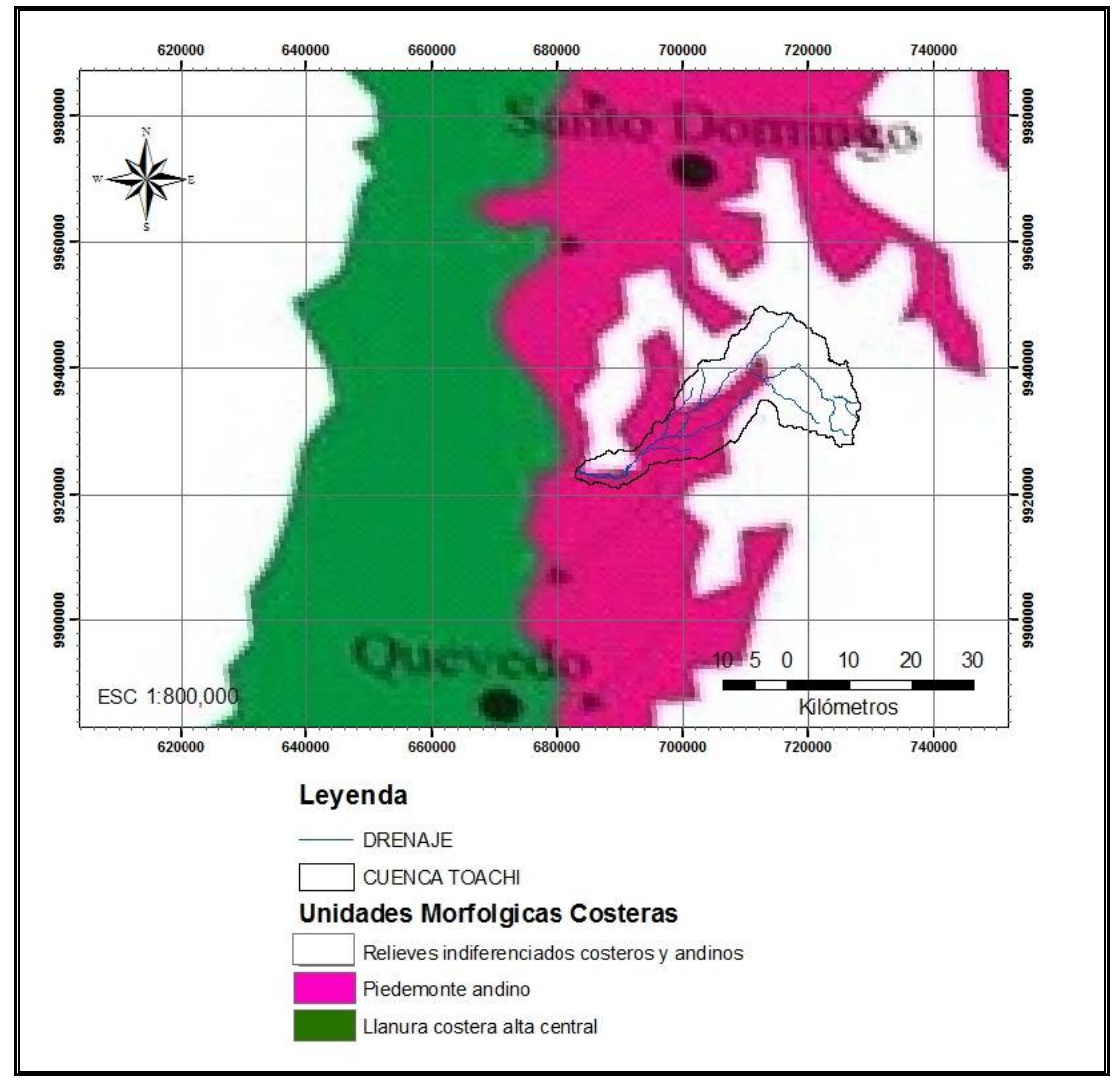

Figura 27 Unidades Morfológicas Costeras. Fuente: Granja. 2010

\section{Reserva Ecológica Los Ilinizas}

La Reserva Ecológica Los llinizas (RELI) pertenece al Sistema Nacional de Áreas Protegidas del Ecuador ${ }^{13}$ (SNAP), se ubica en la Cordillera Occidental de los Andes, entre las provincias de Cotopaxi y Pichincha. Fue creada el 11 de diciembre de 1996 mediante Registro Oficial No. 092 del 19 de diciembre del mismo año.

La característica más importantes que tiene esta reserva es la barrera geológica que forman los nevados Los Ilinizas y El Corazón impidiendo el paso del vapor de agua desde la región de la Costa hacia el callejón interandino, favoreciendo la formación de microcuencas, donde nacen los principales afluentes de los Ríos Esmeraldas, Toachi y Pilatón.

Entre los rasgos geomorfológicos más importantes se encuentran la Cordillera Leila, los volcanes Los Ilinizas (Fotografía 2) y El Corazón, los Cerros, Jaligua Alto, Tenefuerte, Zarapullo, Azul y la laguna del Volcán Quilotoa. En el área de amortiguamiento se distinguen principalmente dos cuencas, la más grande del Río Toachi, y la del Río Pilatón. Los ríos que nacen en esta reservan aumentan su caudal a medida que avanzan

\footnotetext{
${ }^{13}$ Es un instrumento de administración territorial compartida pero diferenciada. Se integra por los subsistemas, estatal, autónomo descentralizado, comunitario y privado, (Asamblea Nacional Constituyente, 2008: Art.405). Fuente:

http://www.fan.org.ec/index.php?option=com_content\&view=article\&id=2\&ltemid=4\&lang=es
} 
entre los restos de los pocos bosques primarios que quedan a lo largo de la cordillera occidental. (MAE, 2010)

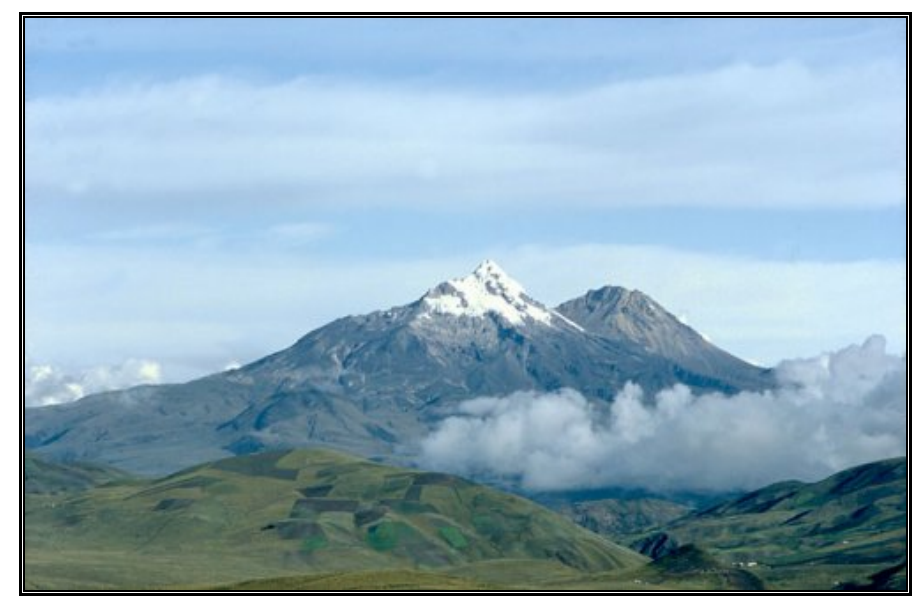

Foto 2. Nevados Los Ilinizas (RELI). Fuente: Internet

La superficie total de la reserva es de 150.000 ha $\left(1.500 \mathrm{~km}^{2}\right)$ aproximadamente, de los cuales 16.600 ha $\left(160 \mathrm{~km}^{2}\right)$ aproximadamente se encuentran en el interior del área de estudio (Figura 28). Su altura fluctúa desde los $887 \mathrm{~m}$ a los $3150 \mathrm{~m} \mathrm{msnm}$. La mayor parte su superficie está situada en la zona climática Ecuatorial Mesotérmico Muy Húmedo y el resto se comparte entre la zona Subtropical Mesotérmico Lluvioso (zona baja) y la zona Ecuatorial Frio Húmedo (zona alta). La temperatura oscila entre $8^{\circ} \mathrm{C}-12^{\circ} \mathrm{C}$ y la precipitación desde $2600 \mathrm{~mm}$ a $3100 \mathrm{~mm}$ de lluvia.

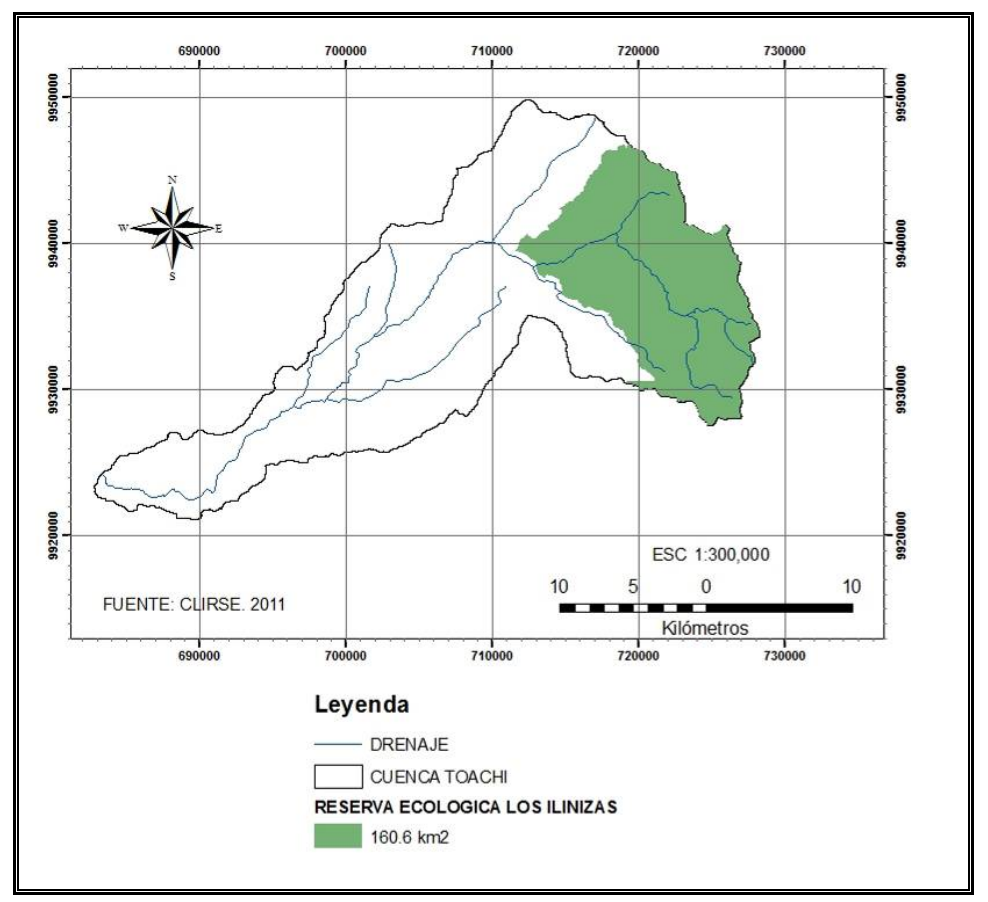

Figura 28. Ubicación geográfica de la Reserva Ecológica Los llinizas (RELI) 
La mayor parte de la reserva presenta rocas volcánicas antiguas que pertenecen a la Formación Macuchi. Se diferencia claramente dos tipos de suelo: los franco-arenosos húmedos, de mayor ocupación en el área de estudio, localizados en las estribaciones de la Cordillera Occidental y se caracterizan por su coloración muy negra (zonas frías) a negro (zonas templadas); y los suelos arenosos ubicados dentro del valle interandino producto de los materiales piroclásticos con baja retención de humedad (MAE, 2010).

\section{Proyecto Hidroeléctrico Baba.}

El Proyecto Multipropósito Baba está ubicado en la microcuenca del Río Baba que forma parte de la cuenca alta del Río Guayas (Figura 29). Tiene como objetivos: la generación de energía hidroeléctrica aprovechando el transvase de $2.773 \mathrm{hm}^{3}$ desde el Río Baba al embalse Daule-Peripa; reducir las inundaciones que afectan a las poblaciones aguas abajo como son Quevedo, Vinces, Babahoyo, entre otras; y mantener el riego de las 8.600 has situadas aguas abajo del embalse.

Geográficamente el proyecto se ubica aguas debajo de la confluencia de los Ríos Baba y Toachi, políticamente se ubica en los cantones Buena Fe y Valencia de la Provincia de Los Ríos (Efficacitas, 2006).

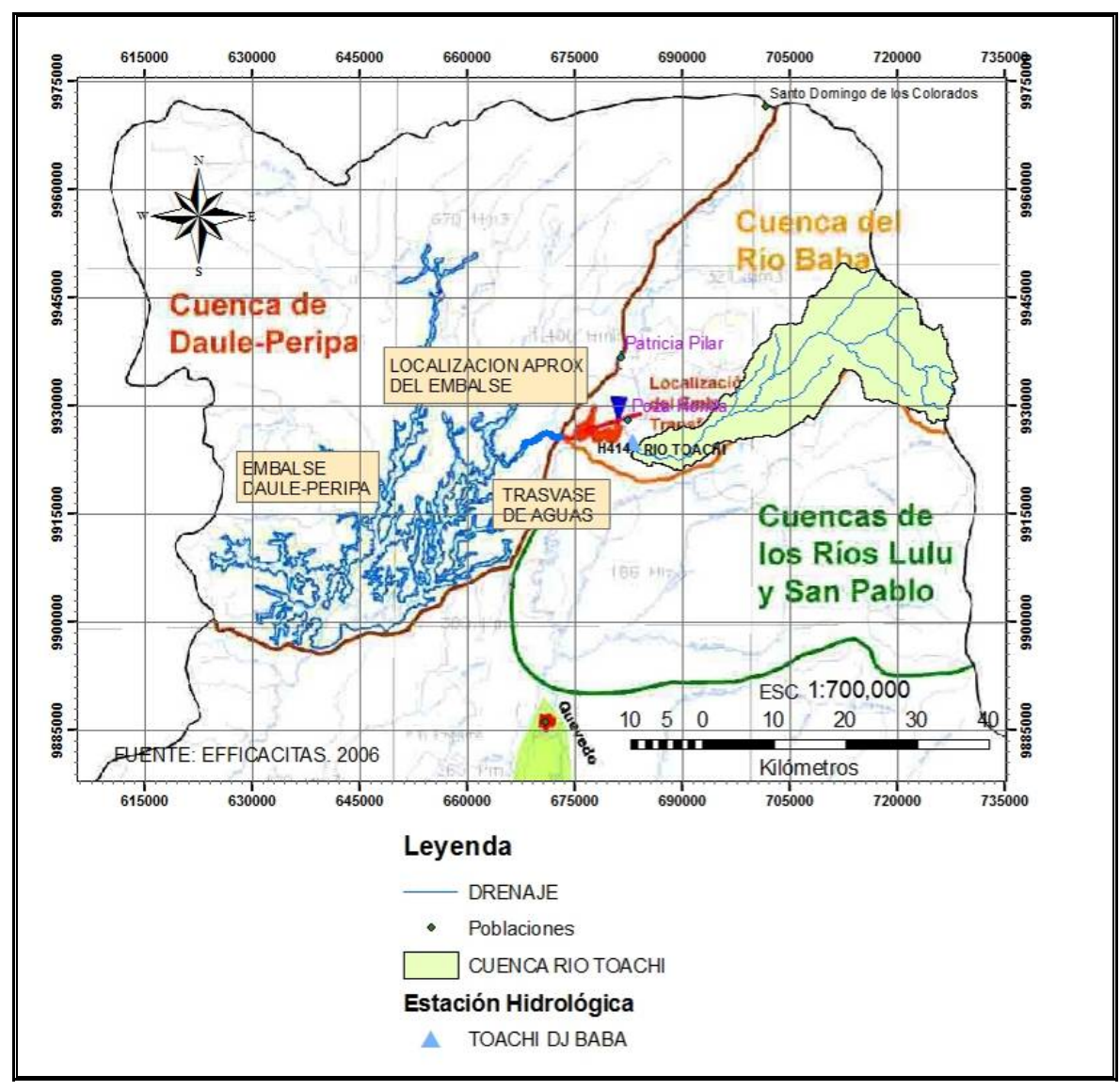

Figura 29. Ubicación del Proyecto Hidroeléctrico Baba. 


\section{2.- Morfometría de la cuenca}

En los tres primeros ítems se hace un análisis de los parámetros morfométricos a nivel cuenca utilizando las fórmulas correspondientes en el programa Excel ${ }^{\circledR}$, y en el ítem 5.2.4 se presenta la caracterización morfométrica que realiza la extensión HECGeo-HMS de la cuenca de estudio a nivel subcuenca.

\subsubsection{Parámetros de Relieve}

La influencia del relieve sobre la Cuenca del Río Toachi es evidente, a mayor pendiente corresponde una menor duración de concentración de las aguas de escorrentía en la red de drenaje y afluentes al curso principal.

A continuación se presentan los resultados de los parámetros utilizados para este estudio a nivel cuenca, los cuales se resumen en la Tabla 30.

\section{a.- Área (A)}

La superficie total de la cuenca de estudio es de $503,71 \mathrm{~km}^{2}$, la cual fue delimitada por la divisoria de aguas que encierran al Río Toachi y sus afluentes desde su naciente. Es considerada como el parámetro físico básico que define a una cuenca, siendo determinante en la escala de varios fenómenos hidrológicos como, el volumen de agua que ingresa por precipitación, la magnitud de los caudales, entre otros.

\section{b.- Perímetro $(P)$}

La Cuenca del Río Toachi posee un perímetro total de 181,92 km.

\section{C.- Longitud Axial (La)}

La longitud axial en la cuenca de estudio es de 58.235,41 m.

\section{d.- Ancho promedio (Ap)}

El ancho promedio de la cuenca de estudio es de 8.649,68 m.

\section{e.- Altura media (h)}

La altura media de la Cuenca del Río Toachi es de $1.500 \mathrm{~m}$.

\section{$\underline{\text { f.- Pendiente Media de la cuenca (PM) o Factor Topográfico }}$}

Para calcular la pendiente media de la cuenca de estudio o factor topográfico, se utilizó el modelo de elevación digital para determinar que la cota máxima es de $3.160 \mathrm{~m}$ y la mínima es de $160 \mathrm{~m}$, obteniendo un desnivel altimétrico de 3.000 metros. 
Se obtuvo el valor de $5,15 \%$ de pendiente media que, según la Tabla 14, corresponde a un relieve suave para la Cuenca del Río Toachi. Este valor indica que la cuenca tiene un relieve regular por lo que los procesos erosivos son medianos

Tabla 30. Resumen de los parámetros de relieve a nivel cuenca de estudio.

\begin{tabular}{|c|c|c|c|c|c|c|}
\hline Cuenca & $\begin{array}{c}\text { Área } \\
\mathbf{( k m}^{\mathbf{2}} \mathbf{)}\end{array}$ & $\begin{array}{c}\text { Perímetro } \\
\mathbf{( k m )}\end{array}$ & $\begin{array}{c}\text { Longitud } \\
\text { Axial } \\
\mathbf{( m )}\end{array}$ & $\begin{array}{c}\text { Ancho } \\
\text { Promedio } \\
\mathbf{( m )}\end{array}$ & $\begin{array}{c}\text { Altura } \\
\text { Media } \\
(\mathbf{m})\end{array}$ & $\begin{array}{c}\text { Pendiente } \\
\text { Media } \\
\text { Cuenca (\%) }\end{array}$ \\
\hline Río Toachi & 503,71 & 181,92 & $58.235,41$ & $8.649,68$ & $1.500,00$ & 5,15 \\
\hline
\end{tabular}

\subsubsection{Parámetros de Forma}

La forma de la cuenca influye sobre los escurrimientos y sobre recorrido del hidrograma de una lluvia, así en una cuenca de forma alargada, el agua discurre en general por un solo cauce principal, mientras que en otra de forma ovalada los escurrimientos recorren cauces secundarios hasta llegar a uno principal, por lo que la duración del escurrimiento es mayor.

A continuación se presentan los resultados de los índices utilizados para este estudio a nivel cuenca, los cuales se resumen en la Tabla 31.

\section{a.- Coeficiente de Gravelius ( $\mathrm{Cg})$ o Índice de compacidad (Kc)}

El coeficiente de compacidad obtenido para la cuenca de estudio es considerado alto de 2,27 , que indica que la cuenca presenta una forma rectangular oblonga y al relacionarlo con su tiempo de concentración se puede decir que el agua dentro de la cuenca escurre a través del canal principal donde su tiempo de concentración aumenta, considerando además una menor circularidad disminuyendo su torrencialidad y menor poder erosivo.

\section{$\underline{\text { b.- Factor de forma (IF) }}$}

El factor de forma de la Cuenca del Río Toachi, presenta un valor bajo de 0,15 con lo cual se confirma el coeficiente de Gravelius indicando que la cuenca presenta forma alargada. Este valor nos indica que al presentar la cuenca, un largo canal colector principal con tributarios cortos y poco ramificados, se tiene un hidrograma de crecidas (tiempo vs descarga) achatado, ya que el agua que proviene de los afluentes debe recorrer una larga circulación por el cauce principal atenuando de esta manera el caudal de salida y aumentando el tiempo de concentración, con probabilidad de crecidas de menor magnitud, menor grado de torrencialidad y por tanto menor poder erosivo. Esto se debe a que el área de drenaje se asemeja a la forma de un rectángulo, lo que implica una pequeña área en una longitud larga.

Tabla 31. Resumen de los parámetros de forma a nivel cuenca de estudio.

\begin{tabular}{|c|c|c|}
\hline Cuenca & Coeficiente de Gravelius (Cg) & Factor de Forma (IF) \\
\hline Río Toachi & 2,27 & 0,15 \\
\hline
\end{tabular}




\subsubsection{Parámetros relativos de la red hidrográfica}

Se llama red hidrográfica al drenaje natural, permanente o temporal por el que fluyen las aguas de las escorrentías superficiales. La forma y densidad de la red de drenaje corresponde a la distribución de los afluentes que lo conforman. A continuación se presentan los resultados de los parámetros relativos de la red hidrográfica a nivel cuenca, los cuales se resumen en la Tabla 32:

\section{a.- Densidad de drenaje (D)}

La densidad de drenaje para el caso de la Cuenca del Río Toachi es considera baja, del orden del $0,02 \%$, que significa que la respuesta de la cuenca ante una lluvia evacuará el agua en un mayor tiempo, propio de una cuenca alargada.

\section{$\underline{\text { b.- Pendiente media del cauce }(\mathrm{J})}$}

La pendiente media del cauce de la Cuenca del Río Toachi es del 3,48\%, que expresa el desnivel topográfico del cauce principal y la longitud del mismo. La cota máxima del cauce es de $2.186 \mathrm{~m}$ y la mínima de $162 \mathrm{~m}$, con una longitud de 58.235,41 metros.

\section{c. Tiempo de concentración (Tc)}

El tiempo de concentración de la Cuenca del Río Toachi es de 6,8 horas, que significa que la cuenca de estudio necesita de ese tiempo para que toda su superficie contribuya con escorrentía superficial en el punto de aforo. Su tiempo de concentración se considera largo, por lo que su caudal pico es mas atenuado y su recesión es mucho más sostenida en el tiempo (retorno al nivel base es más lento).

Tabla 32. Resumen de los parámetros relativos a la red hidrográfica a nivel cuenca de estudio.

\begin{tabular}{|c|c|c|c|}
\hline Cuenca & $\begin{array}{c}\text { Densidad de } \\
\text { drenaje (\%) }\end{array}$ & $\begin{array}{c}\text { Pendiente } \\
\text { media del cauce } \\
\text { (\%) }\end{array}$ & $\begin{array}{c}\text { Tiempo de } \\
\text { concentración } \\
\text { (h) }\end{array}$ \\
\hline Río Toachi & 0,02 & 3,48 & 6,8 \\
\hline
\end{tabular}

En resumen, la morfometría de la Cuenca del Río Toachi presenta forma rectangular oblonga o alargada, con una pendiente media de tipo suave, desarrolla crecientes de menor magnitud, en donde predomina la infiltración ante el escurrimiento, debiendo recorrer el agua una longitud de ladera larga sobre el cauce donde la velocidad de escurrimiento es baja. El tiempo de concentración es largo debido a la atenuación del caudal de salida. Por tanto la cuenca tendrá un menor grado de torrencialidad y menor poder erosivo. 


\subsubsection{Parámetros automáticos con HEC-GeoHMS}

Las unidades generadas por la herramienta HEC-GeoHMS, se presentan en el mapa de la Figura 30 , donde se observa con diferentes colores las siete subcuencas del área de estudio, ubicándose en la zona de la cabecera las subcuencas 1, 2, 3 y 4; en la área media la 5 y 6 , y en la zona de la desembocadura la subcuenca 7 .

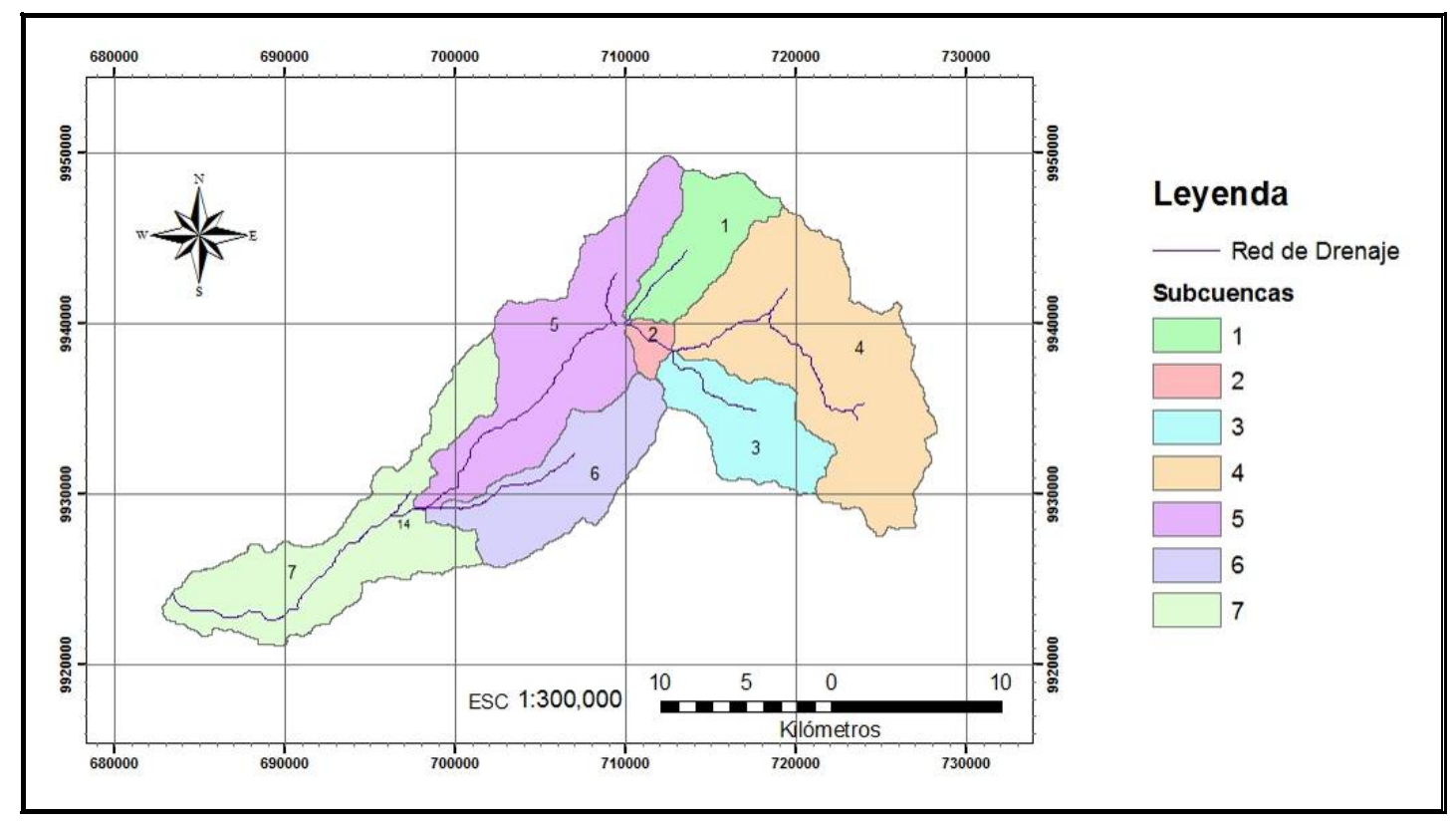

Figura 30. Esquema de las subcuencas generadas con HEC-GeoHMS

Los resultados obtenidos del análisis morfométrico del relieve de la Cuenca del Río Toachi con esta herramienta, se presentan en la Tabla 33.

Tabla 33. Caracterización de las subcuencas según HEC-GeoHMS.

\begin{tabular}{|c|c|c|c|}
\hline $\begin{array}{c}\text { SUB } \\
\text { CUENCAS }\end{array}$ & $\begin{array}{c}\text { PERIMETRO } \\
\mathbf{( m )}\end{array}$ & $\begin{array}{c}\text { PENDIENTE } \\
\text { MEDIA CUENCA } \\
\mathbf{( \% )}\end{array}$ & $\begin{array}{c}\text { AREA } \\
\mathbf{( k m}^{\mathbf{2}} \mathbf{)}\end{array}$ \\
\hline 1 & 40860,0 & 41,38 & 38,96 \\
\hline 2 & 15540,0 & 53,45 & 7,07 \\
\hline 3 & 41280,0 & 50,46 & 46,11 \\
\hline 4 & 79740,0 & 40,38 & 142,27 \\
\hline 5 & 82680,0 & 26,37 & 107,05 \\
\hline 6 & 56220,0 & 26,80 & 62,03 \\
\hline 7 & 94920,0 & 9,05 & 100,22 \\
\hline Total & & & 503,71 \\
\hline
\end{tabular}


Se observa que la subcuenca 4 es la más grande con $142,27 \mathrm{~km}^{2}$ de superficie y la de menor área es la subcuenca 2 con $7,07 \mathrm{~km}^{2}$, además esta subcuenca presenta un relieve muy accidentado con una pendiente media de $53,4 \%$ al igual que la subcuenca 3 con $50,4 \%$. Las subcuencas 1 y 4 presentan un factor topográfico promedio del $40 \%$, todas estas ubicadas en la zona de cabecera. Las subcuencas 5 y 6 presentan una pendiente media del $26 \%$ y la subcuenca 7 una pendiente del $9 \%$, ubicada las dos primeras en la zona media y la última en la zona de desembocadura. Este factor tiene una gran importancia porque, indirectamente, a través de la velocidad del flujo de agua, indica el tiempo de respuesta de la cuenca. A partir de estos resultados, se establece que las subcuencas ubicadas en la zona de cabecera están sometidas a procesos erosivos más drásticos debidos, entre otros factores, a lo muy fuertes que son las pendientes. En la zona media se caracteriza por presentar pendientes accidentadas y la zona baja presenta pendientes suaves, según la clasificación de la Tabla 14.

De igual manera, se generó el archivo de parámetros morfométricos relativos a la red hidrográfica de la Cuenca del Río Toachi, cuyo mapa se presenta en la Figura 31, en el cual se muestran los 15 tramos de ríos generados por el HEC-GeoHMS en diferentes colores, y la respectiva subcuenca a que pertenecen.

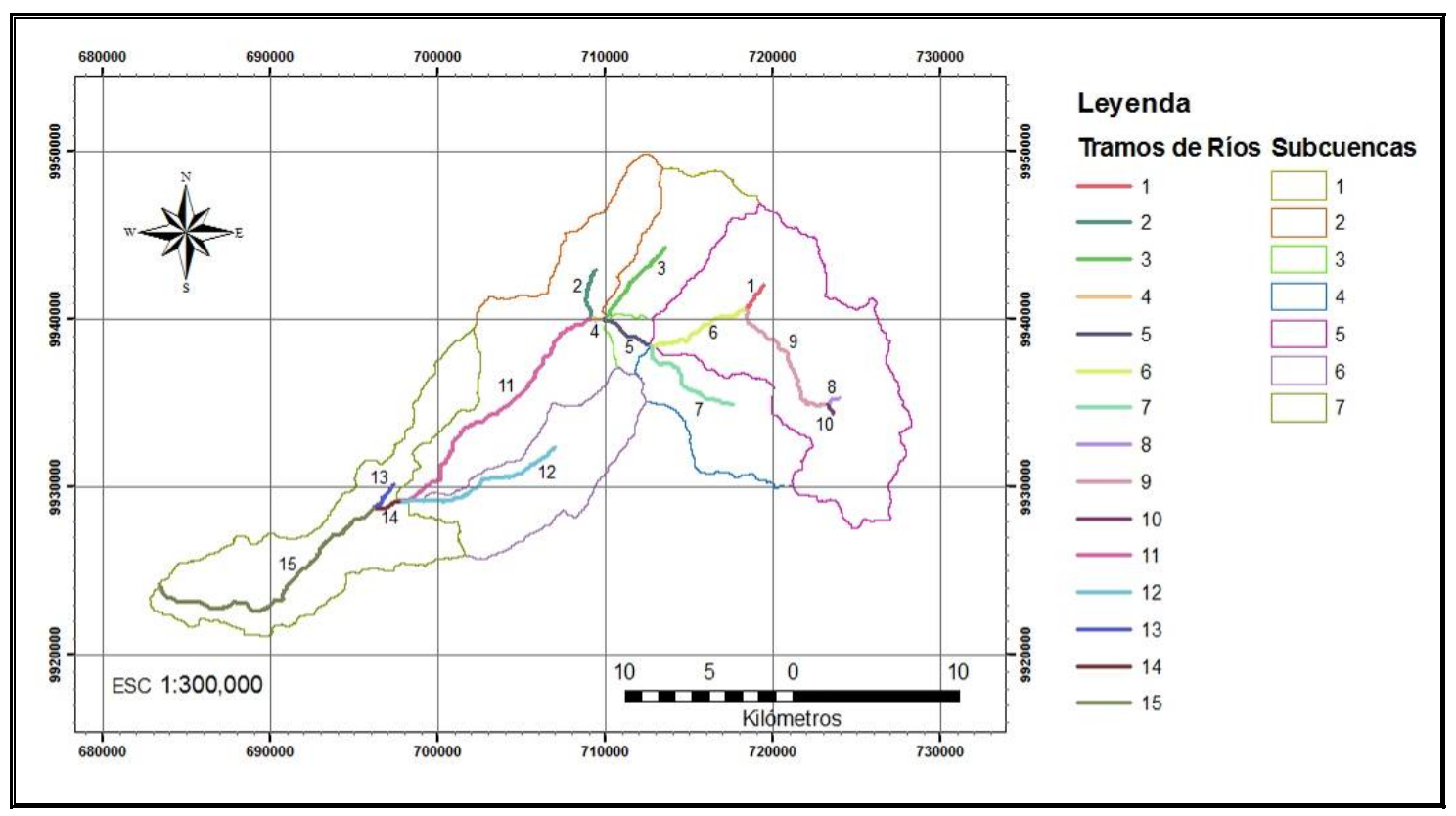

Figura 31. Red Hidrográfica generada con HEC-GeoHMS

Los resultados obtenidos del análisis morfométrico a la red hidrográfica de la Cuenca del Río Toachi, se muestran en la Tabla 34, la cual esta ordenada de acuerdo a la subcuenca que pertenecen los tramos de ríos desde la cabecera hasta la desembocadura. Los números que no tienen paréntesis son los ríos principales, y los que tiene (a) son afluentes que alimentan al principal. 
Se observa que la red de drenaje tiene su nacimiento en la cota $(\mathrm{m}) 2.186$ con el tramo 10 , que además es el más corto con $679,2 \mathrm{~m}$, y finaliza en la cota $(\mathrm{m}) 162$ con el tramo 15 que es el más largo con $17.431,4 \mathrm{~m}$.

La longitud total de la red de drenaje de la Cuenca del Toachi es de 91.161,47 m, con un desnivel de 2.024 metros. La mayor pendiente la presenta el tramo 1 con el $15 \%$ y la menor la tiene el tramo 14 con $0,1 \%$, pertenecientes a las subcuencas 4 (zona de cabecera) y 7 (zona de desembocadura), respectivamente.

Tabla 34. Caracterización de la red hidrográfica según HEC-GeoHMS

\begin{tabular}{|c|c|c|c|c|c|}
\hline \multirow{2}{*}{$\begin{array}{l}\text { TRAMOS } \\
\text { DE RIOS }\end{array}$} & \multirow{2}{*}{$\begin{array}{l}\text { LONGITUD } \\
(\mathrm{m})\end{array}$} & \multirow{2}{*}{$\begin{array}{l}\text { PENDIENTE } \\
\text { MEDIA CAUCE } \\
(\mathrm{m} / \mathrm{m})\end{array}$} & \multicolumn{2}{|c|}{ COTAS (m) } & \multirow{2}{*}{$\begin{array}{c}\text { SUBCUENCA } \\
\text { PERTENECIENTE }\end{array}$} \\
\hline & & & MAX & MIN & \\
\hline 1 & 1990,22 & 0,150 & 1587 & 1288 & 4 (a) \\
\hline 8 & 1052,76 & 0,045 & 2171 & 2124 & 4 (a) \\
\hline 10 & 679,26 & 0,091 & 2186 & 2124 & 4 \\
\hline 9 & 9237,20 & 0,091 & 2124 & 1288 & 4 \\
\hline 6 & 6974,41 & 0,063 & 1288 & 846 & 4 \\
\hline 7 & 7469,41 & 0,122 & 1761 & 846 & 3 \\
\hline 5 & 3478,60 & 0,053 & 846 & 661 & 2 \\
\hline 3 & 6085,69 & 0,103 & 1285 & 661 & 1 \\
\hline 4 & 836,98 & 0,033 & 661 & 633 & 5 \\
\hline 2 & 3383,71 & 0,050 & 803 & 633 & $5(a)$ \\
\hline 11 & 17906,01 & 0,017 & 633 & 322 & 5 \\
\hline 12 & 10917,82 & 0,022 & 564 & 322 & 6 \\
\hline 14 & 1691,54 & 0,001 & 322 & 320 & 7 \\
\hline 13 & 2026,43 & 0,016 & 352 & 320 & 7 (a) \\
\hline 15 & 17431,42 & 0,009 & 320 & 162 & 7 \\
\hline$\sum$ Total & $91.161,47$ & & & & \\
\hline
\end{tabular}

Con el objetivo de identificar los principales ríos que atraviesan las subcuenca de estudio, se elaboró la Tabla 35. Se observa que el tramo de río con mayor longitud es el que atraviesa la subcuenca 7 con 19.123 metros, y el más corto es el tramo 5 que atraviesa la subcuenca 2 con una longitud de $3.478,6 \mathrm{~m}$.

La longitud total de los principales ríos es de $82.708,35$ metros. La mayor pendiente la presenta el tramo 7 que drena la subcuenca 3 con 12,2\% seguida del tramo 3 que drena la subcuenca 1 con $10,3 \%$ ambas ubicadas en la zona de cabecera, y el tramo con la menor pendiente corresponde al 15 con $0,9 \%$ el cual drena la subcuenca 7 , ubicado en la zona de desembocadura. 
Tabla 35. Caracterización de los ríos principales.

\begin{tabular}{|c|c|c|c|c|c|}
\hline \multirow{2}{*}{$\begin{array}{l}\text { TRAMOS } \\
\text { DE RIOS }\end{array}$} & \multirow{2}{*}{$\begin{array}{l}\text { LONGITUD } \\
(\mathrm{m})\end{array}$} & \multirow{2}{*}{$\begin{array}{c}\text { PENDIENTE } \\
\text { MEDIA CAUCE } \\
(\mathrm{m} / \mathrm{m})\end{array}$} & \multicolumn{2}{|c|}{ COTAS (m) } & \multirow{2}{*}{$\begin{array}{c}\text { SUBCUENCA } \\
\text { PERTENECIENTE }\end{array}$} \\
\hline & & & MAX & MIN & \\
\hline 10 & \multirow{3}{*}{16890,87} & \multirow{3}{*}{0,0880} & \multirow{3}{*}{2186} & \multirow{3}{*}{846} & \multirow{3}{*}{4} \\
\hline 9 & & & & & \\
\hline 6 & & & & & \\
\hline 7 & 7469,41 & 0,122 & 1761 & 846 & 3 \\
\hline 5 & 3478,60 & 0,053 & 846 & 661 & 2 \\
\hline 3 & 6085,69 & 0,103 & 1285 & 661 & 1 \\
\hline 4 & \multirow[t]{2}{*}{18743,00} & \multirow[t]{2}{*}{0,017} & \multirow[t]{2}{*}{661} & \multirow[t]{2}{*}{322} & \multirow{2}{*}{5} \\
\hline 11 & & & & & \\
\hline 12 & 10917,82 & 0,022 & 564 & 322 & 6 \\
\hline 14 & \multirow{2}{*}{19122,96} & \multirow{2}{*}{0,009} & \multirow{2}{*}{322} & \multirow{2}{*}{162} & \multirow{2}{*}{7} \\
\hline 15 & & & & & \\
\hline Total & $82.708,35$ & & & & \\
\hline
\end{tabular}

La longitud del río principal desde su naciente hasta el punto de aforo tiene una longitud de $58.235,43$ metros y atraviesa las subcuencas 4, 2, 5 y 7 , desde el origen hasta su desembocadura (Tabla 36).

Tabla 36. Caracterización del río principal.

\begin{tabular}{|c|c|c|c|c|c|}
\hline \multirow{2}{*}{$\begin{array}{l}\text { TRAMOS } \\
\text { DE RÍOS }\end{array}$} & \multirow{2}{*}{$\begin{array}{l}\text { LONGITUD } \\
(\mathrm{m})\end{array}$} & \multirow{2}{*}{$\begin{array}{c}\text { PENDIENTE } \\
(\mathrm{m} / \mathrm{m})\end{array}$} & \multicolumn{2}{|c|}{ COTAS (m) } & \multirow{2}{*}{$\begin{array}{c}\text { SUBCUENCA } \\
\text { PERTENECIENTE }\end{array}$} \\
\hline & & & MAX & MIN & \\
\hline 10 & \multirow{3}{*}{16890,87} & \multirow{3}{*}{0,0880} & 2186 & 2124 & \multirow{3}{*}{4} \\
\hline 9 & & & 2124 & 1288 & \\
\hline 6 & & & 1288 & 846 & \\
\hline 5 & 3478,60 & 0,053 & 846 & 661 & 2 \\
\hline 4 & \multirow{2}{*}{18743,00} & \multirow{2}{*}{0,017} & 661 & 633 & \multirow{2}{*}{5} \\
\hline 11 & & & 633 & 322 & \\
\hline 14 & \multirow{2}{*}{19122,96} & \multirow[t]{2}{*}{0,009} & 322 & 320 & \multirow{2}{*}{7} \\
\hline 15 & & & 320 & 162 & \\
\hline Total & $58.235,43$ & & & & \\
\hline
\end{tabular}

Se realizaron los gráficos de los perfiles longitudinales pertenecientes a los 15 tramos de ríos que conforman la red hidrográfica para caracterizar su relieve (ver Figura 32), para el 
desarrollo del análisis se tomo como referencia la columna "tramos de ríos" de la Tabla 34 ordenados desde la cabecera a la desembocadura:

El tramo 1 corresponde a un río afluente, nace en la estribación de la Cordillera Occidental, en la cota 1587 recorriendo 1990,2 metros para desembocar en la cota 1288 al río principal de nombre Rayo, presenta una ladera con fuertes pendientes del $15 \%$ que en general se presenta estable y regular.

El tramo 8 corresponde a un río secundario, tributario del río principal, nace en la cota 2.171 en las estribaciones de la Cordillera Occidental, recorre 1.052,7 metros de ladera para desembocar en el Río Rayo en la cota 2.124 con una pendiente muy irregular del 4,5\%, que presenta tramos de rectas con caídas abruptas, es especial en el tramo final con una caída de $40 \mathrm{~m}$ en $250 \mathrm{~m}$.

El tramo 10 corresponde a la naciente del Río Toachi en las estribaciones de la Cordillera Occidental con el nombre Rayo en la cota 2186. El río recorre 679,2 m de ladera con pendiente regular muy empinada del $9,1 \%$. Este corresponde al tramo de río más corto de la red de drenaje general.

El tramo 9 corresponde a la continuación del tramo 10, río principal Rayo, inicia en la cota 2.124 recorre $9.237,2 \mathrm{~m}$ hasta la cota 1.288 , donde recibe las aguas del tramo 1 , presenta una pendiente regular muy empinada del $9,1 \%$.

El tramo 6 corresponde a la continuación del tramo 9, rio principal Rayo, desde la cota 1.288 recorriendo 6974,4 m de laderas hasta la cota 846 donde se une con el tramo 7, durante su recorrido presenta una pendiente moderadamente accidentada del 6,3\%. Hasta aquí los tramos descritos pertenecen al sistema hídrico de la subcuenca 4 en la zona de cabecera.

El tramo 7 es un tributario del rio principal Rayo que nace en la cota 1.761 y se une al tramo 6 en la cota 846, en su recorrido de 7.469,4 m de ladera drena la subcuenca 3 con tiene una pendiente muy accidentada del $12,2 \%$ debido a las profundas quebradas existentes en el relieve.

El tramo 5 está formado por la unión de los tramos 6 y 7 en la cota 846, continuando por el cauce del río principal Rayo, recorriendo $3.478,6 \mathrm{~m}$ drena la subcuenca 2 hasta la cota 661 donde se junta con el tramo 3 , presenta una ladera con pendiente moderadamente accidentada del $5,3 \%$.

El tramo 3 es un río secundario llamado Victoria que nace en las estribaciones de la Cordillera Occidental en la cota 1.285, recorre 6.085,7 m drenando la subcuenca 1 hasta juntarse con el tramo 5 en la cota 661 . Presenta una ladera con pendiente regular muy empinada del $10,3 \%$. Hasta aquí corresponden los tramos ubicados en la zona de cabecera.

El tramo 4 está formado por la unión de los tramos 3 y 5 en la cota 661 , a partir de aquí el rio principal cambia de nombre a Toachi Grande. Recorre $837 \mathrm{~m}$ de ladera drenando la subcuenca 5 hasta la cota 633 donde recibe las aguas del tramo 2, presenta una pendiente irregular de 3,3\% alternada con caídas bruscas y tramos de rectas propio de una zona de transición. Este es el segundo tramo de rio más corto de la red de drenaje general. 
El tramo 2 corresponde al río secundario Blanco, es un tributario del río principal Toachi Grande, nace en la cota 803 recorriendo $3.383,7 \mathrm{~m}$ de ladera drenando la subcuenca 5 para desembocar en el tramo 4, río principal, en la cota 633. Presenta una pendiente poco regular del $5 \%$ con tramos de caída y rectas de acuerdo a la zona de garganta o media.

El tramo 11 está formado por la unión de los tramos 2 y 4 en la cota 633 , continuación del rio principal Toachi Grande. Recorre $17906 \mathrm{~m}$ de ladera drenando la mayor superficie de la subcuenca 5, hasta la cota 322 donde recibe el caudal del tramo 12. Presenta una pendiente bastante regular de $1,7 \%$ debido a la extensa longitud del tramo propia de la zona media de la cuenca de estudio. Este es el segundo tramo de río más largo de la red de drenaje.

El tramo 12 corresponde al Río Toachi Chico, afluente del Río Toachi Grande, nace en la cota 564 recorriendo 10.917,8 m de ladera drenando la subcuenca 6 hasta descargar su caudal al rio principal (tramo 11) en la cota 322 . Presenta una pendiente regular de $2,2 \%$ con tramos de caídas y rectas alternadas durante su recorrido conforme a la zona media. Este es el tercer tramo más largo de río de toda la red de drenaje. Hasta aquí los tramos descritos pertenecen al sistema hídrico de las subcuencas de la zona media.

El tramo 14 está formado por la unión de los tramos 11 y 12 en la cota 322, es la continuación del río principal Toachi Grande, pero a partir de aquí se lo conoce como Toachi. Recorre 1.691,5 m por la ladera de llanura en la subcuenca 7 hasta recibir el caudal del tramo 13 en la cota 320 . Presenta una pendiente plana muy regular del $0,1 \%$, es decir de $10 \mathrm{~cm}$ de desnivel por cada $100 \mathrm{~m}$ de distancia. Este es el inicio de la zona de desembocadura o zona baja.

El tramo 13 es un tributario del río principal, nace en la cota 352 recorriendo 2.026,4 m de ladera drenando la parte alta de la subcuenca 7 para desembocar su caudal en el tramo 14, Río Toachi, en la cota 320 . Presenta una pendiente plana poco regular del $1,6 \%$ con tramos de caída y rectas largas pero suaves, que a pesar de estar en la zona de desembocadura tiene características de zona media.

El tramo 15 está formado por la unión de los tramos 13 y 14 en la cota 320 , es la continuación del Río Toachi, recorre $17.431,4 \mathrm{~m}$ por la ladera de llanura drenando la mayor superficie de la subcuenca 7 hasta el punto el punto de aforo en la estación hidrológica Toachi en la cota 162. Presenta una pendiente bastante regular de 0,9\% ( $90 \mathrm{~cm}$ de desnivel por cada $100 \mathrm{~m}$ de distancia) propia de la zona de desembocadura debido a la extensa longitud del tramo, siendo este el tramo más largo de la red hidrográfica de la cuenca de estudio.

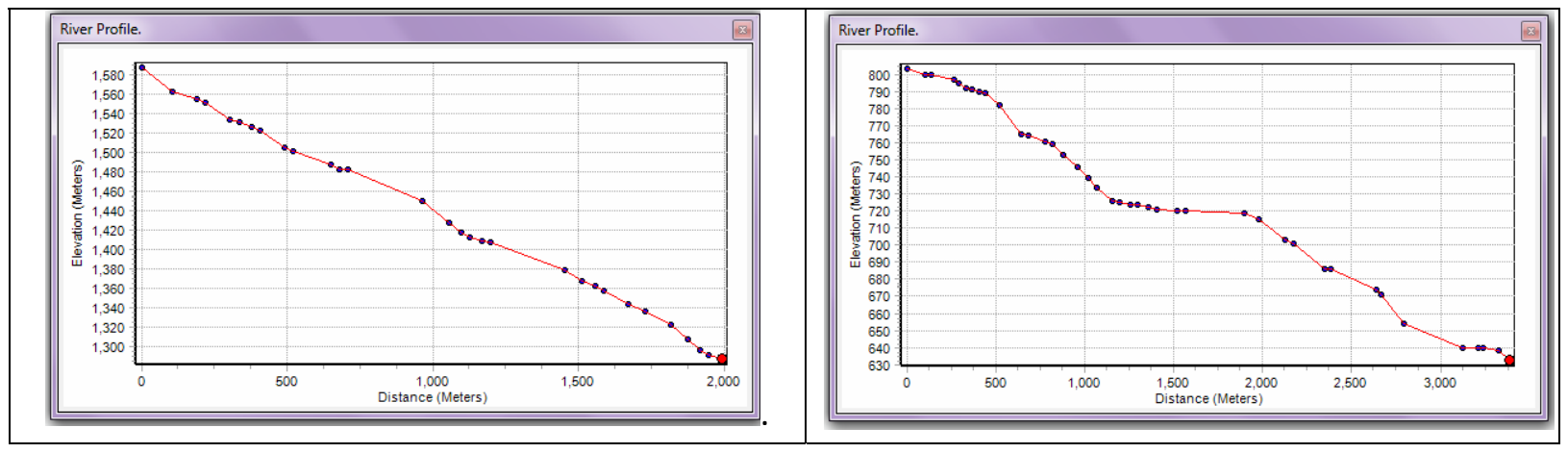




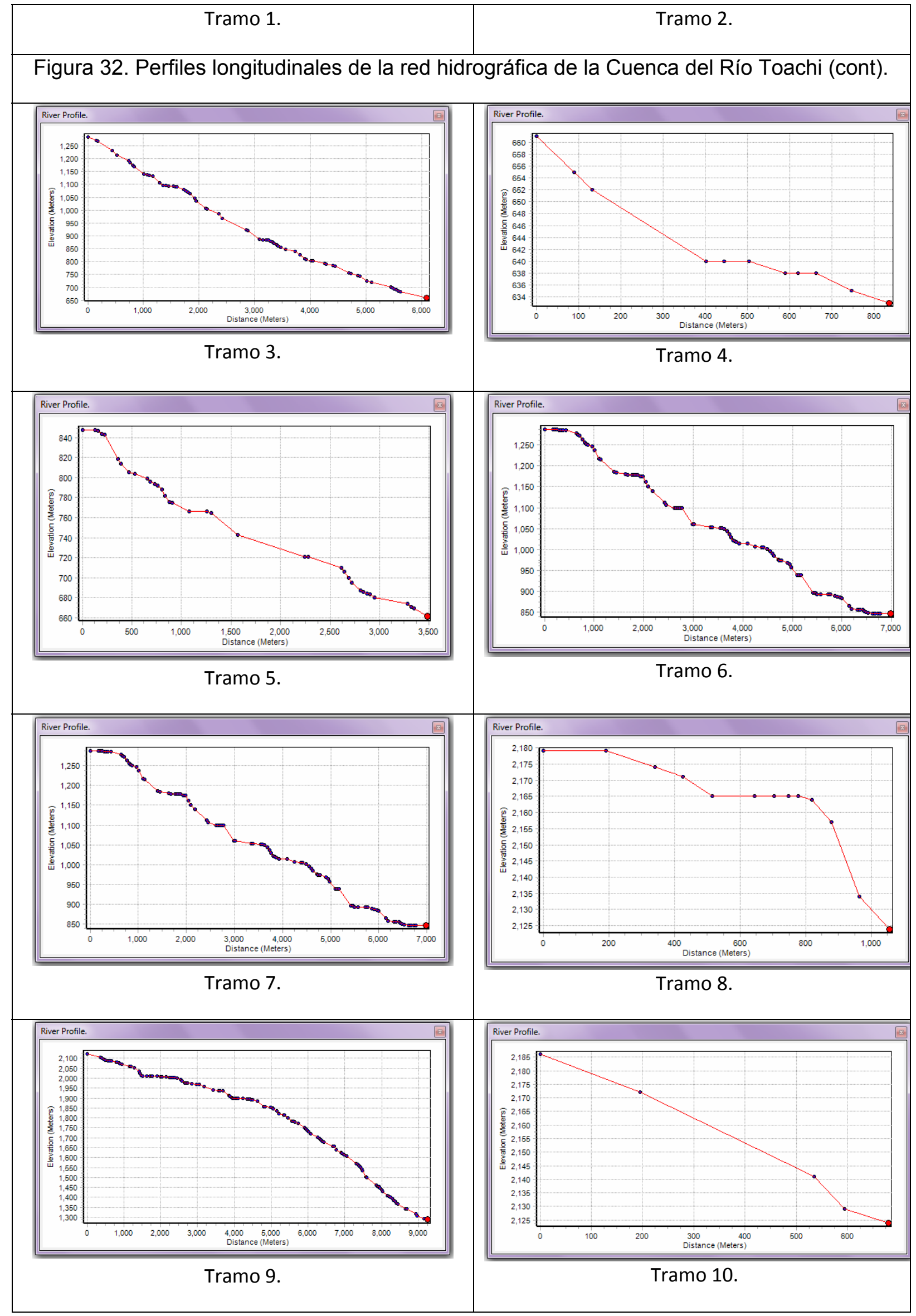


Figura 32. Perfiles longitudinales de la red hidrográfica de la Cuenca del Río Toachi (cont)
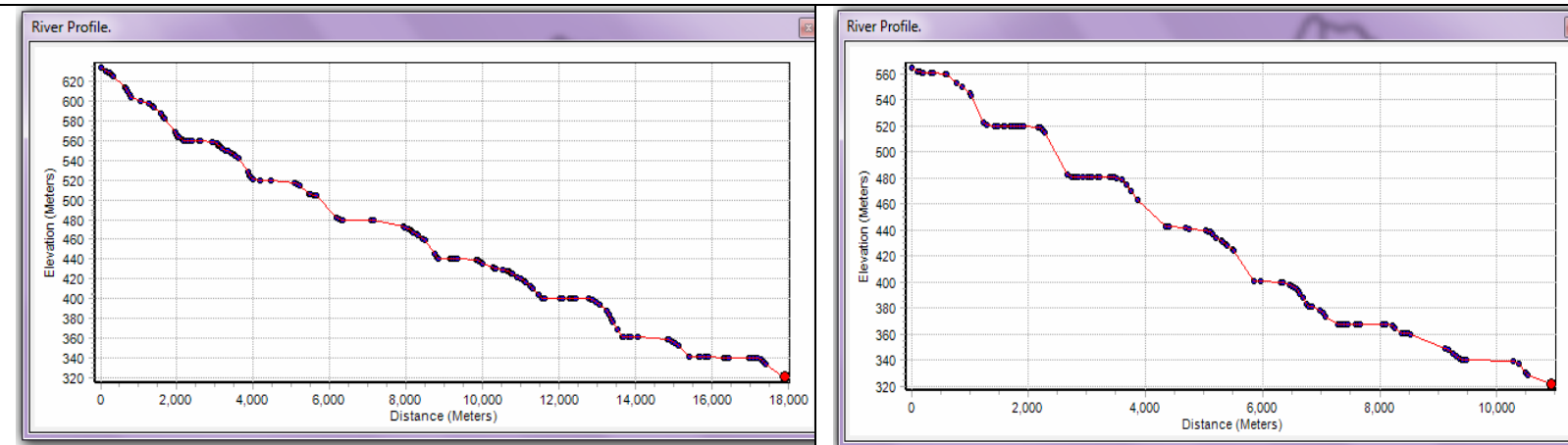

Tramo 11.

Tramo 12.

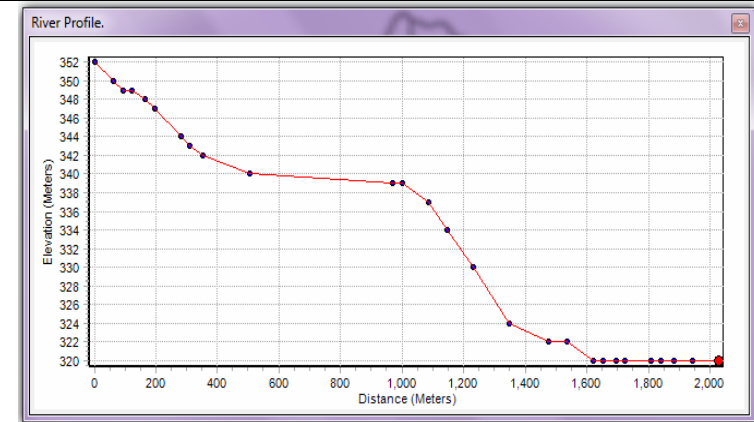

Tramo 13.

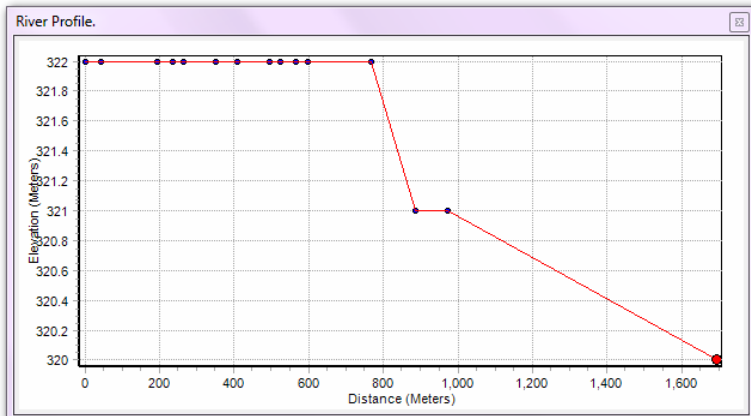

Tramo 14.

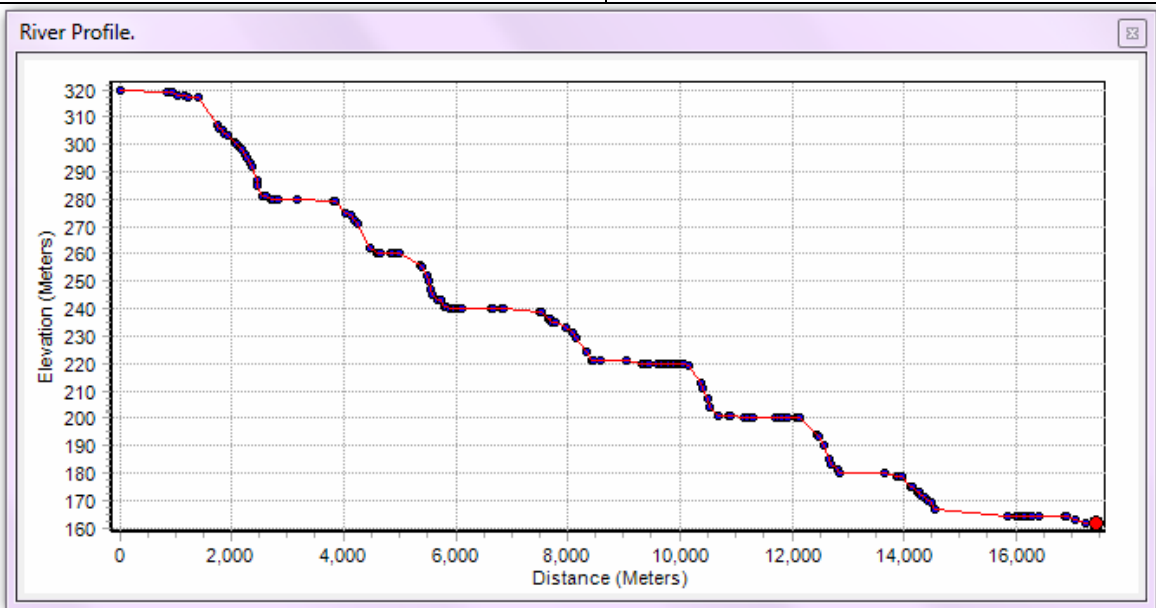

Tramo 15.

Figura 32. Perfiles longitudinales de la red hidrográfica de la Cuenca del Río Toachi.

A continuación se presenta el resultado del análisis de los índices morfométricos del relieve, que no fueron generados por la herramienta HEC-GeoHMS, y que fueron realizados en forma manual usando el programa Excel ${ }^{\circledR}$ :

En la Tabla 37, se presenta el resultado de los parámetros morfométricos del relieve de las subcuencas del área de estudio, donde se observa que la subcuenca 7 presenta la mayor 
longitud axial con $19.123 \mathrm{~m}$, y la subcuenca 2 la menor longitud con 3.478,6 m que además posee el menor ancho promedio con $2.033,6 \mathrm{~m}$ y la subcuenca 4 el mayor ancho con $8.422,8 \mathrm{~m}$. La subcuenca 5 presenta la mayor altura media con $1.248 \mathrm{~m}$ y la subcuenca $7 \mathrm{la}$ menor altura con 483,5 m.

Tabla 37. Resumen de los parámetros de relieve a nivel subcuenca.

\begin{tabular}{|c|c|c|c|}
\hline Subcuencas & $\begin{array}{c}\text { Longitud Axial } \\
(\mathbf{m})\end{array}$ & $\begin{array}{c}\text { Ancho Promedio } \\
\mathbf{( m )}\end{array}$ & $\begin{array}{c}\text { Altura Media } \\
(\mathbf{m})\end{array}$ \\
\hline 1 & 6085,69 & 6401,48 & 798,0 \\
\hline 2 & 3478,60 & 2033,58 & 657,5 \\
\hline 3 & 7469,41 & 6181,09 & 1055,5 \\
\hline 4 & 16890,87 & 8422,85 & 1158,0 \\
\hline 5 & 18743,00 & 5711,64 & 1248,0 \\
\hline 6 & 10917,82 & 4022,26 & 908,5 \\
\hline 7 & 19122,96 & 5240,79 & 483,5 \\
\hline
\end{tabular}

En la Tabla 38, se presenta el resultado de los parámetros morfométricos de forma de las subcuencas del área de estudio, donde se observa que las subcuencas 2 y 3 presentan índices de compacidad $(\mathrm{Cg})$ entre los valores de 1,50 - 1,75 con lo cual su forma es oblonga y los índices de las subcuencas $1,4,5,6$ y 7 tienen valores mayores a 1,75 correspondiendo a la forma rectangular oblonga. Esto significa que las subcuencas 2 y 3 tienen mayor circularidad que el resto de las subcuencas lo que incrementa su torrencialidad.

Tabla 38. Resumen de los parámetros de forma a nivel subcuenca.

\begin{tabular}{|c|c|c|}
\hline Subcuencas & $\begin{array}{c}\text { Coeficiente } \\
\text { Gravelius (Cg) }\end{array}$ & $\begin{array}{c}\text { Factor de } \\
\text { Forma (IF) }\end{array}$ \\
\hline 1 & 1,83 & 1,05 \\
\hline 2 & 1,64 & 0,58 \\
\hline 3 & 1,70 & 0,83 \\
\hline 4 & 1,87 & 0,50 \\
\hline 5 & 2,24 & 0,30 \\
\hline 6 & 2,00 & 0,26 \\
\hline 7 & 2,65 & 0,27 \\
\hline
\end{tabular}

Se observa que las subcuencas 1 y 3 tienen índices cercanos a 1, caracterizadas por poseer formas redondeadas, mientras que las demás subcuencas 2, 4, 5, 6 y 7 muestran factores 
de forma menores a 1 representado formas alargadas, lo que confirma los valores del índice de compacidad. Esto quiere decir que las subcuencas 1 y 3 presentan crecidas más significativas, mayor torrencialidad y por tanto mayor poder erosivo, por el contrario el resto de subcuencas presentan crecidas de menor magnitud, menor torrencialidad y por tanto menor poder erosivo.

En la Tabla 39, se presentan los resultados de los cálculos realizados a los parámetros relativos a la red hidrográfica a nivel subcuenca, donde se observa que la subcuenca 6 , cuya superficie es de $62 \mathrm{~km}^{2}$, presenta un densidad de drenaje de 0,14 , superior al resto de subcuencas, lo que significa que existe predominio del escurrimiento ante la infiltración, aumentando el poder erosivo y los eventos torrenciales. En cambio, el resto de subcuencas un total $441,77 \mathrm{~km}^{2}$ de superficie, tienen valores de densidad de drenaje bajo, predominando la infiltración ante el escurrimiento, disminuyendo el poder erosivo y por tanto los eventos torrenciales. La columna "Pendiente media del cauce" (en la Tabla 39) es la misma que generó el HEC-GeoHMS presentada en porcentaje (\%).

Tabla 39. Resumen de los parámetros relativos a la red de drenaje a nivel subcuenca.

\begin{tabular}{|c|c|c|c|}
\hline Subcuencas & $\begin{array}{c}\text { Densidad de } \\
\text { drenaje (\%) }\end{array}$ & $\begin{array}{c}\text { Pendiente media } \\
\text { del cauce } \\
\text { (\%) }\end{array}$ & $\begin{array}{c}\text { Tiempo de } \\
\text { concentración } \\
\text { (h) }\end{array}$ \\
\hline 1 & 0,02 & 10,3 & 0,8 \\
\hline 2 & 0,05 & 5,3 & 0,6 \\
\hline 3 & 0,02 & 12,2 & 0,9 \\
\hline 4 & 0,01 & 8,8 & 1,7 \\
\hline 5 & 0,02 & 1,7 & 2,5 \\
\hline 6 & 0,14 & 2,2 & 1,6 \\
\hline 7 & 0,02 & 0,9 & 2,9 \\
\hline
\end{tabular}

En la misma Tabla se observa que los tiempos de concentración, tienen relación directa con las longitudes de los ríos que atraviesan las subcuencas respectivas, donde en relación con las longitudes axiales de la Tabla 37 , se visualiza que la subcuenca 7 tiene el mayor tiempo de concentración, luego la subcuenca 5, 4, 6, 3, 1 y el menor tiempo la subcuenca 2.

A partir de estos resultados, se determina que las subcuencas del área de estudio tienen forma alargada, presentan valores de densidad de drenaje bajos con crecientes de menor magnitud y menor probabilidad de ocurrencia de eventos torrenciales, lo que significa un bajo poder erosivo. Los tiempos de concentración son relativamente largos debido a la atenuación del caudal de salida, por lo que predomina la infiltración ante el escurrimiento, debiendo recorrer el agua longitudes de laderas más largas sobre el cauce, siendo la velocidad de escurrimiento baja. 


\section{3.- Análisis y Procesamiento de Datos Meteorológicos}

\subsubsection{Precipitaciones}

El área de estudio se caracteriza por ubicarse entre las zonas muy húmedo (2000-3000 mm anuales) a lluvioso (superior a $3000 \mathrm{~mm}$ anuales) (CLIRSEN, 2009) ${ }^{14}$. La zona de mayor altura anual de precipitaciones se presenta en la zona media alta, en las estribaciones de la Cordillera Occidental. La cantidad de lluvia decrece a medida que la altura aumenta y disminuye. En la Figura 33 se muestra la distribución de la precipitación media anual de la Cuenca del Río Toachi, obtenida por el método de las Isoyetas.

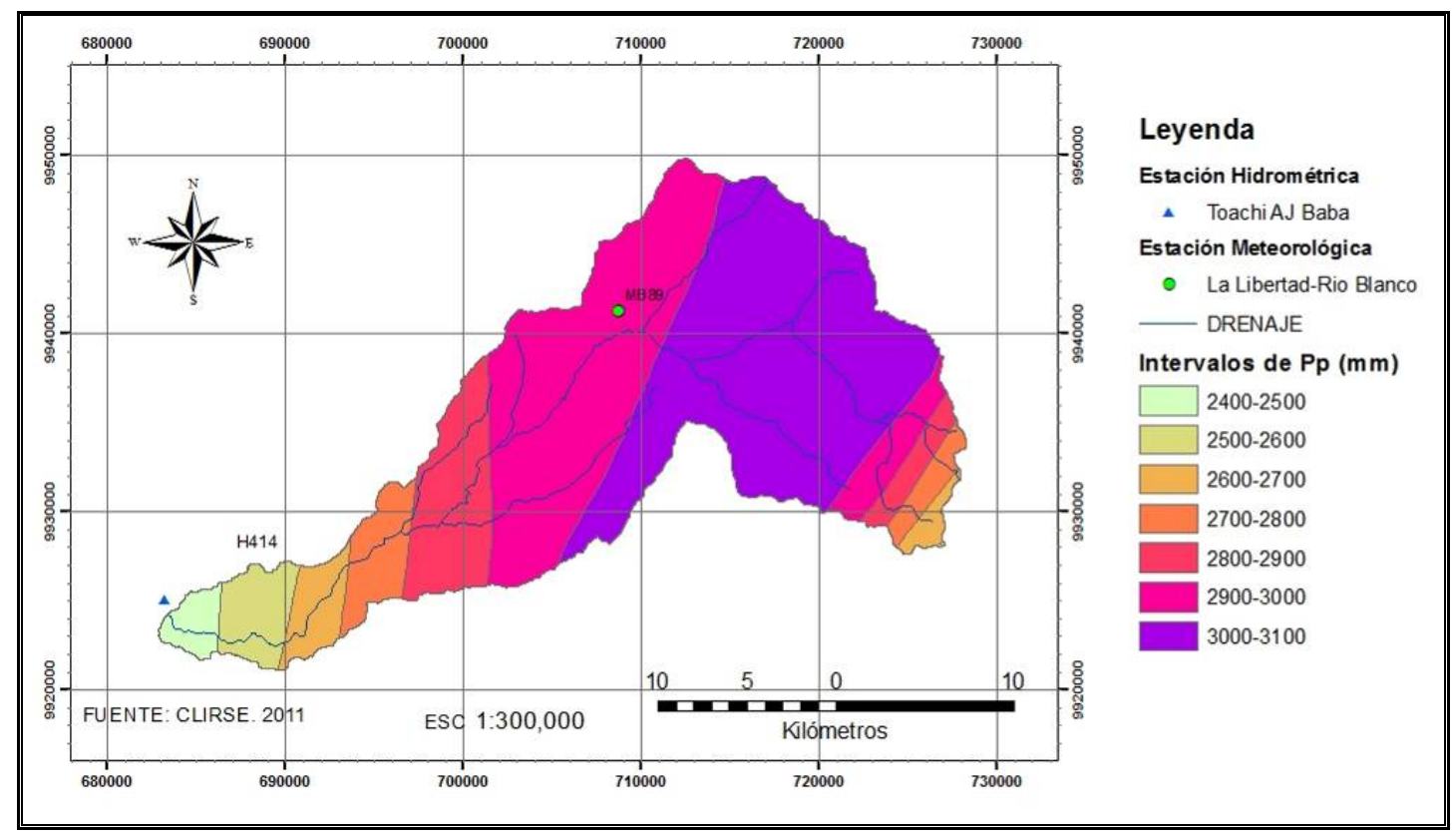

Figura 33. Distribución de la precipitación media anual. Fuente: CLIRSEN, 2009.

En la Tabla 40 se presenta el cálculo realizado para obtener la precipitación media anual de la Cuenca del Río Toachi, siendo de $2.929,1 \mathrm{~mm}$, en la cual se observa que el $72,8 \%$ de la superficie se encuentra en los intervalos de 2900 a $3100 \mathrm{~mm}$.

Tabla 40. Cálculo de la precipitación media anual.

\begin{tabular}{|c|c|c|c|c|c|}
\hline No & $\begin{array}{l}\text { Intervalo de } \\
\text { Isoyetas }\end{array}$ & $\begin{array}{l}\text { Área } \\
\left(\mathrm{km}^{2}\right)\end{array}$ & $\begin{array}{l}\text { Pp media } \\
(\mathrm{mm})\end{array}$ & $\begin{array}{c}\text { Área } \\
\text { (\%) }\end{array}$ & $\begin{array}{l}\text { Área*Ppmedia } \\
\left(\mathrm{km}^{2 *} \mathrm{~mm}\right)\end{array}$ \\
\hline 1 & $2400-2500$ & 9,80 & 2450 & 1,95 & \multirow{7}{*}{2929,1} \\
\hline 2 & $2500-2600$ & 20,26 & 2550 & 4,03 & \\
\hline 3 & $2600-2700$ & 21,04 & 2650 & 4,18 & \\
\hline 4 & $2700-2800$ & 29,95 & 2750 & 5,96 & \\
\hline 5 & $2800-2900$ & 55,70 & 2850 & 11,07 & \\
\hline 6 & $2900-3000$ & 162,29 & 2950 & 32,27 & \\
\hline 7 & $3000-3100$ & 203,92 & 3050 & 40,54 & \\
\hline
\end{tabular}

\footnotetext{
${ }^{14}$ Clasificación propuesta por Pierre Pourrut
} 


\section{Precipitaciones Anuales ${ }^{15}$}

La variación de la precipitación media anual (línea roja) registrada en la estación meteorológica Las Pampas durante los años 1990-2010 (veinte años), muestra una leve tendencia a disminuir las lluvias en el tiempo. El rango en el que se observa la precipitación media anual varía entre $1351,6 \mathrm{~mm}$ a $3081,9 \mathrm{~mm}$, siendo la media de $2100 \mathrm{~mm}$ (línea amarilla) (ver Figura 34).

Como puede verse en la misma Figura, los años en los cuales no se alcanzó los $2100 \mathrm{~mm}$ fueron en los períodos de 1990 a 1992, de 1995 a 1996, del 2001 al 2005, el 2007 y 2010 , siendo la mínima precipitación anual el año de 1990 con 1351,6 mm. Los años que sobrepasaron los $200 \mathrm{~mm}$ fueron de 1993 a 1994, de 1997 al 2000, el 2006 y del 2008 al 2009, siendo el año de 1997 el que registro la máxima precipitación anual con 301,9mm.

Si bien la Figura 34 muestran una variación de las lluvias estas son sólo tendencias, con grandes variaciones interanuales, típico de las lluvias anuales de estas regiones. La diferencia entre el valor máximo de 3081,9 ocurrido en el año 1997 y el valor mínimo de 1351,6 ocurrido en el año de 1990, muestra un amplio intervalo de variación en la precipitación total anual produciendo períodos de humedad y sequía.

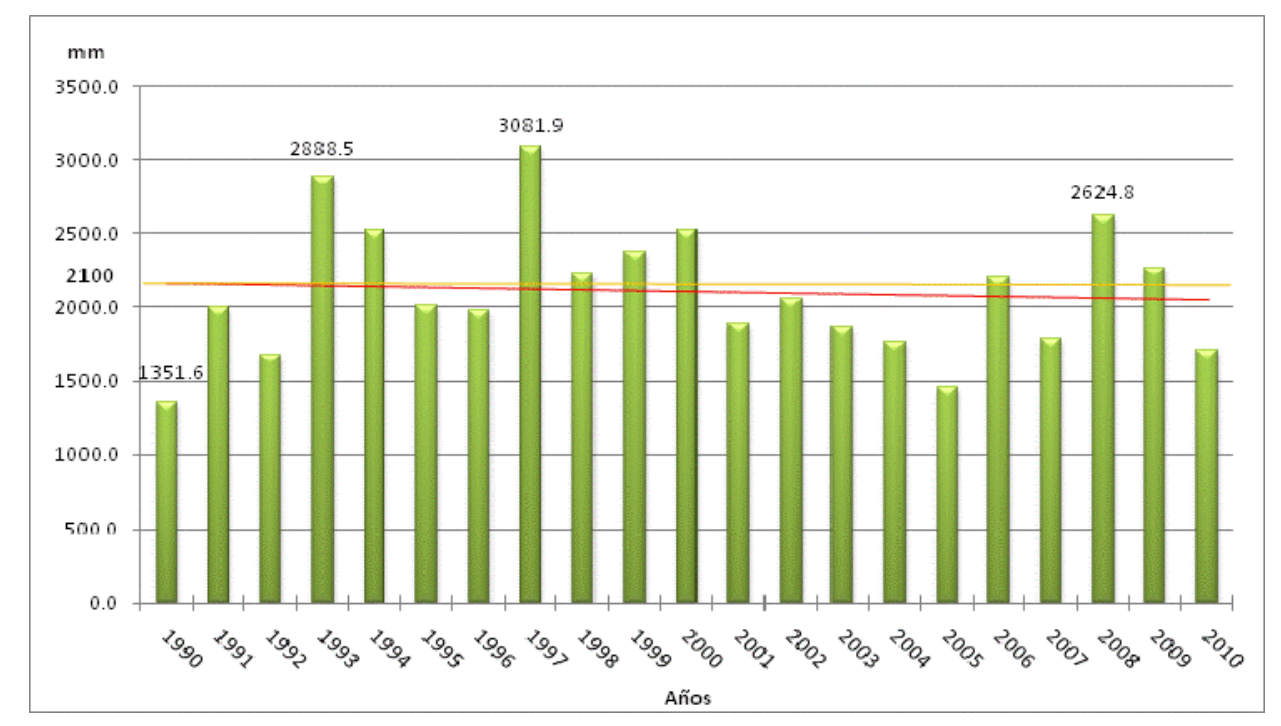

Figura 34. Precipitación Total Anual (mm). Estación Las Pampas.

El análisis del período de registro de la precipitación media anual en la estación meteorológica de La Libertad (5 años), es muy susceptible a interpretaciones debido a que ésta representa la cuarta parte del análisis de las otras estaciones (20 años). Sin embargo con el fin de aplicar la metodología planteada, en forma general, podemos indicar que la variación en el tiempo de la precipitación media anual (línea negra) tiene una fuerte tendencia a aumentar las lluvias (ver Figura 35), El rango de la precipitación media varia de $1031,9 \mathrm{~mm}$ a $3594,1 \mathrm{~mm}$. El valor medio de la precipitación anual es de $2750 \mathrm{~mm}$ de lluvia (línea amarilla).

\footnotetext{
${ }^{15}$ Fuente: INAMHI
} 
Si se analiza la precipitación total anual en el período $2005-2010$ se puede observar que la diferencia entre el valor mínimo de 1031,9 mm ocurrido en el año 2005 con el valor máximo de $3594,1 \mathrm{~mm}$ de lluvia registrado en el año 2008, muestra un gran intervalo de variación.

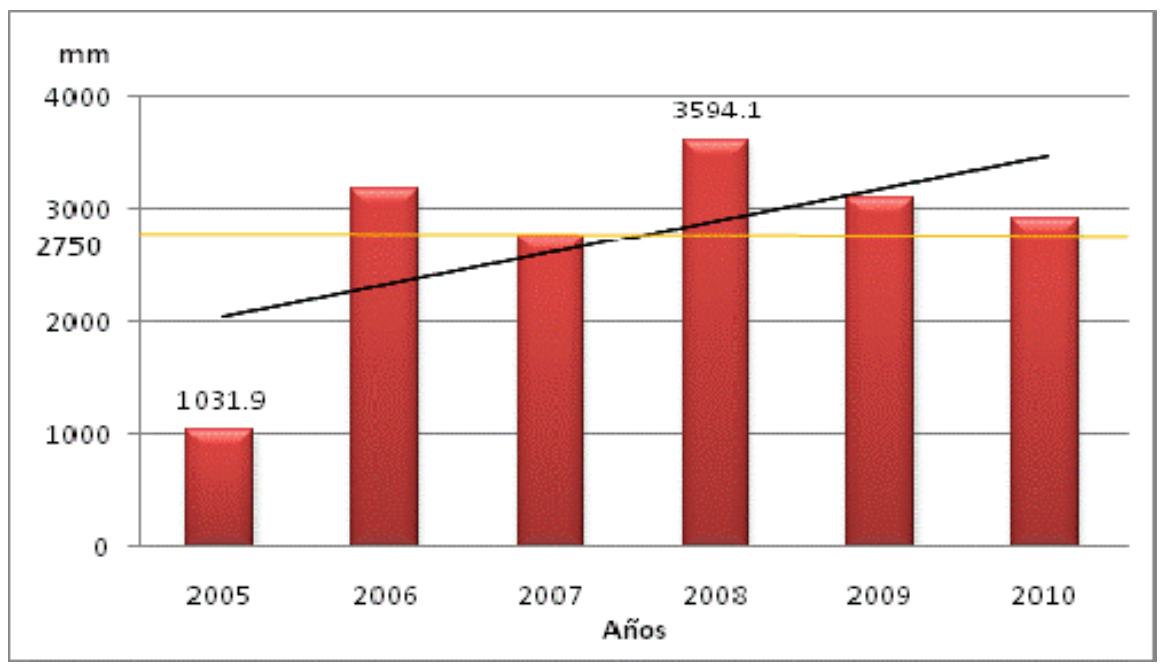

Figura 35. Estación La Libertad. Precipitación Total Anual (mm)

La variación de la precipitación media anual (línea roja) registrada en la estación meteorológica Puerto Ila (ver Figura 36) durante el período 1990-2010, muestra una fuerte tendencia a disminuir las lluvias en el tiempo, el rango de variación en el que se presenta está entre $1144,4 \mathrm{~mm}$ a $6061,4 \mathrm{~mm}$. La media de la precipitación es $2700 \mathrm{~mm}$ (línea amarilla).

Como puede verse en la Figura 36, los años en los cuales no alcanzó los $2700 \mathrm{~mm}$ fueron en los períodos de 1990 a 1991, de 1995 a 1996, el 2001, del 2003 al 2005, el 2007 y del 2009 al 2010, ocurriendo la mínima precipitación anual el año de 2009 con 1144,4 mm. Los años que sobrepasaron los 2700 mm fueron los períodos de 1992 a 1994, de 1997 al 2000, los años 2002, 2006 y 2008, registrándose la máxima acumulación de lluvia el año 1997 con $6061,4 \mathrm{~mm}$.

Si se analiza la precipitación total anual se puede observa que en los últimos 20 años la tendencia de la precipitación disminuye fuertemente a lo largo del tiempo. La diferencia entre el valor máximo de 6061,4 ocurrido en el año 1997 y el valor mínimo de 1144,4 ocurrido en el año 2009, muestran una variación muy amplia de $5917,0 \mathrm{~mm}$ lo cual marca períodos extremos muy húmedos (exceso de lluvias) y muy seco (déficit de lluvias). 


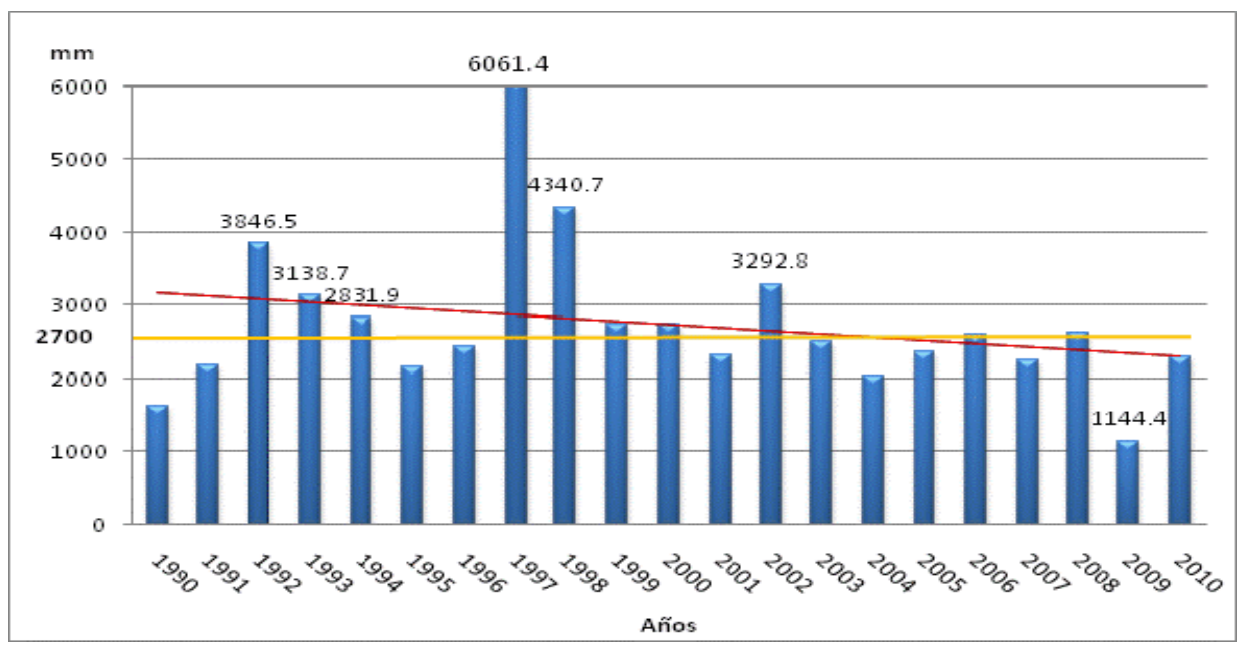

Figura 36. Estación Puerto lla. Precipitación Total Anual (mm)

Como resumen del análisis de las precipitaciones medias anuales, ver Figura 37, en el año 1997 ocurrió un evento extraordinario de aumento de lluvias en las estaciones Las Pampas y Puerto lla coincidente con el fenómeno del Niño, según CLIRSEN (2009).

En las estaciones analizadas, existen iguales tendencias en los períodos lluviosos durante los años de 1992 a 1993, de 1997 al 2000, 2006 y 2008; mientras que durante el período seco la tendencia se mantiene durante los años de 1990 a 1991, de 1995 a 1996, del 2001 al 2005 , el 2007 y 2010.

En el año 1992 y 2002, en la estación Puerto lla, se registra un aumento considerable de las precipitaciones a diferencia que la estación Las Pampas registra para el año 1992 una disminución y para 2002 se mantiene casi constante en el tiempo desde 2001 al 2005.

En general, las tendencias de la precipitación media anual en las tres estaciones tienen coincidencia en los períodos de aumento de precipitaciones y déficit de lluvias.

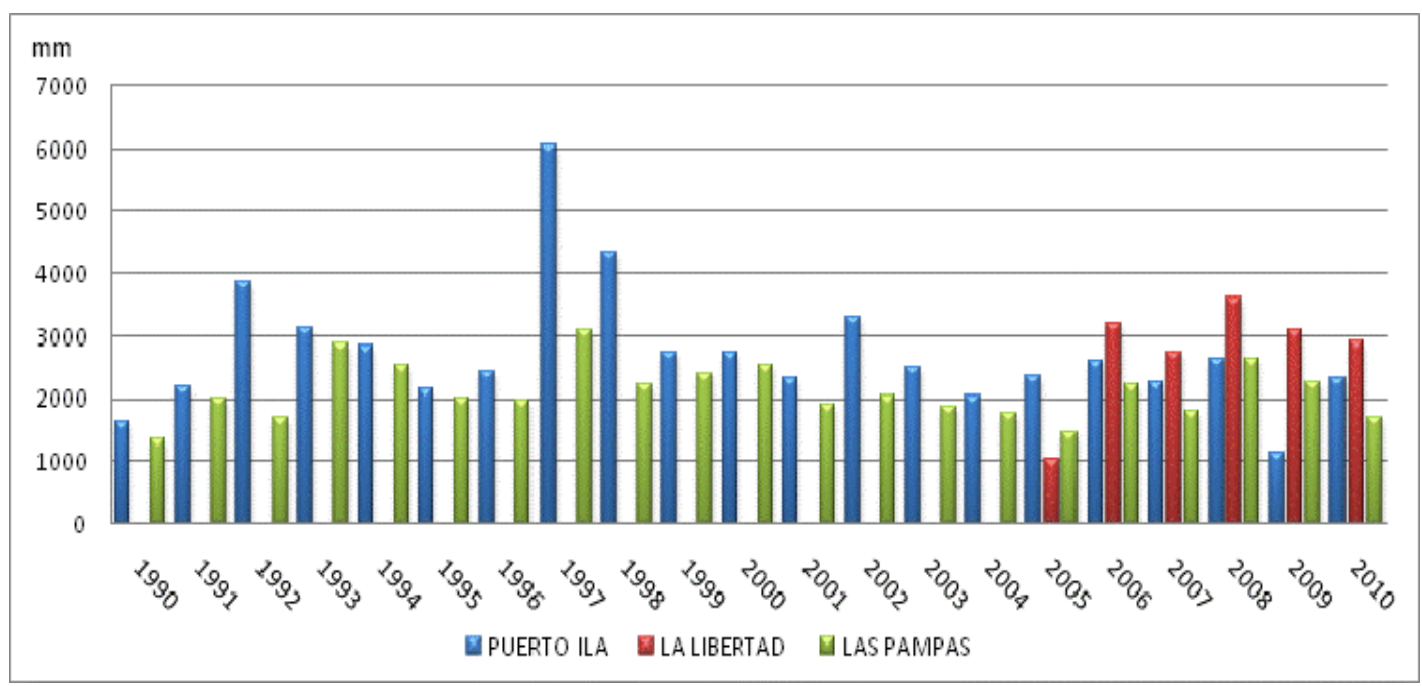

Figura 37. Precipitación total anual de las tres estaciones $(\mathrm{mm})$ 


\section{Precipitaciones Medias Mensuales}

\section{Estación Puerto lla}

Las mayores precipitaciones medias mensuales en la estación meteorológica Puerto lla durante el período de análisis 1990-2010, se presentaron entre los meses de diciembre a mayo considerado como época o estación lluviosa, y las menores precipitaciones ocurrieron durante el período de junio a noviembre llamada época seca o de estiaje, ver Figura 38. Los meses de diciembre y mayo se consideran de "transición" entre la época seca a lluviosa y de la estación lluviosa a seca respectivamente.

El mes con mayor cantidad de precipitación media registrada fue marzo con $521,1 \mathrm{~mm}$, mientras que el mes con menor cantidad de lluvias fue agosto con $38,3 \mathrm{~mm}$. El intervalo de variación pluviográfica del período de registro es de $483 \mathrm{~mm}$.

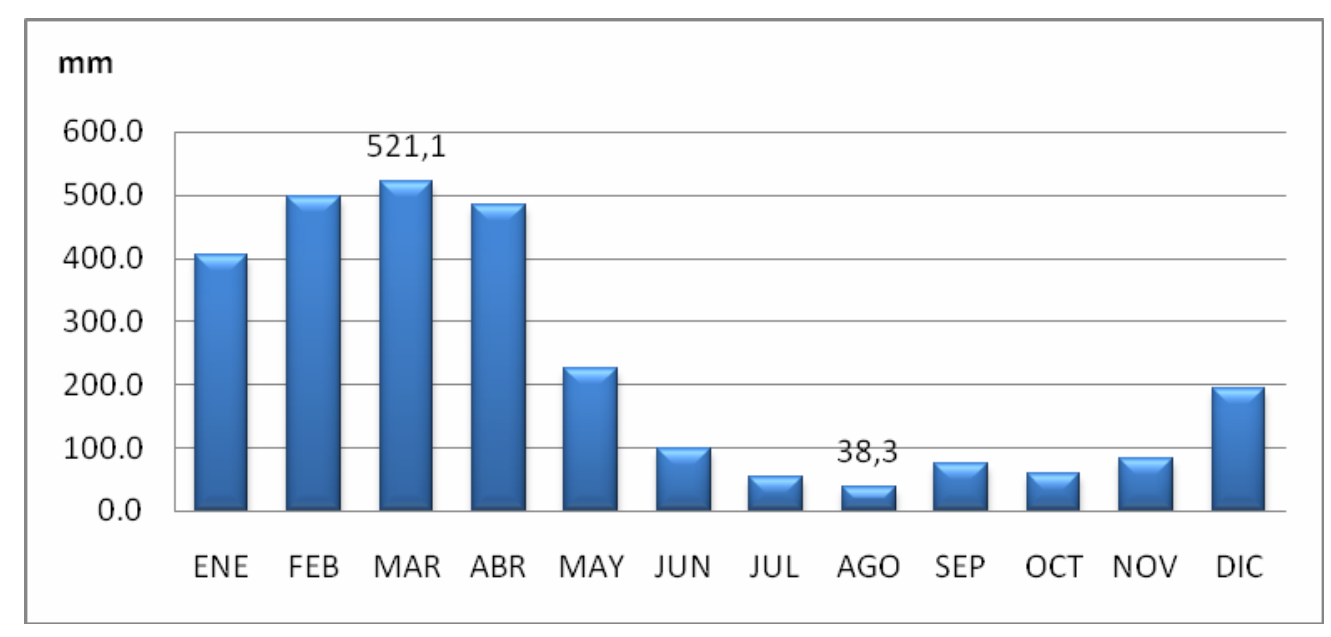

Figura 38. Estación Puerto lla. Precipitación Media Mensual (mm)

\section{Estación La Libertad}

En la estación meteorológica La Libertad durante el período de observación 2005-2010, se registró la mayor cantidad de precipitación media caída entre los meses de diciembre a mayo que se denomina estación lluviosa, y durante los meses de junio a noviembre ocurrieron las menores precipitaciones llamada época seca, ver Figura 39. Los meses de diciembre y mayo se consideran de transición o cambio de la estación seca a la estación lluviosa y de la época lluviosa a la seca respectivamente.

El mes con mayor registro de precipitación media caída es marzo con 460,2 mm seguido de febrero con 453,1 $\mathrm{mm}$ y el mes con menor registro de precipitación fue agosto con 65,.9 $\mathrm{mm}$. El intervalo de variación entre el mes más lluvioso y el más seco es de $394 \mathrm{~mm}$. 


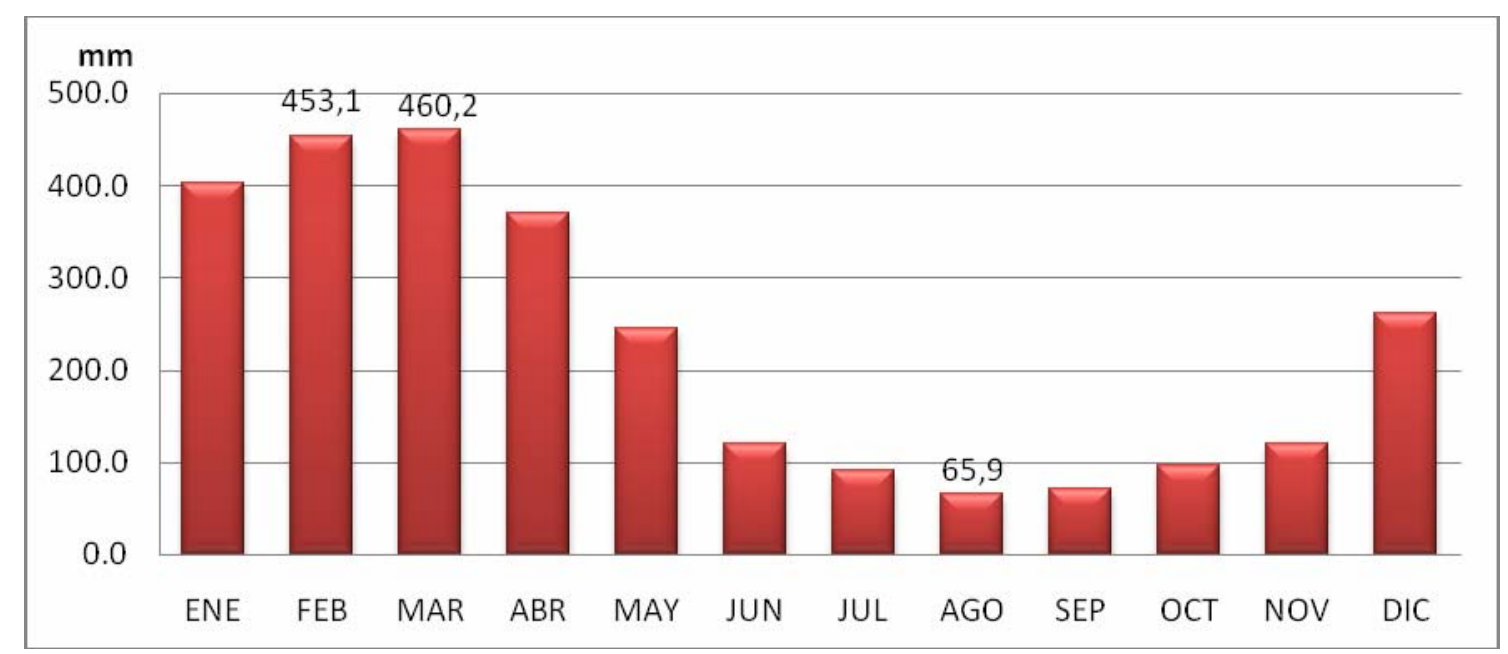

Figura 39. Estación La Libertad. Precipitación Media Mensual (mm)

\section{Estación Las Pampas}

Si se analiza el comportamiento de las precipitaciones medias a lo largo del año de la estación Las Pampas teniendo en cuenta los datos registrados del período 1990-2010, se puede observar que durante los meses de diciembre a mayo ocurrieron los mayores registros de precipitación media denominada época húmeda o lluviosa, y entre los meses de junio a noviembre se produjeron las menores precipitaciones, llamada estación seca o de estiaje, ver Figura 40. Los meses de diciembre y mayo se consideran de "transición o cambio" de la estación seca a la estación lluviosa y de la época lluviosa a la seca respectivamente.

El mes con mayor registro de cantidad de precipitación media mensual fue febrero con $346,3 \mathrm{~mm}$ de lluvia, mientras que el mes con menor cantidad de precipitación fue julio con $45,9 \mathrm{~mm}$, demarcando un intervalo de variación de $300 \mathrm{~mm}$ entre el mes más lluvioso y el mes con menos cantidad de lluvia.

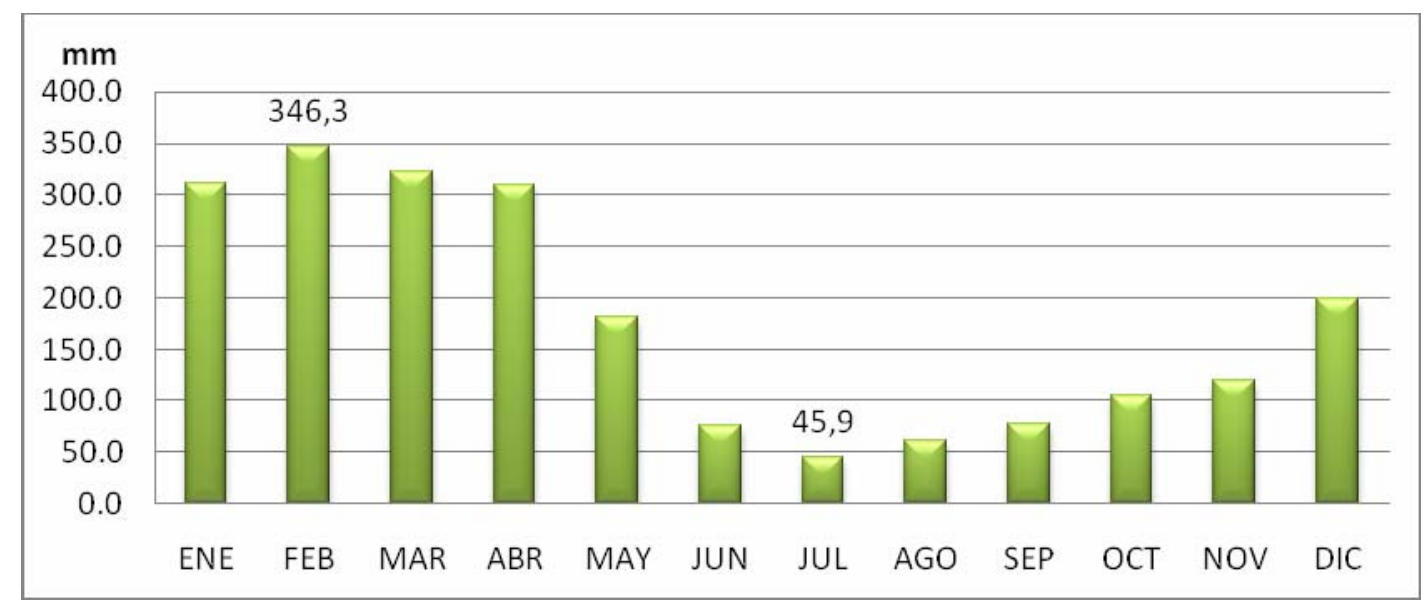

Figura 40. Estación Las Pampas. Precipitación Media Mensual (mm) 
Un análisis general del comportamiento de la precipitación media mensual de las tres estaciones en estudio, permite definir que existe una tendencia similar de las lluvias a lo largo del año en los tres pluviógrafos que representan las tres zonas de la cuenca, y por similitud a toda la cuenca ver Figura 41.

El período de mayor cantidad de precipitación registrada es de diciembre a mayo y de menor cantidad de lluvias es de junio a noviembre, el primer período se denomina húmedo o lluvioso por el aumento de lluvia registrada (intensidad y frecuencia) y el segundo período se lo conoce como seco o estiaje debido a la disminución de las lluvias. El mes más lluvioso es marzo y el menos es agosto.

Como se puede observar en el Figura 41, durante el período lluvioso la estación con mayor cantidad de precipitación caída registrada fue Puerto lla (zona baja), seguido de La Libertad (zona media) y luego Las Pampas (zona alta). Mientras que en período seco la estación La Libertad registra la mayor cantidad de precipitación caída.

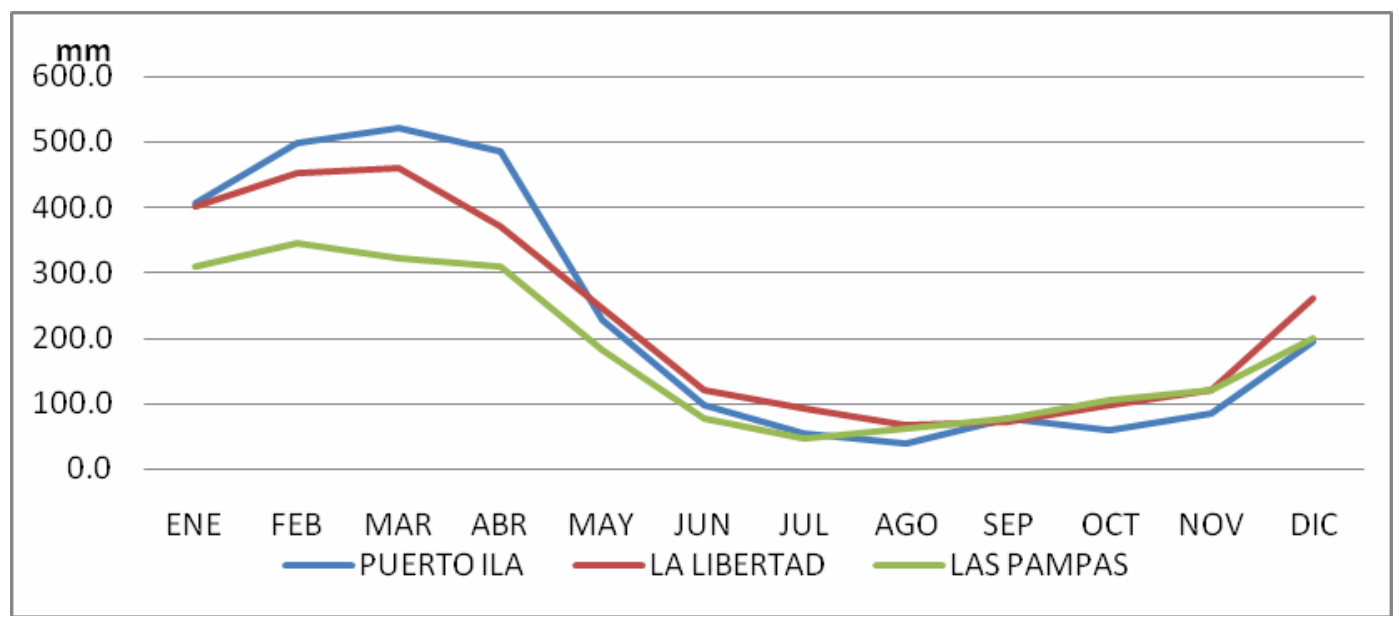

Figura 41. Precipitaciones Medias Mensuales 1990-2010 (La Libertad de 2005 a 2010)

\section{Precipitaciones Totales Mensuales}

\section{Estación Las Pampas período de 1990-2010}

Si se analiza más detalladamente la Figura 42, lo que ocurre en cada mes a lo largo de los años del período de análisis, puede verse que los meses de enero y diciembre muestran una tendencia en aumento de las precipitaciones, los meses de mayo y junio mantienen un comportamiento constante y el resto de los meses presenta tendencia de disminución de las Iluvias. A continuación se presenta una descripción del análisis realizado en forma mensual:

- Enero presenta una tendencia muy marcada de aumento de las lluvias, que oscila en el rango de $200 \mathrm{~mm}$ a $400 \mathrm{~mm}$, sin tener en cuenta los años de 1994 y 2009 con valores extremos de lluvia con $500 \mathrm{~mm}$ y $533 \mathrm{~mm}$ respectivamente, y los años 2002 y 2005 con valores de déficit de lluvias con $150 \mathrm{~mm}$ y 162 , respectivamente. 
- Febrero tiene un comportamiento de disminución de las lluvias durante el período de análisis, oscila entre los $200 \mathrm{~mm}$ y $500 \mathrm{~mm}$ con excepción de los registros de 1993 y 2006 que registraron un exceso de lluvias con valores de $544 \mathrm{~mm}$ y $551 \mathrm{~mm}$ respectivamente, siendo los más altos durante el período de observación; y 2010 que registró déficit de precipitaciones con valor de $136 \mathrm{~mm}$.

- Marzo tiene un comportamiento constante a lo largo de los años en el cual se mantiene en un rango de 300mm a 500mm, con excepción de los años de 1994 y 2003 que registraron un aumento y déficit de lluvias de $514 \mathrm{~mm}$ y $192 \mathrm{~mm}$ respectivamente.

- Abril se caracteriza por tener una tendencia muy marcada de disminución de las precipitaciones a lo largo del período de estudio. Tiene un rango de $200 \mathrm{~mm}$ a $400 \mathrm{~mm}$, sin tener en cuenta los años 1993 y 1994 que llegaron a valores cercanos a 500mm.

- Mayo tiene una tendencia a mantenerse constante durante el período de análisis en un rango de $100 \mathrm{~mm}$ a $300 \mathrm{~mm}$, presenta un valor de excedente de lluvia en el año 2000 con un valor de 450mm; y dos valores de déficit de lluvias en 1992 y 2005 con valores de $47,8 \mathrm{~mm}$ y $64,4 \mathrm{~mm}$ respectivamente.

- Junio se manifiesta con una ligera tendencia a disminuir las lluvias con valores que oscilan entre $20 \mathrm{~mm}$ y $150 \mathrm{~mm}$, a excepción del año 1997 que presenta un valor extremo de de 219,3mm, anormal para esta época del año (seco). A partir de 1998 los valores anuales han fluctuado sobre y bajo la línea de tendencia con un intervalo de variación de $110 \mathrm{~mm}$, los últimos cuatro años ha mantenido la tendencia

- Julio se presenta con una leve tendencia a disminuir las precipitaciones con intervalos de variaciones muy pronunciadas entre un año y el siguiente. El rango de lluvias varía entre $10 \mathrm{~mm}$ y $80 \mathrm{~mm}$, con excepción de los años 1994 y 2005 que registraron valores de $5,7 \mathrm{~mm}$ y $7,2 \mathrm{~mm}$ respectivamente.

- Agosto al igual que julio se manifiesta con una ligera tendencia a disminuir las lluvias, con valores de $10 \mathrm{~mm}$ a $100 \mathrm{~mm}$. Las variaciones anuales son pronunciadas observando una tendencia muy irregular para el período estacional. En los años 92-93 se mantuvo constante $120 \mathrm{~mm}$, en 1995 y 2008 fueron años con valores que llegaron a $120 \mathrm{~mm}$ y $138,2 \mathrm{~mm}$ respectivamente.

- El mes de septiembre presenta una ligera tendencia a disminuir las precipitaciones, oscilando entre $25 \mathrm{~mm}$ y $150 \mathrm{~mm}$, excepto el año de 1997 que llego a $274 \mathrm{~mm}$, siendo un valor anormal de exceso de lluvias para esta época del año.

- Octubre mantiene una ligera tendencia a disminuir las lluvias al igual que el mes de septiembre, con valores que oscilan entre $20 \mathrm{~mm}$ y $150 \mathrm{~mm}$, excepto el año de 1997 que llego a 345,8mm, coincidiendo como un registro anormal de excesos de lluvia para esta época del año.

- El mes de Noviembre se caracteriza por tener una tendencia a disminuir la cantidad de lluvias en un intervalo de variación de $50 \mathrm{~mm}$ a $250 \mathrm{~mm}$. Su máximo registro en el año de 1997 con un total de $450 \mathrm{~mm}$, el más alto de todo el período de observación.

- Diciembre presenta una ligera tendencia a aumentar la precipitación, con un comportamiento irregular que varía de $100 \mathrm{~mm}$ a $300 \mathrm{~mm}$. Se observan varios años que 
superaron este límite, siendo el año de 1993 que acumulo lluvias hasta 362,2mm y 1992 bajo a $32 \mathrm{~mm}$.
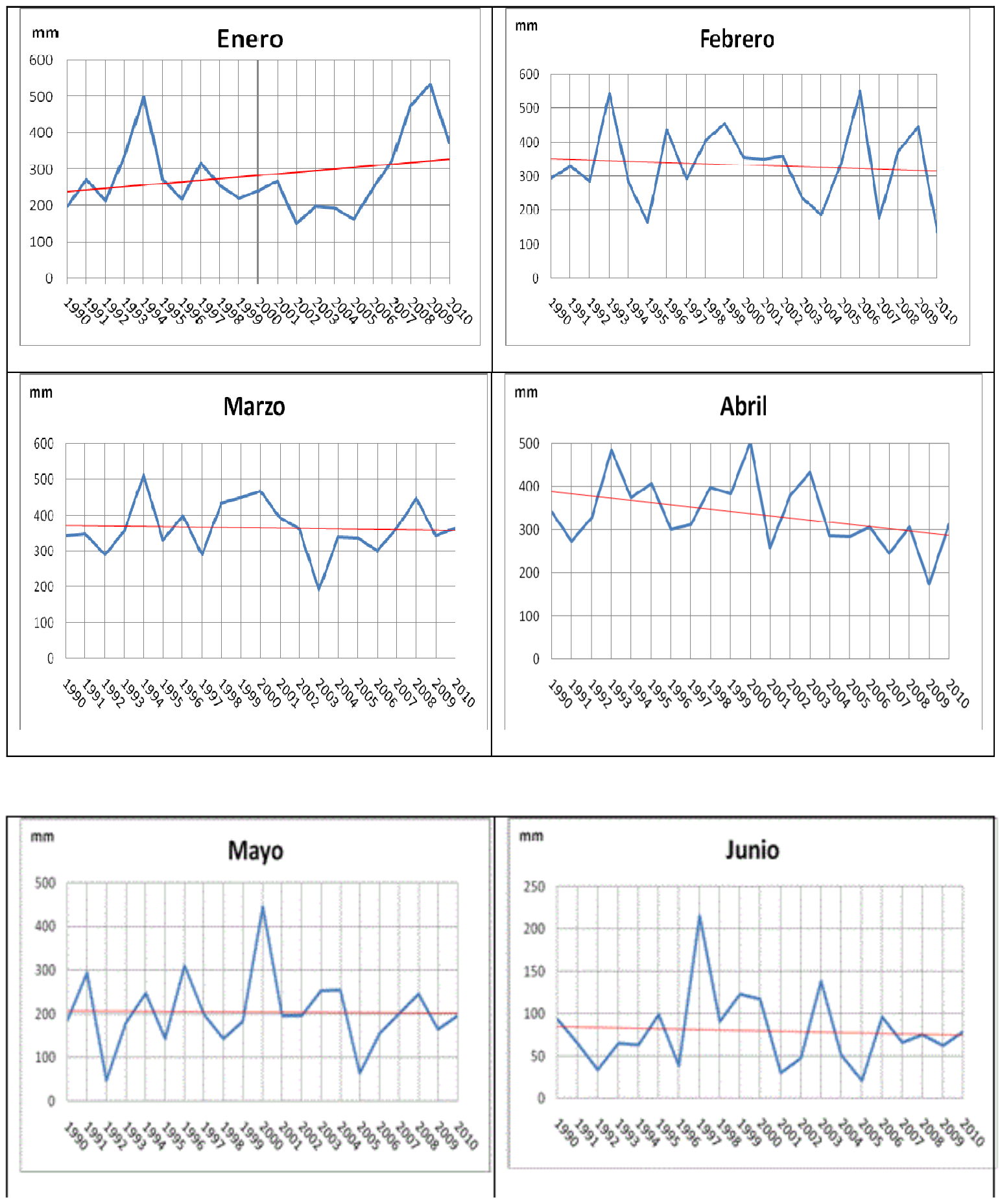

Figura 42. Precipitaciones Totales Mensuales Las Palmas, período 1990-2010 (cont.) 

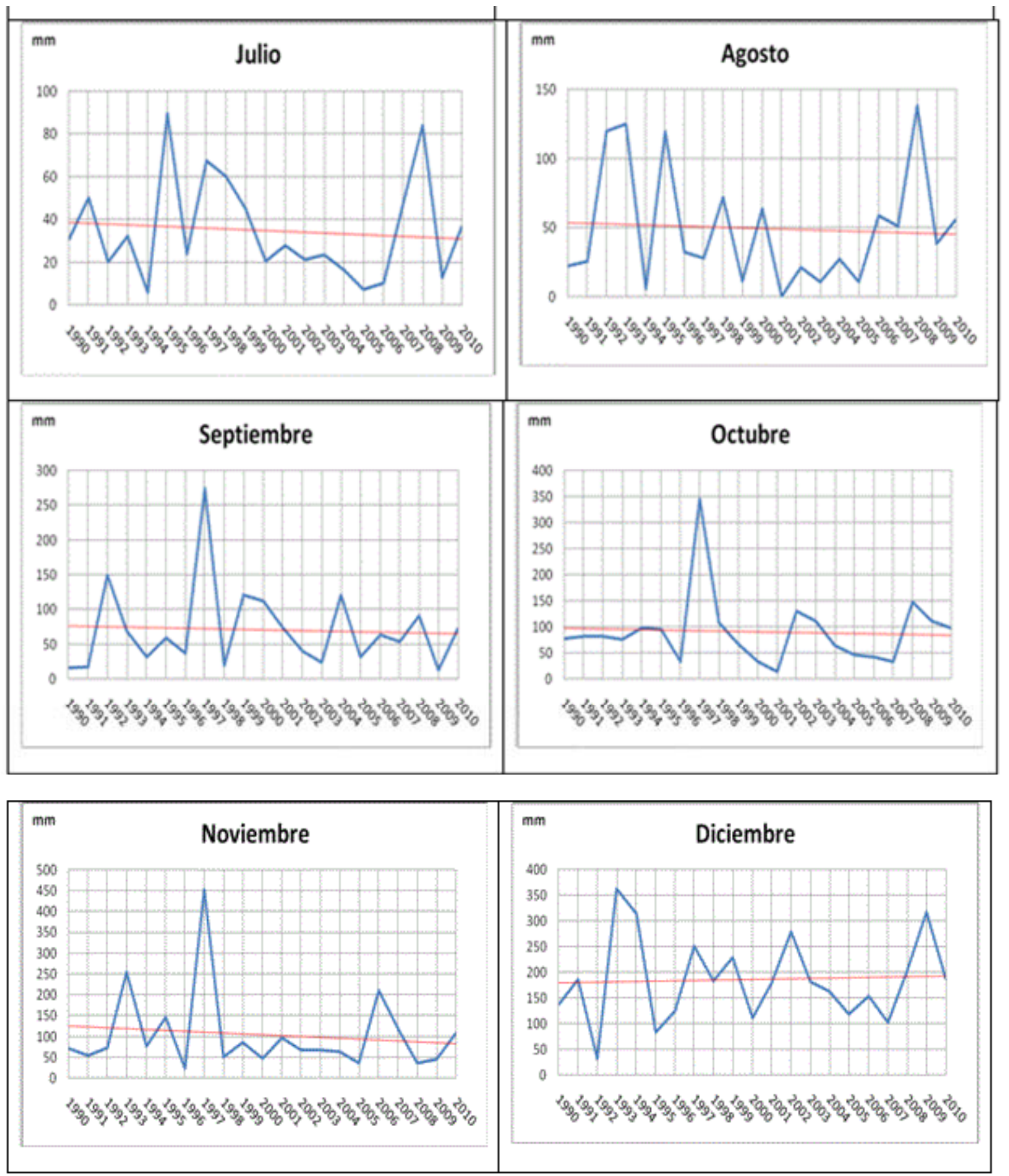

Figura 42. Precipitaciones Totales Mensuales Las Palmas, período 1990-2010.

En resumen, durante los últimos meses en la estación Las Pampas se presentó una tendencia a disminuir la altura de la precipitación debido a la presencia de un evento extraordinario que se dio en el año 1997, el cual acumuló gran cantidad de lluvia en los meses de septiembre, octubre y noviembre. 


\section{Estación La Libertad período de 2005-2010}

De acuerdo a lo mostrado en la Figura 43, del análisis realizado mes a mes a lo largo del período de registro, puede observarse que los meses de diciembre a mayo se produce un aumento en los valores de acumulación de lluvia anual, los meses de junio a noviembre presentan disminución de las lluvias anuales, el mes de agosto se mantiene un comportamiento casi constante durante el período. A continuación se presenta una descripción del análisis realizado en forma mensual:

- El mes de Enero presenta un marcado patrón de aumento de lluvias durante el período de observación, los valores oscilan entre $300 \mathrm{~mm}$ a $800 \mathrm{~mm}$, presenta dos años extremadamente opuestos, en el 2005 un valor de lluvia registrada de $34 \mathrm{~mm}$ y en el 2008 un valor de $810 \mathrm{~mm}$, siendo la máxima registrada durante el período de análisis.

- En Febrero también se muestra una marcada tendencia en aumento de la precipitación, con valores que oscilan entre $300 \mathrm{~mm}$ a $700 \mathrm{~mm}$ en el año 2008, excepto el año 2005 que presenta un valor de 19,8 mm. Se observa que la variación entre los valores anuales presenta un amplio intervalo.

- Marzo mantiene un patrón de aumento de precipitaciones con valores que oscilan entre $400 \mathrm{~mm}$ y $790 \mathrm{~mm}$, excepto el año 2005 que presenta un valor atípico de 19,8 mm.

- Abril se caracteriza por mantener un patrón de precipitaciones en aumento, entre valores de $200 \mathrm{~mm}$ a $570 \mathrm{~mm}$, el año 2005 registra $52 \mathrm{~mm}$, el período del 2006 al 2008 mantiene una tendencia casi constante de $500 \mathrm{~mm}$, en el 2009 desciende a $170 \mathrm{~mm}$ y en el 2010 llega a $570 \mathrm{~mm}$. Se observa una variación muy amplia de valores anuales.

- El mes de mayo mantiene la tendencia de aumento, en un rango de $100 \mathrm{~mm}$ a $400 \mathrm{~mm}$, excepto el año 2007 donde se presenta un valor máximo de $450 \mathrm{~mm}$ y el 2005 registra $87,2 \mathrm{~mm}$.

- Junio tiene una tendencia a disminuir la precipitación a lo largo de los años de observación, aunque puede observarse que durante el primer año su tendencia fue aumentar, luego se mantuvo constante en el 2006 y a partir de 2007 descendió hasta los $100 \mathrm{~mm}$.

- Julio presenta una patrón a disminuir las precipitaciones manteniéndose entre $50 \mathrm{~mm}$ y $150 \mathrm{~mm}$, a excepto del año 2005 que llego a $180 \mathrm{~mm}$ y 2006 que bajo a $20 \mathrm{~mm}$.

- El mes de agosto muestra una tendencia casi constante que se mantiene durante el período de observación, oscilando entre los valores de $40 \mathrm{~mm}$ a $100 \mathrm{~mm}$, es un período muy regular.

- Septiembre se caracteriza por mostrar una tendencia a disminuir las precipitaciones a lo largo del período. Su rango oscila entre $20 \mathrm{~mm}$ y $100 \mathrm{~mm}$, no presenta picos de máximas y de mínimas. Tiene una amplitud pluvial de $80 \mathrm{~mm}$.

- El mes de octubre al igual que septiembre, tiene una tendencia a disminuir la cantidad de lluvias, oscila en un rango que va de $50 \mathrm{~mm}$ a $200 \mathrm{~mm}$, aunque inicia con un aumento en la cantidad de lluvias hasta $200 \mathrm{~mm}$ en el año 2006, luego desciende progresivamente hasta los $50 \mathrm{~mm}$ en el año 2010. Tiene una amplitud pluvial de 150 $\mathrm{mm}$. 
- El mes de noviembre tiene una leve tendencia a disminuir la precipitación a lo largo del período de observación, a pesar que inicia el período con un aumento hasta $250 \mathrm{~mm}$ en el 2006, luego disminuye progresivamente hasta $40,5 \mathrm{~mm}$ en el 2009. Tiene un intervalo de variación pluvial de $100 \mathrm{~mm}$.

- Diciembre presenta una tendencia marcada al aumento de las precipitaciones mensuales, su rango varia de $150 \mathrm{~mm}$ a $490 \mathrm{~mm}$, con una amplitud pluvial de $340 \mathrm{~mm}$.
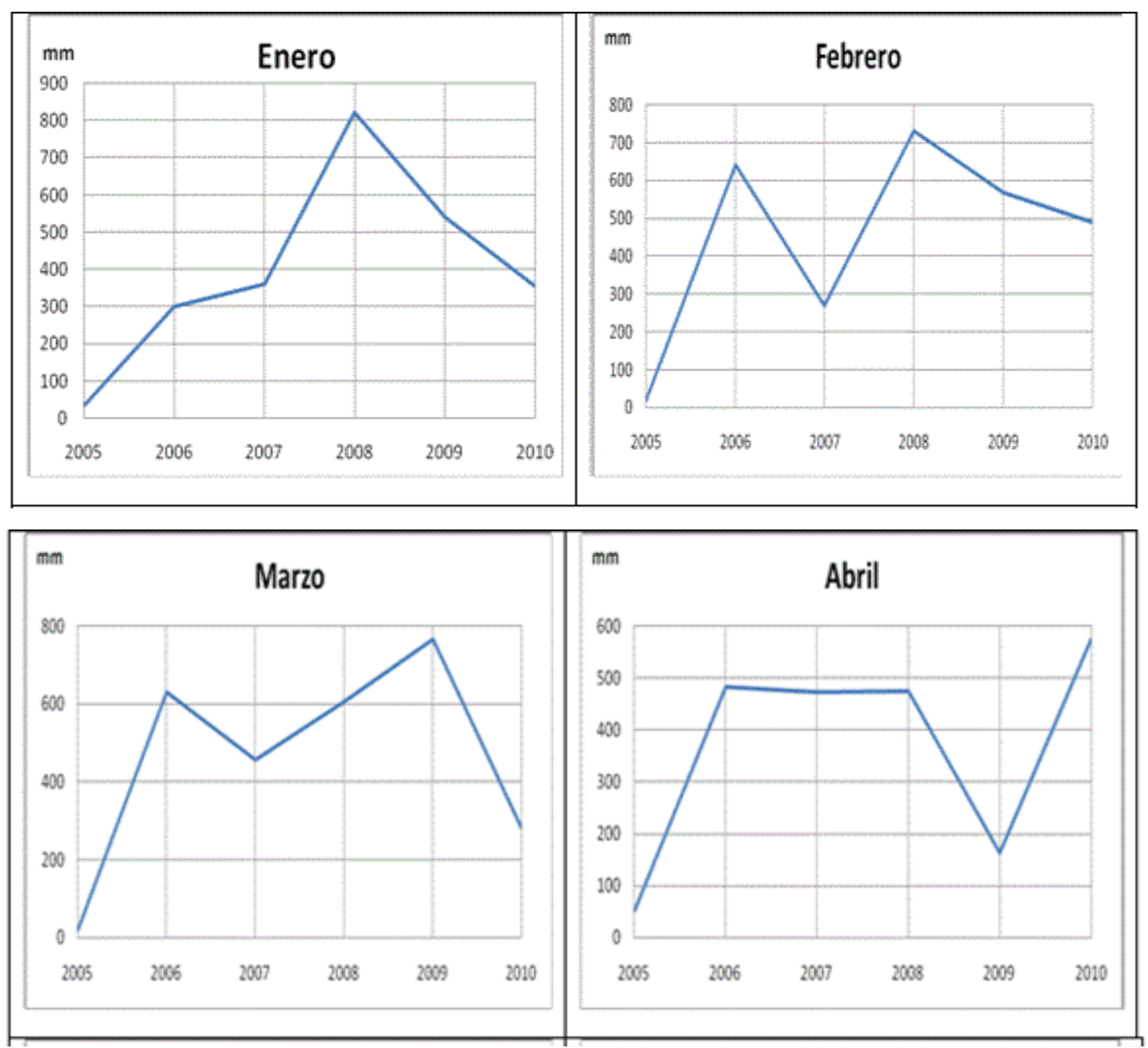

Figura 43. Precipitaciones Totales Mensuales La Libertad, período 2005-2010 (cont). 

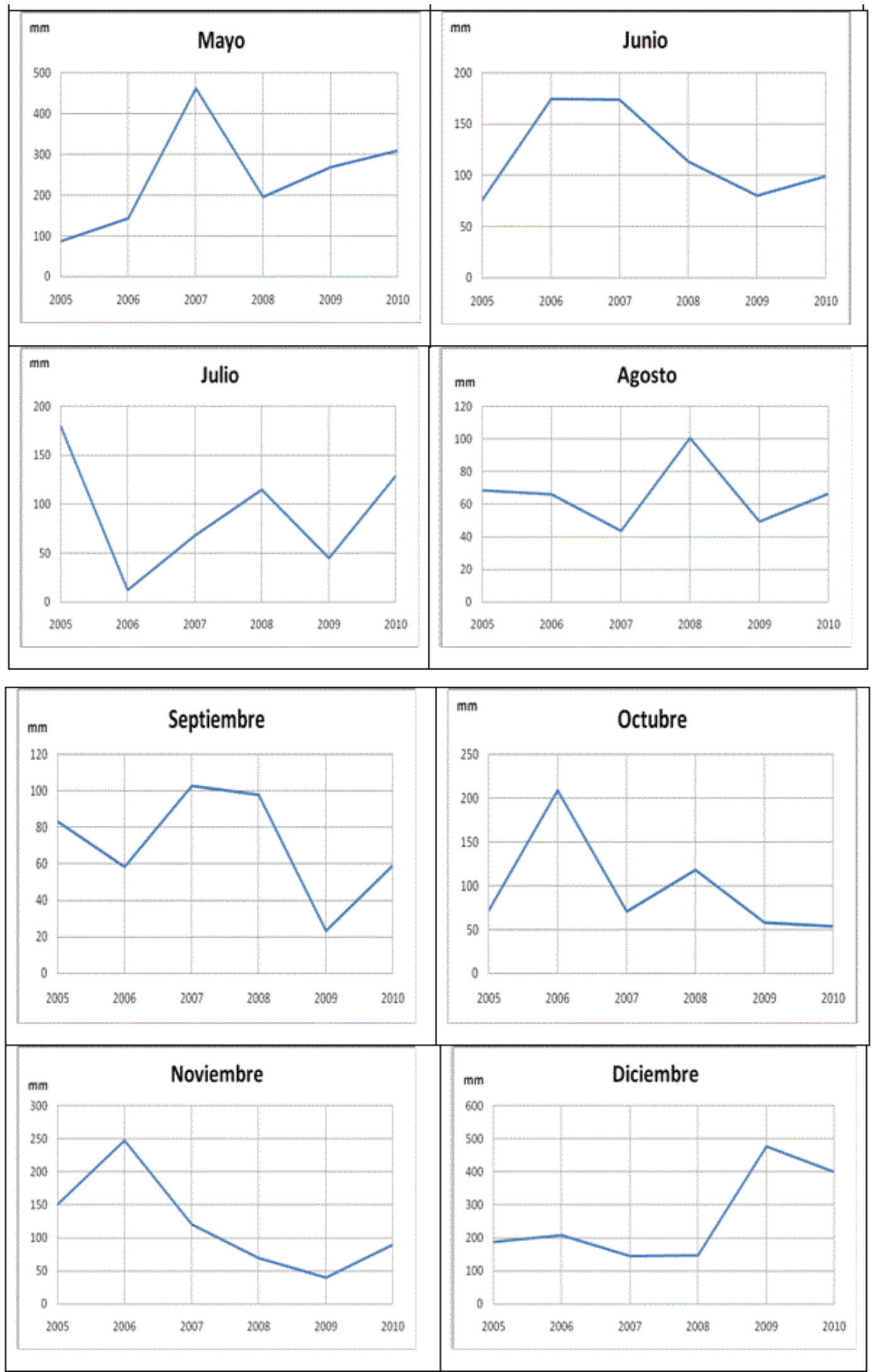

Figura 43. Precipitaciones Totales Mensuales La Libertad, período 2005-2010. 


\section{Estación Puerto lla de 1990-2010}

Del análisis más detallado de cada mes a lo largo de los años, durante el período de observaciones, puede verse en la Figura 44, que los meses de febrero y abril presentan una tendencia muy marcada a disminuir las lluvias, los meses de mayo a julio presentan una leve tendencia de disminuir las precipitaciones y los meses de agosto a diciembre muy ligera tendencia a disminuir las lluvias, el mes de marzo muestra una tendencia de aumento de lluvias.

- El mes de enero se mantiene a lo largo de los años con una ligera tendencia de disminución de la lluvia en el rango de $200 \mathrm{~mm}$ a $600 \mathrm{~mm}$, sin tener en cuenta el año de 1998 que alcanzo el máximo valor registrado en el período de observación de $894 \mathrm{~mm}$. La amplitud pluvial entre 1998 y 1999 es de $700 \mathrm{~mm}$. Del 2001 a 2006 la cantidad de lluvia decreció hasta los $200 \mathrm{~mm}$, luego en el 2008 llego a los 646mm para terminar el 2010 en 360mm.

- El mes de febrero se caracteriza por tener una tendencia a disminuir las precipitaciones, aunque inicia con aumento de las lluvias llegando en 1992 al máximo valor de $858 \mathrm{~mm}$. El rango de variación pluvial general va desde $200 \mathrm{~mm}$ a $700 \mathrm{~mm}$. Entre los años de 1996 a 2000 el intervalo pluvial es de $500 \mathrm{~mm}$ a $600 \mathrm{~mm}$, en el 2001 desciende a $242 \mathrm{~mm}$ y luego de 2002 a 2006 aumenta la cantidad entre $400 \mathrm{~mm}$ y $700 \mathrm{~mm}$, a partir del 2007 comienza a ascender hasta estabilizarse alrededor de los $500 \mathrm{~mm}$.

- Marzo tiene una marcada tendencia de aumentar las lluvias, el rango varía desde $300 \mathrm{~mm}$ a $750 \mathrm{~mm}$, a excepción de los años de 1998 cuando la precipitación llego a $826 \mathrm{~mm}$, y en el período 2003-2004 descendió a la media de $245 \mathrm{~mm}$. La amplitud pluvial es de $697 \mathrm{~mm}$. Se observa períodos con intervalos de variación pluvial muy amplios, así entre 2002 y 2003 existe $534 \mathrm{~mm}$, y entre 2009 y 2010 hay $613 \mathrm{~mm}$.

- Abril se caracteriza por tener una marcada tendencia a disminuir la cantidad de precipitación durante el ciclo de estudio. Este mes tiene un rango de $300 \mathrm{~mm}$ a $700 \mathrm{~mm}$ sin tener en cuenta los años 1992 y 1998 en los cuales se registro precipitaciones de $791 \mathrm{~mm}$ y $772 \mathrm{~mm}$ respectivamente. Por el contrario, el año más seco fue 2009 con 158mm de lluvia. Si consideramos el intervalo de variación es de $633 \mathrm{~mm}$.

- El mes de mayo, al igual que el mes anterior, presenta una fuerte tendencia a disminuir las precipitaciones, el período de registro tiene un rango de $100 \mathrm{~mm}$ a $400 \mathrm{~mm}$. Presenta dos picos de máxima, el primero en el año 1992 llegando a $541 \mathrm{~mm}$, y el segundo el año 1998 con $463 \mathrm{~mm}$. El año de precipitación más baja fue 2005 con $33,4 \mathrm{~mm}$.

- El mes de junio manifiesta una moderada tendencia a disminuir la cantidad de precipitación caída durante el período de estudio. Su máximo registro se dio en el año 1997 con un total de $367 \mathrm{~mm}$ de lluvia, en los años restantes se mantiene en un rango que va de $15 \mathrm{~mm}$ a $200 \mathrm{~mm}$. El intervalo de variación pluvial es de $352 \mathrm{~mm}$.

- El mes de julio continúa la tendencia a disminuir la cantidad de precipitación, la cantidad de lluvia acumulada mensual no sobrepasa los $70 \mathrm{~mm}$, excepto los años de 
1992 que llego a $159 \mathrm{~mm}$ y durante el período $97-98$ que alcanzo los $230 \mathrm{~mm}$. A partir de 1999 hasta el 2010 los valores registrados se encuentran bajo los $70 \mathrm{~mm}$.

- Agosto tiene un comportamiento que se mantiene a lo largo de los años con una leve tendencia de incremento de la cantidad de lluvia mensual, no superando los $80 \mathrm{~mm}$, con excepción de los años 1997 y 2008, en los cuales alcanzo valores de $138 \mathrm{~mm}$ y $125 \mathrm{~mm}$, respectivamente.

- El mes de septiembre muestra una ligera tendencia a disminuir las lluvias durante el período de observación, en un rango que apenas sobrepasa los $100 \mathrm{~mm}$, sin embargo, muestra un gran pico de lluvia en el año de 1997 que llego a los 704mm, produciendo una amplitud pluvial de $695 \mathrm{~mm}$.

- Durante el mes de octubre el comportamiento se mantiene igual que el mes de septiembre, con una leve tendencia a disminuir las precipitaciones. El rango de lluvias normales va de $15 \mathrm{~mm}$ a $100 \mathrm{~mm}$, y presenta un gran pico en el año de 1997 que llego a los $466 \mathrm{~mm}$, produciendo un intervalo de variación de $451 \mathrm{~mm}$.

- En el mes de noviembre el comportamiento pluvial se mantiene, una leve tendencia a disminuir las precipitaciones entre valores normales de $20 \mathrm{~mm}$ a $100 \mathrm{~mm}$ y se observa un gran pico de máxima en el año 1997 que llega a los $801 \mathrm{~mm}$ de lluvia.

- Diciembre tiene la misma tendencia a disminuir las precipitaciones, las lluvias oscilan entre los 50mm a $400 \mathrm{~mm}$, se observa un gran pico de $960 \mathrm{~mm}$ en el año de 1997 que llego a la máxima precipitación anual del período 1990-2010.

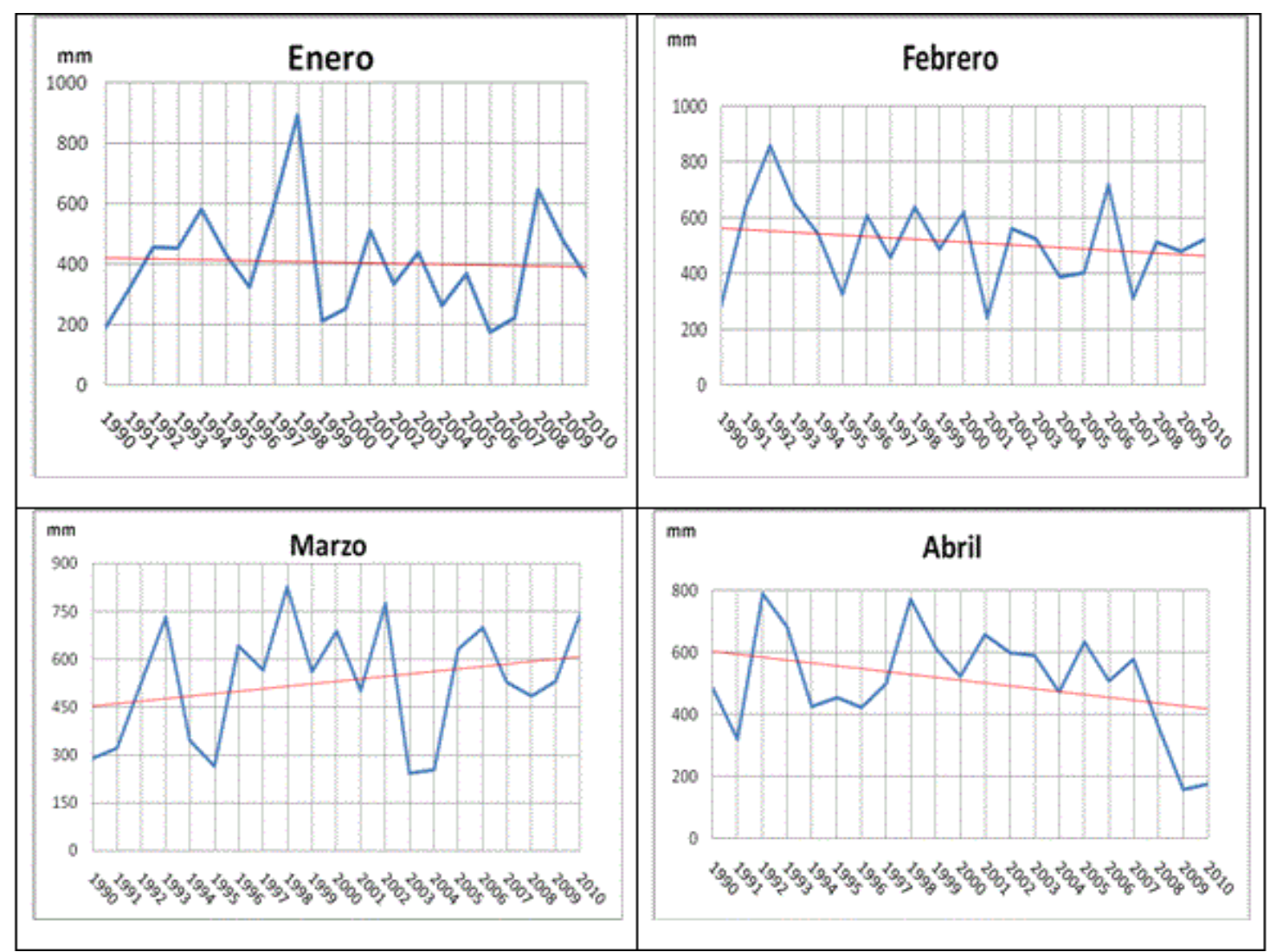

Figura 44. Precipitaciones Totales Mensuales Puerto Ila, período 1990-2010 (cont.) 


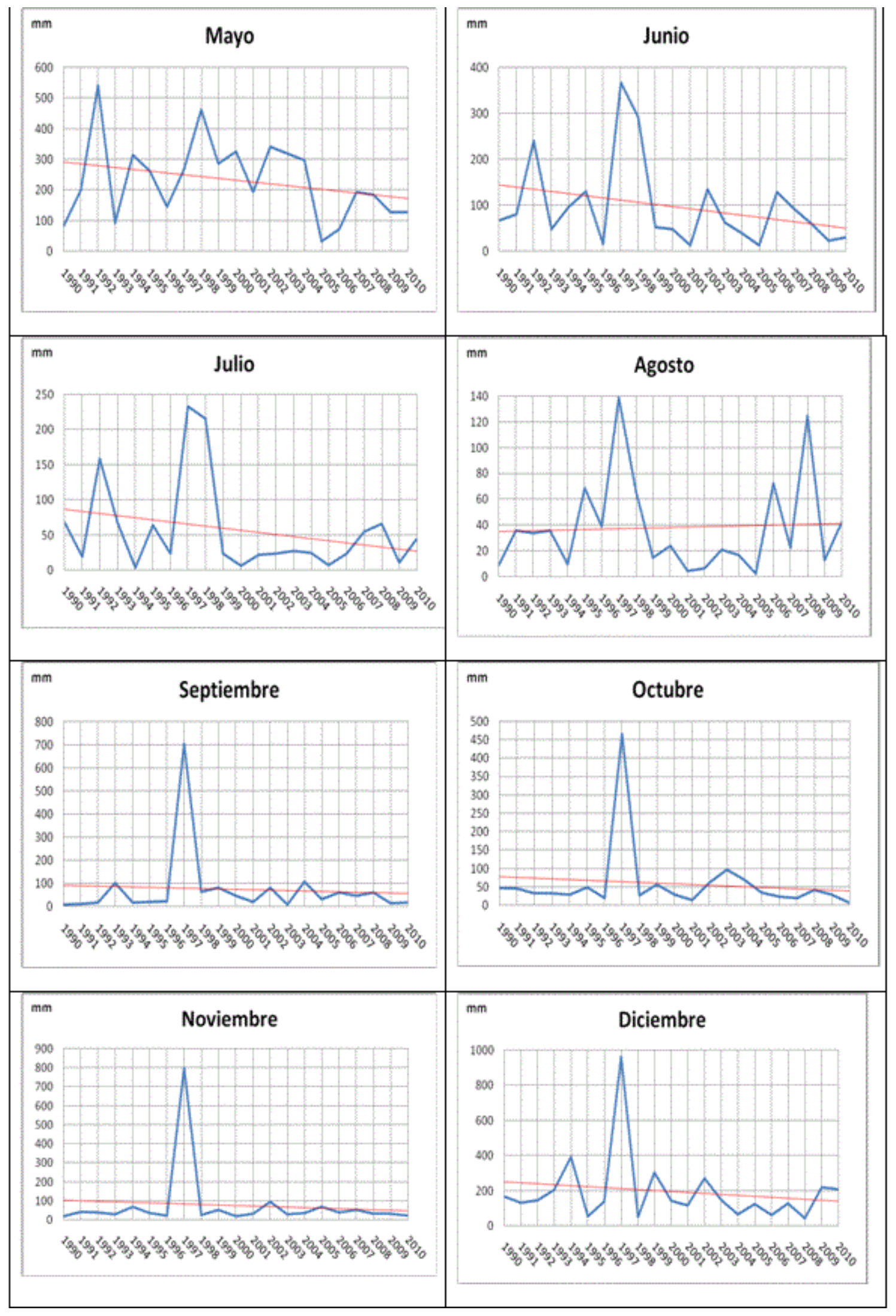

Figura 44. Precipitaciones Totales Mensuales Puerto lla, período 1990-2010. 


\section{Precipitaciones Diarias}

Para el análisis de la precipitación total diaria se tomaron como referencia cuatro series anuales con diferentes condiciones, que representen casos particulares dentro del período de observación 1990-2010, se incluye en este análisis a la estación La Libertad en una serie a pesar que su período de observación es diferente.

La primera serie de análisis corresponde al período de enero a diciembre del año 1997, considerado un año extremadamente lluvioso (muy húmedo) debido a la presencia del fenómeno climatológico, en la cual se consideraron las estaciones meteorológicas Puerto lla y Las Pampas.

Como se observa en la Figura 45, para el caso de la estación Puerto lla, los registros de las mayores alturas de lluvia caída se ubican entre los meses de enero a abril con valores que oscilan entre $50 \mathrm{~mm}$ a $140 \mathrm{~mm}$, luego de mayo a agosto la altura de la precipitación desciende variando entre $10 \mathrm{~mm}$ a $50 \mathrm{~mm}$, para luego de septiembre a diciembre aumentar su altura y frecuencia variando entre $50 \mathrm{~mm}$ a $150 \mathrm{~mm}$. Siendo los meses de diciembre, noviembre y septiembre los más intensos.

Para el caso de la estación Las Pampas, los meses en que se registraron las mayores alturas de lluvia caída son de enero a junio con valores que llegan entre $40 \mathrm{~mm}$ y $60 \mathrm{~mm}$, luego en julio y agosto decrecen a un promedio de $10 \mathrm{~mm}$, aunque en julio ocurrió una lluvia que sobrepaso los $30 \mathrm{~mm}$; y de septiembre a diciembre aumentan su altura y frecuencia llegando a valores de $40 \mathrm{~mm}$ y $60 \mathrm{~mm}$, siendo los meses de noviembre y octubre los más intensos.

En forma general podemos decir que la tendencia de las series registradas en los pluviómetros se mantiene en las dos estaciones (zonas geográficas) siendo la altura de la lluvia en la estación Puerto lla, que cubre la zona media baja, mucho mayor que la estación Las Pampas que cubre la zona media alta. La mayor parte de la lluvia sobrepasa los $20 \mathrm{~mm}$ de altura.

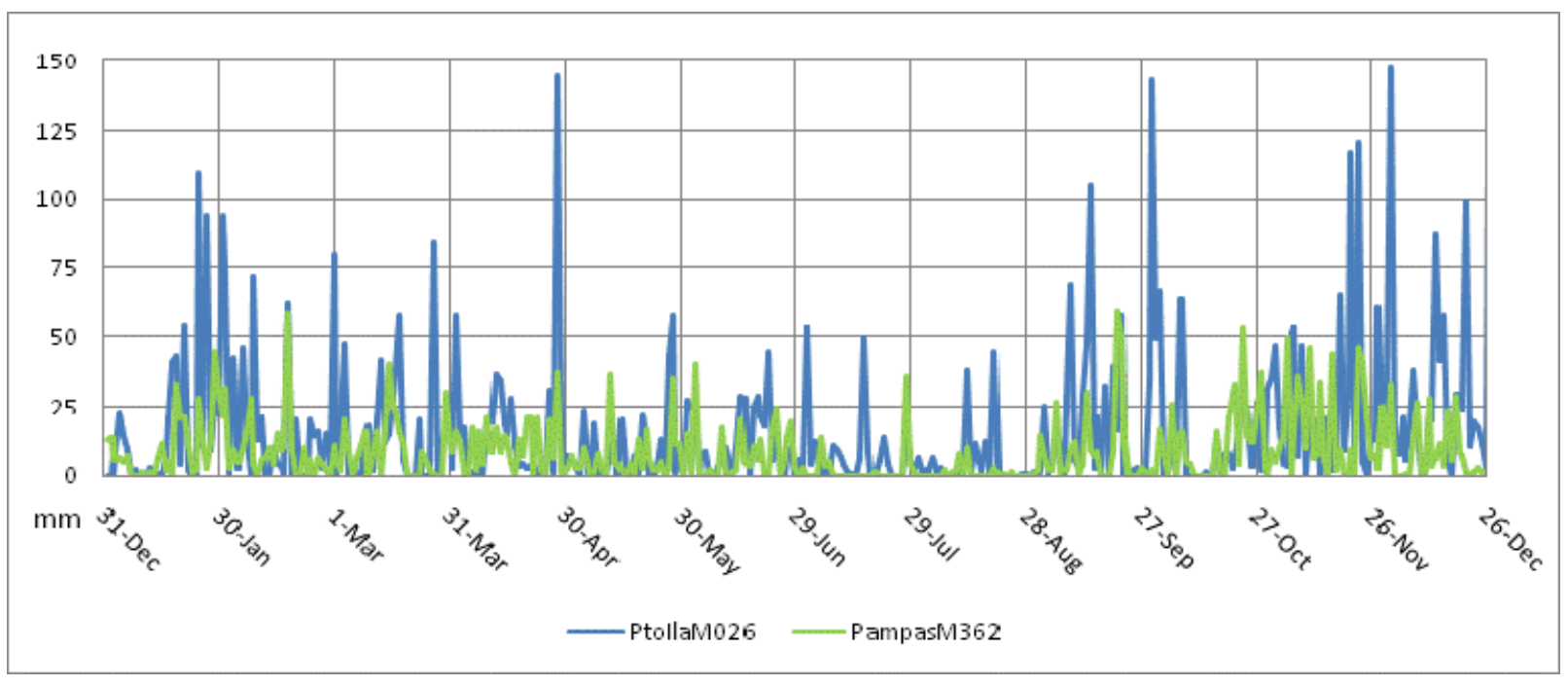

Figura 45. Precipitaciones diarias período 1997. 
La segunda serie de análisis corresponde al período de enero a diciembre del año 2000, considerado un año regular, en el que se consideraron las estaciones meteorológicas Puerto lla y Las Pampas.

Como se observa en la Figura 46, para el caso de la estación Puerto lla, los registros de las mayores alturas de lluvia caída se ubican entre los meses de diciembre a mayo con valores que oscilan entre los $40 \mathrm{~mm}$ a $110 \mathrm{~mm}$, considerado como el período húmedo (mayor frecuencia e intensidad de lluvias). Mientras que entre los meses de junio a noviembre la altura baja considerablemente a valores que no sobrepasan los $20 \mathrm{~mm}$, considerado como el período seco. Siendo los meses de marzo, febrero y abril los más intensos.

Para el caso de la estación Las Pampas, el período en el que se registraron las mayores alturas de lluvia caída fue entre los meses de diciembre a junio con valores que van entre 25 $\mathrm{mm}$ y $70 \mathrm{~mm}$. Mientras que entre los meses de julio a noviembre la altura desciende a valores que no sobrepasan los $25 \mathrm{~mm}$. Siendo los meses de abril, marzo y mayo considerados los más intensos.

En forma general podemos decir que la tendencia de las observaciones durante esta serie considerada normal, se mantiene en lo largo del período de análisis en las dos estaciones, siendo la altura de la lluvia caída en la estación Puerto lla mayor que en la estación Las Pampas. Coincidiendo los períodos de lluvia y estiaje con los períodos normales, mayor cantidad de lluvias en un caso y menor cantidad en el otro. La mayor concentración de la lluvia está entre los $20 \mathrm{~mm}$ a $50 \mathrm{~mm}$.

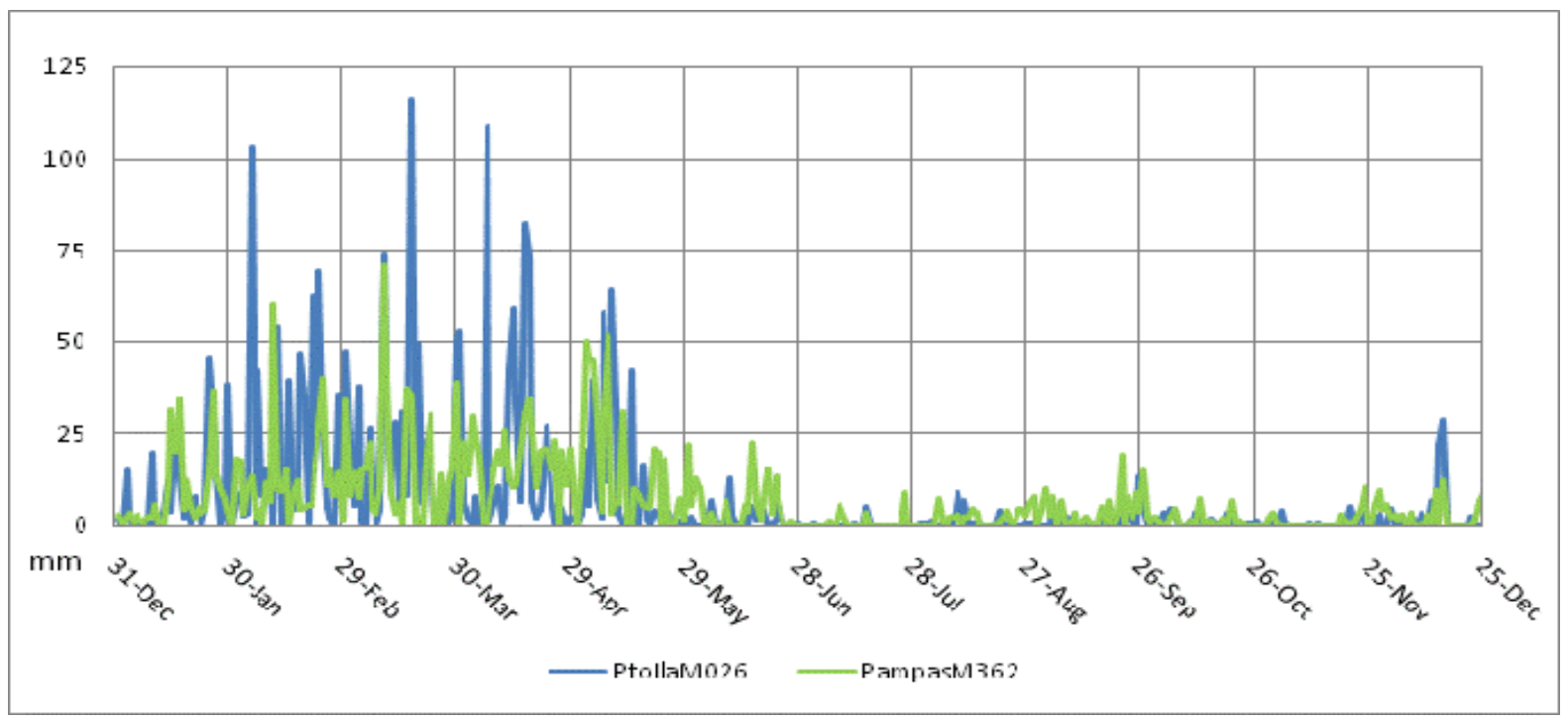

Figura 46. Precipitaciones diarias período 2000. 
La tercera serie de análisis corresponde al período de enero a diciembre del año 2004, considerado un año de déficit de lluvias (seco).

Como se observa en la Figura 47, para la estación Puerto lla, los registros de las lluvias caídas con mayor altura se encuentran entre los meses de enero a mayo con valores que van desde los $20 \mathrm{~mm}$ a $100 \mathrm{~mm}$; mientras que el período entre junio a diciembre la altura de la lluvia bajo a valores menores de $15 \mathrm{~mm}$, con un caso excepcional en el mes de septiembre. Los meses con mayor intensidad fueron abril, febrero y mayo.

Del análisis a la estación Las Pampas, se observa que el período en el que se registraron las mayores alturas de lluvias caídas fue entre diciembre a mayo con valores que van fluctúan de $20 \mathrm{~mm}$ a $50 \mathrm{~mm}$. Mientras que entre los meses de junio a noviembre la altura desciende considerablemente a valores que no sobrepasan los $20 \mathrm{~mm}$. Siendo los meses más intensos marzo, abril y mayo.

En general, la tendencia de las observaciones registradas durante este período considerado seco, se mantiene a lo largo de la serie de análisis en las dos estaciones. La altura de la lluvia caída en la estación Puerto lla tiene es parcialmente mayor que la estación Las Pampas. La mayor concentración de la lluvia esta bajo los $50 \mathrm{~mm}$

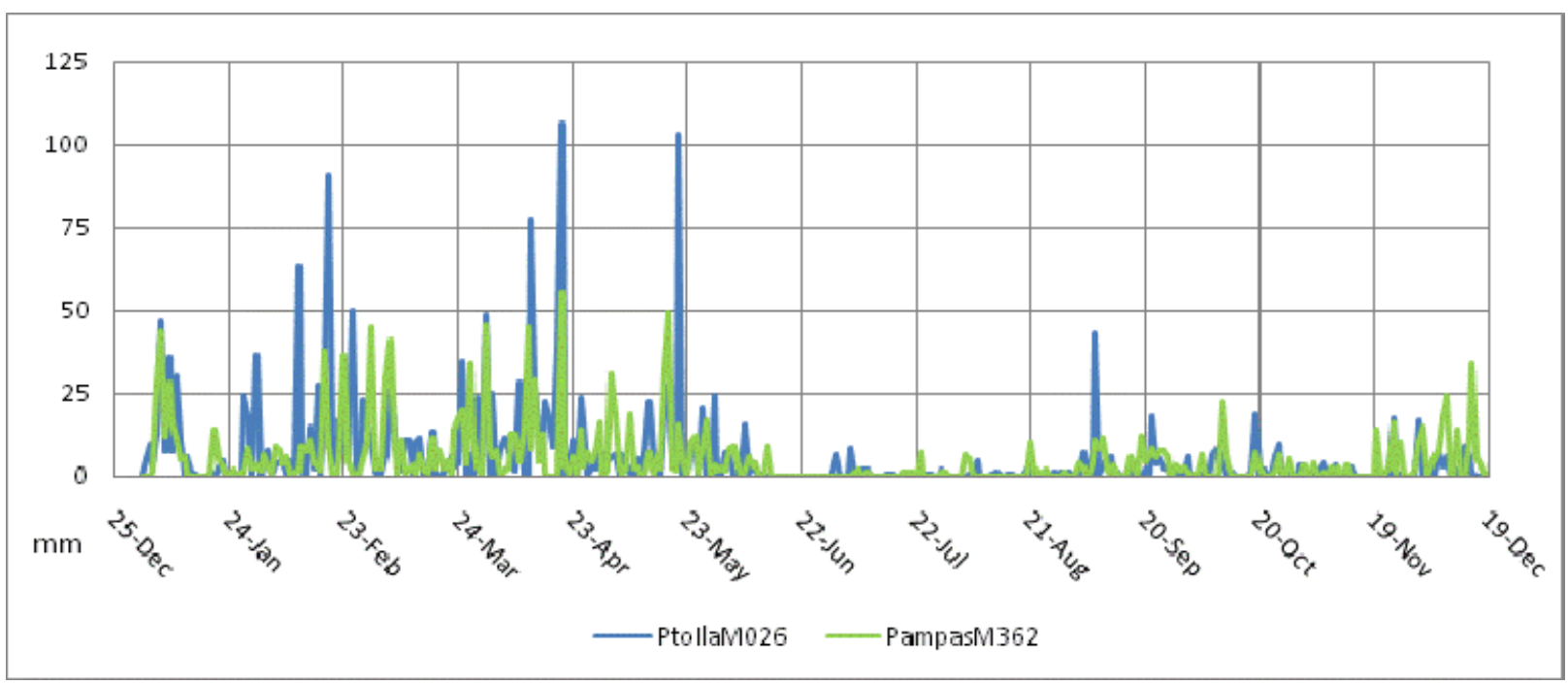

Figura 47. Precipitaciones diarias período 2004.

La cuarta serie de analisis corresponde al período de enero a diciembre del año 2007, considerado un año regular en el cual se consideraron las tres estaciones meteorologicas de estudio, Puerto lla, La Libertad y Las Pampas.

Como se observa en la Figura 48, en la estación Puerto lla se registran las mayores altura de precipitación caida entre los meses de diciembre a mayo con valores que oscilan de $20 \mathrm{~mm}$ a $50 \mathrm{~mm}$, existiendo tres datos puntuales fuera del rango que son $107,9 \mathrm{~mm}$ el $19 \mathrm{de}$ febrero, $96,3 \mathrm{~mm}$ el 23 de marzo y $97,5 \mathrm{~mm}$ el 30 de abril. Mientras que durante los meses de junio a noviembre se registraron los menores valores de lluvia que no sobrepason los $20 \mathrm{~mm}$. Siendo los meses de abril, marzo y febrero los mas intensos. 
En el caso de la estación La Libertad, se registraron las mayores alturas de lluvia durante los meses de noviembre a junio, con valores que fluctuan entre $15 \mathrm{~mm}$ a $50 \mathrm{~mm}$; mientras que entre los meses de julio a octubre la altura de la precipitación decrecio a valores por debajo de los $15 \mathrm{~mm}$. Siendo los meses de marzo, abril y mayo los mas intensos en lluvias.

Durante el período de analisis en la estación Las Pampas, los meses con mayor altura de Iluvia fueron de noviembre a mayo con observaciones entre $15 \mathrm{~mm}$ a $45 \mathrm{~mm}$, mientras que de junio a octubre la precipitación descendio a valores menores a $15 \mathrm{~mm}$, excepto el dia 29 de junio que registra un valor de $66 \mathrm{~mm}$. Los meses de mayor intensidad son marzo, enero y abril.

En forma general podemos concluir que la tendencia de los patrones de observacion de las tres estaciones, en esta serie, se mantienen iguales durante el período de observacion, manteniendo las mayores alturas de lluvia caida en la estación Puerto lla sobre los valores de las otras estaciones. Coinciden los períodos lluvioso y secos en las tres estaciones.

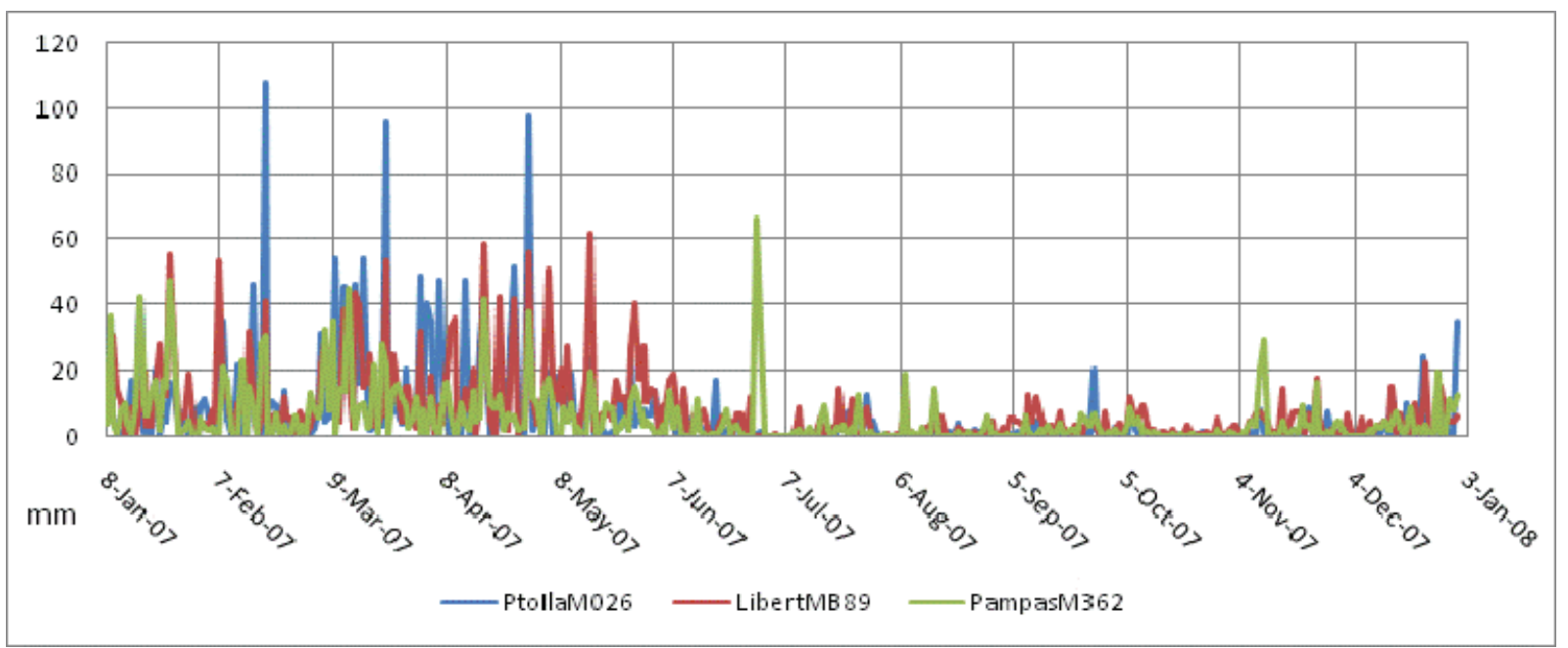

Figura 48. Precipitaciones diarias período 2007.

\subsubsection{Temperaturas}

Para la descripción de los resultados, primero se presentará a la estación Puerto lla y luego a la estación Las Pampas, dentro de cada una de estas se realizarán las descripciones de los análisis de las temperaturas mensuales y anuales.

\section{Estación Puerto lla}

La distribución de las temperaturas medias mensuales durante los años 1990-2010 se presenta en la Figura 49, en el que se muestran las tres variables de la temperatura mensual, máxima, media y mínima. A continuación se describe cada una de ellas:

- Las temperaturas máximas mensuales oscilan entre los $25^{\circ} \mathrm{C}-27^{\circ} \mathrm{C}$. Durante el período de septiembre a abril se produce un aumento de la temperatura alcanzando 
el máximo valor en el mes de abril con $26,8^{\circ} \mathrm{C}$, y desde mayo a agosto desciende la temperatura alcanzando el mínimo registro en el mes de agosto con un valor de $25,3^{\circ} \mathrm{C}$, la amplitud térmica es de $1,5^{\circ} \mathrm{C}$.

- Las temperaturas medias mensuales varían en un rango de $23^{\circ} \mathrm{C}-25,5^{\circ} \mathrm{C}$. Durante los meses de septiembre a marzo se produce un aumento de la temperatura alcanzando el máximo valor en el mes de marzo con $25,5^{\circ} \mathrm{C}$ manteniéndose constante durante abril, y desde mayo a julio desciende la temperatura alcanzando el mínimo valor en el mes de julio con $23,4^{\circ} \mathrm{C}$ manteniéndose constante hasta agosto, la amplitud térmica es de $2,1^{\circ} \mathrm{C}$.

- Las temperaturas mínimas mensuales se presentan en un rango de $22,5^{\circ} \mathrm{C}-25^{\circ} \mathrm{C}$. Durante los meses de septiembre a abril se produce un incremento en la temperatura alcanzando el máximo registro en el mes de abril con $24,9^{\circ} \mathrm{C}$, luego disminuye la temperatura desde mayo a agosto siendo $22,6^{\circ} \mathrm{C}$ el menor registro ocurrido durante los meses de julio a agosto. La amplitud térmica es de $2,3^{\circ} \mathrm{C}$.

Como conclusión podemos decir que la variación de la amplitud térmica en cada una de las temperaturas es pequeña, siendo la más grande en la temperatura media mínima mensual con $2,3^{\circ} \mathrm{C}$, el mes más frio fue agosto y el mes más caliente abril.

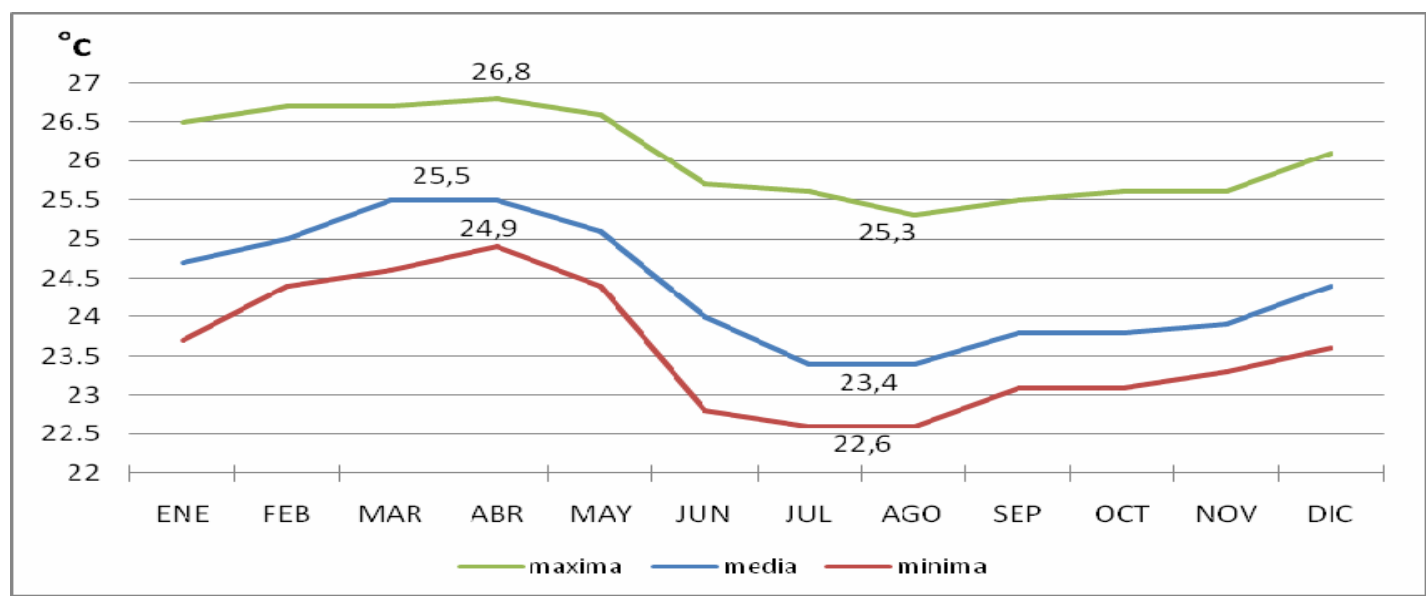

Figura 49. Distribución de las Temperaturas Medias Mensuales de la estación Puerto lla para el período 1990-2010

La distribución de las temperaturas anuales durante el período 1990 a 2010 se muestra en la Figura 50, en el que se presentan las tres variables de la temperatura anual, máxima, media y mínima las cuales describen sendas tendencias a aumentar la temperatura conforme pasan los años. A continuación se describe cada una de ellas:

- La temperatura máxima anual del período 1990-2010 se registró en el mes de abril de 1998 con un valor de $26,8^{\circ} \mathrm{C}$, mientras que la mínima se registró en abril de 1994 con un valor de $24,9^{\circ} \mathrm{C}$. El rango de los valores en que oscilan el resto de años está entre $25^{\circ} \mathrm{C}$ y $26^{\circ} \mathrm{C}$. La amplitud térmica es de $1,9^{\circ} \mathrm{C}$. 
- En el año 1997 se registró el valor máximo de las temperaturas medias anuales, con un valor de $25,5^{\circ} \mathrm{C}$, mientras que entre los años 1999 y 2000 se registró el menor valor de $23,9^{\circ} \mathrm{C}$, con una amplitud térmica de $1,6^{\circ} \mathrm{C}$.

- La temperatura mínima anual del período 1990-2010 se registro durante los meses de julio y agosto de 1994 con un valor de $22,6^{\circ} \mathrm{C}$, mientras que la máxima se registró en enero de 1997 con un valor de $24,2^{\circ} \mathrm{C}$. El rango de valores en que fluctúan el resto de años está entre $22,5^{\circ} \mathrm{C}$ y $24^{\circ} \mathrm{C}$ con una amplitud térmica de $1,3^{\circ} \mathrm{C}$.

Para resumir, la temperatura anual en la estación Puerto lla tiene una tendencia a aumentar los valores a través de los años, lo que muestra un incremento en la amplitud térmica. El período en el que ocurrieron los mayores registros de temperatura fueron los años de 1997 y 1998, que coincide con el período que se registraron los valores más altos de altura de precipitación anual (sección 5.3.1).

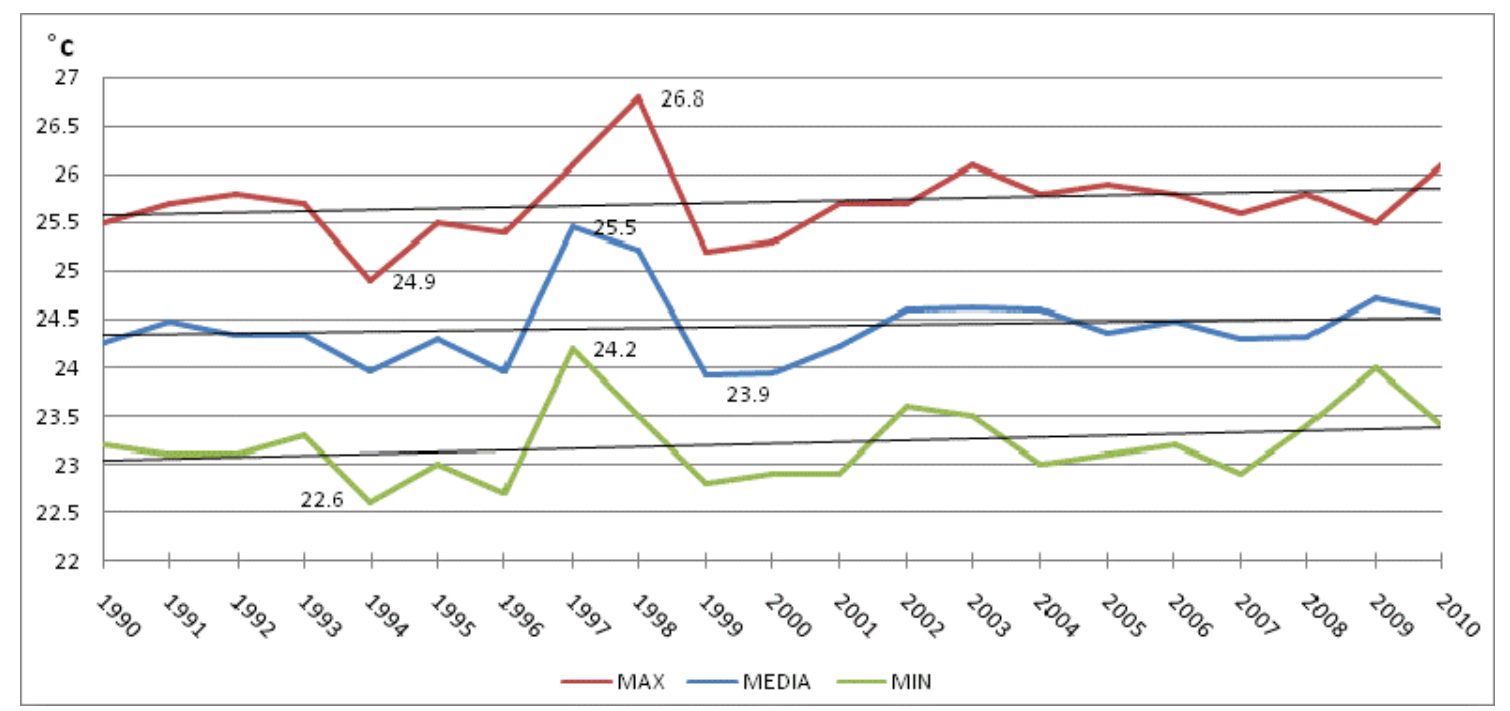

Figura 50. Distribución de las Temperaturas Anuales de la estación Puerto lla para el período 1990-2010

\section{Estación Las Pampas}

La distribución de las temperaturas mensuales durante los años 2005-2010 se presenta en la Figura 51, en el que se observa las tres variables de la temperatura mensual, máxima, media y mínima. A continuación se describe un resumen de ellas:

- Las temperaturas medias máximas mensuales oscilan entre los $18^{\circ} \mathrm{C}-19^{\circ} \mathrm{C}$. Durante los meses de enero, marzo, abril, julio, agosto, septiembre y octubre se presento un aumento de la temperatura alcanzando el máximo valor en el mes de abril con $18,8^{\circ} \mathrm{C}$, y los meses de febrero, mayo, junio, noviembre y diciembre descendió la temperatura alcanzando el mínimo registro en el mes de diciembre con un valor de $17,9^{\circ} \mathrm{C}$, la amplitud térmica fue de $0,9^{\circ} \mathrm{C}$. 
- Las temperaturas medias mensuales varían en un rango de $17,5^{\circ} \mathrm{C}-18,5^{\circ} \mathrm{C}$. Durante los meses de enero a mayo se produce un aumento de la temperatura alcanzando el máximo valor en el mes de mayo con $18,4^{\circ} \mathrm{C}$, luego la temperatura desciende entre los meses de junio a agosto y diciembre alcanzando el mínimo valor en diciembre con $17,5^{\circ} \mathrm{C}$, se observa que durante el período de septiembre a noviembre la es temperatura constante en $18^{\circ} \mathrm{C}$, la amplitud térmica es de $0,9^{\circ} \mathrm{C}$.

- Las temperaturas medias mínimas mensuales se presentan en un rango de $17^{\circ} \mathrm{C}-$ $18^{\circ} \mathrm{C}$. Durante los meses de febrero a mayo se incrementa gradualmente la temperatura alcanzando el máximo registro en el mes de mayo con $18,1^{\circ} \mathrm{C}$, en los meses de junio, julio, octubre, diciembre y enero disminuyó la temperatura siendo $17,1^{\circ} \mathrm{C}$ el menor registro ocurrido durante el mes de enero, entre julio y septiembre se mantuvo constante en $17,6^{\circ} \mathrm{C}$. La amplitud térmica es de $1,0^{\circ} \mathrm{C}$.

A partir de estos resultados, la amplitud térmica en cada una de las temperaturas es mínima, siendo $0,93^{\circ} \mathrm{C}$ el promedio de las tres, el mes más frio fue enero y el mes más caliente abril con una variación térmica de $1,7^{\circ} \mathrm{C}$.

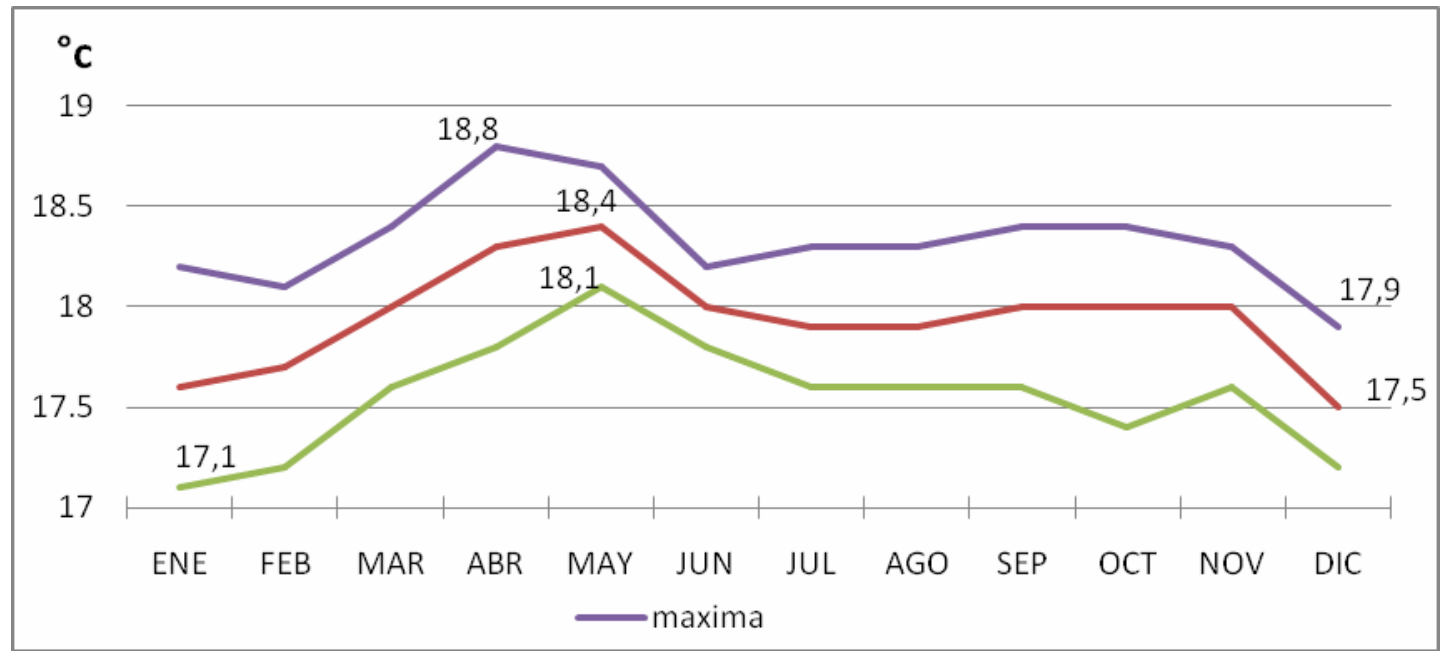

Figura 51. Distribución de las Temperatura Medias Mensuales de la estación Las Pampas para el período $2005-2010$

La distribución de las temperaturas anuales durante el período 2005 a 2010 se muestra en la Figura 52, en el que se presentan las tres variables de la temperatura anual, máxima, media y mínima las cuales describen tendencias diferentes durante el período de observación. A continuación se detalla cada una de ellas:

- La temperatura máxima anual del período 2005-2010 se registró en el mes de abril del año 2005 con un valor de $18,8^{\circ} \mathrm{C}$, mientras que la mínima de la máxima se registró en mayo del 2008 con un valor de $18,19^{\circ} \mathrm{C}$. El rango de los valores en que oscilan el resto de años está entre $18^{\circ} \mathrm{C}$ y $19,6^{\circ} \mathrm{C}$. La amplitud térmica es de $0,7^{\circ} \mathrm{C}$.

- En los años 2005 a 2006 y 2009 a 2010 se registró el valor máximo de las temperaturas medias anuales, con un valor de $18,1^{\circ} \mathrm{C}$, mientras que en el año 2008 se registró el menor valor de $17,1^{\circ} \mathrm{C}$, con una amplitud térmica de $0,4^{\circ} \mathrm{C}$. 
- La temperatura mínima anual del período 2005-2010 se registro en el mes de enero del 2008 con un valor de $17,1^{\circ} \mathrm{C}$, mientras que la máxima de la mínima se registró durante los meses de enero y febrero del 2008 con un valor de $17,8^{\circ} \mathrm{C}$. El rango de valores en que fluctúan el resto de años está entre $17^{\circ} \mathrm{C}$ y $18^{\circ} \mathrm{C}$ con una amplitud térmica de $0,7^{\circ} \mathrm{C}$.

En resumen, dada la poca información disponible de la temperatura en la estación Las Pampas, no se pudo realizar un análisis más profundo sobre el comportamiento de las temperaturas, sin embargo, durante el período 2005-2010 la temperatura máxima anual tiene una tendencia a disminuir los valores a través de los años y la temperatura mínima anual tiene la tendencia a aumentar, lo que produce una tendencia constante de la temperatura media anual y disminución de la amplitud térmica, como se pudo observar en los análisis realizados.

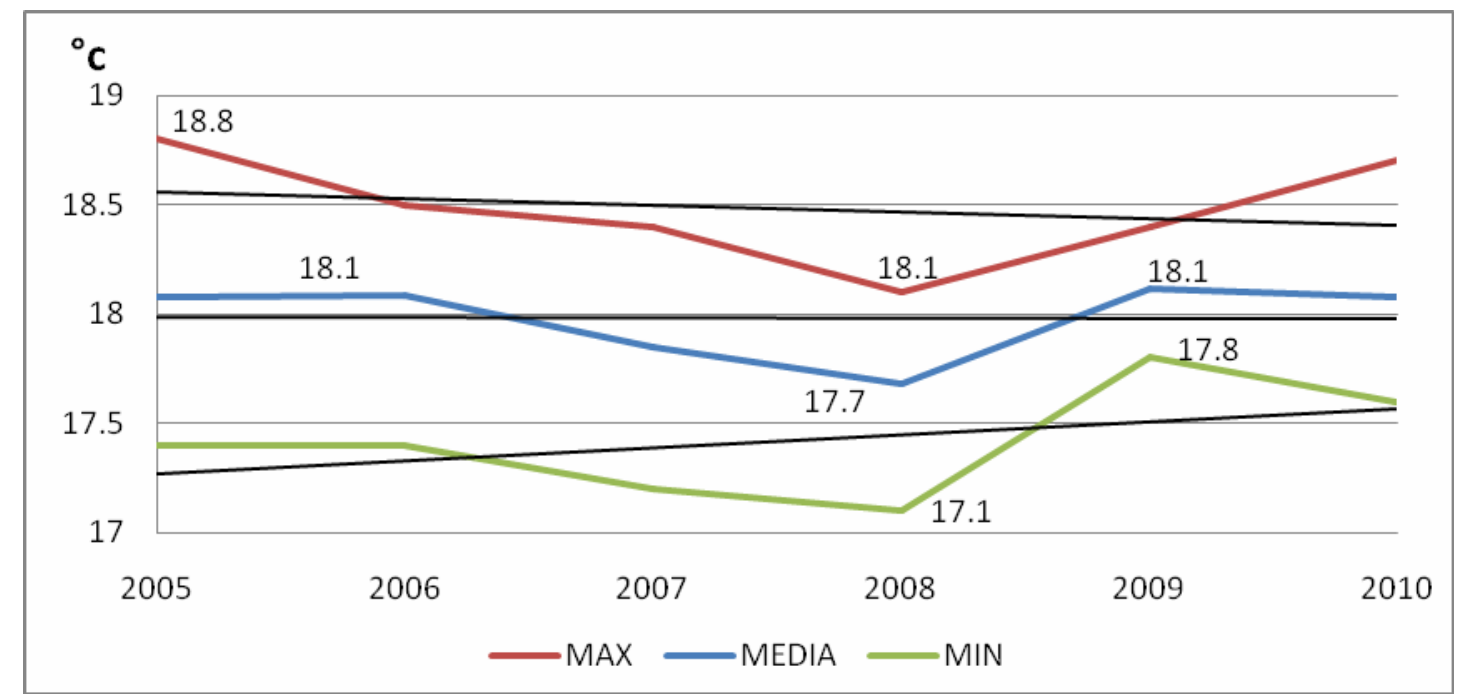

Figura 52. Distribución de las Temperaturas Anuales de la estación Las Pampas para el período 2005-2010

\section{4.- Análisis y Procesamiento de Datos Hidrológicos}

\subsubsection{Caudales}

Los datos utilizados para el desarrollo de este estudio proceden de los Anuarios Hidrológicos del INAMHI y de información proporcionada por ese Instituto, correspondiente a los Caudales Medios Mensuales (QMM) y a los Caudales Medios Diarios (QMD) desde enero del 2003 a junio del 2010 de la estación H414 Toachi AJ Baba. A continuación se presenta su análisis y procesamiento.

\section{Distribución de los Caudales Medios Mensuales}

En la cuenca del Toachi la distribución de los caudales tiene una tendencia uniforme a lo largo del tiempo considerado para el estudio, tal como se observa en la Figura 53, los caudales presentan dos períodos bien marcados en los cuales se agrupan los valores máximos y los valores mininos respectivamente. 
En forma general al analizar la curva de la media mensual del período (línea punteada color amarillo), los caudales máximos aparecen siempre en el período comprendido entre los meses de enero a junio y los caudales mínimos se presentan durante los meses de julio a diciembre. El caudal promedio de los caudales medios mensuales es de $35 \mathrm{~m}^{3} / \mathrm{s}$.

El rango de los caudales medios durante enero a junio oscila entre $20 \mathrm{~m}^{3} / \mathrm{s}$ y $120 \mathrm{~m}^{3} / \mathrm{s}$, registrándose los máximos caudales en el año 2003 en los meses de febrero $151,9 \mathrm{~m}^{3} / \mathrm{s}$, marzo $161,5 \mathrm{~m}^{3} / \mathrm{s}$ y abril $164,6 \mathrm{~m}^{3} / \mathrm{s}$. Mientras que durante los meses de julio a diciembre el caudal no sobrepasa los $20 \mathrm{~m}^{3} / \mathrm{s}$, excepto en agosto del 2007 que se registró $33,5 \mathrm{~m}^{3} / \mathrm{s}$ y en el año 2008 en los meses de julio, agosto y septiembre con valores de $23,3 \mathrm{~m}^{3} / \mathrm{s}, 24 \mathrm{~m}^{3} / \mathrm{s}$ y $22 \mathrm{~m}^{3} / \mathrm{s}$ respectivamente.

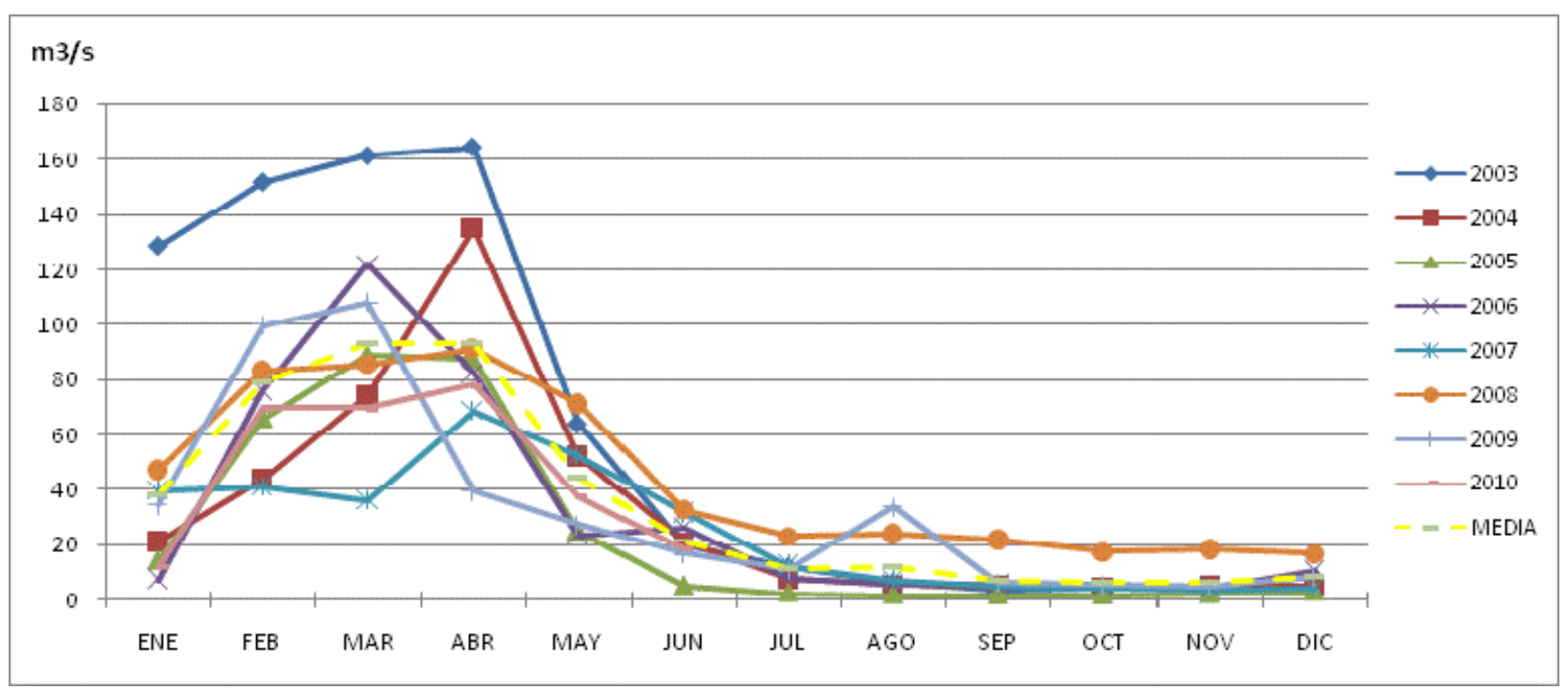

Figura 53. Distribución de los Caudales Medios Mensual desde enero 2003 a junio 2010.

\section{Variación mensual de los Caudales Medios Mensuales}

Haciendo un análisis más detallado de los caudales medios mensuales, se presenta la Figura 54 de la variación mensual del caudal medio, en el cual se puede observar que la variación durante el período enero 2003 a junio 2010, describe dos comportamientos diferentes entre los meses de enero a junio y de julio a diciembre.

Entre los meses de enero a junio se caracteriza por presentar los niveles más altos de caudal, variando desde $20 \mathrm{~m}^{3} / \mathrm{s}$ hasta $90 \mathrm{~m}^{3} / \mathrm{s}$, siendo los meses de marzo a abril el período de mas aporte de caudal con $93,4 \mathrm{~m}^{3} / \mathrm{s}$, y el mes de junio se registró el nivel más bajo con $21,4 \mathrm{~m}^{3} / \mathrm{s}$, produciendo una variación de $72 \mathrm{~m}^{3} / \mathrm{s}$. A este período se lo denomina húmedo.

Por el contrario durante los meses de julio a diciembre se caracterizó por mostrar los niveles más bajos de caudal, cuyos valores no superaron los $15 \mathrm{~m}^{3} / \mathrm{s}$, siendo el mes de agosto el que mayor aporte presento de caudal con $12,1 \mathrm{~m}^{3} / \mathrm{s}$ y los mese de octubre a noviembre los más bajos con $6,1 \mathrm{~m}^{3} / \mathrm{s}$, produciendo una variación de $6 \mathrm{~m}^{3} / \mathrm{s}$. A este período se lo denomina seco o de estiaje. 
En resumen el comportamiento del Río Toachi, durante el período de observación 20032010, presento dos períodos bien diferenciados en cuanto al volumen de agua registrado en el punto de aforo (caudal), de enero a junio y de julio a diciembre que coinciden con las épocas de mayor y menor precipitación respectivamente que fue analizada en la sección 5.3.1, registrándose una variación del caudal medio entre los dos períodos de $83,7 \mathrm{~m}^{3} / \mathrm{s}$.

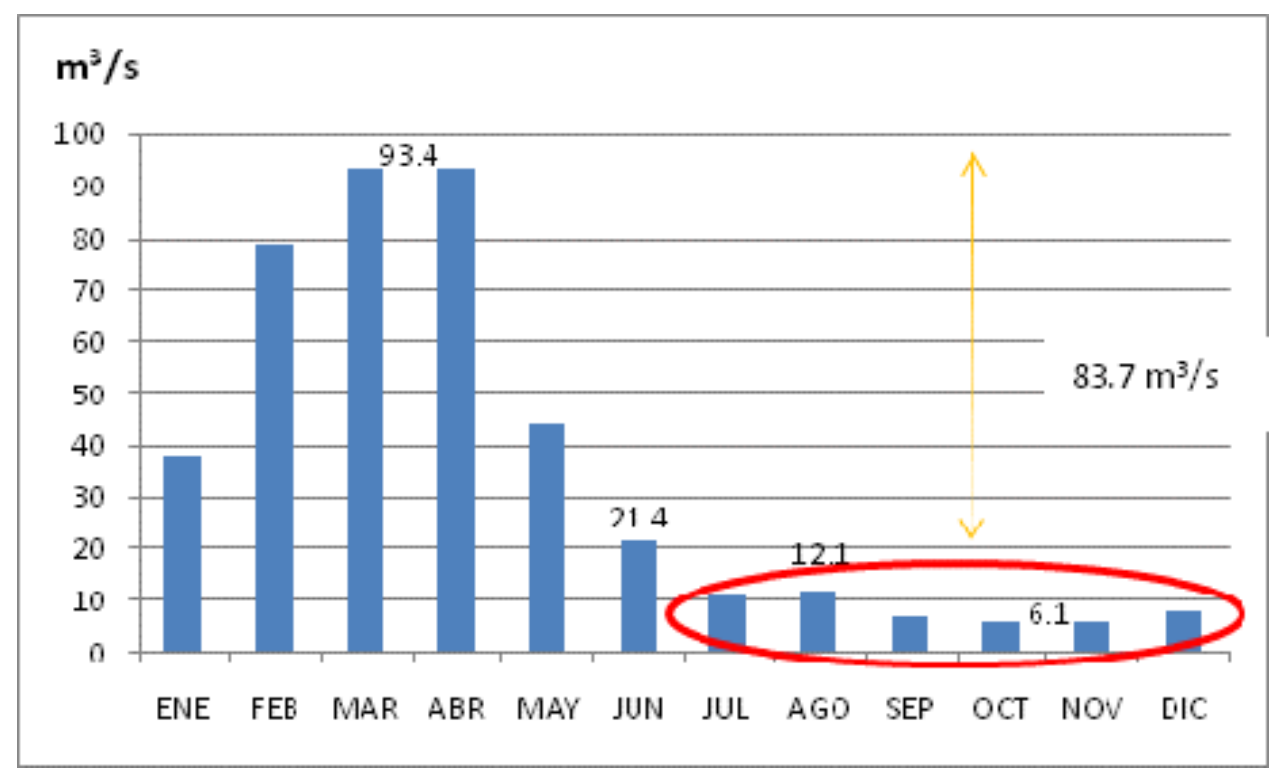

Figura 54. Variación mensual de los Caudales Medios Mensuales en el período 20032010

\section{Distribución de los caudales mensuales durante el período 2003-2010}

En la cuenca de estudio la distribución de los caudales mensuales durante el período enero 2003 a junio 2010 presenta una tendencia uniforme con respecto al tiempo de análisis, así observamos, en la Figura 55, que entre los meses de marzo a abril se producen los máximos caudales y entre los meses de septiembre a noviembre se presentan los caudales más bajos.

El caudal mensual más alto registrado fue en abril del 2003 con un valor de $4938,5 \mathrm{~m}^{3} / \mathrm{s}$ y el más bajo fue en septiembre del 2005 con un valor de $51,2 \mathrm{~m}^{3} / \mathrm{s}$. 


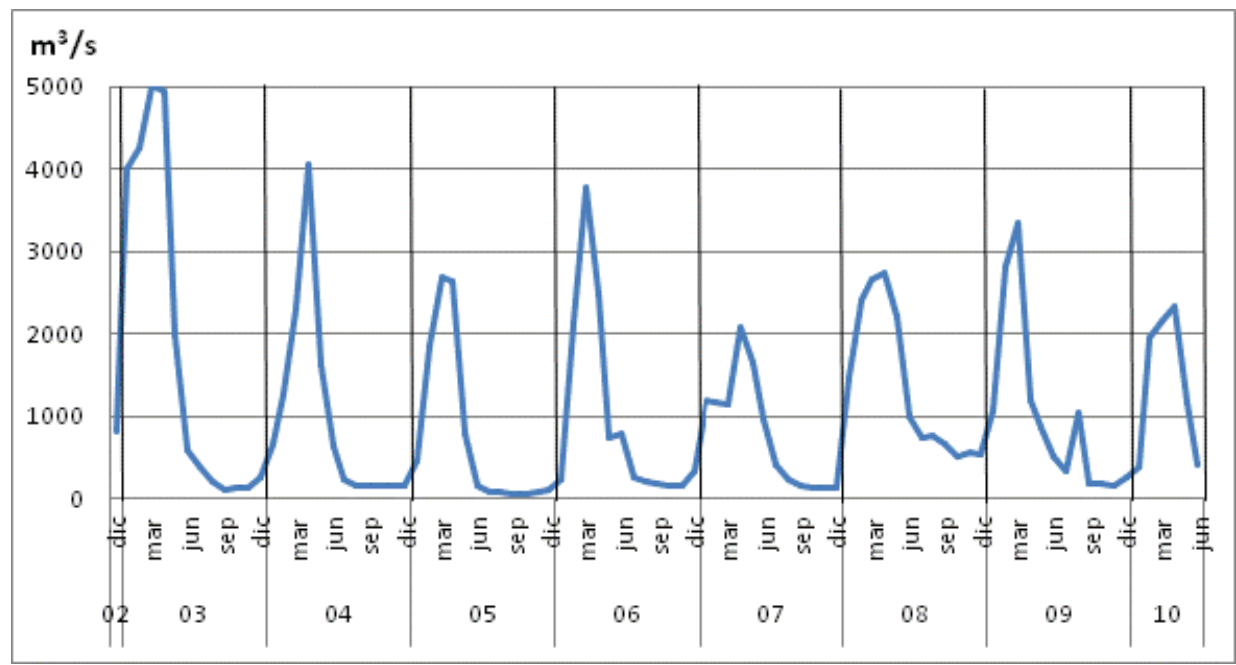

Figura 55. Caudales Mensuales durante el período 2003-2010

\section{Relación Caudal-Precipitación}

Para efectuar el análisis de esta relación se utilizaron las estaciones Toachi AJ Baba con la variable caudal medio mensual durante el período 2003-2010 y la estación La Libertad con la variable precipitación media mensual durante el período 2005-2010.

De la Figura 56 representando la relación indicada podemos inferir que la distribución de los escurrimientos mensuales está marcada por la existencia de un caudal base constante a lo largo de todo el año que varía según el período, así de enero a junio fluctúa entre $20 \mathrm{~m}^{3} / \mathrm{s}$ a $30 \mathrm{~m}^{3} / \mathrm{s}$, y de julio a diciembre entre $5 \mathrm{~m}^{3} / \mathrm{a} 15 \mathrm{~m}^{3} / \mathrm{s}$.

Se observa además que existe relación directa entre la tendencia de la altura pluviográfica con el caudal correspondiente mensual, como lo demuestra la sección final del hidrograma que los caudales tienden a incrementar conforme se incrementa la lluvia.

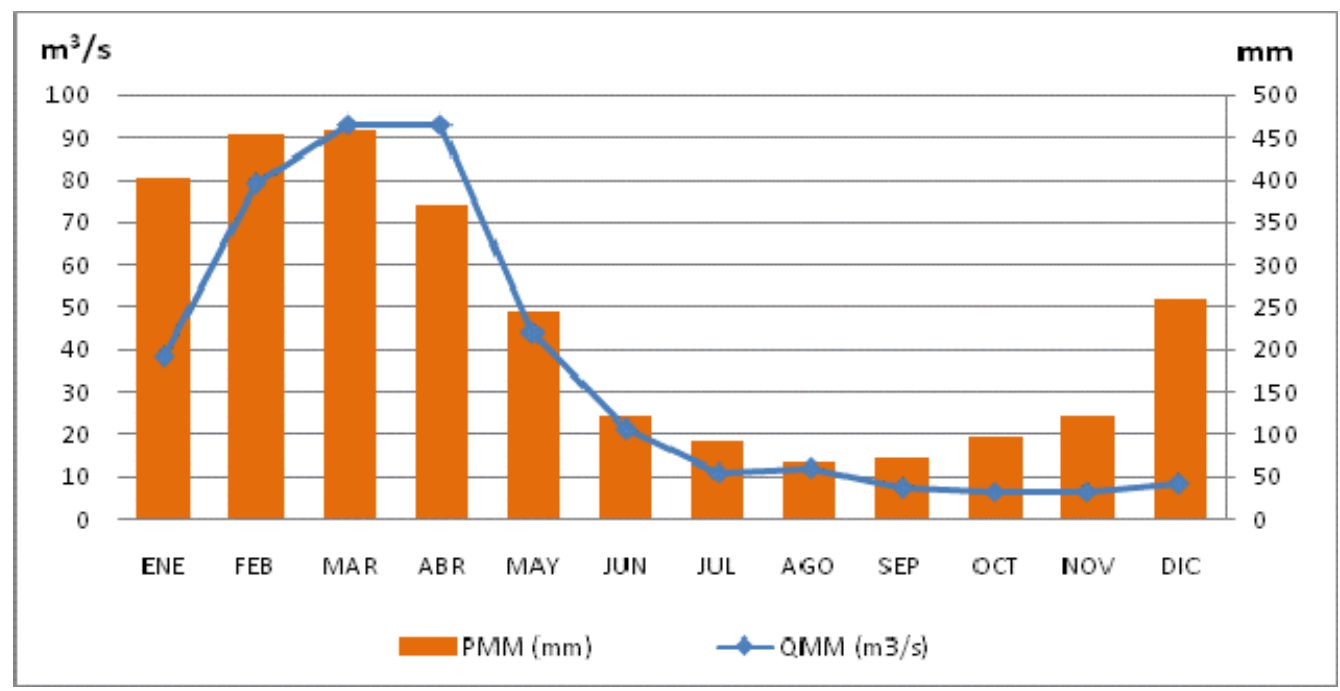

Figura 56. Relación del Caudal Medio Mensual con la Precipitación Media Mensual 


\section{5.- Análisis del Balance Hídrico}

Con la metodología explicada y con la ayuda del programa Excel $₫$ se realizaron los análisis hidro-climáticos, para la obtención de los balances mes a mes del agua en el suelo de las tres zonas de la cuenca del Río Toachi.

Como información general para el cálculo del balance hídrico de las tres áreas de la cuenca de estudio, se utilizó el dato de $300 \mathrm{~mm}$ como capacidad máxima de retención de agua en el suelo (reserva máxima) para la estación de Puerto lla y de $200 \mathrm{~mm}$ para las estaciones Las Pampas y La Libertad; y de 12 horas como el número de horas de luz por día.

\subsubsection{Cálculo del Balance Hídrico}

\section{Estación Puerto lla}

El análisis hidro-climático utilizando la información de la estación Puerto lla corresponde a la zona baja de la cuenca de estudio durante el período 1990-2010. En la Tabla 41 se presenta los datos usados y los resultados obtenidos de la aplicación del programa para el cálculo del balance hídrico a nivel mensual. Se observa las temperaturas y precipitaciones medias mensuales y los resultados de los cálculos de la evapotranspiración potencia corregida (ETP corr), la evapotranspiración real (ETR), el déficit, la reserva y el excedente del agua en el suelo.

En la Figura 57 se muestra el comportamiento del balance hídrico a nivel mensual, observando que en los meses de septiembre a noviembre existe un déficit de agua, en los meses de diciembre a mayo se produjo almacenamiento del agua en reserva y excedentes, y de junio a agosto se usó el agua de la reserva del suelo.

Este comportamiento coincide con las estaciones climáticas de la zona, de diciembre a mayo en la época lluviosa se produjo almacenamiento de agua en reserva y excedentes, y de junio a noviembre en la época seca o estiaje se presentó primero el uso del agua de la reserva en el suelo hasta agotarse y luego el déficit, para nuevamente comenzar el ciclo con la época lluviosa y las primeras lluvias que alimentan la reserva y excedentes.

En la Tabla 41 se observa que, en el mes de diciembre con las primeras lluvias de la época húmeda se termina el déficit de agua y comienza a llenarse las reservas en el suelo hasta el mes de enero que se presenta la máxima capacidad de humedad y el exceso de agua se escurre por los excedentes. Luego en junio, una vez que las lluvias disminuyen propio de la época, el agua deja de ser excedente y el suelo utiliza las reservas hasta agotarse en agosto; posteriormente comienza el período deficitario de agua desde septiembre hasta noviembre debido a la falta de lluvias y a la demanda del liquido vital; iniciando nuevamente el ciclo en diciembre con el llenado de las reserva propio de las lluvias de la época.

En el mes de diciembre se presenta la transición de la época seca a la lluviosa y en el mes de mayo de la estación lluviosa a la seca. 
Tabla 41. Resumen del Balance Hídrico de la estación Puerto lla

\begin{tabular}{|c|c|c|c|c|c|c|c|}
\hline Mes & $\begin{array}{c}\text { Temp } \\
\text { Media Mens } \\
\left({ }^{\circ} \mathbf{C}\right)\end{array}$ & $\begin{array}{c}\text { ETP corr } \\
(\mathbf{m m})\end{array}$ & $\begin{array}{c}\text { Precip } \\
\text { Media Mens } \\
(\mathbf{m m})\end{array}$ & $\begin{array}{c}\text { ETR } \\
(\mathbf{m m})\end{array}$ & $\begin{array}{c}\text { Déficit } \\
(\mathbf{m m})\end{array}$ & $\begin{array}{c}\text { Reserva } \\
(\mathbf{m m})\end{array}$ & $\begin{array}{c}\text { Excedentes } \\
(\mathbf{m m})\end{array}$ \\
\hline Sep & 23,8 & 97,5 & 75,8 & 75,8 & 21,7 & 0,0 & 0,0 \\
\hline Oct & 23,8 & 100,8 & 57,7 & 57,7 & 43,1 & 0,0 & 0,0 \\
\hline Nov & 23,9 & 98,8 & 83,1 & 83,1 & 15,7 & 0,0 & 0,0 \\
\hline Dic & 24,4 & 108,8 & 194,8 & 108,8 & 0,0 & 86,0 & 0,0 \\
\hline Ene & 24,7 & 112, & 402,3 & 112,9 & 0,0 & 300,0 & 75,4 \\
\hline Feb & 25,0 & 106,8 & 514,2 & 106,8 & 0,0 & 300,0 & 407,4 \\
\hline Mar & 25,5 & 124,5 & 504,2 & 124,5 & 0,0 & 300,0 & 379,7 \\
\hline Abr & 25,5 & 120,5 & 491,9 & 120,5 & 0,0 & 300,0 & 371,4 \\
\hline May & 25,1 & 118,6 & 232,3 & 118,6 & 0,0 & 300,0 & 113,7 \\
\hline Jun & 24,0 & 100,1 & 97,1 & 100,1 & 0,0 & 297,1 & 0,0 \\
\hline Jul & 23,4 & 95,7 & 53,8 & 95,7 & 0,0 & 255,2 & 0,0 \\
\hline Ago & 23,4 & 95,7 & 38,3 & 95,7 & 0,0 & 197,9 & 0,0 \\
\hline Sep & 23,8 & 97,5 & 75,8 & 75,8 & 21,7 & 0,0 & 0,0 \\
\hline
\end{tabular}

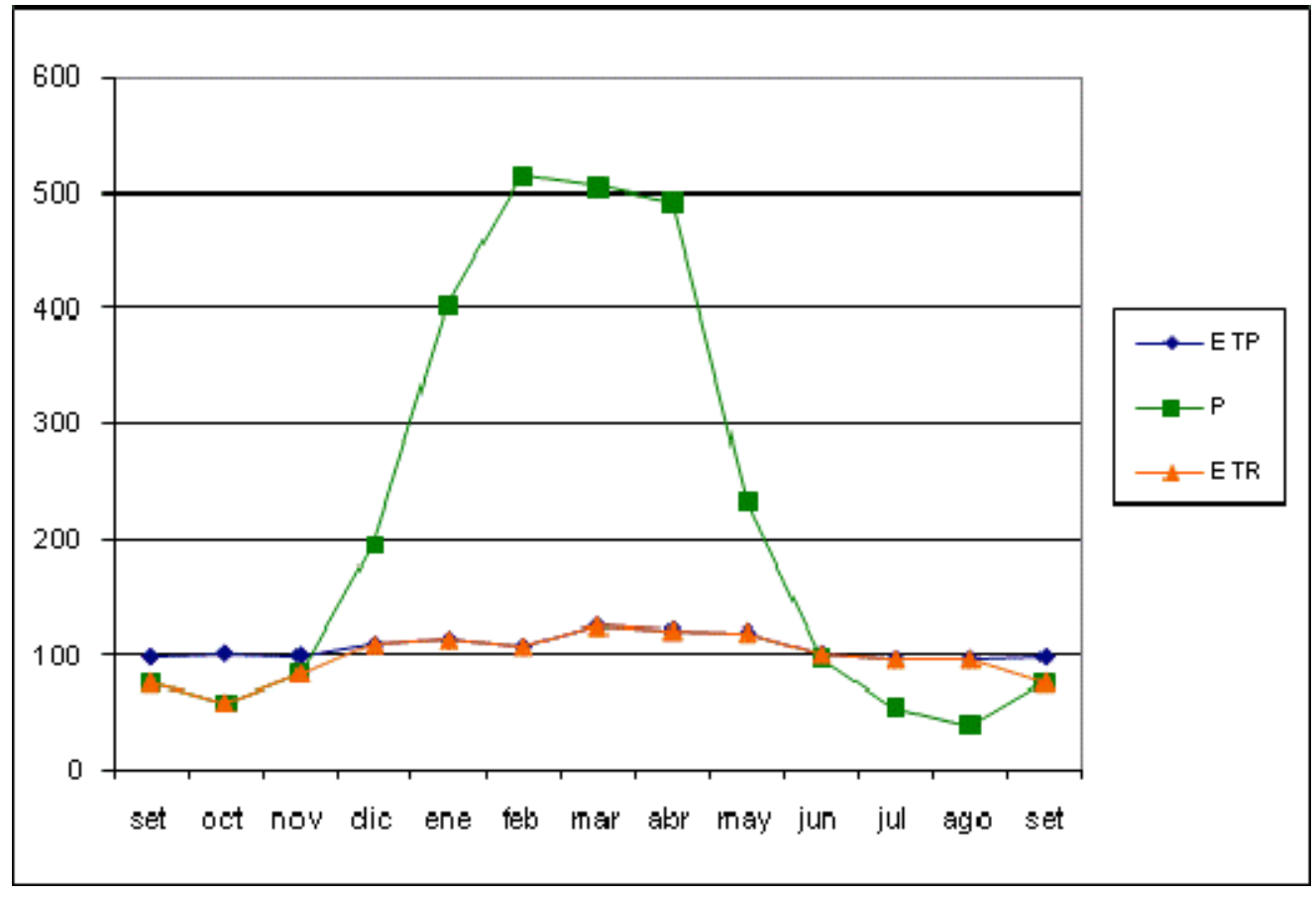

Figura 57. Balance Hídrico de Puerto lla durante el período 1990-2010 


\section{Estación La Libertad}

Se sigue el procedimiento detallado en la sección 4.5.1 para el cálculo de la temperatura media mensual en la estación La Libertad, en la Figura 38 se ilustra la ubicación de las estaciones meteorológicas utilizadas para el análisis climático, en la cual se verificó que la estación La Libertad se encuentra en la zona climática Subtropical Mesotérmico Muy Húmedo $\left(18^{\circ} \mathrm{C}-22^{\circ} \mathrm{C}\right)$, en el intervalo de temperatura de $21^{\circ} \mathrm{C}$ a $22^{\circ} \mathrm{C}$.

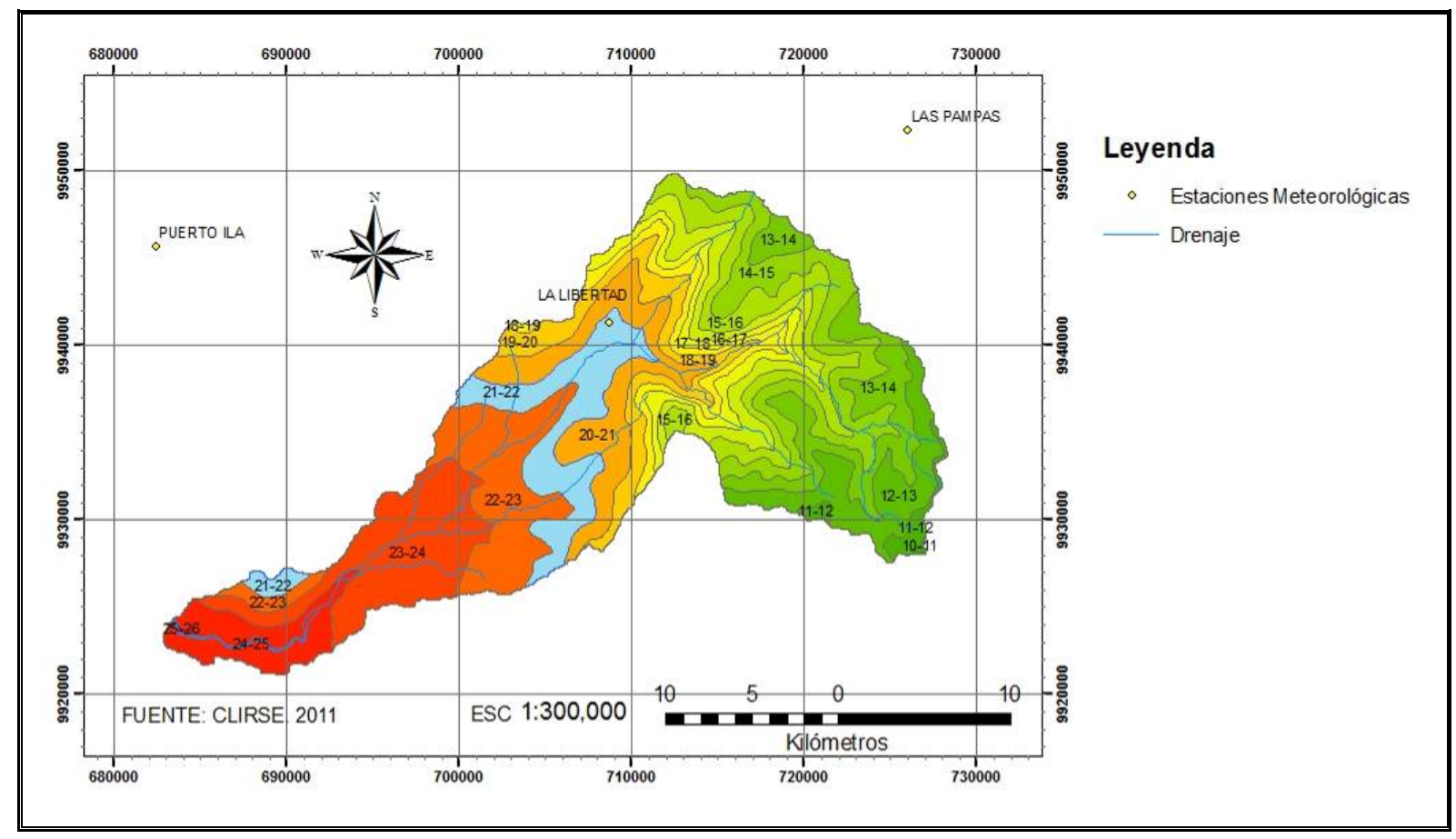

Figura 58. Ubicación de las estaciones meteorológicas.

Si se compara con los rangos de temperatura media mensual de las estaciones Puerto lla, $24^{\circ} \mathrm{C}-26^{\circ} \mathrm{C}$ y Las Pampas, $17^{\circ} \mathrm{C}-19^{\circ} \mathrm{C}$, utilizadas en la sección 5.3 .2 , se comprobó que el rango de temperatura de La Libertad, $21^{\circ} \mathrm{C}-22^{\circ} \mathrm{C}$, se ubica entre estos valores definiendo que existe variabilidad climática entre las tres estaciones, por lo tanto, mediante el cálculo de la media aritmética entre los valores mensuales de las estaciones Las Pampas y Puerto lla se obtuvieron los valores medios mensuales de temperatura para la estación La Libertad, los cuales se presentan en la Tabla 42 y el gráfico en la Figura 59. 
Tabla 42. Temperatura media mensual de la estación La Libertad.

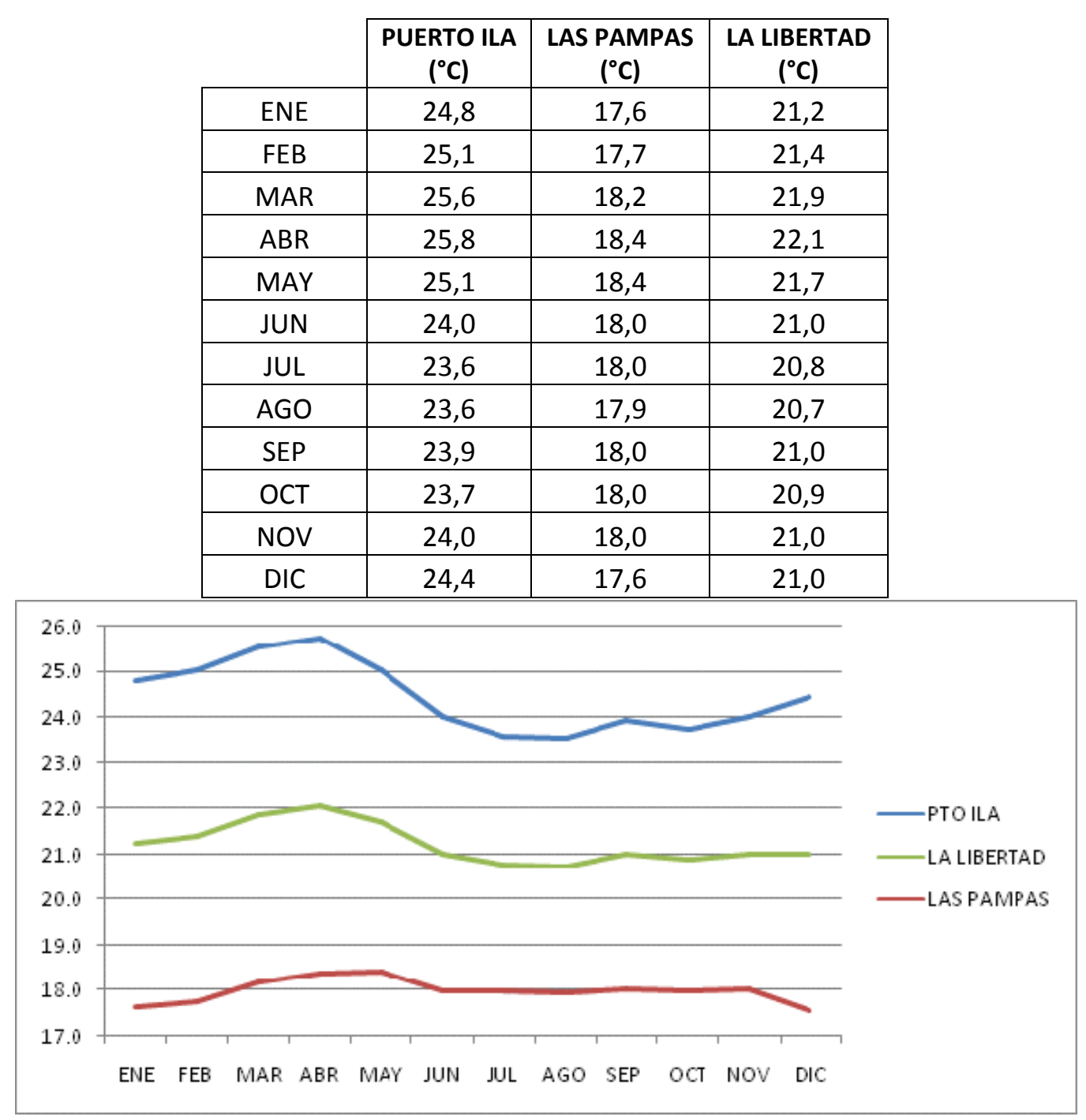

Figura 59. Gráfico de las temperaturas media mensual.

Una vez determinada la temperatura media mensual y con los valores de la precipitación mensual se realizó el análisis hidro-climático de la zona media de la cuenca de estudio durante el período 2005-2010 que le corresponde a la estación La Libertad. En la Tabla 43 se presenta los datos usados y los resultados obtenidos de la aplicación del programa para el cálculo del balance hídrico a nivel mensual. Se observa las temperaturas y precipitaciones medias mensuales y los resultados de los cálculos de la evapotranspiración potencial corregida (ETP corr), la evapotranspiración real (ETR), el déficit, la reserva y el excedente del agua en el suelo.

En la Figura 60, se muestra el comportamiento del balance hídrico a nivel mensual, observando que en el mes de septiembre se presentó un pequeño déficit de agua en el 
suelo, luego de octubre a julio se produce almacenamiento del agua en reserva y excedentes, y finalmente en agosto el suelo utilizó el agua de la reserva.

Este comportamiento es propio de las estaciones climáticas de la zona, caracterizada por mantener un rigen de lluvias durante casi todo el año alimentando constantemente las reservas y excedentes con un ligero déficit en el mes de septiembre, sin embargo debemos considerar para este análisis la época húmeda desde noviembre a junio debido al aumento de las lluvias produciendo almacenamiento de agua en reserva y excedentes, y de julio a octubre se considera la época seca por la disminución de las lluvias provocando que el suelo utilice el agua de la reserva en agosto y en septiembre se produzca déficit, comenzando así el nuevo ciclo con el llenado de la reserva producto de las primeras lluvias de la época húmeda.

Si se observa la Figura 60, durante casi todo el año se produce el llenado de la reserva producto a las continuas lluvias en la zona, excepto en el mes de septiembre que se presenta un ligero déficit de agua en el suelo debido a la disminución de las precipitaciones y a la constante demanda de agua; en enero el suelo llega a su capacidad máxima de humedad provocando que el exceso de agua escurra por los excedentes, luego en agosto, una vez que las lluvias disminuyen propio de la época de estiaje, el agua deja de ser excedente y el suelo consume las reservas hasta llegar a septiembre con un pequeño déficit, luego en octubre con las primeras lluvias de la época húmeda se inicia nuevamente el llenado de la reserva continuando el ciclo climático. Sin embargo se considera los meses de diciembre y mayo como de transición de la época seca a lluviosa y de la estación lluviosa a la seca respectivamente.

Tabla 43. Resumen del Balance Hídrico de la estación La Libertad.

\begin{tabular}{|c|c|c|c|c|c|c|c|}
\hline Mes & $\begin{array}{c}\text { Temp } \\
\text { Media Mens } \\
\left({ }^{\circ} \mathbf{C}\right)\end{array}$ & $\begin{array}{c}\text { ETP corr } \\
(\mathbf{m m})\end{array}$ & $\begin{array}{c}\text { Precip } \\
\text { Media Mens } \\
(\mathbf{m m})\end{array}$ & $\begin{array}{c}\text { ETR } \\
(\mathbf{m m})\end{array}$ & $\begin{array}{c}\text { Déficit } \\
(\mathbf{m m})\end{array}$ & $\begin{array}{c}\text { Reserva } \\
(\mathbf{m m})\end{array}$ & $\begin{array}{c}\text { Excedentes } \\
(\mathbf{m m})\end{array}$ \\
\hline Sep & 21,0 & 78,1 & 70,7 & 70,7 & 7,4 & 0,0 & 0,0 \\
\hline Oct & 20,9 & 79,6 & 96,9 & 79,6 & 0,0 & 17,3 & 0,0 \\
\hline Nov & 21,0 & 78,4 & 120,0 & 78,4 & 0,0 & 58,8 & 0,0 \\
\hline Dic & 21,0 & 80,7 & 261,2 & 80,7 & 0,0 & 200,0 & 39,3 \\
\hline Ene & 21,2 & 82,8 & 402,2 & 82,8 & 0,0 & 200,0 & 319,4 \\
\hline Feb & 21,4 & 76,9 & 453,1 & 76,9 & 0,0 & 200,0 & 376,2 \\
\hline Mar & 21,9 & 88,9 & 460,2 & 88,9 & 0,0 & 200,0 & 371,3 \\
\hline Abr & 22,1 & 87,9 & 370,5 & 87,9 & 0,0 & 200,0 & 282,6 \\
\hline May & 21,7 & 87,5 & 244,6 & 87,5 & 0,0 & 200,0 & 157,1 \\
\hline Jun & 21,0 & 78,3 & 119,7 & 78,3 & 0,0 & 200,0 & 41,4 \\
\hline Jul & 20,8 & 78,8 & 91,5 & 78,8 & 0,0 & 200,0 & 12,7 \\
\hline Ago & 20,7 & 78,5 & 65,9 & 78,5 & 0,0 & 187,4 & 0,0 \\
\hline Sep & 21,0 & 78,1 & 70,7 & 70,7 & 7,4 & 0,0 & 0,0 \\
\hline
\end{tabular}




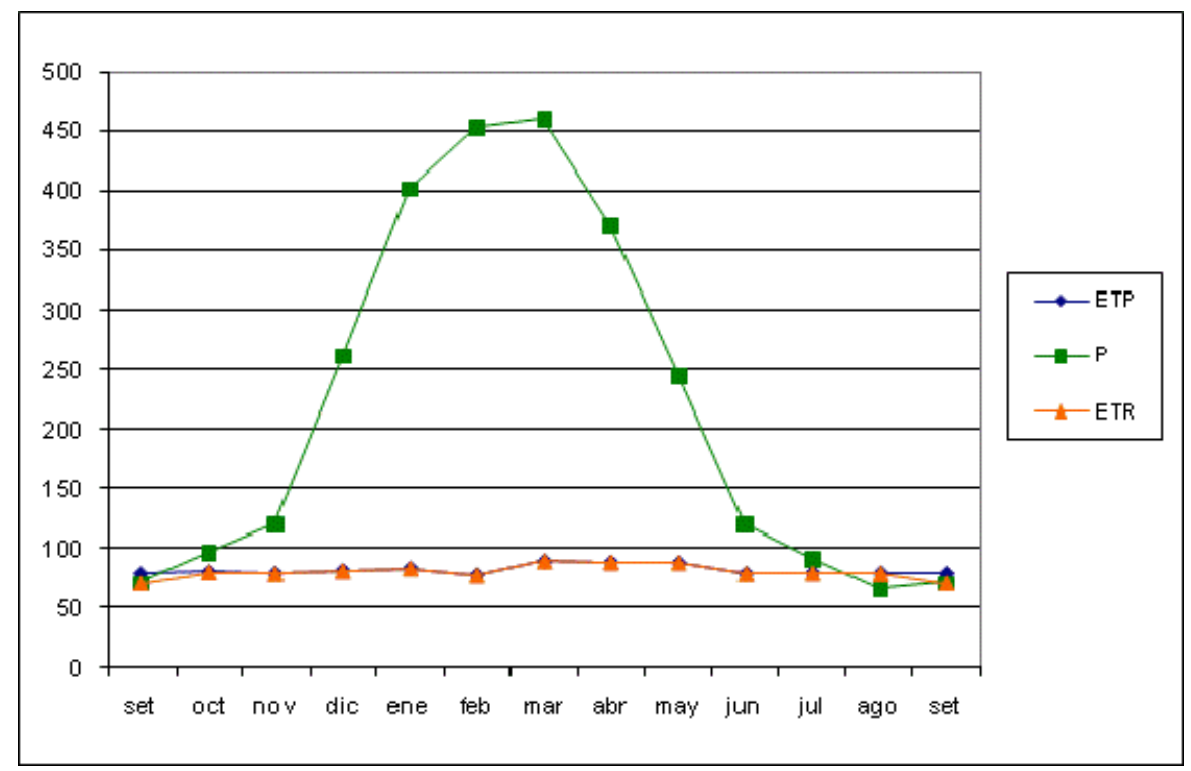

Figura 60. Balance Hídrico de La Libertad durante el período 2005-2010

\section{Estación Las Pampas}

El análisis hidro-climático utilizando la información de la estación Las Pampas corresponde a la zona alta de la cuenca de estudio durante el período 2005-2010. En la Tabla 44 se presenta los datos usados y los resultados obtenidos de la aplicación del programa para el cálculo del balance hídrico a nivel mensual. Se observa las temperaturas y precipitaciones medias mensuales y los resultados de los cálculos de la evapotranspiración potencia corregida (ETP corr), la evapotranspiración real (ETR), el déficit, la reserva y el excedente del agua en el suelo.

En la Figura 61 se muestra un comportamiento particular en el balance hídrico a nivel mensual, se observa que no existe déficit durante el año, de septiembre a junio se produce almacenamiento del agua en reserva y excedentes, y en julio y agosto el suelo utiliza el agua de las reservas.

Este comportamiento particular es característico de la zona debido a las estaciones climáticas, prácticamente durante todo el año se producen precipitaciones por lo que no hay déficit y toda el agua se va a llenar las reservas y a los excedente, sin embargo debemos considerar para este análisis la época húmeda de noviembre a mayo debido al aumento en las lluvias produciendo almacenamiento de agua en reserva y excedentes, y de junio a octubre se considera la época seca por la disminución de las lluvias provocando que el suelo utilice el agua de la reserva sin llegar al déficit, para nuevamente comenzar el llenado de la reserva con las lluvias de la época húmeda.

Si se observa la Tabla 44, durante todo el año se mantiene el llenado de la reserva debido a las permanentes lluvias en la zona, en enero el suelo llega a su capacidad máxima de humedad provocando que el exceso de agua escurra por los excedentes, entre julio y agosto una vez que disminuye la cantidad de lluvias propio de la época seca, el agua deja de ser excedente y el suelo consume las reservas, luego a partir de septiembre se inicia 
nuevamente el llenado del almacenamiento con las primeras lluvias de la época húmeda. Sin embargo se considera los meses de diciembre y mayo como de transición de la época seca a lluviosa y de la estación lluviosa a la seca respectivamente.

Tabla 44. Resumen del Balance Hídrico de la estación Las Pampas.

\begin{tabular}{|c|c|c|c|c|c|c|c|}
\hline Mes & $\begin{array}{c}\text { Temp Media } \\
\left.\text { Mens } \mathbf{(}{ }^{\circ} \mathbf{C}\right)\end{array}$ & $\begin{array}{c}\text { ETP corr } \\
(\mathbf{m m})\end{array}$ & $\begin{array}{c}\text { Precip Media } \\
\text { Mens }(\mathbf{m m})\end{array}$ & ETR $(\mathbf{m m})$ & $\begin{array}{c}\text { Déficit } \\
\mathbf{( m m})\end{array}$ & $\begin{array}{c}\text { Reserva } \\
\mathbf{( m m})\end{array}$ & $\begin{array}{c}\text { Excedentes } \\
\mathbf{( m m} \mathbf{)}\end{array}$ \\
\hline Sep & 18,0 & 66,2 & 76,6 & 66,2 & 0,0 & 10,3 & 0,0 \\
\hline Oct & 18,0 & 68,4 & 99,6 & 68,4 & 0,0 & 41,6 & 0,0 \\
\hline Nov & 18,0 & 66,2 & 119,5 & 66,2 & 0,0 & 94,9 & 0,0 \\
\hline Dic & 17,5 & 64,9 & 198,8 & 64,9 & 0,0 & 200,0 & 28,7 \\
\hline Ene & 17,6 & 65,6 & 310,6 & 65,6 & 0,0 & 200,0 & 24,9 \\
\hline Feb & 17,7 & 60,4 & 346,3 & 60,4 & 0,0 & 200,0 & 285,9 \\
\hline Mar & 18,0 & 68,4 & 342,3 & 68,4 & 0,0 & 200,0 & 273,9 \\
\hline Abr & 18,3 & 68,2 & 320,3 & 68,2 & 0,0 & 200,0 & 252,1 \\
\hline May & 18,4 & 71,2 & 186,7 & 71,2 & 0,0 & 200,0 & 115,5 \\
\hline Jun & 18,0 & 66,2 & 76,6 & 66,2 & 0,0 & 200,0 & 10,4 \\
\hline Jul & 17,9 & 67,7 & 44,7 & 67,7 & 0,0 & 177,0 & 0,0 \\
\hline Ago & 17,9 & 67,7 & 56,9 & 67,7 & 0,0 & 166,3 & 0,0 \\
\hline Sep & 18,0 & 66,2 & 76,6 & 66,2 & 0,0 & 10,3 & 0,0 \\
\hline
\end{tabular}

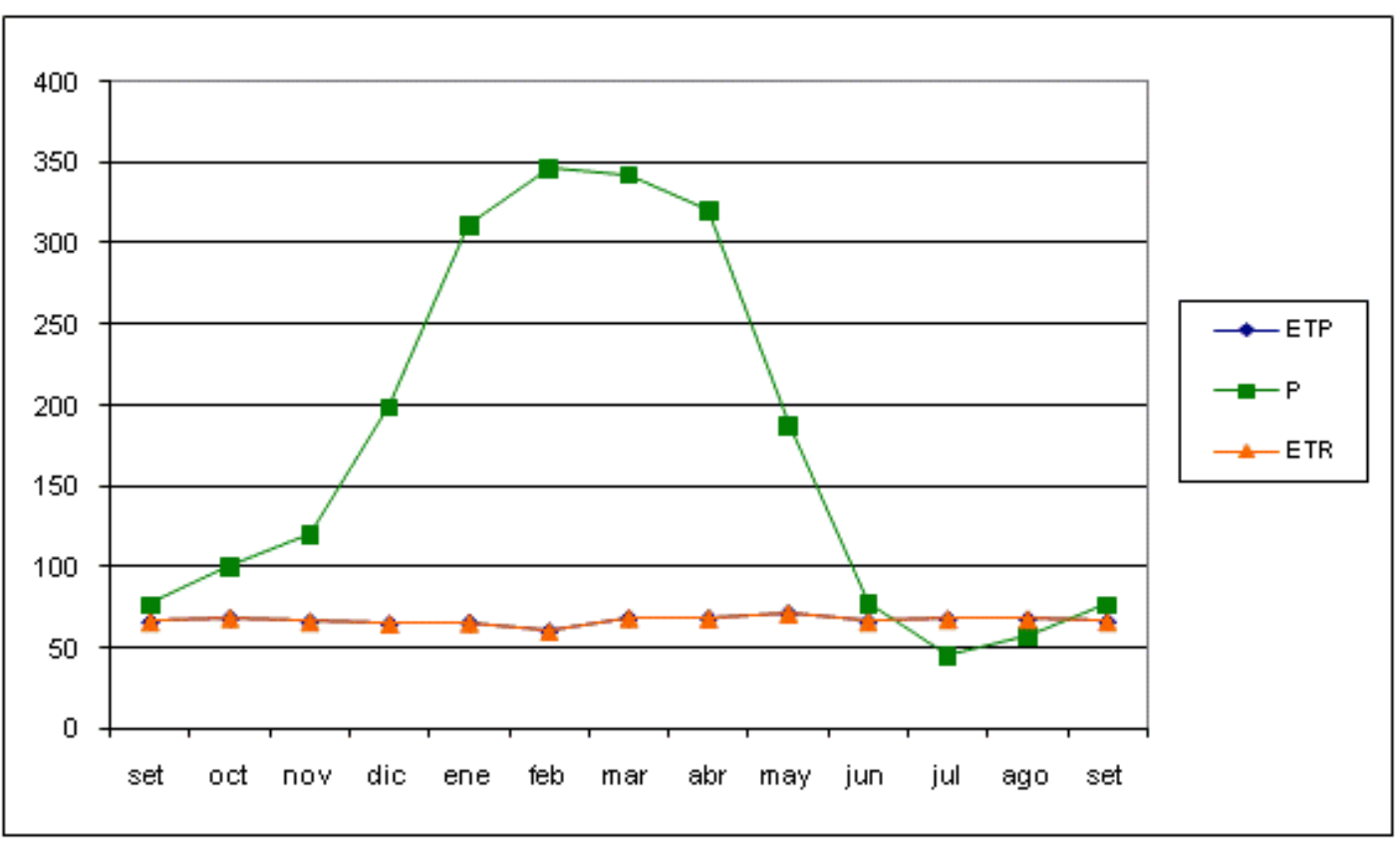

Figura 61. Balance Hídrico de Las Pampas durante el período 2005-2010 


\section{6.- Integración de los Sistemas de Información Geográfica (SIG)}

\subsubsection{Generación del Modelo Cartográfico}

El modelo cartográfico diseñado para la elaboración de los mapas temáticos del área de la cuenca de estudio, que se muestra en la Figura 62, expresa la secuencia del proceso de análisis cartográfico desarrollado en este trabajo. A partir de la información temática disponible en internet y recopilada de los organismos rectores se obtuvo información básica del área de estudio, reflejada en la cartografía elaborada.

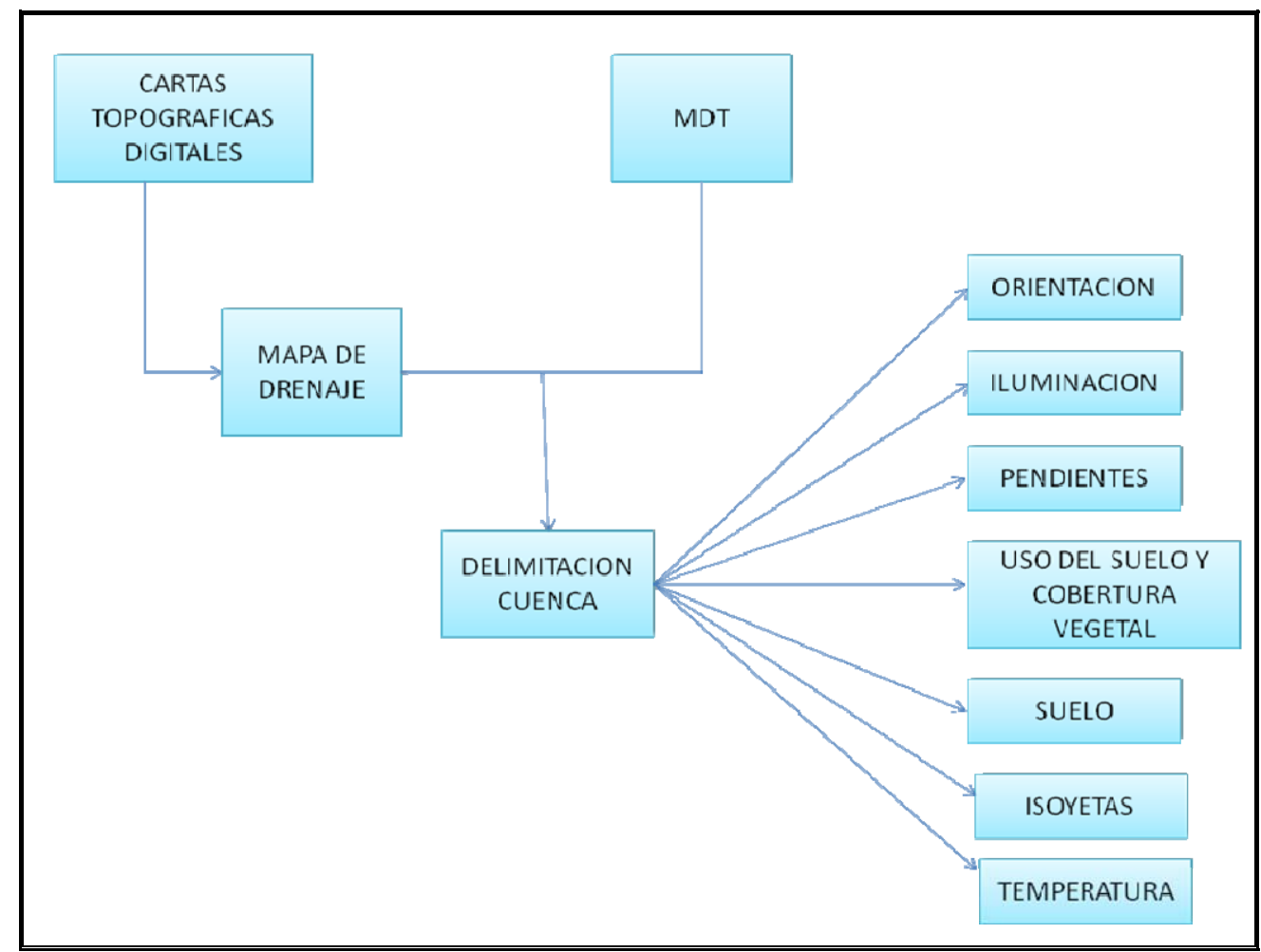

Figura 62. Esquema del Modelo Cartográfico para la elaboración de mapas temáticos.

\section{Mapa Topográfico y Modelo de Elevación Digital (MED)}

El mapa topográfico proporciona la distribución de las curvas de nivel que describen el relieve de la cuenca del Río Toachi. La cota máxima que presenta la cuenca es de 3.160 metros sobre el nivel del mar, y la mínima de 160 metros. En la Figura 63 se ven representado por color verde las cotas mínimas y en color rojo las cotas máximas. Cabe mencionar que en el mapa se presenta también el límite de la cuenca 


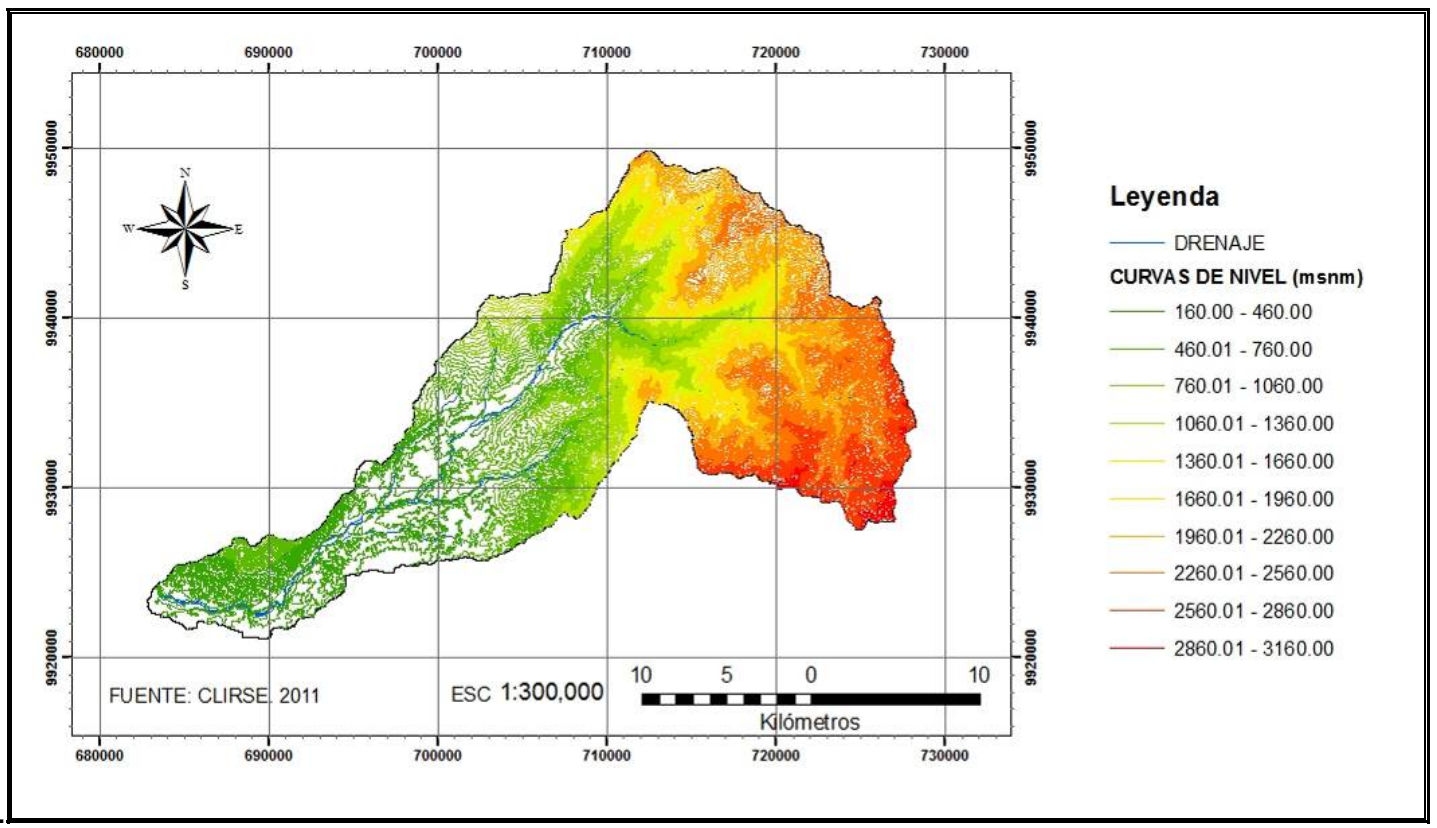

Figura 63. Mapa Topográfico de la Cuenca del Río Toachi

La interpretación altimétrica del Modelo de Elevación Digital (MED), que se presenta en la Figura 64, se realizó a través de la paleta de colores de la leyenda del mapa, correspondiendo el color rojo a las cotas más altas de la cuenca, del orden de los 3150 metros sobre el nivel del mar (m.s.n.m.) y la de menor cota de color verde correspondiendo a niveles de 160 metros sobre el nivel del mar. En este mapa también puede observarse el sistema de drenaje de la cuenca de estudio en color celeste.

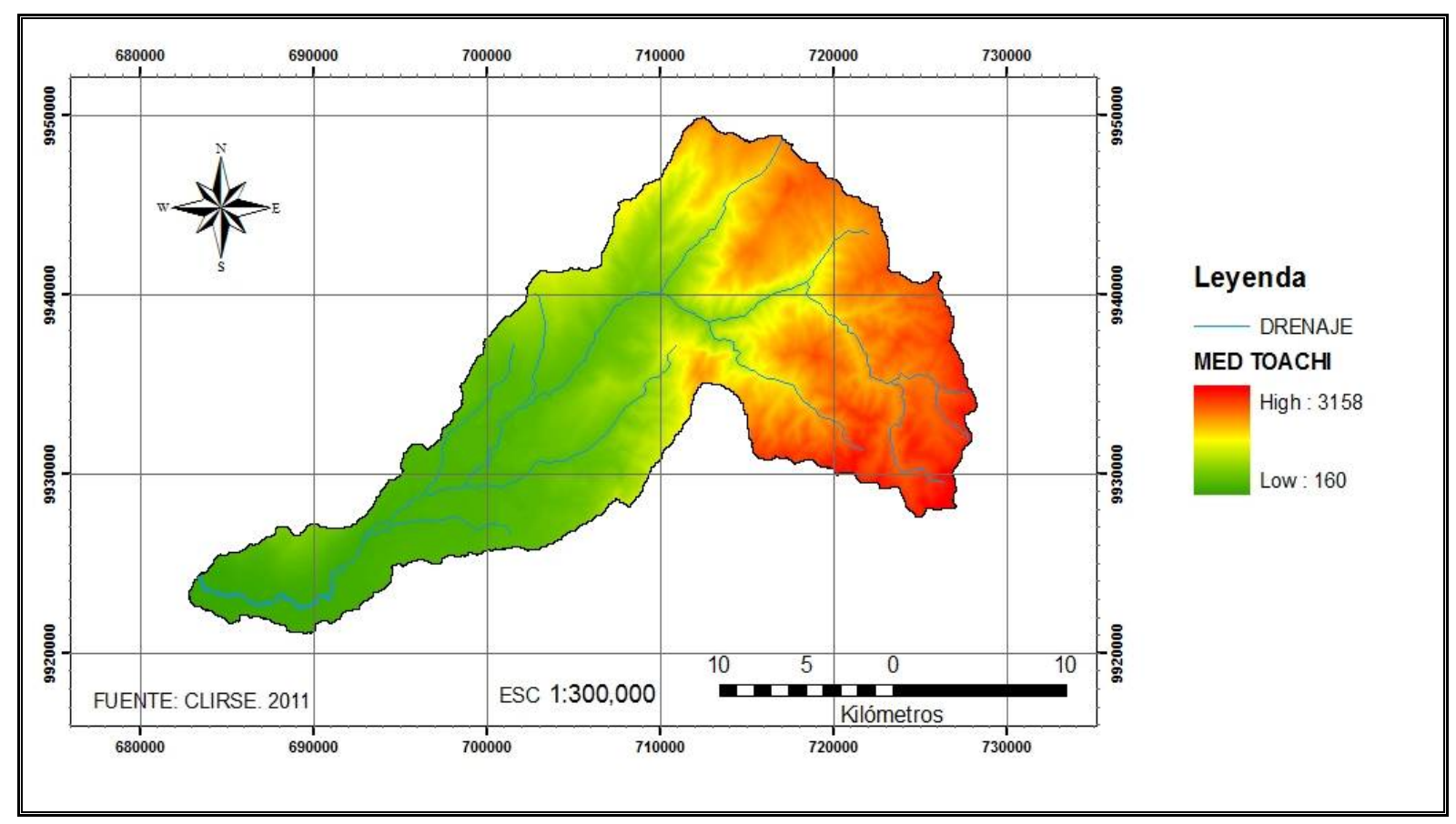

Figura 64. Modelo de Elevación Digital (MED) de la Cuenca del Río Toachi 


\subsubsection{Red de Drenaje}

El Río Toachi tiene su origen en las estribaciones de la Cordillera Occidental, nace de la conjunción de los Ríos Rayo y Cochapamba, siguiendo una trayectoria Noroeste por donde recoge las aguas de varios cauces permanentes y semipermanentes, luego gira hacia el Oeste para recibir las aguas del Río Victoria, Río Blanco y otros afluentes donde pasa a llamarse Río Toachi Grande. Luego cambia su trayectoria hacia el Suroeste descendiendo por la ladera de la cordillera recibiendo el caudal del Río Toachi Chico y más adelante las aguas del Río Damas donde se denomina Río Toachi hasta descargar su caudal en el Río Baba 4 km aguas abajo de la estación de aforo H414 Toachi DJ Baba, posteriormente pasa a llamarse Río Quevedo. Desde su nacimiento hasta el sitio donde se ubica la estación de aforo, el río tiene una longitud aproximada de $70 \mathrm{~km}$. (ver Figura 65).

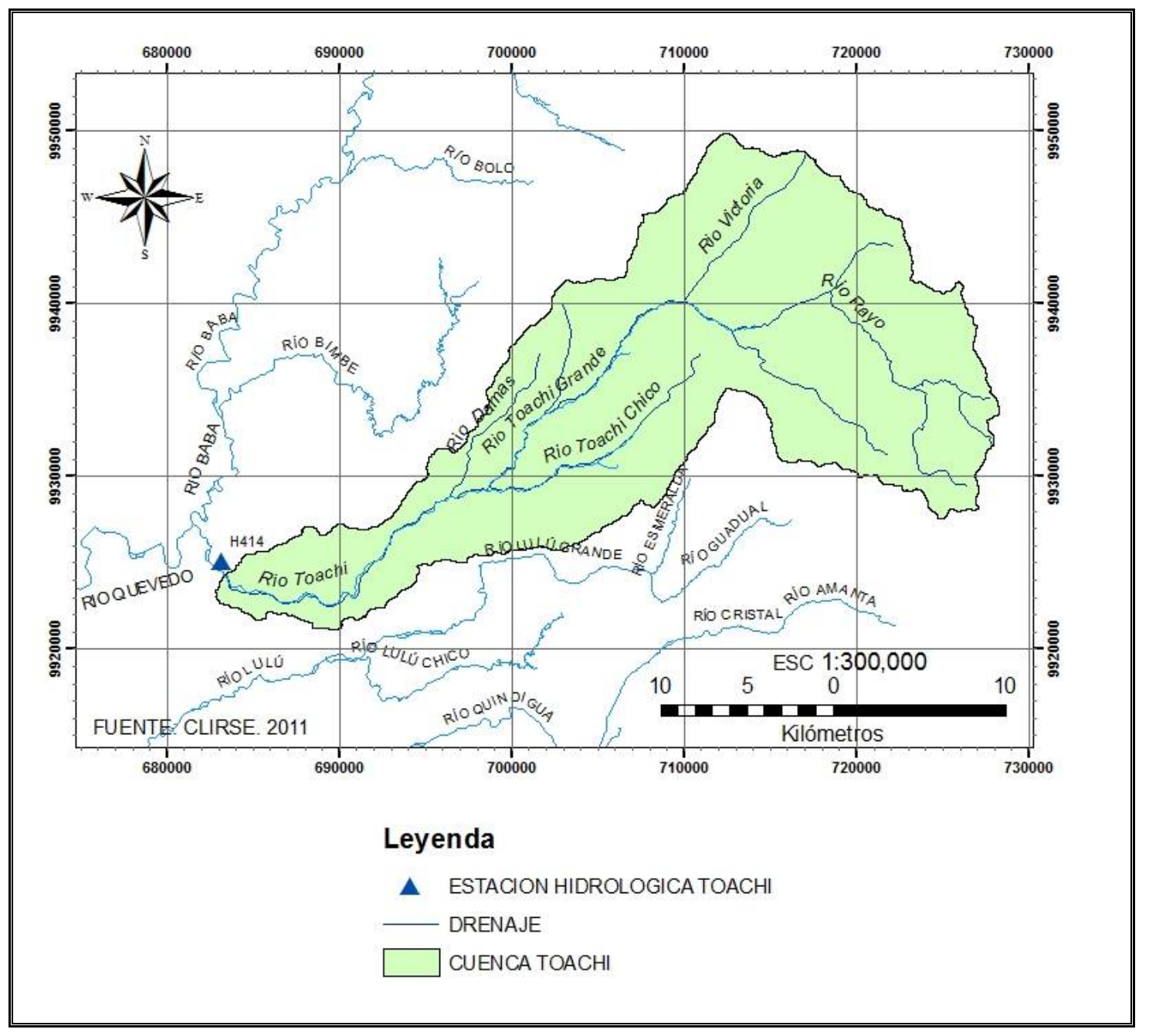

Figura 65. Mapa de la Red de Drenaje del área de estudio 


\subsubsection{Delimitación de cuenca y subcuencas}

Para obtener un mayor nivel de detalle y uniformidad de los parámetros característicos de la cuenca, y siendo los grupos hidrológicos del suelo el factor predominante para la determinación de la producción de caudales y sedimentos, se procedió a la división de la cuenca del Río Toachi a nivel de subcuenca.

Se identificaron 7 subcuencas, en la zona alta se establecieron las subcuencas 1, 2, 3 y 4 , en la zona media las subcuencas 5 y 6 , y en la zona baja la subcuenca 7 , asignando a cada una un color diferente que se detalla en la leyenda correspondiente del mapa de la Figura 66. En las Tablas de la sección 5.2.4 se presentan las características morfométricas de las subcuencas.

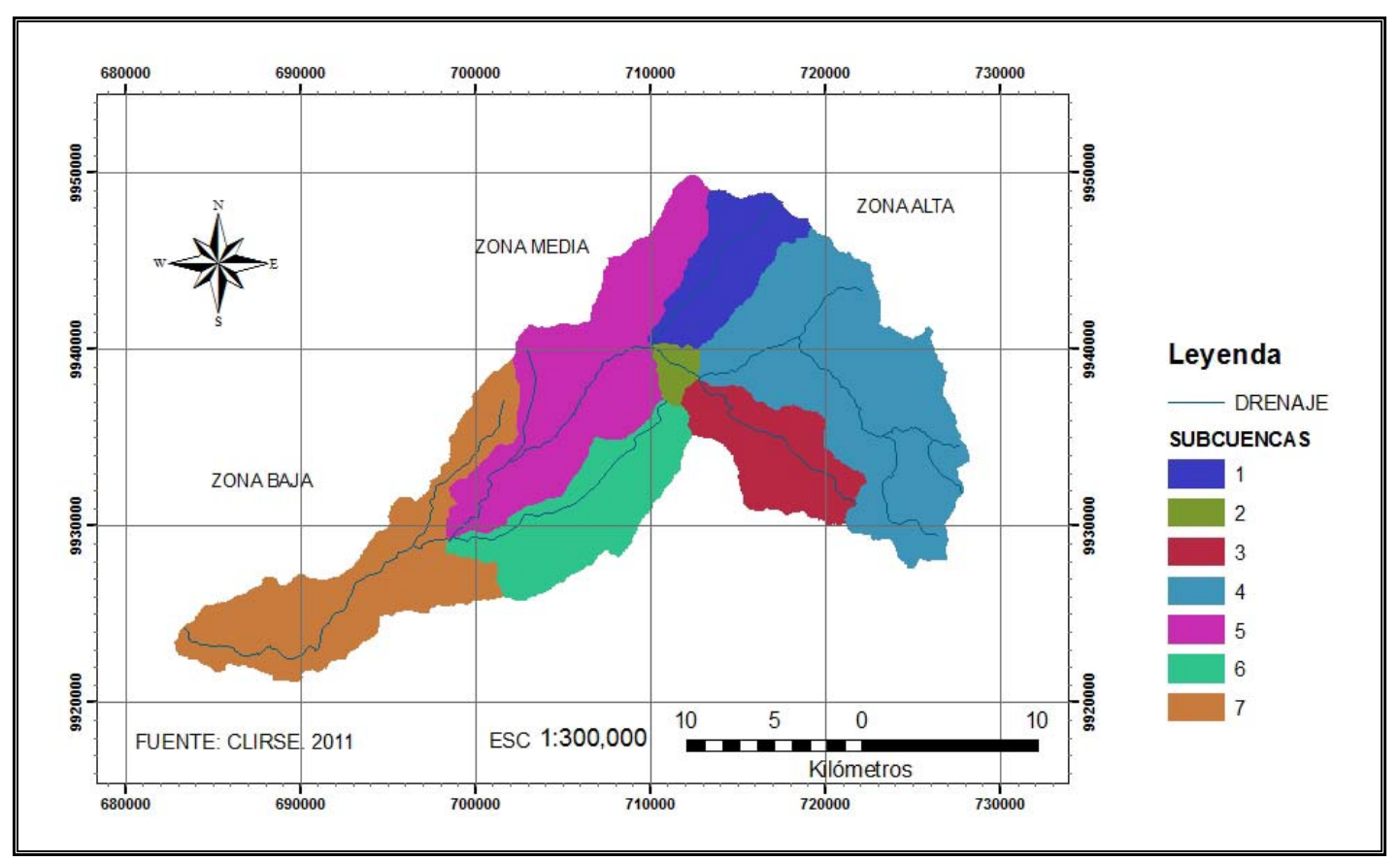

Figura 66. Mapa del Límite de la Cuenca con sus subcuencas del Río Toachi.

\subsubsection{Mapa de Orientación de laderas}

La clasificación de la cuenca de estudio, según su orientación o exposición, se efectuó mediante el comando Surface Analysis de la extensión Spatial Analysis del programa ArcGIS $9.3 \AA$, obteniendo el mapa representado en la Figura 67 con la orientación de las laderas en grados $\left(^{\circ}\right)$ respecto al norte de la cuadrícula. 


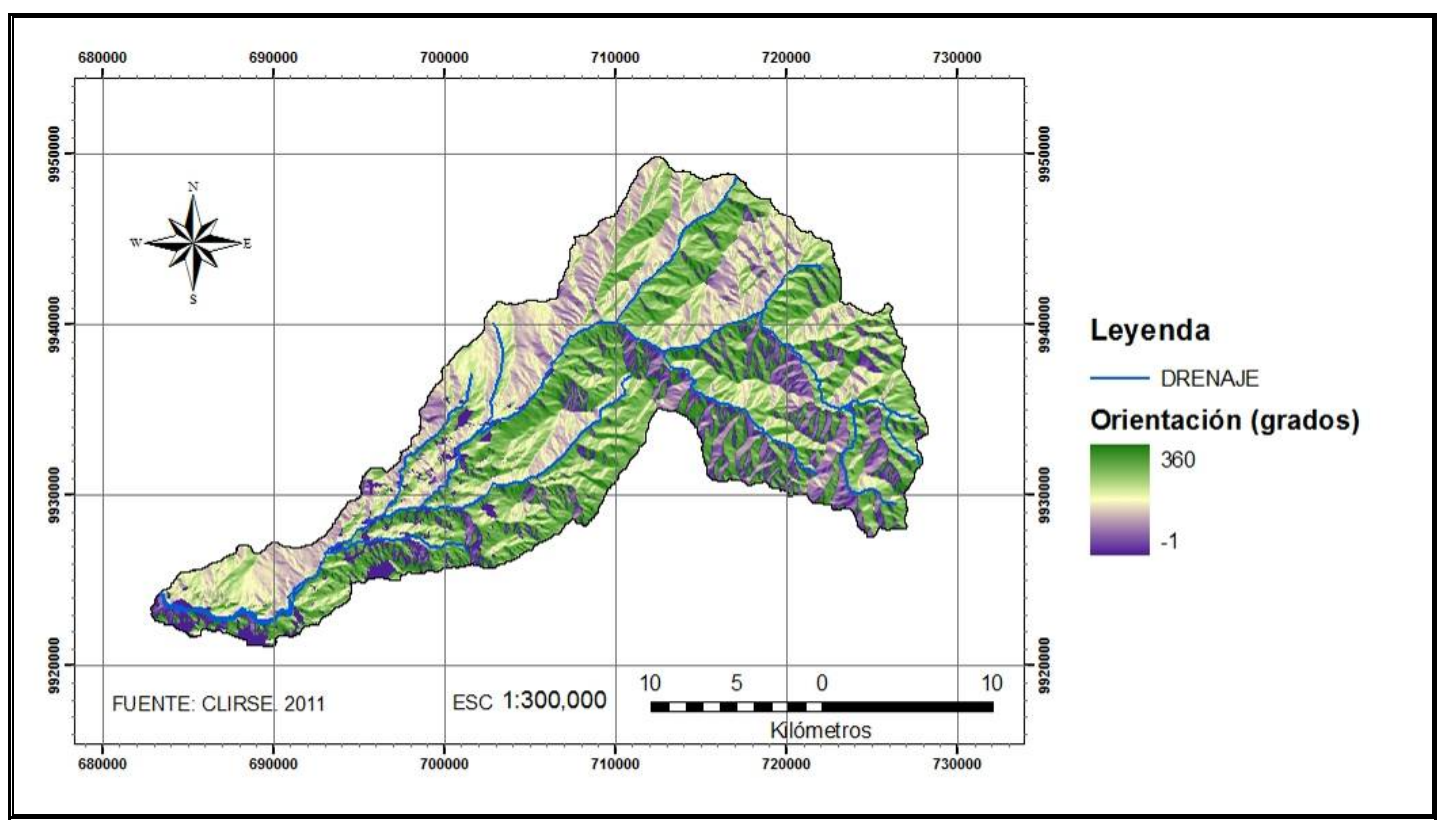

Figura 67. Mapa de Orientación de las laderas en grados de la Cuenca del Río Toachi.

Agrupando el mapa anterior en rangos de $45^{\circ}$, se obtuvieron nueve clases, las cuales se presentan en la Tabla 45, que refleja la clasificación en rangos de orientación con respecto al norte de la cuadrícula, una corresponde a las zonas llanas o sin pendientes y las otras con relación a los puntos cardinales, quedando representado el mapa de orientaciones en la Figura 68.

Tabla 45. Rangos de orientación de las laderas de la Cuenca del Río Toachi. 
Modelización Hidrológica de un área experimental en la Cuenca del Rio Guayas

\begin{tabular}{|c|c|c|}
\hline Clases & $\begin{array}{c}\text { Rangos de orientación con respecto al } \\
\text { Norte cuadrícula (grados) }\end{array}$ & $\begin{array}{l}\text { Exposición de } \\
\text { laderas }\end{array}$ \\
\hline 1 & -1 & Llano \\
\hline 2 & $0^{\circ}-22,5^{\circ}$ y $337,5^{\circ}-360^{\circ}$ & Norte \\
\hline 3 & $22,5^{\circ}-67,5^{\circ}$ & Noreste \\
\hline 4 & $67,5^{\circ}-112,5^{\circ}$ & Este \\
\hline 5 & $112,5^{\circ}-157,5^{\circ}$ & Sureste \\
\hline 6 & $157,5^{\circ}-202,5^{\circ}$ & Sur \\
\hline 7 & $202,5^{\circ}-247,5^{\circ}$ & Suroeste \\
\hline 8 & $247,5^{\circ}-292,5^{\circ}$ & Oeste \\
\hline 9 & $292,5^{\circ}-337,5^{\circ}$ & Noroeste \\
\hline
\end{tabular}




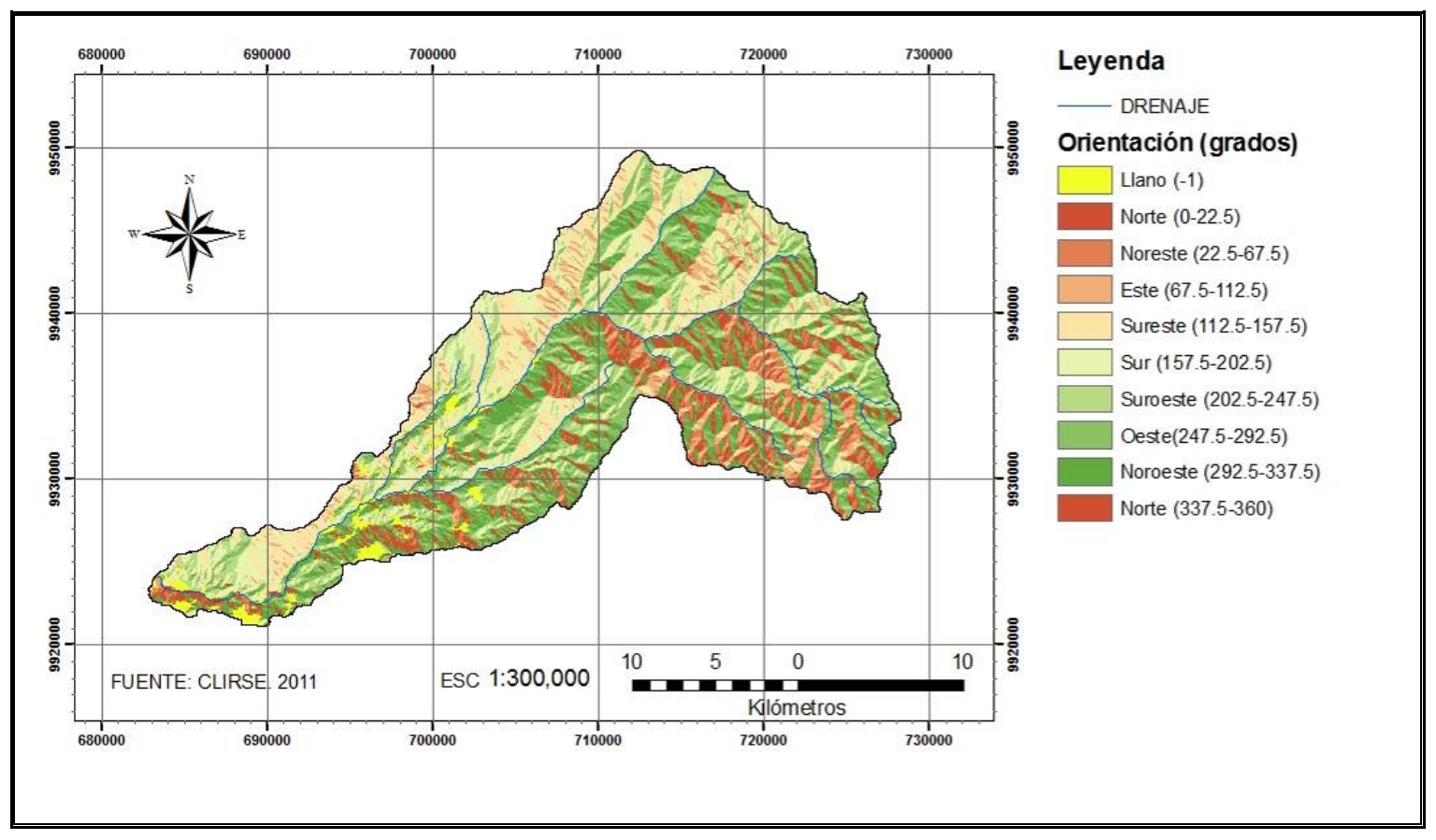

Figura 68. Mapa de Orientación de las laderas en rangos de exposición.

Dentro de las múltiples aplicaciones que podemos hacer con el mapa de orientaciones, Moreno et al., (2008) destaca que se pueden comparar las diferencias de radiación solar, en función de la orientación de las vertientes, con el objeto de evaluar su influencia sobre diversos aspectos como la variedad de vegetación, los proceso morfológicos, riesgo de aludes, etc.

\subsubsection{Mapa de lluminación}

A partir del modelo de elevación digital (MED) y mediante el uso de la extensión Spatial Analysis con el comando Surface Analysis del programa ArcGIS $9.3 \AA$, se obtuvo el mapa de sombreado del relieve que se presenta en la Figura 69.

Este mapa de iluminación de laderas se corrobora con el mapa de orientaciones, en el cual los valores expresan la rugosidad del relieve a través de la incidencia de los rayos solares sobre el terreno. El sombreado más oscuro representa las zonas de sombra de en las laderas y las áreas claras la incidencia del sol sobre el terreno. Se observa el color claro en la zona media baja y los colores obscuros en la zona alta. 


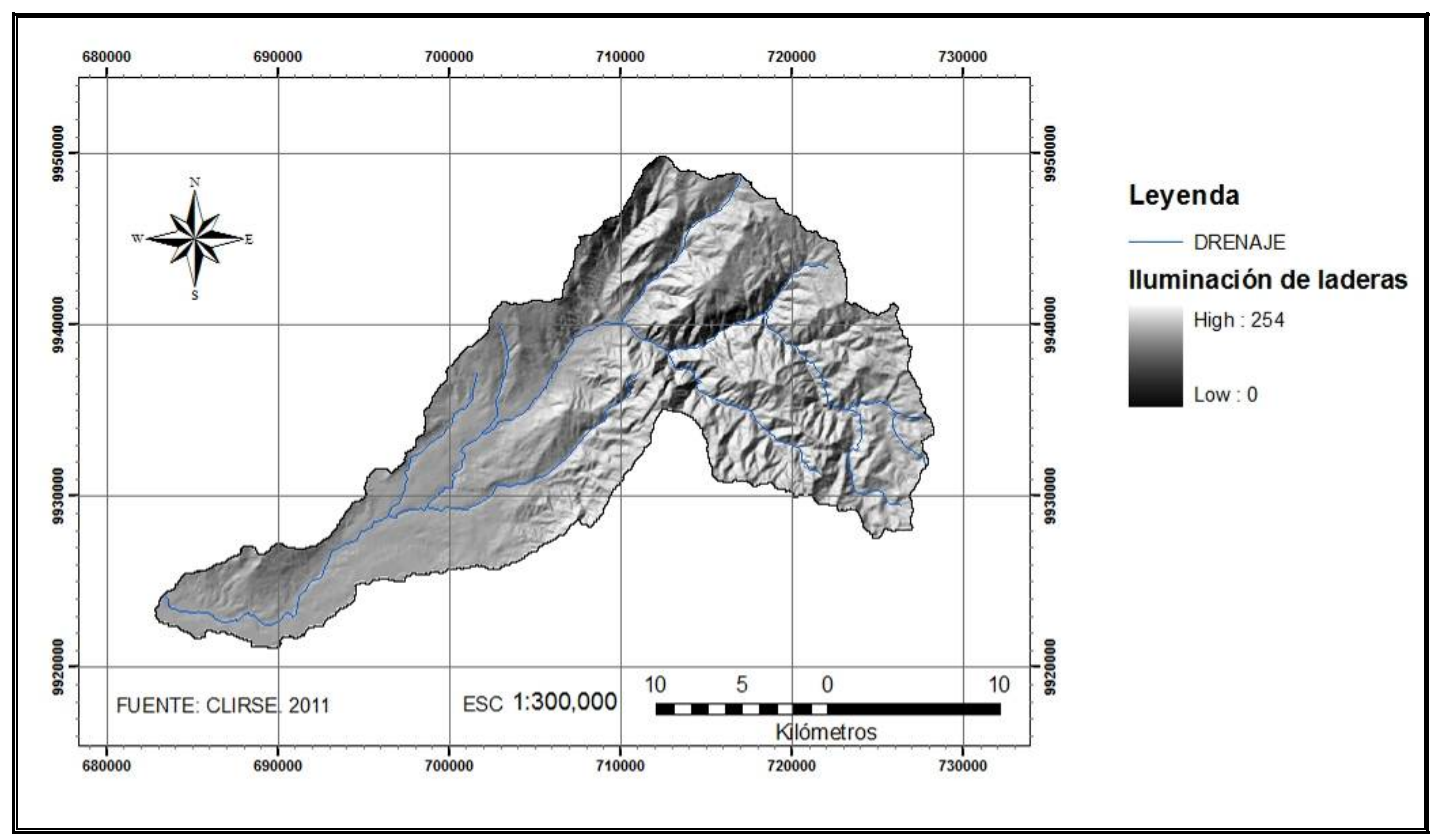

Figura 69. Mapa de lluminación del terreno de la Cuenca del Río Toachi.

\subsubsection{Mapa de Pendientes}

Con las herramientas para el Análisis Espacial del programa ArcGIS $9.3 \AA$, se zonificó el área en estudio según los intervalos de clases de pendiente de acuerdo a la clasificación propuesta por Mintegui Aguirre (1988) a partir del modelo de elevación digital (MDE), de esta manera se obtuvo el mapa de rango de pendiente de la Cuenca del Río Toachi (ver Figura 70)

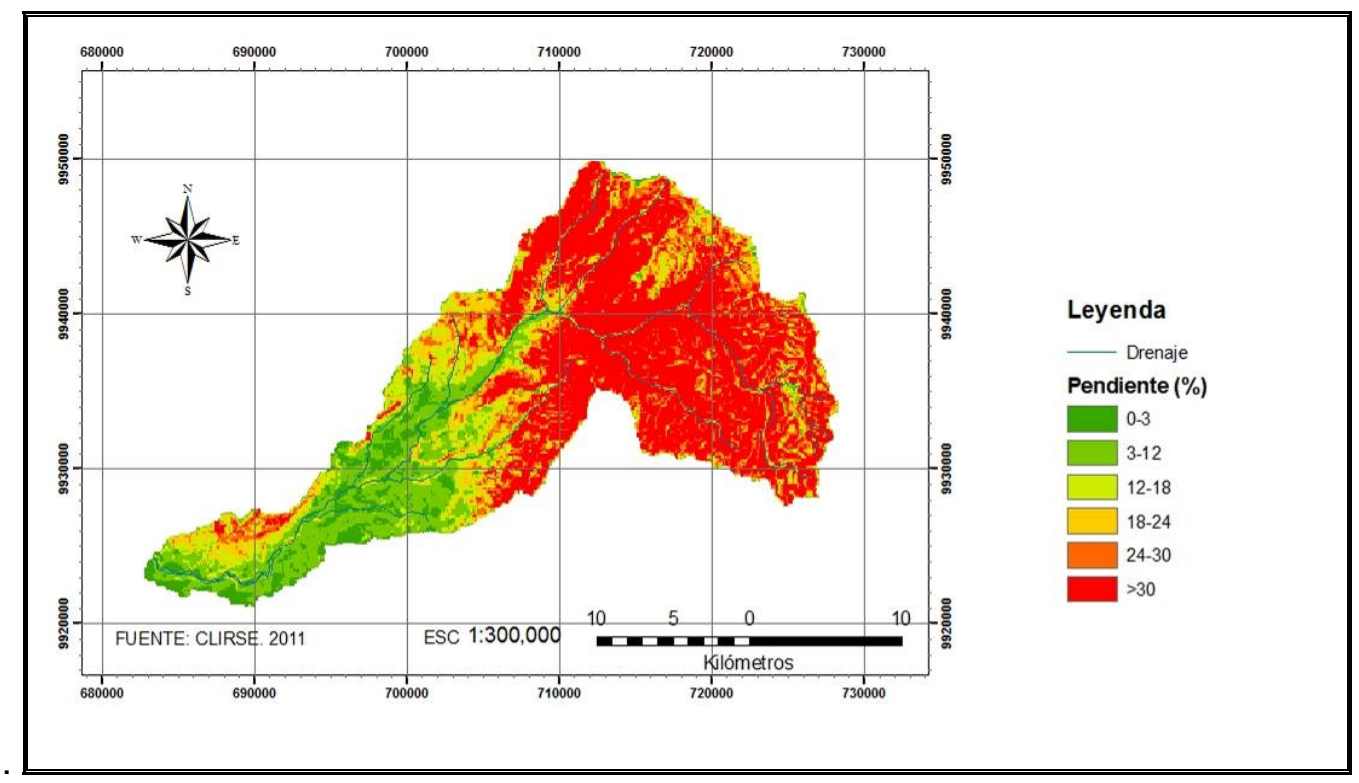

Figura 70. Mapa de Pendiente de la Cuenca del Río Toachi según su rango porcentual. 
A partir de la interpretación de la Figura 70 y según el tipo de relieve expresado en la Tabla 14 se realizó el cálculo de la superficie ocupada por cada rango de pendiente en la cuenca del Río Toachi, la cual se presenta en la Tabla 46.

Tabla 46. Superficie ocupada según rango de pendiente.

\begin{tabular}{|c|c|c|c|}
\hline $\begin{array}{c}\text { Pendientes } \\
\mathbf{( \% )}\end{array}$ & Tipo de relieve & $\begin{array}{c}\text { Superficie } \\
\text { ocupada (km }\end{array}$ & $\begin{array}{c}\text { Superficie } \\
\text { ocupada (\%) }\end{array}$ \\
\hline $0-3$ & Plano & 39,9 & 7,9 \\
\hline $3-12$ & Suave & 85,6 & 17,0 \\
\hline $12-18$ & Mediano & 51,4 & 10,2 \\
\hline $18-24$ & Levemente Accidentado & 54,9 & 10,9 \\
\hline $24-30$ & Accidentado & 47,5 & 9,4 \\
\hline$>30$ & Fuerte & 224,5 & 44,6 \\
\hline
\end{tabular}

De acuerdo a los autores Mintegui Aguirre y López Unzú (1990), la iniciación de la erosión laminar por arrastre de los elementos más finos aparece para pendientes entre $2 \%$ y $3 \%$ para un suelo con laboreo, con lo cual el área de la cuenca estudio posee un 7,9\% de la superficie con susceptible riesgo de sufrir erosión hídrica superficial ante el laboreo.

El $17 \%$ de la cuenca se caracteriza por tener un relieve suave que presenta pendientes con potencial uso agropecuario, con una recomendada implementación de medidas conservacionistas sobre el rango de pendiente de $3 \%-12 \%$.

El rango de pendiente de los $12 \%$ - $30 \%$, ocupa una superficie de $30,5 \%$ del total de la cuenca, implicando además zonas de alto riego de erosión hídrica. En estas pendientes no son aptas para cultivos, si para pastura o bosques.

En el caso de pendientes mayores a $30 \%$ se encuentra representando el $44,6 \%$ de la cuenca, en donde es alto el riesgo de erosión hídrica, no debería destinarse a explotación productiva alguna, ni agrícola ni forestal. Se debe mantener la vegetación forestal para la protección contra la erosión hídrica.

\subsubsection{Mapa de Suelos}

El mapa de suelos de la cuenca del Río Toachi, se presenta en la Figura 71. La identificación y clasificación de los suelos está de acuerdo al Sistema de Clasificación de Suelos de los Estados Unidos "Soil Taxonomy, USDA, $2006^{16}$.

\footnotetext{
${ }^{16}$ PRONAREG-ORSTOM , 1980
} 


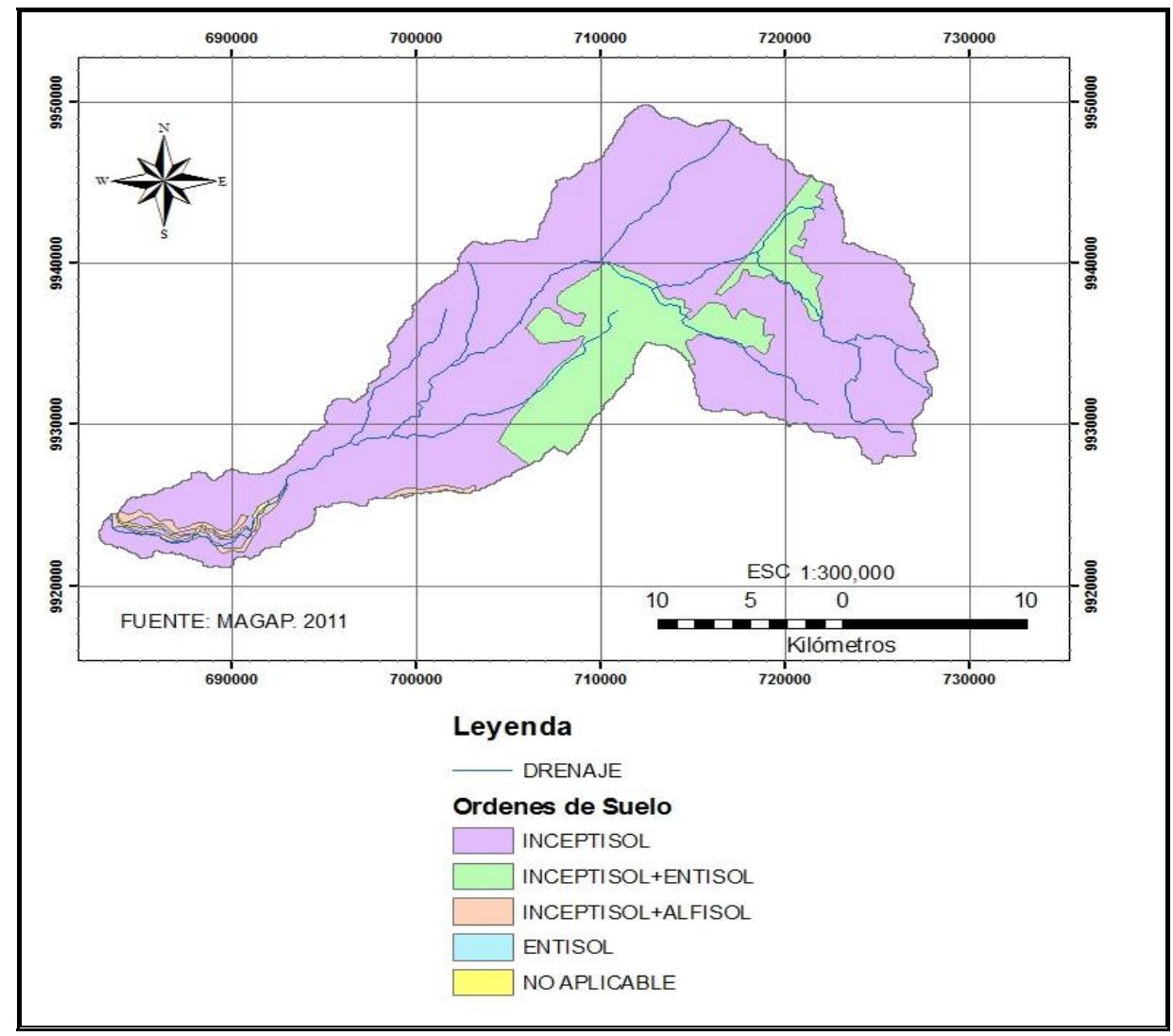

Figura 71. Clasificación del suelo de la Cuenca del Río Toachi

De manera general, los suelos en la cuenca del Río Toachi se clasifican bajo el Orden de los Inceptisoles, principalmente del tipo arcilloso, caracterizado por tener un buen drenaje y una profundidad entre 50 y $100 \mathrm{~cm}$.

El grupo Entisol es despreciable debido a la pequeña cantidad encontrada, así lo refleja la Figura 72. La descripción del grupo Entisol, se realizó en la sección 3.7

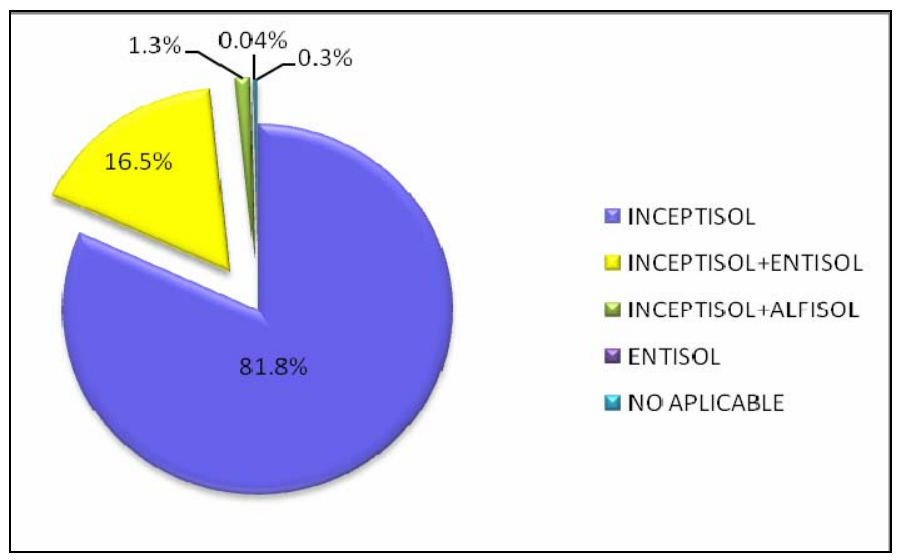

Figura 72. Porcentajes de tipos de suelos en la Cuenca del Guayas. 


\subsubsection{Mapa de Cobertura Vegetal y Uso de Suelo}

EL mapa correspondiente a la cobertura vegetal y uso de suelo de la cuenca del Río Toachi se presenta en la Figura 73, cuya identificación y clasificación de usos se realizó en base a la información proporcionada por CLIRSEN.

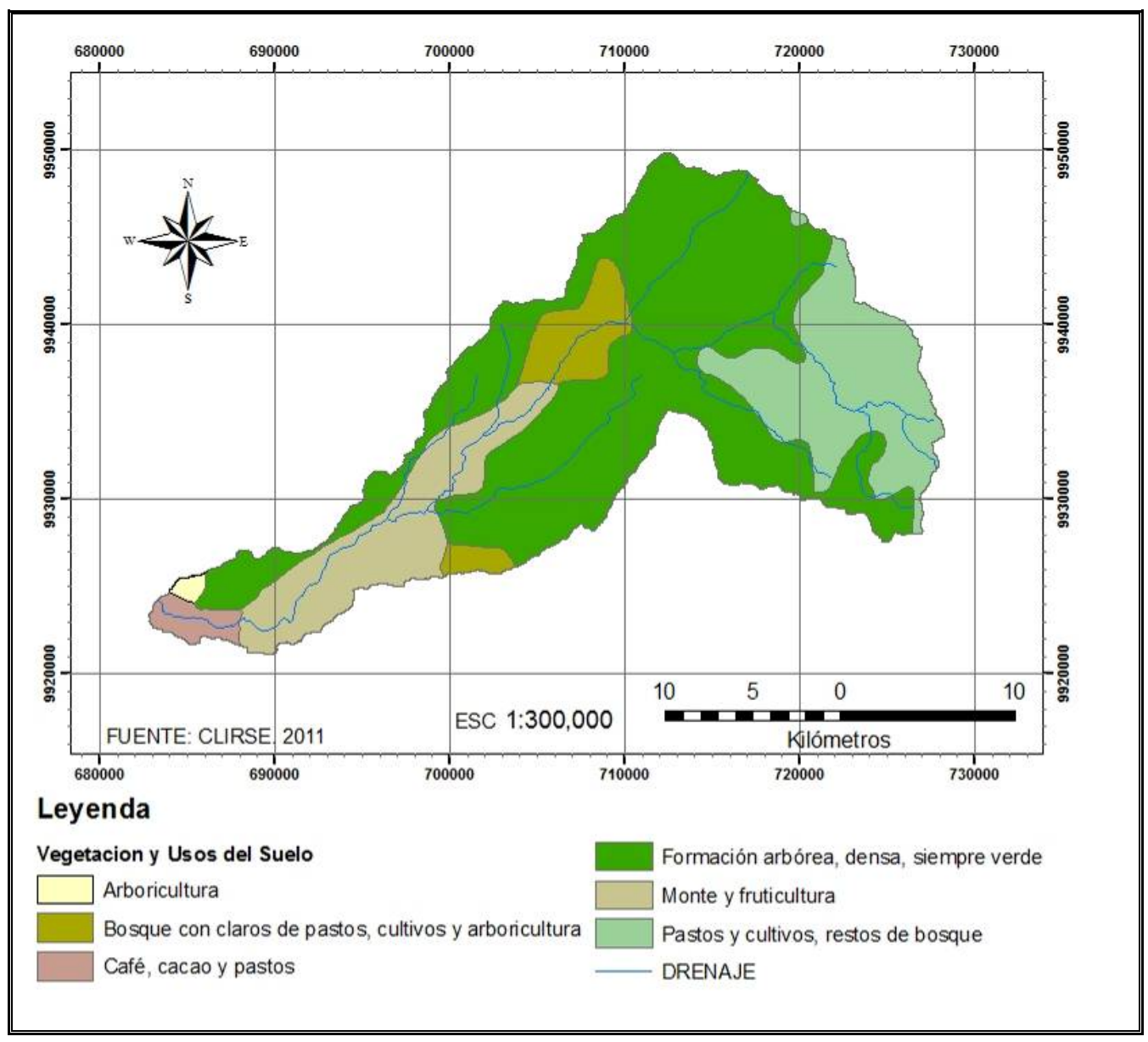

Figura 73. Mapa de la cobertura vegetal y uso del suelo de la cuenca del Río Toachi

En la Tabla 47, se presentan las clasificaciones de cobertura vegetal, las cuales se describen a continuación: 


\section{Café, cacao y pastos}

Las principales plantaciones están representadas por aquellas que tiene un manejo especial debido a su elevada inversión y alto rendimiento económico como son los cultivos permanentes de café y cacao. Además se asocian a este grupo los cultivos permanentes de ciclo corto como el maíz, arroz y soya, los cuales han sido representados en esta clasificación por estar agrupados en su mayor parte con esta clase de vegetación. Esta clasificación ocupa una superficie de $9,76 \mathrm{~km}^{2}$ equivalente al $2,0 \%$ del área total de la cuenca.

\section{Monte y fruticultura}

Está constituido por cultivos de banano, plátano y palma africana que tienen un elevado rendimiento en los mercados internacionales. Las plantaciones son permanentes durante todo el año y ocupan varias zonas de la cuenca de estudio. Pertenecen a este grupo el abacá y la caña de azúcar, que es utilizada para la producción artesanal de alcohol y azúcar, además los cultivos permanentes de ciclo corto de yuca, cebada, habas y papas. Ocupan una superficie de $73 \mathrm{~km}^{2}$ que representa el $14,53 \%$ del área total.

\section{Bosques con claros de pasto}

Vegetación natural compuesta principalmente por comunidades de plantas consideradas como remanentes de la vegetación primaria, comprende arboles que alcanzan los 30 metros de alto, con especies comerciales importantes económicamente que contribuyen a la regeneración natural, también llamado Bosque natural. Dominan un área de $31,55 \mathrm{~km}^{2}$ que representa el $6,0 \%$ de la superficie total.

\section{Arboricultura}

Comprende cultivos permanentes de árboles frutales como guaba, cítricos, guanábana, zapote, papaya, maracuyá, banano, caña de azúcar, entre otros que se asocian junto con plantaciones dominantes de cacao y café. Ocupan una pequeña área de $2,30 \mathrm{~km}^{2}$ representando una superficie menor al $1,0 \%$ de la superficie total.

\section{Pastos y cultivos, restos de bosques}

Los pastos han permitido que se desarrolle una ganadería con pastoreo intensivo los cuales se encuentran por toda la cuenca formando áreas de pasto puro y en otras se encuentran en asociación con cultivos de ciclo corto como el maíz, soya, con plantaciones de árboles frutales y en otras zonas con vegetación del bosque secundario en crecimiento. Este grupo ocupa una superficie de $95 \mathrm{~km}^{2}$ representando el 19,0\% del área total de la cuenca de estudio.

\section{Formación arbórea, densa, variante de las vertientes exteriores de Los Andes}

Vegetación natural compuesta por la regeneración del bosque natural con presencia de especies de rápido crecimiento como la balsa y moral fino, se la conoce como bosque secundario. Se encuentra en extensas área de plantaciones distribuidas en toda la cuenca de estudio, en grupos de plantaciones puras de bosque secundario y además en asociación con pastos y árboles frutales. Esta clasificación de uso es dominante, está en forma 
progresiva y se halla distribuida en toda la cuenca de estudio ocupando la mayor superficie con $290,8 \mathrm{~km}^{2}$ que representa una superficie del $57,8 \%$ del área total.

Tabla 47. Clasificación de la cobertura vegetal y uso del suelo.

\begin{tabular}{|c|c|c|}
\hline VEGETACIÓN Y USO DEL SUELO & $\begin{array}{l}\text { AREA } \\
\left(\mathrm{km}^{2}\right)\end{array}$ & $\begin{array}{l}\text { PORC } \\
\text { (\%) }\end{array}$ \\
\hline Café, cacao y pastos & \multirow{3}{*}{9,76} & \multirow{3}{*}{1,94} \\
\hline Cultivos permanentes de cacao, café y pastos. & & \\
\hline Cultivos permanentes de ciclo corto de maíz, arroz y soya & & \\
\hline Monte $y$ fruticultura & \multirow{3}{*}{73,83} & \multirow{3}{*}{14,53} \\
\hline $\begin{array}{l}\text { Cultivos permanentes de banano, plátano, palma africana, } \\
\text { caña de azúcar, abacá }\end{array}$ & & \\
\hline $\begin{array}{l}\text { Cultivos permanentes de ciclo corto maíz, yuca, cebada, } \\
\text { habas, papas }\end{array}$ & & \\
\hline Bosques con claros de pasto & \multirow{2}{*}{31,55} & \multirow{2}{*}{6,27} \\
\hline Vegetación natural. Bosque natural & & \\
\hline Arboricultura & \multirow[b]{2}{*}{2,30} & \multirow{2}{*}{0,46} \\
\hline $\begin{array}{l}\text { Cultivos permanentes de arboricultura con cacao y café } \\
\text { dominante }\end{array}$ & & \\
\hline Pastos y cultivos, restos de bosque & \multirow{3}{*}{95,39} & \multirow{3}{*}{18,97} \\
\hline Pastos & & \\
\hline Cultivos de ciclo corto, arboricultura y bosques & & \\
\hline $\begin{array}{l}\text { Formación arbórea, densa, variante de las vertientes } \\
\text { exteriores de Los Andes }\end{array}$ & \multirow{3}{*}{290,88} & \multirow{3}{*}{57,84} \\
\hline Vegetación natural, bosque secundario & & \\
\hline Pastos y arboricultura & & \\
\hline TOTAL & 503,71 & 100,00 \\
\hline
\end{tabular}




\section{$\underline{\text { 5.6.1.8 Mapa de Isoyetas }}$}

El mapa de la distribución espacial de la precipitación en la cuenca del Río Toachi, se presenta en la Figura 74, como una red de Isoyetas medias anuales con intervalos de 100 $\mathrm{mm}$. La variación de las precipitaciones en la cuenca va desde $2400 \mathrm{~mm}$ en la zona baja en el extremo suroeste, hasta $3100 \mathrm{~mm}$ en la zona alta hacia el norte y este. En la cordillera los niveles de precipitación descienden hasta los $2500 \mathrm{~mm}$ con dirección sureste.

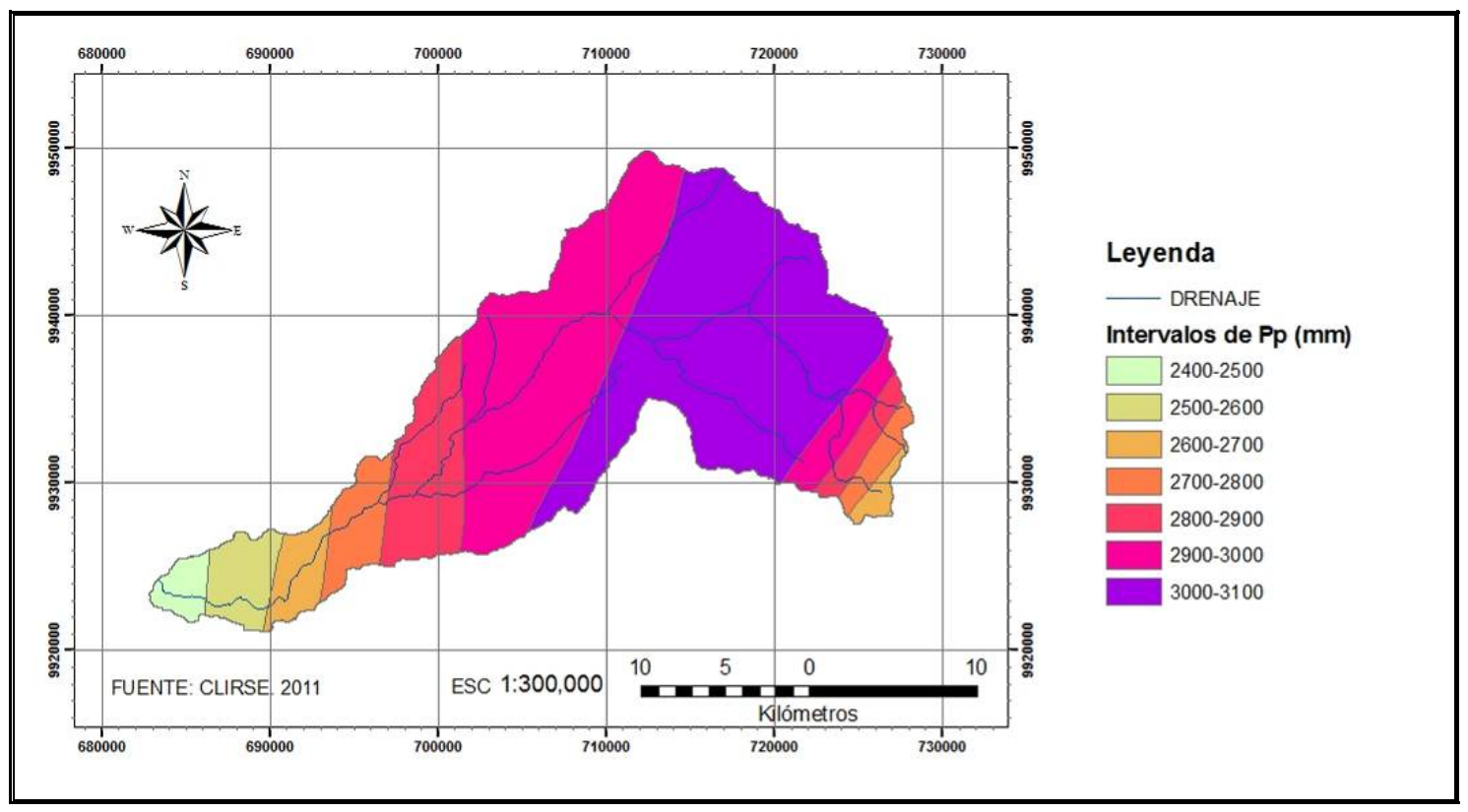

Figura 74. Mapa de Isoyetas de la Cuenca del Río Toachi.

\subsubsection{Mapa de Isotermas}

El mapa de la distribución espacial de la temperatura atmosférica en la cuenca del Río Toachi se presenta en la Figura 75 como Isolíneas con intervalos de $1^{\circ} \mathrm{C}$. La variación de la temperatura del aire en la cuenca del Río Toachi varía desde temperaturas de $10^{\circ} \mathrm{C}$ en la zona alta hasta los $25^{\circ} \mathrm{C}$ en la zona baja. 


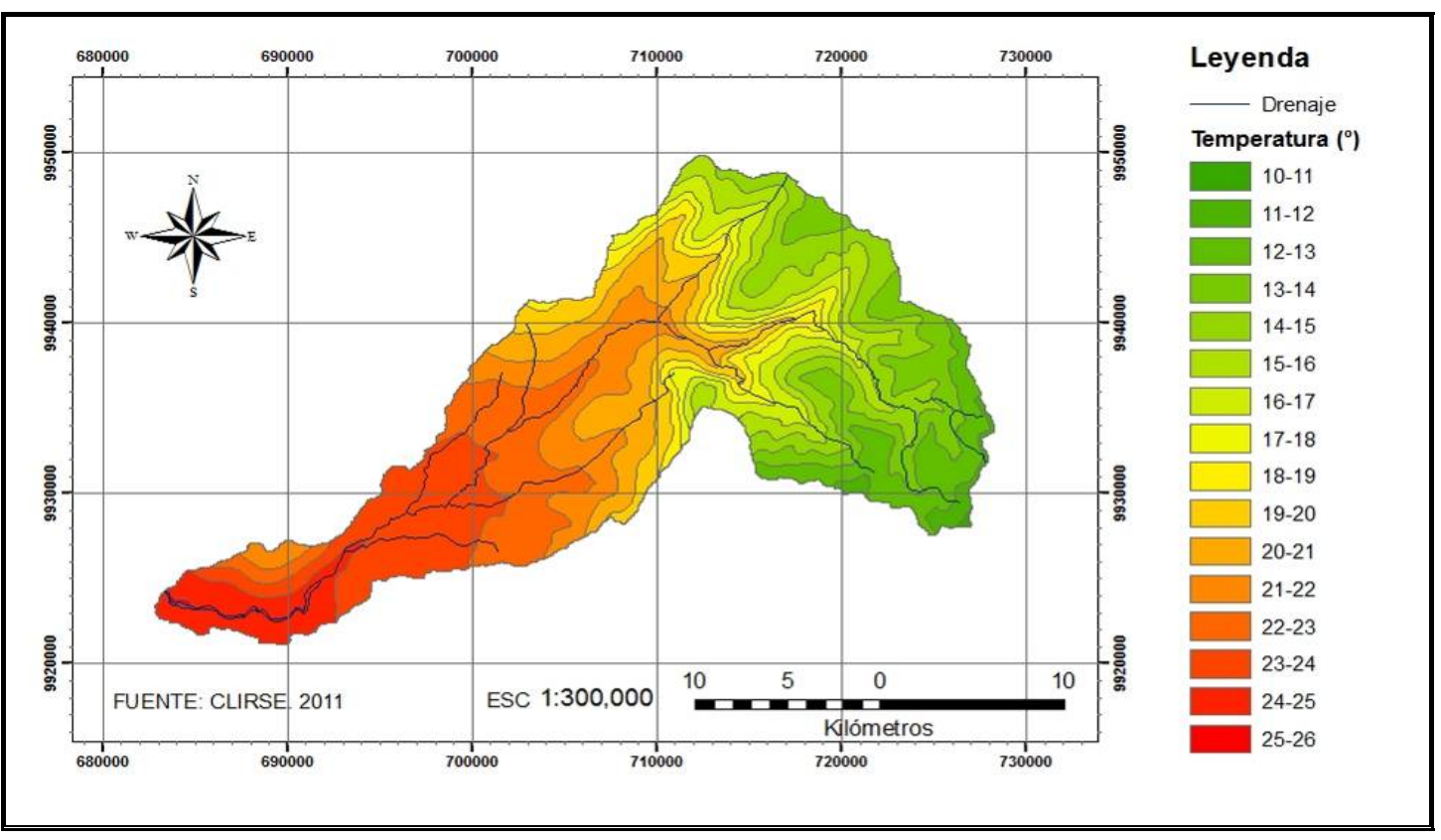

Figura 75. Mapa de Isotermas de la Cuenca del Río Toachi.

\subsubsection{Mapa de Zonas Climáticas}

Según la metodología descrita para la elaboración de las zonas climáticas en la cuenca del Río Toachi, en la Figura 76 se presenta el mapa de la interacción de la precipitación total anual y la temperatura media mensual que según la clasificación de Porrut determina las zonas climáticas del área de estudio. Como se puede observar en el mapa, las zonas climáticas varían desde Tropical Megatérmico muy Húmedo en la zona baja hasta Ecuatorial Frio Húmedo en la zona alta.

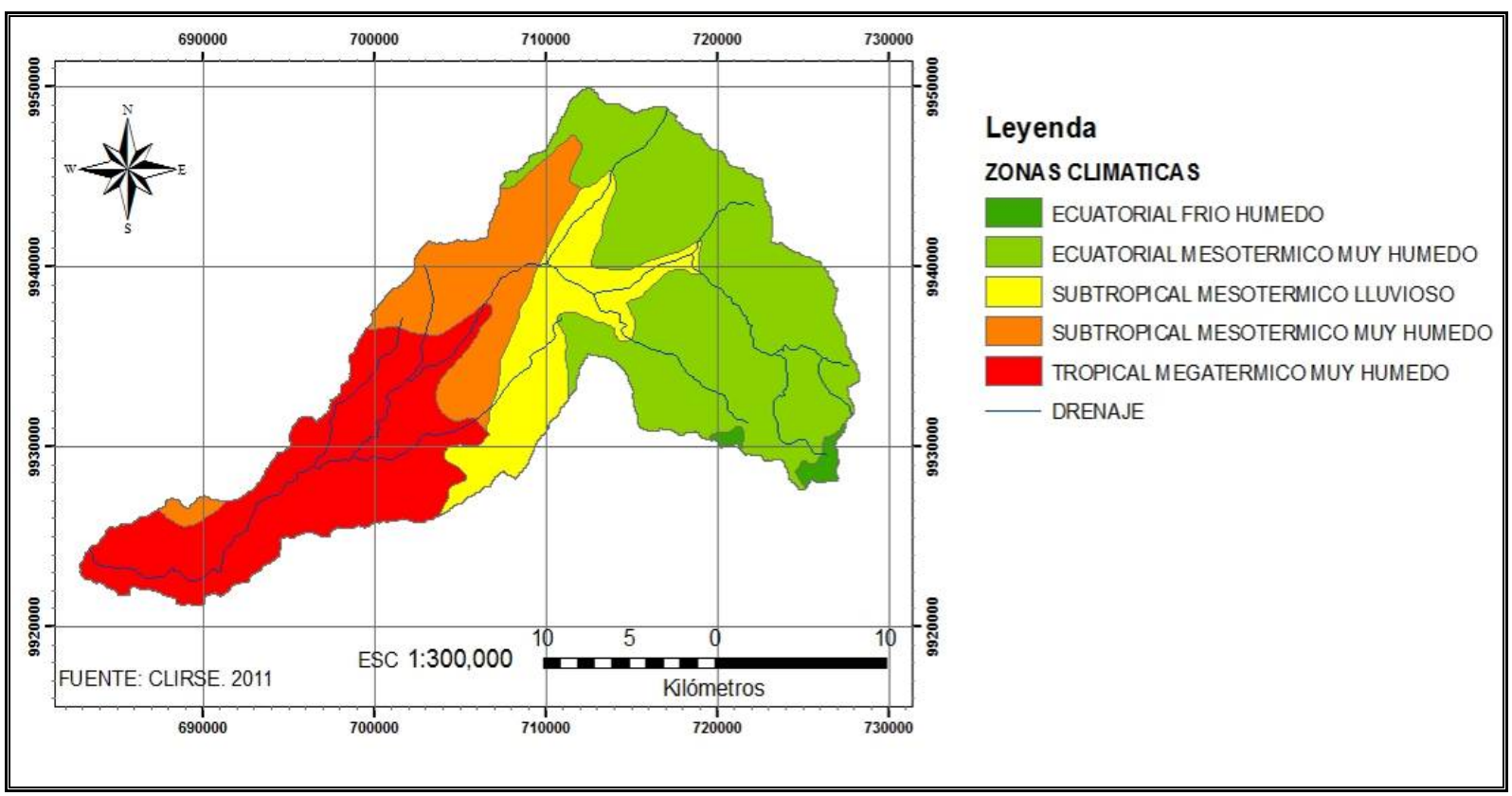

Figura 76. Mapa de Zonas Climáticas de la Cuenca del Río Toachi. 
Los tipos de clima Ecuatorial con sus variaciones de acuerdo a la temperatura y precipitación, se encuentran en las estibaciones de la Cordillera Occidental, los climas subtropicales en la zona central y el tropical en la zona baja de la cuenca.

En la Tabla 48 se detallan los rangos de temperatura media anual $\left({ }^{\circ} \mathrm{C}\right)$ y los rangos de precipitación total anual $(\mathrm{mm})$ para el área de la cuenca experimental.

Tabla 48. Tipos de Zonas Climáticas en la Cuenca del Río Toachi

\begin{tabular}{|l|c|c|c|}
\hline \multicolumn{1}{|c|}{ Tipo de Clima } & Símbolo & $\begin{array}{c}\text { Rango Temp } \\
\left({ }^{\circ} \mathbf{C}\right)\end{array}$ & $\begin{array}{c}\text { Rango Precip } \\
(\mathbf{m m})\end{array}$ \\
\hline ECUATORIAL FRIO HUMEDO & $\mathrm{Ew}$ & $08-12$ & $1000-2000$ \\
\hline ECUATORIAL MESOTERMICO MUY HUMEDO & $\mathrm{Cm}$ & $12-22$ & $2000-3000$ \\
\hline SUBTROPICAL MESOTERMICO LLUVIOSO & $\mathrm{Sf}$ & $12-22$ & $>3000$ \\
\hline SUBTROPICAL MESOTERMICO MUY HUMEDO & $\mathrm{Sm}$ & $12-22$ & $2000-3000$ \\
\hline TROPICAL MEGATERMICO MUY HUMEDO & $\mathrm{Am}$ & $>22$ & $2000-3000$ \\
\hline
\end{tabular}




\section{7.- Cálculo del Caudal Líquido}

\subsubsection{Método del S.C.S. para las abstracciones}

\subsubsection{Obtención del Número de Curva (NC)}

El método aplicado para la zonificación del escurrimiento superficial se basó en que las combinaciones del suelo-vegetación de características semejantes bajo un mismo grupo hidrológico, responderán de manera análoga bajo el efecto de una lluvia. A cada combinación suelo-vegetación, según el grupo hidrológico, se le asignó un Número de Curva (NC) que define las condiciones hidrológicas, es decir, su comportamiento frente al escurrimiento superficial. Para la obtención del Número de Curva se aplicó el esquema del modelo cartográfico presentado en la Figura 77.

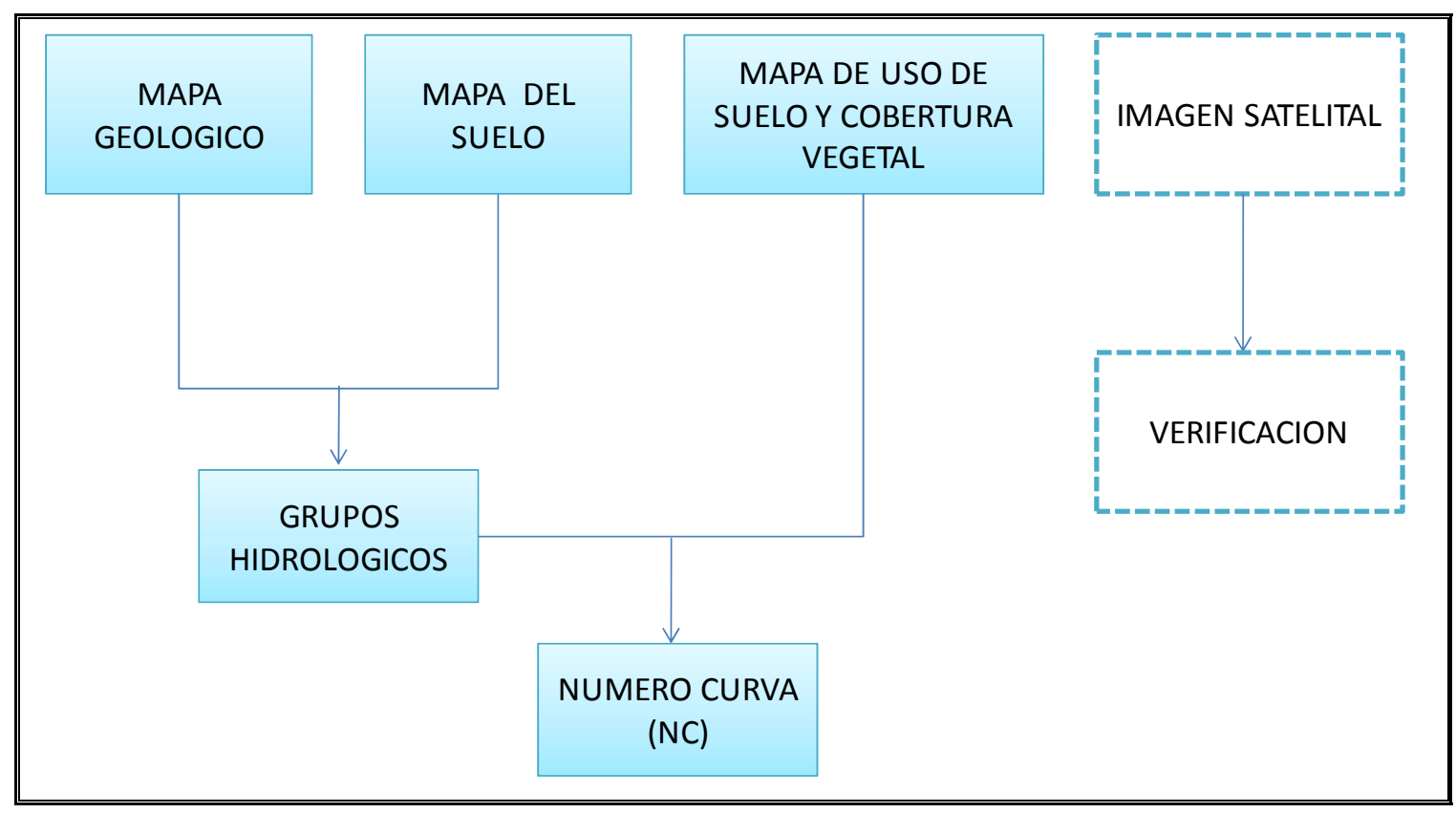

Figura 77. Modelo Cartográfico para generar el mapa del Número de Curva.

En base a los mapas geológico y de suelo, obtenido de CLIRSEN-SIGAGRO a escala 1:250.000 en formato shape (.shp). Se realizó la clasificación de los suelos utilizando la Tabla 22 (sección 4.7.1.1) en función de sus características litológicas, potencial de escorrentía, tasa de infiltración, porcentaje de humedad, capacidad de transmisión de agua, porcentaje de arcilla y arena, obteniendo los grupos hidrológicos del suelo para la cuenca de estudio.

Luego, según la cobertura del suelo y el grupo hidrológico determinado, se escogieron los valores de número de curva particulares. Cuanto más denso es el cultivo mejor es su condición hidrológica, siendo menor su número de curva y consecuentemente mayor la infiltración.

La Tabla 49 muestra el grupo hidrológico y el número de curva que mas predominan en las siete subcuencas, obtenidas del entrecruzamiento de las clases de tipo de cobertura y uso de suelo con el tipo de suelo. 
Tabla 49. Caracterización de número de curva según grupo hidrológico y tipo de cobertura y uso del suelo.

\begin{tabular}{|c|c|c|c|c|}
\hline $\begin{array}{c}\text { SUB } \\
\text { CUENCAS }\end{array}$ & TIPO DE COBERTURA Y USO DEL SUELO & GH & NC & $\begin{array}{c}\text { AREA } \\
\mathbf{k m}^{2}\end{array}$ \\
\hline \multirow{2}{*}{1} & Bosque, pastos, cultivos y arboricultura & \multirow[t]{2}{*}{ C } & 72 & 0,33 \\
\hline & Formación arbórea, densa, siempre verde & & 63 & 38,61 \\
\hline \multirow{2}{*}{2} & Bosque, pastos, cultivos y arboricultura & \multirow[t]{2}{*}{ C } & 72 & 0,23 \\
\hline & Formación arbórea, densa, siempre verde & & 63 & 6,75 \\
\hline \multirow{4}{*}{3} & Pastos y cultivos, restos de bosque & $\mathrm{C}$ & 82 & 13,78 \\
\hline & Pastos y cultivos, restos de bosque & A & 57 & 0,06 \\
\hline & Formación arbórea, densa, siempre verde & C & 63 & 26,98 \\
\hline & Formación arbórea, densa, siempre verde & A & 26 & 5,27 \\
\hline \multirow{4}{*}{4} & Pastos y cultivos, restos de bosque & C & 81 & 73,87 \\
\hline & Pastos y cultivos, restos de bosque & A & 57 & 7,70 \\
\hline & Formación arbórea, densa, siempre verde & C & 63 & 59,85 \\
\hline & Formación arbórea, densa, siempre verde & A & 26 & 0,16 \\
\hline \multirow{3}{*}{5} & Monte y fruticultura & \multirow{3}{*}{$\mathrm{C}$} & 76 & 20,77 \\
\hline & Bosque, pastos, cultivos y arboricultura & & 72 & 25,22 \\
\hline & Formación arbórea, densa, siempre verde & & 63 & 60,42 \\
\hline \multirow{3}{*}{6} & Monte y fruticultura & \multirow{3}{*}{ C } & 76 & 1,10 \\
\hline & Bosque con claros de pastos, cultivos y arboricultura & & 76 & 2,91 \\
\hline & Formación arbórea, densa, siempre verde & & 63 & 57,95 \\
\hline \multirow{8}{*}{7} & Café, cacao y pastos & \multirow{7}{*}{$\mathrm{C}$} & 88 & 9,08 \\
\hline & Monte y fruticultura & & 76 & 50,42 \\
\hline & Monte y fruticultura & & 76 & 1,54 \\
\hline & Bosque con claros de pastos, cultivos y arboricultura & & 76 & 2,86 \\
\hline & Arboricultura & & 73 & 2,31 \\
\hline & Café, cacao y pastos & & 88 & 0,68 \\
\hline & Formación arbórea, densa, siempre verde & & 63 & 34,87 \\
\hline & Área Total & & & 503,71 \\
\hline
\end{tabular}

Para la elaboración del mapa de número de curva de la cuenca del Río Toachi, se utilizó el programa ArcGIS 9.3 @ con el cual se realizó el entrecruzamiento de las coberturas temáticas de los mapas de uso de suelo y grupo hidrológico $(\mathrm{GH})$. La representación cartográfica de la distribución del número de curva expresa la dinámica posible del agua a nivel superficial. En la Figura 78 se presenta el mapa de número de curva para la cuenca del Río Toachi. 


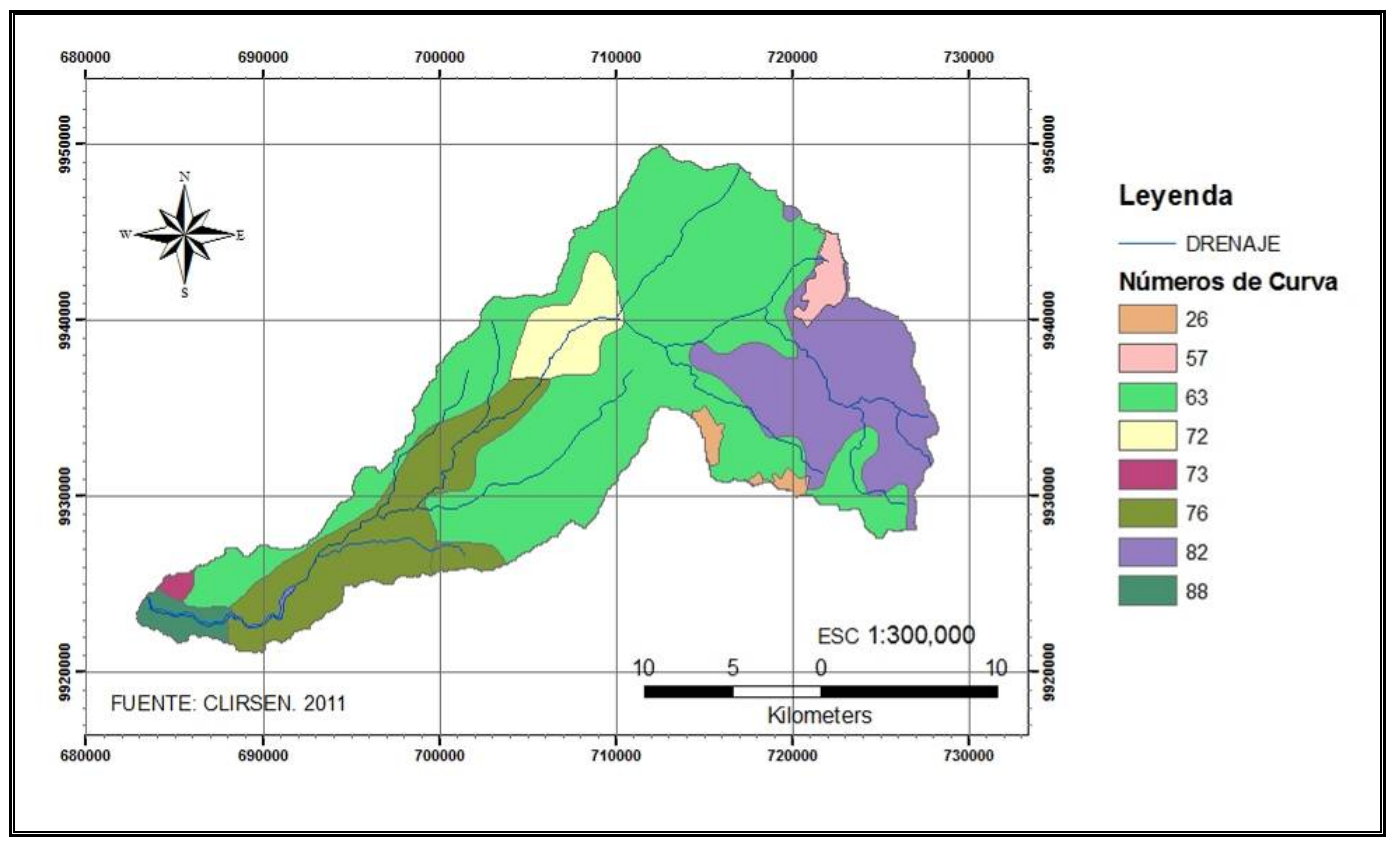

Figura 78. Mapa del Número de Curva para la Cuenca del Río Toachi.

\subsubsection{Modelización Matemática con HEC-HMS ${ }^{\circledR}$}

Para realizar la modelización del proyecto, primeramente se subdividió a la cuenca de estudio en tres áreas de características fisiográficas y climáticas homogéneas. Se agruparon las subcuencas 1, 2, 3 y 4 en la denominada zona alta; las subcuencas 5 y 6 en la zona media; y la subcuenca 7 en la zona baja. En la Figura 79 se presenta la zonificación de la cuenca de estudio, una vez que se unieron las subcuencas definidas en la delimitación.

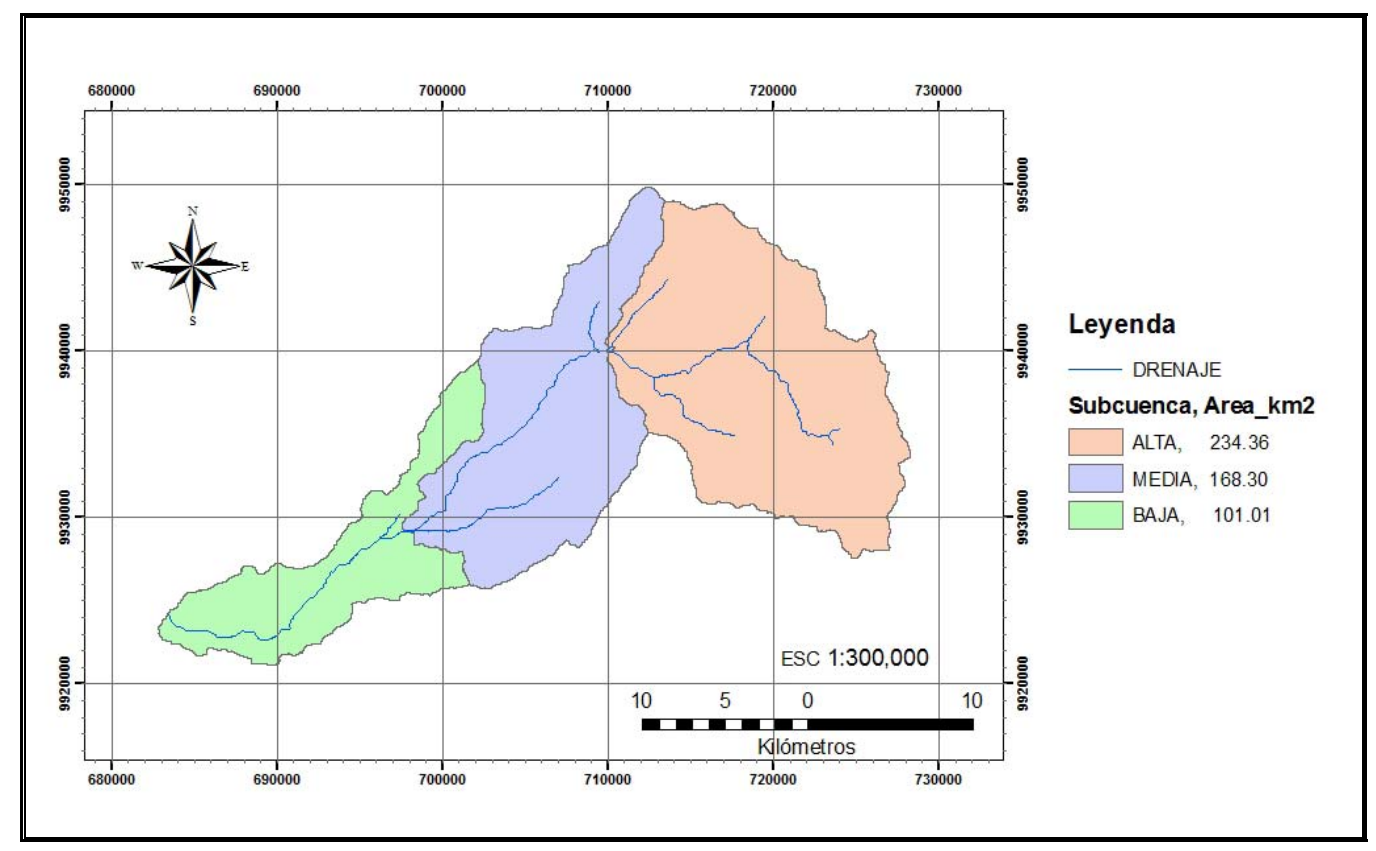

Figura 79. Zonificación de la Cuenca del Río Toachi 
Para calcular el número de curva ponderado de cada zona alta, media y baja, se determinó el número de curva ponderado para cada subcuenca (de la 1 a la 7) por medio de un breve análisis estadístico, obtenida con una planilla de cálculo, según la metodología explicada de unir las subcuencas por características de homogeneidad fisiográfica y climática.

En la Tabla 50 se presenta el cuadro final de la zonificación ponderada del número de curva para la cuenca de estudio que permitió realizar la modelización hidrológica en el programa HEC-HMS $®$.

Tabla 50. Números de Curva para cada zona de la Cuenca del Río Toachi

\begin{tabular}{|c|c|c|c|c|c|c|c|}
\hline $\begin{array}{c}\text { SUB } \\
\text { CUENCAS }\end{array}$ & NC & $\begin{array}{l}\text { AREA } \\
\left(\mathrm{km}^{2}\right)\end{array}$ & $\begin{array}{l}\text { AREA X } \\
\text { SUBCC } \\
\left(\mathrm{km}^{2}\right)\end{array}$ & $\begin{array}{c}\text { NC } \\
\text { PONDERADO } \\
\text { X SUBCC }\end{array}$ & $\begin{array}{c}\text { NC } \\
\text { PONDERADO } \\
\text { X ZONA }\end{array}$ & $\begin{array}{l}\text { AREA } \\
\left(\mathrm{km}^{2}\right)\end{array}$ & ZONA \\
\hline \multirow{2}{*}{1} & 72 & 0,33 & \multirow{2}{*}{38,94} & \multirow{2}{*}{63,08} & \multirow{12}{*}{68,7} & \multirow{12}{*}{234,36} & \multirow{12}{*}{ ALTA } \\
\hline & 63 & 38,61 & & & & & \\
\hline \multirow{2}{*}{2} & 72 & 0,23 & \multirow{2}{*}{6,98} & \multirow{2}{*}{63,30} & & & \\
\hline & 63 & 6,75 & & & & & \\
\hline \multirow{4}{*}{3} & 82 & 13,78 & \multirow{4}{*}{46,10} & \multirow{4}{*}{64,44} & & & \\
\hline & 57 & 0,06 & & & & & \\
\hline & 63 & 26,98 & & & & & \\
\hline & 26 & 5,27 & & & & & \\
\hline \multirow{4}{*}{4} & 81 & 73,87 & \multirow{4}{*}{141,57} & \multirow{4}{*}{72,02} & & & \\
\hline & 57 & 7,70 & & & & & \\
\hline & 63 & 59,85 & & & & & \\
\hline & 26 & 0,16 & & & & & \\
\hline \multirow{3}{*}{5} & 76 & 20,77 & \multirow{3}{*}{106,41} & \multirow{3}{*}{67,67} & \multirow{6}{*}{66,2} & \multirow{6}{*}{168,3} & \multirow{6}{*}{ MEDIA } \\
\hline & 72 & 25,22 & & & & & \\
\hline & 63 & 60,42 & & & & & \\
\hline \multirow{3}{*}{6} & 76 & 1,10 & \multirow{3}{*}{61,96} & \multirow{3}{*}{63,84} & & & \\
\hline & 76 & 2,91 & & & & & \\
\hline & 63 & 57,95 & & & & & \\
\hline \multirow{7}{*}{7} & 88 & 9,08 & \multirow{7}{*}{101,01} & \multirow{7}{*}{72,60} & \multirow{7}{*}{72,6} & \multirow{7}{*}{101,0} & \multirow{7}{*}{ BAJA } \\
\hline & 76 & 50,42 & & & & & \\
\hline & 76 & 0,79 & & & & & \\
\hline & 76 & 2,86 & & & & & \\
\hline & 73 & 2,31 & & & & & \\
\hline & 88 & 0,68 & & & & & \\
\hline & 63 & 34,87 & & & & & \\
\hline
\end{tabular}




\subsubsection{Selección de los Métodos de Cálculo en el programa HEC-HMS ®}

A continuación, se indica la información ingresada en cada zona, para determinar el Volumen de Escurrimiento, la Transformación en Escorrentía Directa, el Caudal Base y el Tránsito de Caudales para el modelo HEC-HMS ${ }^{\circledR}$ :

Los valores utilizados para el cálculo del volumen de escurrimiento mediante el método de "pérdidas iniciales y tasa constante de pérdidas" están directamente relacionados con la característica de tipo de suelo en la cuenca. Para realizar el análisis de este parámetro no se disponía de suficiente información respecto a la textura, contenido de materia orgánica, estructura del suelo, por lo cual se identificaron los suelos según sus tasas de infiltración. En general, se caracterizaron con tasas de moderadas a lenta, con bajo contenido orgánico y usualmente altos en arcilla, considerados como suelo del grupo hidrológico $\mathrm{C}$, aplicado en el cálculo de la tasa de infiltración constante.

Los valores de pérdida inicial (la) se calcularon del $20 \%$ de la capacidad máxima de retención del suelo en base de los números de curva ponderados para cada parte, así, se obtiene la Tabla 51.

Tabla 51. Valores de pérdida inicial para cada zona.

\begin{tabular}{|c|c|c|c|}
\hline ZONA & NC POND & $\begin{array}{c}\text { CAPACIDAD DE } \\
\text { RETENCION MAXIMA } \\
\text { (S) }\end{array}$ & $\begin{array}{c}\text { PÉRDIDA INICAL } \\
\text { (la) }\end{array}$ \\
\hline ALTA & 68,7 & 115,3 & 23,0 \\
\hline MEDIA & 66,2 & 129,3 & 25,8 \\
\hline BAJA & 72,6 & 95,8 & 19,1 \\
\hline
\end{tabular}

Se ha cuantificado el área impermeable por zona, a partir del mapa de pendientes, considerando, que las áreas con pendientes mayores, con alta probabilidad de tener poca profundidad de suelo y alto escurrimiento. También se analizó a partir de la interpretación de las imágenes satelital Landsat 19870326 TM y 19991114 y con la ayuda del Google Earth $\circledast$, donde se observaron áreas con afloramiento de rocas en superficie, especialmente en la parte alta, coincidentes con zonas con la escasa información de textura del suelo, poca profundidad de perfil de suelo, y/o presencia de cuerpos de agua y pequeñas zonas urbanas. Los valores obtenidos para este método se presentan en la Tabla 52. 
Tabla 52. Parámetros para el cálculo del volumen de escurrimiento.

\begin{tabular}{|c|c|c|c|}
\hline \multicolumn{4}{|c|}{ METODO DE PERDIDA INICIAL Y TASA CONSTANTE } \\
\hline PARÁMETROS & $\begin{array}{c}\text { ZONA } \\
\text { ALTA }\end{array}$ & $\begin{array}{c}\text { ZONA } \\
\text { MEDIA }\end{array}$ & $\begin{array}{c}\text { ZONA } \\
\text { BAJA }\end{array}$ \\
\hline $\begin{array}{c}\text { Tasa de infiltración } \\
\text { constante (mm/h) }\end{array}$ & 1,8 & 1,8 & 1,8 \\
\hline $\begin{array}{c}\text { Pérdidas iniciales } \\
\text { (mm) }\end{array}$ & 23 & 26 & 19 \\
\hline $\begin{array}{c}\text { Área impermeable } \\
\text { (\%) }\end{array}$ & 15 & 10 & 10 \\
\hline
\end{tabular}

Los valores del tiempo de retardo (Tlag) usados para el cálculo de la transformación del excedente de lluvia en escurrimiento directo (cálculo del hidrograma de salida), mediante el método "hidrograma unitario del SCS", se obtuvieron mediante la Fórmula 35, cuyos resultados se presentan en la Tabla 53.

Tabla 53. Parámetros para el cálculo del hidrograma de salida (escurrimiento directo)

\begin{tabular}{|c|c|c|c|l|}
\hline \multicolumn{5}{|c|}{ MÉTODO DEL HIDROGRAMA UNITARIO DEL SCS } \\
\hline \multicolumn{1}{|c|}{ PARÁMETRO } & $\begin{array}{c}\text { ZONA } \\
\text { ALTA }\end{array}$ & $\begin{array}{c}\text { ZONA } \\
\text { MEDIA }\end{array}$ & $\begin{array}{l}\text { ZONA } \\
\text { BAJA }\end{array}$ & \multicolumn{1}{|c|}{ FUENTE } \\
\hline $\begin{array}{l}\text { Tiempo de retardo, } \\
\text { Tlag, (min) }\end{array}$ & 2838 & 3142 & 3500 & $\begin{array}{l}\text { Tiempo de concentración } \\
\text { Pendiente del río (\%) y } \\
\text { Longitud del río (km) }\end{array}$ \\
\hline
\end{tabular}

Los valores utilizados para alimentar al caudal base del modelo, de acuerdo al método "constantes mensuales", se aplicó a la subcuenca baja tomando como referencia los valores del caudal mensual de la estación hidrológica Toachi DJ Baba $(\mathrm{H} 414)$ durante el período del 01 de julio de 2006 al 01 de Julio de 2007, los cuales se presentan en la Tabla 54. 
Tabla 54. Caudales constantes mensuales para la subcuenca baja.

\begin{tabular}{|c|c|c|c|c|c|c|c|c|c|c|c|c|}
\hline \multicolumn{10}{|c|}{ METODO DE CONSTANTE MENSUAL } \\
\hline & ENE & FEB & MAR & ABR & MAY & JUN & JUL & AGO & SEP & OCT & NOV & DIC \\
\hline $\begin{array}{c}\text { ZONA } \\
\text { BAJA } \\
\left(\mathbf{m}^{3} / \mathbf{s}\right)\end{array}$ & 15 & 30 & 28 & 32 & 20 & 12 & 10 & 5 & 5 & 5 & 2 & 3 \\
\hline
\end{tabular}

Los valores proporcionados al programa HEC-HMS $₫$ para el cálculo del tránsito de los caudales a través de canales por el método Muskingum-Cunge se presentan en la Tabla 55.

Tabla 55. Valores de los parámetros para el cálculo de caudales.

\begin{tabular}{|l|c|c|}
\hline \multicolumn{1}{|c|}{ PARÁMETROS } & TRAMO 1 & TRAMO 2 \\
\hline Longitud del cauce (m) & 18740 & 19120 \\
\hline Pendiente del cauce (\%) & 0,0195 & 0,0090 \\
\hline $\begin{array}{l}\text { Coeficiente de rugosidad de } \\
\text { Manning del lecho del cauce }\end{array}$ & 0,04 & 0,035 \\
\hline Forma de sección transversal & Rectángulo & Ocho puntos \\
\hline Ancho (m) & 60 & 0,04 \\
\hline Manning del lado izquierdo & & 0,03 \\
\hline Manning del lado derecho & & \\
\hline
\end{tabular}

Los datos de la sección transversal de la estación de aforo H414 Toachi DJ Baba, tomado a 162 msnm, según la forma del canal de ocho puntos se presentan en la Tabla 56 y la Figura 80.

Tabla 56. Datos de la sección transversal del cauce del Río Toachi.

\begin{tabular}{|c|c|c|c|c|c|c|c|c|}
\hline Distancia (m) & 0,0 & 13,6 & 24,9 & 48,9 & 68,9 & 84,4 & 101,4 & 106,9 \\
\hline $\begin{array}{c}\text { Profundidad } \\
\text { (msnm) }\end{array}$ & 107,5 & 101,0 & 99,1 & 99,0 & 99,4 & 100,4 & 104,5 & 107,6 \\
\hline
\end{tabular}




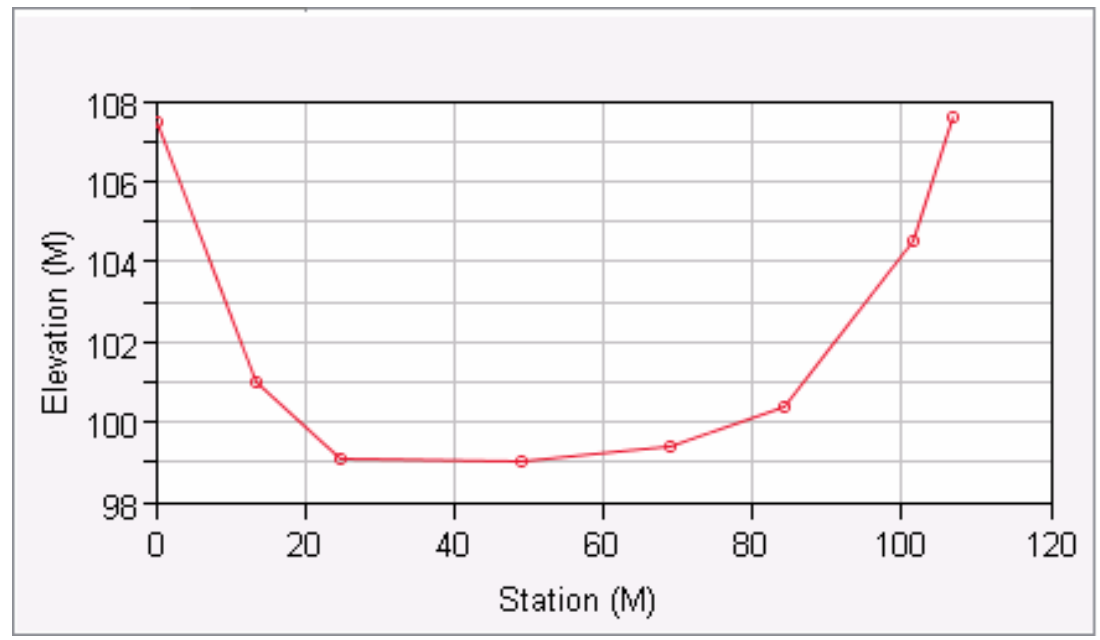

Figura 80. Gráfico de la sección transversal del Río Toachi

\subsubsection{Selección de datos de lluvia}

Se armaron dos modelos meteorológicos con las estaciones seleccionadas, en función de la ubicación geográfica. El primer modelo meteorológico se estableció a partir del resultado del método de Polígonos de Thiessen; y el segundo modelo se asignó a partir de los pluviógrafos más representativos a la correspondiente subcuenca. En la Tabla 57 se presentan los períodos de precipitación que se utilizaron para las diferentes simulaciones.

Tabla 57. Períodos de precipitación usados para la calibración y validación

\begin{tabular}{|c|c|}
\hline CALIBRACION & VALIDACION \\
\hline 01 junio 2005 - 30 junio 2007 & 01 julio 2007 - 30 junio 2009 \\
\hline
\end{tabular}

\section{$\underline{\text { 5.7.2.3 Selección de datos de caudal observado }}$}

Los datos de caudal observado que se usaron para ingresar al modelo fueron los de la estación hidrológica H414 Toachi DJ Baba en los períodos que se indican en la Tabla 58.

Tabla 58. Períodos de caudales usados para la calibración y validación

\begin{tabular}{|c|c|}
\hline CALIBRACIÓN & VALIDACION \\
\hline 01 junio $2005-30$ junio 2007 & 01 julio $2007-30$ junio 2009 \\
\hline
\end{tabular}




\subsection{Pruebas de Calibración del Modelo HEC-HMS ${ }^{\circledR}$}

La identificación de los valores óptimos de los parámetros que utilizan los métodos seleccionados para la modelización, se realizó de forma manual y luego se comprobó de forma automática usando el método de ajuste ponderado por mínimos cuadrados de la Función Objetivo que incluye en la herramienta de Optimización del programa HEC-HMS ${ }^{\circledR}$.

A continuación se explica los criterios utilizados para la calibración, indicando los parámetros ingresados y los resultados obtenidos de las dos series de precipitación utilizadas en las pruebas de calibración.

\subsubsection{Primera Prueba}

Para la primera prueba de calibración, se trabajo con las tres subcuencas, alta, media y baja, utilizando el período comprendido entre el 01 de julio del 2006 al 30 de junio del 2007 con la información de la estación meteorológica La Libertad (M252) a nivel diario (24 horas en $\mathrm{mm}$ ) y los datos de caudal diario $\left(\mathrm{m}^{3} / \mathrm{s}\right)$ medido de la estación hidrológica Toachi DJ Baba (H414).

Fueron ingresados al modelo HEC-HMS ${ }^{\circledR}$ los parámetros iniciales que se presentaron en la sección 5.7.2.

La influencia de las estaciones meteorológicas para el área de estudio se realizó con el método Polígonos de Thiessen, procesado con la herramienta SIG, arrojando los resultados que se presentan en la Tabla 59.

Tabla 59. Área de cobertura de las estaciones meteorológicas

\begin{tabular}{|c|c|c|c|}
\hline Zona & $\begin{array}{l}\text { Estación } \\
\text { Pluviográfica }\end{array}$ & $\begin{array}{c}\text { Área Influencia } \\
\left(\mathrm{km}^{2}\right)\end{array}$ & $\begin{array}{l}\text { Área Zona } \\
\left(\mathrm{km}^{2}\right)\end{array}$ \\
\hline \multirow{3}{*}{ Alta } & La Libertad & 158,85 & \multirow{3}{*}{234,46} \\
\hline & Las Pampas & 35,81 & \\
\hline & Sigchos & 39,79 & \\
\hline Media & La Libertad & 169,08 & 169,08 \\
\hline \multirow{3}{*}{ Baja } & La Libertad & 53,36 & \multirow{3}{*}{100,22} \\
\hline & Puerto lla & 16,55 & \\
\hline & San Antonio & 30,19 & \\
\hline
\end{tabular}

La interpretación de la Tabla 59 indica que hay una muy alta incidencia geoespacial de la estación pluviografica La Libertad (MB89) para el área de estudio, que representa un $76 \%$ del área de influencia ( ver Figura 81). 


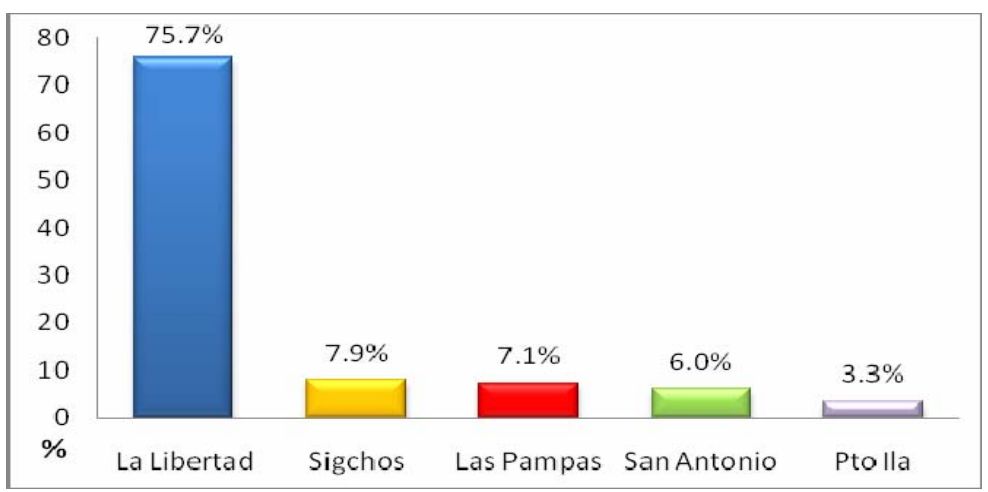

Figura 81. Representación del área de cobertura de las estaciones meteorológicas

Por esta razón, se consideró como pluviógrafo del modelo meteorológico (Met1) a la estación La Libertad (MB89), como única estación meteorológica para toda la cuenca. Con estos parámetros ingresados al modelo HEC-HMS $®$ se procedió a realizar la simulación. Se obtuvieron los parámetros estadísticos de coeficiente de $\mathrm{Nash}=0,68$ y $\mathrm{R}^{2}=0,76$.

Este procesamiento, determinó el cálculo de optimización del parámetro "tasa de infiltración constante" para las tres subcuencas, obteniendo los valores expresados en la Tabla 60.

Tabla 60. Valores del parámetro "tasa de infiltración constante" optimizada primera prueba

\begin{tabular}{|c|c|c|c|}
\hline PARÁMETRO & ZONA ALTA & ZONA MEDIA & ZONA BAJA \\
\hline $\begin{array}{c}\text { Tasa de infiltración constante } \\
(\mathbf{m m} / \mathbf{h})\end{array}$ & 1,36 & 0,61 & 2,64 \\
\hline
\end{tabular}

Obtenidos estos valores, se volvió a cargar el programa y se realizó la simulación obteniendo el hidrograma presentado en la Figura 82.

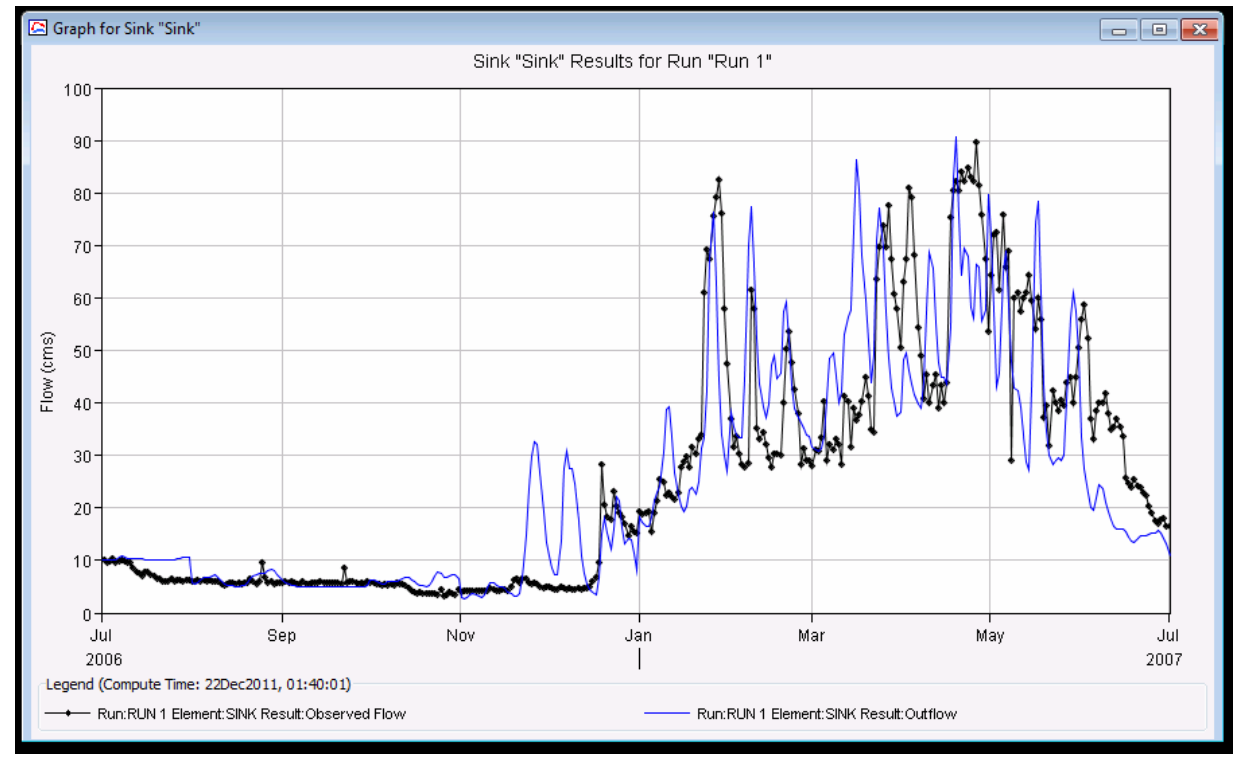

Figura 82. Hidrograma final de la primera prueba de calibración. 
En la Figura 83, se presenta el resultado de eficiencia de los datos simulados versus los datos observados realizados en el programa WHAT, los cuales dieron un coeficiente de Nash $=0,71 \%$ y un coeficiente de determinación $R^{2}=0,72$. Finalmente, se presenta la Figura 84 con el resumen de los resultados obtenidos en la primera calibración.

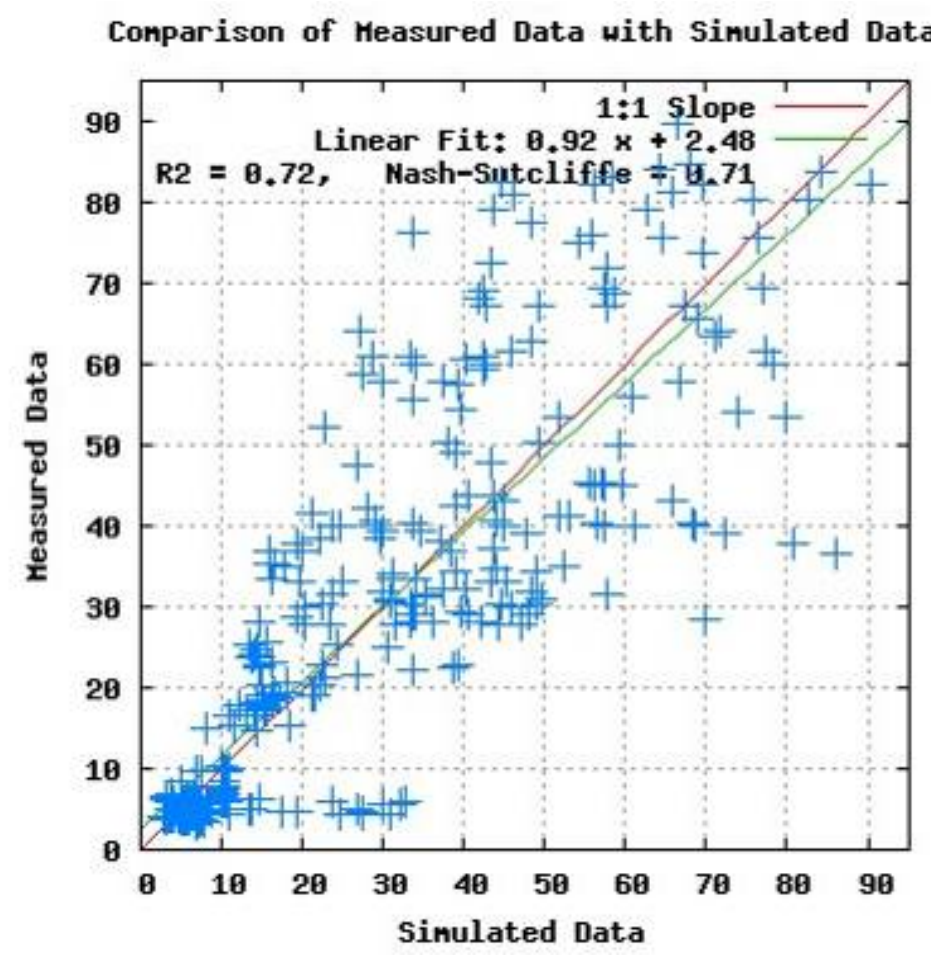

Figura 83. Gráfico de Eficiencia de los valores simulados

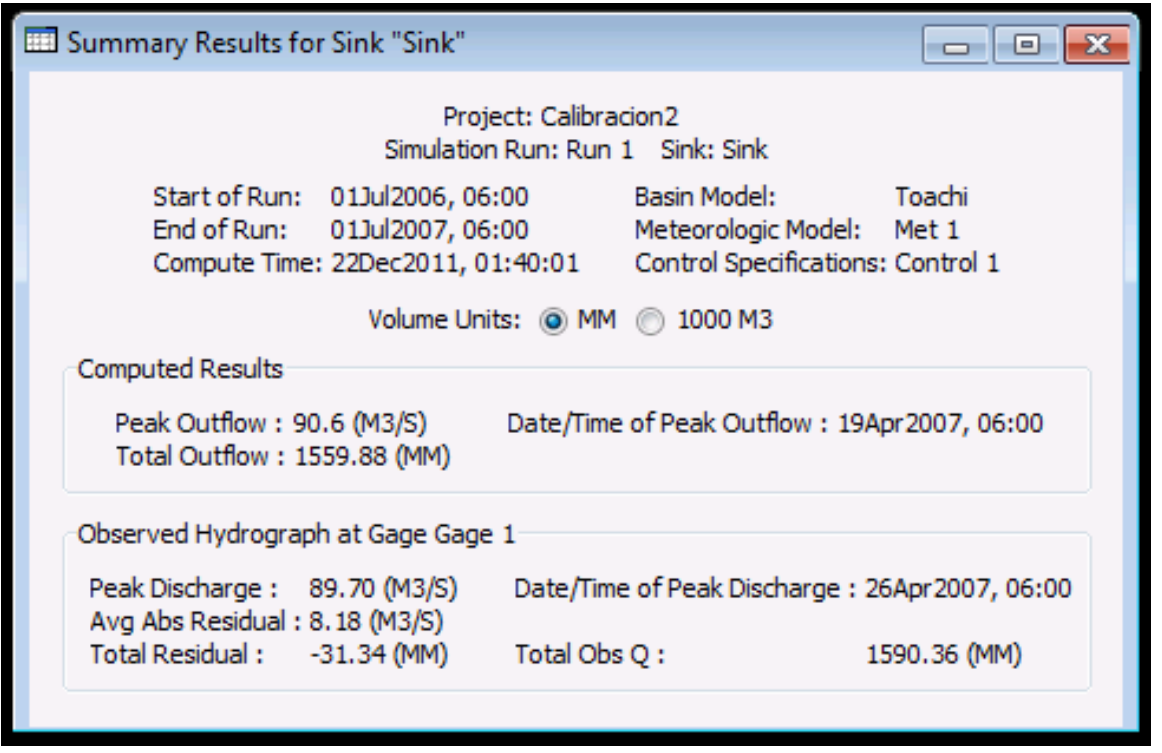

Figura 84. Resumen de los resultados de la primera calibración 


\subsubsection{Segunda Prueba}

Para la segunda prueba de calibración, se trabajó con las tres subcuencas en el período comprendido entre el 01 de julio del 2006 al 30 de junio del 2007 con la información de las estaciones meteorológicas Las Pampas (M362), La Libertad (MB89) y Puerto lla (M026) a nivel diario (24 horas en $\mathrm{mm}$ ) y los datos de caudal diario $\left(\mathrm{m}^{3} / \mathrm{s}\right)$ medido de la estación hidrológica Toachi DJ Baba.

Fueron ingresados al programa HEC-HMS $®$ los parámetros iniciales que se presentaron en la sección 5.7.2.

De acuerdo a la Tabla 59, se eligieron los tres pluviógrafos que alimentaron al modelo meteorológico (Met2) del programa para cada una de las subcuencas, quedando distribuidas de la siguiente manera: para la zona alta la estación Las Pampas por tener información más confiable de precipitación en 24 horas; para la zona media la estación La Libertad; y para la zona baja la estación Puerto lla por ser una estación meteorológica completa que tiene mayor cantidad de información histórica.

Con estos parámetros ingresados al modelo HEC-HMS ${ }^{\circledR}$ se procedió a realizar la simulación obtenido un coeficiente de $\mathrm{Nash}=0,68$ y $\mathrm{R}^{2}=0,74$. Se realizó el cálculo de optimización del parámetro "tasa de infiltración constante" para las tres zonas, obteniendo los valores que se muestran en la Tabla 61:

Tabla 61. Valores del parámetro "tasa de infiltración constante" optimizada segunda prueba

\begin{tabular}{|c|c|c|c|}
\hline PARÁMETRO & ZONA ALTA & ZONA MEDIA & ZONA BAJA \\
\hline $\begin{array}{c}\text { Tasa de infiltración constante } \\
(\mathbf{m m} / \mathbf{h})\end{array}$ & 0,93 & 1,35 & 1,79 \\
\hline
\end{tabular}

Con estos valores se volvió a cargar al modelo y se realizó la simulación obteniendo el hidrograma presentado en la Figura 85.

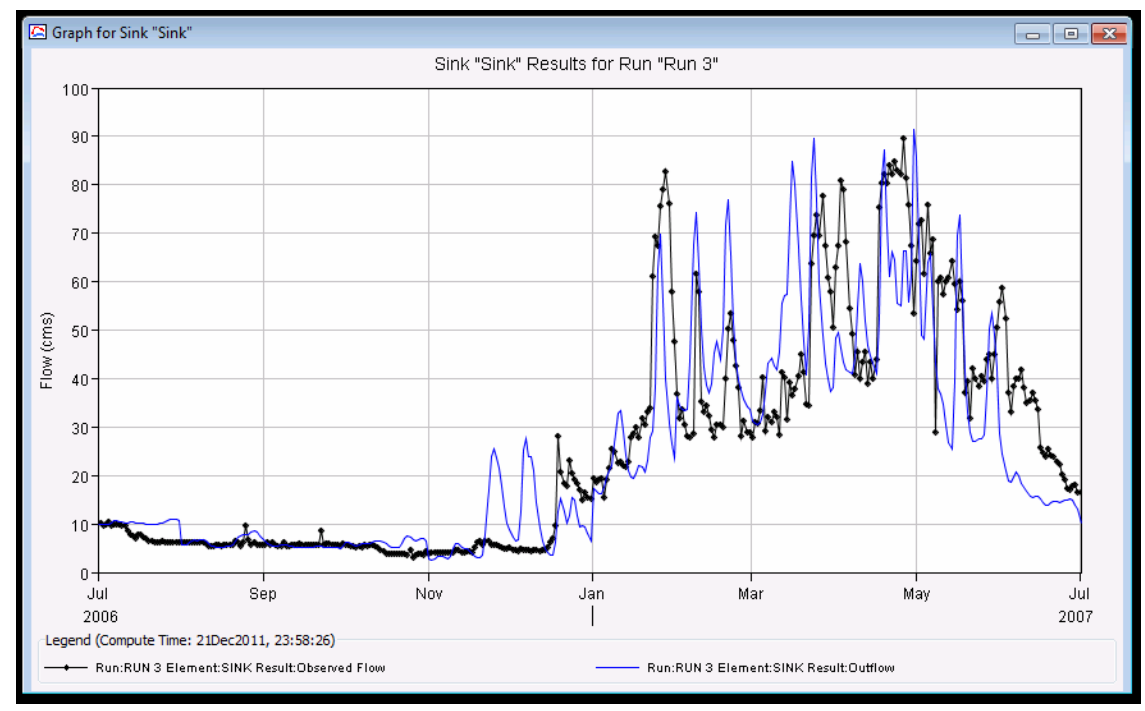

Figura 85. Hidrograma final de la segunda prueba de calibración 
En la Figura 86 se presenta el resultado de eficiencia de los datos simulados versus los datos observados realizados en el programa WHAT para esta prueba, que dieron un coeficiente de Nash $=0,70 \%$ y un coeficiente de determinación $R^{2}=0,71$. Finalmente se presenta la Figura 87 con el resumen de los resultados obtenidos en la segunda calibración.

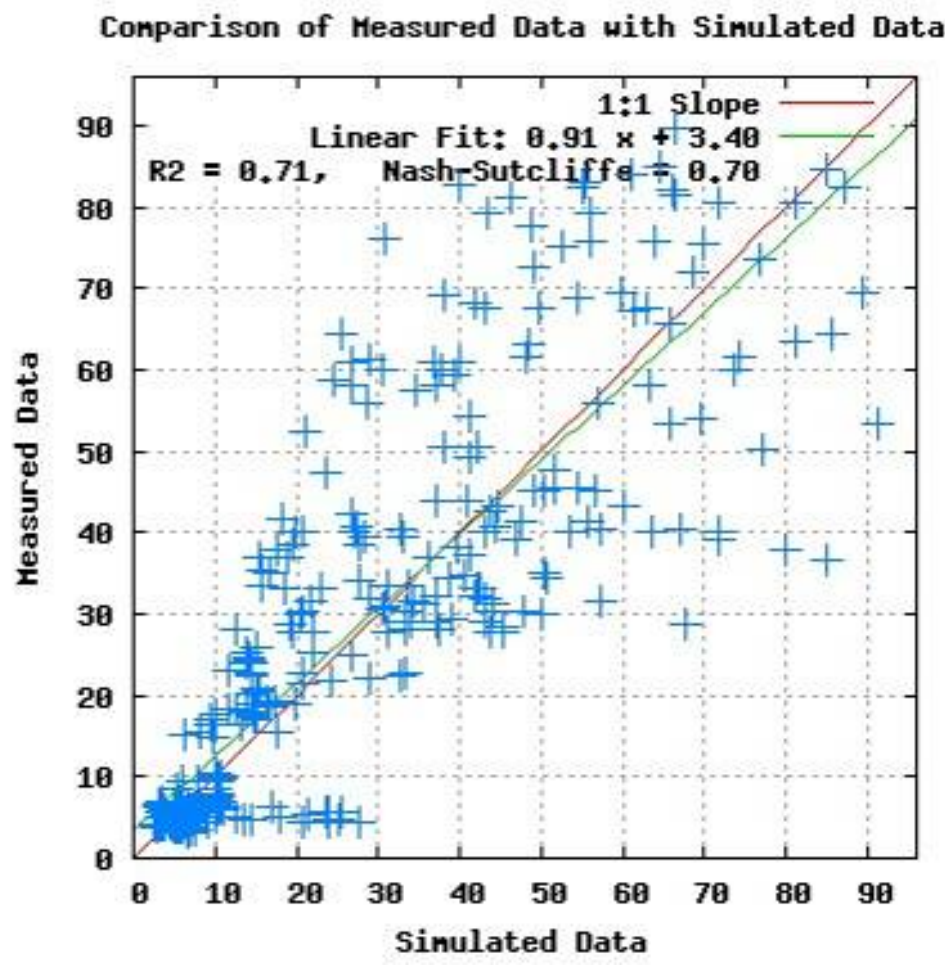

Figura 86. Gráfico de Eficiencia de los valores simulados

Summary Results for Sink "Sink"

Project: Calibracion2

Simulation Run: Run 3 Sink: Sink

Start of Run: $011 \mathrm{Jul} 2006,06: 00$

End of Run: $\quad$ 01Jul2007, 06:00

Basin Model:

Compute Time: 21Dec2011, 23:58:26

Meteorologic Model: Met 2

Volume Units: (0) MM $\bigcirc 1000 \mathrm{M} 3$

Computed Results

Peak Outflow : 91.4 (M3/S)

Total Outflow : 1513.84 (MM)

Date/Time of Peak Outflow : 30Apr 2007, 06:00

Observed Hydrograph at Gage Gage 1

Peak Discharge : 89.70 (M3/S) Date/Time of Peak Discharge : 26Apr 2007, 06:00 Avg Abs Residual : 8.34 (M3/S)

Total Residual : $\quad-77.38(\mathrm{MM})$

Total Obs Q :

$1590.36(\mathrm{MM})$

Figura 87. Resumen de los resultados de la primera calibración 


\subsection{Sensibilidad de los parámetros del modelo HEC-HMS ${ }^{\circledR}$}

El análisis de sensibilidad se realizó durante la segunda prueba de calibración en el período comprendido entre julio 2006 a junio 2007, observando que los parámetros variaron en las diferentes pruebas. Como fue indicado en la sección 4.9, el parámetro a ser sensibilizado se modifica mientras que los otros se mantienen fijos.

El parámetro más sensible es el "área impermeable", está directamente relacionado con el tipo de suelo, uso de suelo y tipo de vegetación. La variación del $10 \%$ de este valor produce una variación del caudal pico simulado de $9 \mathrm{~m}^{3} / \mathrm{s}$ aproximadamente, representando un cambio en los caudales totales de salida de $21,2 \%$ promedio, como se presenta en la Tabla 62.

Tabla 62. Resultados obtenidos del parámetro "área impermeable"

\begin{tabular}{|c|c|c|c|c|}
\hline & \multicolumn{3}{|c|}{ AREA IMPERMEABLE (\%) } & \\
\hline PARÁMETROS: & $\mathbf{0}$ & 10 & $\mathbf{2 0}$ & $\begin{array}{c}\text { CAUDAL } \\
\text { OBSERVADO }\end{array}$ \\
\hline CAUDAL PICO (m $3 / \mathrm{s})$ & 59,1 & 68,5 & 77,8 & 89,7 \\
\hline $\begin{array}{c}\text { FECHA } \\
\text { CAUDAL TOTAL DE SALIDA } \\
(\mathrm{mm})\end{array}$ & $30-$ ABR-07 & $30-$ ABR-07 & $30-$ ABR-07 & $26-$ ABR-07 \\
\hline $\begin{array}{c}\text { PROMEDIO RESIDUAL } \\
\left(\mathrm{m}^{3} / \mathrm{s}\right)\end{array}$ & 10,49 & 1241,17 & 1498,01 & 1590,36 \\
\hline \begin{tabular}{c} 
TOTAL DE RESIDUAL (mm) \\
\hline
\end{tabular} & $-606,82$ & $-350,05$ & $-93,21$ & \\
\hline
\end{tabular}

El parámetro "tasa de pérdida constante" también representa un alto porcentaje de sensibilidad que se interpreta como la capacidad última de infiltración del suelo y está directamente relacionado con la característica del tipo de suelo. Para el análisis se consideró el límite de transición de los grupos de suelo $B$ y $C$. La variación que produce esta variable es de aproximadamente $40 \mathrm{~m}^{3} / \mathrm{s}$ en el caudal pico $(80,88 \%)$ lo cual representa el $20,3 \%$ del caudal total de salida, expresado en la Tabla 63. 
Tabla 63. Resultados obtenidos del parámetro "tasa de pérdida constante"

\begin{tabular}{|c|c|c|c|}
\hline & \multicolumn{2}{|c|}{ GRUPO SUELO } & \\
\hline PARÁMETROS: & B & C & $\begin{array}{c}\text { CAUDAL } \\
\text { OBSERVADO }\end{array}$ \\
\hline $\begin{array}{c}\text { LIMITE INFERIOR PERDIDA } \\
\text { CONSTANTE }(\mathrm{mm} / \mathrm{h})\end{array}$ & 3,81 & 1,27 & 89,7 \\
\hline CAUDAL PICO $\left(\mathrm{m}^{3} / \mathrm{s}\right)$ & 49,7 & 89,9 & $26-$ ABR-07 \\
\hline FECHA & $19-\mathrm{ABR}-07$ & $30-\mathrm{ABR}-07$ & 1590,36 \\
\hline CAUDAL TOTAL DE SALIDA $(\mathrm{mm})$ & 1202,69 & 1472,20 & \\
\hline PROMEDIO RESIDUAL $\left(\mathrm{m}^{3} / \mathrm{s}\right)$ & 9,0 & 8,29 & $-119,02$ \\
\hline TOTAL DE RESIDUAL $(\mathrm{mm})$ & $-388,53$ & & \\
\hline
\end{tabular}

El parámetro "tiempo de retraso" está relacionado con las características del hidrograma, se lo estima a partir del tiempo de concentración que está basado en la longitud del cauce y la pendiente. Es una medida del tiempo de respuesta de una cuenca para que la lluvia neta se transforme en escurrimiento. Para esta prueba se duplicó el tiempo de retraso en las tres áreas sin obtener cambios significativos en el caudal total de salida, cuyos valores se presentan en la Tabla 64.

Tabla 64. Resultados obtenidos del parámetro "tiempo de retraso"

\begin{tabular}{|c|c|c|c|}
\hline & \multicolumn{2}{|c|}{ TIEMPO DE RETRASO (min) } & \\
\hline PARÁMETROS: & $\begin{array}{c}\text { NORMALES: } \\
\mathbf{( 2 8 3 8 , 3 1 4 2 , 3 5 0 0 )}\end{array}$ & $\begin{array}{c}\text { DUPLICADOS: } \\
\mathbf{( 5 6 7 6 , 6 2 8 4 , 7 0 0 0 )}\end{array}$ & $\begin{array}{c}\text { CAUDAL } \\
\text { OBSERVADO }\end{array}$ \\
\hline CAUDAL PICO $\left(\mathrm{m}^{3} / \mathrm{s}\right)$ & 70,8 & 56,5 & 89,7 \\
\hline FECHA & $30-A B R-07$ & $26-A B R-07$ & $26-A B R-07$ \\
\hline $\begin{array}{c}\text { CAUDAL TOTAL DE SALIDA } \\
(\mathrm{mm})\end{array}$ & 1303,87 & 1302,52 & 1590,36 \\
\hline $\begin{array}{c}\text { PROMEDIO RESIDUAL }\left(\mathrm{m}^{3} / \mathrm{s}\right) \\
\text { TOTAL DE RESIDUAL }(\mathrm{mm})\end{array}$ & 8,12 & 8,10 & \\
\hline
\end{tabular}

El parámetro de "pérdida inicial" tiene directa relación con el tipo de suelo y las condiciones de humedad antecedente del suelo, es decir, si el suelo de la cuenca está saturado, la pérdida inicial será aproximadamente cero, por el contrario si está seco, la pérdida se incrementara y será igual la precipitación máxima que puede caer dentro del la cuenca sin producir escurrimiento. La variación de este parámetro no presento cambios considerables en los caudales de salida. 


\subsection{Prueba de Validación del modelo HEC-HMS ${ }^{\circledR}$}

La prueba de validación consistió en utilizar los parámetros de la mejor prueba de calibración, para aplicarle un período diferente de precipitación y comparar con el hidrograma de salida medido para ese mismo año.

En este caso, las dos pruebas tienen un buen coeficiente de Nash, sin embargo se escogió la primera prueba ya que presenta un mejor coeficiente de determinación, $R^{2}=0,72$.

Empleando la estación pluviográfica MB89 La Libertad que cubre el $76 \%$ de la cuenca de estudio, con registros diarios en $\mathrm{mm}$ ( 24 horas) durante el período de 01 julio de 2007 al 30 junio de 2008, se obtuvo como resultado un coeficiente de Nash de $0,64 \%$ y un coeficiente de determinación $R^{2}=0,68$, como se observa en la Figura 88 .

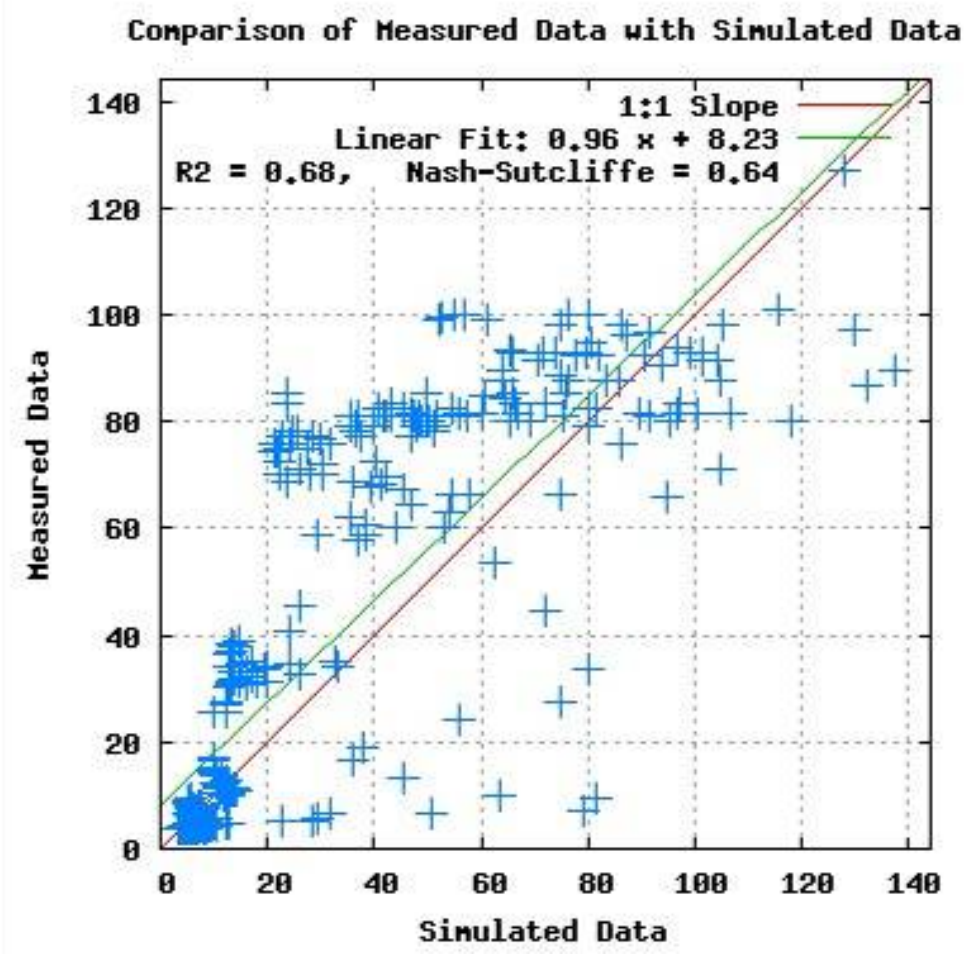

Figura 88. Gráfico de Eficiencia de la prueba de validación.

Los resultados de la validación son aceptables donde la distribución de la crecida se representa en forma muy aproximada a la realidad (ver Figura 89). Los picos y los caudales mínimos están bien representados, indicando que la etapa de calibración cumplió con los parámetros definidos para la cuenca del Río Toachi (ver Figura 90). 
Summary Results for Sink "Sink"

\section{$\square$ 回}

Project: Validacion2

Simulation Run: Run 1 Sink: Sink

Start of Run: 01Jul2007, 06:00

End of Run: 01Jul2008, 06:00

Basin Model:

Toachi

Compute Time: 22Dec2011, 02:35:04

Meteorologic Model: Met 1

Control Specifications: Control 1

Volume Units: (C) MM $\bigcirc 000 \mathrm{M} 3$

Computed Results

Peak Outflow : 137.2 (M3/S)

Total Outflow : 1871.05 (MM)

Date/Time of Peak Outflow : 18Feb2008, 06:00

Observed Hydrograph at Gage Gage 1

Peak Discharge : $\quad 100.70$ (M3/S)

Avg Abs Residual : 13.93 (M3/S)

Total Residual : $\quad-434.93(\mathrm{MM})$

Date/Time of Peak Discharge : 20Feb2008, 06:00

Total Obs Q :

$2305.11(\mathrm{MM})$

Figura 89. Resumen de los resultados de la validación.

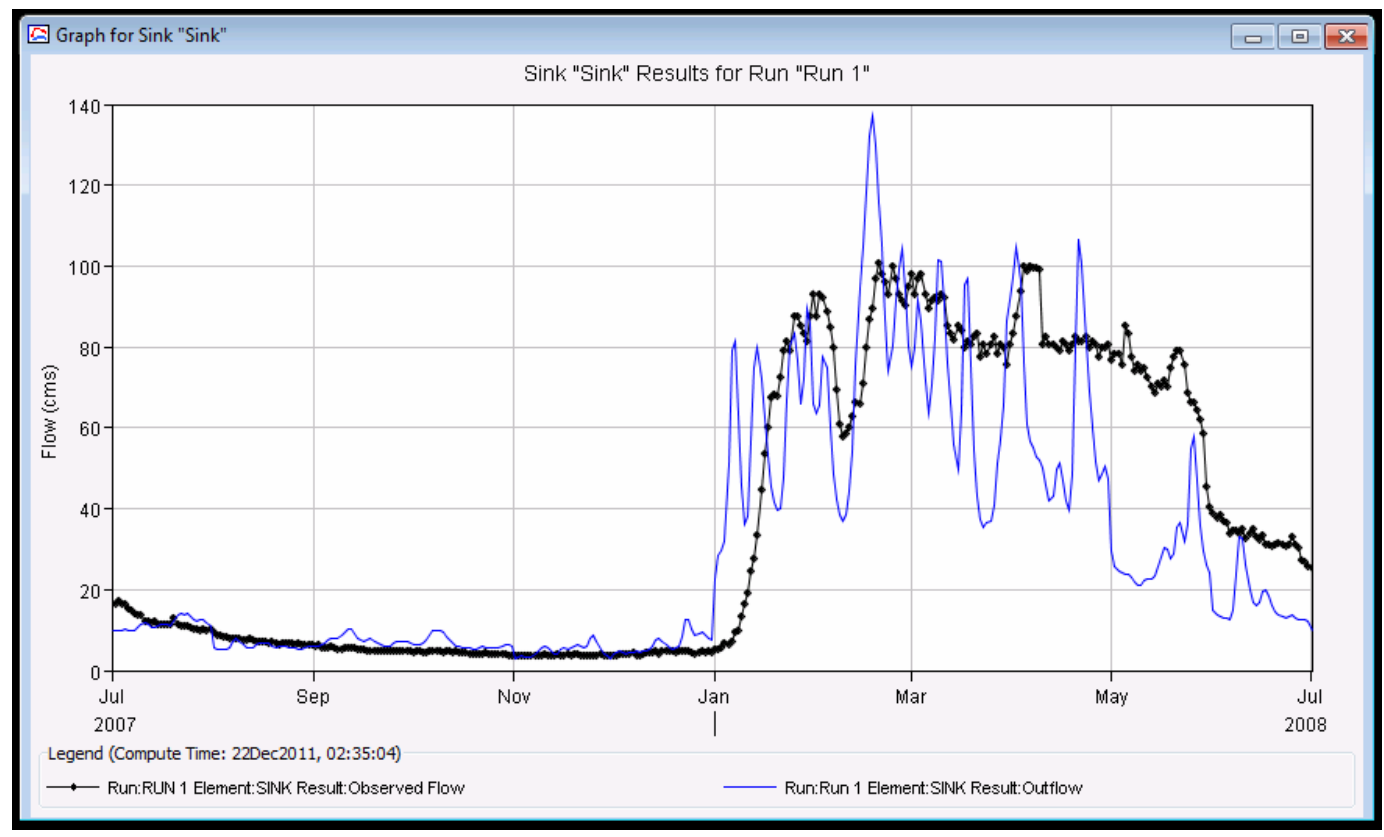

Figura 90. Hidrograma final de la prueba de validación. 


\subsection{1.- Determinación de la Pérdida de Suelo}

\subsubsection{Método de la Ecuación Universal de Pérdida de Suelo (U.S.L.E.)}

El modelo U.S.L.E., Ecuación Universal de Pérdida de Suelo, es una herramienta para estimar la erosión de los suelos agrícolas, elemento central determinante de la sustentabilidad de los sistemas de producción agropecuarios, ya que a nivel de unidades productivas (predios), la erosión reduce el potencial productivo por la propia pérdida de masa de suelo y porque se asocia siempre a degradación de las propiedades del suelo que permanece in situ. La posibilidad de evaluar cuantitativamente alternativas de uso y manejo (gerenciamiento) de suelos en términos de la erosión que generan, constituye una guía a la toma de decisiones.

En la Figura 91, se presenta el modelo cartográfico diseñado para la determinación de los factores que conforman la ecuación de la U.S.L.E. y para la elaboración de los mapas temáticos respectivos utilizando los sistemas de información geográfica (SIG). El modelo cartográfico permitió representar los procesos que se realizaron empleando el software de ArcGIS $9.3{ }^{\circledR}$ de ESRI para el manejo de los datos.

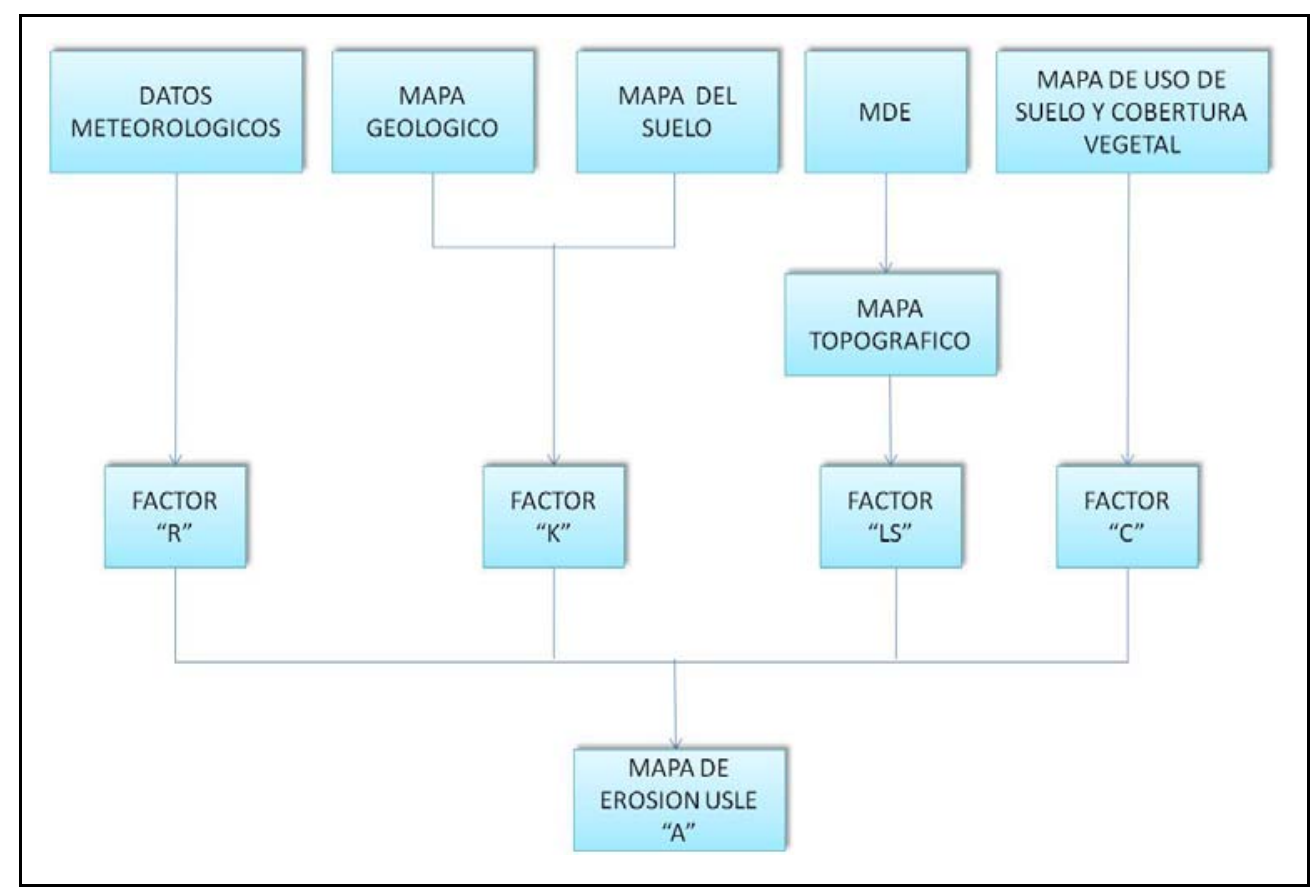

Figura 91. Modelo Cartográfico para la obtención de los factores de la U.S.L.E. y generación de los mapas temáticos correspondientes.

La estimación de los factores R, K, LS y C sirvió para hacer un diagnostico general sobre el riesgo de erosión hídrica a nivel cuenca de estudio, donde cada uno de las variables constituyó una capa de información, que al ser analizadas con los sistemas de información geográfica (SIG), dio como resultado final un mapa con la tasa de pérdida de suelo en Mg.ha/año en la cuenca del Río Toachi.

A continuación se presentan los resultados del cálculo de los factores del modelo U.S.L.E. a nivel cuenca de estudio: 


\subsubsection{Factor de Erosividad por la Lluvia "R"}

En la Tabla 65, se presentan los resultados de los factores de erosividad de la lluvia "R" para cada estación meteorológica comprendida en este análisis, los cuales fueron usados para representar la variabilidad pluviométrica espacial del área de la cuenca hidrográfica del Río Toachi.

Tabla 65. Factores de Erosividad por Lluvia (R).

\begin{tabular}{|l|c|}
\hline \multicolumn{1}{|c|}{ ESTACIÓN } & $\begin{array}{c}\text { FACTOR R } \\
\text { (Mj.mm/(ha.hr.año) }\end{array}$ \\
\hline Puerto lla & 2838,46 \\
\hline La Pitita & 915,43 \\
\hline Salgana & 2197,93 \\
\hline Pucayacu & 7635,81 \\
\hline Chavica & 882,69 \\
\hline Santo Domingo & 2980,32 \\
\hline Las Pampas & 772,28 \\
\hline Sigchos & 165,95 \\
\hline
\end{tabular}

Fuente: Efficacitas. 2006

Mapa de Erosionabilidad de la Lluvia "R"

Una vez obtenidos los valores finales del factor $(R)$ correspondientes a las ocho estaciones meteorológicas incluidas en este análisis, se elaboró, con esta información, una plantilla en Excel $\AA^{\circledR}$ y utilizando el programa ArcGIS $9.3 \AA$, se siguió el modelo de proceso cartográfico presentado en la Figura 92 para obtener la variación espacial de la erosividad de la lluvia en la cuenca hidrográfica del Río Toachi.

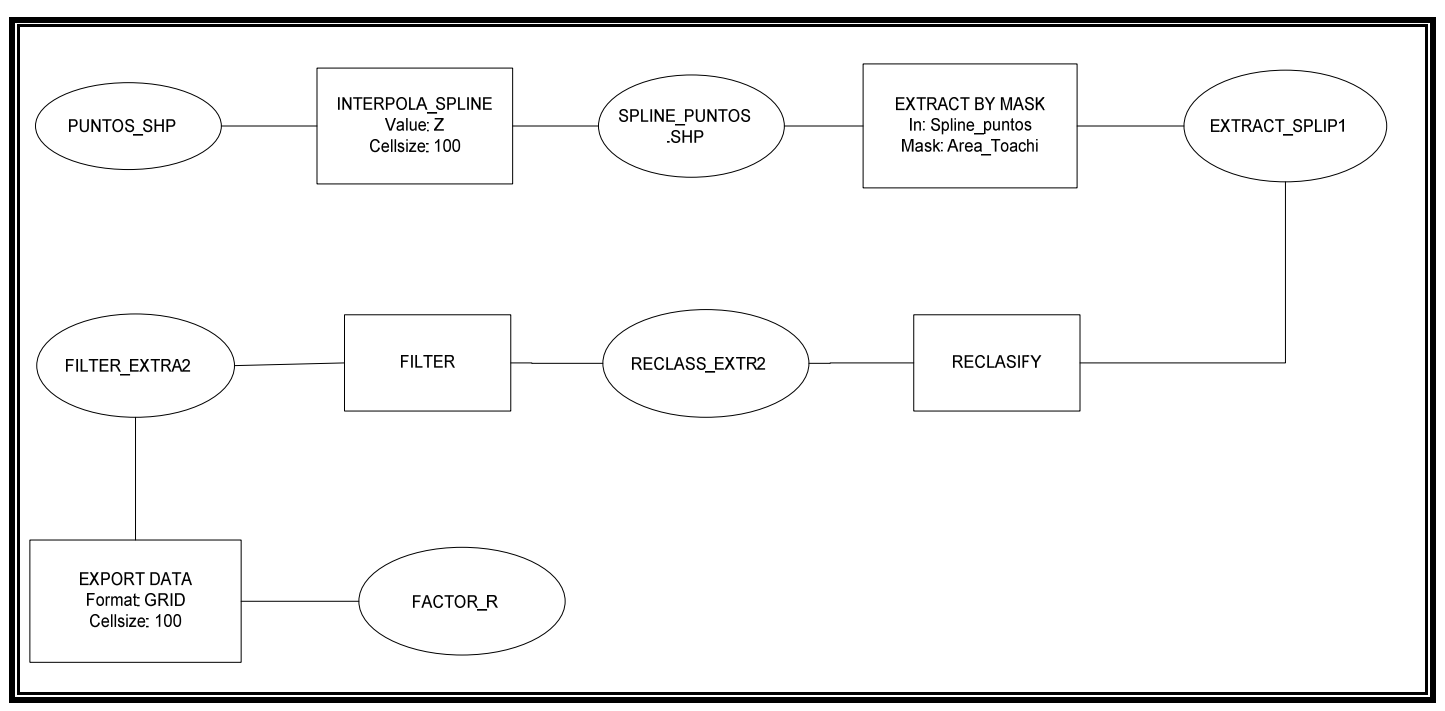

Figura 92. Modelo de Proceso Cartográfico para la obtención del Factor $\mathrm{R}$ (Mj.mm/ha.hr.año). 
Mediante la herramienta de Interpolación Spline del Análisis Espacial se realizó el cálculo de interpolación de los valores de R, luego se realizó la extracción del polígono correspondiente al área de estudio, y finalmente se efectuó la reclasificación de los valores de la erosividad de la lluvia para la cuenca de estudio, siendo el mínimo 2084,71 Mj.mm/ha.hr.año y el máximo 7162,17 Mj.mm/ha.hr.año, obteniendo de esta manera el mapa de erosividad de la lluvia en la cuenca hidrográfica del Río Toachi (ver Figura 93), donde el color rojo representa el valor más alto, el verde el más bajo y entre estos la variabilidad del factor $R$.

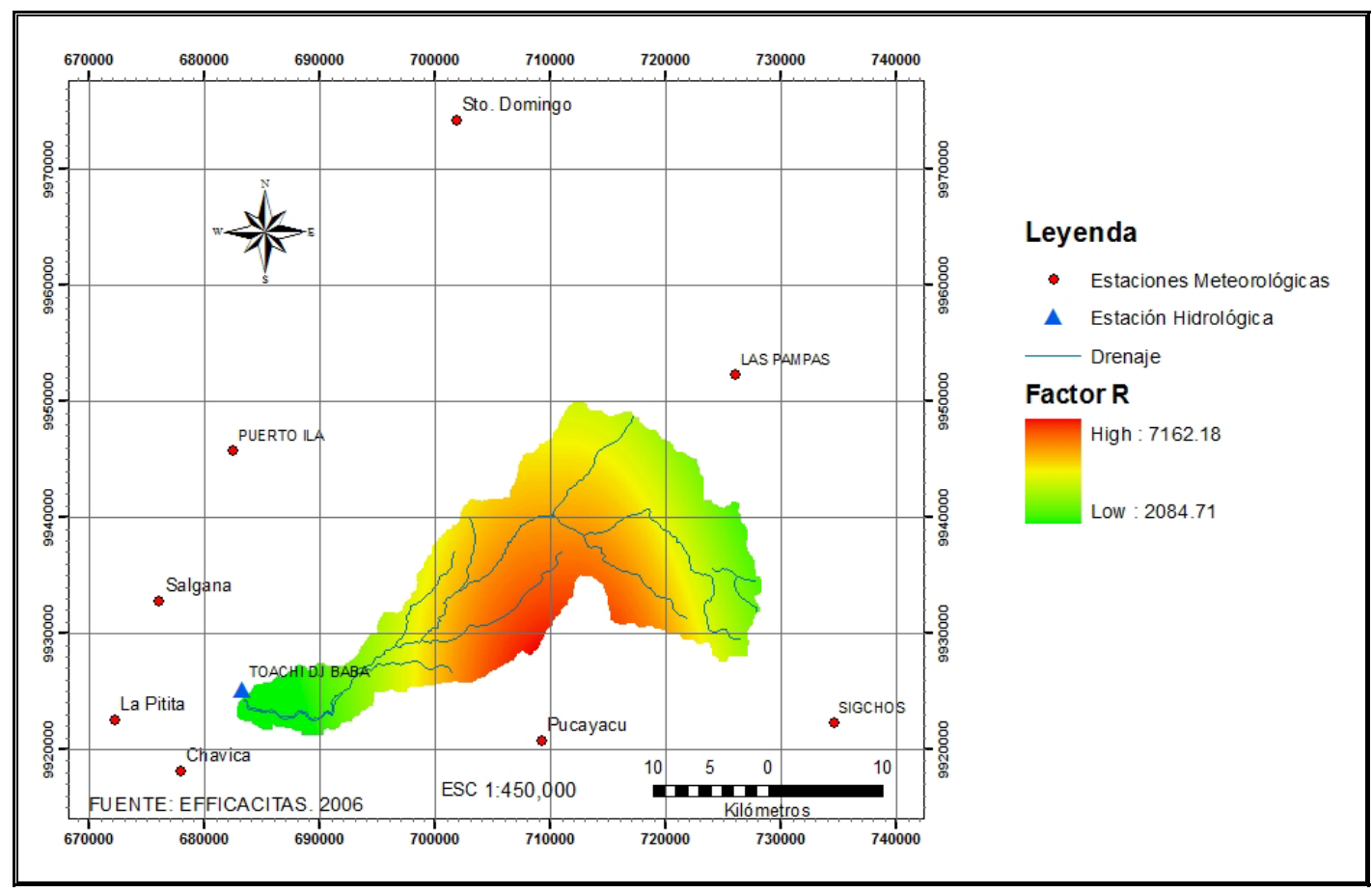

Figura 93. Mapa de Erosividad de la Lluvia "R" (Mj.mm/ha.hr.año) para la Cuenca del Río Toachi.

La estación meteorológica que presenta la mayor cantidad de concentración del factor de erosividad de la lluvia es Pucayacu con 7.635,81 Mj.mm/ha.hr.año, el cual se disipa lentamente en dirección NW hacia la zona de las estaciones de Salgana, Puerto lla y Santo Domingo con valores promedios de 2.672,23 Mj.mm/ha.hr.año; mientras que hacia el E y NE los valores promedios son de $850 \mathrm{Mj} . \mathrm{mm} / \mathrm{ha}$.hr.año y hacia él SE, la estación Sigchos, tiene el valor mínimo de 165,95 Mj.mm/ha.hr.año.

Lo que evidencia que la zona media de la cuenca del Río Toachi está sometida a tormentas con alto poder erosivo y aunque, el área de estudio, tiene las dos estaciones climáticas, la época húmeda es más intensa y de mayor duración, además el nivel de erosividad decrece conforme se aleja hacia la Cordillera Occidental (este) y hacia la Llanura Costera (oeste). 


\section{$\underline{\text { 5.11.1.2 Factor de Erodabilidad del Suelo "K" }}$}

Con los valores de $\mathrm{K}$ para la cuenca de estudio de 0,031 y 0,035 Mg.ha.hr/ha.MJ.mm, y usando las herramientas del programa ArcGIS $9.3 \AA$, se generó el mapa de erodabilidad de la cuenca de estudio (ver Figura 94), el cual guarda concordancia con el tipo de suelo predominante en el área que son del Orden de los Inceptisoles.

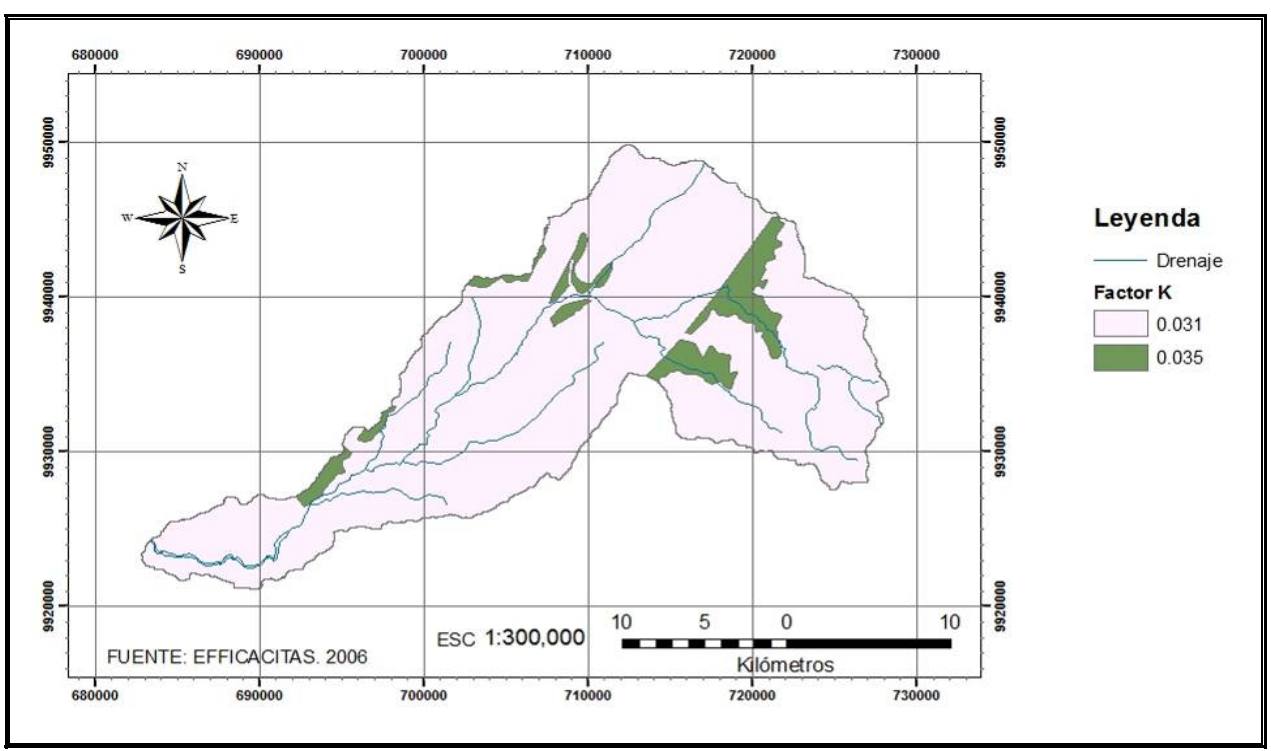

Figura 94. Mapa de Erodabilidad "K" (Mg.ha.hr/ha.MJ.mm) para la Cuenca del Río Toachi.

Como se puede observar en la Figura 94, el valor de K=0,031 (Mg.ha.hr/ha.MJ.mm) ocupa la mayor cantidad de superficie de la cuenca de estudio, se caracteriza por presentar menor susceptibilidad a la erosión con suelos profundos $(>100 \mathrm{~cm})$ de buen drenaje y fertilidad media, de textura moderadamente gruesa, predominando los suelos franco limoso y pocos franco arenoso. El valor de $\mathrm{K}=0,035$ (Mg.ha.hr/ha.MJ.mm), se muestra en pequeñas áreas puntuales en la zona de estudio, se caracteriza por presentar mayor susceptibilidad a la erosión del suelo está compuesto por Inceptisoles y Entisoles con moderada profundidad (50-100 cm) de buen drenaje y baja fertilidad, de textura media predominando los suelos francos. 


\section{$\underline{5.11 .1 .3}$ Factor Topográfico "LS"}

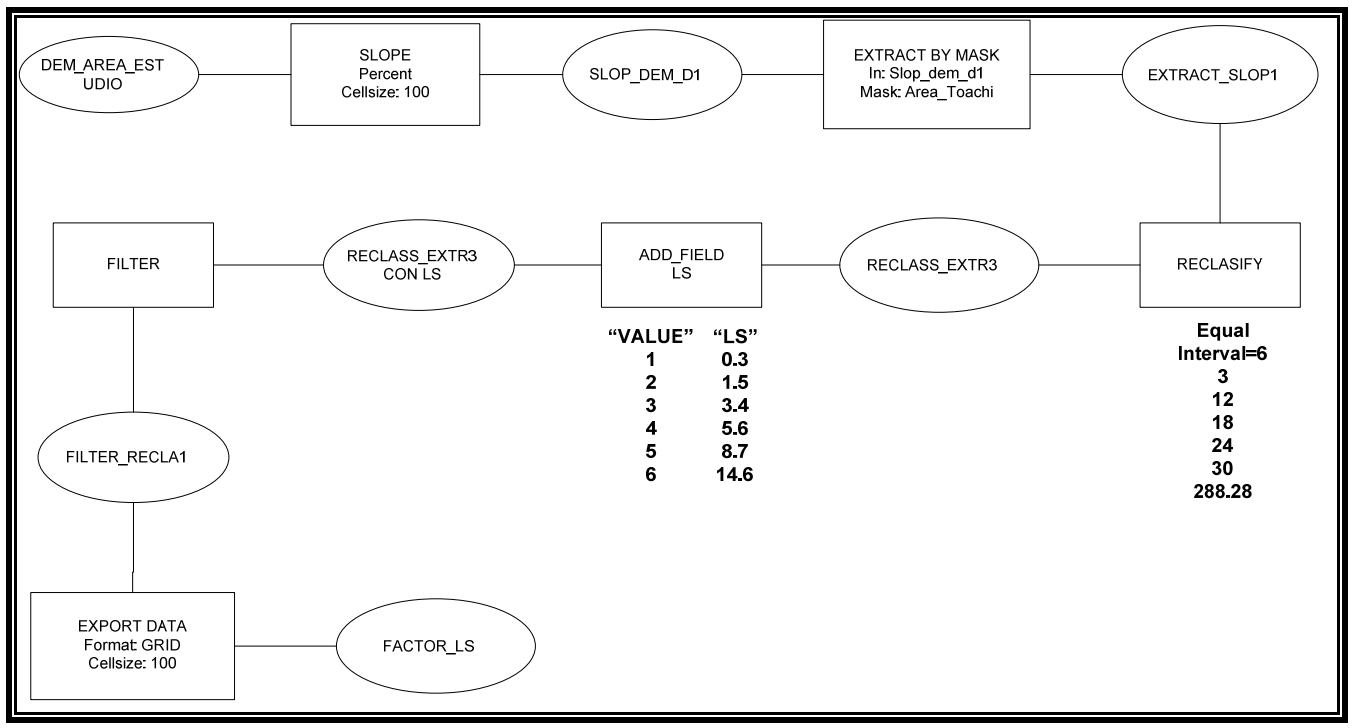

Figura 95. Modelo de Proceso Cartográfico para la obtención del Factor LS

El esquema del proceso cartográfico presentado en la Figura 95 se empleó utilizando el programa ArcGIS $9.3 \AA$, el mismo que inicia con el modelo de elevación digital (MDE) del área de trabajo (ver Figura 96), al cual se realiza la extracción del área de estudio (ver Figura 97) y finalmente se aplica una de las funciones del análisis de superficies "Slope" (Análisis Espacial de ArcGIS $9.3 \AA$ ), obteniendo el mapa de pendientes puras (ver Figura 98).

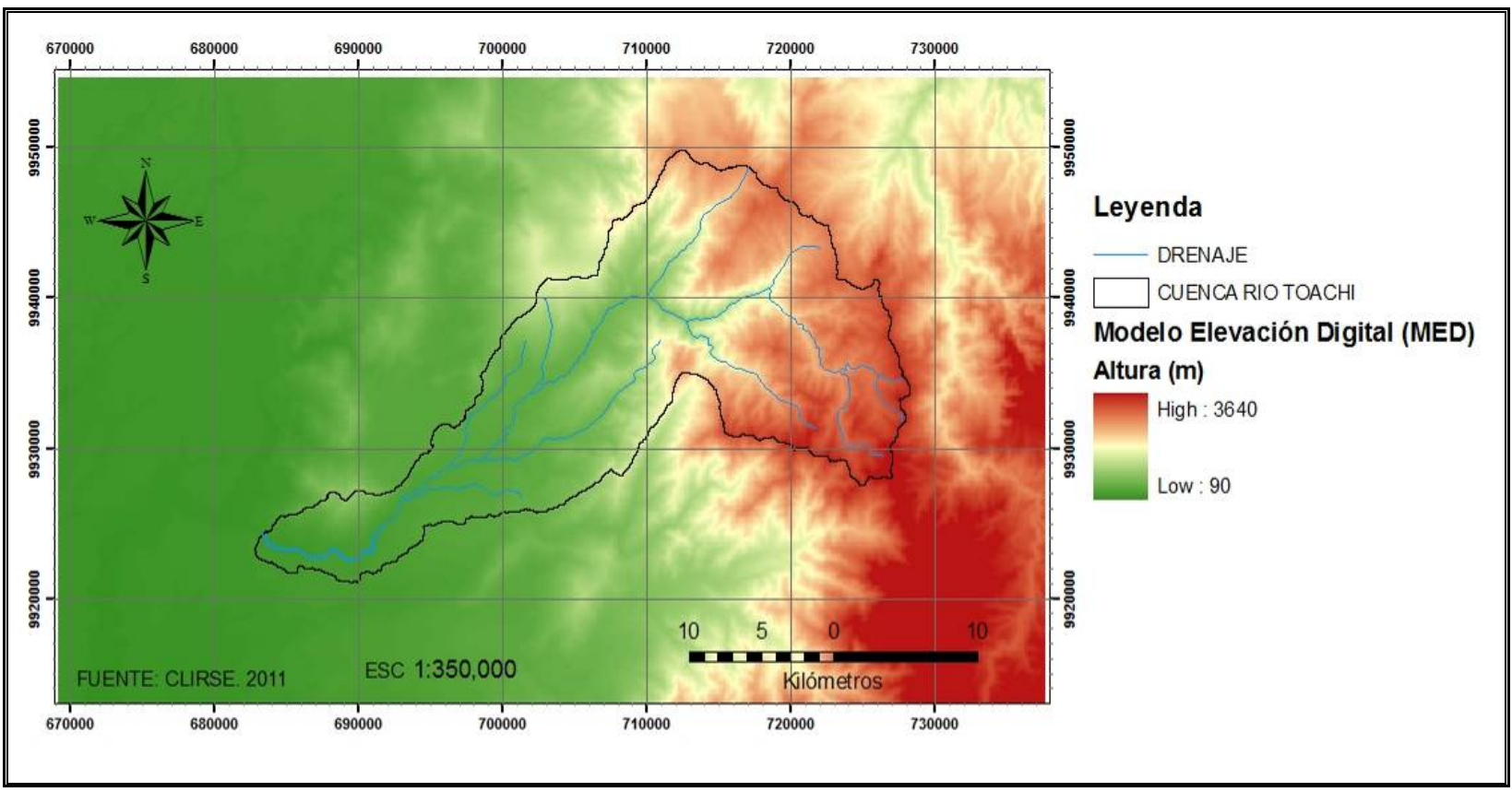

Figura 96. Modelo de Elevación Digital del área de trabajo. 


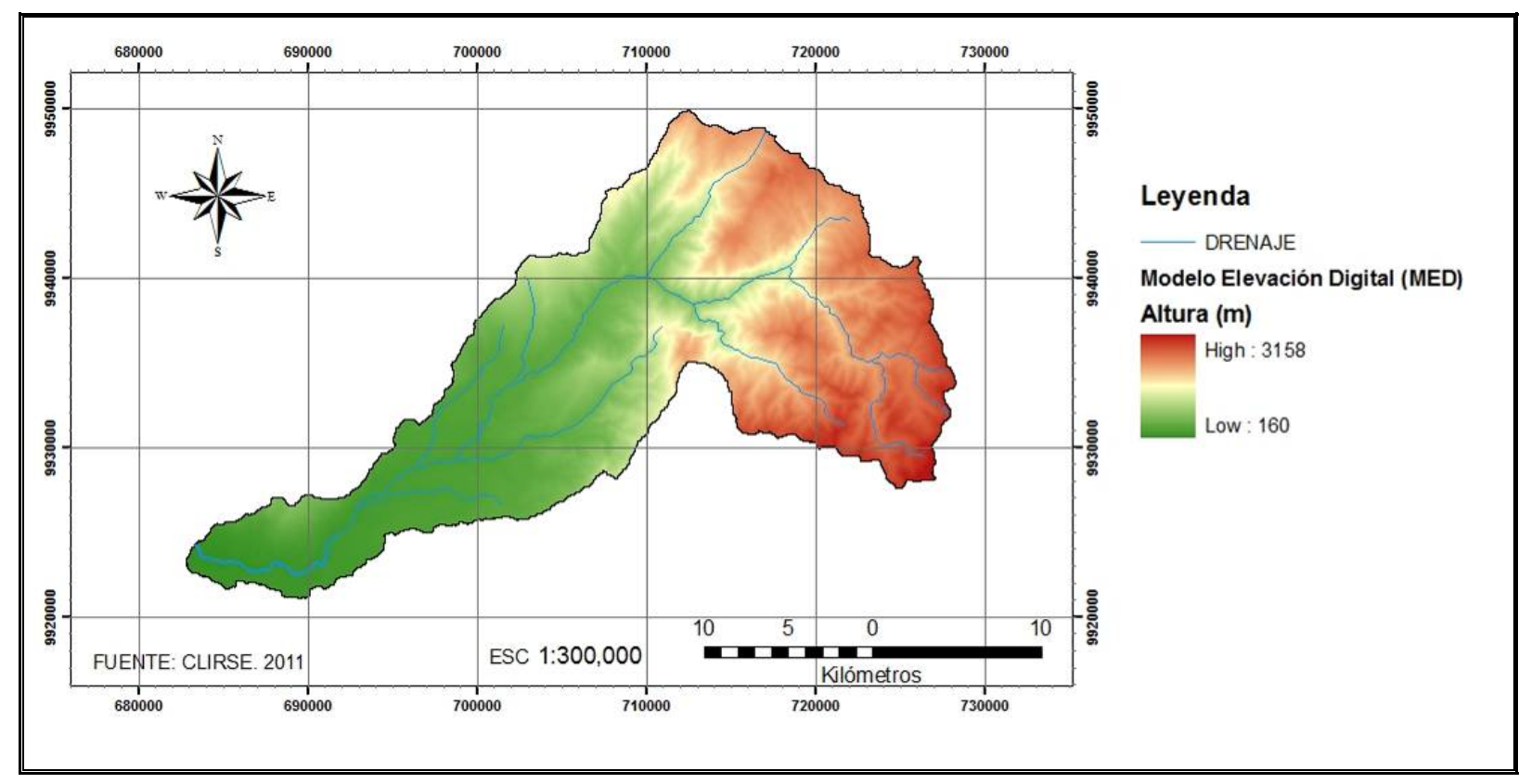

Figura 97. Modelo de Elevación Digital de la Cuenca del Rio Toachi.

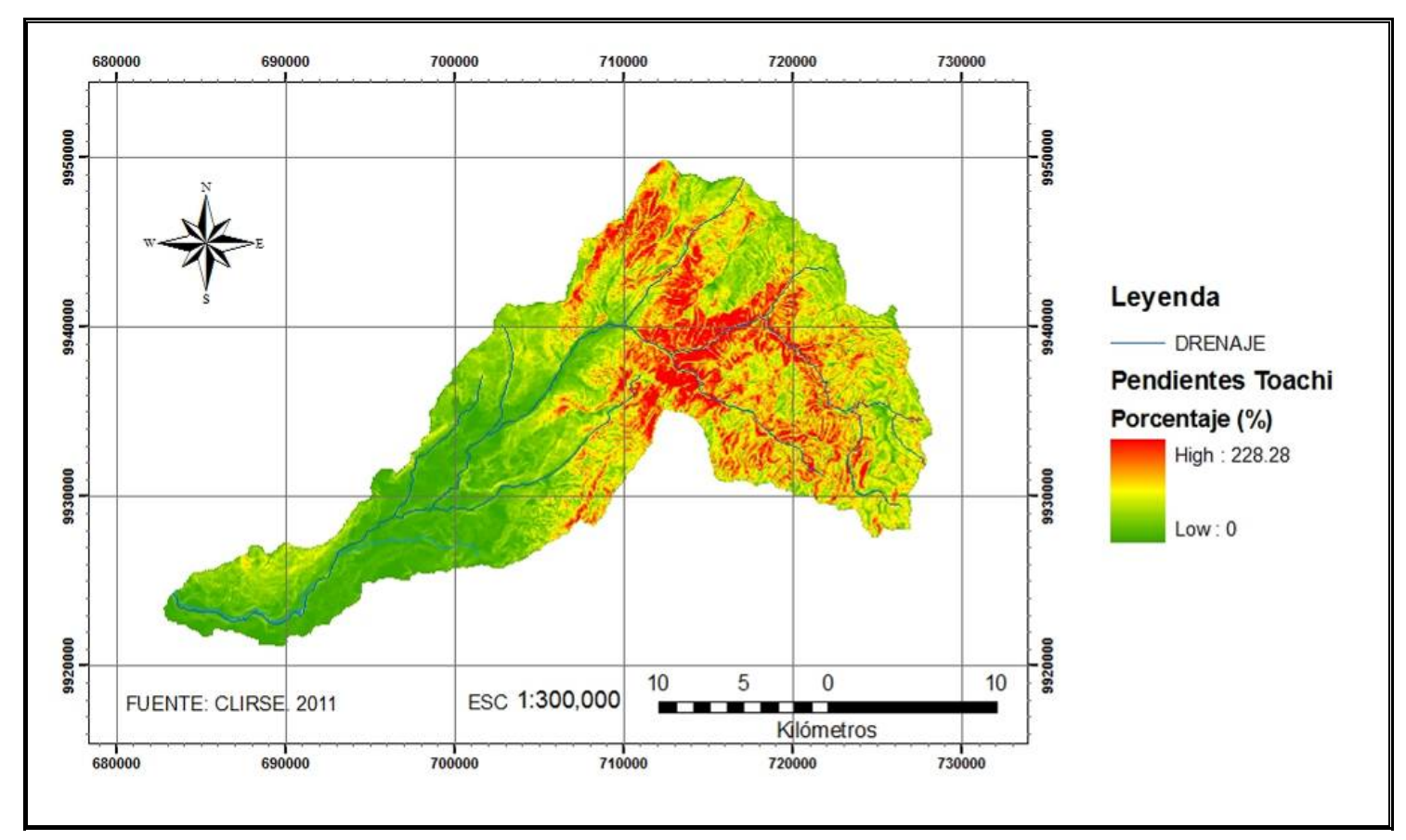

Figura 98. Mapa de Pendientes puras de la Cuenca del Rio Toachi expresado en (\%)

De acuerdo a la Tabla 66, propuesta por Mintegui Aguirre (1998) para la determinación del factor LS según rangos porcentuales de pendiente, se utilizaron los seis rangos de pendiente [columna pendiente (\%)] establecidos para cada LS ponderado realizando una reclasificación de los valores de pendiente del mapa 98. 
Tabla 66. Valores de LS según rangos de pendiente.

\begin{tabular}{|c|c|}
\hline $\begin{array}{c}\text { PENDIENTE } \\
\text { (\%) }\end{array}$ & LS \\
\hline $0-3$ & 0,3 \\
\hline $3-12$ & 1,5 \\
\hline $12-18$ & 3,4 \\
\hline $18-24$ & 5,6 \\
\hline $24-30$ & 8,7 \\
\hline$>30$ & 14,6 \\
\hline
\end{tabular}

Una vez realizada la reclasificación del mapa de pendiente con los seis rangos de valores, se ingresa los correspondientes valores de "LS" para cada rango de pendiente (columna LS en la Tabla 66). De esta manera se obtuvo el mapa raster de las pendientes de la cuenca del Río Toachi, la cual puede ser presentada en porcentaje (\%) de pendiente (ver Figura 99) o en valores de LS (ver Figura 100).

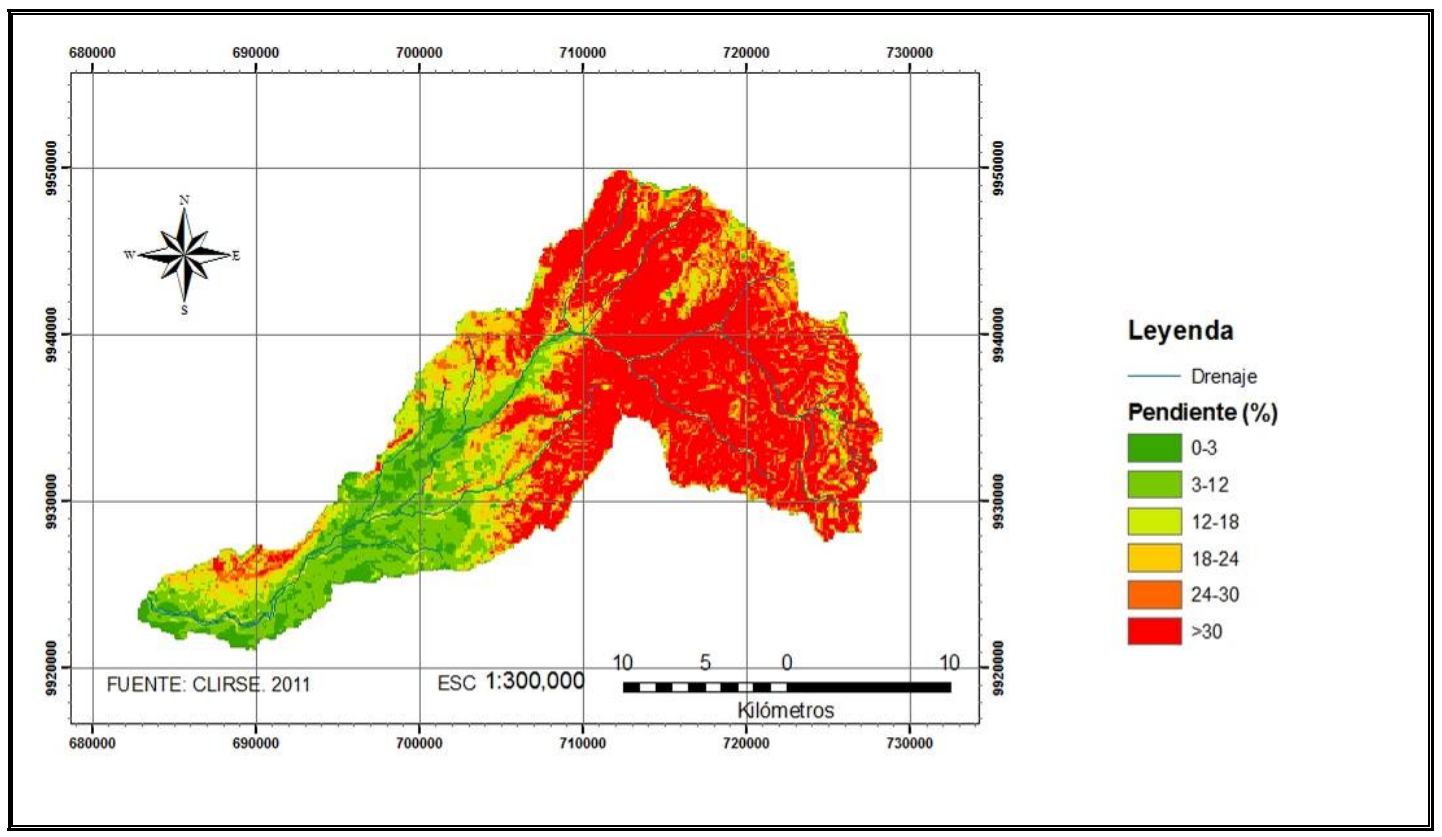

Figura 99. Mapa de Pendientes de la Cuenca hidrográfica del Río Toachi según (\%)

En la Figura 99 se muestra el mapa de pendientes en la cuenca del Río Toachi de acuerdo al porcentaje, según la figura, el factor topográfico evidencia que la zona de estudio está sometida a grandes valores de pendientes $(>18 \%)$, especialmente en la zona media alta, donde se presentan las estribaciones de la Cordillera Occidental formada por pendientes pronunciadas. Mientras que de la zona media hacia abajo, se presentan valores bajos de pendiente $(<18 \%)$, observando que sobre el perímetro norte existe pequeñas zonas con altos valores de pendientes. 


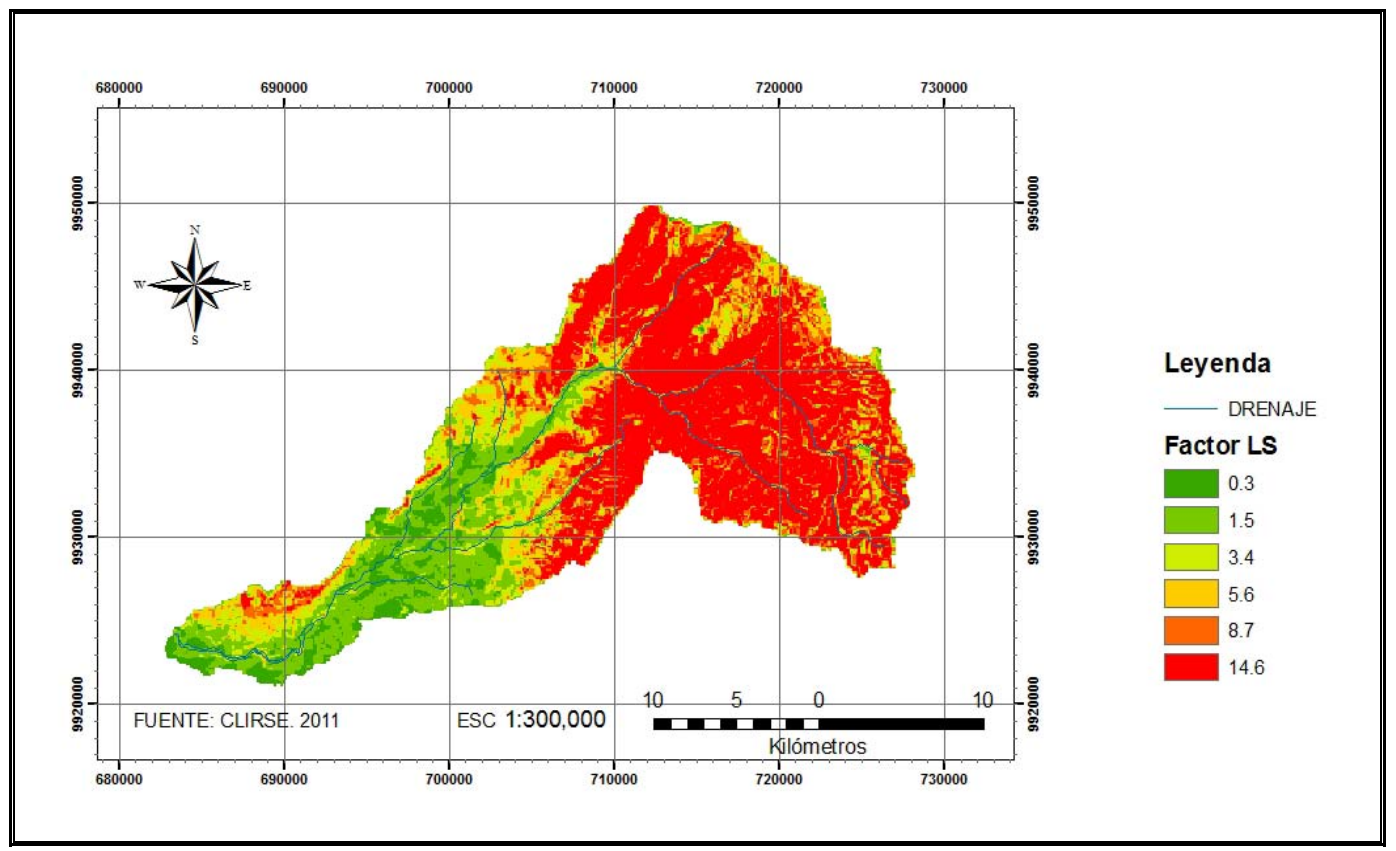

Figura 100. Mapa de Pendientes de la Cuenca del Río Toachi según el factor topográfico (LS).

En la Figura 100 se presenta el mapa de la distribución espacial del factor LS en la cuenca de estudio, se observa que sobresalen los altos valores del factor topográfico en color rojo debido a que las longitudes de las pendientes $(L)$ son considerablemente grandes 0 extensas. Las áreas donde se producen estas variaciones se deben a las fuertes pendientes existentes en la zona de cabecera. Esto se pude corroborar con la Figura 98 que presenta la imagen de la cuenca de estudio según las pendientes puras (sin tratamiento), en la cual se muestra que la zona de cabecera presenta valores altos debido a las fuertes pendientes que carecen de vegetación natural.

Para el cálculo del índice topográfico y con el fin de mejorar la precisión del factor LS en la U.S.L.E. usando SIG, se siguieron las recomendaciones del concepto de $L$, es decir, se consideraron los puntos en donde la pendiente decrece hasta que se produce la sedimentación o el escurrimiento entra a una red de drenaje. También para evitar la pérdida de información, durante el procesamiento de las imágenes, se trabajó con un tamaño de pixel de $100 \times 100$ para tener buena resolución, especialmente en zonas donde existen pendientes cóncavas, pues las depresiones inducen a grandes errores, además del error generado por el cambio de escala y el ajuste del área mínima cartografiable (Flores et al., 2003).

\subsubsection{Factor de Cobertura del Suelo " $\mathrm{C}$ "}

Se sigue la metodología de los diferentes autores, se presenta la Tabla 67 con los valores de $\mathrm{C}$, los cuales hacen referencia a condiciones puntuales de uso de suelo, situación que se puede considerar una fuente de error potencial para el cálculo de la pérdida de suelo. 
Tabla 67. Factor C para Uso del Suelo.

\begin{tabular}{|l|c|}
\hline \multicolumn{1}{|c|}{ USO DEL SUELO } & FACTOR \\
Café y cacao, pastos & 0,02 \\
\hline Monte y fruticultura & 0,02 \\
\hline Bosque con claros de pastos, cultivos y arboricultura & 0,03 \\
\hline Arboricultura & 0,02 \\
\hline Pastos y cultivos, restos de bosque & 0,03 \\
\hline $\begin{array}{l}\text { Formación arbórea, densa, siempre verde; variante de las vertientes } \\
\text { exteriores de Los Andes }\end{array}$ & 0,01 \\
\hline
\end{tabular}

Con estos valores y mediante el uso del programa ArcGIS $9.3 \AA$, se realizó la representación espacial del factor cobertura vegetal en la cuenca del Río Toachi, obteniendo el mapa que se presenta en la Figura 101.

Se observa que en toda la cuenca de estudio está presente el coeficiente más bajo de cobertura de suelo, $\mathrm{C}=0,01$, lo que significa que se existen campos cultivados o con vegetación, así, en gran parte de la zona baja y zona media, se observan valores del factor cobertura $\mathrm{C}=0,02$, que corresponden a terrenos en las se realizan prácticas agrícolas, en ambos casos se ubican las haciendas agrícolas y cultivos permanentes, que reducen considerablemente los procesos erosivos. Mientras que en la mayor parte de la zona alta se observan valores elevados del factor cobertura $\mathrm{C}=0,03$, correspondiente a bosques con claros, restos de bosque y pastos, donde las prácticas agrícolas son casi nulas, y más aún si se considera que se trata de áreas en las que no se realizan prácticas de conservación.

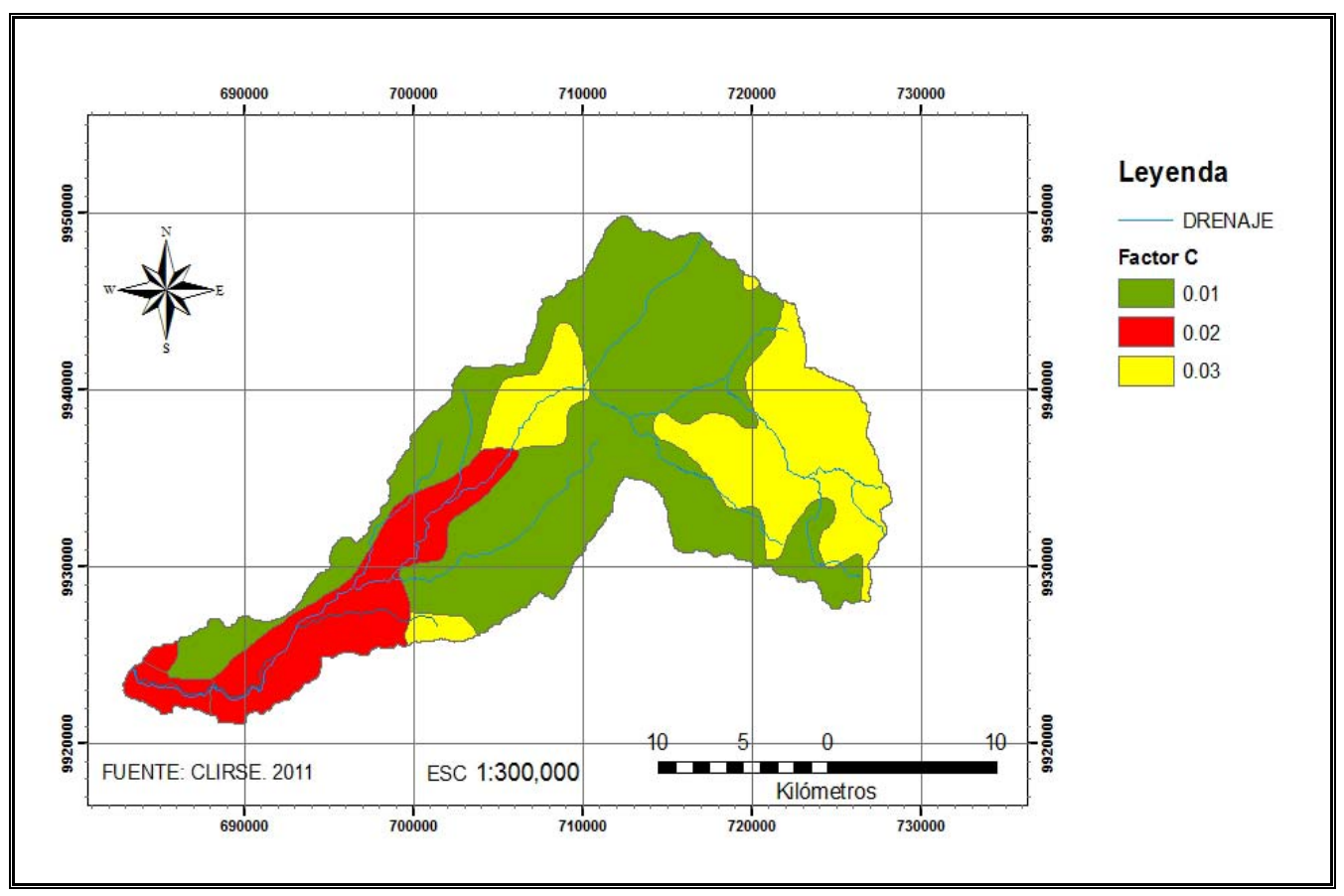

Figura 101. Mapa de Factor de Cobertura Vegetal "C", en la Cuenca del Río Toachi. 
Para este análisis se utilizó el mapa de Uso de Suelos y Cobertura Vegetal del CLIRSEN ${ }^{17}$ sin embargo, se recomienda un trabajo más detallado para identificar con mayor precisión la distribución espacial de la cobertura y manejo del suelo, (uso de imágenes satelitales, trabajo de campo, etc) puesto que mejora la precisión del cálculo de la erosión hídrica.

\subsubsection{Estimación de la Pérdida de Suelo "A" (Erosión Actual y Erosión Tolerante del $\underline{\text { Suelo) }}$}

Después de la operación aritmética del producto de los factores de la U.S.L.E. (archivos raster) que fueron tomados en cuenta para este análisis (R.K.LS.C), utilizando el SIG con el programa ArcGIS $9.3 \AA$, se obtuvo el mapa raster (stretched) de la distribución espacial de la pérdida de suelo en la cuenca del Río Toachi, el cual se muestra en la Figura 102, donde se observa que la pérdida promedio de suelo anual, para toda la cuenca de estudio, oscila entre 0,38 - 93,08 Mg.ha/año. En la Tabla 68, se presenta el grado de erosión, la superficie afectada y el porcentaje correspondiente.

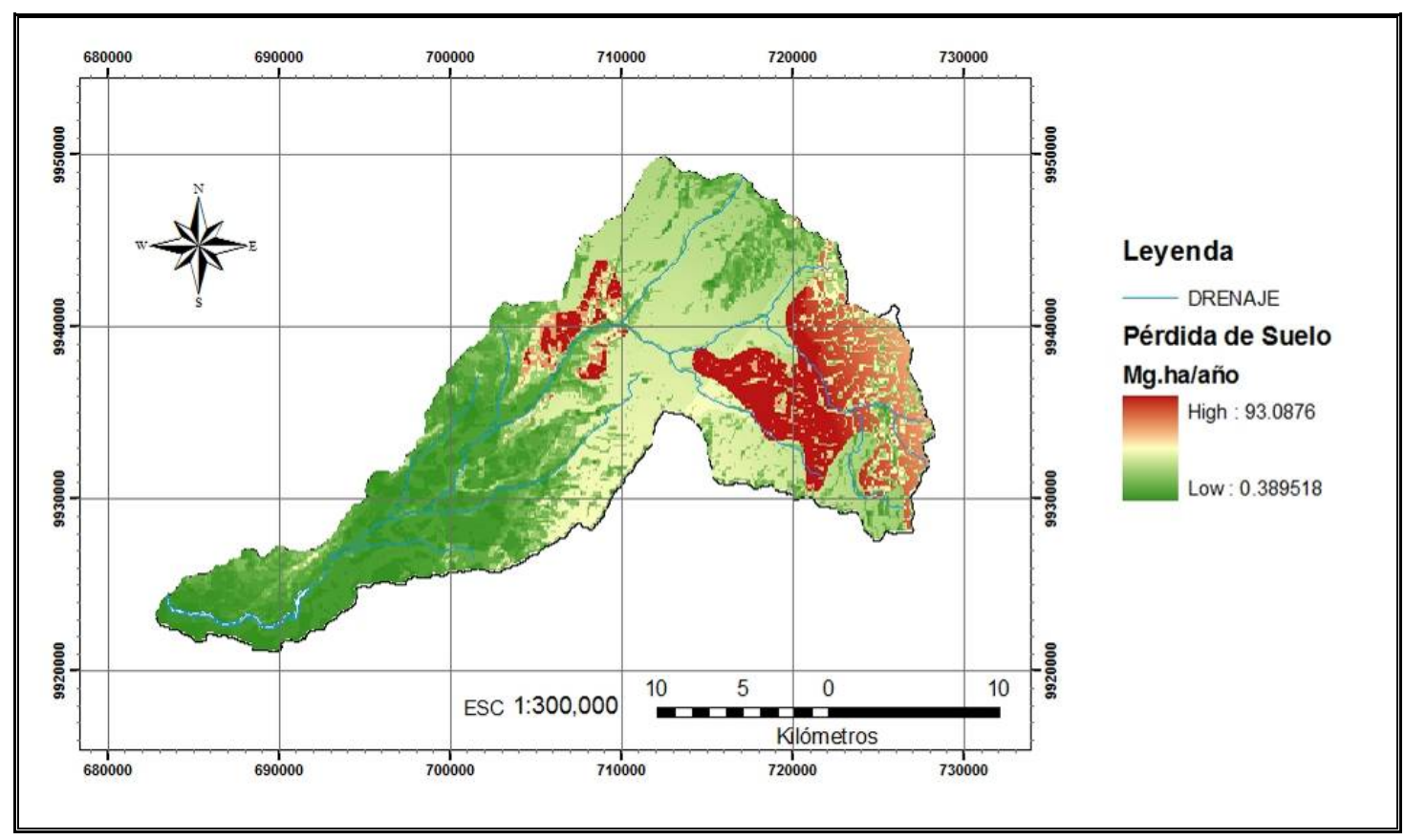

Figura 102 Mapa de Pérdida de Suelo (Mg.ha/año) en la Cuenca del Río Toachi.

\footnotetext{
${ }^{17}$ CLIRSEN. 2009 (2)
} 
Tabla 68. Superficie y porcentaje de la pérdida de suelo en la Cuenca del Río Toachi.

\begin{tabular}{|c|c|c|}
\hline $\begin{array}{c}\text { GRADOS DE EROSIÓN } \\
\text { (Mg.ha/año) }\end{array}$ & $\begin{array}{c}\text { SUPERFICIE } \\
\mathbf{( k m}^{\mathbf{2}} \text { ) }\end{array}$ & $\begin{array}{c}\text { PORCENTAJE } \\
\mathbf{( \% )}\end{array}$ \\
\hline $\begin{array}{c}\text { Nulo } \\
\mathbf{<} \mathbf{1 0}\end{array}$ & 169,52 & $33,77 \%$ \\
\hline $\begin{array}{c}\text { Moderado } \\
\mathbf{1 0}-\mathbf{5 0}\end{array}$ & 262,98 & $52,39 \%$ \\
\hline $\begin{array}{c}\text { Alto } \\
\mathbf{5 0}-\mathbf{2 0 0}\end{array}$ & 69,47 & $13,84 \%$ \\
\hline
\end{tabular}

En los terrenos donde la erosión actual del suelo (R.K.LS.C) no supera la erosión tolerable, se considera que no existe deterioro de este recurso. En este análisis, el 33,7\% de la superficie no tiene ningún grado de erosión, el $52,4 \%$ del área tiene erosión moderada y el $13,8 \%$ tiene alta erosión.

En la Figura 103, se presenta el mapa raster de la Figura 102, que fue reclasificado con los tres primeros grados de erosión de la Tabla 28, en el cual se observa que la mayor cobertura geográfica donde se ubica el nivel que tiene una condición libre de erosión $(<10$ Mg.ha/año) es en la zona baja, caracterizada por grandes planicies; el nivel donde existe erosión moderada (10-50 Mg.ha/año) se ubica en la zona media-alta y el nivel que presenta alta erosión (>50 Mg.ha/año) se halla en la zona alta propiamente dicha, caracterizada por grandes elevaciones y fuertes pendientes.

Este tipo de resultados permite a quienes desarrollan planes para el manejo de recursos naturales, de proyectar los cambios e inclusive modelarlos y evaluar su impacto antes de implementarlos (Flores et al., 2003).

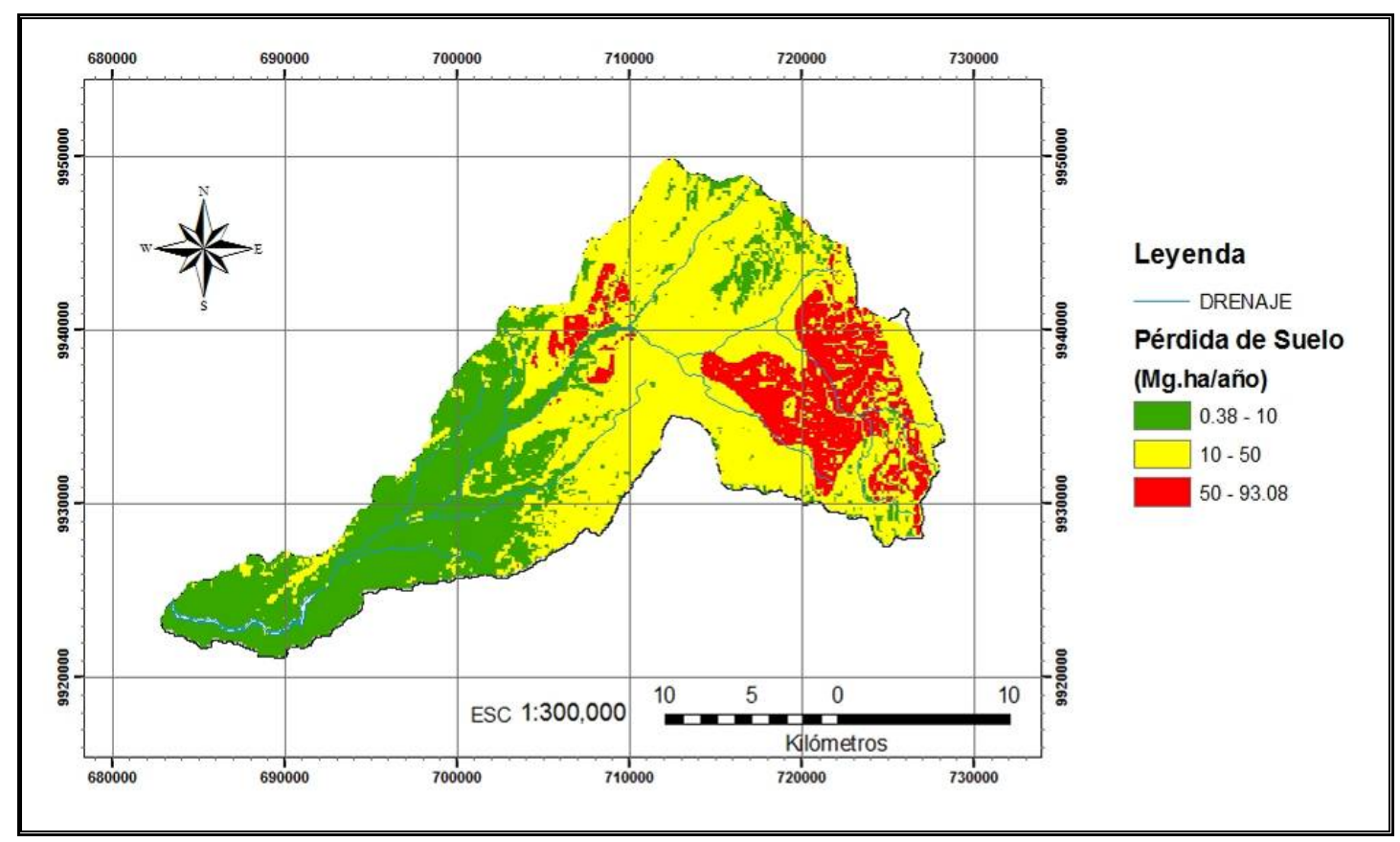

Figura 103. Mapa de Pérdida de Suelo (Mg.ha/año) en la Cuenca del Río Toachi reclasificado. 
A continuación se presenta la Tabla 69, con los resultados del estudio particular realizado a nivel unidades hidrológicas, a partir del análisis geoespacial de la cartografía de la zonificación de los factores de la U.S.L.E. (K, LS, C y R), determinando la superficie ponderada $\left(\mathrm{km}^{2}\right)$ por subcuenca.

Tabla 69. Valores ponderados y medios de los Factores de la U.S.L.E.

\begin{tabular}{|l|c|c|c|c|c|c|c|c|}
\hline Subcuencas & $\mathbf{1}$ & $\mathbf{2}$ & $\mathbf{3}$ & $\mathbf{4}$ & $\mathbf{5}$ & $\mathbf{6}$ & $\mathbf{7}$ & $\begin{array}{c}\text { VALOR } \\
\text { MEDIO }\end{array}$ \\
\hline $\begin{array}{l}\text { Factor R } \\
\text { Mj.mm/(ha.hr.año) }\end{array}$ & 5041,5 & 6086 & 5884,7 & 4693,25 & 5563,3 & 6128 & 4052,35 & 5349,87 \\
\hline $\begin{array}{l}\text { Factor K } \\
\text { (Mg.hr/Mj.mm) }\end{array}$ & 0,031 & 0,031 & 0,032 & 0,031 & 0,031 & 0,031 & 0,031 & 0,0317 \\
\hline Factor LS (\%) & 11,91 & 13,25 & 13,02 & 11,50 & 7,46 & 7,81 & 2,43 & 9,627 \\
\hline Factor C & 0,010 & 0,011 & 0,016 & 0,022 & 0,017 & 0,011 & 0,017 & 0,015 \\
\hline $\begin{array}{l}\text { Pérdida Suelo (A) } \\
\text { (Mg,ha/año) }\end{array}$ & 18,93 & 26,67 & 39,23 & 36,00 & 21,47 & 16,50 & 5,15 & 23,422 \\
\hline Área [km ${ }^{2}$ ] & 38,97 & 6,95 & 46,16 & 142,09 & 106,45 & 61,79 & 101,14 & \\
\hline
\end{tabular}

La cuenca del Río Toachi se caracterizó por presentar un R de 5349,87 [Mj.mm/(ha.hr.año)], lo que indica un alto nivel de erosividad promedio. Como se puede observar en la Figura 104, los valores más fuertes se presentaron en las subcuenca 6 y 2 con valores que sobrepasan los 6000; las subcuencas 3,5 y 1 presentan valores fuertes entre 6000 y 5000 , y las subcuencas 4 y 7 presentan valores moderadamente fuertes entre 4000 y 5000 . La variación del factor de erosividad es de 2075,7 [Mj.mm/(ha.hr.año)]. Lo que corrobora que las zonas media y alta tienen un alto nivel de lluvias anuales.

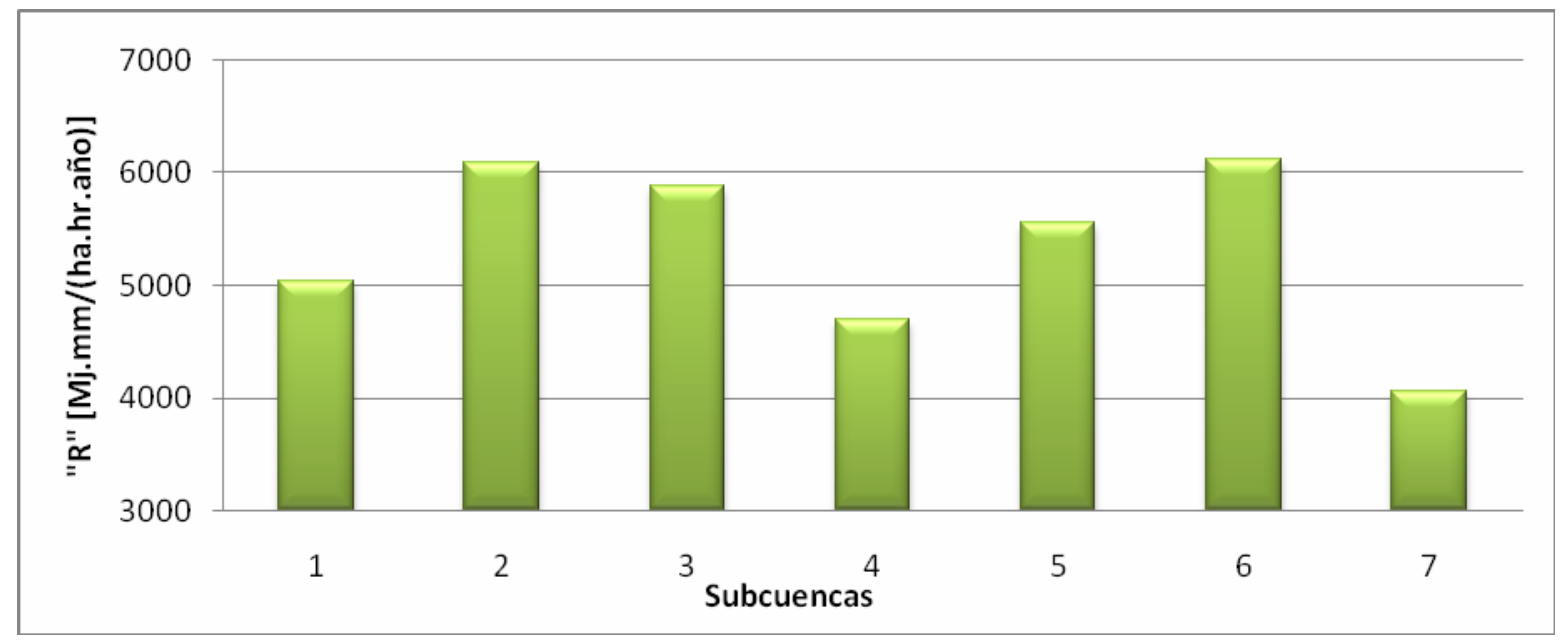

Figura 104. Factor "R" a nivel subcuenca. 
El valor ponderado del factor $\mathrm{K}$ para la cuenca de estudio está en el promedio de 0,031 (Mg.hr/Mj.mm), lo que indica que la erodabilidad de los suelos en muy baja debido al buen contenido de materia orgánica y que la fracción de limo y arena fina es reducida, confirmando la presencia de arcilla en el suelo (ver Figura 105).

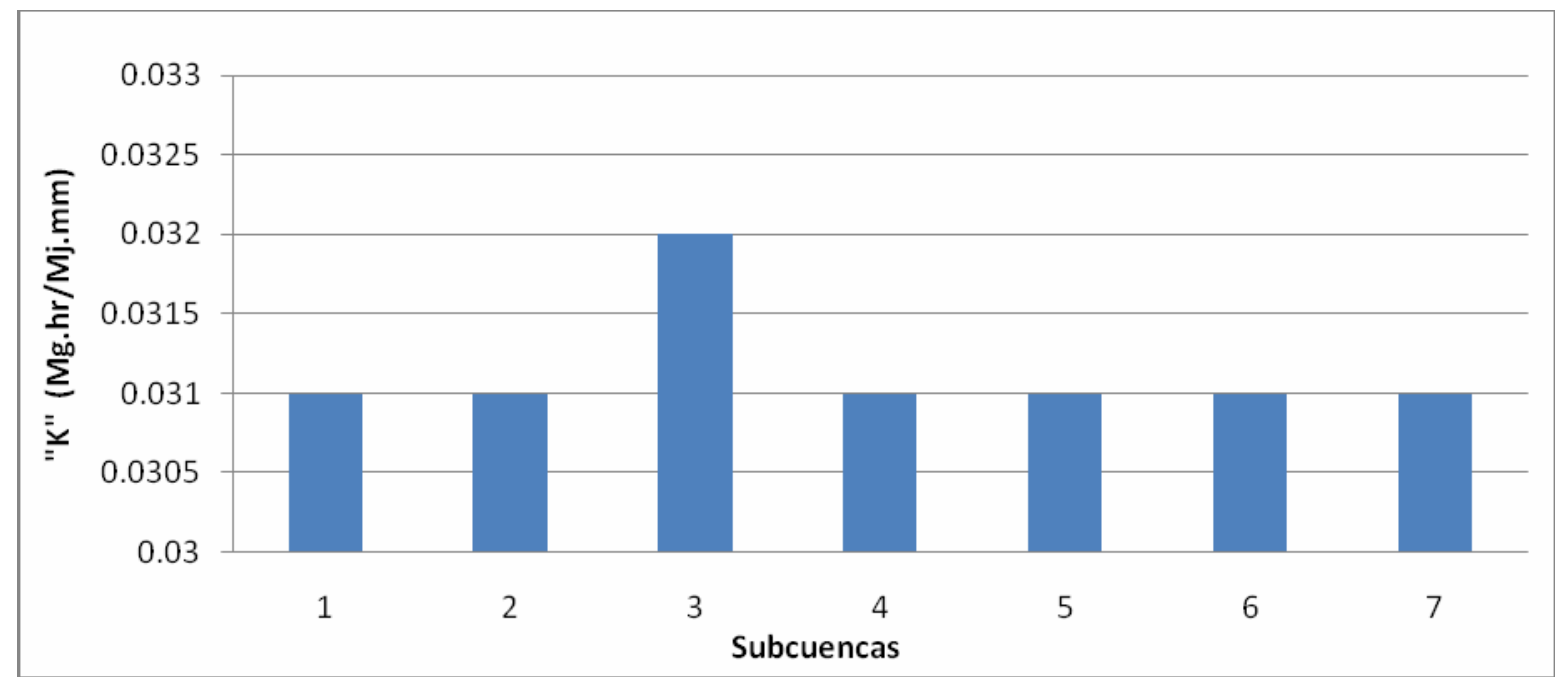

Figura 105. Factor "K" a nivel subcuenca.

El valor ponderado del factor LS para la cuenca de estudio está en el promedio de 9,63\%, lo que indica que la mayor cantidad de superficie de los suelos se encuentra en zonas de fuertes pendientes. Como se puede observar en la Figura 106, las subcuencas 2, 3, 1 y 4 sobrepasan el 10\%; las subcuencas 6 y 5 están entre 10 y $3 \%$; y la subcuenca 7 presenta una pendiente del 2,4\%. Esto confirma que en las zonas altas se caracterizan por presentar pendientes fuertes, en la zona media, pendientes moderadas y en la zona baja las pendientes son leves.

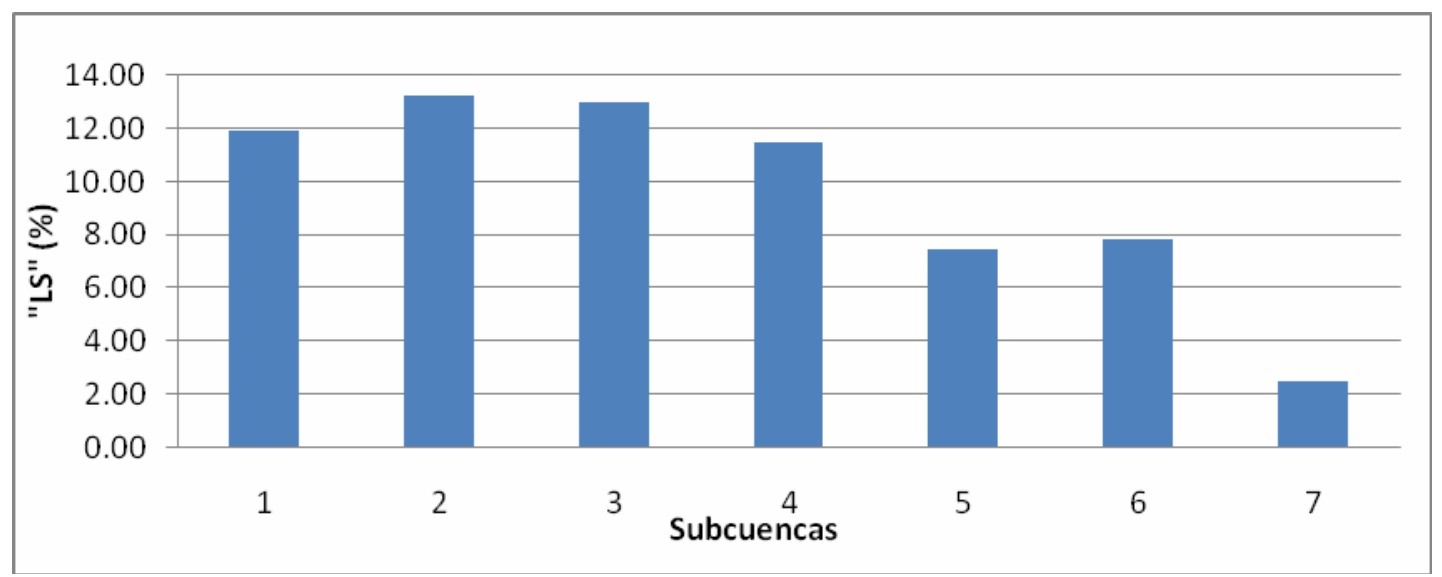

Figura 106. Factor "LS" a nivel subcuenca.

El valor ponderado del factor C para la cuenca de estudio es de 0,015 (Mg.hr/Mj.mm), que indica que el uso de los suelos está entre bueno a regular debido a la proporcionada cobertura de la vegetación. Como se observa en la Figura 107, las subcuencas 1, 2 y 6 presentan buena cobertura del suelo, las subcuencas 3,5 y 7 muestran una cobertura media 
y la subcuenca 4 una cobertura mala, siendo estas zonas donde se encuentra la mayor cantidad de tierras de cultivo cuya producción es durante todo el año (permanentes); y la subcuenca 4 que presenta una pobre cobertura, donde existen áreas descubiertas debido a la deforestación.

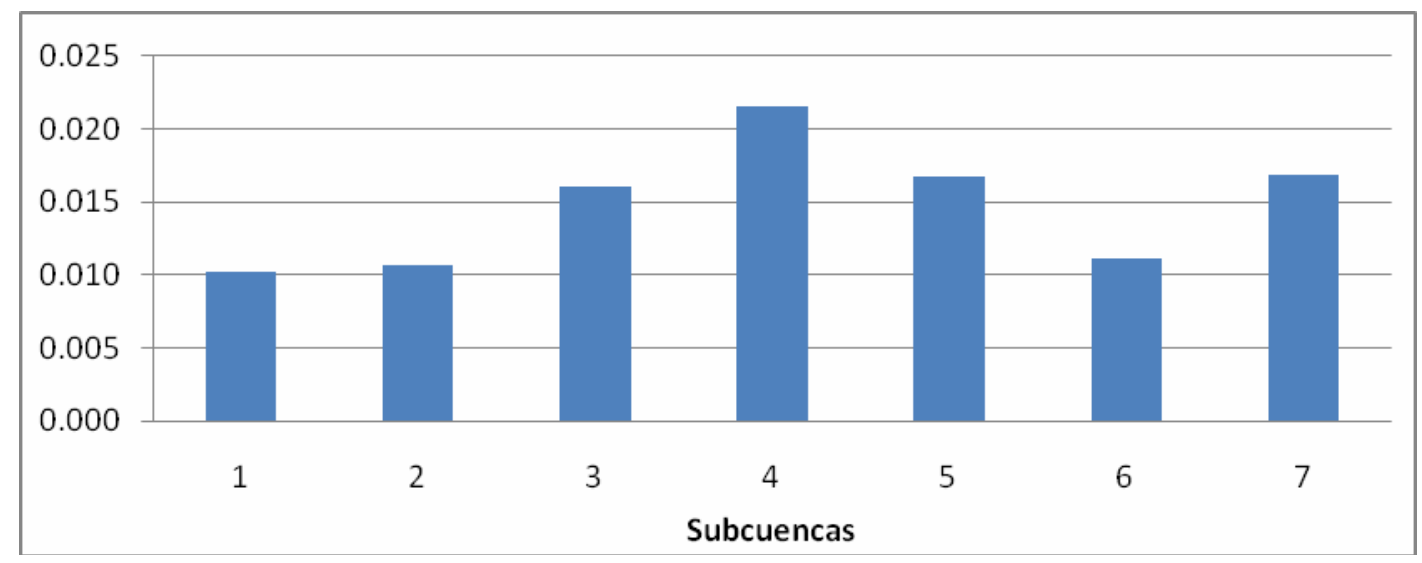

Figura 107. Factor "C" a nivel subcuenca.

Como resultado del producto ponderado de los factores de la U.S.L.E., podemos observar en la Figura 108 que las subcuencas 3 y 4 son las zonas que mayor cantidad de sedimentos aportan dentro de la cuenca de estudio, presentando valores de pérdida de suelo superiores a los $30 \mathrm{Mg}$.ha/año; a continuación se ubican las subcuencas 2, 5, 1 y 6 con valores entre 30 y 10; y finalmente la subcuenca 7 con la menor cantidad 5,15 Mg.ha/año.

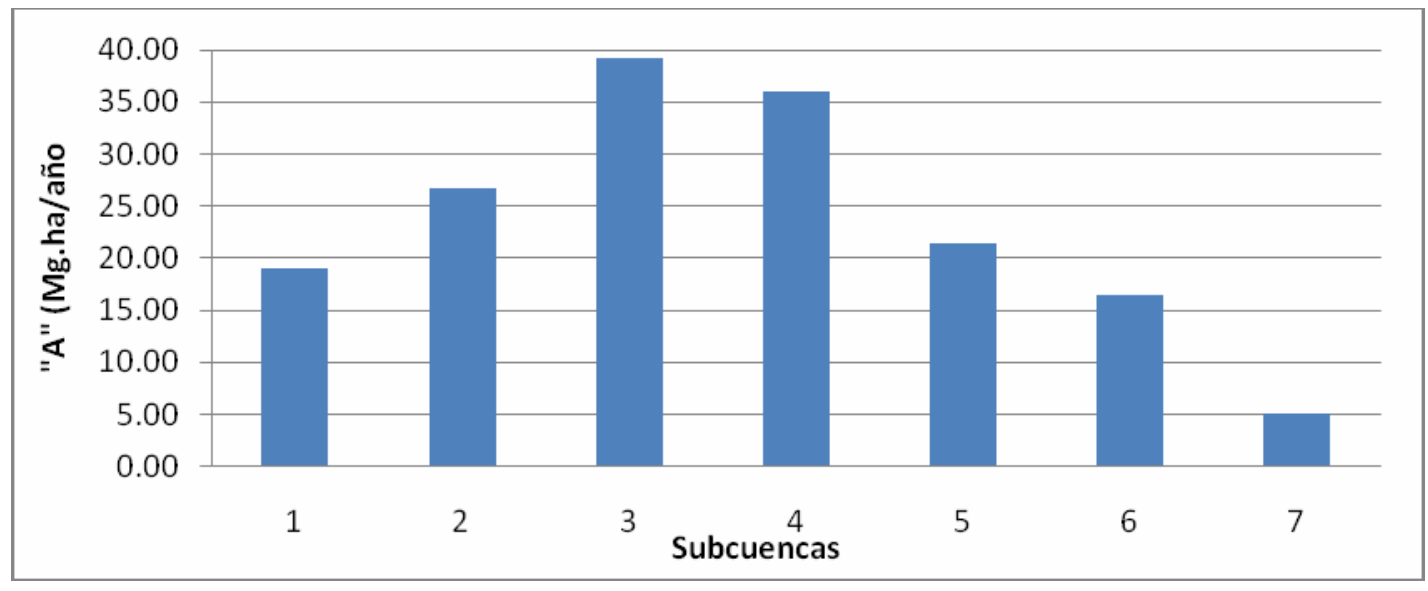

Figura 108. Pérdida de Suelo a nivel subcuenca.

Resumiendo el estudio particular de la estimación de pérdida de suelo que produce a nivel unidades hidrológicas, el área de la cuenca del Río Toachi, se presenta la Tabla 70, la cual muestra la superficie y el porcentaje que corresponden a cada subcuenca por cada rango de clasificación de pérdida de suelo según FAO (1981). Así, la subcuenca 1, produce un 12,6\% de pérdida nula o leve, un $87,3 \%$ de pérdida moderada y el $0,1 \%$ de pérdida alta. De acuerdo a esto, la subcuenca 4 produce el $34,3 \%$ de pérdida alta junto con la subcuenca 3 que produce el $27,0 \%$, el resto no supera el $9,0 \%$. Dentro del rango de las pérdidas moderadas, tenemos que la subcuenca 2 produce el $95,1 \%$, la subcuenca 1 el $87,3 \%$ y la 
subcuenca 7 el $7,4 \%$. Dentro de las pérdidas nulas o leves la subcuenca 7 produce el $92,6 \%$, seguida de las subcuencas 5 y 6 que producen el $33,7 \%$ y $33,6 \%$ respectivamente, el resto alcanza el $27,3 \%$.

Tabla 70. Porcentaje y superficie de pérdida de suelo a nivel subcuencas

\begin{tabular}{|c|c|c|c|c|c|c|c|c|}
\hline \multirow{2}{*}{$\begin{array}{c}\text { SUB } \\
\text { CUENCAS }\end{array}$} & \multicolumn{2}{|c|}{$\begin{array}{c}\text { NULO } \\
\text { (< 10 Mg.ha/año) }\end{array}$} & \multicolumn{2}{c|}{$\begin{array}{c}\text { MODERADO } \\
\text { (10 - 50 } \\
\text { Mg.ha/año) }\end{array}$} & \multicolumn{2}{c|}{$\begin{array}{c}\text { ALTO } \\
\text { (50 -200 } \\
\text { Mg.ha/año) }\end{array}$} & \multicolumn{2}{c|}{ TOTAL } \\
\cline { 2 - 9 } & $\mathbf{\%}$ & $\mathbf{k m 2}$ & $\mathbf{\%}$ & $\mathbf{k m 2}$ & $\mathbf{\%}$ & $\mathbf{k m 2}$ & $\%$ & km2 \\
\hline $\mathbf{1}$ & 12,60 & 4,91 & 87,30 & 34,03 & 0,10 & 0,04 & 100,00 & 38,98 \\
\hline $\mathbf{2}$ & 4,03 & 0,28 & 95,11 & 6,61 & 0,86 & 0,06 & 100,00 & 6,95 \\
\hline $\mathbf{3}$ & 2,32 & 1,06 & 70,66 & 32,27 & 27,02 & 12,34 & 100,00 & 45,67 \\
\hline $\mathbf{4}$ & 8,05 & 11,46 & 57,65 & 82,03 & 34,30 & 48,81 & 100,00 & 142,3 \\
\hline $\mathbf{5}$ & 36,70 & 39,07 & 55,59 & 59,18 & 7,70 & 8,2 & 100,00 & 106,45 \\
\hline $\mathbf{6}$ & 33,65 & 21,07 & 66,32 & 41,52 & 0,03 & 0,02 & 100,00 & 62,61 \\
\hline $\mathbf{7}$ & 92,59 & 91,67 & 7,41 & 7,34 & 0,00 & 0 & 100,00 & 99,01 \\
\hline TOTAL & $33,77 \%$ & 169,52 & $52,39 \%$ & 262,98 & $13,84 \%$ & 69,47 & 100,00 & 501,97 \\
\hline
\end{tabular}

En las Figuras 109 y 110, se representan el porcentaje final de pérdida de suelo de acuerdo a los rangos sugeridos por la FAO (1981) y la superficie en $\mathrm{km}^{2}$ que ocupan estas clases dentro de la cuenca de estudio, respectivamente. Como se observa en las Figuras indicadas, la cuenca del Río Toachi presenta el $52,4 \%$ de pérdida de suelos dentro de la clase moderada, con una área aproximada de $263 \mathrm{~km}^{2}$; el $13,8 \%$ dentro de un alto porcentaje de pérdida de suelo con una superficie aproximada de $70 \mathrm{~km}^{2}$, y el $33,7 \%$ presenta pérdidas de suelo nulas o muy leves con una área aproximada de $170 \mathrm{~km}^{2}$.

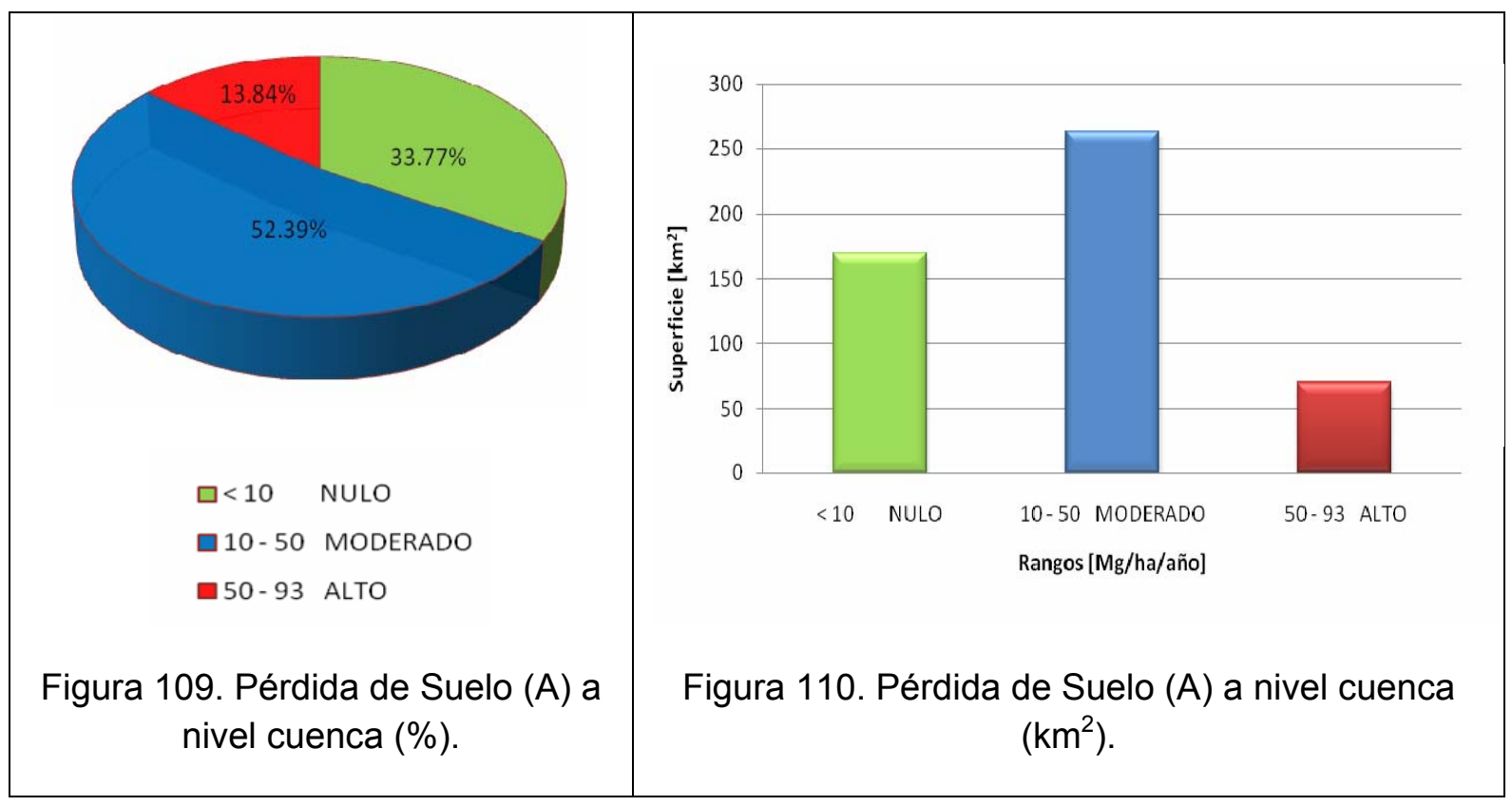




\section{CAPITULO 6}

\section{CONCLUSIONES}

1. El presente estudio permitió definir un área experimental dentro de la Cuenca del Río Guayas, denominada Cuenca del Río Toachi, en la cual se generó la caracterización morfométrica de los principales parámetros. El análisis cualitativo de la Cuenca del Río Toachi definió una forma rectangular oblonga, con una pendiente media del $5 \%$ de relieve suave, que tiene un canal colector principal largo y tributarios cortos poco ramificados. A partir de ellos se estableció que el agua escurre a través de ese canal principal en mayor tiempo, atenuando de esta manera el caudal de salida, favoreciendo la contención de eventos torrenciales extremos y minimizando el poder erosivo de la cuenca.

2. El análisis del comportamiento de la precipitación anual durante el período de observación de 1990-2010 (20 años) en las estaciones meteorológicas Las Pampas (1640 msnm) y Puerto Ila (260 msnm), utilizadas para caracterizar las precipitaciones medias mensuales, definieron dos tendencias a lo largo del período de observación. Se precisaron dos épocas definidas durante el año, que representan un período lluvioso (húmedo) de diciembre a mayo y la otra un período de menor cantidad de lluvia (seco o estiaje) de junio a noviembre.

3. El comportamiento de la variación mensual de los caudales durante el período de observación de 2003-2010 (7 años) identificó dos períodos uniformes en cuanto al volumen de agua registrado en el punto de aforo. Los mismos se expresa temporalmente de enero a junio registrando los máximos caudales y de julio a diciembre los caudales mínimos.

4. El análisis de la relación caudal-precipitación permitió establecer que la distribución de los escurrimientos mensuales, está marcada por la existencia de un caudal base constante a los largo de todo el año, que varía según el período, así de enero a junio fluctúa entre $10-15 \mathrm{~m}^{3} / \mathrm{s}$, y de julio a diciembre entre $3-8 \mathrm{~m}^{3} / \mathrm{s}$.

5. La elaboración del balance hídrico modal permitió determinar que entre los meses de septiembre a junio se produce almacenamiento del agua en reserva y excedentes en las tres zonas de la cuenca de estudio, cuantificando la cantidad de agua contenida en el suelo disponible para uso agrícola o humano.

6. La elaboración y procesamiento de un modelo cartográfico para la Cuenca del Río Toachi con los Sistemas de Información Geográfica (SIG) permitieron crear una extensa base cartográfica georreferenciada del área cuyos ejes temáticos fueron clima, geología, topografía, red de drenaje, suelos, usos de suelo actual, entre otros. Esta 
base de datos permitió la simulación hidrológica y la zonificación de la pérdida de suelo superficial.

7. La base cartográfica creada permitió determinar los Número de Curva (NC) del área experimental, para posteriormente ser usada en el modelo hidrológico HEC-HMS ${ }^{\circledR}$ calculando el caudal simulado y los hidrogramas de salida por unidades hidrológicas. Se realizó la calibración y validación del modelo con datos antecedentes. En base a los resultados alcanzados se realizó una prueba de eficiencia cuyo coeficiente de Nash de $0,64 \%$ y coeficiente de determinación $R^{2}=0,68$, permiten determinar que la calibración y validación del modelo hidrológico HEC-HMS $®$ fue óptima. Este modelo también se aplicó para completar el análisis morfométrico por subcuencas.

8. La determinación de la tasa anual de pérdida de suelos obtenida con la aplicación SIG en el método USLE, se estableció a nivel de cuenca y subcuencas.

La extensa variación espacial de la erosividad de la lluvia en la cuenca de estudio, que oscila en un rango de 2084,7 a $7162,1 \mathrm{Mj} . \mathrm{mm} / \mathrm{ha}$.hr.año, permitió evidenciar que la Cuenca del Río Toachi está sometida a tormentas con alto poder erosivo especialmente en la zona media durante la época lluviosa.

En base a los diferentes tipos de suelo que conforman el área de estudio, se cuantificó el índice de erodabilidad obteniendo que la mayor superficie de la Cuenca del Río Toachi presenta el valor de 0,031 Mg.ha.hr/ha.MJ.mm, lo cual favorece el drenaje caracterizados por presentar suelos profundos con predominio de textura franco limoso.

A partir del análisis topográfico de la Cuenca del Río Toachi se determinó que el $44,5 \%$ de la superficie de la cuenca presenta pendientes mayores al 30\%, con laderas muy abruptas y empinadas con alto grado de erosión hídrica lo que impide el desarrollo de cualquier clase de producción agrícola, ganadera o forestal alcanzando un LS de 14,6. El $30,5 \%$ de la superficie de la cuenca presenta pendientes entre $12 \%$ y $30 \%$, correspondiente a un tipo de relieve mediano a accidentado, con zonas de alto riesgo de erosión hídrica que impiden el cultivo de productos agrícolas, limitando la producción de pasturas o bosques, cuyo LS se estableció entre 3,4 y 14,6 . El $25 \%$ de la cuenca presenta pendientes menores a $12 \%$, que corresponde a relieves planos a suaves, con zonas susceptibles de sufrir erosión hídrica superficial ante el laboreo, las cuales permiten el desarrollo de toda clase de producción con implementación de medidas conservacionistas, con valores de LS menores a 3,4.

La bibliografía recopilada permitió determinar cartográficamente el tipo de cobertura del área experimental.

La distribución espacial de la pérdida promedio de suelo en la Cuenca del Río Toachi oscilaría en un rango de 0,38 a 93,08 Mg.ha/año, de los cuales el 33,7\% de la superficie de la cuenca no presenta ningún grado de erosión hídrica, ubicándose en la zona de desembocadura caracterizada por grandes planicies. El $52,5 \%$ de la superficie de la cuenca presenta un moderado grado de erosión hídrica está ubicado en la zona media hacia la cabecera. El $13,8 \%$ de la superficie de la cuenca presenta un alto grado de erosión hídrica, se ubica en la zona de cabecera. 
9. La presente tesis permitió integrar metodologías basadas en modelización hidrológica y cuantificación de sedimentos con SIG. Las mismas se podrán extrapolar a otras áreas de características homólogas a la Cuenca del Río Toachi. La versatilidad de la metodología aplicada en esta tesis, permitirá crear escenarios hipotéticos para condiciones presentes y futuras, estableciendo tendencias de producción de caudales y sedimentos a partir de la manipulación de bases de datos hidrológicos preexistentes.

10. La tesis permitió la modelación hidrológica de la microcuenca del Río Toachi, tributario del Río Guayas, para cuantificar la producción de caudales líquidos y sólidos que se generan a partir de la caracterización morfológica e hidrometeorológica. Estos resultados permitirán desarrollar futuros estudios en otras subcuencas del Río Guayas y establecer la dinámica hídrica superficial en toda la región. 


\section{AGRADECIMIENTOS}

Hemos llegado a puerto seguro, el periplo ha terminado, recuerdo hace dieciocho meses, cuando asumí el mando de este barco, estar sentado en el sillón del capitán zarpando en un mar desconocido, lleno de dudas e ilusiones, con visibilidad reducida, hacia un puerto grande e interesante, durante el cual encontré gente que me enseño el derrotero a seguir por el cual hoy estoy aquí con la satisfacción del deber cumplido.

Debo agradecer primeramente a Dios por su infinita ayuda, siendo la luz del faro que iluminó mi camino en todo momento, me dio la fuerza necesaria para seguir adelante en los tiempos de debilidad y cuidó de mi familia siempre.

A mis padres y hermanos, por su confianza y apoyo moral que me dieron durante el desarrollo de esta tesis, a mi madre por sus sabios consejos entregados a lo largo de toda mi vida, son parte importante en mi vida.

A mi directora de tesis, Fernanda Gaspari, "Pachi", por sus orientaciones, consejos y mucha, mucha paciencia para transmitirme un poco de la cantidad de conocimiento y experiencia sobre modelos hidrológicos, manejo de cuencas hidrográficas, sistemas de información geográfica, etc. Su siempre dispuesta y pronta colaboración en todo momento para despejar la neblina de la duda logró que el barco navegue por aguas tranquilas llegando a puerto final. Misión cumplida Pachi...!

A mi co-director de tesis Eduardo Kruse, quien a más de ser guía en el desarrollo de mi tesis, fue un amigo en el cual pude "confiar", sus conocimientos en el campo profesional me ayudaron a conocer el fantástico mundo de la Hidrología, fue mi primer punto de control durante esta travesía, y estoy seguro que fue de mucha ayuda...a él mis respeto y consideración.

Debo también agradecer a dos personas que son pilares fundamentales en mi vida, a mi esposa Alejandra por ser una madre inmensamente protectora, a pesar de que su paciencia no es una de sus virtudes, ayudó a mantener el rumbo, gracias por sus orientaciones, consejos y por entenderme. A mi pequeña hija Lydia, por ser la fuente de mis energías, por su inmensa ternura y amor, por ser la razón de mi vida...a ellas por aguantarse durante este tiempo momentos que no pudimos compartir juntos pero que gracias a ese sacrificio estoy escribiendo estas líneas.

A una persona especial, que durante todo este tiempo estuvo pendiente de mi situación, por la ayuda en la recolección de información, por sus consejos y por su apoyo incondicional.

A la Secretaria Nacional de Educación Superior, Ciencia, Tecnología e Investigación SENESCYT por el financiamiento y promoción de becas, al Instituto Oceanográfico de la Armada (INOCAR), por permitir que pueda estar aquí preparándome profesionalmente para fortalecer al INOCAR y llegar a ser el Centro de Investigaciones más grande del país, al Instituto Geográfico Militar (IGM), al Instituto Nacional de Hidrología y Meteorología (INAMHI) y al Centro de Levantamientos Integrados de Recursos Naturales por Sensores Remotos (CLIRSEN) por su invalorable ayuda en la información proporcionada. 
Espero no olvidarme de alguien, pero seguramente si, la verdad que son muchas las personas que de una u otra manera pusieron su "granito de arena" y me ayudaron a salir adelante, la lista y los motivos serían muchos, a ellos mil disculpas.

A todos ustedes mi eterno agradecimiento, son parte del título que obtenga, gracias. 


\section{CAPITULO 7}

\section{BIBLIOGRAFÍA}

Aparicio, F. 1997. Fundamentos de Hidrología de Superficie. Editorial Limusa. México 302 p.

Arias, M. 2010. Modelación de crecidas glaciares a distintas escalas de tiempo en los ríos Humboldt y los Crespos a partir de la meteorología del volcán Antisana. Disponible en: http://www.epn.edu.ec/epnsenacyt/documents/mar magister.pdf.

Busnelli, J. 2009. Evolución histórica, situación actual y perspectivas futuras del riesgo de inundación en la cuenca del Río Gastona. Tucumán. Argentina. 626 p. (Digital).

Caminos y Canales. 2007. Estudio de factibilidad y diseño definitivo previo a la ingeniería de detalle durante la construcción para el Proyecto Hidroeléctrico Salto del Bimbe. Vol. 4 Estudios Ambientales. Tomo 2. Estudios de Impacto Ambiental. Disponible en: http://Www.favoritafruitcompany.com/descarga/credito_multilaterales/estudio_impacto_ambie ntal/PRIN/In313EIA-V4T2-2-Vso.pdf.

Cellini, J. 2005. Estado y Propuesta de Manejo de los Recursos Naturales de la Cuenca del Arroyo Grande, Tierra del Fuego. Argentina. 133 p. (Digital).

CLH. 2009. Estudio de Impacto Ambiental Definitivo. Proyecto Hidroeléctrico Baba. Consorcio Hidroenergético del Litoral. Capitulo 3. Disponible en: http://www.elaw.org/node/5272.

Chow, V. T., Maidment, D. R. y L. Mays. 1994. Hidrología Aplicada. Ediciones McGraw-Hill. (Digital). Santa Fé, Colombia. 583 p.

CISP. 2005. Guía para la Activación del Sistema de Alerta Temprana en la Cuenca del Río Quevedo. Cantones Quevedo y Mocache, Provincia de Los Ríos. Comitato Internazionale per lo Sviluppo Dei Popoli. Disponible en: http://www.desaprender.org/tools/guia-paraactivacion-del-sistema-de-alerta-temprana-sat-en-la-cuenca-del-río-quevedo-cantones-

quevedo-y-mocache-provincia-los-ríos.

Clair, E. 2011. Curso de Sistemas de Información Geográfica (SIG). Maestría en Geomática FI - FCAG. Universidad Nacional de La Plata. Argentina. 89 p.

CLIRSEN. 2009. Generación de Geoinformación para la Gestión del Territorio y Valoración de Tierras Rurales de la Cuenca del Río Guayas, escala 1:25.000. Módulo 3: Clima e Hidrología. $30 \mathrm{p}$ (Digital).

CLIRSEN. 2009 (2). Generación de Geoinformación para la Gestión del Territorio y Valoración de Tierras Rurales de la Cuenca del Río Guayas, escala 1:25.000. Módulo 2: Suelos. 19 p. (Digital). 
Dumont, J., Santana E., Soledispa, B. y A. King. 2007. El Islote El Palmar, Resultado de una Evolución de Largo Plazo de la Distribución del Drenaje entre los Ríos Daule y Babahoyo en el Cuenca del Guayas. Acta Oceanográfica del Pacífico. Vol. 14, No.1. Disponible en: http://www.oceandocs.net/bitstream/1834/2366/1/El\%20lslote\%20El\%20Palmar,\%20resultad o\%20de\%20una\%20evoluci\%C3\%B3n\%20a\%20largo\%20plazo.....pdf.

EFFICACITAS. 2009. Línea de Transmisión Eléctrica y Subestación para la Central Hidroeléctrica Baba-Proyecto Multipropósito Baba. Quito. 165 pp. Disponible en http://www.conelec.gob.ec/images/documentos/EIA\%20Linea\%20de\%20230\%20KV\%20y\% 20Subestación\%20Baba.pdf.

ESPOL. 2000. Estudio Económico-Ambiental del Sistema de Cultivo del Mango en la Región de la Sub-Cuenca del Río Daule. Tesis de Grado. Escuela Superior Politécnica del Litoral Guayaquil. Disponible en: http://www.dspace.espol.edu.ec/bitstream/123456789/3506/1/6033.pdf

Feldman, A. 2000. Hydrologic Modeling System HEC-HMS. Technical Reference Manual. Disponible en: http://www.hec.usace.army.mil/software/hec-hms/documentation.html.

Flores, H., Martínez, M., Oropeza, J. L., Mejía, E. y R. Carrillo. 2003. Integración de la EUPS a un SIG para Estimar la Erosión Hídrica del Suelo en una Cuenca Hidrográfica de Tepatitlán, Jalisco, México. TERRA Latinoamericana, vol.21, num2, pp. 233-244. Disponible en: $h$ ttp://redalyc. uaemex.mx/src/inicio/ArtPdfRed.jsp?iCve=57315595010.

Oñate, F. y Aguilar, G. 2003. Aplicación del modelo SWAT para la estimación de caudales y sedimentos en la cuenca alta del Río Catamayo. Disponible en: http://www.fronate.pro.ec/fronate/wp-content/media/2006/10/swat_catamayo.pdf.

Gaspari, F., Sinisterra, G., Delgado, M., Rodríguez, A. y S. Besterio. 2009. Manual de Manejo Integral de Cuencas Hidrográficas. Primera Edición. La Plata. 321 p.

Gonzales, A., Acosta, J. y S. Andrade. 2008. Evaluación de las Inundaciones de la Cuenca baja del Guayas, Datos y Manejo. CLIRSEN. Quito. Disponible en: http://www.secsuelo.org/PDF\%20todo\%20simposio/PDF\%20Plenaria/6.\%20Ing.\%20Augusto \%20Gonzalez.pdf.

Granja, C. 2010. Estudio de Impacto Ambiental Definitivo de la L/T Milagro - Machala a 230 kv. Disponible en:

http://www.transelectric.com.ec/transelectric_portal/files/capitulo\%203\%20linea\%20base.pdf

Hämmerly, R., Tardivo, R., Giacosa, R., Paoli C., Cacik P., y C. Inglese. 2006. Modelización Hidrológica con SIG. Contribuciones en su difusión y aplicación. Universidad Nacional del Litoral. Ediciones UNL. 35 p.

HASKONING y CEDEGE. 1990. Estudios de Factibilidad y Diseño del Control de Inundaciones de la Cuenca Baja del Guayas. Convenio de Cooperación Técnica HolandaEcuador. HASKONING, Consultora Real Holandesa de Ingenieros y Arquitectos-CEDEGE, Comisión de Estudios para el Desarrollo de la Cuenca del Río Guayas. Anexo F Aspectos Sociales; Anexo M Plan Maestro. Guayaquil. (Digital). 
Henao, J. E. 1988. Introducción al Manejo de Cuencas Hidrográficas. Universidad Santo Tomas. Centro de enseñanza desescolarizada. Bogotá. 1988. 396 p.

INAMHI. 2000-2008. Anuarios Hidrológicos y Meteorológicos. Instituto Nacional de Meteorología e Hidrología. Disponible en http://www.inamhi.gov.ec/html/inicio.htm.

INOCAR. 2010. Memoria Técnica de la comisión realizada en el área del Río Guayas sur. 29 de noviembre al 08 de diciembre del 2009. Instituto Oceanográfico de la Armada. Guayaquil. $183 \mathrm{p}$.

IRENAT. 2002. Empleo del Modelo SWAT para Generar Alternativas de Manejo en la Cuenca del Río Laja, Gto., México. México. Disponible en: http://www.micascuencas.com/swat.pdf.

Linsley, R., Kohler, M., y J. Paulhus. 1993. Hidrología para Ingenieros. Segunda Edición. McGraw Hill. México, D.F. 386 p.

López, A. y Delgado, K. 2009. Modelización Hidrológica en la Subcuenca Lempa Alto, en Cooperación con la Comisión Trinacional del Plan Trifinio (El Salvador, Honduras, Guatemala). Disponible en: http://www.pnuma.org/aguamiaac/SUBREGIONAL\%20MESO/MATERIAL\%20ADICIONAL/BIBLIOGRAFIAWEBGRAFIA/Modulo\%202\%20Herramientas\%20claves\%20para\%20l\%20MIAAC/Balance \%20hidrico\%20y\%20caudal\%20ecologico/Doc\%204.\%20TESIS\%20UNIVERSIDAD.pdf

López Cadena de Llano, F. 1998. Restauración hidrológica forestal y control de la erosión. Ingeniería Ambiental. Tragsa-Tragsatec. Ministerio del Medio Ambiente, Ediciones Mundiprensa, Madrid, España. 945 p.

MAE. 2010. Disponible en: http://www.ambiente.gob.ec.

Mena, S. 2010. Evolución de la Dinámica de los escurrimientos en zonas de alta montaña: caso del volcán Antisana. Disponible www.dspace.espol.edu.ec/.../6083/.../CAPITULO\%203.-CAUDAL.doc

Michelena, R. 2011. Erosión Hídrica. Manejo de Cuencas Hidrográficas. Universidad Nacional de La Rioja.

MINISTERÍO DEL AMBIENTE. 2000. Estrategias de Adaptación al Cambio Climático en la Cuenca Baja del Río Guayas y Golfo Interior de Guayaquil. Disponible en: http://www. bibliotecaonu.org.ec/ResultsPreli.aspx?Code=422.

Mintegui, J. A. 1988. Análisis de la influencia del relieve en la en la erosión hídrica. Hipótesis de estudio para correlacionar la pendiente con la longitud del declive en un terreno. $\mathrm{V}$ Asamblea Nacional de Geodesia y Geofísica. Pp: 2229-2245. Madrid.

Mintegui Aguirre, J. A. y F. López Unzú. 1990. La Ordenación Agroecológica en la Planificación. Servicio Central de Publicaciones del Gobierno Vasco. 306 p.

Monsalve, G. 2000. Hidrología en la Ingeniería. Segunda Edición. Editorial Escuela Colombiana de Ingeniería. Colombia. 382 p. 
Montoya, Á. 2010. Apuntes de clase del curso de Hidrología. 50 p.

Moreno, A., Cañada, R., Cervera, B., Fernández, F., Gómez, N., Martínez, P., Prieto, M., Rodríguez, J. y M. Vidal. Sistemas y Análisis de la Información Geográfica. 2008. Manual de autoaprendizaje con ArcGIS. Alfaomega Grupo Editor, S.A. México. 940 p.

Neitsch, S.L., Arnold, J.G., Kiniry, J.R., Williams, J.R. y K.W. King. 2002. Soil and Water Assessment Tool. Theoretical Documentation. Versión 2000. Disponible en: http://swatmodel.tamu.edu/documentation.

PNUMA. 2008. Geo Ecuador 2008. Informe sobre el estado del medio ambiente. Disponible en:

http://www.pnuma.org/deat1/pdf/Ecuador\%20pdf/05.\%20Capitulo\%203.\%20Estado\%20del\% 20agua-1.pdf.

SENAGUA-DED. 2009. Estudio Exploratorio: "Problemática y Conflictos sobre los Recursos Hídricos por efectos del cambio Climático" (en línea). Capitulo 2. Disponible en: http://www.utpl.edu.ec/obsa/images/stories/pro Relacionados/5 ded-senagua capt2 eje $\% 20$ recursos $\% 20$ hdricos.pdf

Sarría, F. y Palazón F. 2008. Estimación de parámetros, validación de modelos y análisis de sensibilidad. Modelización de sistemas ambientales. Modelización de sistemas ambientales. Disponible en: http://ocw.um.es/ciencias/modelizacion-de-sistemas-ambientales/material-declase-1/msa-cap-06.pdf/view.

Silva, M., Alvear, C. y J. Carpio. 2005. Modelación Hidrológica para pronóstico de caudales mediante la aplicación del paquete HEC-HMS ® en la cuenca del Río Paute. Disponible en: http://www3.espe.edu.ec:8700/bitstream/21000/2090/1/T-ESPE-014940.pdf

Torres-Benites, E., Fernández-Reynoso, D., Oropeza-Mota, J., y E. Mejía-Sáenz. 2004. Calibración del Modelo Hidrológico SWAT en la Cuenca "EI Tejocote", Atlacomulco, Estado de México. México. (en línea). Disponible en: http://redalyc.uaemex.mx/src/inicio/ArtPdfRed.jsp?iCve=57311096007.

Irurtia, C., Cruzate, G. y F. Gaspari. 2007. Aplicación de la USLE en la Provincia de Buenos Aires para establecer Tasas de Erosión Hídrica: guía de divulgación técnica. Primera edición. Buenos Aires. 25 pp. 


\section{ANEXOS}


TABLA PARA EL CÁLCULO DE HORAS DE LUZ SOLAR DIARIA

\begin{tabular}{|c|c|c|c|c|c|c|c|c|c|c|c|c|c|c|c|c|c|c|c|c|c|c|c|c|}
\hline \multicolumn{12}{|c|}{ Northern Hemisphere } & & \multicolumn{12}{|c|}{ Southern Hemisphere } \\
\hline Jan & Feb & Mar & Apr & May & Jun & July & Aug & Sep & Oct & Nov & Dec & & $\operatorname{Jan}$ & Feb & Mar & Apr & May & Jun & July & Aug & Sep & Oct & Nov & Dec \\
\hline 0.0 & 6.6 & 11.0 & 15.6 & 21.3 & 24.0 & 24.0 & 17.6 & 12.8 & 8.3 & 2.3 & 0.0 & 70 & 24.0 & 17.4 & 13.0 & 8.4 & 2.7 & 0.0 & 0.0 & 6.4 & 11.2 & 15.7 & 21.7 & 24.0 \\
\hline 2.1 & 7.3 & 11.1 & 15.3 & 19.7 & 24.0 & 22.3 & 17.0 & 12.7 & 8.7 & 4.1 & 0.0 & 68 & 21.9 & 16.7 & 12.9 & 8.7 & 4.3 & 0.0 & 1.7 & 7.0 & 11.3 & 15.3 & 19.9 & 24.0 \\
\hline 3.9 & 7.8 & 11.2 & 14.9 & 18.7 & 22.0 & 20.3 & 16.4 & 12.7 & 9.0 & 5.2 & 1.9 & 66 & 20.1 & 16.2 & 12.8 & 9.1 & 5.3 & 2.0 & 3.7 & 7.6 & 11.3 & 15.0 & 18.8 & 22.1 \\
\hline 5.0 & 8.2 & 11.2 & 14.7 & 17.9 & 20.3 & 19.2 & 16.0 & 12.6 & 9.3 & 6.0 & 3.7 & 64 & 19.0 & 15.8 & 12.8 & 9.3 & 6.1 & 3.7 & 4.8 & 8.0 & 11.4 & 14.7 & 18.0 & 20.3 \\
\hline 5.7 & 8.5 & 11.3 & 14.4 & 17.3 & 19.2 & 18.4 & 15.7 & 12.6 & 9.5 & 6.6 & 4.8 & 62 & 18.3 & 15.5 & 12.7 & 9.6 & 6.7 & 4.8 & 5.6 & 8.3 & 11.4 & 14.5 & 17.4 & 19.2 \\
\hline 6.4 & 8.8 & 11.4 & 14.2 & 16.8 & 18.4 & 17.7 & 15.3 & 12.5 & 9.7 & 7.1 & 5.6 & 60 & 17.6 & 15.2 & 12.6 & 9.8 & 7.2 & 5.6 & & 8.7 & 11.5 & 14.3 & 16.9 & 18.4 \\
\hline 6.9 & 9.1 & 11.4 & 14.1 & 16.4 & 17.8 & 17.2 & 15.1 & 12.5 & 9.9 & 7.5 & 6.2 & 58 & 17.1 & 14.9 & 12.6 & 9.9 & 7.6 & & & 8.9 & 11 & 14.1 & 16.5 & 17.8 \\
\hline 7.3 & 9.3 & 11.5 & 13.9 & 16.0 & 17.3 & 16.8 & 14.8 & 12.4 & 10.1 & 7.9 & 6.7 & 56 & 16.7 & 14.7 & 12.5 & 10.1 & 8.0 & & 7 & 9.2 & 11. & 13.9 & 16.1 & 17.3 \\
\hline 7.7 & 9.5 & 11.5 & 13.8 & 15.7 & 16.8 & 16.4 & 14.6 & 12.4 & & 8.2 & 7.1 & 54 & 16.3 & 14.5 & 12.5 & 10.2 & & & & 9. & & 13.8 & 15.8 & 16.9 \\
\hline 8.0 & 9.7 & 11.5 & 13.6 & 15.4 & 16.5 & 16.0 & 14.4 & 12.4 & 10.3 & 8.5 & 7.5 & 52 & 16.0 & 14.3 & 12.5 & 10.4 & 8.6 & 7. & 8. & 9.6 & 11 & 13.7 & 15.5 & 16.5 \\
\hline 8.3 & 9.8 & 11.6 & 13.5 & 15. & 16 & 15. & 14.3 & 12.3 & 10. & 8.7 & 7.9 & 50 & 15.7 & 14. & 12.4 & 10.5 & 8.8 & & & 9.7 & & 13.6 & 15.3 & 16.1 \\
\hline 8.6 & 10.0 & 11.6 & 13.4 & 15.0 & 15.8 & 15.5 & 14.1 & 12.3 & 10. & 9.0 & 8.2 & 48 & 15.4 & 14. & 12.4 & 10.6 & 9.0 & 8. & & 9.9 & 11.7 & 13.4 & 15.0 & 15.8 \\
\hline 8.8 & 10.1 & 11.6 & 13.3 & 14.8 & 15 & 15.2 & 14.0 & 12.3 & 10. & 9.2 & 8.5 & 46 & 15.2 & 13 & 12.4 & 10.7 & 9. & & & 10 & 11 & 13 & 14.8 & 15.5 \\
\hline 9.1 & 10 & 11.6 & 13.2 & 14.6 & 15. & 15.0 & 13.8 & 12.3 & 1 & & 8.7 & 44 & 14.9 & 13.7 & 12.4 & 10.8 & 9.4 & & & 10 & 11 & 13 & 14.6 & 15.3 \\
\hline 9.3 & 10.4 & 11.7 & 13.2 & 14.4 & 15.0 & 14.8 & 13. & 12.3 & 10. & 9.6 & 9.0 & 42 & 14.7 & 13. & 12.3 & 10 & 9. & 9 & 9 & 10 & 11 & 13 & 14.4 & 15.0 \\
\hline 9.5 & 10.5 & 11.7 & 13.1 & 14.2 & 14. & 14. & 13. & 12.2 & 10. & 9.7 & 9.2 & 40 & 14.5 & 13 & 12. & 10 & 9 . & 9 & 9 & 10 & 11 & 13 & 14.3 & 14.8 \\
\hline 9.6 & 10.6 & 11.7 & 13.0 & 14.1 & 14. & 14. & 13 & 12.2 & 11. & 9. & 9.4 & 38 & 14.4 & 13. & 12 & 11 & 9 & 9. & 9. & 10 & & 13 & 14.1 & 14.6 \\
\hline 9.8 & 10.7 & 11.7 & 12.9 & 13.9 & 14 & 14 & 13. & 12.2 & 11. & 0.1 & 9.6 & 36 & 14.2 & 13. & 12.3 & 11. & 10.1 & 9. & 9 & 10 & & 12 & 13.9 & 14.4 \\
\hline 10.0 & 10.8 & 11. & 12.9 & 13. & 14. & 14 & 13 & 12.2 & & 1 & 9.7 & 34 & 14.0 & 13 & 12 & 11 & 10 & 9 & 9. & 10 & & 12 & 13.8 & 14.3 \\
\hline 10.1 & 10.9 & 11.8 & 12.8 & 13 & 14 & 13 & 13 & 12.2 & & & 9.9 & 32 & 13.9 & & & & & & & & & & 13.7 & 14.1 \\
\hline 10.3 & 11.0 & 11.8 & 12.7 & 13. & 13 & 13 & 13 & 12.2 & & & 10.1 & 3 & 13.7 & 13 & 12 & 11 & 10 & 10 & 10 & 10 & 11 & 12 & 13.5 & 13.9 \\
\hline 10.4 & 11.0 & 11.8 & 12.7 & 13.4 & 13.8 & 13 & & 12.2 & & & 10.2 & 28 & 13.6 & & & & 10 & 10 & & & & & 13.4 & 13.8 \\
\hline 10.5 & 11.1 & 11. & 12.6 & 13. & 13 & 13 & 12 & 12.1 & 11 & 10 & 10.4 & 2 & 13.5 & 12. & 12. & 11 & 10 & 10 & 10 & 11 & 11 & 12.6 & 13.3 & 13.6 \\
\hline 10.7 & 11.2 & 11.8 & 12.6 & 13. & 13 & 13 & & 12.1 & & & 10.5 & 24 & 13 & & & & & & & & & & 13.2 & 13.5 \\
\hline 10.8 & 11.3 & 11.9 & 12.5 & 13.1 & 13 & 13,2 & 12 & 12.1 & & & 10.7 & 2 & 13.2 & 12 & 12 & 11 & 10 & 10 & 10. & 11 & 11 & 12.5 & 13.1 & 13.3 \\
\hline 10.9 & & 11. & 12. & 12 & & & & 12.1 & & & & & & & & & & & & & & & 13.0 & 13.2 \\
\hline 11.0 & 11.4 & 11 & 12.4 & 12.8 & 13 & 13 & 12 & 12.1 & & 11 & 10.9 & 1 & 13.0 & 12 & & & & 10 & 11 & & & 12 & 12.9 & 13.1 \\
\hline 11.1 & 11.5 & 11.9 & 12.4 & 12. & 12 & & & 12.1 & & & & & 12.9 & & & & & & & & & 12 & 12.8 & 12.9 \\
\hline 11.3 & 11.6 & 11.9 & 12.3 & 12.6 & 12.8 & 12.8 & 12.5 & 12.1 & 11,7 & 11.3 & 112 & 16 & 12.7 & 12.4 & 12.1 & 11. & 11 & 11 & 11 & & 11 & 12.3 & 12.7 & 12.8 \\
\hline 11.4 & 11.6 & 11.9 & 12.3 & 12.6 & & & & 12.1 & & & 11.3 & 12 & 12.6 & & & & 11 & & & & & & 12.6 & 12.7 \\
\hline 11.5 & 11.7 & 11.9 & 12.2 & 12.5 & 12.6 & 12.5 & 12.3 & 121 & 11 & 11.5 & 11.4 & 10 & 12.5 & 123 & 12.1 & 11.8 & 11.5 & 11.4 & 11. & 11.7 & 11.9 & 12.2 & 12.5 & 126 \\
\hline 11.6 & 11.7 & 11.9 & 12.2 & 12.4 & 12.5 & & 12.3 & 12.0 & & & 11.5 & 8 & 12.4 & & & & 11.6 & & & & & 12.2 & 12.4 & 12.5 \\
\hline 11.7 & 11.8 & 12.0 & 12.1 & 12.3 & 12.3 & 12.3 & 12.2 & 120 & 11.9 & 117 & 11.7 & 6 & 12.3 & 12.2 & 12.0 & 11.9 & 11.7 & 11.7 & 11.7 & 11.8 & 120 & 12.1 & 12,3 & 12.3 \\
\hline 11.8 & 11.9 & 12.0 & 12.1 & 12.2 & 12.2 & & & 12.0 & & & & 4 & 12.2 & & 12.0 & & 11 & 11 & & & 12.0 & 12.1 & 12.2 & 12.2 \\
\hline 11.9 & 11.9 & 12.0 & 12.0 & 12.1 & 12.1 & 12.1 & 12.1 & 12.0 & 120 & 11.9 & 11.9 & 2 & 12.1 & 12.1 & 12.0 & 120 & 11.9 & 11.9 & 11.9 & 11.9 & 12.0 & 12.0 & 12.1 & 12.1 \\
\hline 12.0 & 12.0 & 12.0 & 12.0 & 12.0 & 12.0 & 12.0 & 12.0 & 12.0 & 12.0 & 12.0 & 12.0 & 0 & 12.0 & 120 & 12.0 & 12.0 & 12.0 & 120 & 12.0 & 12.0 & 12.0 & 12.0 & 12.0 & 12.0 \\
\hline
\end{tabular}




\section{TABLAS DE PRECIPITACION MENSUAL}

$\begin{array}{lllll}\text { INSTITUTO } & \text { NACIONAL } & \text { DE } & \text { METEOROLOGE } & \text { HIDROLOGIA } \\ \text { UNIDAD } & \text { ATENCION } & \text { AL } & \text { USUARIO } & \end{array}$

PRECIPITACIO MENSUAL $\quad(\mathrm{mm})$

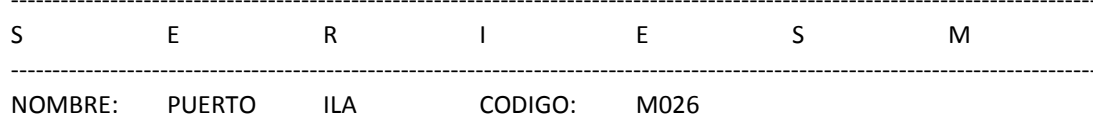

PERIODO: $\quad 1990-2010$ LATITUD: 0

\begin{tabular}{|c|c|c|c|c|c|c|c|c|c|c|c|c|c|c|}
\hline ALOS & ENE & FEB & MAR & ABR & MAY & JUN & JUL & AGO & SEP & OCT & NOV & DIC & SUMA & MEDIA \\
\hline 1990 & 189.2 & 287.9 & 483.5 & 84.4 & 83.5 & 68.1 & 4.4 & 9 & 47 & 19.6 & 161.9 & & & \\
\hline 1991 & 321.9 & 638.8 & 322 & 321.2 & 201.2 & 81.4 & 19.6 & 36.2 & 12.3 & 45.2 & 41.2 & 133.5 & 2174.5 & 181.2 \\
\hline 1992 & 457.5 & 858.3 & 524.9 & 791.6 & 541.8 & 240.6 & 159.2 & 34.1 & 18.2 & 32.6 & 41 & \begin{tabular}{|l|}
146.7 \\
\end{tabular} & 3846.5 & 320.5 \\
\hline 1993 & 455.3 & 654.8 & 733.1 & 681.7 & 91.4 & 48.5 & 69 & 36 & 101.4 & 32.3 & 28.8 & 206.4 & 3138.7 & 261.5 \\
\hline 1994 & 583.8 & 543.7 & 346 & 424.4 & 315.8 & 97 & 4 & 9.9 & 16.7 & 29.4 & 70.2 & 391 & 2831.9 & 235.9 \\
\hline 1995 & 432.3 & 327.3 & 264.4 & 455.2 & 262.4 & 130.1 & 64 & 68.7 & 19.2 & 48.8 & 34.4 & 53.1 & 2159.9 & 179.9 \\
\hline 1996 & 325.7 & 608.4 & 641.9 & 423.7 & 145.7 & 16.1 & 23.6 & 38.9 & 24 & 19.2 & 23 & 137.8 & 2428 & 202.3 \\
\hline 1997 & 596.8 & 458 & 565.2 & 500.2 & 269.6 & 367 & 233.3 & 138.8 & 704.4 & 466.6 & 801.3 & 960.2 & 6061.4 & 505.1 \\
\hline 1998 & 894.2 & 639.1 & 826.3 & 772.5 & 463.3 & 291.7 & 216.1 & 66.9 & 64.4 & 27.7 & 25.7 & 52.8 & 4340.7 & 361.7 \\
\hline 1999 & 211.7 & 487.6 & 561.2 & 614.3 & 286.7 & 53.3 & 23.4 & 14.8 & 82.3 & 57.6 & 52.7 & 305 & 2750.6 & 229.2 \\
\hline 2000 & 252.1 & 621.5 & 689 & 522.3 & 325.6 & 48 & 6.5 & 24.2 & 48.1 & 29.4 & 20.5 & 144.7 & 2731.9 & 227.6 \\
\hline 2001 & 510.2 & 242.3 & 499.9 & 658.3 & 193.8 & 12.4 & 22.4 & 4.6 & 21.2 & 15.1 & 32.9 & 116.6 & 2329.7 & 194.1 \\
\hline 2002 & 334.6 & 563.3 & 775 & 599.8 & 341.3 & 134.9 & 23.9 & 6.4 & 83.4 & 61.9 & 95.1 & 273.2 & 3292.8 & 274.4 \\
\hline 2003 & 441.6 & 523.3 & 241.5 & 590.6 & 318.6 & 62.7 & 27.2 & 21.1 & 9.5 & 96.7 & 30.7 & 145.2 & 2508.7 & 209 \\
\hline 2004 & 263.1 & 390.3 & 252.3 & 474 & 296.9 & 38.8 & 25 & 16.7 & 107.5 & 69.9 & 34.8 & 64.2 & 2033.5 & 169.4 \\
\hline 2005 & 370.6 & 402.8 & 630.6 & 635.5 & 33.4 & 13.1 & 7.3 & 2.7 & 32.8 & 35.6 & 67.6 & 124.3 & 2356.3 & 196.3 \\
\hline 2006 & 175.9 & 720.7 & 700.5 & 508 & 72.2 & 129.1 & 24.1 & 72.7 & 60.2 & 23.8 & 144.5 & 62.9 & 2694.6 & 224.5 \\
\hline 2007 & 222.4 & 311.6 & 528.6 & 577.8 & 193 & 93.1 & 55.1 & 22.4 & 47.2 & 20.6 & 51.7 & 129.9 & 2253.4 & 187.7 \\
\hline 2008 & 646 & 513.4 & 484.6 & 358.9 & 185.6 & 60.1 & 65.9 & 125 & 61 & 42.2 & 34.1 & 43.1 & 2619.9 & 218.3 \\
\hline 2009 & 480.6 & 157.9 & 129.9 & 19 & 8.9 & 24.1 & 11.2 & 12.6 & 15.6 & 293.2 & & & & \\
\hline 2010 & 359.7 & 523.9 & 743.4 & 177.1 & & & & & & & & & & \\
\hline
\end{tabular}

\begin{tabular}{|c|c|c|c|c|c|c|c|c|c|c|c|c|c|c|}
\hline suma & 8044.6 & 10509.7 & 9874.9 & 11294.8 & 4929.7 & 2020.4 & 1146.6 & 768.6 & 1534 & 1214.2 & 1665.4 & 3945.7 & 56948.6 & 4745.7 \\
\hline media & 402.2 & 525.4 & 519.7 & 537.8 & \begin{tabular}{|r|}
234.7 \\
\end{tabular} & \begin{tabular}{r|}
101 \\
\end{tabular} & 57.3 & \begin{tabular}{|l|}
38.4 \\
\end{tabular} & 76.7 & 60.7 & 83.2 & 197.2 & 2834.7 & 236.2 \\
\hline minima & 175.9 & 242.3 & 241.5 & 157.9 & 33.4 & 12.4 & 4 & \begin{tabular}{|l|}
2.7 \\
\end{tabular} & 9 & 12.6 & 15.6 & 43.1 & 2.7 & \\
\hline maxima & 894.2 & 858.3 & 826.3 & 791.6 & 541.8 & 367 & 233.3 & 138.8 & 704.4 & $\begin{array}{l}466.6 \\
\end{array}$ & 801.3 & 960.2 & 960.2 & \\
\hline
\end{tabular}




$\begin{array}{lllll}\text { INSTITUTO } & \text { NACIONAL } & \text { DE } & \text { METEOROLOCE } & \text { HIDROLOGIA } \\ \text { UNIDAD } & \text { ATENCION } & \text { AL } & \text { USUARIO } & \end{array}$

PRECIPITACIO MENSUAL $\quad(\mathrm{mm})$

\begin{tabular}{|c|c|c|c|c|c|c|c|c|c|c|c|c|c|c|}
\hline s & $\mathrm{E}$ & $\mathrm{R}$ & 1 & $\mathrm{E}$ & $\mathrm{s}$ & M & $\mathrm{E}$ & $\mathrm{N}$ & $\mathrm{s}$ & $u$ & A & $\mathrm{L}$ & $\mathrm{E}$ & $\mathrm{s}$ \\
\hline NOMBRE: & LA & LIBERTAD-RIO & BLANCO & CODIGO: & MB89 & & & & & & & & & \\
\hline PERIODO: & 1990 & & 2010 & LATITUD: & 0 & 31 & 54 & & LONGITUD: & 79 & 7 & 20 & $w$ & ELEVACION: \\
\hline ALOS & ENE & FEB & MAR & $A B R$ & MAY & JUN & JUL & AGO & SEP & OCT & NOV & DIC & SUMA & MEDIA \\
\hline 2005 & 34.4 & 19.8 & 19.8 & 52 & 87.2 & 76.5 & 179.7 & & & & & & & \\
\hline 2006 & 299.3 & 641.2 & 630.6 & 483.8 & 143.8 & 174.4 & 12.4 & 66.3 & 58.4 & 208.9 & 247.3 & & & \\
\hline 2007 & 359.9 & 269.7 & 456.7 & 473.2 & 462.9 & 173.8 & 68.1 & 43.7 & 102.6 & 70.7 & 120.9 & 145.5 & 2747.7 & 228.9 \\
\hline 2008 & 823.2 & 730.5 & 606.6 & 476 & 195.2 & 113.8 & 114.9 & 100.6 & 97.8 & 117.9 & 69.8 & 147.7 & 3594 & 299.5 \\
\hline 2009 & 541.3 & 567.4 & 767.2 & 162.8 & 268.9 & 80 & 45 & 49.3 & 23.2 & 57.6 & 40.5 & 477.8 & 3081 & 256.7 \\
\hline 2010 & 355 & 490 & 280.4 & 575.4 & 309.8 & 99.5 & 129.1 & 66.5 & 59.1 & 53.9 & 89.7 & 400.2 & 2908.6 & 242.3 \\
\hline suma & 2378.7 & 2698.8 & 2741.5 & 2171.2 & 1380.6 & 675.9 & 389.3 & 346.2 & 334.7 & 445.7 & 606.3 & 1598.2 & 15767.1 & 1313.9 \\
\hline media & 475.7 & 539.7 & 548.3 & 434.2 & 276.1 & 112.6 & 64.8 & 57.7 & \begin{tabular}{rl|}
66.9 \\
\end{tabular} & 74.2 & 101 & 266.3 & 3018 & 251.5 \\
\hline minima & 299.3 & 269.7 & 280.4 & 162.8 & 143.8 & 34.4 & 12.4 & $\begin{array}{l}19.8 \\
\end{array}$ & 23.2 & 53.9 & 40.5 & 145.5 & 12.4 & \\
\hline maxima & 823.2 & 730.5 & 767.2 & 575.4 & 462.9 & 174.4 & 129.1 & 100.6 & 102.6 & 117.9 & 208.9 & 477.8 & 823.2 & \\
\hline
\end{tabular}


$\begin{array}{lll}\text { INSTITUTO NACIONAL DE } & \text { METEOROLOGE }\end{array}$

UNIDAD ATENCION AL

USUARIO

PRECIPITACIO MENSUAL (mm)

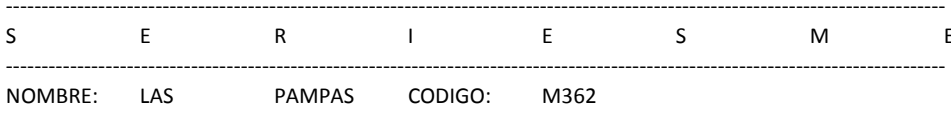

PERIODO: 2010 LATITUD: $\quad 1980-\quad 0$

\begin{tabular}{|c|c|c|c|c|c|c|c|c|c|c|c|c|c|c|}
\hline ALOS & ENE & FEB & MAR & ABR & MAY & JUN & JUL & AGO & SEP & OCT & NOV & DIC & SUMA & MEDIA \\
\hline 1981 & 233.7 & 526.6 & 481.8 & \begin{tabular}{ll|}
319.3 \\
\end{tabular} & 79 & 24.9 & 81.9 & 71.2 & 52.7 & 61 & 32.8 & $\begin{array}{ll}219.9 \\
\end{array}$ & 2184.8 & 182 \\
\hline 1982 & 282.5 & 392.9 & 229.6 & 292.8 & 270.1 & 33.4 & 62 & 12.2 & 162.6 & 372.9 & 330.3 & 366.9 & 2808.2 & 234 \\
\hline 1983 & 471.2 & 236.4 & 447.9 & 441.6 & 328.4 & 199.8 & 130.7 & 150.9 & 105.8 & 111.1 & 182.4 & 180.5 & 2986.7 & 248.8 \\
\hline 1985 & 307.8 & 188.8 & 244.5 & \begin{tabular}{ll|}
183.4 \\
\end{tabular} & 221.8 & 9.7 & 27.1 & 41.4 & $\begin{array}{l}48.3 \\
\end{array}$ & 51.4 & 182.3 & & & \\
\hline 1986 & 586.9 & 234.2 & 265.3 & \begin{tabular}{l|l}
563.3 \\
\end{tabular} & 141.2 & 28.1 & 20.9 & 16.8 & 41.8 & 100.4 & 162 & & & \\
\hline 1987 & 292.9 & 405.4 & 309.3 & 268.9 & 21.2 & 56 & 106.9 & 91.7 & 22.2 & 54.5 & $\begin{array}{ll}197.4 \\
\end{array}$ & & & \\
\hline 1988 & 408.9 & 504.2 & 136.1 & 53.8 & 55 & 49.3 & 103.3 & 123.4 & 152.1 & & & & & \\
\hline 1989 & 417.4 & 333.8 & 192.7 & 153 & 10.1 & 23.4 & & & & & & & & \\
\hline 1992 & 213.3 & 286 & 291.8 & 329.4 & 47.8 & 33.9 & 20.2 & 120.3 & & & & & & \\
\hline 1993 & 338.6 & 544.2 & 356.8 & \begin{tabular}{ll|}
485.3 \\
\end{tabular} & 178.7 & 64.7 & 32.4 & 124.8 & 69.3 & 75.9 & 255.6 & & & \\
\hline 1994 & 499.8 & 283.8 & 514.3 & 373.6 & 247.8 & 63.5 & 5.7 & 5.9 & 31.4 & 99 & 77.2 & 314.4 & 2516.4 & 209.7 \\
\hline 1995 & 272.5 & 162.9 & 330.5 & 408 & 143.7 & 99.4 & 89.5 & 119.5 & 59.4 & 95.5 & 146 & 83.9 & 2010.8 & 167.5 \\
\hline 1996 & 218 & 435.5 & 398.4 & 300.6 & 309.8 & 38.3 & 24 & $\begin{array}{ll}32.4 \\
\end{array}$ & 37.8 & 33.7 & 24.5 & 124.3 & 1977.3 & 164.7 \\
\hline 1997 & 316.8 & 293.3 & 301.2 & 305.1 & 229.7 & 216.1 & 67.5 & 28 & 262.3 & 358.2 & 452.7 & 251 & 3081.9 & 256.8 \\
\hline 1998 & 254.9 & \begin{tabular}{ll|}
404.7 \\
\end{tabular} & 433.2 & 398.9 & 143 & 90.9 & 60.3 & 72.1 & 20.1 & 109.3 & 51.5 & & & \\
\hline 1999 & 220.6 & 455 & 449.7 & 383.1 & 182.9 & 122.7 & 45.2 & 11.4 & 120.9 & 67.8 & $\begin{array}{l}86.8 \\
8.8\end{array}$ & 229.2 & 2375.3 & 197.9 \\
\hline 2005 & 337.5 & 335.9 & 284.9 & \begin{tabular}{|l|}
64.4 \\
\end{tabular} & $\begin{array}{l}20.7 \\
\end{array}$ & 7.2 & $\begin{array}{ll}10.8 \\
\end{array}$ & 32.1 & $\begin{array}{l}47.1 \\
\end{array}$ & 35.8 & \begin{tabular}{|l|l|}
118.4 \\
\end{tabular} & & & \\
\hline 2006 & 246.8 & 551.1 & 301.5 & 305.9 & 155.9 & 96.7 & $\begin{array}{l}10.1 \\
\end{array}$ & 59 & \begin{tabular}{|c|}
63.7 \\
\end{tabular} & 42.6 & 211.7 & 154.3 & 2199.3 & 183.2 \\
\hline 2007 & 322.6 & 176 & 363.9 & 246.7 & 200.8 & 66.2 & 47.5 & 51.2 & 53.4 & 34.3 & 119.9 & 102.6 & 1785.1 & 148.7 \\
\hline 2008 & 475.1 & 373.5 & 446.5 & 306 & 246.5 & 75.5 & 84.2 & 138.2 & 91.2 & 148.5 & 35.7 & 203.9 & 2624.8 & 218.7 \\
\hline 2009 & 534.4 & 444.1 & 343.5 & 174 & 165.1 & 62.8 & 13 & 38.3 & 13.1 & 111 & 45.9 & 317.6 & 2262.8 & 188.5 \\
\hline 2010 & 374.1 & 136.6 & 49.1 & & & & & & & & & & & \\
\hline
\end{tabular}

\begin{tabular}{|l|r|r|r|r|r|r|r|r|r|r|r|r|r|r|}
\hline suma & 8205.3 & 10571.7 & 9567.4 & 10000.5 & 6099.7 & 2366.8 & 1204.7 & 1361.2 & 2122.3 & 2706.9 & 2779.1 & 5494 & 62479.6 & 5206.6 \\
\hline media & 303.9 & 352.3 & 354.3 & 344.8 & 217.8 & 84.5 & 41.5 & 46.9 & 75.7 & 96.6 & 99.2 & 189.4 & 2207.5 & 183.9 \\
\hline minima & 105.8 & 162.9 & 136.1 & 174 & 64.4 & 20.7 & 5.7 & 0.7 & 12.9 & 14.5 & 20.2 & 51.5 & 0.7 & \\
\hline maxima & 586.9 & 551.1 & 514.3 & 563.3 & 444.7 & 237.9 & 130.7 & 150.9 & 262.3 & 372.9 & 452.7 & 36.9 & 586.9 & \\
\hline
\end{tabular}


TABLAS DE PRECIPITACION TOTAL DIARIA

INSTITUTO NACIONAL DE METEOROE HIDROLOGIA

DIRECCION DE INFORMATPRECIPITA TOTAL DIARIA (mm)

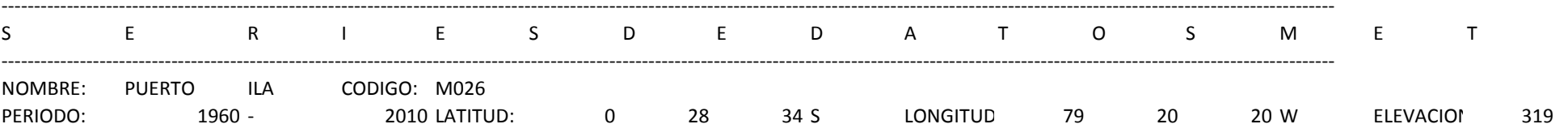

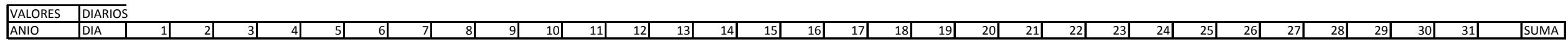

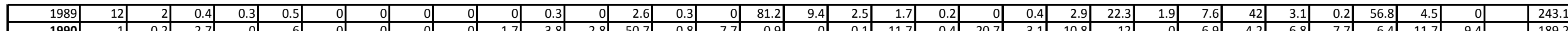

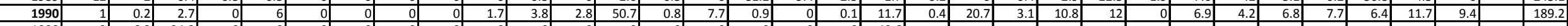

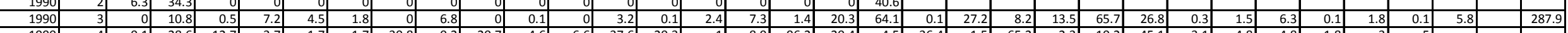

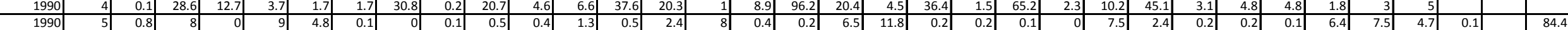

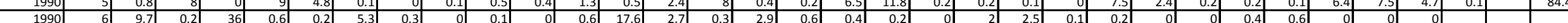

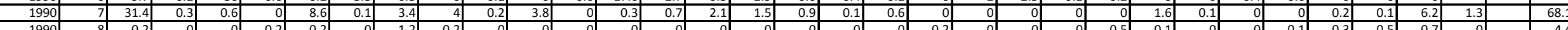

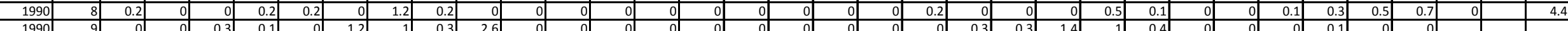

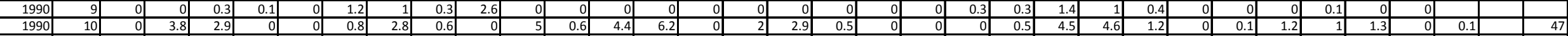

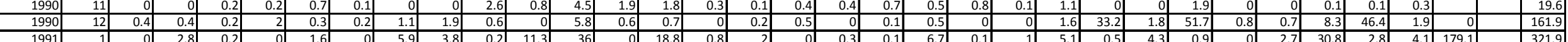

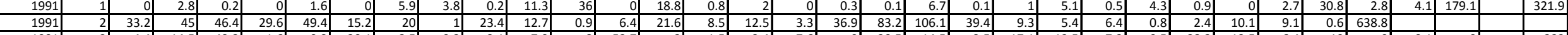

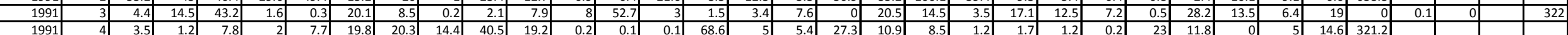

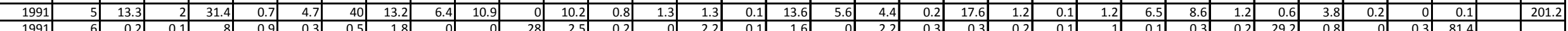

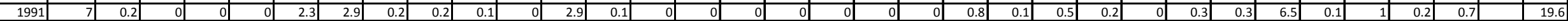

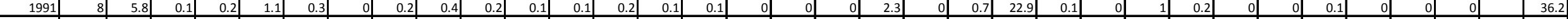

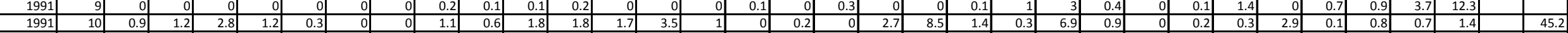

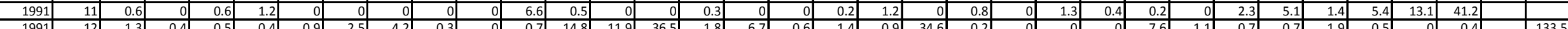

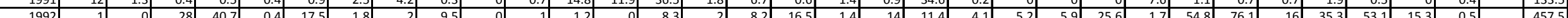

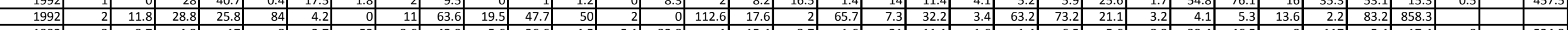

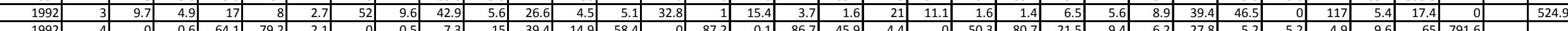

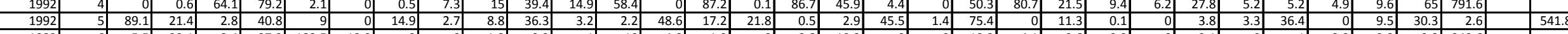

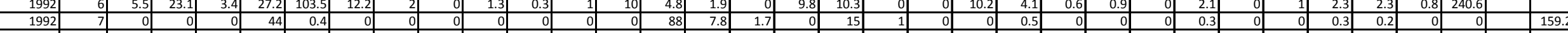

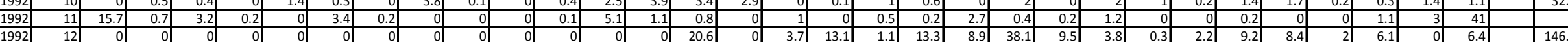




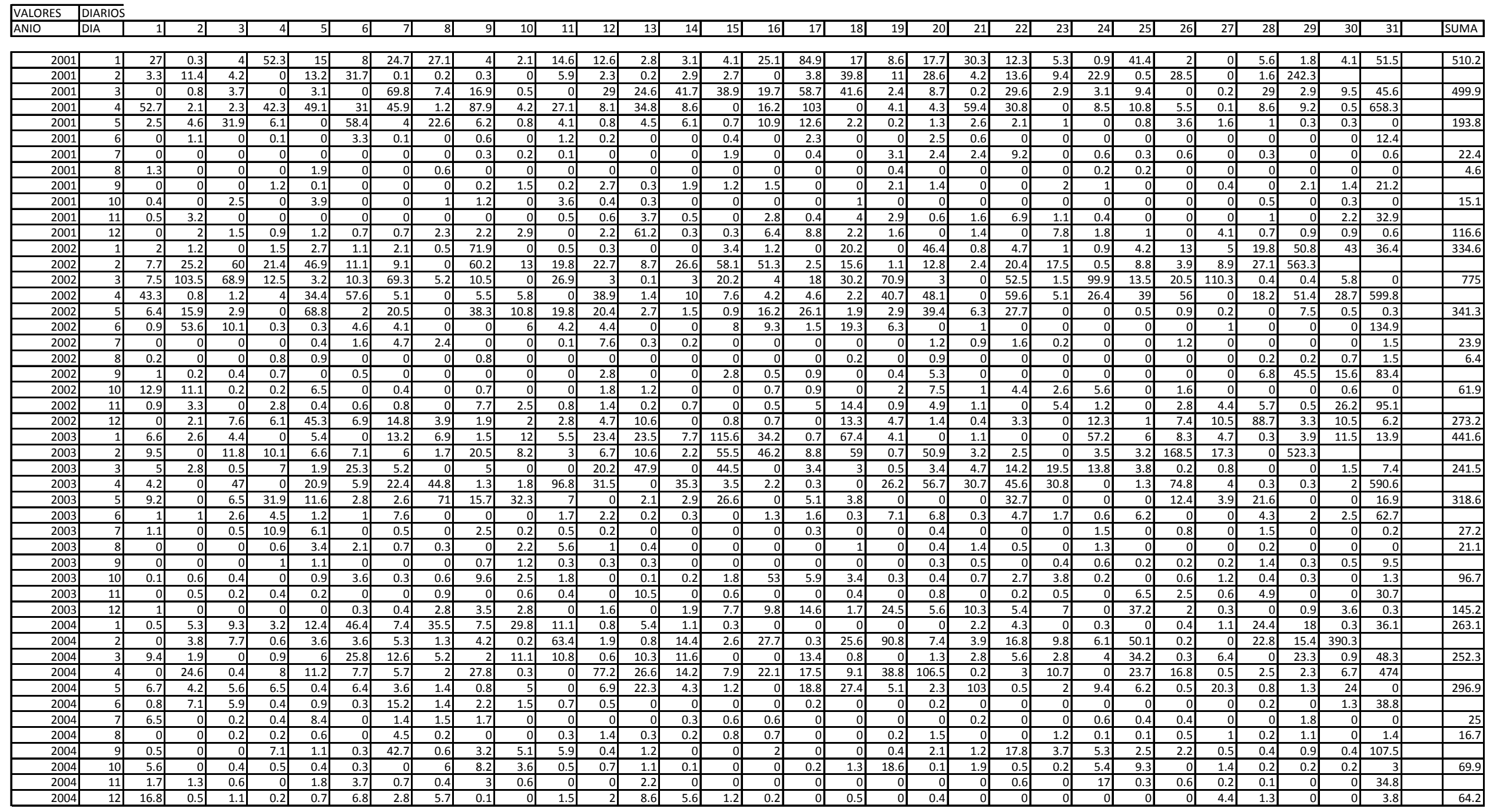

Juan Carlos Tapia 


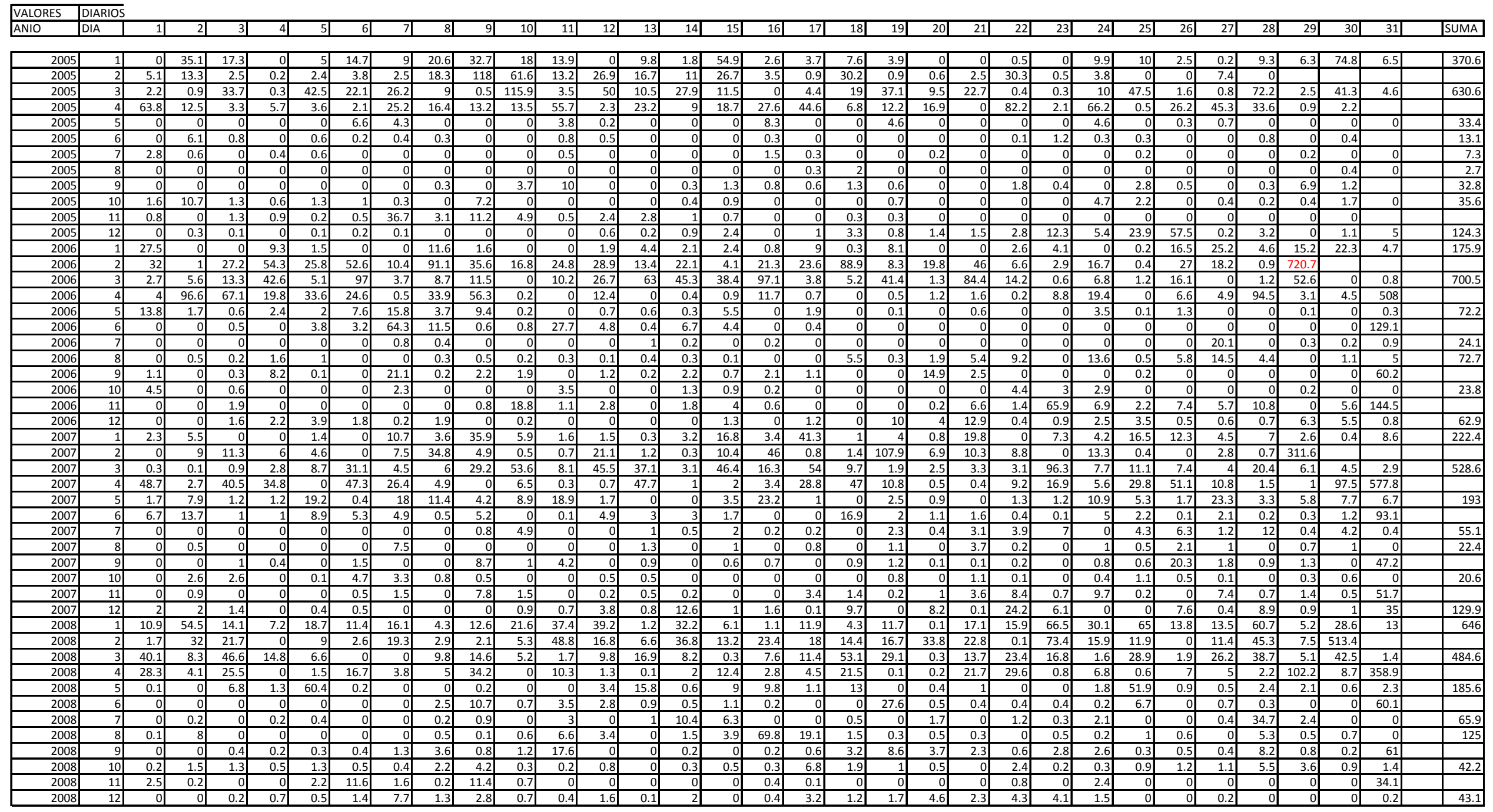

Juan Carlos Tapia 


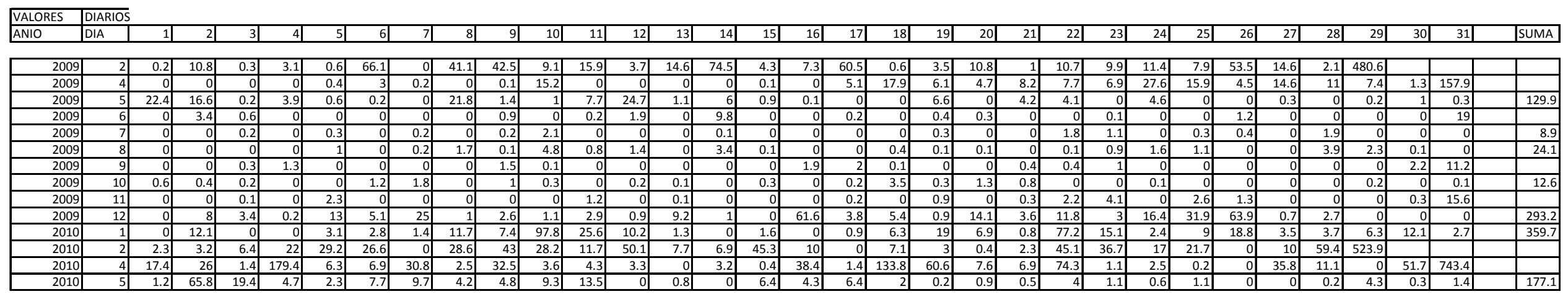




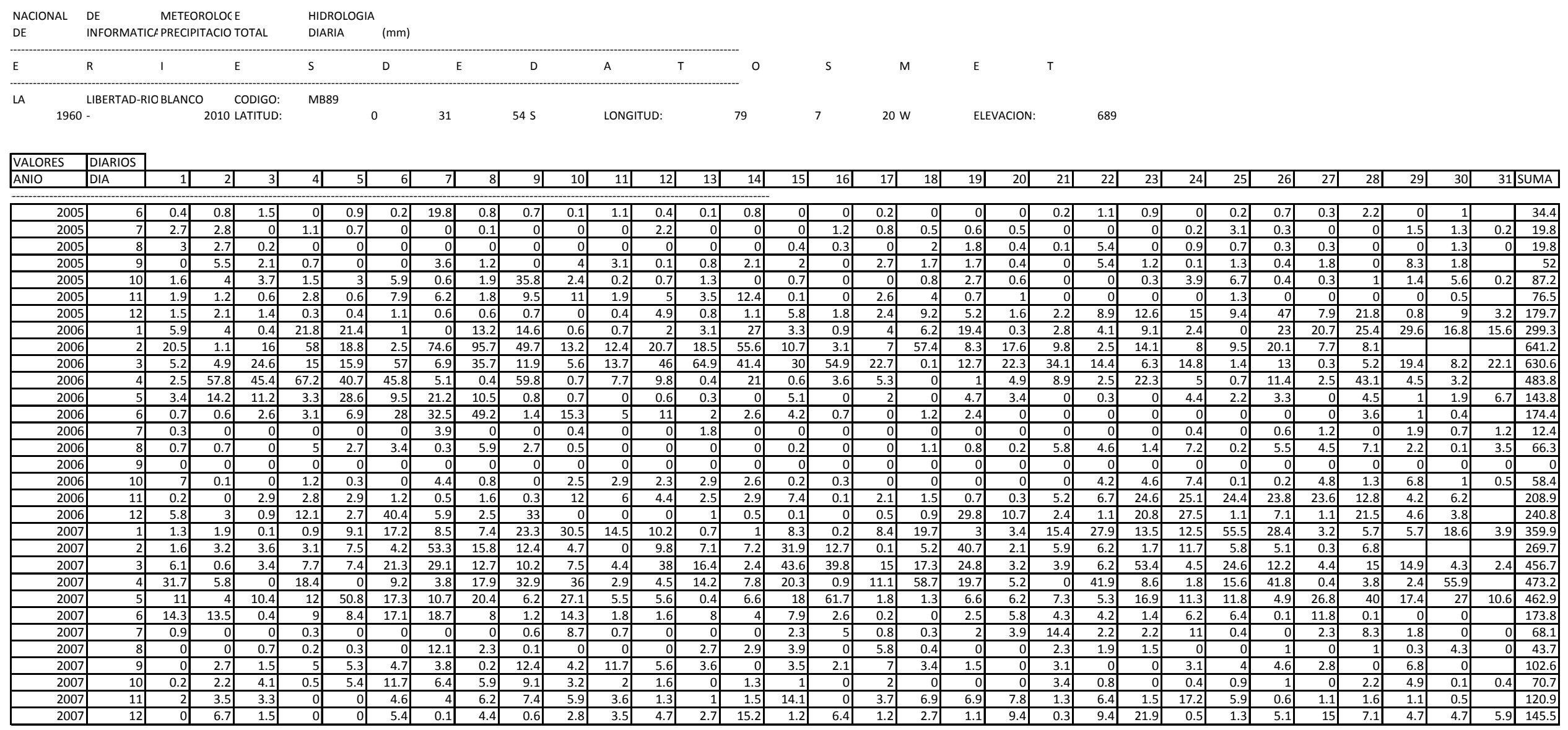




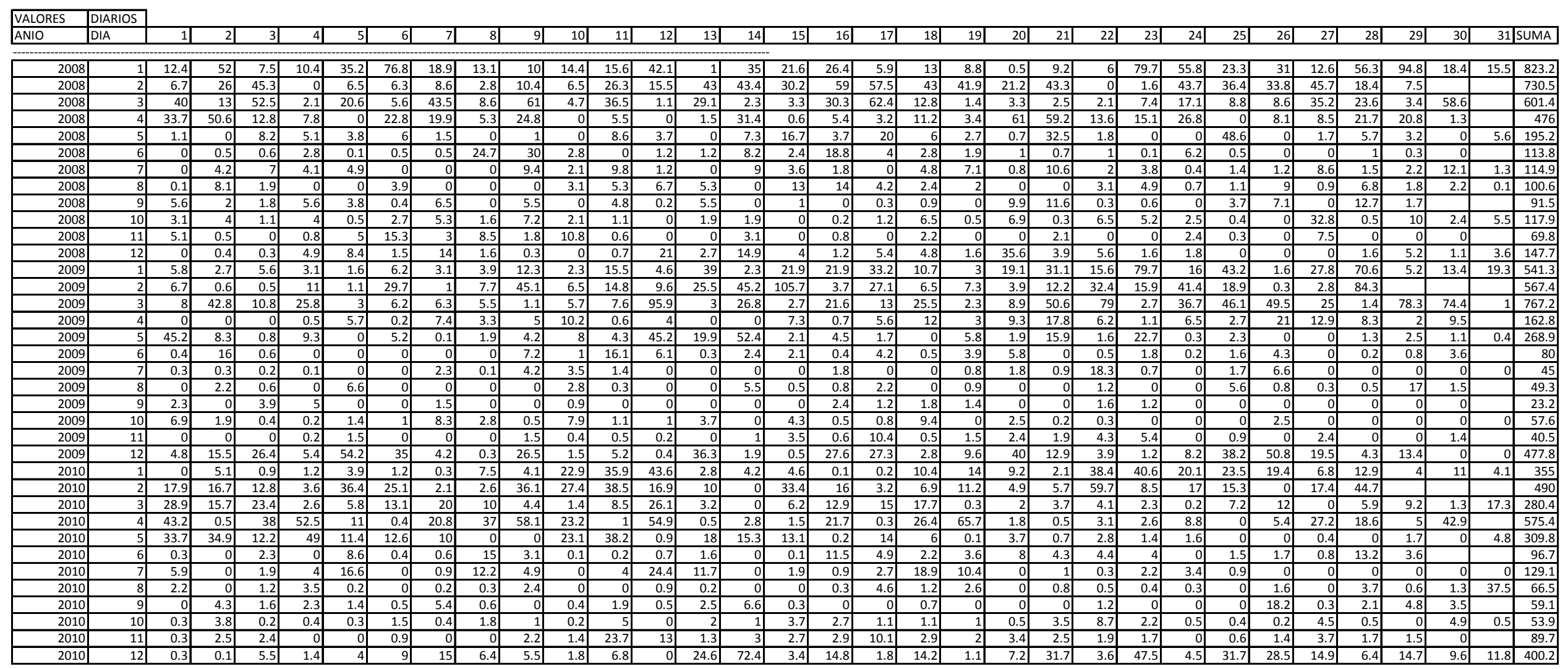




\begin{tabular}{|c|c|c|c|c|c|c|c|c|c|c|c|c|c|c|c|}
\hline INSTITUTO & NACIONAL & $\mathrm{DE}$ & METEORO & & HIDROLC & GIA & & & & & & & & & \\
\hline DIRECCION & DE & INFORMA] & PRECIPITA & TOTAL & DIARIA & $(\mathrm{mm})$ & & & & & & & & & \\
\hline S & E & $\mathrm{R}$ & I & E & $S$ & D & $\mathrm{E}$ & D & A & T & 0 & S & M & $\mathrm{E}$ & - \\
\hline $\begin{array}{l}\text { NOMBRE: } \\
\text { PERIODO: }\end{array}$ & 1960 & $\begin{array}{l}\text { PAMPAS } \\
-\end{array}$ & $\begin{array}{r}\text { CODIGO: } \\
2010\end{array}$ & $\begin{array}{l}\text { M362 } \\
\text { LATITUD: }\end{array}$ & & 0 & 25 & $32 \mathrm{~s}$ & & & 78 & 57 & $54 \mathrm{~W}$ & ELEVACIOI & 1583 \\
\hline
\end{tabular}

\section{\begin{tabular}{|l|l|}
\hline VALORES DIARIOS \\
\hline
\end{tabular}}

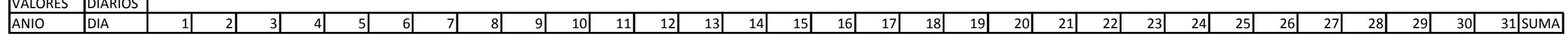

\begin{tabular}{|c|c|c|c|c|c|c|c|c|c|c|c|c|c|c|c|c|c|c|c|c|c|c|c|c|c|c|c|c|c|c|c|c|c|}
\hline 1990 & 1 & 0 & \begin{tabular}{|l|}
2.2 \\
\end{tabular} & 1.4 & 4.3 & 0 & 0 & 0 & 1.2 & 1 & \begin{tabular}{|r|}
2.4 \\
\end{tabular} & \begin{tabular}{|l|}
9.4 \\
\end{tabular} & 38.2 & 29.5 & 0 & \begin{tabular}{ll|}
0.9 \\
\end{tabular} & 2.1 & \begin{tabular}{|l|}
8.8 \\
\end{tabular} & $\begin{array}{l}1.9 \\
\end{array}$ & 0 & 3.9 & $\begin{array}{l}5.2 \\
\end{array}$ & 3.9 & \begin{tabular}{|l|}
2.4 \\
\end{tabular} & \begin{tabular}{|l|}
1.8 \\
\end{tabular} & 0 & 20 & 3.6 & 28.5 & \begin{tabular}{|l|l}
50.6 \\
\end{tabular} & \begin{tabular}{|l|}
13.7 \\
\end{tabular} & 0 & 0196.9 \\
\hline 1990 & 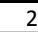 & 7.9 & 26.6 & 0 & 52.3 & 26.6 & 0 & $\begin{array}{l}1.5 \\
\end{array}$ & 0 & 2.8 & 16.2 & $\begin{array}{ll}1.3 \\
\end{array}$ & 10 & 4 & 31.5 & 14.9 & 7.4 & \begin{tabular}{|l|}
33.4 \\
\end{tabular} & $\begin{array}{c}13.4 \\
\end{array}$ & 0 & 3.9 & 18.2 & \begin{tabular}{|c|}
4.8 \\
\end{tabular} & 16.2 & 14.2 & 2.1 & 1.9 & 0 & 0 & 311.1 & & & \\
\hline 1990 & 7 & 0 & 2.3 & 2.5 & 0 & 2.8 & 0 & 2 & 0 & 0 & 0 & 0 & \begin{tabular}{|l|}
3.3 \\
\end{tabular} & 1.5 & 2.8 & 4 & 0 & 0 & 0 & 0 & 0 & 0 & 1.8 & 0 & 0 & 0 & 5.5 & 2 & 0 & 0 & 0 & 0.2 & 30.7 \\
\hline 1990 & 8 & 0.8 & 0.5 & 0 & 1.5 & 0 & 0 & 0 & 0 & 0 & 0 & 0 & 0 & 0 & 2.9 & 0 & 0 & 0 & 0.8 & 0 & \begin{tabular}{|l|}
11.7 \\
\end{tabular} & 0 & 2.6 & 0 & 0 & 0 & 0 & 0 & 0 & 0 & 1.9 & 0 & 22.7 \\
\hline 1990 & 9 & 1.9 & $\begin{array}{l}1.2 \\
\end{array}$ & 0 & 0 & 0 & 0 & 0 & 0 & 0.5 & \begin{tabular}{|l|}
3.1 \\
\end{tabular} & 2.6 & 0 & 1.8 & 0 & 0 & 0 & \begin{tabular}{l|l|}
0.5 \\
\end{tabular} & 0 & \begin{tabular}{|c|}
0.4 \\
\end{tabular} & & 0 & 0 & 3.1 & & 0 & 0 & 0 & 0 & \begin{tabular}{c|}
0.9 \\
\end{tabular} & 0 & 16 & \\
\hline & 10 & 3.8 & 7.9 & \begin{tabular}{l|l|}
0.6 \\
\end{tabular} & 8 & 2.5 & 2.4 & \begin{tabular}{|l|}
4.3 \\
\end{tabular} & 0.8 & 0.9 & 0 & 01 & 0 & 1.4 & 4.5 & \begin{tabular}{|l|}
19.1 \\
\end{tabular} & 11.3 & \begin{tabular}{l|l}
0.3 \\
\end{tabular} & 0 & 0 & 0 & 0 & 0 & 0 & 0 & 4.3 & 1.2 & 3.9 & 0.7 & & 0 & 0 & 78 \\
\hline 1990 & 11 & 0 & 0 & 0 & 0 & 1 & 1.3 & \begin{tabular}{|l|} 
\\
\end{tabular} & 2.6 & 7.9 & $\begin{array}{ll} \\
\end{array}$ & \begin{tabular}{|c|}
0.7 \\
\end{tabular} & 1.5 & 1.3 & 2.5 & 0 & $\begin{array}{l}0.5 \\
\end{array}$ & 14 & 1 & 0.6 & \begin{tabular}{|l|}
8.7 \\
\end{tabular} & 7 & 0 & \begin{tabular}{l|} 
\\
\end{tabular} & 11.4 & 0 & 0 & 0 & 0.3 & 0 & 0 & 64.6 & \\
\hline 1996 & 12 & 2.2 & 0 & 0 & 0 & 1.4 & 0 & 0 & 0 & 0 & 3.6 & \begin{tabular}{l|}
4.9 \\
\end{tabular} & 0.9 & 0 & 0 & 0 & 0 & 8.3 & 0 & 0 & ( & 2.4 & 25.2 & 3.6 & 11.2 & 10.8 & 18.9 & 25.1 & 1.6 & 4.6 & 12.2 & 12.1 & 149 \\
\hline 1991 & 1 & 0 & 0 & 0 & 0 & 1.3 & 2.8 & \begin{tabular}{c|c}
0.9 \\
\end{tabular} & 6.6 & 2.5 & \begin{tabular}{l|l}
0.3 \\
\end{tabular} & 30.5 & 0 & $\begin{array}{ll}6.3 \\
\end{array}$ & \begin{tabular}{|c|}
40.4 \\
\end{tabular} & 0 & \begin{tabular}{|l|}
9.8 \\
\end{tabular} & 31.1 & \begin{tabular}{|l|}
13.9 \\
\end{tabular} & 21.7 & 27.6 & 1.2 & 1.8 & 0.3 & 0 & 2.6 & 0 & 0.2 & 9.9 & 7.1 & 12.4 & 19.1 & \begin{tabular}{l|l}
11250.3 \\
\end{tabular} \\
\hline 1991 & 2 & 9.8 & 0 & \begin{tabular}{ll|}
66.3 \\
\end{tabular} & 4.7 & 2.8 & 12.9 & 11.2 & 4.1 & 5.6 & \begin{tabular}{|l|}
3.4 \\
\end{tabular} & 4.9 & $\begin{array}{c}19.5 \\
\end{array}$ & 0 & 3.5 & \begin{tabular}{l|l|}
11.4 \\
\end{tabular} & \begin{tabular}{|l|}
4.7 \\
\end{tabular} & 11.2 & $\begin{array}{l}15.9 \\
\end{array}$ & 43.1 & 28.1 & \begin{tabular}{|l|}
15.1 \\
\end{tabular} & 2.1 & 3.4 & 2.9 & 0 & 0 & 12.7 & 0 & 299.3 & & & \\
\hline 19 & 3 & 23.8 & 15.7 & 0 & 1 & 29.8 & 7.9 & 3.6 & 0.5 & 5.6 & 9.1 & 17.8 & 7 & 18.6 & 1.2 & \begin{tabular}{|l|}
18.7 \\
\end{tabular} & 42.5 & $\begin{array}{r}9.7 \\
\end{array}$ & \begin{tabular}{l|}
2.7 \\
\end{tabular} & \begin{tabular}{|r|}
9.9 \\
\end{tabular} & 8.9 & 17.1 & 15.5 & 9.1 & 0.6 & 29.3 & 1.7 & 7.8 & 12.2 & 20 & 14 & 0.7 & 342 \\
\hline 19 & 4 & 0.5 & 0 & $\begin{array}{l}0.4 \\
\end{array}$ & 19.3 & $\begin{array}{l}7.3 \\
\end{array}$ & 2.7 & 20.5 & 24.4 & 1.8 & 25.2 & \begin{tabular}{|l|}
10.8 \\
\end{tabular} & 13.5 & 14.6 & $\begin{array}{l}16.7 \\
\end{array}$ & 0 & 29.2 & \begin{tabular}{|c|}
10.4 \\
\end{tabular} & 0 & 0 & 0 & $\begin{array}{l}11.3 \\
\end{array}$ & $\begin{array}{r}3.5 \\
\end{array}$ & 25.2 & 7.1 & 4.2 & \begin{tabular}{|c|}
0.4 \\
\end{tabular} & \begin{tabular}{|c|}
11.8 \\
\end{tabular} & 12 & $\begin{array}{l}9.1 \\
\end{array}$ & 13.1 & 295 & \\
\hline 1991 & 5 & 17 & 5.9 & 31.1 & 6.7 & 2.6 & 25.8 & 14.2 & 1 & 20.5 & \begin{tabular}{|r|}
3.7 \\
\end{tabular} & 2.2 & $\begin{array}{l}7.7 \\
\end{array}$ & 3.9 & 3.3 & 2.8 & 35.7 & 35.5 & 6.9 & 0 & 27.9 & 7.9 & 0.6 & 3.7 & 2.3 & 3.6 & 0 & 1.8 & 4.3 & 17.3 & $\begin{array}{l}0.8 \\
\end{array}$ & 0 & \begin{tabular}{l|l}
0296.7 \\
\end{tabular} \\
\hline & 6 & 0 & 0 & 4.5 & 0 & 2.5 & 0 & 3.2 & 0.9 & 0.6 & 0 & $\begin{array}{ll}0.5 \\
\end{array}$ & 0 & 0 & 2.2 & 0 & 0 & 1.3 & 6.4 & 0 & & 3 & 2.9 & 0 & 0.9 & 0 & 14.6 & 0 & 16.2 & 0 & \begin{tabular}{|l|}
5.6 \\
\end{tabular} & 65.3 & \\
\hline 1991 & 7 & 0 & 0 & 0 & 0.3 & 6.2 & 16.2 & \begin{tabular}{l|}
4.4 \\
\end{tabular} & 0 & 1.4 & 0.6 & 2.5 & 0 & $\begin{array}{l}0.3 \\
\end{array}$ & 0 & 0 & 0 & 0 & 0 & 0 & 0 & 0 & 5.8 & 0.6 & 0 & 2 & 1 & 0 & 3.5 & 1.2 & 0 & 5 & 51 \\
\hline 1991 & 8 & 1.2 & 0.4 & \begin{tabular}{|c|}
9.7 \\
\end{tabular} & 5.9 & 0 & $\begin{array}{l}1.5 \\
\end{array}$ & \begin{tabular}{|c|}
0.7 \\
\end{tabular} & 6.2 & 0 & 0 & 0 & 0 & 0 & 0 & 0 & 0 & 0 & 0 & 0 & 0 & 0 & 0 & 0 & 0 & 0 & 0 & 0 & 0 & 0 & 0 & 0 & 25.6 \\
\hline & 9 & 0 & 0 & 0 & 0 & 0 & \begin{tabular}{l|l}
0.9 \\
\end{tabular} & 0 & 0 & 0 & \begin{tabular}{|l|}
5.1 \\
\end{tabular} & 0 & 0 & 0 & 0 & 0 & 0 & 0 & 0 & 0 & \begin{tabular}{|l|} 
\\
1.1
\end{tabular} & 3.8 & 0 & 5.1 & 3.1 & 3 & 0 & 0 & 0 & 0 & 0 & 22.1 & \\
\hline 1991 & 10 & 2.6 & 35.4 & 6.6 & 0 & 0 & 1.7 & 0 & 0.8 & 0 & \begin{tabular}{l|l}
0.8 \\
\end{tabular} & 0 & $\begin{array}{ll}0.3 \\
\end{array}$ & 0 & 0.2 & 0 & 0 & 1 & $\begin{array}{l}16.3 \\
\end{array}$ & 0 & 0.1 & 2.2 & 1.7 & 0.8 & 0.8 & 0 & 1.5 & 1.2 & 4.1 & 0 & 1.5 & 2.3 & 81.9 \\
\hline 199 & 11 & 1.9 & $\begin{array}{l}5.6 \\
\end{array}$ & 0.6 & 0 & 0 & 0 & 0 & 4.6 & 0 & 0 & 0 & 0 & 0 & \begin{tabular}{|l|}
4.7 \\
\end{tabular} & 0 & \begin{tabular}{l|l}
0.1 \\
\end{tabular} & 0 & $\begin{array}{r}2.5 \\
\end{array}$ & \begin{tabular}{|c|}
7.8 \\
\end{tabular} & 1.3 & 0 & 3.8 & 0 & 0 & 9.5 & 1.3 & 6.9 & 0 & 0 & \begin{tabular}{|c|}
1.7 \\
\end{tabular} & 52.3 & \\
\hline & 12 & 1.2 & 0.3 & $\begin{array}{l}0.5 \\
\end{array}$ & 39.4 & 2.1 & 3.5 & 0 & 18 & 0 & \begin{tabular}{|l|}
4.8 \\
\end{tabular} & $\begin{array}{l}5.7 \\
\end{array}$ & \begin{tabular}{l|}
6.5 \\
\end{tabular} & $\begin{array}{l}7.5 \\
\end{array}$ & 3.6 & 21.2 & 0 & 0 & 0.5 & 5.3 & 0 & 3.4 & 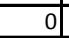 & \begin{tabular}{|l|}
4.8 \\
\end{tabular} & 14.4 & 0 & 0 & 0 & 40 & 0.5 & 3 & 0 & \begin{tabular}{|l|l|l}
0 & 186.2 \\
\end{tabular} \\
\hline 1992 & 1 & 3.1 & 2.8 & 12.6 & 9.5 & 22.4 & 21.1 & 3.6 & 1.9 & 0.6 & 7.2 & 10.2 & 4.8 & 22.3 & 3.5 & \begin{tabular}{|l|}
3.9 \\
\end{tabular} & $\begin{array}{l}1.6 \\
\end{array}$ & 0 & 0 & 2.1 & 15.4 & 14.2 & 3.9 & \begin{tabular}{l|}
7.2 \\
\end{tabular} & 10.8 & 1.6 & \begin{tabular}{|l|}
9.7 \\
\end{tabular} & 5.3 & 7.5 & 3.1 & $\begin{array}{c}1.4 \\
\end{array}$ & 0 & \begin{tabular}{l|l}
0 & 213.3
\end{tabular} \\
\hline & 2 & 0 & 1.7 & 0 & 18.1 & 5.5 & 12.1 & 1.5 & $\begin{array}{l}3.5 \\
\end{array}$ & 11.2 & 22.4 & 67.5 & 0 & 0 & 11.2 & $\begin{array}{l}9.2 \\
\end{array}$ & \begin{tabular}{|l|}
5.7 \\
\end{tabular} & \begin{tabular}{|l|}
8.7 \\
\end{tabular} & 3.8 & \begin{tabular}{l|}
7.1 \\
\end{tabular} & 3.5 & 23.9 & 21.3 & 22.4 & 7.6 & 2.5 & 13.4 & 2.8 & 0 & 0 & 296.6 & & \\
\hline 1992 & 4 & 0 & 0 & $\begin{array}{l}7.9 \\
\end{array}$ & 0 & 0 & \begin{tabular}{|l|}
9.5 \\
\end{tabular} & 0 & 2.9 & 0 & 5 & 2 & 20.2 & 3.5 & 20.7 & 2.6 & 21.6 & \begin{tabular}{|l|}
4.4 \\
\end{tabular} & 10 & 0 & 19 & 30 & 40 & 5 & 10 & 30 & 20 & 11.5 & 1.7 & 0 & 2 & 279.5 & \\
\hline 1992 & 5 & 19.1 & 4.7 & \begin{tabular}{|l|}
13.7 \\
\end{tabular} & 1.9 & 33.1 & 11 & 5.9 & 13.7 & 15.8 & 6.1 & $\begin{array}{l}3.3 \\
\end{array}$ & 10.1 & 7.1 & \begin{tabular}{|l|}
8.1 \\
\end{tabular} & \begin{tabular}{|l|}
10.3 \\
\end{tabular} & 12.1 & 20.1 & 15 & 20 & 12 & 5.1 & $\begin{array}{l}4.2 \\
\end{array}$ & 6.1 & 10.4 & 0 & 3.8 & \begin{tabular}{ll|}
15.3 \\
\end{tabular} & \begin{tabular}{|l|}
13.2 \\
\end{tabular} & \begin{tabular}{|c|}
25.4 \\
\end{tabular} & 14.4 & 2.2 & \begin{tabular}{|l|l|l}
2333.2 \\
\end{tabular} \\
\hline & 6 & $\begin{array}{l}1.1 \\
\end{array}$ & 2 & \begin{tabular}{|l|}
5.1 \\
\end{tabular} & 6 & $\begin{array}{l}0.1 \\
\end{array}$ & 1.1 & \begin{tabular}{|l|}
2.2 \\
\end{tabular} & 1.2 & 2 & \begin{tabular}{l|l}
0.8 \\
\end{tabular} & 3 & 4 & 2.4 & \begin{tabular}{l|l|}
1.8 \\
\end{tabular} & 0 & $\begin{array}{l}1.1 \\
\end{array}$ & $\begin{array}{l}1.2 \\
\end{array}$ & 0 & $\begin{array}{l}1.1 \\
\end{array}$ & \begin{tabular}{|l|}
1.2 \\
\end{tabular} & 0 & & \begin{tabular}{l|l}
0.8 \\
\end{tabular} & 0 & & 0 & 1 & 2 & \begin{tabular}{|l|l|} 
\\
\end{tabular} & $\begin{array}{l}1.2 \\
\end{array}$ & $\begin{array}{l}44.6 \\
\end{array}$ & \\
\hline 1992 & 8 & 0 & 0 & $\begin{array}{l}0.1 \\
\end{array}$ & 0 & 0 & 1 & 0 & 0 & 0 & \begin{tabular}{|l|}
0.1 \\
\end{tabular} & 0 & 0 & 0 & \begin{tabular}{|c|}
7.8 \\
\end{tabular} & \begin{tabular}{|l|}
12.3 \\
\end{tabular} & \begin{tabular}{|c|}
3.7 \\
\end{tabular} & 1.2 & \begin{tabular}{l|l}
0.3 \\
\end{tabular} & 0 & \begin{tabular}{l|l}
0.2 \\
\end{tabular} & 0 & 0.8 & 0.1 & 0 & 0 & 0 & 0 & 0 & 0 & \begin{tabular}{l|l|}
0.8 \\
\end{tabular} & 5.6 & 34 \\
\hline 1992 & & 8.3 & $\begin{array}{l}0.1 \\
\end{array}$ & $\begin{array}{l}0.5 \\
\end{array}$ & 1.3 & 0 & 0 & 0 & 2.3 & 0 & 0 & 0 & 0 & \begin{tabular}{|c|}
0.8 \\
\end{tabular} & 0 & $\begin{array}{l}0.6 \\
\end{array}$ & 0 & \begin{tabular}{|l|}
1.7 \\
\end{tabular} & 3.2 & 0 & 1 & \begin{tabular}{|c|}
0.4 \\
\end{tabular} & 0 & 0 & 0 & 0 & 0 & 0 & 0 & 0 & 0 & 20.2 & \\
\hline 1992 & 12 & 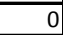 & 0 & 0 & 0 & 0 & 0 & 0 & 0.8 & 0.8 & 13.5 & 0 & 0 & 0 & 1.6 & \begin{tabular}{|l|}
4.1 \\
\end{tabular} & 0 & 17.5 & 0.5 & \begin{tabular}{c|c|}
14.9 \\
\end{tabular} & 18.5 & $\begin{array}{l}18.4 \\
\end{array}$ & 5.9 & 13.5 & 8.1 & 0 & 3.4 & 5.9 & 3.3 & 1.5 & 0 & 1.6 & \begin{tabular}{l|l}
6 & 133. \\
\end{tabular} \\
\hline
\end{tabular}


\begin{tabular}{|l|l|}
\hline VALORES & DIARIOS \\
\hline
\end{tabular}

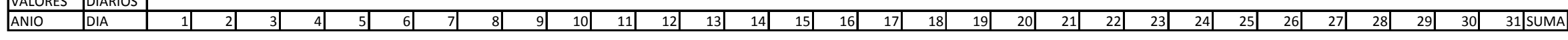

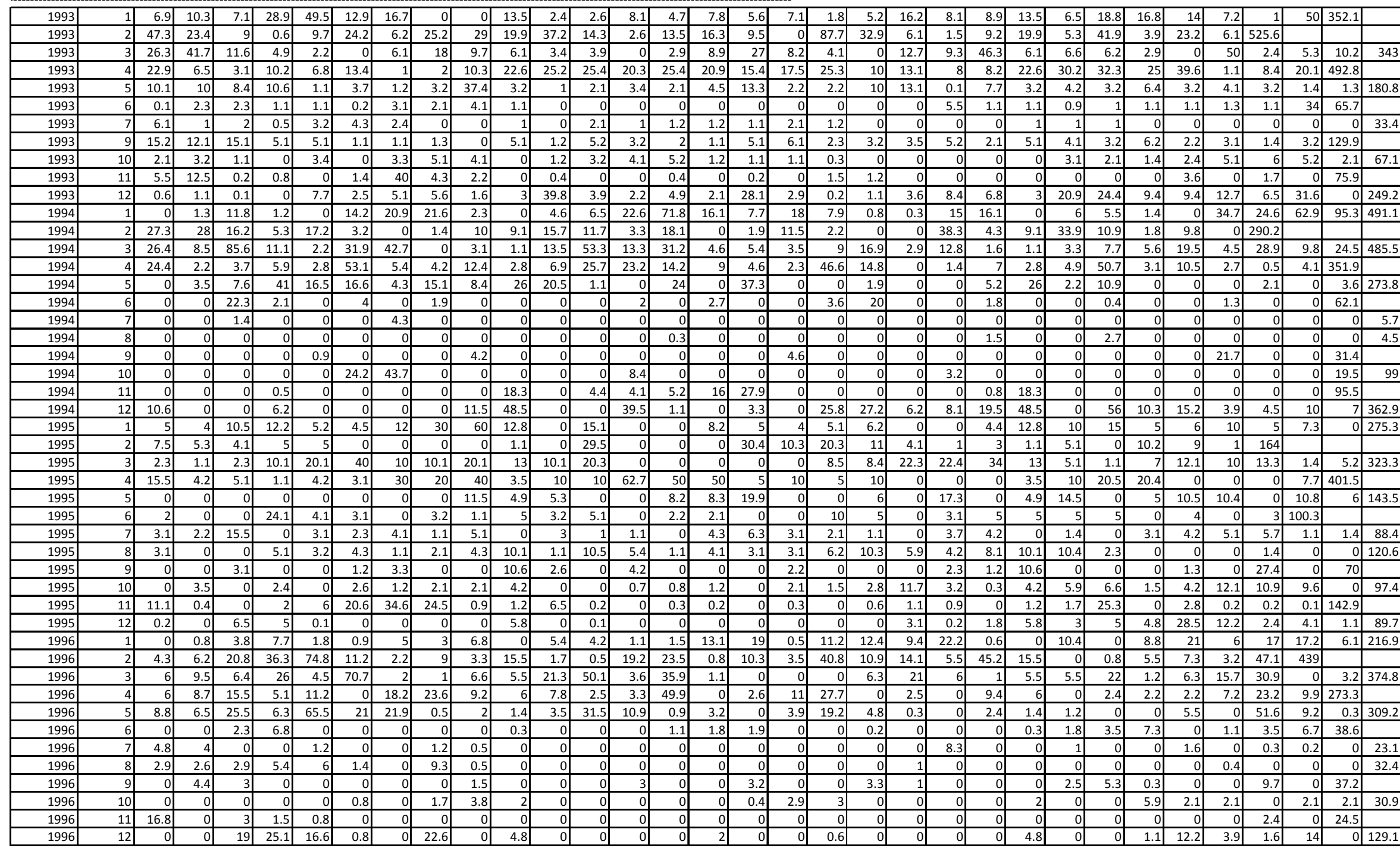


\begin{tabular}{|l|l|}
\hline VALORES & DIARIOS \\
\hline
\end{tabular}

\begin{tabular}{|l|l|l|l|l|l|l|l|l|l|l|l|l|l|l|l|l|l|l|l|l|l|l|l|l|l|l|l|l|l|l|l|l|l|}
\hline ANIO & DIA & 1 & 2 & 3 & 4 & 5 & 6 & 7 & 8 & 9 & 10 & 11 & 12 & 13 & 14 & 15 & 16 & 17 & 18 & 19 & 20 & 21 & 22 & 23 & 24 & 25 & 26 & 27 & 28 & 29 & 30 & 31 & SUMA \\
\hline
\end{tabular}

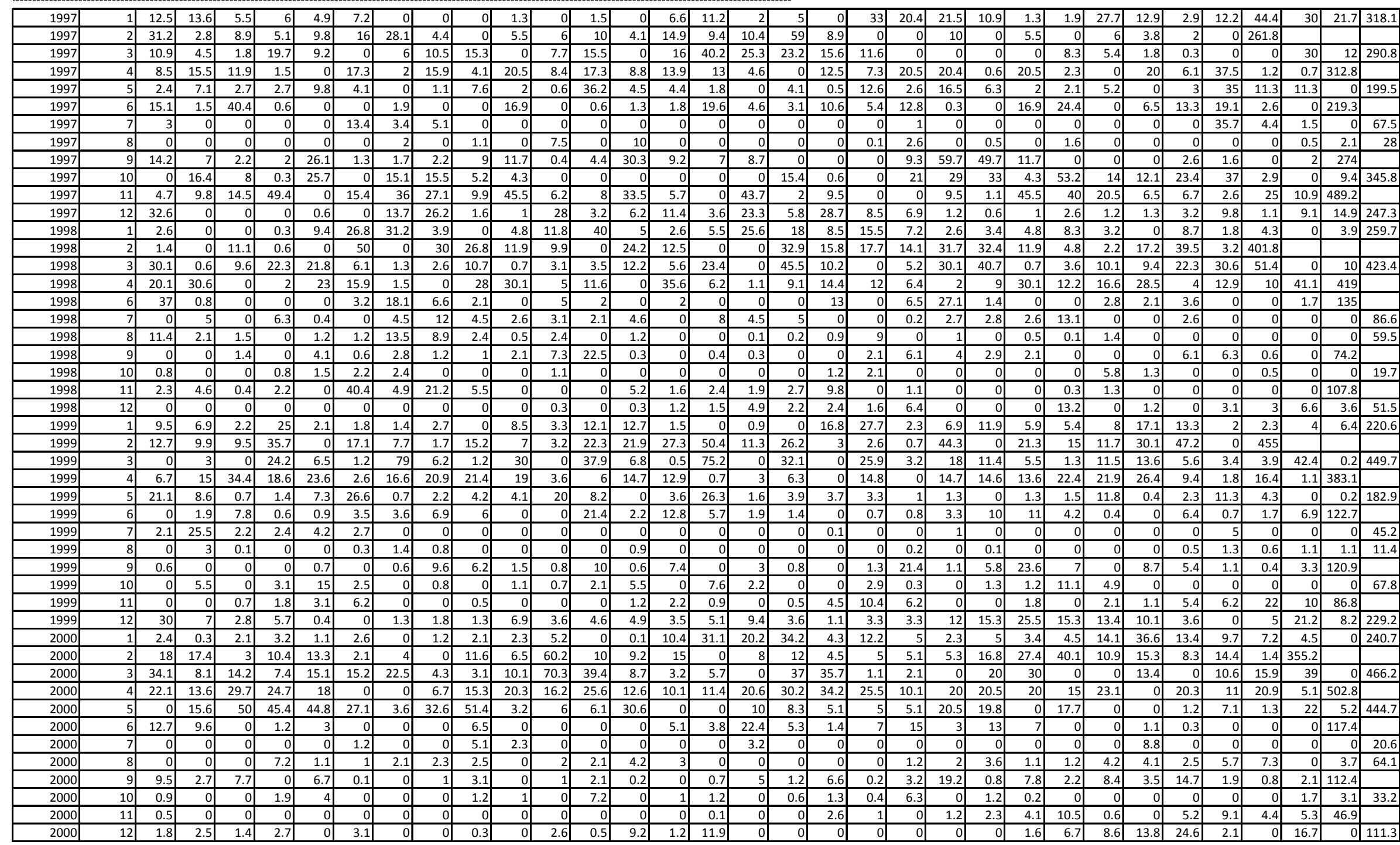


\begin{tabular}{|l|l|}
\hline VALORES & DIARIOS \\
\hline
\end{tabular}

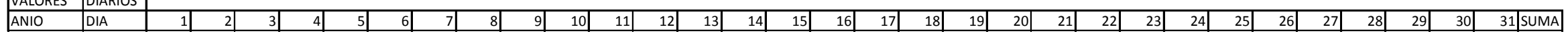

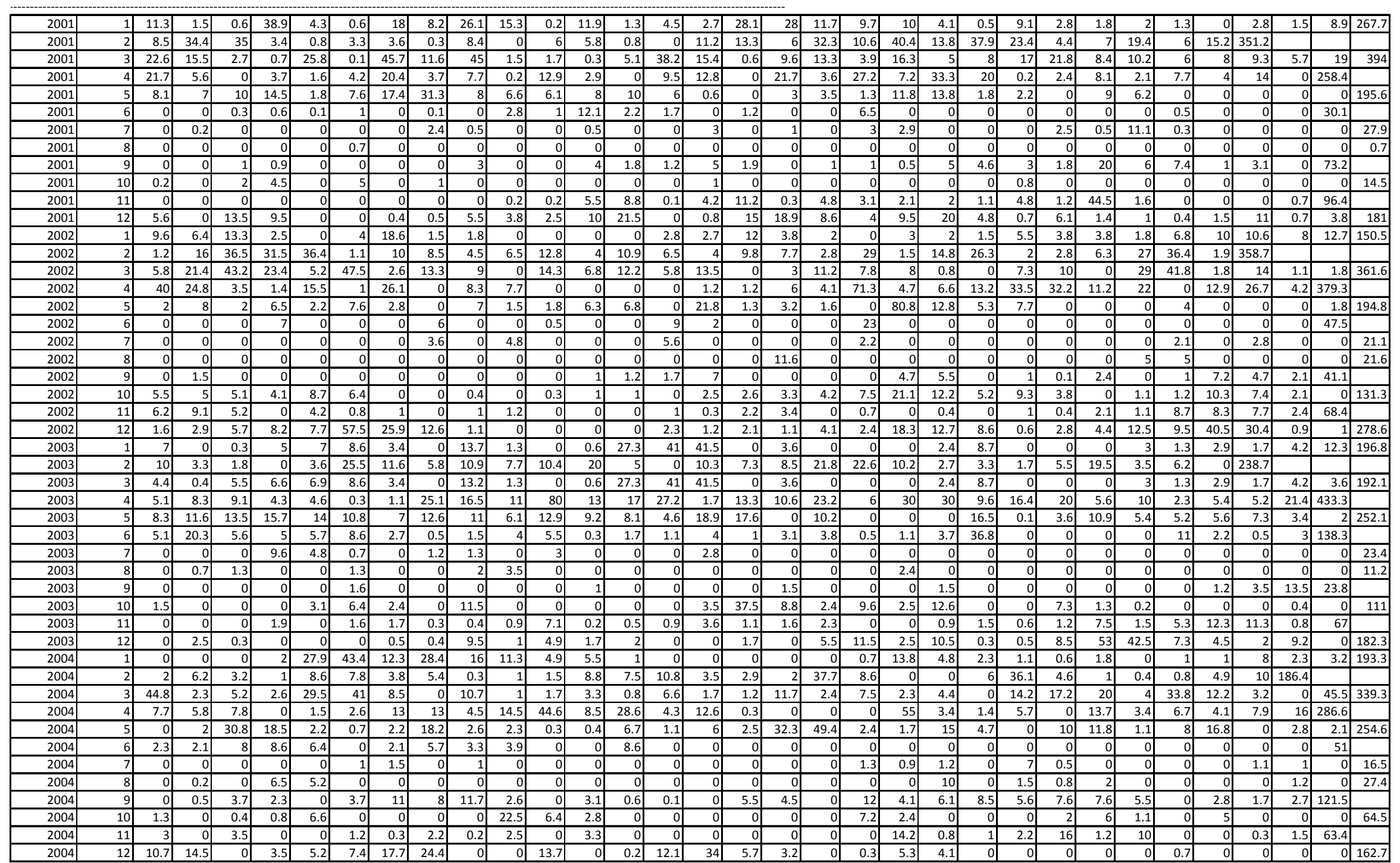


\begin{tabular}{|l|l|}
\hline VALORES & DIARIOS \\
\hline
\end{tabular}

\begin{tabular}{|c|c|c|c|c|c|c|c|c|c|c|c|c|c|c|c|c|c|c|c|c|c|c|c|c|c|c|c|c|c|c|c|c|c|}
\hline 2008 & 1 & 11.7 & \begin{tabular}{|l|l|}
31.3 \\
\end{tabular} & \begin{tabular}{|l|}
8.3 \\
\end{tabular} & 8 & 21.5 & 15.1 & \begin{tabular}{|c|}
16 \\
\end{tabular} & 29.4 & 23.1 & \begin{tabular}{|l|}
10.8 \\
\end{tabular} & \begin{tabular}{|c|}
6.8 \\
\end{tabular} & $\begin{array}{l}14.3 \\
\end{array}$ & \begin{tabular}{|c|}
9.4 \\
\end{tabular} & \begin{tabular}{|l|}
13 \\
\end{tabular} & 37.7 & 14.8 & 3.6 & 2.1 & \begin{tabular}{|l|}
6.3 \\
\end{tabular} & \begin{tabular}{|l|}
7.3 \\
\end{tabular} & \begin{tabular}{|l|}
4.1 \\
\end{tabular} & 6.5 & 39.2 & 23.8 & 25.5 & 9.7 & 27.5 & \begin{tabular}{|c|}
12.8 \\
\end{tabular} & \begin{tabular}{|c|}
16.9 \\
\end{tabular} & $\begin{array}{l}10.1 \\
\end{array}$ & 8.5 & 475.1 \\
\hline 2008 & 2 & 3 & 6.3 & $\begin{array}{l}4.5 \\
\end{array}$ & 4.9 & 1.5 & 7.9 & \begin{tabular}{|l|}
6.7 \\
\end{tabular} & 3.2 & 20 & \begin{tabular}{|l|}
10.7 \\
\end{tabular} & $\begin{array}{l}6.3 \\
\end{array}$ & 15.1 & 18 & 50.2 & 33.9 & 16.9 & 40.5 & \begin{tabular}{|l|}
9.8 \\
\end{tabular} & 23.8 & 14 & \begin{tabular}{|c|}
11.4 \\
\end{tabular} & 2.5 & 26.9 & 9.2 & 4.8 & 2.8 & 5.3 & 0.9 & \begin{tabular}{|l|}
12.5 \\
\end{tabular} & \begin{tabular}{|l|}
373.5 \\
\end{tabular} & & \\
\hline 2008 & 3 & 49 & 14.5 & 46.9 & 23 & 16.8 & 64.8 & 1.9 & \begin{tabular}{|l|}
4.7 \\
\end{tabular} & 5.1 & 10.3 & 8.2 & & \begin{tabular}{|l|}
9.7 \\
\end{tabular} & 2.8 & 8 & 4.3 & 26.5 & 7.7 & 30.8 & 8.2 & \begin{tabular}{|l|}
10.8 \\
\end{tabular} & 1.6 & & 8.3 & 2.2 & 3.4 & 20.8 & 9.9 & 5 & 33.6 & 4.7 & 446.5 \\
\hline$\overline{08}$ & 4 & 20.8 & 20.3 & 4.1 & 3.9 & 0 & 18.5 & 3.2 & 13.9 & 8 & 2.5 & 8.5 & 28.9 & 0.9 & 3.1 & 0 & $\begin{array}{ll}6.2 \\
\end{array}$ & 1.6 & 2.7 & \begin{tabular}{|c|}
14.2 \\
\end{tabular} & 16.3 & \begin{tabular}{|l|}
15.7 \\
\end{tabular} & 6 & 17.8 & \begin{tabular}{ll|}
10.4 \\
\end{tabular} & 11.4 & 16.4 & 16.8 & 2.8 & 11 & 20.1 & 306 & \\
\hline 2008 & 5 & 8.9 & 0 & 10 & 0.6 & 0.7 & 0.3 & 2.3 & 3 & 0.4 & \begin{tabular}{|l|}
3.1 \\
\end{tabular} & 0 & 9.2 & \begin{tabular}{l|}
1.1 \\
\end{tabular} & 35 & \begin{tabular}{|l|}
5.4 \\
\end{tabular} & \begin{tabular}{l|}
5.1 \\
\end{tabular} & 5 & 31.7 & \begin{tabular}{|c|}
13.6 \\
\end{tabular} & 9.4 & 15.4 & \begin{tabular}{|l|}
9.8 \\
\end{tabular} & 9.5 & 21.6 & 15.2 & 0.6 & 9.4 & \begin{tabular}{|c|}
16.9 \\
\end{tabular} & 0.7 & 1.5 & 1.1 & 246.5 \\
\hline 2008 & 6 & 0 & 0 & 0 & 4.4 & 0.7 & $\begin{array}{l}0.3 \\
\end{array}$ & 2.5 & 8 & 7.3 & \begin{tabular}{ll|}
4.6 \\
\end{tabular} & 0 & 0 & 0.6 & \begin{tabular}{l|}
1.2 \\
\end{tabular} & 4.6 & 0.7 & \begin{tabular}{|l|}
14.6 \\
\end{tabular} & 3.4 & 3.9 & 5.1 & 6.4 & 0.6 & 3.2 & 0.4 & 1.7 & 0 & & 0.3 & 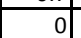 & 1 & 75.5 & \\
\hline 2008 & 7 & 0 & 8.2 & \begin{tabular}{|l|}
1.7 \\
\end{tabular} & 4.8 & 0.1 & \begin{tabular}{|l|}
1.1 \\
\end{tabular} & 0.3 & \begin{tabular}{|l|}
4.1 \\
\end{tabular} & 4.1 & \begin{tabular}{|l|}
1.4 \\
\end{tabular} & 3.8 & 0 & \begin{tabular}{|l|}
7.3 \\
\end{tabular} & \begin{tabular}{|c|}
10.7 \\
\end{tabular} & 20.8 & 0 & 3.1 & & 1.2 & \begin{tabular}{l|}
1.5 \\
\end{tabular} & \begin{tabular}{l|}
1.8 \\
\end{tabular} & & $\begin{array}{l}0.3 \\
\end{array}$ & 0.2 & 1.4 & 0.8 & 0.1 & 2 & 0.2 & \begin{tabular}{l|l|}
0.2 \\
\end{tabular} & & 84.2 \\
\hline 2008 & 8 & 0.8 & 2.3 & 0.4 & 3.2 & 0.4 & 1 & 0.8 & 0 & 2.2 & 2.2 & 2.4 & 1 & 0.8 & 2.8 & 4.9 & \begin{tabular}{|c|}
6.6 \\
\end{tabular} & \begin{tabular}{|l|}
3.5 \\
\end{tabular} & 1.9 & $\begin{array}{ll}7.1 \\
\end{array}$ & 0 & \begin{tabular}{l|}
10.6 \\
\end{tabular} & \begin{tabular}{|l|}
19.5 \\
\end{tabular} & & 0.7 & \begin{tabular}{|l|}
14.8 \\
\end{tabular} & 0.2 & 1.2 & 45 & 0.5 & \begin{tabular}{l|}
0.8 \\
\end{tabular} & 0.6 & \begin{tabular}{|l|}
138.2 \\
\end{tabular} \\
\hline 20 & 9 & 0.5 & 0.6 & 0.2 & 2.5 & 2.6 & $\begin{array}{l}0.5 \\
\end{array}$ & \begin{tabular}{|l|}
1.5 \\
\end{tabular} & \begin{tabular}{|l|}
0.2 \\
\end{tabular} & 1.7 & 0 & 0 & \begin{tabular}{|l|}
0.1 \\
\end{tabular} & 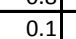 & 1.5 & \begin{tabular}{|l|}
1.7 \\
\end{tabular} & $\begin{array}{l}3.5 \\
.5\end{array}$ & 0 & 1.4 & \begin{tabular}{l|}
0.1 \\
\end{tabular} & 11.2 & 8.9 & & 6.6 & & 8.3 & 0.9 & 9.8 & 21.4 & & $\begin{array}{l}3.3 \\
\end{array}$ & $\begin{array}{r}91.2 \\
\end{array}$ & \\
\hline 2008 & 10 & 1.4 & 0.6 & \begin{tabular}{|l|}
1.3 \\
\end{tabular} & 1.5 & & 0 & 4.8 & 10 & 8.2 & 7.8 & 2 & $\begin{array}{l}0.8 \\
\end{array}$ & 1.1 & 0.4 & 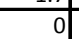 & & 0 & 2.2 & \begin{tabular}{l|l|}
0.4 \\
\end{tabular} & 2.2 & $\begin{array}{l}1.2 \\
\end{array}$ & $\begin{array}{l}0.5 \\
\end{array}$ & $\begin{array}{l}0.1 \\
\end{array}$ & 5 & 1.1 & 0.4 & 35.6 & 35.3 & 14.2 & \begin{tabular}{|l|}
6.1 \\
\end{tabular} & 3.4 & 148.5 \\
\hline 2008 & 11 & 1.4 & 0.1 & 0 & 0 & 0.1 & \begin{tabular}{|l|}
1.1 \\
\end{tabular} & \begin{tabular}{l|}
0.5 \\
\end{tabular} & \begin{tabular}{l|}
0.3 \\
\end{tabular} & 1.5 & 2.5 & 0.2 & 16.8 & 1.8 & 1.6 & 0 & \begin{tabular}{|c|}
0.3 \\
\end{tabular} & 0 & 0 & 0 & 0 & 0 & 0 & 0 & 7.1 & 0 & 0 & & 0.2 & 0 & $\begin{array}{l}0.2 \\
\end{array}$ & 35.7 & \\
\hline 2008 & 12 & 0.2 & 0.3 & 0.2 & 0 & 1 & 14.9 & \begin{tabular}{|c|}
8.6 \\
\end{tabular} & \begin{tabular}{|l|}
2.7 \\
\end{tabular} & 1.3 & 2.4 & 46.1 & 1.1 & $\begin{array}{l}0.5 \\
\end{array}$ & 39.4 & & \begin{tabular}{|l|}
7.7 \\
\end{tabular} & 8.9 & 2 & \begin{tabular}{l|}
0.1 \\
\end{tabular} & 25.8 & \begin{tabular}{|l|l|}
19.4 \\
\end{tabular} & 13.2 & 4.5 & 0.2 & 1.2 & 0.1 & & 0.3 & 0.3 & & 0.5 & 203.9 \\
\hline 2009 & 1 & 5.1 & 3.3 & 13.6 & 9.5 & 3.7 & 2.9 & \begin{tabular}{|l|}
5.4 \\
\end{tabular} & 5.8 & 22.3 & 10.8 & 23.1 & \begin{tabular}{c|}
16.1 \\
\end{tabular} & \begin{tabular}{|c|}
12.7 \\
\end{tabular} & 56.4 & 54.6 & 51 & \begin{tabular}{|l|}
1.8 \\
\end{tabular} & \begin{tabular}{|l|}
5.1 \\
\end{tabular} & 4.9 & 26.2 & 16.5 & \begin{tabular}{|c|}
12.8 \\
\end{tabular} & 35.8 & & 9.9 & 4.3 & 28 & 51.1 & 21.5 & \begin{tabular}{|l|}
9.7 \\
\end{tabular} & 10.5 & 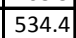 \\
\hline 2009 & 2 & 6.9 & \begin{tabular}{|c|}
19.1 \\
\end{tabular} & 1.8 & 8.2 & 3 & \begin{tabular}{|l|}
14.1 \\
\end{tabular} & 0 & 0 & 15.2 & \begin{tabular}{|l|}
15.4 \\
\end{tabular} & 7.1 & 20 & 38.5 & 45.4 & 36.3 & 30.2 & \begin{tabular}{|c|}
10.9 \\
\end{tabular} & $\begin{array}{l}1.5 \\
\end{array}$ & 27.2 & 21.9 & 22.7 & \begin{tabular}{|l|}
15.3 \\
\end{tabular} & 6.3 & 10.4 & $\begin{aligned} 19.9 \\
\end{aligned}$ & 2 & $\begin{array}{l}10.1 \\
\end{array}$ & 34.7 & \begin{tabular}{|l|}
444.1 \\
\end{tabular} & & & \\
\hline & 3 & $\begin{array}{l}1.1 \\
\end{array}$ & 29.4 & 18.1 & 7.7 & 7.7 & 2.9 & \begin{tabular}{|l|}
5.7 \\
\end{tabular} & \begin{tabular}{|l|}
4.3 \\
\end{tabular} & 0.6 & 3.9 & 2.6 & \begin{tabular}{|c|}
14.9 \\
\end{tabular} & 26.9 & 29.6 & \begin{tabular}{|c|}
0.7 \\
\end{tabular} & $\begin{array}{r}4.2 \\
\end{array}$ & 3 & \begin{tabular}{|r|}
14.6 \\
\end{tabular} & 5.1 & 12 & 14.1 & \begin{tabular}{|l|}
10.1 \\
\end{tabular} & \begin{tabular}{|l|}
11.6 \\
\end{tabular} & 25.3 & 20.8 & 18 & 2.4 & 38.3 & & 0 & \begin{tabular}{|c|}
5.7 \\
\end{tabular} & 343.5 \\
\hline 2009 & 4 & 0 & 0 & 0 & 0 & 0 & 0 & 0 & 0 & 0 & \begin{tabular}{|l|}
19.3 \\
\end{tabular} & 0 & 0 & 6.2 & $\begin{array}{r}1.8 \\
\end{array}$ & \begin{tabular}{|l|}
1.1 \\
\end{tabular} & \begin{tabular}{|l|}
4.2 \\
\end{tabular} & \begin{tabular}{|c|}
6.8 \\
\end{tabular} & $\begin{array}{r}4.7 \\
\end{array}$ & \begin{tabular}{|r|}
10.9 \\
\end{tabular} & \begin{tabular}{|l|}
19.1 \\
\end{tabular} & 31 & $\begin{array}{r}7.6 \\
\end{array}$ & 0 & 2.7 & 9.5 & 9.8 & 7.6 & 14.1 & $\begin{array}{l}9.6 \\
\end{array}$ & 8 & 174 & \\
\hline 200 & 5 & 23.3 & 24.2 & \begin{tabular}{|c|}
14 \\
\end{tabular} & 2.9 & 1.3 & 0 & 0 & 0 & 0 & 0 & \begin{tabular}{l|}
6.1 \\
\end{tabular} & 49.4 & \begin{tabular}{|l|}
1.5 \\
\end{tabular} & 0 & $\begin{array}{ll}0.2 \\
\end{array}$ & & 0 & \begin{tabular}{l|l}
0.3 \\
\end{tabular} & 3.6 & 0.5 & & 2.6 & 7.8 & 8 & 11.4 & & & 0.6 & & 0 & 3.4 & \begin{tabular}{|l|}
165.1 \\
\end{tabular} \\
\hline 200 & 6 & 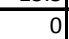 & 2.2 & 5.6 & \begin{tabular}{|l|}
1.1 \\
\end{tabular} & & \begin{tabular}{|l|}
1.4 \\
\end{tabular} & 0 & 0 & 0 & 7.6 & 3.6 & 8.2 & \begin{tabular}{|l|}
7.7 \\
\end{tabular} & 4 & 2.8 & 0 & \begin{tabular}{|l|}
5.7 \\
\end{tabular} & & 4.6 & 0 & 3.8 & 0 & 0 & 0 & 1.5 & $\begin{array}{l}0.3 \\
\end{array}$ & & 0.6 & \begin{tabular}{|l|}
1.1 \\
\end{tabular} & 0 & 62.8 & \\
\hline 2009 & 7 & 0 & 0 & 0 & 0 & 0 & 0 & 1.9 & 0 & 1.8 & 0 & 0 & 0 & \begin{tabular}{l|}
1.2 \\
\end{tabular} & 0.9 & & \begin{tabular}{|l|}
1.3 \\
\end{tabular} & 0 & 0 & 1.8 & 0.2 & 2. & 0 & & & & 1.5 & & 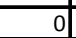 & & & 0 & 13 \\
\hline 2009 & 8 & 0.1 & 0.1 & 0 & 0 & 1.5 & \begin{tabular}{|l|}
0.7 \\
\end{tabular} & 0 & 0 & 0 & 0 & 0 & \begin{tabular}{|l|}
1.6 \\
\end{tabular} & \begin{tabular}{l|}
0.9 \\
\end{tabular} & 1.4 & \begin{tabular}{|l|}
1.2 \\
\end{tabular} & 0 & \begin{tabular}{|l|}
1.1 \\
\end{tabular} & \begin{tabular}{l|}
0.5 \\
\end{tabular} & 4 & \begin{tabular}{c|}
1.5 \\
\end{tabular} & $\begin{array}{l}1.2 \\
\end{array}$ & 0.1 & 7.9 & 1.2 & 0.2 & 0.1 & & $\begin{array}{l}4.7 \\
\end{array}$ & 3.9 & 1.6 & 2.8 & 38.3 \\
\hline 2009 & 9 & 0 & 0 & \begin{tabular}{|l|}
1.6 \\
\end{tabular} & 0 & 0 & 0 & 0 & 0 & 0.2 & 0 & 0 & 0 & \begin{tabular}{|l|}
0.7 \\
\end{tabular} & $\begin{array}{l}1.8 \\
\end{array}$ & & \begin{tabular}{l|}
0.1 \\
\end{tabular} & 0 & & 0 & \begin{tabular}{l|l}
0.1 \\
\end{tabular} & 3.6 & 0 & 0 & 0 & 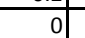 & 0 & 5 & 0 & 0 & 0 & \begin{tabular}{|l|}
13.1 \\
\end{tabular} & \\
\hline 2009 & 10 & 14.9 & 0 & 0 & 0 & 0 & 0 & 32 & \begin{tabular}{|c|}
3.7 \\
\end{tabular} & 2.1 & 10.5 & 26.4 & 0 & 0.2 & 3.2 & \begin{tabular}{|c|}
14.6 \\
\end{tabular} & & 0 & 0 & 0 & 0 & 0 & 0 & $\begin{array}{l}0.5 \\
\end{array}$ & & 0 & 0 & & 0 & \begin{tabular}{|l|}
109.1 \\
\end{tabular} & & & \\
\hline 2009 & & 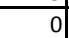 & 0 & 0 & 0 & - & 0 & 0 & 0 & 0 & 0 & 1.3 & \begin{tabular}{l|l|}
0.2 \\
\end{tabular} & 0 & 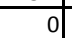 & 5.7 & & \begin{tabular}{l|}
0.9 \\
\end{tabular} & & & 1.3 & 2.5 & 12.3 & 2.3 & 3.6 & 2.4 & 2.5 & 2.3 & & 0 & 6.2 & 45.9 & \\
\hline 2009 & 12 & 2 & \begin{tabular}{|l|}
4.7 \\
\end{tabular} & \begin{tabular}{|l|}
4.3 \\
\end{tabular} & 2.3 & 11.5 & \begin{tabular}{c|}
2.4 \\
\end{tabular} & 0 & \begin{tabular}{l|}
0.2 \\
\end{tabular} & \begin{tabular}{|l|}
14.3 \\
\end{tabular} & \begin{tabular}{|c|}
1.8 \\
\end{tabular} & 0.3 & 0.9 & $\begin{array}{l}3.5 \\
\end{array}$ & $\begin{array}{l}4.3 \\
\end{array}$ & \begin{tabular}{l|}
2.1 \\
\end{tabular} & 45.9 & \begin{tabular}{|c|}
15.4 \\
\end{tabular} & 8.8 & 6.3 & 57 & 7 & 4.6 & 0.4 & 0 & 33.4 & 67.2 & 13.8 & 0 & 2.1 & 0.9 & 0.2 & 317.6 \\
\hline 201 & 4 & 5.8 & \begin{tabular}{|l|}
19.7 \\
\end{tabular} & 25.3 & 6.2 & 16.8 & 16.8 & 0 & \begin{tabular}{|l|}
8.7 \\
\end{tabular} & 8.6 & \begin{tabular}{|c|}
16.7 \\
\end{tabular} & 7.2 & 28.4 & 0 & $\begin{array}{l}4.5 \\
\end{array}$ & \begin{tabular}{|l|l|}
5.3 \\
\end{tabular} & 11 & 1.4 & 23.3 & 39.2 & 16.8 & 0 & 2.5 & 10.5 & \begin{tabular}{|c|}
14.7 \\
\end{tabular} & 8.4 & 11.3 & & 45.1 & 2.8 & \begin{tabular}{|c|}
17.1 \\
\end{tabular} & \begin{tabular}{|l|}
374.1 \\
\end{tabular} & \\
\hline 201 & 5 & 24.3 & 19 & 20.4 & 7.8 & 4.3 & 4.2 & 16.5 & 7.1 & 0.5 & 0.6 & 8.4 & 0.6 & 3.2 & 0.9 & & 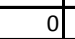 & 3.4 & 2.8 & \begin{tabular}{l|}
0.6 \\
\end{tabular} & \begin{tabular}{|l|}
3.7 \\
\end{tabular} & \begin{tabular}{l|l}
0.6 \\
\end{tabular} & & & 1.9 & 4 & & 0.9 & 1.3 & 0.7 & $\begin{array}{ll}0.6 \\
\end{array}$ & 2.3 & 136. \\
\hline 2010 & 6 & $\begin{array}{c}0.4 \\
\end{array}$ & 0 & & \begin{tabular}{l|l}
1.9 \\
\end{tabular} & 0.2 & 3.2 & $\begin{array}{l}4.4 \\
\end{array}$ & \begin{tabular}{|l|}
6.9 \\
\end{tabular} & 3.4 & 0 & & 0 & $0 \mid$ & & \begin{tabular}{|c|}
0.8 \\
\end{tabular} & \begin{tabular}{l|l}
0.3 \\
\end{tabular} & $0 \mid$ & \begin{tabular}{|c|}
10.3 \\
\end{tabular} & 6.1 & \begin{tabular}{l|l|}
1.8 \\
\end{tabular} & \begin{tabular}{l|}
0.3 \\
\end{tabular} & 1.5 & & & 0.5 & 0.3 & 2.2 & & 1.6 & & \begin{tabular}{|l|l}
49.1 \\
\end{tabular} & \\
\hline
\end{tabular}


TABLAS DE TEMPERATURA MEDIA MENSUAL

INSTITUTO NACIONAL DE METEOROLOGE HIDROLOGIA

UNIDAD ATENCION AL USUARIO

TEMPERATUR MEDIA MENSUAL (GC)

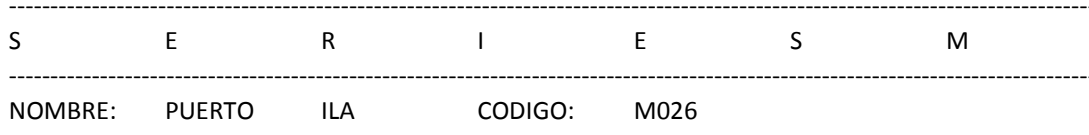

NOMBRE: PUERTO ILA CODIGO: M026

PERIODO: 2010 LATITUD: $\quad 1990$ - 0

LONGITUD:

79

20

$20 \mathrm{~W}$

ELEVACION:

\begin{tabular}{|c|c|c|c|c|c|c|c|c|c|c|c|c|c|c|}
\hline AÑOS & ENE & FEB & MAR & ABR & MAY & JUN & JUL & AGO & SEP & OCT & NOV & DIC & SUMA & MEDIA \\
\hline 1990 & 24.8 & 25 & 25.5 & 25.2 & 24.8 & 24.2 & 23.6 & 23.2 & 23.8 & 23.2 & 23.9 & 24 & & 24.3 \\
\hline 1991 & 25 & 25.3 & 25.7 & 25.7 & 25.5 & 24 & 23.4 & 23.1 & 23.4 & 23.8 & 24.3 & 24.5 & 293.7 & 24.5 \\
\hline 1992 & 24.7 & 25.1 & 25.8 & 25.8 & 25.5 & 24.6 & 23.2 & 23.3 & 23.1 & 23.6 & 23.3 & 24 & 292 & 24.3 \\
\hline 1993 & 24.5 & 24.5 & 25.4 & 25.7 & 25.5 & 24.7 & 23.8 & 23.3 & 23.6 & 23.5 & 23.4 & 24.2 & 292.1 & 24.3 \\
\hline 1994 & 24.1 & 24.4 & 24.6 & 24.9 & 24.7 & 23.5 & 22.6 & 22.6 & 24.1 & 23.9 & 23.7 & 24.5 & 287.6 & 24.0 \\
\hline 1995 & 24.8 & 25 & 25.5 & 25.3 & 24.9 & 24.4 & 23.4 & 23 & 23.8 & 23.6 & 23.4 & 24.5 & 291.6 & 24.3 \\
\hline 1996 & 24.2 & 24.8 & 25.4 & 24.9 & 24.5 & 22.8 & 22.7 & 23 & 23.8 & 23.7 & 23.5 & 24.3 & 287.6 & 24.0 \\
\hline 1997 & 24.2 & 25.1 & 25.7 & 25.5 & 25.7 & 25.6 & 25.6 & 25.3 & 25.5 & 25.6 & 25.6 & 26.1 & 305.5 & 25.5 \\
\hline 1998 & 26.5 & 26.7 & 26.7 & 26.8 & 26.6 & 25.7 & 24.7 & 24.1 & 24 & 23.5 & 23.8 & 23.6 & 302.7 & 25.2 \\
\hline 1999 & 24.4 & 24.5 & 25.2 & 25.1 & 25 & 23.3 & 22.8 & 22.9 & 23.2 & 23.4 & 23.6 & 23.7 & 287.1 & 23.9 \\
\hline 2000 & 23.9 & 24.4 & 24.9 & 25.3 & 24.4 & 23.5 & 22.9 & 23.1 & 23.2 & 23.7 & 23.7 & 24.2 & 287.2 & 23.9 \\
\hline 2001 & 24.4 & 25.1 & 25.7 & 25.6 & 24.4 & 23 & 22.9 & 23.2 & 23.9 & 23.9 & 24.2 & 24.4 & 290.7 & 24.2 \\
\hline 2002 & 24.4 & 24.9 & 25.7 & 25.6 & 25.6 & 24.3 & 23.6 & 23.6 & 24.5 & 24 & 24.1 & 24.8 & 295.1 & 24.6 \\
\hline 2003 & 25.1 & 25.3 & 26.1 & 25.7 & 25.5 & 24.2 & 23.5 & 23.7 & 23.6 & 24 & 24.2 & 24.5 & 295.4 & 24.6 \\
\hline 2004 & 25.6 & 25.5 & 25.8 & 25.6 & 24.9 & 23.6 & 23 & 23.9 & 23.9 & 24.2 & 24.1 & 25 & 295.1 & 24.6 \\
\hline 2005 & 25.2 & 24.8 & 25.6 & 25.9 & 25 & 24.1 & 23.4 & 23.5 & 23.9 & 23.1 & 23.6 & 24.3 & 292.4 & 24.4 \\
\hline 2006 & 24.8 & 25.2 & 25.8 & 25.6 & 24.6 & 23.6 & 23.2 & 23.6 & 23.9 & 24.4 & 24.3 & 24.7 & 293.7 & 24.5 \\
\hline 2007 & 25.2 & 25.3 & 25.4 & 25.6 & 24.8 & 24.1 & 23.5 & 22.9 & 23.8 & 23.3 & 23.8 & 23.8 & 291.5 & 24.3 \\
\hline 2008 & 23.7 & 24.8 & 25.5 & 25.8 & 25 & 24 & 23.9 & 23.9 & 23.7 & 23.4 & 23.7 & 24.3 & 291.7 & 24.3 \\
\hline 2009 & 24.7 & 24.7 & 25.5 & 25.5 & 25.2 & 24.3 & 24 & 24 & 24.5 & 24.4 & 24.8 & 25.1 & & 24.7 \\
\hline 2010 & 25.3 & 25.5 & 25.5 & 26.1 & 25.7 & 24 & 23.4 & 23.4 & 23.8 & 23.8 & 23.9 & 24.4 & & 24.6 \\
\hline
\end{tabular}

\begin{tabular}{|c|c|c|c|c|c|c|c|c|c|c|c|c|c|}
\hline media & 24.7 & 25 & 25.5 & 25.5 & 25.1 & 24 & 23.4 & 23.4 & 23.8 & 23.8 & 23.9 & 24.4 & 293.1 \\
\hline minima & 23.7 & 24.4 & 24.6 & 24.9 & 24.4 & 22.8 & 22.6 & 22.6 & 23.1 & 23.1 & 23.3 & 23.6 & 22.6 \\
\hline maxima & 26.5 & 26.7 & 26.7 & 26.8 & 26.6 & 25.7 & 25.6 & \begin{tabular}{|l|}
25.3 \\
\end{tabular} & 25.5 & 25.6 & 25.6 & 26.1 & 26.8 \\
\hline
\end{tabular}


INSTITUTO NACIONAL DE METEOROLOGE HIDROLOGIA

UNIDAD ATENCION AL USUARIO

TEMPERATUR MEDIA MENSUAL (GC)

\begin{tabular}{|c|c|c|c|c|c|c|c|c|c|c|}
\hline$S$ & $\mathrm{E}$ & $\mathrm{R}$ & 1 & $\mathrm{E}$ & S & $M$ & $\mathrm{E}$ & $\mathrm{N}$ & S & \\
\hline
\end{tabular}

PAMPAS CODIGO: M362

PERIODO: $\quad 2010$ LATITUD: $\quad 0$

\begin{tabular}{|c|c|c|c|c|c|c|c|c|c|c|c|c|c|c|}
\hline AÑOS & ENE & FEB & MAR & ABR & MAY & JUN & JUL & AGO & SEP & OCT & NOV & DIC & SUMA & MEDIA \\
\hline 2005 & 17.6 & 17.7 & 18.4 & 18.8 & 18.7 & 17.8 & 18.2 & 18.3 & 18.2 & 18.1 & 18.2 & 17.4 & & \\
\hline 2006 & 17.4 & 17.9 & 18.4 & 18.5 & 18.4 & 18 & 18 & 18 & 18.1 & 18.2 & \begin{tabular}{l|l|}
18.3 \\
\end{tabular} & 17.8 & 217 & 18 \\
\hline 2007 & 18.2 & 18.1 & 18.3 & 18.4 & 18.3 & 17.9 & 17.6 & 17.6 & 17.6 & 17.4 & 17.6 & 17.2 & 214.2 & 17.8 \\
\hline 2008 & 17.1 & 17.2 & 17.6 & 17.8 & 18.1 & 18 & 17.6 & 17.7 & 17.9 & 17.9 & 17.8 & 17.5 & 212.2 & 17.6 \\
\hline 2009 & 17.8 & 17.8 & 18 & 18.1 & 18.3 & 18.1 & 18.3 & 18.1 & 18.4 & 18.4 & 18.2 & 17.9 & 217.4 & 18.1 \\
\hline 2010 & 17.6 & 17.7| & 18.4 & 18.7 & 18.6 & 18.2 & 18.2 & 17.9 & 18.0 & 18.0 & 18.0 & 17.5 & & \\
\hline media & 17.6 & 17.7 & 18 & 18.3 & 18.4 & 18 & 17.9 & 17.9 & 18 & 18 & 18 & 17.5 & 215.7 & 17.9 \\
\hline minima & 17.1 & 17.2 & 17.6 & 17.8 & 18.1 & 17.8 & 17.6 & 17.6 & 17.6 & 17.4 & 17.6 & 17.2 & 17.1 & \\
\hline maxima & 18.2 & 18.1 & 18.4 & 18.8 & 18.7 & 18.2 & 18.3 & 18.3 & 18.4 & 18.4 & 18.3 & 17.9 & 18.8 & \\
\hline
\end{tabular}




\section{TABLAS DE CAUDALES MEDIOS DIARIOS ( $\left.\mathrm{M}^{3} / \mathrm{s}\right)$}

INSTITUTO NACIONAL DE METEOROLOCE

DRECION DE INFORMATICFCAUDALES MEDIOS DIARIOS (m3/s)

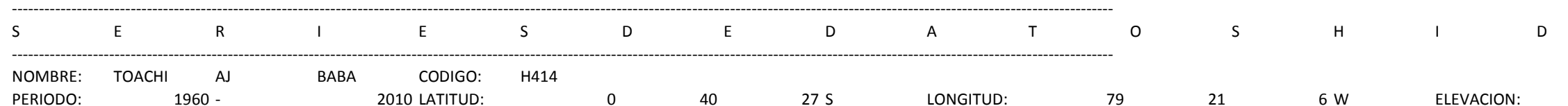

VALORESDIARIOS

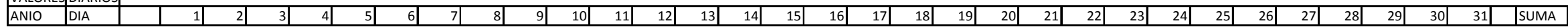

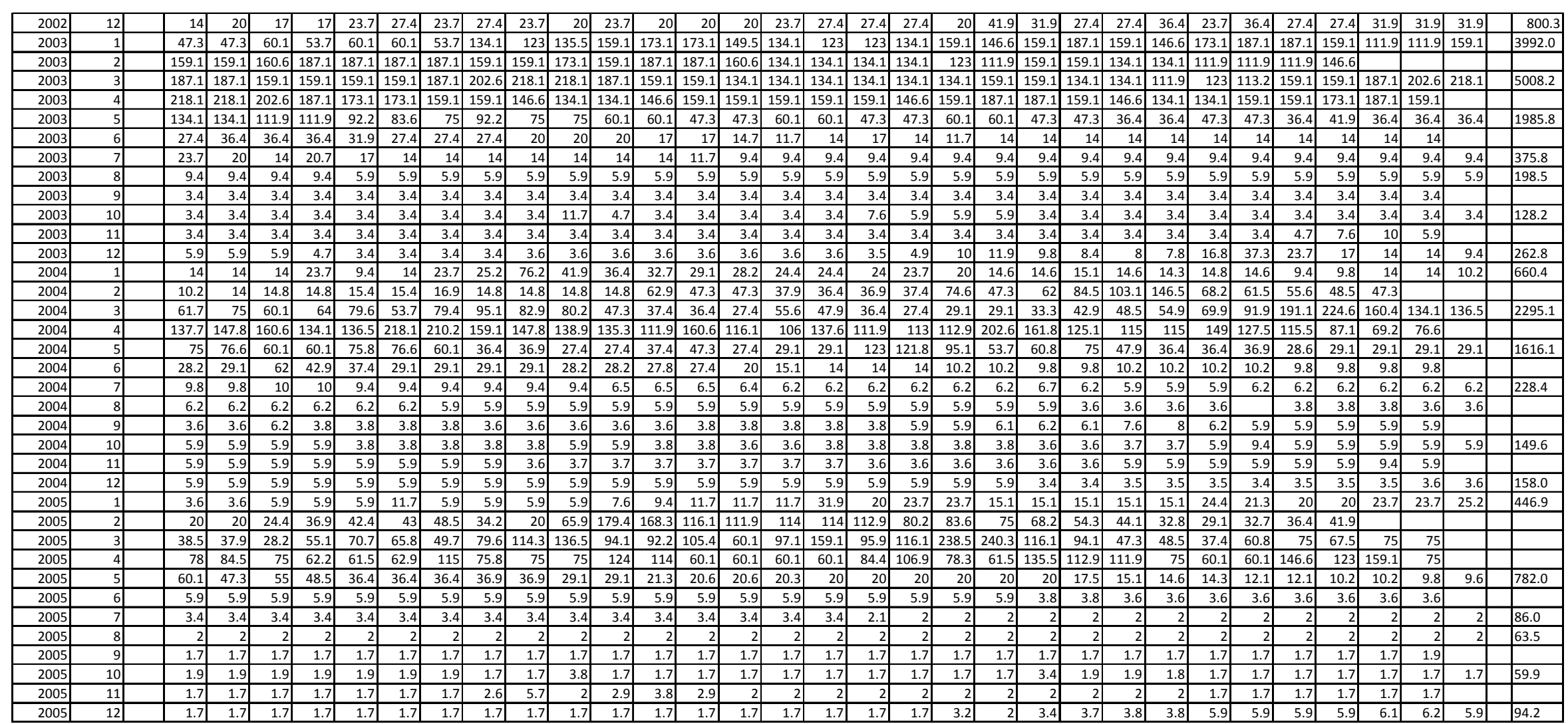




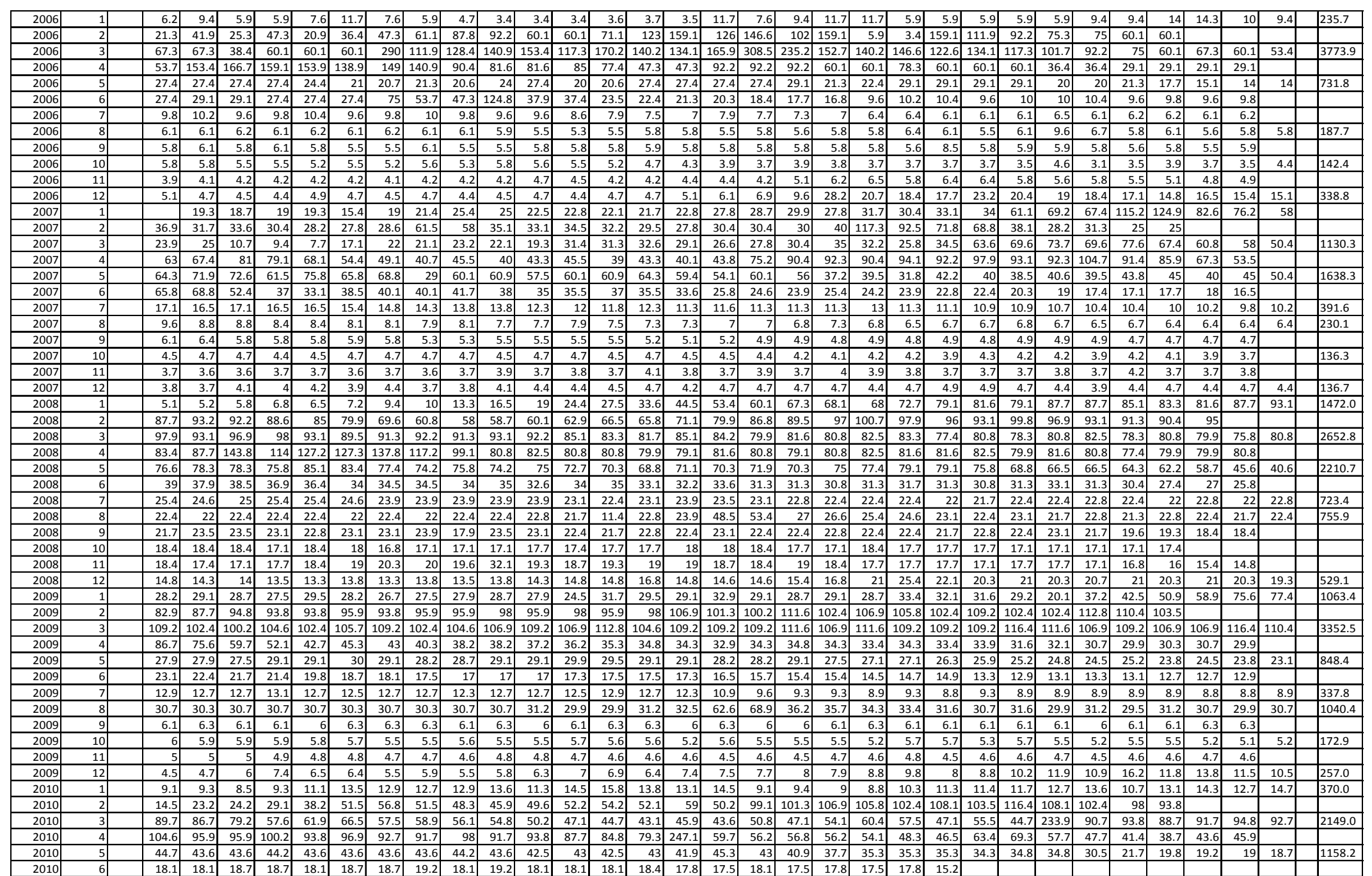




\section{TABLAS DE CAUDALES MEDIOS MENSUALES $\left(\mathrm{m}^{3} / \mathrm{s}\right)$}

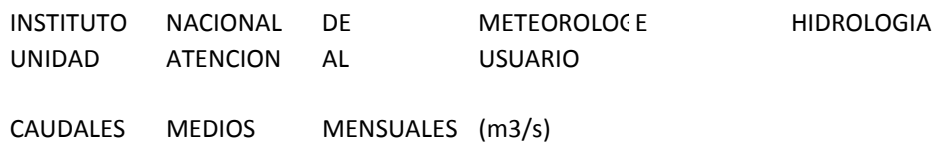

\begin{tabular}{|c|c|c|c|c|c|c|c|c|c|c|c|c|c|c|}
\hline s & $\mathrm{E}$ & $\mathrm{R}$ & 1 & $\mathrm{E}$ & s & M & E & $\mathrm{N}$ & s & U & A & $\mathrm{L}$ & E & $\mathrm{s}$ \\
\hline NOMBRE: & TOACHI & AJ & BABA & CODIGO: & H414 & & & & & & & & & \\
\hline PERIODO: & 1960 & & 2010 & LATITUD: & 0 & 40 & 27 & & LONGITUD: & 79 & 21 & & w & ELEVACION: \\
\hline ALOS & ENE & FEB & MAR & ABR & MAY & JUN & JUL & AGO & SEP & OCT & NOV & DIC & SUMA & MEDIA \\
\hline 2003 & 128.775 & 151.91 & 161.556 & \begin{tabular}{|l|}
164.667 \\
\end{tabular} & $\begin{array}{r}64.059 \\
\end{array}$ & 19.454 & 12.125 & 6.404 & 3.451 & 4.139 & 3.937 & 8.479 & \begin{tabular}{|l|}
728.956 \\
\end{tabular} & \begin{tabular}{|l|}
60.746 \\
\end{tabular} \\
\hline 2004 & 21.303 & 43.716 & 74.038 & 134.73 & 52.135 & 20.873 & 7.371 & 5.348 & 4.964 & 4.827 & 5.026 & 5.1 & 379.431 & 31.619 \\
\hline 2005 & 14.417 & 66.117 & 89.111 & 87.837 & 25.226 & 5.204 & 2.775 & 2.049 & 1.775 & 1.934 & 2.192 & 3.041 & 301.678 & 25.139 \\
\hline 2006 & 7.605 & 76.185 & 121.74 & 82.405 & 23.609 & 26.496 & 7.961 & 6.055 & 5.89 & 4.596 & 4.901 & 10.931 & 378.374 & 31.531 \\
\hline 2007 & 39.791 & 41.391 & 36.462 & 68.856 & 52.85 & 31.75 & 12.635 & 7.423 & 5.279 & 4.399 & 3.832 & 4.41 & 309.078 & 25.756 \\
\hline 2008 & 47.485 & 83.077 & 85.576 & 91.115 & 71.314 & 32.902 & 23.338 & 24.387 & 22.087 & \begin{tabular}{|l|}
17.7 \\
\end{tabular} & 18.57 & 17.068 & 534.619 & 44.551 \\
\hline 2009 & 34.304 & 99.981 & 108.148 & 39.599 & 27.37 & 16.528 & 10.897 & 33.563 & 6.214 & 5.58 & 4.772 & 8.293 & 395.249 & 32.937 \\
\hline 2010 & 11.936 & 69.548 & 69.322 & 78.037 & 37.364 & 18.112 & & & & & & & & \\
\hline media & 37.753 & 65.754 & 72.244 & 76.907 & 38.856 & 18.759 & 10.935 & 11.382 & 7.826 & 12.587 & \begin{tabular}{|l|}
17.074 \\
\end{tabular} & 17.602 & 387.684 & 32.307 \\
\hline minima & 7.605 & 15.826 & 4.906 & 21.835 & 15.432 & 0.339 & 2.775 & 2.049 & 1.775 & 1.934 & 2.192 & 3.041 & 0.339 & \\
\hline maxima & 128.775 & 151.91 & 161.556 & 164.667 & 71.314 & 32.902 & 23.338 & 33.563 & 22.087 & 65.876 & 99.168 & 86.877 & 164.667 & \\
\hline
\end{tabular}




\section{IMAGEN SATELITAL}

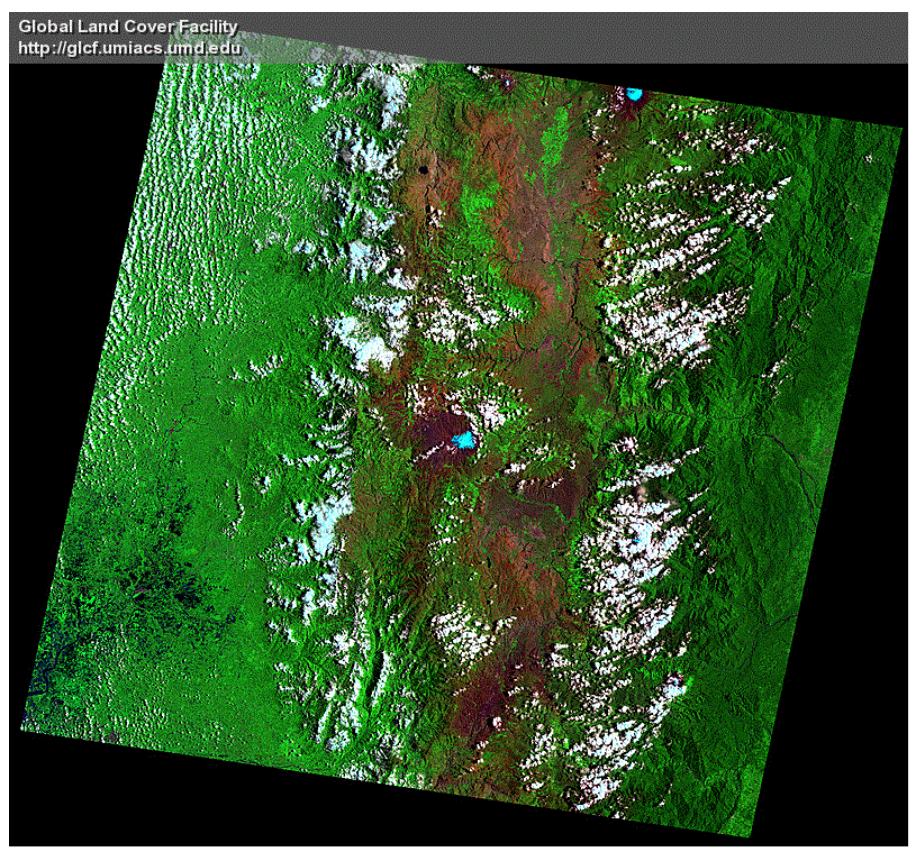

LANDSAT 19870326 TM

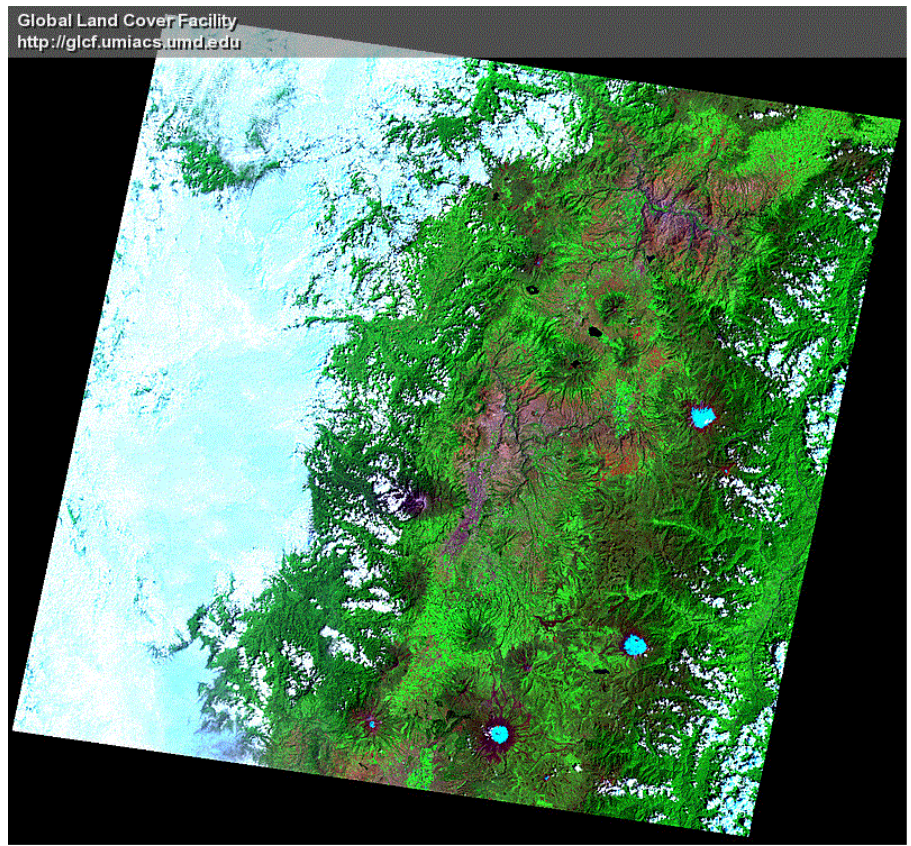

LANDSAT 19991114 